\section{)}

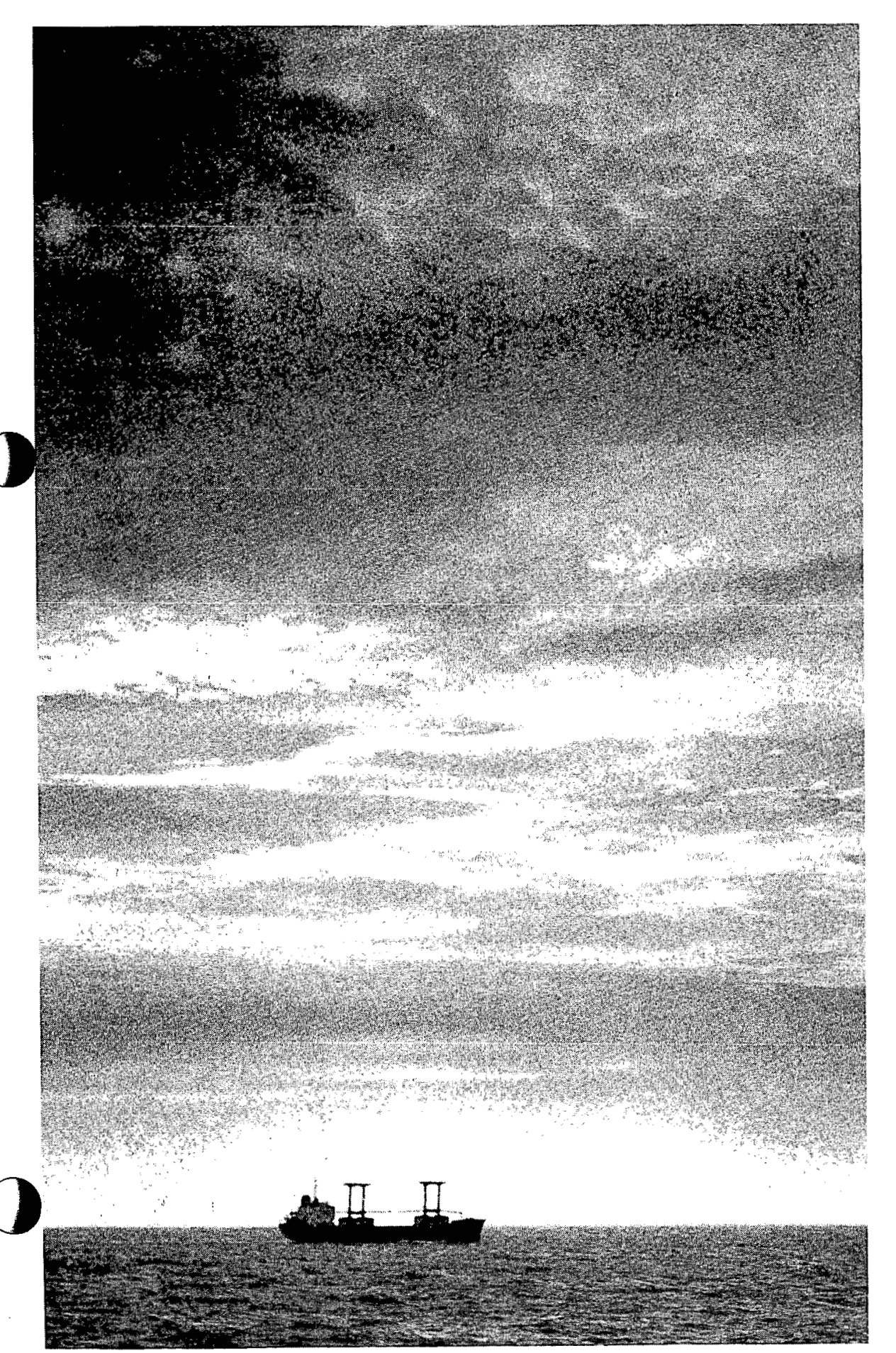

Prepared for:

United States Department of Energy

Office of Energy Research

Office of Basic Energy Sciences

Carbon Dioxide Research Division

$$
\text { and }
$$

National Center for Atmospheric Research Boulder, Colorado 80307
DOE/ER-0406

NCAR/TN-317+STR

DOE/ER--0406

DE90 003187

\title{
Global Distribution of Total Cloud Cover and Cloud Type Amounts over the Ocean
}

Stephen G. Warren

Dept of Atmospheric Sciences AK-40,

University of Washington, Seattle, WA 98195

Carole J. Hahn

Cooperative Institute for Research in Environmental Sciences

University of Colorado, Boulder, CO 80309 Julius London

Dept of Astrophysical Planetary and Atmospheric Sciences

University of Colorado, Boulder, CO 80309

Robert M. Chervin

Roy L. Jenne
National Center for Atmospheric Research

Boulder, CO 80307

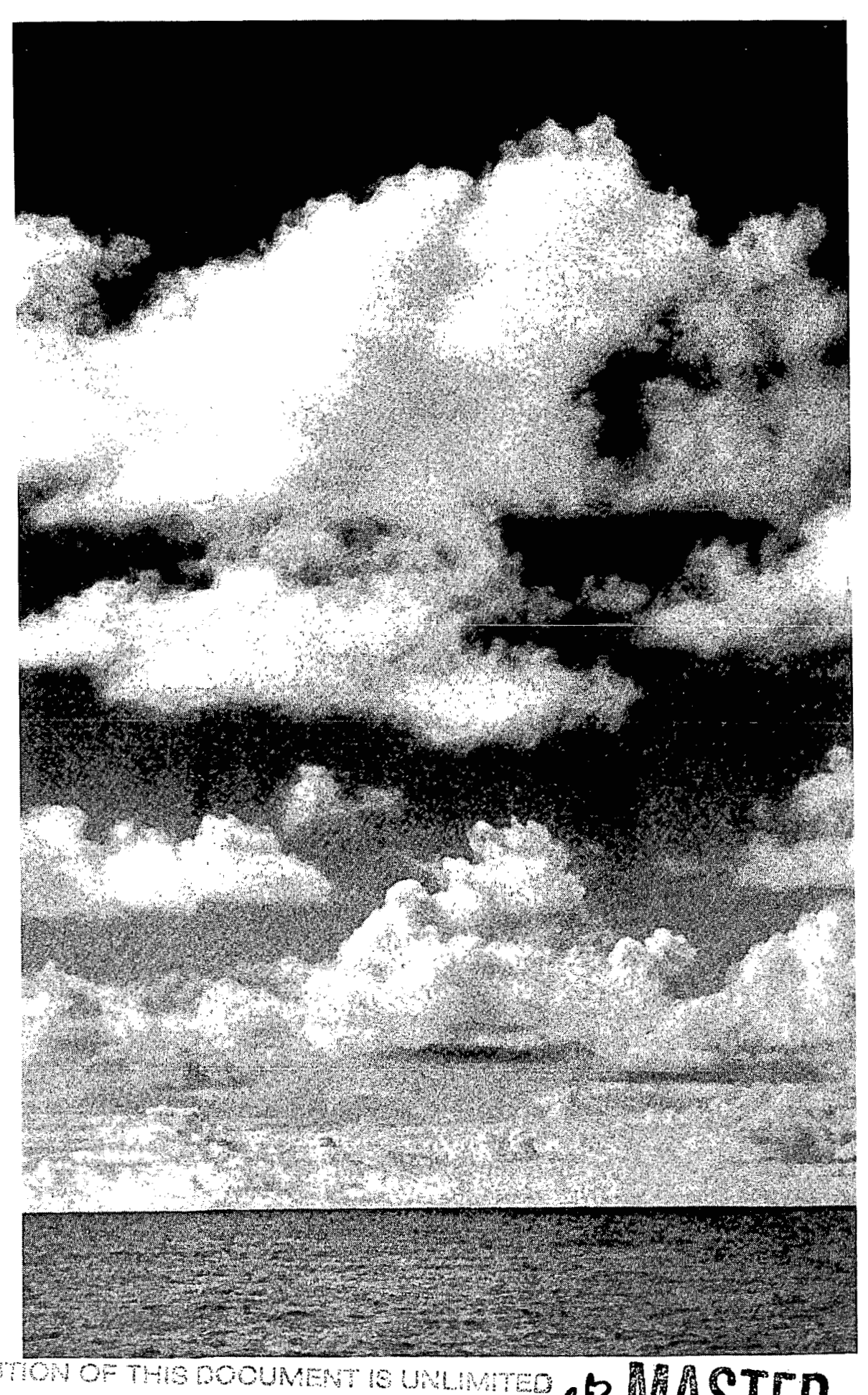




\section{DISCLAIMER}

This report was prepared as an account of work sponsored by an agency of the United States Government. Neither the United States Government nor any agency Thereof, nor any of their employees, makes any warranty, express or implied, or assumes any legal liability or responsibility for the accuracy, completeness, or usefulness of any information, apparatus, product, or process disclosed, or represents that its use would not infringe privately owned rights. Reference herein to any specific commercial product, process, or service by trade name, trademark, manufacturer, or otherwise does not necessarily constitute or imply its endorsement, recommendation, or favoring by the United States Government or any agency thereof. The views and opinions of authors expressed herein do not necessarily state or reflect those of the United States Government or any agency thereof. 


\section{DISCLAIMER}

Portions of this document may be illegible in electronic image products. Images are produced from the best available original document.

some front pages (TOC) are missing from the original document 


\section{Preface}

This is the fourth of a series of atlases to result from a study of the global cloud distribution from ground-based observations. The first two atlases (NCAR/TN-201+STR and NCAR/TN$241+$ STR) described the frequency of occurrence of each cloud type and the co-occurrence of different types, but included no information about cloud amounts. The third atlas (NCAR/TN$273+$ STR) described, for the land areas of the earth, the average total cloud cover and the amounts of each cloud type, and their geographical, diurnal, seasonal, and interannual variations, as well as the average base heights of the low clouds. The present atlas does the same for the ocean areas of the earth. These atlases are published with the cooperation of the National Center for Atmospheric Research, supported by the National Science Foundation.

Cover photographs. Left: Altostratus and altocumulus in the South China Sea $\left(23^{\circ} \mathrm{N}, 128^{\circ} \mathrm{E}\right), 26$ September 1984. Right: Cumulus in the western Pacific (15², $\left.169^{\circ} \mathrm{E}\right), 2$ June 1987.

Cover photographs on the land atlas were not identified there; they are as follows. Left: Cirrus over Seattle, Washington $\left(47^{\circ} \mathrm{N}, 122^{\circ} \mathrm{W}\right), 2$ December 1984 . Right: Cumulus over castem Xinjiang $\left(43^{\circ} \mathrm{N}, 9^{\circ} \mathrm{E}\right), 16$ September 1984. 


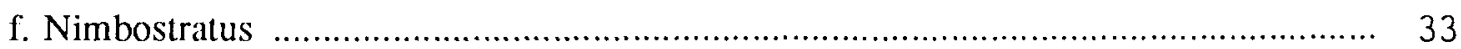

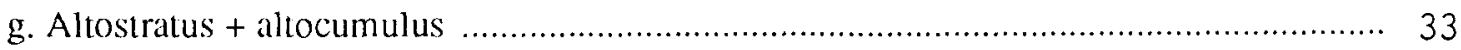

h. Cirrus + cirrostratus + cirrocumulus ...................................................................... 35

i. Sky obscured due to $f \circ g$.................................................................................

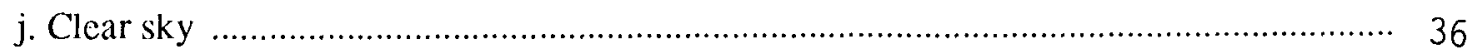

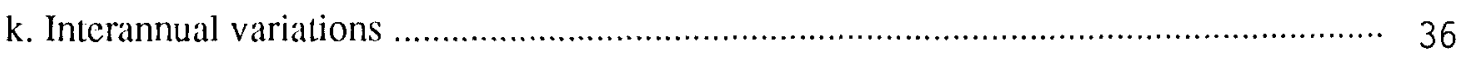

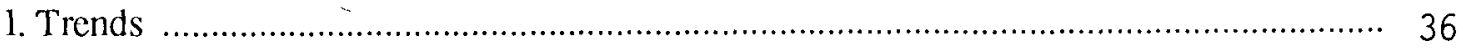

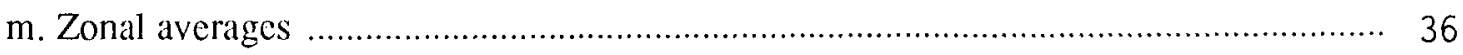

8. Comparison with earlicr ground-based cloud climatologies ...................................... 36

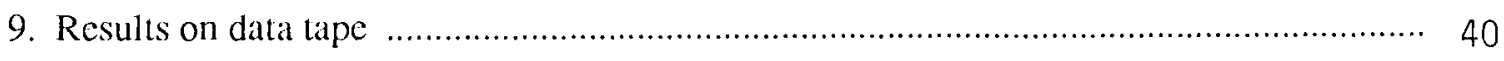

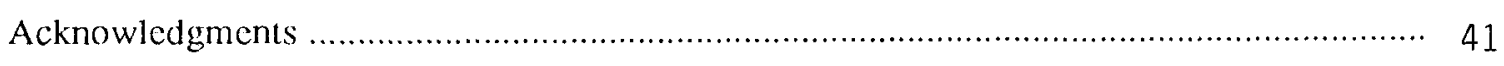

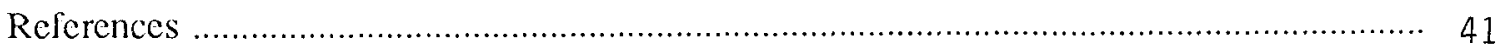

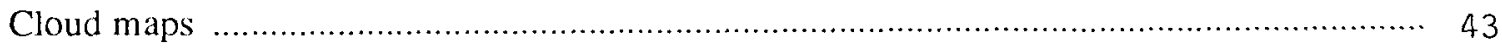

Time-series plots of seasonal cloud amounts on microfiche ……….................................. end

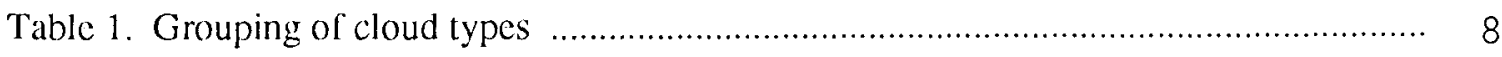

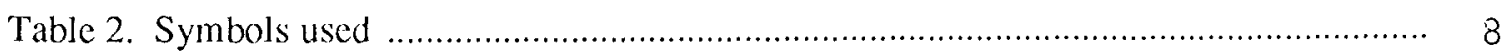

Table 3. Number of observations discarded or corrected ……...................................... 14

Table 4. Estimated changes to Ns maps which would result from

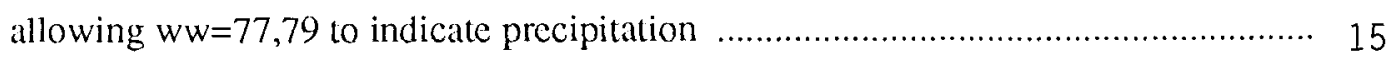

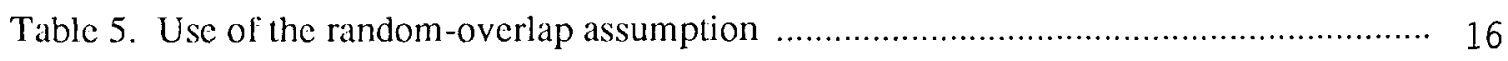

Table 6a. Test of the hidden-cloud assumption for amount-when-present ......................... 17

Table 6 b. Distribution of middle and high cloud reports among various categories ............ 17

Table 7. Data used for estimating expected error in cloud cover as a function of number of observations .................................................................. 20

Table 8. Fair-weather bias and observer bias ............................................................ 27

Table 9a. Annual average global cloud type quantities for ocean areas ............................. 34

Table 9b. Global average seasonal cloud type amounts and their interannual variations, for ocean areas ................................................................................ 34

Table 9 c. Hemispheric average seasonal cloud type amounts and their interannual variation, for ocean areas ................................................................. 35

Table 10. Quantities archived on magnetic tape for land and occan grid boxes 
Figure 1. Fraction of COADS observations in which total cloud cover is not reported

Figure 2. Number of observations per year which include total cloud cover

Figure 3. Fraction of observations which include cloud type information 10

Figure 4. Middle and high types missing

Figure 5. Frequency of reports of code values of clouds

Figure 6. Frequency of occurrence of middle and high clouds as a function of low cloud amount

Figure 7. Number of compressed observations per year

Figure 8. Expected error in mean cloud cover as a function of number of observations used

Figure 9. Examples of diurnal cycles 23

Figure 10. Zonal average total cloud cover over ocean as a function of latitude

Figure 11. Average amount of each cloud type over ocean as a function of latitude 


\section{LIST OF CLOUD MAPS}

A. $\quad 5^{\circ} \times 5^{\circ} \mathrm{MAPS}$

1. Fraction of area which is ocean

Map number

$$
1
$$

$\frac{\text { DJF* }}{2} \quad \frac{\text { MAM }}{3} \quad \frac{\text { JJA }}{4} \quad \frac{\text { SON }}{5}$

3. Total cloud cover

Average cloud cover

Standard deviation of observations

6

7

8

9

Total cloud cover by month (Jan-Dec)

10

11

12

13

Annual cycle: amplitude, phase

4. Cloud types

\begin{tabular}{|c|c|c|c|c|c|c|c|c|}
\hline & $\mathrm{Cu}$ & $\mathrm{Cb}$ & $\mathrm{St}$ & Ns & As & $\mathrm{Ci}$ & fog & clear \\
\hline & \multicolumn{8}{|c|}{ frequency of occurrence } \\
\hline DJF & 28 & 40 & 52 & 64 & 76 & 88 & 100 & 104 \\
\hline MAM & 29 & 41 & 53 & 65 & 77 & 89 & 101 & 105 \\
\hline JJA & 30 & 42 & 54 & 66 & 78 & 90 & 102 & 106 \\
\hline SON & 31 & 43 & 55 & 67 & 79 & 91 & 103 & 107 \\
\hline & \multicolumn{8}{|c|}{ amount-when-present } \\
\hline DJF & 32 & 44 & 56 & 68 & 80 & 92 & & \\
\hline MAM & 33 & 45 & 57 & 69 & 81 & 93 & & \\
\hline JJA & 34 & 46 & 58 & 70 & 82 & 94 & & \\
\hline SON & 35 & 47 & 59 & 71 & 83 & 95 & & \\
\hline & \multicolumn{8}{|c|}{ average cloud amount } \\
\hline DJF & 36 & 48 & 60 & 72 & 84 & 96 & & \\
\hline MAM & 37 & 49 & 61 & 73 & 85 & 97 & & \\
\hline JJA & 38 & 50 & 62 & 74 & 86 & 98 & & \\
\hline SON & 39 & 51 & 63 & 75 & 87 & 99 & & \\
\hline
\end{tabular}

*Abbreviations used: DJF=December, January, February; MAM=March, April, May; JJA=June, July, August; SON=September, October, November. 
B. $10^{\circ} \times 20^{\circ} \mathrm{MAPS}$

1. Fraction of area which is ocean

Map number

2. Distribution of reports

Number of compressed observations

Percent of observations made during daytime

Number of years sampled

3. Total cloud cover

Average cloud cover

Standard deviation of observations

Diurnal cycle: amplitude

Diurnal cycle: phase

Interannual variation

Trend from 1952 to 1981
DJF MAM JJA SON

$\begin{array}{llll}109 a & 109 b & 109 c & 109 d\end{array}$

$110 \mathrm{a} \quad 110 \mathrm{~b} \quad 110 \mathrm{c} \quad 110 \mathrm{~d}$

$111 \mathrm{a} \quad 111 \mathrm{~b} \quad 111 \mathrm{c} \quad 111 \mathrm{~d}$

$112 \mathrm{a} \quad 112 \mathrm{~b} \quad 112 \mathrm{c} \quad 112 \mathrm{~d}$

$113 \mathrm{a} \quad 113 \mathrm{~b} \quad 113 \mathrm{c} \quad 113 \mathrm{~d}$

$114 \mathrm{a} \quad 114 \mathrm{~b} \quad 114 \mathrm{c} \quad 114 \mathrm{~d}$

$115 \mathrm{a} \quad 115 \mathrm{~b} \quad 115 \mathrm{c} \quad 115 \mathrm{~d}$

$116 \mathrm{a} \quad 116 \mathrm{~b} \quad 116 \mathrm{c} \quad 116 \mathrm{~d}$

$117 \mathrm{a} \quad 117 \mathrm{~b} \quad 117 \mathrm{c} \quad 117 \mathrm{~d}$ 
LIST OF CLOUD MAPS (continued)

4. Cloud types

\begin{tabular}{|c|c|c|c|c|c|c|c|c|}
\hline & $\mathrm{Cu}$ & $\mathrm{Cb}$ & St & Ns & As & $\mathrm{Ci}$ & fog & clear \\
\hline & \multicolumn{8}{|c|}{ frequency of occurrence } \\
\hline DJF & $118 a$ & $126 a$ & $134 a$ & $142 \mathrm{a}$ & $149 \mathrm{a}$ & $154 a$ & $159 \mathrm{a}$ & $164 a$ \\
\hline MAM & $118 \mathrm{~b}$ & $126 \mathrm{~b}$ & $134 \mathrm{~b}$ & $142 b$ & $149 \mathrm{~b}$ & $154 b$ & $159 b$ & $164 \mathrm{~b}$ \\
\hline JJA & $118 \mathrm{c}$ & $126 \mathrm{c}$ & $134 \mathrm{c}$ & $142 c$ & $149 \mathrm{c}$ & $154 \mathrm{c}$ & $159 \mathrm{c}$ & $164 c$ \\
\hline \multirow[t]{2}{*}{ SON } & $118 \mathrm{~d}$ & $126 \mathrm{~d}$ & $134 d$ & $142 \mathrm{~d}$ & $149 \mathrm{~d}$ & $154 d$ & $159 \mathrm{~d}$ & $164 d$ \\
\hline & \multicolumn{8}{|c|}{ amount-when-present } \\
\hline DJF & $119 a$ & $127 \mathbf{a}$ & $135 \mathrm{a}$ & $143 \mathrm{a}$ & $150 \mathrm{a}$ & $155 a$ & & \\
\hline MAM & $119 \mathrm{~b}$ & $127 \mathrm{~b}$ & $135 b$ & $143 b$ & $150 \mathrm{~b}$ & $155 \mathrm{~b}$ & & \\
\hline JJA & $119 \mathrm{c}$ & $127 \mathrm{c}$ & $135 \mathrm{c}$ & $143 \mathrm{c}$ & $150 \mathrm{c}$ & $155 \mathrm{c}$ & & \\
\hline \multirow[t]{2}{*}{ SON } & $119 \mathrm{~d}$ & $127 \mathrm{~d}$ & $135 \mathrm{~d}$ & $143 d$ & $150 \mathrm{~d}$ & $155 \mathrm{~d}$ & & \\
\hline & \multicolumn{8}{|c|}{ average cloud amount } \\
\hline DJF & $120 \mathrm{a}$ & $128 \mathrm{a}$ & $136 a$ & $144 a$ & $151 \mathrm{a}$ & $156 a$ & & \\
\hline MAM & $120 \mathrm{~b}$ & $128 \mathrm{~b}$ & $136 \mathrm{~b}$ & $144 b$ & $151 \mathrm{~b}$ & $156 \mathrm{~b}$ & & \\
\hline JJA & $120 \mathrm{c}$ & $128 \mathrm{c}$ & $136 \mathrm{c}$ & $144 \mathrm{c}$ & $151 \mathrm{c}$ & $156 \mathrm{c}$ & & \\
\hline \multirow[t]{2}{*}{ SON } & $120 \mathrm{~d}$ & $128 \mathrm{~d}$ & $136 \mathrm{~d}$ & 144d & $151 d$ & $156 \mathrm{~d}$ & & \\
\hline & \multicolumn{8}{|c|}{ average base height } \\
\hline DJF & $121 \mathrm{a}$ & $129 a$ & $137 a$ & & & & & \\
\hline MAM & $121 \mathrm{~b}$ & $129 \mathrm{~b}$ & $137 \mathrm{~b}$ & & & & & \\
\hline JJA & $121 \mathrm{c}$ & $129 \mathrm{c}$ & $137 \mathrm{c}$ & & & & & \\
\hline \multirow[t]{2}{*}{ SON } & $121 \mathrm{~d}$ & $129 \mathrm{~d}$ & $137 d$ & & & & & \\
\hline & \multicolumn{8}{|c|}{ diurnal cycle amplitude, phase } \\
\hline DJF & $122 \mathrm{ab}$ & $130 \mathrm{ab}$ & $138 \mathrm{ab}$ & $145 \mathrm{ab}$ & & & $160 \mathrm{ab}$ & \\
\hline MAM & $122 \mathrm{~cd}$ & $130 \mathrm{~cd}$ & $138 \mathrm{~cd}$ & $145 \mathrm{~cd}$ & & & $160 \mathrm{~cd}$ & \\
\hline JJA & $123 a b$ & $131 a b$ & $139 a b$ & $146 a b$ & & & $161 \mathrm{ab}$ & \\
\hline \multirow[t]{2}{*}{ SON } & $123 \mathrm{~cd}$ & $131 \mathrm{~cd}$ & $139 \mathrm{~cd}$ & $146 \mathrm{~cd}$ & & & $161 \mathrm{~cd}$ & \\
\hline & \multicolumn{8}{|c|}{ interannual variation } \\
\hline DJF & $124 a$ & $132 a$ & $140 \mathrm{a}$ & $147 \mathrm{a}$ & $152 a$ & $157 \mathrm{a}$ & $162 a$ & $165 \mathrm{a}$ \\
\hline MAM & $124 \mathrm{~b}$ & $132 \mathrm{~b}$ & $140 \mathrm{~b}$ & $147 \mathrm{~b}$ & $152 b$ & $157 \mathrm{~b}$ & $162 \mathrm{~b}$ & $165 b$ \\
\hline JJA & $124 \mathrm{c}$ & $132 \mathrm{c}$ & $140 c$ & $147 \mathrm{c}$ & $152 \mathrm{c}$ & $157 \mathrm{c}$ & $162 \mathrm{c}$ & $165 \mathrm{c}$ \\
\hline \multirow[t]{2}{*}{ SON } & $124 d$ & $132 \mathrm{~d}$ & $140 \mathrm{~d}$ & $147 \mathrm{~d}$ & $152 d$ & $157 \mathrm{~d}$ & $162 \mathrm{~d}$ & $165 \mathrm{~d}$ \\
\hline & \multicolumn{8}{|c|}{ trend from 1952 to 1981} \\
\hline DJF & $125 \mathrm{a}$ & $133 a$ & $141 \mathrm{a}$ & $148 \mathrm{a}$ & $153 a$ & $158 a$ & $163 \mathbf{a}$ & $166 \mathrm{a}$ \\
\hline MAM & $125 \mathrm{~b}$ & $133 b$ & $141 \mathrm{~b}$ & $148 \mathrm{~b}$ & $153 b$ & $158 \mathrm{~b}$ & $163 \mathrm{~b}$ & $166 \mathrm{~b}$ \\
\hline JJA & $125 \mathrm{c}$ & $133 \mathrm{c}$ & $141 \mathrm{c}$ & $148 \mathrm{c}$ & $153 c$ & $158 \mathrm{c}$ & $163 \mathrm{c}$ & $166 \mathrm{c}$ \\
\hline SON & $125 \mathrm{~d}$ & $133 d$ & 141d & $148 \mathrm{~d}$ & $153 d$ & $158 \mathrm{~d}$ & $163 d$ & $166 \mathrm{~d}$ \\
\hline
\end{tabular}

\begin{tabular}{llllll} 
& Most-frequently-occurring cloud type & $\frac{D J F}{167 a}$ & $\frac{\text { MAM }}{167 b}$ & $\frac{\text { JJA }}{167 \mathrm{c}}$ & $\frac{\text { SON }}{167 \mathrm{~d}}$ \\
Cloud type contributing most to total cloud cover & $168 \mathrm{a}$ & $168 \mathrm{~b}$ & $168 \mathrm{c}$ & $168 \mathrm{~d}$ \\
\cline { 2 - 5 } & Blank Maps & \multicolumn{3}{c}{169,170} &
\end{tabular}


LIST OF MICROFICHE CARDS (Time Series of Seasonal Cloud Amounts)

A. Seasonal $\left(10^{\circ} \times 20^{\circ}\right.$ boxes, $10^{\circ}$ zones,

DJF MAM JJA SON

hemispheres, and globe)

\begin{tabular}{lrrrr} 
total cloud cover & 1 & 2 & 3 & 4 \\
cumulus amount & 5 & 6 & 7 & 8 \\
cumulonimbus amount & 9 & 10 & 11 & 12 \\
$\mathrm{St}+\mathrm{Sc}+$ fog amount & 13 & 14 & 15 & 16 \\
Nimbostratus amount & 17 & 18 & 19 & 20 \\
As + Ac amount & 21 & 22 & 23 & 24 \\
Ci + Cs + Cc amount & 25 & 26 & 27 & 28 \\
fog frequency & 29 & 30 & 31 & 32 \\
clear-sky frequency & 33 & 34 & 35 & 36 \\
\cline { 2 - 5 }
\end{tabular}

B. Annual $\left(10^{\circ}\right.$ zones, hemispheres, and globe $)$ 


\section{INTRODUCTION}

Clouds have important roles in earth-atmosphere energy exchanges, and in the hydrological cycle. The effects of clouds depend on cloud thickness, height, water or ice content, and geometrical shape, and therefore it is useful to distinguish different types of cloud. In this atlas we present the distribution of total cloud cover and the amounts of several cloud types for the ocean areas of the earth, as obtained by analysis of surface weather observations. This atlas complements our cloud climatology for the land (Warren et al., 1986), which will often be referred to here as "the land atlas". Since the methods of analysis are in large part the same for both ocean and land cloud observations, extensive discussion of those methods is not repeated here. The text of the land atlas should be considered as background information for this atlas. The text of this atlas discusses problems which are specific to the ocean data

The land atlas presented a method for determining the average fractional coverage of each cloud type, taking into account the overlap of different cloud types which were present simultaneously in a single observation from the surface. The method was designed to derive the true average amounts rather than the amounts seen from below or above. (The amounts scen from below or above will be referred to as the non-overlapped amounts.) The method obtains separately the average frequency of occurrence and the average amount-when-present, and multiplics these to derive the average amount of the cloud type. These quantities are mapped for six cloud types for each of four seasons at $5^{\circ} \times 5^{\circ}$ latitude-longitude resolution. [Poleward of $50^{\circ}$ latitude the size of the grid boxes is increased in longitude to maintain approximately cqual area in each box. For convenience, the term " $5^{\circ} \times 5^{\circ}$ box" is used to refer to any of these boxes.] They are also mapped at $10^{\circ} \times 20^{\circ}$ latitude-longitude resolution to provide more complete geographical coverage. The average total cloud cover is also mapped at both resolutions. Diurnal and interannual variations, and base heights of the low cloud types, are mapped only at $10^{\circ} \times 20^{\circ}$ resolution becausc in many parts of the ocean there are insufficient numbers of observations to compute these quantitics at $5^{\circ} \times 5^{\circ}$ resolution. More detailed information, not included in this atlas, such as average frequencies and amounts for individual year-seasons and individual reporting-hours, are available on a magnetic tape (Sec. 9). Time-series plots of the amount of each cloud type (for the 30 years 1952-81), and of total cloud cover (for the 52 years $1930-1981$ ) for each $10^{\circ} \times 20^{\circ}$ box are included on microfiche (attached inside the back cover).

This climatology is based entirely on weather observations from ships. It will therefore be complementary to cloud climatologies derived from satellite data such as the International Satellite Cloud Climatology Project (ISCCP). Satellites can be expected to provide more information about the high clouds, whereas ground observers often have a better view of the low clouds. Satellites also observe the clouds more frequently than do observers on ships, in most parts of the 
ocean; and satellites are in the best position to determine the effects of clouds on the earth's radiation budget. Ground-based observers have the advantages that they are closer to the clouds and that they can make use of pattern-recognition, so they can readily identify the different types of cloud. Ground-based observations are also available for a longer period of years than are satellite observations. Ground-based cloud reports are less "objective" than satellite-derived estimates of clouds, but when large numbers of observations are available, the averages can be quite precise. To quote McDonald's Atlas of Climatic Charts of the Oceans (1938):

"It is not within the scope of this atlas to attempt an explanation of the phenomena and their variations. A careful study of the charts will demonstrate, however, that the observations supplied by seamen have not been careless or perfunctory; otherwise, the seasonal and geographical variations of the various elements would not be so consistently in evidence."

\section{DATA SOURCE}

The only type of data used for this climatology is the individual routine weather observations made from ships and coded by the observers into the standard form (at the time) of the WMO synoptic code (e.g. WMO, 1974). No observations from islands or coastal weather stations are included. We began our study using the Consolidated Data Set (CDS) of the Fleet Numerical Oceanography Center (FNOC) covering the years 1946-78. That was the source of data for our atlas of co-occurrence of different cloud types over the ocean (Hahn et al., 1982). Subsequently, the Comprehensive Ocean-Atmosphere Data Set (COADS; Woodruff et al., 1987) became available, and we used it for this study principally because it contains many more observations than does the FNOC-CDS. We used the "compressed marine reports", listed as Product 10 in Table 5 of Woodruff et al. (1987). This is the dataset of individual observations, not monthly summaries. We used an early version of this dataset, Version CMR.4, obtained from Scott Woodruff (NOAA-ERL).

The COADS project merged several existing datasets of synoptic observations from ships, primarily merchant ships but also military ships and weatherships. [Ocean data buoys are also included in the same format, but they of course contain no information about clouds.] A major source for COADS was the dataset used and described in the Marine Climatic Atlas of the World (U.S. Navy, 1974-1979). Many observations were present in more than one of the source datasets; after the elimination of as many of these duplicates as possible there remained 70 million observations for the years 1854-1979. There are many observations from those years which are still not included in COADS because they exist only in archived logbooks of the ships and have not yet been keyed into a computer-readable storage medium. The COADS project is continuing, and observations for 1980 and later years are being added. Since data for the 1980s were not yet available from COADS at the time of our analysis, we used for these recent ycars the 
dataset of observations received via telecommunications by FNOC. The number of observations per year available to us from the 1980s is only about half that of a typical year in the 1970s because we have only the observations that were transmitted by radio and not those that were recorded only in the ships' logbooks.

COADS contains sufficient numbers of observations in some parts of the ocean to extend our climatology as far back as 1890 . However, the synoptic code for cloud types was not defined until 1930, so we did not analyze any observations prior to 1930 . We have further restricted most of our analyses to the 30-year period 1952-1981, inclusive. The reason for not using data prior to 1952 is that observing procedures in those years were not consistent for ships of all countrics, as discussed below. The reason for not using data after 1981 is that there were changes in the synoptic code in January 1982 which, together with our quality-control procedures, would introduce biases into the analysis. [However, the analysis of diumal cycles did use data through 1983, as described below.]

The analyses are done for each of the four meteorological seasons, designated by the first letter of each month: DJF, MAM, JJA, SON, where (for example) DJF 1979 includes the months December 1978 - February 1979. The data therefore include all months December 1951 November 1981.

The observations are normally made every three or six hours, with considerably more observations at GMT hours divisible by 6 . Prior to 1940 , observations were equally likely at any of the 24 hours. The practice of reporting only at GMT hours divisible by 3 (the cight "synoplic hours") apparently began in the 1940s and was almost universal by 1950 (based on our inventory of COADS data). In our analysis of the diurnal cycle, we use only these eight hours, so observations made at other times are grouped together with those of the nearest synoptic hour. Somewhat less than $2 \%$ of the observations are made at GMT hours not divisible by 3 .

Observations from ships are made around-the-clock; the night-time hours are sampled almost as well as the daytime hours. However, on some ships the observations made at night are not transmitted until the next day. FNOC (for example) will not archive observations received more than 21 hours after they are made. This leads to a daytime bias in the years beginning 1980 because we have the logbook data only through 1979. It has a very small effect on our multi-year average cloud amounts but does cause a small apparent increase in cloud cover after 1979 discussed below in Section 4 .

Not all the observations in COADS contain cloud information. About $6 \%$ of the 1930-1979 observations do not report total cloud cover (Figure 1). Many of these non-cloud observations in the late 1970s are from buoys, but we do not know the reason for the time-dependence of the absence of information on total cloud cover in the years 1945-1950. One reason for missing clements in COADS was the practice of eliminating some types of erroneous data from the Marine 


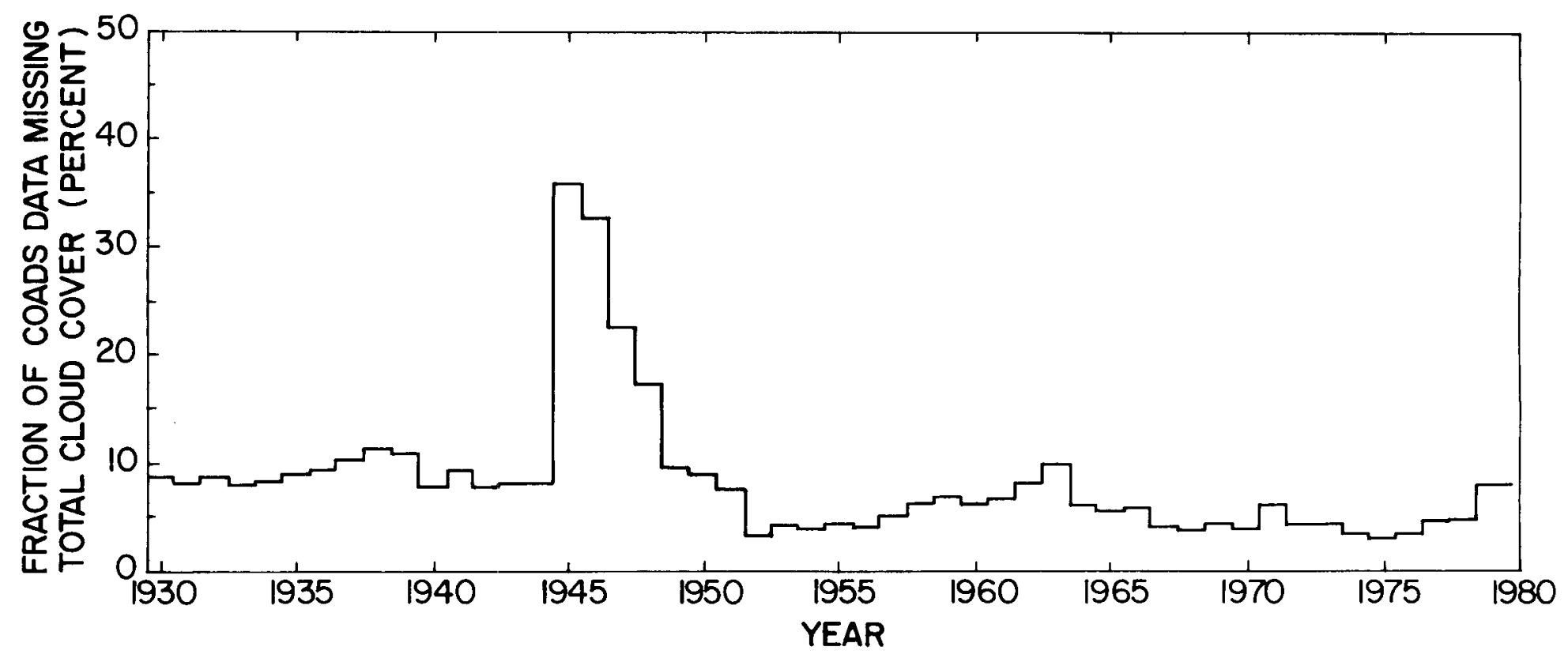

Figure 1. Fraction of COADS observations which do not include total cloud cover N.

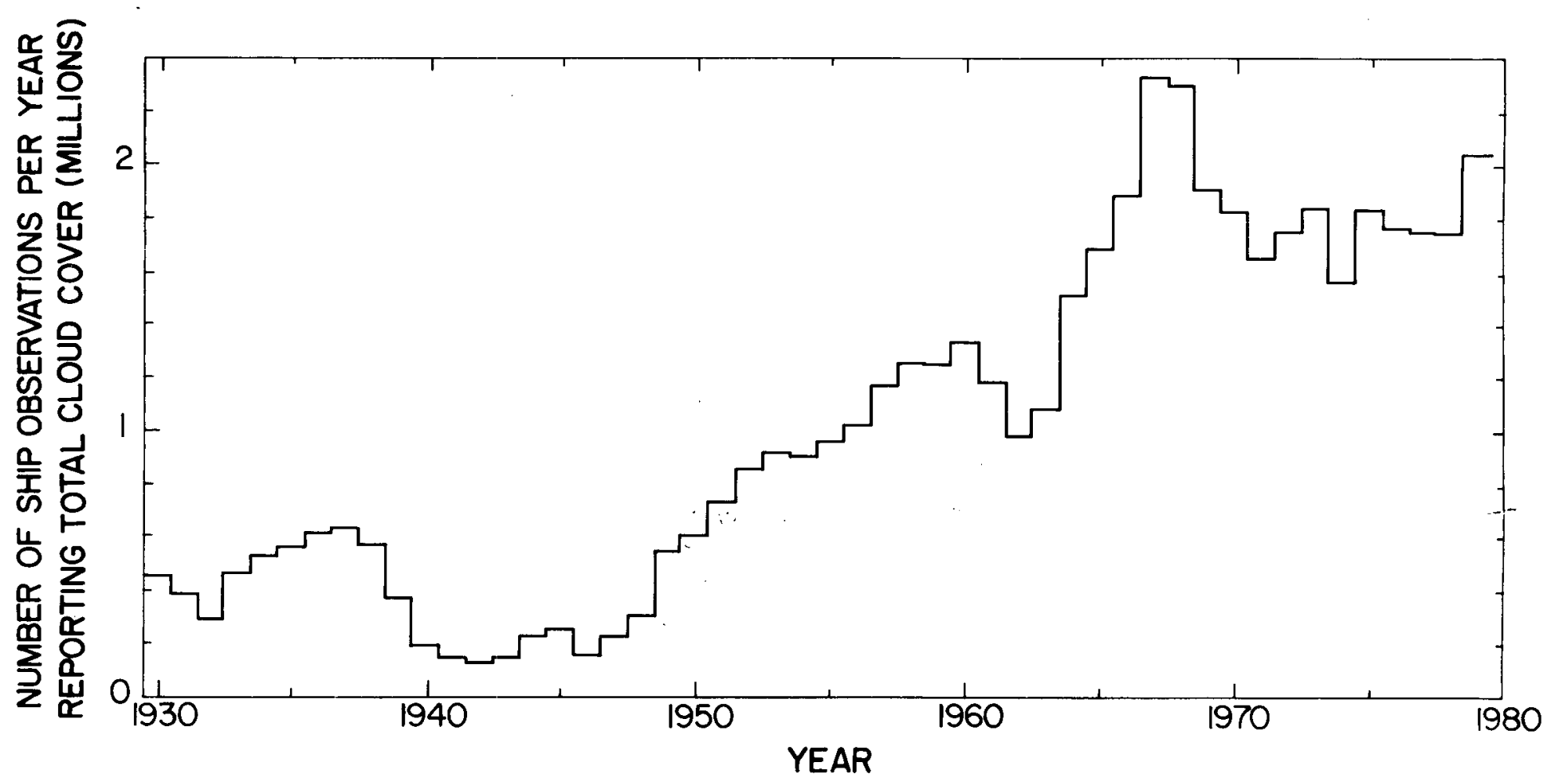

Figure 2. Number of ship observations in COADS reporting total cloud cover. 
Climatic Atlas files which were later used to create COADS.

Of the 70 million observations in COADS (total period of record 1856-1979) we used 41.6 million which were from the restricted period 1952-1979 and which included total cloud cover. We supplemented these with 1.7 million observations from 1980-81 obtained from FNOC, giving a total of 43.3 million observations used for the analyses in this atlas. [We subsequently learned that a more complete set of data for 1980-81 would have been available from NCDC.] For a special study of long-term changes of total cloud cover (included on the microfiche plots but not on the maps) we used an additional 8.5 million observations from COADS for the period 1930-1951. The number of observations per year from COADS which included total cloud cover is shown in Figure 2.

\section{a. Cloud information in the synoptic code}

The information on clouds which we used from the synoptic weather reports consisted of total cloud cover $(N)$, lower cloud amount $\left(N_{h}\right)$, low cloud type $\left(C_{L}\right)$, middle cloud type $\left(C_{M}\right)$, high cloud type $\left(C_{\mathrm{I}}\right)$, present weather ( $\left.w w\right)$, and base height of the lowest cloud (h). If information was lacking in a particular category, a slash $(S)$ was recorded by the observer. In the cloud portion of the report, the same code used by land stations is also used by ships.

$\mathrm{N}$ and $\mathrm{N}_{\mathrm{h}}$ are integers from 0 to 8 , signifying eighths of sky-cover, rounded to the nearest eighth, except that $\mathrm{N}=0$ means completely clear sky and $\mathrm{N}=8$ means completely unbroken overcast. $\mathrm{N}=9$ means "sky obscured", often due to fog, rain or snow. In cases of $\mathrm{N}=9$ we consult the present weather code in order to determine the cloud type, if any. If ww indicates fog, rain, snow, or thunderstorm, a cloud type is then assigned as indicated in Table 1, with symbols defined in Table 2. If the sky is obscured for other reasons, e.g. haze, smoke or darkness, the report is discarded (2.6\% of all reports). $\mathrm{C}_{\mathrm{L}}, \mathrm{C}_{\mathrm{M}}$, and $\mathrm{C}_{\mathrm{H}}$ can obtain values $1-9$, signifying onc of 27 defined types ( 9 for each level), or 0 , meaning no clouds at that level. $\mathrm{N}_{h}$ is the amount of all low clouds present, but if $C_{L}=0$ then $N_{h}$ is the amount of middle clouds. The base height of the lowest cloud present, whether low or middle, is coded in $\mathrm{h}$ as a number from 0 to 9 . This is the height of the lowest part of the lowest cloud present, even if the predominant low cloud layer is higher. [There is more detailed supplementary information on clouds in the optional section of some of the synoptic reports. We did not analyze these "significant cloud" observations because they are not often included in the reports and because the reporting practices vary from one country to another.]

A history of the synoptic code is given by National Climatic Data Center (1962). In the code as defined in 1921 the quantities $\mathrm{N}, \mathrm{N}_{\mathrm{h}}$, h, and ww were included. In 1929 the cloud types $C_{L}, C_{M}$ and $C_{H}$ were added to the code, to be used beginning 1930 . We therefore initially 
Table 1. Grouping of cloud types

cloud types used shorthand

observer codes included

in this paper notation in each type ${ }^{1}$

$\mathrm{Ci} / \mathrm{Cs} / \mathrm{Cc}$

As/Ac

$\mathrm{Ns}^{2}$

$\mathrm{Cu}$

$\mathrm{St} / \mathrm{Sc}$

$\mathrm{Cb}^{5}$
$\mathrm{Ci}$

As

Ns

$\mathrm{Cu}$

St

$\mathrm{Cb}$
$\mathrm{C}_{\mathrm{H}}$ 1-9

$\mathrm{C}_{M} 1,3,4,5,6,8,9 ; \mathrm{C}_{\mathrm{M}} 2,7$ if not precipitating ${ }^{3}$

If (precipitating) ${ }^{3}$ and $\left(\mathrm{C}_{\mathrm{M}} 2,7\right.$ or $\left.\mathrm{C}_{\mathrm{L}} 6,7\right)$

$\mathrm{C}_{\mathrm{L}} 1,2$

$\mathrm{C}_{\mathrm{L}} 4,5,8 ; \mathrm{C}_{\mathrm{L}} 6,7$ if not precipitating ${ }^{3}$ or if $\mathrm{C}_{\mathrm{M}}=2,7, /$; $\mathrm{N}=9$ with fog $^{4}$

$\mathrm{C}_{\mathrm{L}} 3,9$

${ }^{1} \mathrm{C}_{\mathrm{H}}=$ high cloud type; $\mathrm{C}_{\mathrm{M}}=$ middle cloud type; $\mathrm{C}_{\mathrm{L}}=$ low cloud type. The numbering scheme is defined in WMO (1956).

${ }^{2} \mathrm{Ns}$ is also considered to be present when the cloud reports indicate "sky obscured"

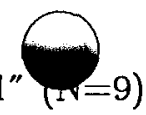
due to rain or snow (present weather code ww 50-75). Note that if the report has both $\left(\mathrm{C}_{\mathrm{M}}=2\right.$ or 7$)$ and $\left(\mathrm{C}_{\mathrm{L}}=6\right.$ or 7$)$ with precipitation, this is counted as a co-occurrence of Ns with St. The case $C_{M}=/$ and $C_{L}=4,5,8$ with precipitation is also considered to be a co-occurrence of Ns with St. The present weather codes are defined in WMO (1974).

3"Precipitating" means present weather code 50-75.

4"Fog" means present weather code $10-12$ or $40-49$.

${ }^{5} \mathrm{Cb}$ is also considered to be present when the cloud report indicates "sky obscured" and the present weather code is $80-99$. This combination occurs in only $0.2 \%$ of the observations. 
Table 2. Symbols Used

a) in synoptic code

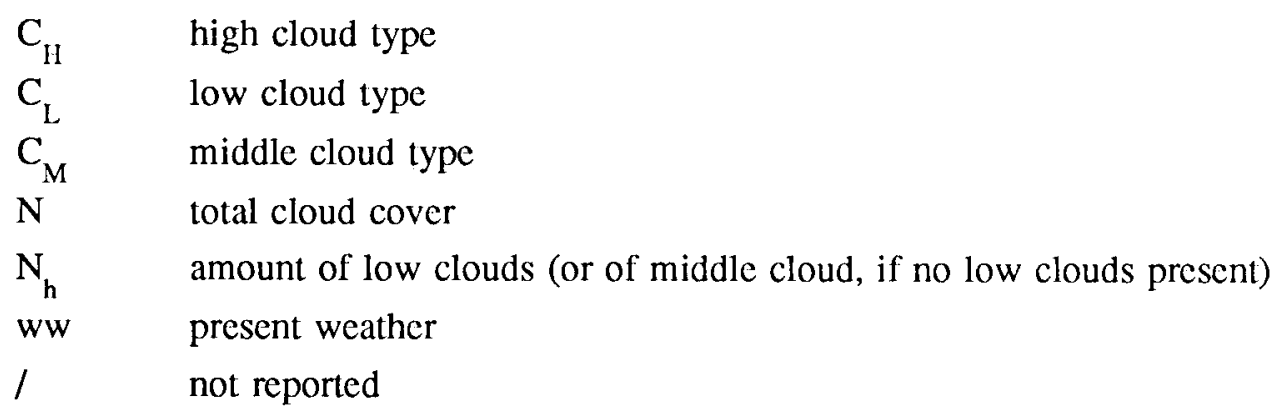

b) in Table 3

F fog (ww 10-12, 40-49)

LAT latitude

LON longitude

$\mathrm{R}$ rain or snow (ww 50-75)

$\mathrm{T}$ thunderstorm (ww 80-99)

c) for cloud types
Ac Altocumulus
As Altostratus; shorthand for As/Ac
$\mathrm{Cb}$ Cumulonimbus
Cc Cirrocumulus
$\mathrm{Ci} \quad$ Cirrus; shorthand for $\mathrm{Ci} / \mathrm{Cs} / \mathrm{Cc}$
Cs Cirrostratus
$\mathrm{Cu} \quad$ Cumulus
Ns Nimbostratus
Sc Stratocumulus
St Stratus; shorthand for St/Sc/fog 
d) in analysis

$\begin{array}{ll}\text { awp } & \text { amount-when-present } \\ \text { f } & \text { fractional frequency of occurrence } \\ \text { GMT } & \text { Greenwich mean time } \\ \text { IAV } & \text { interannual variation } \\ \text { LT } & \text { local time } \\ \text { RMS } & \text { root mean square } \\ \text { sd } & \text { standard deviation }\end{array}$

e) acronyms

CDIAC Carbon Dioxide Information Analysis Center (Department of Energy, Oak Ridge, Tennessee)

CDS Consolidated Data Set of FNOC

CIRES Cooperative Institute for Research in Environmental Sciences (Univ. of Colorado)

CMR Condensed marine reports of COADS

COADS Comprehensive Ocean-Atmosphere Data Set (Woodruff et al, 1987)

CSIRO Commonwealth Scientific and Industrial Research Organization (Australia)

ERL Environmental Research Laboratories of NOAA (Boulder, Colorado)

FGGE First GARP Global Experiment (Dec. 1978 -Nov. 1979)

FNOC Fleet Numerical Oceanography Center (Monterey, Califormia)

GARP Global Atmospheric Research Program

GFDL Geophysical Fluid Dynamics Laboratory of NOAA (Princeton, New Jersey)

HSST Historic Sea-Surface Temperature Project

ISCCP International Satellite Cloud Climatology Project

ITCZ Intertropical Convergence Zone

NASA National Aeronautics and Space Administration

NCAR National Center for Atmospheric Research (Boulder, Colorado)

NCDC National Climatic Data Center (Asheville, North Carolina)

NOAA National Oceanic and Atmospheric Administration

SPCZ Southern Pacific Convergence Zone

WMO World Meteorological Organization

3DNEPH 3-dimensional Nephanalysis (U.S. Air Force) 
planned to analyze all data from COADS beginning 1930. Our inventory of these data, however, shows that it was not until after 1950 that the reporting procedures for 1930 were uniformly adopted, so that it is not useful to look for interdecadal changes in cloud variables prior to 1950 , with the possible exception of total cloud cover.

\section{b. Inventory of COADS cloud data and changes in observing procedures}

Although most of the of the individual reports in COADS provide information on total cloud cover, the cloud types are missing prior to 1930 when they were added to the synoptic code. [Present weather is also missing prior to 1930 even though it was introduced into the code in 1921.] COADS contains many observations from the Historic Sea Surface Temperature (HSST) project for the years 1861-1960. All observations from HSST are missing cloud types and present weather. This is not because the observers were negligent, but rather because the HSST project did not keypunch the present-weather and cloud type information from the logbooks. Total cloud cover data are present in these observations. The HSST contributes about $16 \%$ of the total volume of COADS in the 1950s.

It appears that many of the observations, even after 1930, which do include cloud type information were not actually coded into the International Meteorological Organization code by the observer. The evidence for this is that certain codes ( $w$ w 20-39; $C_{L} 2,4 ; C_{M} 4,6,8,9 ; C_{I I} 3,4$ ) almost never appear in the pre - 1940 data. This suggests that informal observations in the logbook were coded later by data processors into the standard code. We will show that the inclusion of such data in our analysis would cause spurious trends in cloud amounts.

Many different data sets were merged for COADS, and complete documentation is not available for each of them, telling how the logbook entries were coded. Since we cannot track down all the reasons for errors that may have entered during the coding or compilation procedures, we just inventory the data in a variety of ways so that we can decide whether to exclude whole classes of data that we judge to be unreliable.

\section{1) Cloud type information}

In what follows, we consider only those observations which include total cloud cover $\mathrm{N}$. [All other observations (Figure 1) were discarded.] Of this set of observations, in the 1970s, about $99 \%$ also report ww, $91 \%$ report $\mathrm{N}_{\mathrm{h}}, 86 \%$ report $\mathrm{C}_{\mathrm{L}}, 84 \%$ report $\mathrm{h}, 68 \%$ report $\mathrm{C}_{\mathrm{M}}$ and $60 \%$ report $\mathrm{C}_{\mathrm{H}}$. These statistics differ somewhat from those for the land stations (Table 1 of the land atlas). The number of reports of $C_{M}$ and $C_{H}$ is lower than that of $C_{L}$, because observations of low overcast lack information about $\mathrm{C}_{\mathrm{M}}$ and $\mathrm{C}_{\mathrm{H}}$.

In the earlier years a smaller fraction of the observations included cloud type information. Figure 3a shows that the reporting of $\mathrm{N}_{\mathrm{h}}$ and $\mathrm{h}$ was almost nonexistent before 1940, increased 


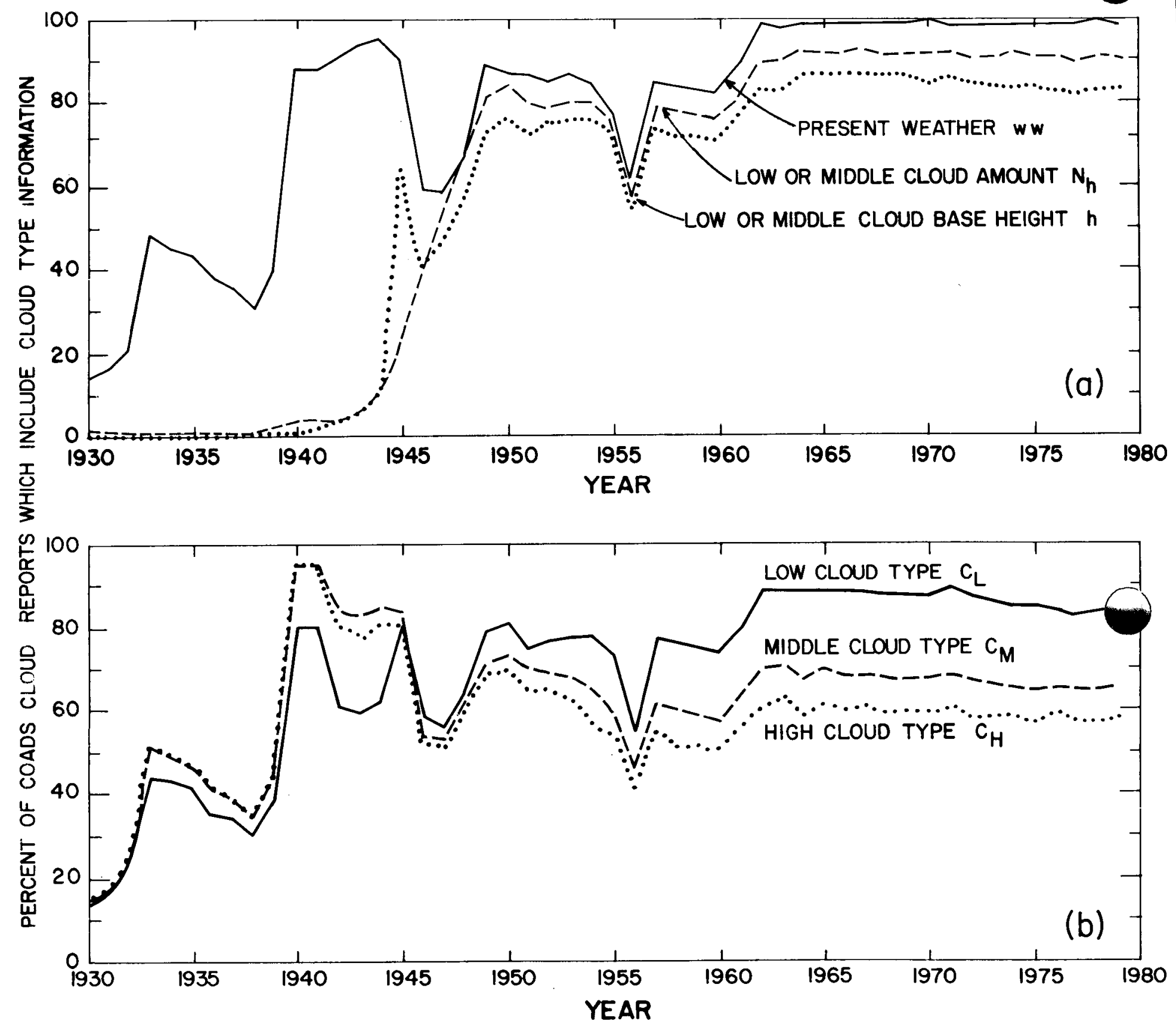

Figure 3. Percent of ocean cloud reports (i.e. of reports which include total cloud cover $\mathrm{N}$ ) which include cloud type information. (a) Present weather, low-or-middle cloud amount, low-or-middle cloud base height; (b) low, middle, and high cloud types. 
sharply by 1948 , and reached its present level by about 1960-62. This final increase occurs because the HSST data, in which cloud-type information had been artificially deleted, do not contribute any observations to COADS after 1961. We estimate from Figure 3 (and other figures below) that the non-HSST observations reached their present level of quality around 1948. However, the dip in Figure 3 at 1956 is unexplained.

The reporting of ww (Figure 3a) is more common than $N_{h}$ in the 1930s and 1940s (ww is generally reported whenever $C_{L}$ is) but follows the same pattern as $N_{h}$ after 1947.

Figure $3 \mathrm{~b}$ suggests that the modern normal pattern of reporting practice for $\mathrm{C}_{\mathrm{L}}, \mathrm{C}_{\mathrm{M}}$, and $\mathrm{C}_{\mathrm{H}}$ was achieved by 1949. However, the years before 1945 are very odd indeed, because $C_{M}$ and $C_{H}$ appear more often than $\mathrm{C}_{\mathrm{L}}$. A common "observation" in the 1930s, consistent with this anomaly, is ww=61, N=8, $N_{h}=/, C_{L}=1, C_{M}=2, C_{H}=0$. Such an observation is probably a report of nimbostratus which was coded not by the observer but rather by a later recipient of the data. Since our analysis procedure for cloud types (Figures 1-4 of the land atlas) discards observations in which $\mathrm{C}_{\mathrm{L}}$ is missing, we would underestimate the amount of Ns in the 1930s.

\section{2) Middle and high types missing}

A common coding error is to report $\mathrm{C}_{\mathrm{M}}=0$ or $\mathrm{C}_{\mathrm{H}}=0$ when the lower cloud is overcast $\left(\mathrm{N}_{\mathrm{h}}=8\right)$. The correct report would have $\mathrm{C}_{\mathrm{M}}$ and $\mathrm{C}_{\mathrm{H}}$ coded as missing. Figure 4 suggests that this error is much more common in earlier years. In the 1930s, the observations which include a low cloud report almost never have $\mathrm{C}_{\mathrm{H}}=1$.

In our analysis, we correct these miscoded observations by converting $\mathrm{C}_{\mathrm{II}}=0$ to $\mathrm{C}_{\mathrm{II}}=/$ and $C_{M}=0$ to $C_{M}=/$ when appropriate (Figure 1 of the land atlas). However, our procedure probably does not catch all the observations miscoded in this way. For example, observers code $\mathrm{C}_{\mathrm{H}}=/$ not only when $\mathrm{N}_{h}=8$ but also sometimes when $\mathrm{N}_{h}=7$. Thus a straightforward analysis of COADS would lead to an apparent increase with time of the frequency of high and middle clouds. We avoid this bias by performing the analysis for frequency of high types only on the set of observations for which $N_{h} \leq 6$, as discussed further in Section 3d.

\section{3) Low cloud height}

Figure 5 is in the form of histograms showing the frequency distributions of reports in several multi-year epochs. The dataset is broken into ten epochs with about five million observations each, starting with 1930-39 and ending with 1977-79.

The reports which include an estimate of low cloud height are grouped according to height class in Figure 5a. The most commonly reported height is class 5 (600-1000 m) for 1930-1949, changing gradually to class $4(300-600 \mathrm{~m})$ by 1955 . We might speculate that this change is the result of more accurate reporting beginning during the 1940s because of increasing opportunities for calibration by reports from aircraft, rather than any real change in the cloud base heights over that time. 

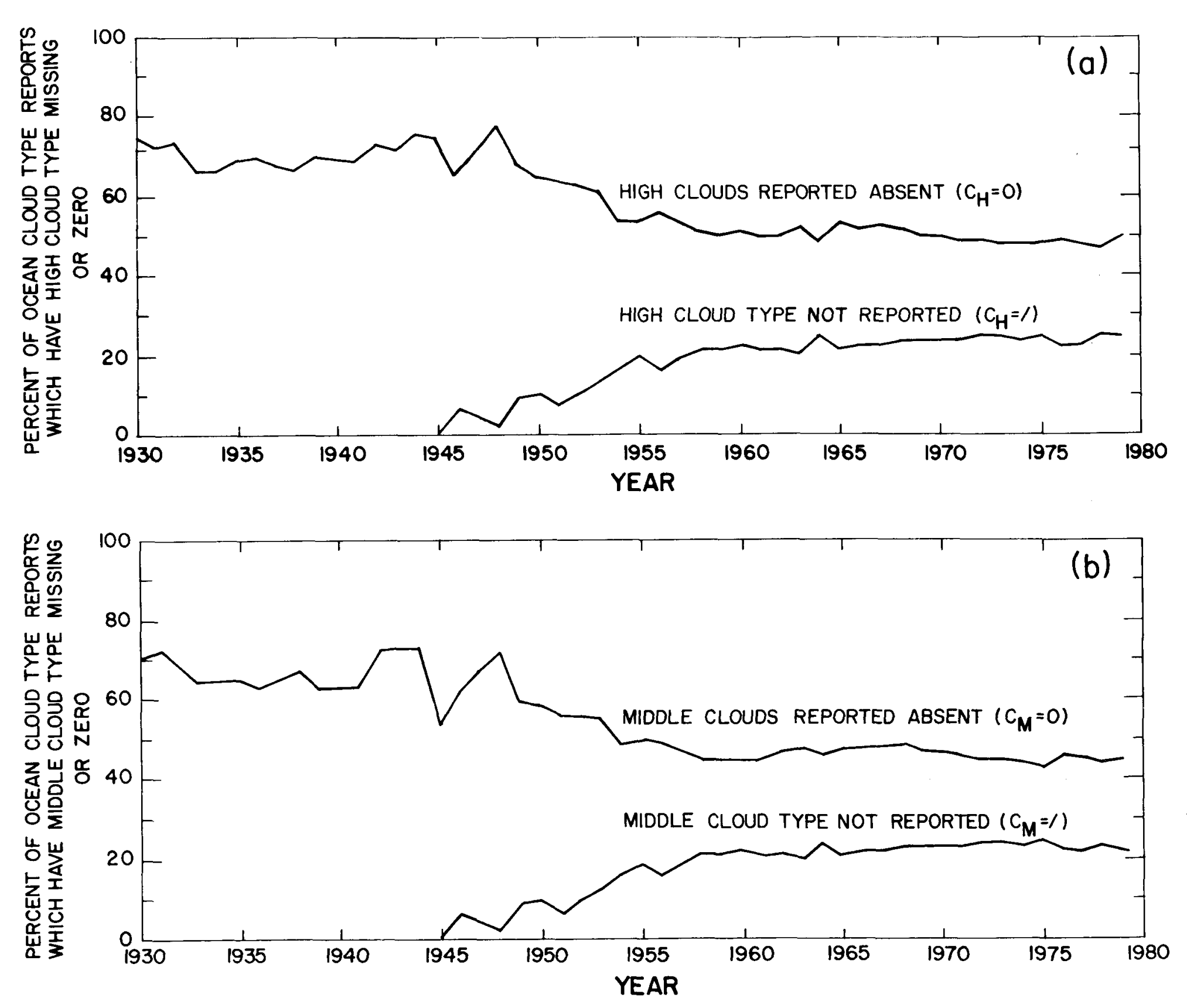

Figure 4. Percent of ocean cloud type reports (i.e. of reports which include low cloud type $\mathrm{C}_{\mathrm{L}}$ ) which have (a) high type missing or zero; (b) middle type missing or zero.

\section{4) Total cloud cover and low cloud amount}

Figure $5 \mathrm{~b}$ shows that the reporting of total cloud cover stabilized about 1950. Earlicr years had a greater percentage of reports of $\mathrm{N}=2$ and $\mathrm{N}=6$. This is probably due to roundoff in the conversion of a report of cloud cover in tenths to the present code of cloud cover in eighths: both $2 / 10$ and $3 / 10$ round to $2 / 8$; and both $7 / 10$ and $8 / 10$ round to $6 / 8$. It is unlikely that this characteristic of the data would bias our analysis of trends for total cloud cover. The frequency of $\mathrm{N}=8$ is lower in 1930-1949, then stabilizes after 1950.

The frequency of $\mathrm{N}=9$ (sky obscured) increases throughout the period 1930-1979. The sky is often obscured due to fog, and sometimes due to rain or snow. The reporting of both of thesc obscuring conditions has increased with time. Ships in conditions of poor visibility sometimes neglect weather observations because they are too büsy with navigation to take time for the weather report. We might speculate that this increase with time of $\mathrm{N}=9$ means that the tendency to skip observations during times of poor visibility has decreased with time. However, there is an even greater increase in the reporting of $\mathrm{N}=9$ in the absence of fog or precipitation, which we cannot explain.

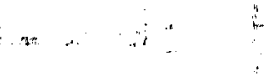

Figure $5 c$ shows the distribution of reports of lower-cloud amount $N_{h} . N_{h}=0$ appears to be reported far too often in the 1930s. This may be the result of incorrect re-coding of the observations by data processors, as suggested by Wright (1986). The frequency of $N_{h}=8$, by contrast, seems too low in the carly years; it stabilizes about 1955.

\section{5) Low, middle and high cloud types}

Figure $5 \mathrm{~d}$ shows the distributions of low cloud type. Frequencies of the cumulus types $C_{L}=1$ and $C_{L}=2$ are about equal after 1955. Prior to $1955, C_{L}=1$ dominates at the expense of $C_{L}=2$. Cumulonimbus type $C_{L}=9$ is rather large in the 1930s. Total $\mathrm{Cb}$ (the sum of $C_{L}=3$ and $\left.C_{L}=9\right)$ stabilizes after 1940. The frequencies of stratus $\left(C_{L}=6\right.$ and $\left.C_{L}=7\right)$ appear sicady after 1950 .

In the middle-cloud-type distribution (Figure 5e) the frequency of $\mathrm{C}_{\mathrm{M}}=2$ (nimbostratus or thick altostratus) before 1950 is far in excess of values for subsequent years. The high-cloud-type distribution (Figure 5f) remains nearly constant after 1954. Since we group all high types together in this atlas (Table 1), changes in this distribution do not affect our analysis.

\section{6) Summary}

We conclude that the analysis of cloud types should be restricted to the 30 year period 1952-1981. Low cloud height distributions were still changing in 1952, and we consider those 


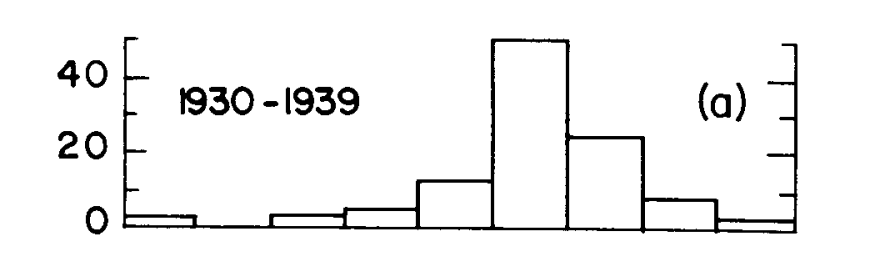
${ }^{40}$

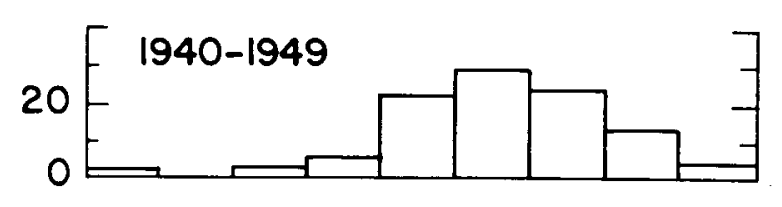
20

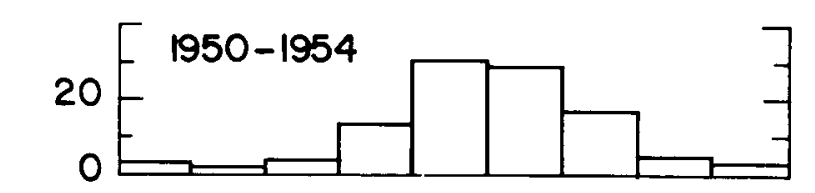
20
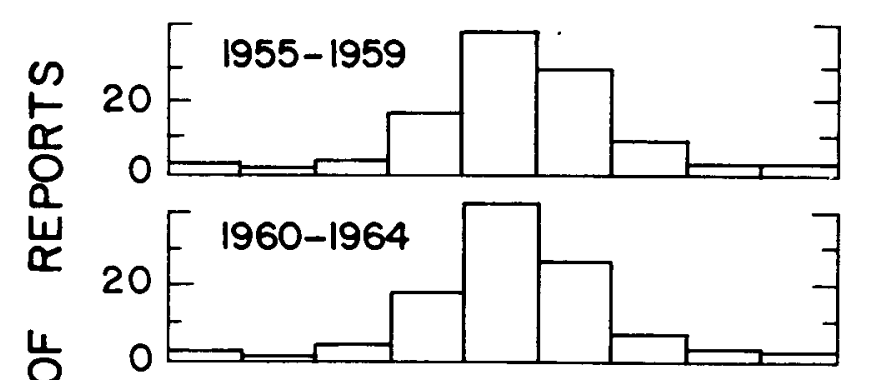

능
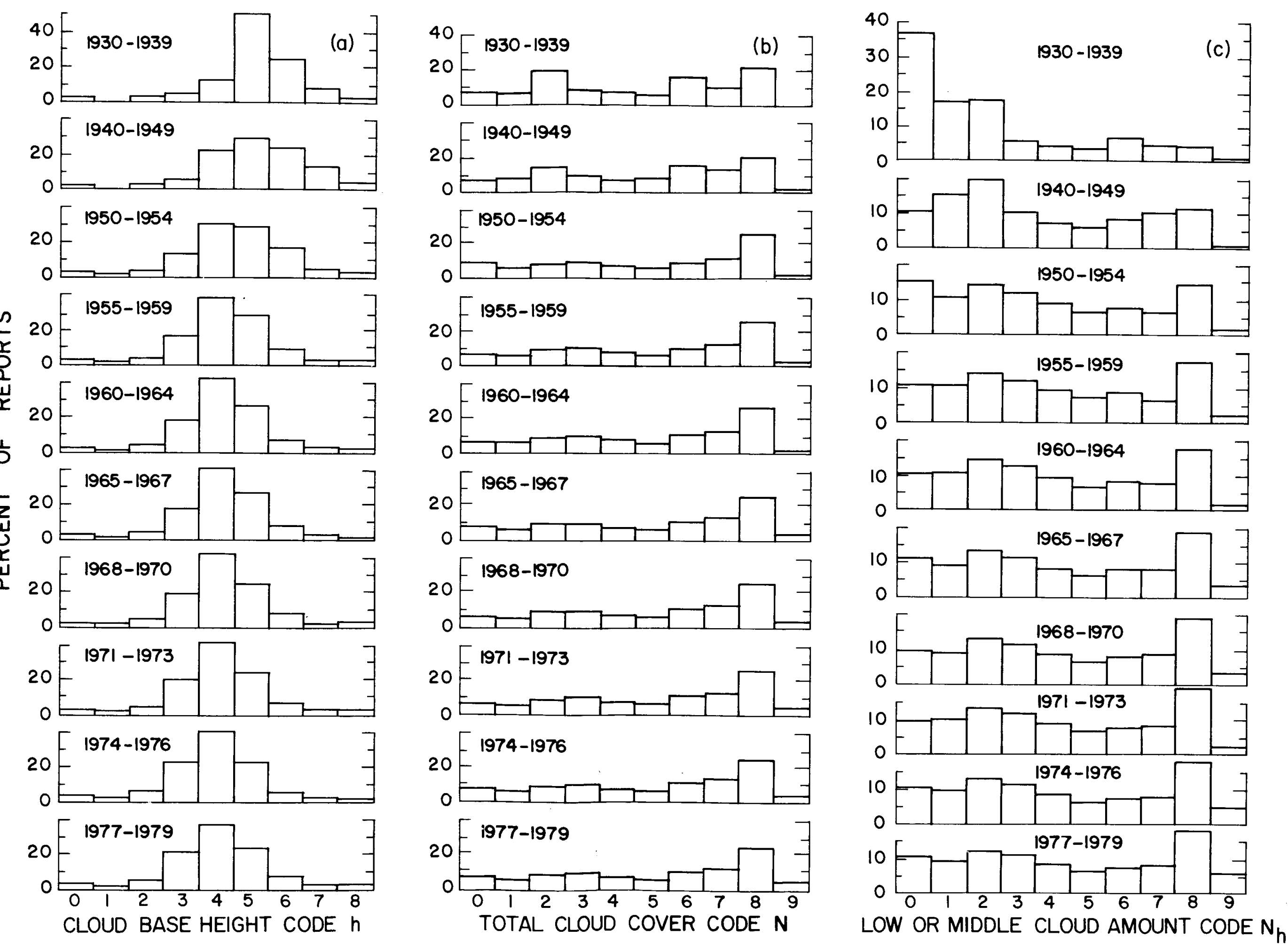

Figure 5. Frequency distribution of code values in reports from ships in the entire ocean, for ten epochs of about 5 million observations each.

(a) Percent of reports with various code values of low-or-middle cloud base height $h$, from the set of reports which have $h \leq 8$.

(b) Percent of reports with various code values of total cloud cover $\mathrm{N}$, from the set of reports which include $\mathrm{N}$.

(c) Percent of reports with various code values of low-or-middle cloud amount

$\mathrm{N}_{\mathrm{h}}$, from the set of reports which include $\mathrm{N}_{\mathrm{h}}$. 

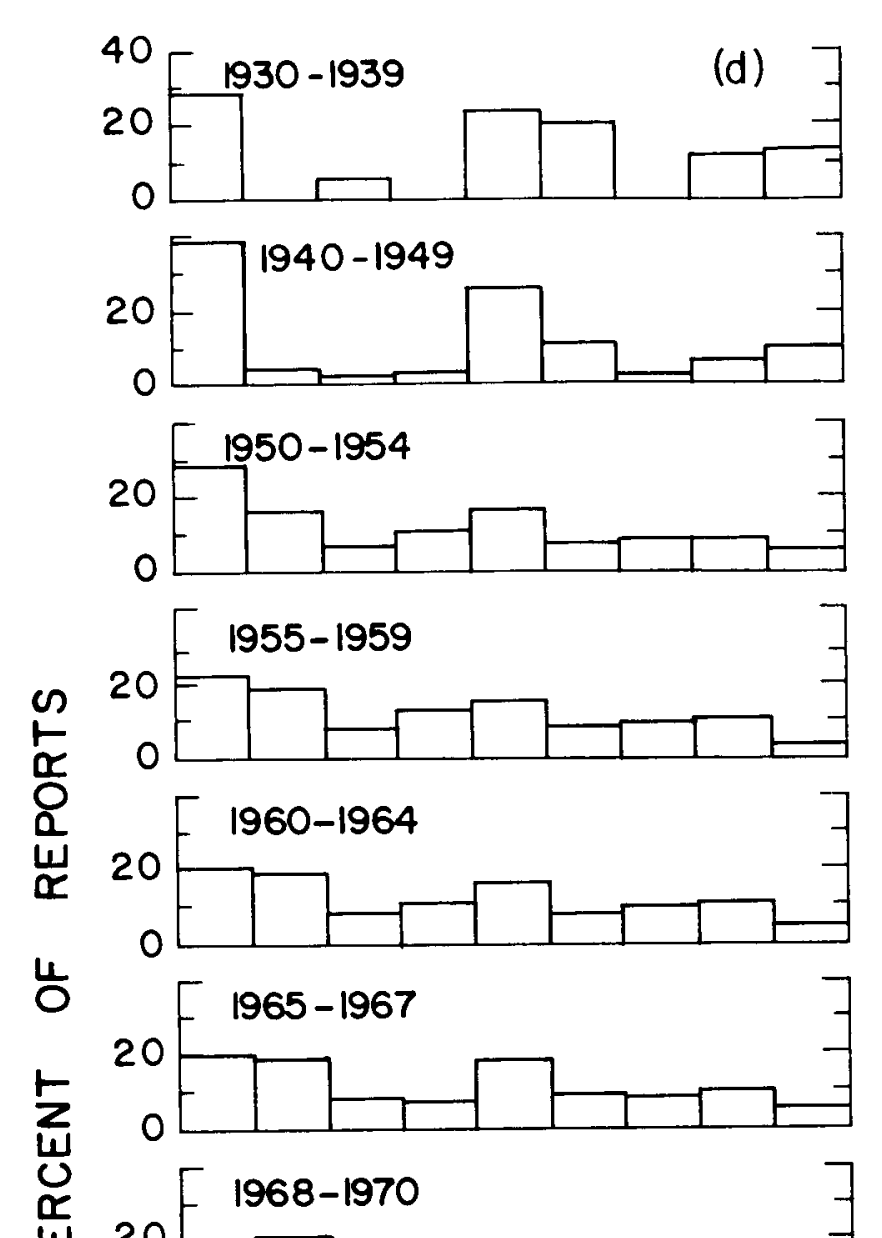

总 20 每
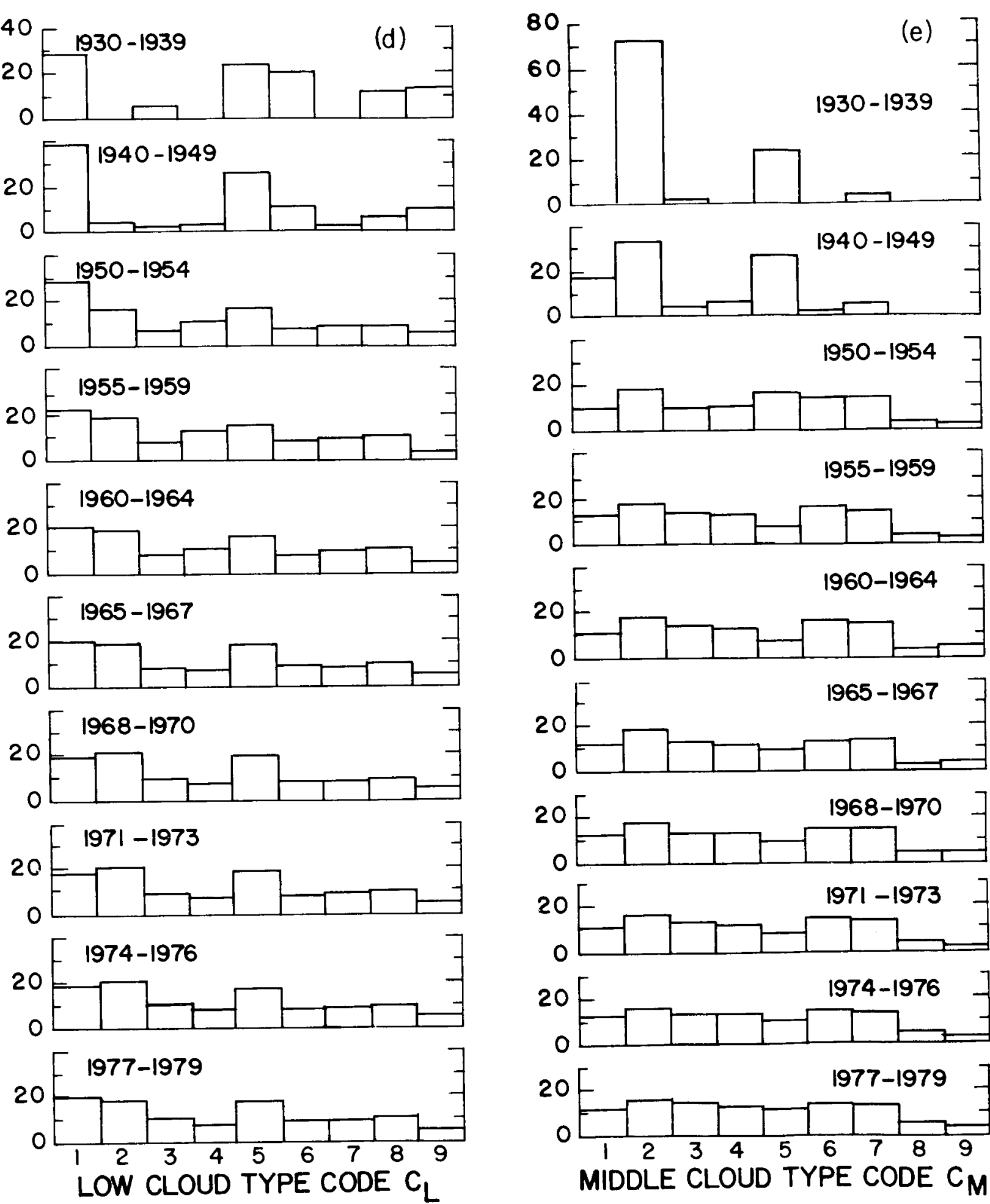

${ }^{40}-1930-1939$

20

(f) 7
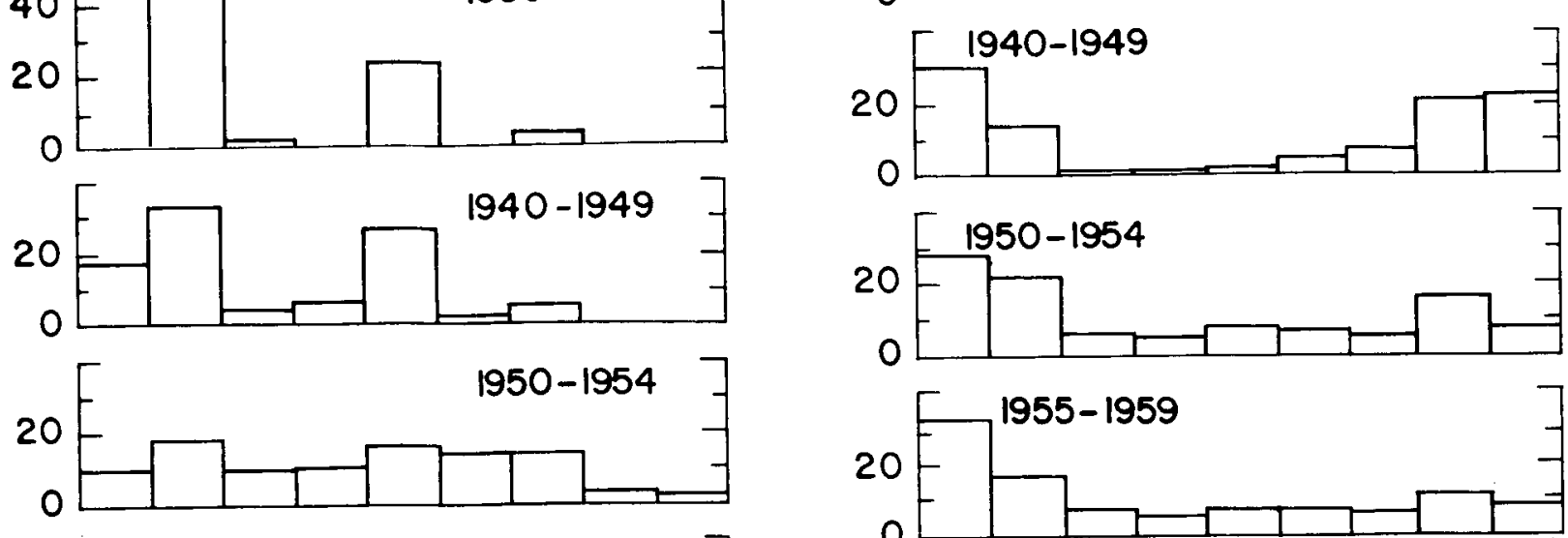

$E^{1955-1959}$

$20=$

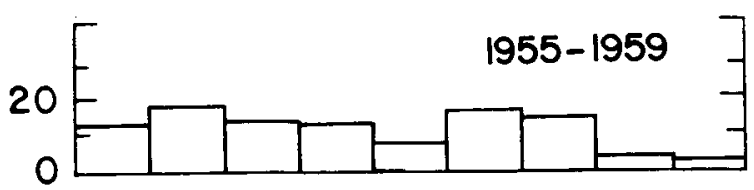

4 [1960-1964 20

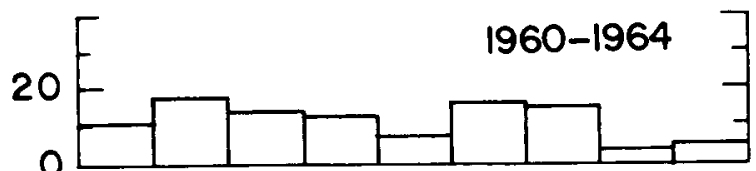

[1965-1967

$20=$
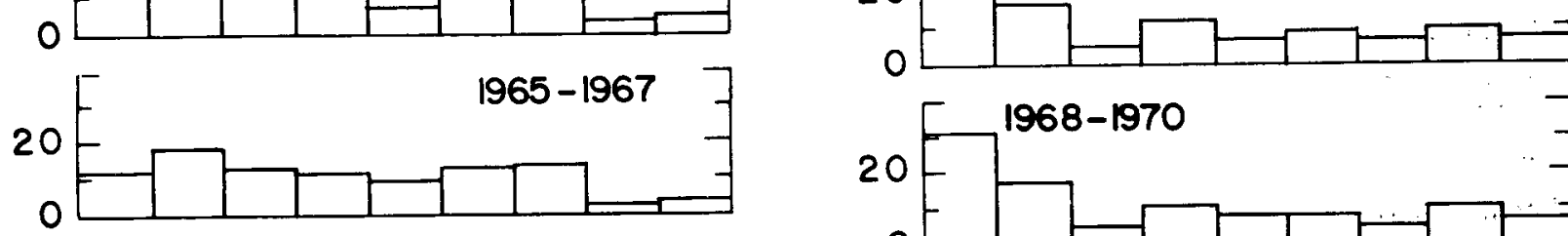

F $1968-1970$
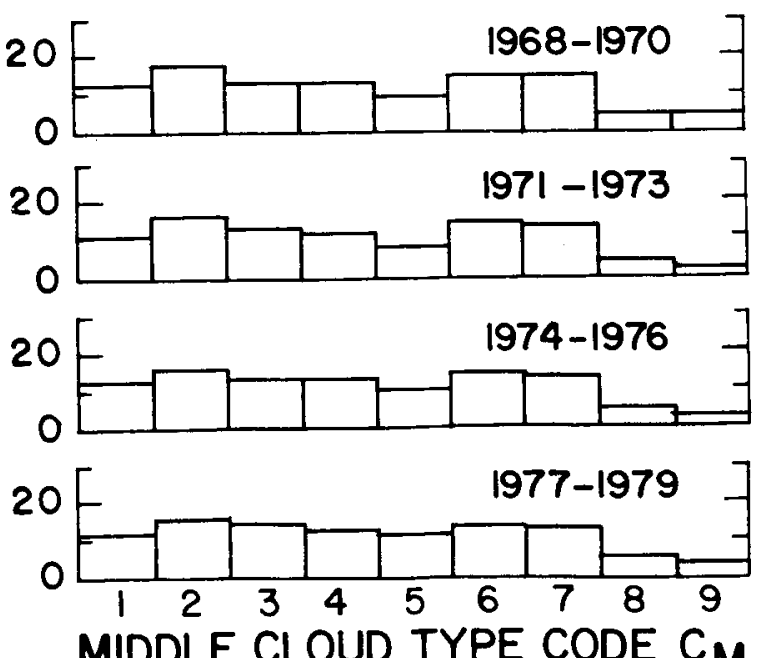
LOW CLOUD TYPE CODE $C_{L}$

MIDDLE CLOUD TYPE CODE CM
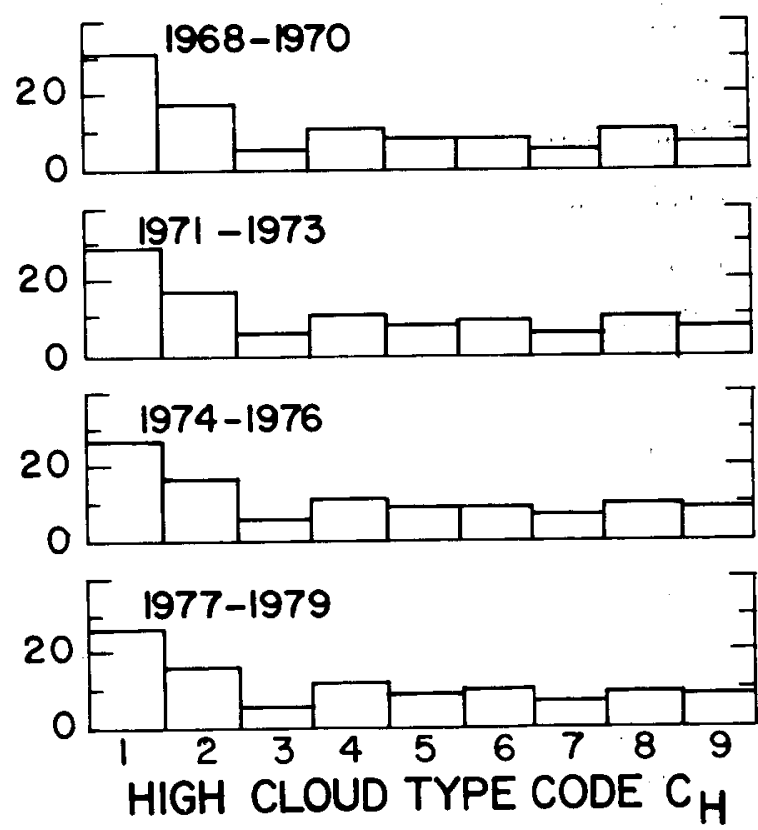

(d) Percent of reports with various code values of low cloud type $\mathrm{C}_{\mathrm{L}}$, from the

(c) Percent of reports with various code values of middle cloud type $\mathrm{C}_{\mathrm{M}}$, from the set of reports with middle cloud reported present $\left(1 \leq \mathrm{C}_{\mathrm{M}} \leq 9\right)$.

(f) Percent of reports with various code values of high cloud type $\mathrm{C}_{\mathrm{H}}$, from the set of reponts with high cloud reported present $\left(1 \leq \mathrm{C}_{\mathrm{H}} \leq 9\right)$. 
changes to be spurious, so we restrict the analysis of cloud heights to 1954-1981.

The inventory for total cloud cover (Figure $5 \mathrm{~b}$ ) did not turn up compelling reasons for restricting its analysis to the post-1952 data. It is the only cloud element which we have analyzed back to 1930, and the results are plotted on the microfiche cards. However, for the maps in this atlas, no data prior to 1952 were used.

\section{METHOD OF ANALYSIS \\ a. Data selection and checking}

Some of the observations are internally inconsistent so that they had to be corrected if possible, or else discarded. Each observation was put through a series of tests shown in Figure 1 of the land atlas. The fraction of observations failing each of these tests in 1979 is given here in Table 3. A large fraction is missing $C_{L}$ or $N_{h}$, and that fraction is even larger prior to 1960 (Figure 3) due to the inclusion of HSST data in COADS. The HSST observations must be excluded from the cloud type analysis because, since they are also missing ww, they can be analyzed for types only when $\mathrm{N}=0$ (no clouds), which would cause an obvious bias.

There is one test shown in Figure 1 of the land atlas which was not applied to the ocean data. Observations with $w w=/$ were not rejected for the analysis of ocean total cloud (but they were rejected as usual for cloud types). This was necessary in order to analyze the HSST data for total cloud, since they all have $w w=/$, and is also necessary in order to extend the total cloud cover analysis back to 1930 , because ww is missing in a large fraction of the reports made prior to 1952. In those observations which have $w w=/$ and $N=9$ we are not able to consult ww to determine the cloud type, so we just convert all these reports to $\mathrm{N}=8$ for our analysis of total cloud cover. In the years 1952-1979 the fraction of all observations so altered was steady at the small value of $0.1 \%$. It rose to $0.3 \%$ in 1981 , the end of our 30-year climatology. [Prior to 1952 the fraction of all reports with $\mathrm{N}=9$, irrespective of ww, was quite small (Figure $5 \mathrm{~b}$ ).]

The quality-control procedures we have used (Figure 1 of the land atlas) are intentionally rather minimal, because we are aware that quality control can sometimes do more harm than good, by introducing biases into the analysis. Observations which have erroncous temperatures, for example, may still have accurate cloud information. In a pilot study of total cloud cover using the FNOC-CDS we obtained spurious trends of cloud cover increasing with time because, by inappropriate quality-control, we rejected all observations that had been flagged as erroneous. These trends appeared because (1) the fraction of data that were flagged decreased in time from $40 \%$ in 1954 to $0 \%$ in 1976 , and (2) the flagged data had greater average cloud cover than the unflagged data. The trends in zonal average ocean cloud cover which were based on those analyses (Figure 3 of Warren et al., 1981) are therefore suspect.

Table 3. Number of observations discarded or corrected

Symbols are defined in Table 2. Explanation is given in Figure 1 of the land atlas, which also gives the comparable quantities for land station reports. The year 1979 is used here as an example; the variation with time of some of these quantities is shown in Figures 1 and 3.

$$
\text { Fault }
$$

Fraction of all observations (\%), 1979

$\mathrm{N}=$ / (discard; many of these are buoys)

$|\mathrm{LAT}|>90^{\circ}$ or $|\mathrm{LON}|>180^{\circ}$ (discard)

$\mathrm{ww}=/$ (discard for types)

miscoded $\mathrm{C}_{\mathrm{M}}, \mathrm{C}_{\mathrm{H}}$

a) $\mathrm{C}_{\mathrm{M}}=0 \stackrel{\mathrm{M}^{\prime}}{\rightarrow} \mathrm{C}_{\mathrm{H}}=/$ or $\mathrm{C}_{\mathrm{H}}=0 \rightarrow \mathrm{C}_{\mathrm{H}}=1$

b) $\mathrm{C}_{\mathrm{M}}^{\mathrm{M}}=1 \rightarrow \mathrm{C}_{\mathrm{M}}=0$
c) $\mathrm{C}_{\mathrm{H}}=l \rightarrow \mathrm{C}_{\mathrm{H}}=0$

$\mathrm{C}_{\mathrm{L}}=/$ or $\mathrm{N}_{\mathrm{h}}=/$ (discard for types unless $\mathrm{N}=9$ )

$\mathrm{N}=0$ but $\mathrm{ww}=\mathrm{R}, \mathrm{T}$ (discard for types)

$\mathrm{N}=9$ but $\mathrm{ww} \neq \mathrm{R}, \mathrm{T}, \mathrm{F}, /$ (discard)

$\mathrm{N}>0$ but $\mathrm{C}_{\mathrm{L}}=\mathrm{C}_{\mathrm{M}}=\mathrm{C}_{\mathrm{II}}=0$ (discard for types)

$\mathrm{N}<\mathrm{N}_{\mathrm{h}}$ (discard) 
COADS contains observations which are flagged as erroneous in some respect (e.g. unrealistic winds or temperatures) but they remain in the dataset. We process all the available data, including those flagged as erroneous in COADS, and apply our own tests which reject only a few percent of the data.

\section{$\underline{\text { b. Total cloud cover }}$}

The code $\mathrm{N}$ was interpreted directly as fractional sky cover in eighths for code values $0-8$. The case N=9 ("sky obscured") was classified by reference to ww. If the present weather indicated fog, rain, snow, or thunderstorm, or if $w w=/$ as discussed above, the observation was changed to $\mathrm{N}=8$; otherwise it was not used.

\section{c. Classification of types}

The 27 cloud types of the synoptic code were grouped into six classes as shown in Table 1. This is the same grouping that was used in the land atlas. The detailed procedure for assigning types from a single observation is given in Figures 2-4 of the land atlas. As discussed in the land atlas, we mistakenly excluded ww=77 (pellet-snow) and 79 (sleet) from the "precipitating" classification, leading us to underestimate Ns amount in some parts of the polar regions. We estimated the effects of this mistake by reprocessing all the observations for three years (19771979), allowing $w w=77$ and 79 to be precipitation. The $5^{\circ} \times 5^{\circ}$ boxes in the ocean whose Ns amounts would be affected by more than 1\%, based on the 1977-1979 data, are listed in Table 4 . Most boxes are not affected at all. Allowing $w w=77$ and 79 to be precipitation would increase the global average Ns amount (for the ocean) by only about $0.03 \%$.

\section{d. Frequency of occurrence and amount-when-present}

The amount of a cloud type is defined as the fraction of the sky covered by that type, whether visible or not (WMO, 1956). Therefore, as stated by WMO (1956), "when clouds occur in superposition, the sum of the different cloud amounts may of course exceed the total cloud cover." The time-averaged amount of a cloud type can be obtained as the product of frequencyof-occurrence (fraction of weather observations in which a cloud of this type is present, whether visible or not) and amount-when-present (the average fraction of the sky covered by this cloud type when it is present). For example, if cumulus is present in $30 \%$ of the weather obscrvations from a station, and if it covers an average of $40 \%$ of the sky when it is present, then the average amount of cumulus at that station is $12 \%$. 
Table 4.

Estimated changes to Ns maps (\%) which would result from allowing $w w=77,79$ to indicate precipitation. (All changes would be positive.) All boxes are listed whose change is more than $1 \%$ in any season. These estimates are based on three years of data (1977-79). Different boxes in these regions would possibly appear in the list if different years were tested. The change in amount of $\mathrm{Ns}$ is essentially the same as the change in $\mathrm{f}(\mathrm{Ns})$ because awp $(\mathrm{Ns}) \approx 100 \%$. No change in amount of As would result, because essentially all observations of $\mathrm{ww}=77,79$ had $\mathrm{C}_{\mathrm{M}}=1$. Entries in the table are left blank if the total number of cloud reports was less than 50 .

grid box

Change in Ns amount (\%)

\begin{tabular}{|c|c|c|c|c|c|}
\hline latitude & longitude & DJF & MAM & JJA & SON \\
\hline $85-90 \mathrm{~N}$ & $0-360 \mathrm{E}$ & 0 & 0 & 1 & 2 \\
\hline $80-85 \mathrm{~N}$ & $120-160 \mathrm{E}$ & 0 & 0 & 3 & 1 \\
\hline $80-85 \mathrm{~N}$ & $120-160 \mathrm{~W}$ & 0 & 1 & 1 & 2 \\
\hline $75-80 \mathrm{~N}$ & $140-160 \mathrm{E}$ & 0 & & 5 & 3 \\
\hline $75-80 \mathrm{~N}$ & $160-180 \mathrm{E}$ & 0 & 0 & 2 & 3 \\
\hline $75-80 \mathrm{~N}$ & $120-140 \mathrm{~W}$ & 0 & & 4 & 1 \\
\hline $70-75 \mathrm{~N}$ & $160-180 \mathrm{E}$ & & & 0 & 2 \\
\hline $70-75 \mathrm{~N}$ & $160-180 \mathrm{~W}$ & 2 & 0 & 0 & 1 \\
\hline $70-75 \mathrm{~N}$ & $140-160 \mathrm{~W}$ & & & 2 & 2 \\
\hline $70-75 \mathrm{~N}$ & $120-140 \mathrm{~W}$ & & & 0 & 2 \\
\hline $70-75 \mathrm{~N}$ & $100-120 \mathrm{~W}$ & & & 0 & 2 \\
\hline $65-70 \mathrm{~N}$ & $130-140 \mathrm{~W}$ & & & 0 & 3 \\
\hline $60-65 \mathrm{~N}$ & $170-180 \mathrm{~W}$ & 0 & 4 & 0 & 1 \\
\hline $60-65 \mathrm{~N}$ & $90-100 \mathrm{~W}$ & & & 0 & 3 \\
\hline $60-65 \mathrm{~N}$ & $80-90 \mathrm{~W}$ & & & 0 & 3 \\
\hline $55-60 \mathrm{~N}$ & $170-180 \mathrm{E}$ & 2 & 1 & 0 & 0 \\
\hline $50-55 \mathrm{~N}$ & $20-30 \mathrm{E}$ & 2 & 0 & 0 & 0 \\
\hline $50-55 \mathrm{~N}$ & $140-150 \mathrm{E}$ & 2 & 0 & 0 & 0 \\
\hline $50-55 \mathrm{~S}$ & $70-80 \mathrm{E}$ & 0 & 0 & 3 & \\
\hline $55-60 \mathrm{~S}$ & $40-50 \mathrm{~W}$ & 0 & 0 & & 2 \\
\hline $60-65 \mathrm{~S}$ & $110-120 \mathrm{E}$ & 2 & & & \\
\hline $65-70 \mathrm{~S}$ & $140-150 \mathrm{E}$ & 2 & & & \\
\hline Global A & & 0.05 & 0.02 & 0.02 & 0.04 \\
\hline
\end{tabular}




\section{$16^{A}$}

The method used here, and described in the land atlas, is designed to obtain the true average amounts of each type of cloud, not the non-overlapped amounts seen from above or below. The low cloud amounts are always directly observed, but often for As/Ac and $\mathrm{Ci}$ (and occasionally for Ns), assumptions must be made about the amounts of upper clouds which are hidden from the ground-observer's view by intervening lower clouds. To obtain amount-when-present (awp) of a middle or high cloud the method uses the random-overlap assumption (Telegadas and London, 1954) when just two layers of cloud are present, and assumes that awp is the same on average for observations where it cannot be calculated as for observations where it can. The awp of middle and high clouds is computed only if $N_{h} \leq 6$, because the random-overlap equation is inaccurate when $N_{h}=7$, as explained on pp. 11-12 of the land atlas.

The situations where the random-overlap assumption was used are listed in Table 5. The validity of this assumption has been examined by Tian and Curry (1989), using the cloud levels obtained by the Air Force 3-D Nephanalysis (3DNEPH) over the North Atlantic, which includes aircraft reports of clouds. For vertically-separated cloud layers the random-overlap assumption performed better than either maximum-overlap or minimum-overlap. If the 3DNEPH analysis of vertical cloud distributions is accurate and representative, it appears that we could not do better than to assume random overlap. For horizontal resolution $45 \mathrm{~km}$ the 3 DNEPH data implied slightly more overlap than random overlap, by $1 \%$, and at $90 \mathrm{~km}$ resolution there was slightly less than random overlap (the random overlap assumption causing the calculated sum of middle and high cloud amounts to be about $5 \%$ too high). The ground observer's field of view is probably in general intermediate between 45 and $90 \mathrm{~km}$ diameter.

The assumption that awp for upper clouds when it cannot be calculated is the same as when it can be calculated is tested by comparing awp for the various classes of observations in which it can be calculated. For example, awp of $\mathrm{Ci}$ can be computed when $\mathrm{Ci}$ occurs alone, or together with a low but no middle cloud, or together with a middle but no low cloud. It cannot be computed when Ci occurs together with both low and middle clouds, or when the lower cloud is overcast so that even the presence or absence of $\mathrm{Ci}$ is not known. Table 6a shows, for selected oceanic boxes, the average awp of $\mathrm{As}, \mathrm{Ns}$, and $\mathrm{Ci}$ in the various situations. The values are often very similar for the different situations. Even where they are not, the error in overall awp caused by using their average in the cases where awp cannot be computed is usually rather small. The potential error is greater for cirrus than for other types. Table $6 \mathrm{~b}$ shows that half of the occurrences of cirrus are either hidden above a lower overcast or visible but present together with both low and middle clouds. Thus if the true awp for this category of $\mathrm{Ci}$ was $10 \%$ different from the average of the computable cases, then our assumption that it was no different would cause a $5 \%$ error in the average awp for $\mathrm{Ci}$ of all categories, and in a typical box with $37 \%$ frequency of Ci would cause a $2 \%$ error in cirrus amount. 
Table 5.

Use of the random-overlap assumption.

\begin{tabular}{|c|c|c|c|c|}
\hline \multirow[t]{2}{*}{ In computation of } & \multicolumn{4}{|c|}{ The random-overlap assumption is } \\
\hline & always used & frequently used & occasionally used & never used \\
\hline total cloud cover & & & & $\mathbf{x}$ \\
\hline amount of $\mathrm{Cu}$ & & & & $\mathrm{x}$ \\
\hline $\mathrm{Cb}$ & & & & $\mathrm{x}$ \\
\hline $\mathrm{St} / \mathrm{Sc}$ & & & & $\mathrm{x}$ \\
\hline $\mathrm{Ns}$ & & & $x$ & \\
\hline $\mathrm{As} / \mathrm{Ac}$ & & $\mathrm{x}$ & & \\
\hline $\mathrm{Ci} / \mathrm{Cs} / \mathrm{Cc}$ & & $x$ & & \\
\hline & & & & \\
\hline frequency of fog & & & & $\mathrm{x}$ \\
\hline clear sky & & & & $\mathrm{x}$ \\
\hline & & & & \\
\hline co-occurrence probabilities & & & & $\mathrm{x}$ \\
\hline
\end{tabular}


Table 6a.

Test of the hidden-cloud assumption for amount-when-present. Ship observations for MAM 1971 were analyzed in twenty $5^{\circ} \times 5^{\circ}$ boxes selected because they had large numbers of observations and were well distributed geographically across the ocean. The average amount-when-present was obtained for each middle or high cloud type under various situations. Results are listed here if there were at least fifteen observations in a category.

\begin{tabular}{|c|c|c|c|c|c|c|c|c|}
\hline & & \multicolumn{7}{|c|}{ Amount when present (percent) } \\
\hline \multicolumn{2}{|c|}{ Grid box } & \multicolumn{2}{|c|}{$\mathrm{As} / \mathrm{Ac}$} & \multicolumn{2}{|c|}{$\mathrm{Ns}$} & \multicolumn{3}{|c|}{$\mathrm{Ci} / \mathrm{Cs} / \mathrm{Cc}$} \\
\hline latitude & longitude & $\begin{array}{c}\text { with low } \\
\text { but no } \\
\text { high }\end{array}$ & $\begin{array}{l}\text { alone or with } \\
\text { high but } \\
\text { no low }\end{array}$ & $\begin{array}{c}\text { with } \\
\text { low but } \\
\text { no high }\end{array}$ & $\begin{array}{l}\text { alone or with } \\
\text { high but } \\
\text { no low }\end{array}$ & $\begin{array}{l}\text { with middle } \\
\text { but no } \\
\text { low }\end{array}$ & $\begin{array}{l}\text { with low } \\
\text { but no } \\
\text { middle }\end{array}$ & alone \\
\hline $75-80 \mathrm{~N}$ & $175-180 \mathrm{~W}$ & & 81 & & 98 & & & 68 \\
\hline $65-70 \mathrm{~N}$ & $0-5 \mathrm{E}$ & 52 & 41 & 98 & 98 & & 21 & 20 \\
\hline $55-60 \mathrm{~N}$ & $0-5 \mathrm{E}$ & 44 & 53 & 97 & 94 & 29 & 34 & 38 \\
\hline $55-60 \mathrm{~N}$ & $15-20 \mathrm{~W}$ & 62 & 64 & 96 & 97 & & 33 & \\
\hline $50-55 \mathrm{~N}$ & $140-145 \mathrm{~W}$ & 65 & 52 & 97 & 100 & & 41 & \\
\hline $50-55 \mathrm{~N}$ & $35-40 \mathrm{~W}$ & 66 & 54 & 99 & 99 & 45 & 42 & 54 \\
\hline $50-55 \mathrm{~N}$ & $15-20 \mathrm{~W}$ & 54 & & 100 & 99 & & 30 & \\
\hline $45-50 \mathrm{~N}$ & $50-55 \mathrm{~W}$ & 68 & 51 & & 100 & & 48 & 28 \\
\hline $40-45 \mathrm{~N}$ & $70-75 \mathrm{~W}$ & 19 & 66 & & 100 & 25 & 27 & 43 \\
\hline $40-45 \mathrm{~N}$ & $65-70 \mathrm{~W}$ & 60 & 57 & & 99 & 44 & 34 & 37 \\
\hline $35-40 \mathrm{~N}$ & $70-75 \mathrm{~W}$ & 59 & 52 & 99 & 99 & 47 & 41 & 42 \\
\hline $35-40 \mathrm{~N}$ & $65-70 \mathrm{~W}$ & 64 & 55 & & 97 & 48 & 36 & 48 \\
\hline $30-35 \mathrm{~N}$ & $155-160 \mathrm{E}$ & 47 & & & 99 & & 25 & \\
\hline $30-35 \mathrm{~N}$ & $160-165 \mathrm{E}$ & 62 & 42 & 96 & 99 & 43 & 45 & 50 \\
\hline $30-35 \mathrm{~N}$ & $135-140 \mathrm{~W}$ & 50 & 60 & & 97 & & 43 & \\
\hline $30-35 \mathrm{~N}$ & $115-120 \mathrm{~W}$ & 40 & 46 & & 99 & 36 & 39 & 38 \\
\hline $15-20 \mathrm{~N}$ & $105-110 \mathrm{E}$ & 43 & 46 & & 99 & 47 & 42 & 43 \\
\hline $0.5 \mathrm{~N}$ & $0-5 \mathrm{E}$ & 50 & 51 & 97 & 100 & 23 & 32 & 43 \\
\hline $0-5 \mathrm{~N}$ & $85-90 \mathrm{~W}$ & 47 & & & & & & \\
\hline $10-15 \mathrm{~S}$ & $150-155 \mathrm{E}$ & 65 & & & & & 33 & \\
\hline $\begin{array}{l}\text { Average of all re } \\
\text { in these boxes }\end{array}$ & & 54.2 & 53.7 & 97.0 & 98.7 & 43.5 & 38.3 & 44.4 \\
\hline
\end{tabular}


Table $6 b$.

Distribution of middle and high cloud reports among various categories, for the boxes listed in Table 6a, as fractions of the set of observations in which the specified cloud type was present, whether observable or not. The percent frequency with which higher clouds are inferred to be present behind a lower overcast was taken from global average values given in Figure 2 of Hahn et al (1982).

As/Ac

with low but no high

percent of reports with this

alone or with high but no low

three levels reported present

inferred present behind a lower overcast

Ns

with low but no high

alone or with high but no low

three levels reported present

inferred present behind a lower overcast

\section{$\mathrm{Ci} / \mathrm{Cs} / \mathrm{Cc}$}

with low but no middle with middle but no low

alone

three levels reported present

inferred present behind a lower overcast situation

*The presence or absence of Ns can always be ascertained by checking the presentweather code; Ns néver has to be inferred statistically. 
The frequency of occurrence ( $f$ ) of cirrus is assumed to be the same when it cannot be seen as when it can be seen, but for As/Ac an adjustment is applied, based on Figure 6, which show that $f(A s)$ increases as low cloud amount in individual observations increases from $0 / 8$ to $7 / 8$. This probably happens because small values of $\mathrm{N}_{h}$ are usually associated with $\mathrm{Cu}$ and large values with $\mathrm{St}$, and the probability of $\mathrm{As}$ given $\mathrm{St}$ is larger than that given $\mathrm{Cu}$ [i.e.P( $\mathrm{St} \rightarrow \mathrm{As})>\mathrm{P}(\mathrm{Cu} \rightarrow \mathrm{As})$ ] (Warren et al., 1985). Figure 1a of Hahn et al. (1982) shows that $\mathrm{P}(\mathrm{St} \rightarrow \mathrm{As})$ is nearly independent of $\mathrm{St}$ amount, at about $50 \%$, the same as the asymptote in Figure 6 here. The case of $C_{M}=l$, when the presence or absence of As cannot be determined, occurs with low overcast $\left(\mathrm{N}_{\mathrm{h}}=8\right)$, which is likely to be $\mathrm{St}$ rather than $\mathrm{Cu}$. For As, therefore, $\mathrm{f}$ is assumed to be the same when it cannot be seen as when it can be seen with low cloud amount in the range $3 / 8$ $7 / 8$, not $0 / 8-7 / 8$ [In the land atlas this was incorrectly stated as $6 / 8$ instead of $7 / 8$ ]. No such adjustment was applied for $\mathrm{Ci}$ because the bias to be avoided is smaller in the case of $\mathrm{Ci}$ (Figure 6 ); however, $f(C i)$ was computed only from observations for which $N_{h} \leq 6$, to reduce the partialundercast bias. Further details and discussion of the method are given in the land atlas. The fraction of reports that contain information about the middle and high cloud levels over the oceans is given in Maps 8-9 of Hahn et al. (1982). It is on average $75 \%$ and 65\%, respectively.

\section{$\underline{\text { e. Base heights }}$}

The base height of the lowest cloud is sometimes measured, but in most of the reports it is estimated subjectively. To compute the average base height, we assign to each report the midpoint of the range in meters corresponding to the code value (WMO, 1974). Meaningful averages can only be formed for cloud types whose bases are always reported as less than the upper limit of the code, $2500 \mathrm{~m}$. These types are $\mathrm{Cu}, \mathrm{St}$, and $\mathrm{Cb}$. Because the reporting of height codes did not stabilize until about 1954 (Figure 5a), the maps of base height use only data for 1954-1981.

\section{f. Calculation of average cloud amounts}

The true mean cloud cover, or frequency of occurrence or awp of a cloud type, may differ from the mean of a finite number of reports, which is what we compute. Inadequate sampling can lead to both random errors and biases. We first describe a pre-averaging procedure which is designed to reduce (but not eliminate) a number of possible biases. Then we examine the random error in order to specify a minimum number of reports required to form representative averages.

\section{1) "Compressed" observations}

Unlike the situation on land, the clouds in a $5^{\circ} \times 5^{\circ}$ grid box in the ocean are not reported regularly. At 12:00 GMT on a particular day there may be several ships in the grid box making weather observations but at 12:00 GMT on the next day only one ship, and on the third day no ships. In this example our policy is to say that the $5^{\circ} \times 5^{\circ}$ grid box was sampled only twice for the 


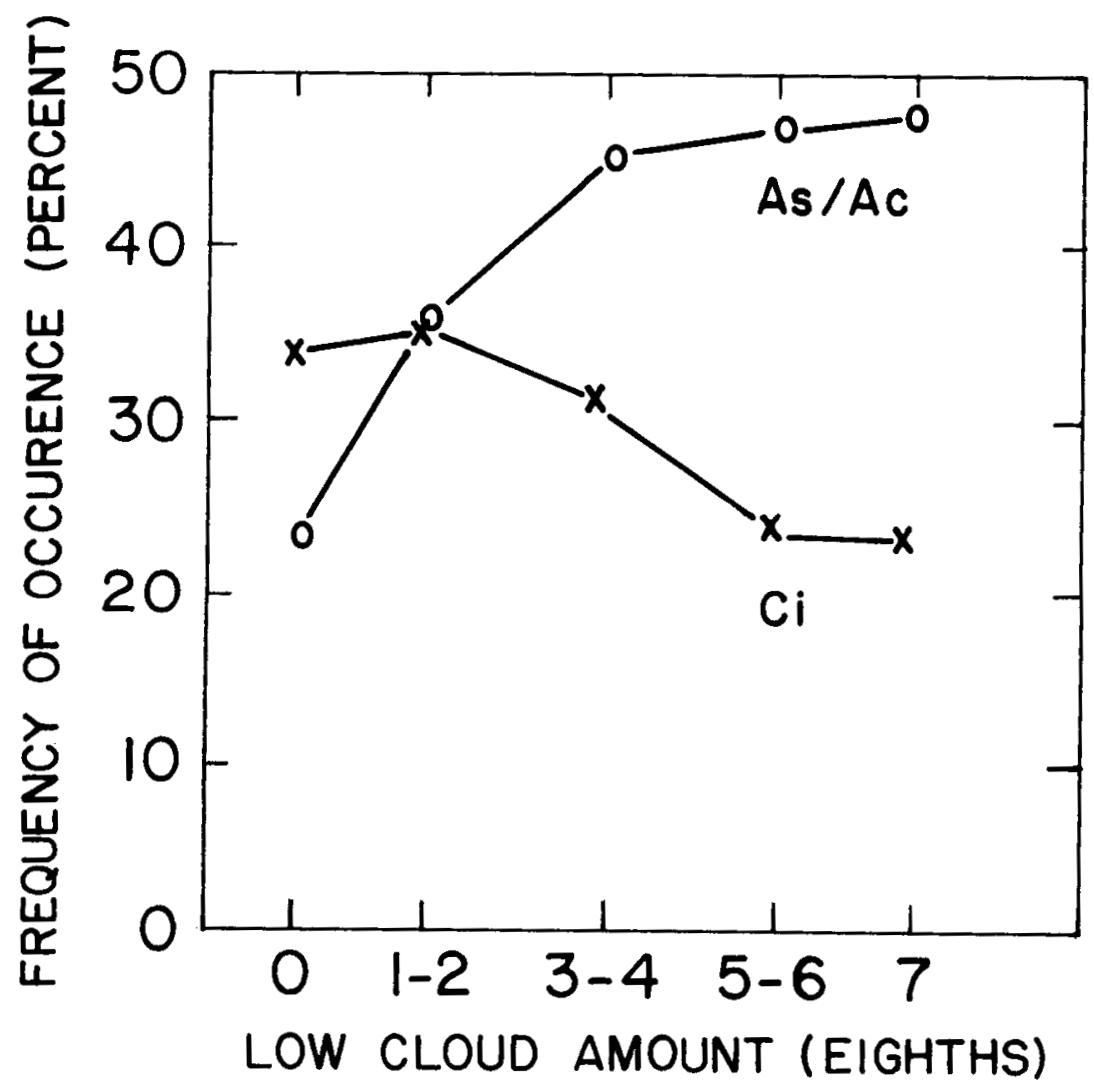

Figure 6. Frequency of occurrence of $\mathrm{As} / \mathrm{Ac}$ and $\mathrm{Ci}$ as functions of low cloud amount $\mathrm{N}_{\mathrm{b}}$. Data are for ships in the entire northern-hemisphere ocean, March-April-May 1971. $N_{h}$ code values $1 \& 2,3 \& 4$, and $5 \& 6$ were grouped in pairs for the analysis. 
12:00 synoptic hour. All observations made during a single three-hour period (centered on the GMT hours divisible by 3 ) on a particular date in a particular $5^{\circ} \times 5^{\circ}$ grid box are averaged together to form a "compressed observation" (not to be confused with "compressed marine reports" mentioned in Section 2). Subsequent analysis of average cloud amounts is based on compressed observations. The justification for this policy is our expectation that the cloud cover (and type) usually changes from day to day more than it changes geographically within a $5^{\circ} \times 5^{\circ}$ box at a particular instant. [However, we have not performed a quantitative test of this expectation.] In the example above, the first and second days count equally in our analysis, even though the second day was sampled by only one ship.

The use of compressed observations reduces the fair-weather bias (the tendency for more ships to enter a $5^{\circ} \times 5^{\circ}$ box on days of fair weather), the foul-weather bias (the tendency of ships to oversample stormy or foggy weather because they are traveling more slowly), the day-night bias (somewhat more reports are transmitted by ships during the day than at night), and the trend bias (a box may be sampled more in later years than in earlier years). Furthermore, the presence of duplicate observations in the dataset (some duplicates still remain in COADS) does not damage our analysis if they are preaveraged by us to form a compressed observation

The procedure to create a compressed observation is straightforward for total cloud cover, and for cloud types was done as follows. If different ships in the box reported different cloud types, each of those types was given a fractional count in the sums being accumulated to obtain frequency of occurrence of the types. Amount-when-present for a cloud type was also averaged to form a compressed observation if there were more than one ship (in the $5 \times 5^{\circ}$ box in the 3 -hour period) reporting that particular type of cloud. The analysis of base height, however, used individual observations not compressed observations.

The space-time grid for creation of compressed obscrvations is always $5^{\circ} \times 5^{\circ}$ and 3 hours. A $10^{\circ} \times 20^{\circ}$ box, therefore, could acquire as many as 8 compressed observations during a single three-hour period. The number of compressed observations used in the analysis for cach year is shown in Figure 7.

2) Minimum number of reports required to compute an average

A series of tests was performed to estimate the expected error in average total cloud cover as a function of the number of observations used to compute the average. Most of these tests were done on observations from ocean weatherships, because they sampled essentially every synoptic hour in their entire period of record. Periods of record from one month to 26 years were used (Table 7). The average of all the observations in the period of record was assumed to be the true average cloud cover for that period. Averages formed from subsets of varying size drawn randomly and repeatedly from the complete set differ from the "true" average, giving an estimate of the expected sampling error. The experiment was done as described in section $3 \mathrm{f} 1$ of the land

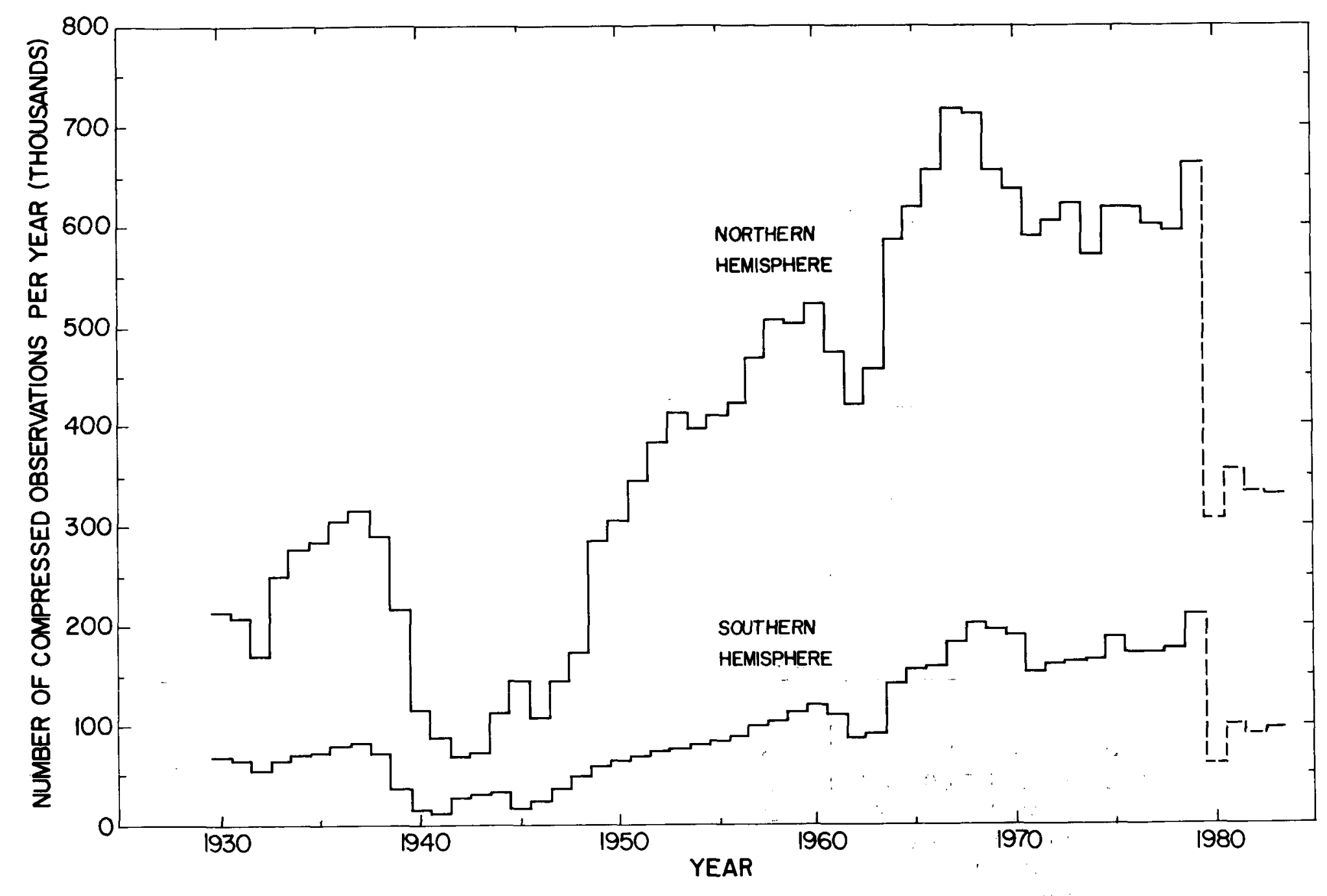

Figure 7. Number of compressed observations per year, by hemisphere. Data prior to and including 1979 came from COADS; data for 1980-83 (dashed lines) came from FNOC telecommunications receipts. 
Table 7.

Data used for estimating expected error in cloud cover as a function of number of observations

\begin{tabular}{|c|c|c|c|c|c|}
\hline $\begin{array}{l}\text { Weathership } \\
\text { name and } \\
\text { location }\end{array}$ & $\begin{array}{l}\text { Period of } \\
\text { record used }\end{array}$ & $\begin{array}{c}\text { Number } \\
\text { of cloud } \\
\text { reports }\end{array}$ & $\begin{array}{l}\text { Average } \\
\text { cloud } \\
\text { cover }(\%)\end{array}$ & $\begin{array}{l}\text { Standard } \\
\text { deviation of } \\
\text { individual } \\
\text { observations } \\
\text { of } \% \text {-cloud-cover }\end{array}$ & $\begin{array}{l}\text { RMS error } \\
\text { in average } \\
\% \text {-cloud-cover } \\
\text { if only } 100 \\
\text { reports used }\end{array}$ \\
\hline $\begin{array}{c}\mathrm{P} \\
50^{\circ} \mathrm{N} 145^{\circ} \mathrm{W}\end{array}$ & MAM 1966 & $730^{\mathrm{a}}$ & 86 & 21 & 2.0 \\
\hline $\begin{array}{c}\mathrm{T} \\
29^{\circ} \mathrm{N} 135^{\circ} \mathrm{E}\end{array}$ & $\mathrm{JJA}^{\mathrm{b}} 1966$ & $730^{\mathrm{a}}$ & 65 & 32 & 3.3 \\
\hline $\begin{array}{c}\mathrm{V} \\
34^{\circ} \mathrm{N} 164^{\circ} \mathrm{E}\end{array}$ & MAM 1966 & $730^{\mathrm{a}}$ & 79 & 27 & 2.5 \\
\hline $\begin{array}{l}\text { All ships, } \\
\text { including } \\
\text { transients, } \\
30^{\circ}-45^{\circ} \mathrm{N}, \\
150^{\circ}-180^{\circ} \mathrm{E}\end{array}$ & MAM 1971 & $\begin{array}{c}6386 \\
\text { compressed } \\
\text { observations }\end{array}$ & 78 & 26 & 2.8 \\
\hline $\begin{array}{c}\mathrm{M} \\
66^{\circ} \mathrm{N} 02^{\circ} \mathrm{E}\end{array}$ & $\begin{array}{l}\text { MAM 1966 } \\
\text { MAM 1949-1970 } \\
\text { MAM 1949-1970, 0 GMT } \\
\text { MAM 1949-1970, 3 GMT } \\
\text { MAM 1949-1970, 6 GMT } \\
\text { MAM 1949-1970, 9 GMT } \\
\text { MAM 1949-1970, 12 GMT } \\
\text { MAM 1949-1970, 15 GMT } \\
\text { MAM 1949-1970, 18 GMT } \\
\text { MAM 1949-1970, } 21 \text { GMT } \\
\text { March 1966 } \\
\text { April 1966 } \\
\text { May 1966 } \\
\text { March 1949-1970 } \\
\text { April 1949-1970 } \\
\text { May 1949-1970 }\end{array}$ & $\begin{array}{c}730^{\mathrm{a}} \\
16000^{\mathrm{a}} \\
2000^{\mathrm{a}} \\
2000^{\mathrm{a}} \\
2000^{\mathrm{a}} \\
2000^{\mathrm{a}} \\
2000^{\mathrm{a}} \\
2000^{\mathrm{a}} \\
2000^{\mathrm{a}} \\
2000^{\mathrm{a}} \\
249 \\
243 \\
252 \\
5269 \\
5071 \\
5329\end{array}$ & $\begin{array}{l}78 \\
79 \\
78 \\
78 \\
80 \\
79 \\
79 \\
79 \\
80 \\
78 \\
82 \\
76 \\
77 \\
78 \\
80 \\
79\end{array}$ & $\begin{array}{l}22 \\
25 \\
27 \\
27 \\
23 \\
24 \\
24 \\
25 \\
23 \\
26 \\
20 \\
23 \\
23 \\
26 \\
24 \\
25\end{array}$ & $\begin{array}{l}2.2 \\
2.3 \\
2.6 \\
2.6 \\
2.4 \\
2.5 \\
2.4 \\
2.4 \\
2.0 \\
3.1 \\
1.6 \\
1.9 \\
1.9 \\
2.5 \\
2.2 \\
2.7\end{array}$ \\
\hline
\end{tabular}

Table 7 continued.

\begin{tabular}{|c|c|c|c|c|c|}
\hline $\begin{array}{l}\text { Weathership } \\
\text { name and } \\
\text { location }\end{array}$ & $\begin{array}{l}\text { Period of } \\
\text { record used }\end{array}$ & $\begin{array}{c}\text { Number } \\
\text { of cloud } \\
\text { reports }\end{array}$ & $\begin{array}{l}\text { Average } \\
\text { cloud } \\
\text { cover (\%) }\end{array}$ & $\begin{array}{l}\text { Standard } \\
\text { deviation of } \\
\text { individual } \\
\text { observations } \\
\text { of \%-cloud-cover }\end{array}$ & $\begin{array}{l}\text { RMS error } \\
\text { in average } \\
\% \text {-cloud-cover } \\
\text { if only } 100 \\
\text { reports used }\end{array}$ \\
\hline \multirow{16}{*}{$\begin{array}{c}\mathrm{N} \\
30^{\circ} \mathrm{N} 140^{\circ} \mathrm{W}\end{array}$} & MAM 1966 & $730^{\mathrm{a}}$ & 70 & 32 & 3.1 \\
\hline & MAM $1947-1972$ & $16000^{\mathrm{a}}$ & 74 & 29 & 3.0 \\
\hline & MAM 1947-1972, 0 GMT & $2000^{\mathrm{a}}$ & 72 & 29 & 2.8 \\
\hline & MAM 1947-1972, 3 GMT & $2000^{\mathrm{a}}$ & 73 & 28 & 3.3 \\
\hline & MAM 1947-1972, 6 GMT & $2000^{\mathrm{a}}$ & 68 & 33 & 3.0 \\
\hline & MAM 1947-1972, 9 GMT & $2000^{\mathrm{a}}$ & 70 & 33 & 3.6 \\
\hline & MAM 1947-1972, 12 GMT & $2000^{a}$ & 72 & 33 & 3.3 \\
\hline & MAM 1947-1972, 15 GMT & $2000^{\mathrm{a}}$ & 78 & 28 & 2.9 \\
\hline & MAM 1947-1972, 18 GMT & $2000^{\mathrm{a}}$ & 77 & 27 & 2.5 \\
\hline & MAM 1947-1972, 21 GMT & $2000^{\mathrm{a}}$ & 73 & 28 & 2.9 \\
\hline & March 1966 & 253 & 67 & 35 & 3.1 \\
\hline & April 1966 & 245 & 74 & 30 & 2.3 \\
\hline & May 1966 & 253 & 70 & 31 & 2.8 \\
\hline & March $1947-1972^{c}$ & 6538 & 74 & 29 & 2.9 \\
\hline & April $1947-1972^{c}$ & 6302 & 74 & 29 & 2.6 \\
\hline & May $1947-1972^{c}$ & 6559 & 72 & 30 & 3.2 \\
\hline
\end{tabular}

${ }^{\mathrm{a}}$ Approximate number of reports

${ }^{b}$ Weathership T operated primarily during the summer typhoon season, so JJA was used instead of MAM

${ }^{c}$ These data are used in Figure 8 
atlas. The March-April-May season was used for convenience.

The results were similar for all five weatherships tested. Two ships ( $M$ and $N$ ) were selected for more exhaustive studies than the other three, and expected errors obtained from data of these two ships are plotted $(\log -\log )$ in Figure 8. Also plotted for comparison are lines with slope $=-0.5$ exactly (not a least-squares fit). As was the case for the land data, the points fit approximately to these lines, which means that the error is proportional to $\sqrt{n} / n$ (where $n$ is the number of observations), as would be expected for independent samples. The expected error is smaller for ship $M$ than for ship $N$. This is because the cloud cover is less variable in the Norwegian Sea than in the eastem Pacific (standard deviation of observations typically $25 \%$ and $30 \%$, respectively, as shown in Table 7). This difference is consistent with the fact that the average cloud cover is greater at ship $\mathrm{M}$ than at ship $\mathrm{N}$. As the average cloud cover approaches $100 \%$, the standard deviation of observations must approach zero. There is a good correlation, apparent in Table 7, between the root-mean-square (RMS) error and the standard deviation of observations.

The expected error is smaller for the ocean areas than for land areas, because of the smaller day-to-day variability in cloud cover over ocean. To reduce the expected error in mean cloud cover below 3\%, only 100 observations are needed, as opposed to 200 over land (Figure 5 of the land atlas). [Note that whenever values for standard deviation, or changes, or differences, or expected error, or variability, of the quantities cloud frequency or amount are given in this atlas, the units are always percent of sky covered or percent frequency of occurrence, not percent of the mean. For example, if the average cloud cover fraction is 0.5 and its expected error is 0.03 , we report these values as 50\% and $3 \%$ respectively.]

Table 7 shows that the expected error with 100 observations is not much affected by the length of the averaging period. It is about the same whether the observations used for the test are pooled from one month, or one season, or many years of one month, or many years of one season. It is also insignificantly smaller if the observations are all taken from just one of the eight synoptic hours. This is because the systematic month-to-month, year-to-year and day-to-night variation in average cloud cover is much smaller than the random variations in instantaneous cloud cover, as explained in the land atlas.

These tests on weatherships do not include the sampling error caused by geographical variation of average cloud cover within the $5^{\circ} \times 5^{\circ}$ or $10^{\circ} \times 20^{\circ}$ boxes used for the climatology. We therefore also tested one large oceanic box $\left(15^{\circ} \times 30^{\circ}\right.$; in the central North Pacific). Table 7 shows that random sampling of these data leads to only slightly greater RMS error than for the weathership $\mathrm{V}$ which is contained within that box. 


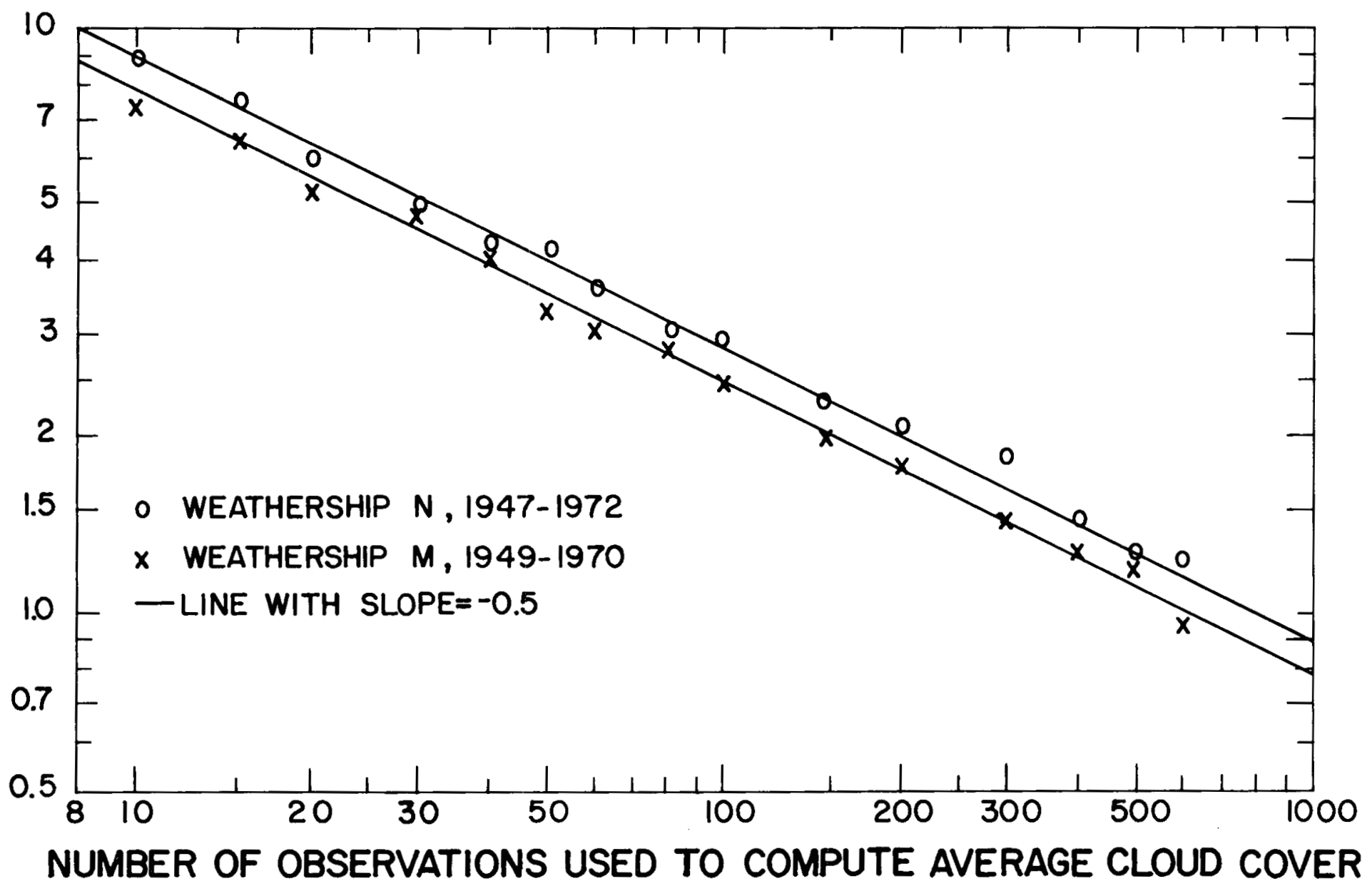

Figure 8. Expected error in monthly or seasonal mean cloud cover for an ocean weather station, as a function of the number of observations used to compute the mean. The dataset used here was synoptic observations for many years of the month of March, or April or May, from Weathership M in the Norwegian Sea and Weathership $\mathrm{N}$ in the eastern North Pacific (see Table 7). Root-mean-square (RMS) errors were similar for the three months, so only the average of the three values is plotted here. Also plotted for comparison are lines with slope $=-0.5$ exactly (not a least-squares fit). 
The expected error as a function of the number of compressed observations would be somewhat smaller than shown in Figure 8, in boxes which usually have more than one ship reporting simultaneously, because the tests for the figure were done on individual observations. However, in such well-sampled boxes the sampling error is small anyway; reference to this figure is needed not for those boxes but rather for the poorly sampled boxes where the number of observations is a few hundred or less, and in such boxes the number of compressed observations is nearly the same as the number of individual observations.

On the basis of this analysis we require a minimum of 100 compressed observations to form a multi-year seasonal average cloud cover or an average frequency-of-occurrence for a cloud type in a $5^{\circ} \times 5^{\circ}$ or $10^{\circ} \times 20^{\circ}$ box. Boxes which are blank on the maps failed to satisfy this criterion or other criteria described below. Unlike the situation on land, the accuracy of our average oceanic cloud amounts is often limited by the number of observations. Maps 2-5 and 109 show the number of compressed observations in each box; they can be used together with Figure 8 to estimate the random sampling error. The true error will be larger than this because there are also bias errors, and because the data set contains mislocated observations; both are discussed below. The bias errors will be the dominant sources of error in many of the northern-hemisphere boxes where the number of observations greatly exceeds 100 .

The minimum number of observations needed to obtain an average value of amount-whenpresent was usually set lower than 100 , as described in the land atlas. A value of awp was used to compute amount (as $\mathrm{f} x \mathrm{awp}$ ) only if awp was computable in at least $0.6 \times 100 \times \mathrm{f}$ observations; otherwise amount was left blank. For maps of awp itself, we required that awp was computable in at least 30 or $0.6 \times 100 \times$ feports, whichever was larger. The discussion and justification of this is on page 15 of the land atlas.

\section{3) Order of steps in the averaging procedure}

There are several ways in which the multi-year average cloud cover or frequency of occurrence of a cloud type can be obtained for a season:

(a) All observations averaged together, weighted equally;

(b) All observations from a single year averaged together irrespective of time of day, then the yearly means averaged together;

(c) All observations for a particular synoptic hour averaged together, irrespective of year, then the eight means averaged together.

This list is, of course, not exhaustive. The averages formed in different ways may differ because of sampling biases.

Method (c), applied to individual observations, was used for the land atlas. For the ocean analysis we used instead method (a), applied to compressed observations. Over the ocean we do 
not have severe geographical biases because of the homogeneous topography. Method (b) would eliminate the trend bias, and method (c) would eliminate the day-night sampling bias, if there were sufficient numbers of observations to form averages of cloud amount for each synoptic hour or for each year-season, or (ideally) for each synoptic hour of each year-season. However, there are many $5 \times 5^{\circ}$ boxes in the ocean where only 100 observations were reported in the entire 30 years (of one season), so for these areas method (a) is the only option. The day-night sampling bias, which was severe at some land locations, is not as important in the ocean areas because almost as many observations are made at night as during the day and because of our preaveraging to form compressed observations. In regions of heavy ship traffic where other averaging methods are feasible, we find that the average cloud cover computed according to methods (a), (b), or (c) differ from each other generally by less than $1 \%$ for individual boxes, and the differences are randomly distributed so that regional or global averages are essentially unaffected.

\section{4) Special considerations}

The frequencies of reported cirrus and As/Ac over the ocean exhibit a diurnal cycle which we think is partly spurious, due to the frequent inability of observers to detect these clouds when they are present at night. This also may cause a spurious signal in the diurnal cycle computed for the frequency of clear sky, with maximum near midnight. This is a problem which has long been recognized. It was documented by comparing the average cloud cover reported at night from ships at the time of full moon with that for the time of new moon (Figure 107 of Sverdrup, 1933; Riehl, 1947).

We find that the reported frequency of occurrence of cirrus is $37 \%$ during daytime and $20 \%$ at night (global ocean average), and of As/Ac is $47 \%$ in daytime and $34 \%$ at night; while awp for these types exhibits a much smaller (and oppositely directed) diumal cycle. This pattern is illustrated in Figure 9 for one grid-box. The abrupt rise and fall at sunrise and sunset (in contrast to smoother variation of $\mathrm{Cu}$ and $\mathrm{St}$ ), and the longer span of high frequency of occurrence in summer corresponding to the greater number of daylight hours, suggest an observer bias (the "nightdetection bias") rather than a true diurnal cycle. The night-detection bias appears to be more severe over ocean than over land, probably because of the more frequent occurrence of low clouds over the ocean, which make night-time detection of the higher clouds more difficult than over land.

Therefore, for the maps of $\mathrm{Ci}$, As, and clear-sky, only the observations made between 0600 and 1800 local time were used. This is indicated on the map headings as "6-18 LT". [Poleward of $75^{\circ}$ latitude for $5^{\circ} \times 5^{\circ}$ boxes, and poleward of $70^{\circ}$ for $10^{\circ} \times 20^{\circ}$ boxes, all observations were used.] Frequencies of $\mathrm{Ci}$ and of As reported in this atlas therefore differ from those given by Hahn et al. (1982) because that earlier atlas included night-time observations. 
DJF
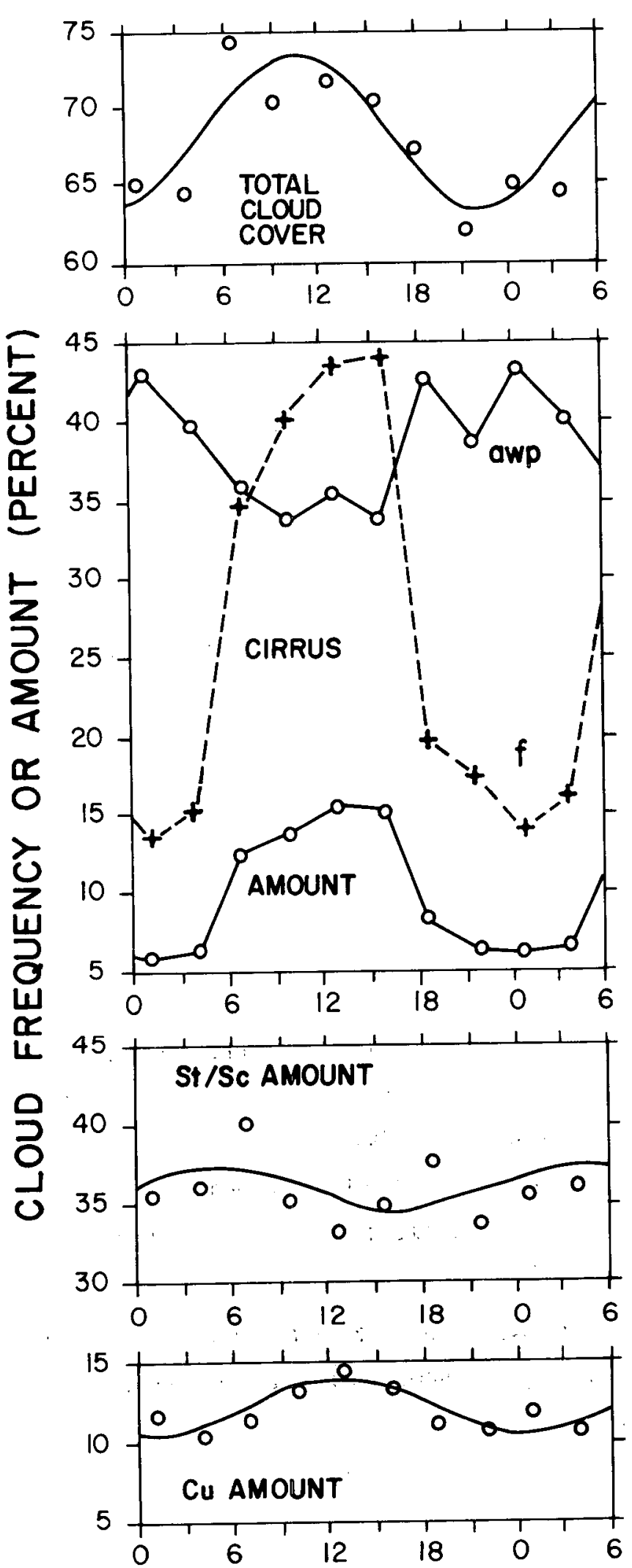

JJA

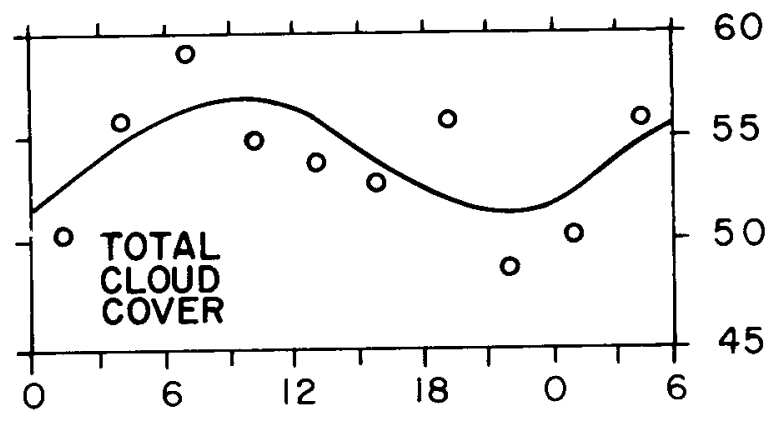$$
+1+1+1+1+1+40
$$
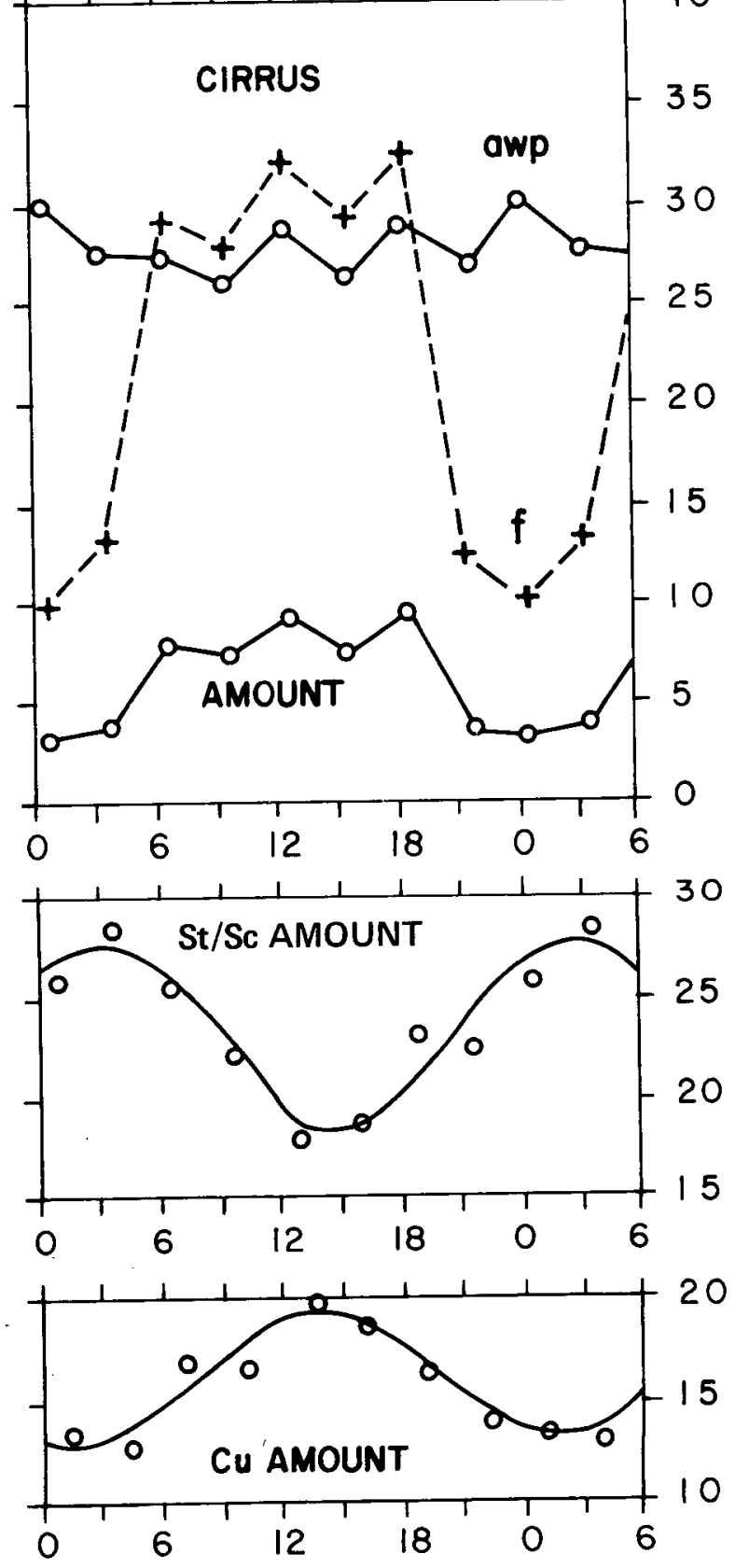

LOCAL TIME (HOUR) 
No diurnal cycles of $\mathrm{Ci}$, As, and clear-sky are included in the maps because of the nightdetection bias. [The values are, however, available on tape (Section 9).] The diurnal cycle of total cloud cover is mapped but it is surely contaminated to some extent by spurious diurnal cycles of As and Ci. Day-only values of total cloud cover are also available on the tape but are not included in this atlas. They are larger than the average of all synoptic hours, by $1.4 \%$ on global average.

The diurnal variation is not always well represented by a single harmonic, as illustrated in Figure 9 for St/Sc in DJF. The average values for each of the eight synoptic hours, as well as the variance accounted for by the first harmonic, are available on tape (Sec. 9), and these can be consulted if more detail is desired about the diumal cycle. The diurnal cycle is reported on maps for cloud-type amounts, but not for $\mathrm{f}$ and awp. Their diumal cycles are available on tape.

The diurnal cycle of total cloud cover was computed using data from 1954 to 1983 . It was completed before we decided to use the 1952-81 period instead for our climatological analyses. This should not affect the results because (a) the changes in the synoptic code beginning 1982 should not affect the diumal analysis of total cloud cover, and (b) the difference in number of observations between day and night (which becomes significant after 1980) cannot bias the computation of harmonic analyses.

\section{$\underline{\text { h. Zonal and global averages }}$}

The ocean box values in a zone were averaged, weighted by the fraction of ocean area in each box, to give the zonal average for the ocean part of the zone. The zonal average is listed off the right-hand side of each map if the quantity to be averaged was available for at least one-third of the ocean boxes in that zone. These zonal averages were then averaged, weighted by the ocean area in each zone, to obtain the global average printed at the bottom of each map. On maps with large zonal variations in the mapped quantity, missing zones can cause the computed global averages to be inaccurate (e.g. Map 144c for Ns in JJA).

The zonal and global averages printed on maps of awp are averages for boxes, not weighted by $f$ for each box, so the zonal and global averages of amount may not exactly equal the product of zonal and global averages of $f$ and awp.

Zonal and global averages were not computed for the phases of the annual and diurnal cycles. 
In many regions the frequencies and amounts of the cloud types undergo systematic variations over the course of the day. These variations can also cause a diurnal cycle in total cloud cover. The diurnal cycle is sampled at most eight times per day in our analysis because of our use of compressed observations and because most synoptic reports are made only at GMT hours divisible by 3 .

Here we examine only one aspect of the diumal variations: the amplitude and phase of the first Fourier component (24-hour period) of the mean diurnal cycle. Multi-year seasonal mean values of cloud amount are formed for each of the eight synoptic hours. A cosine curve is fitted to these eight values if all are available (i.e. if there were at least 100 compressed observations at each synoptic hour so that an average could be formed at each hour); otherwise the curve is fitted to the four values for $0,6,12,18$ GMT if those four were all available. Diurnal cycles were computed only for the $10^{\circ} \times 20^{\circ}$ boxes because the number of observations was insufficient in many of the $5^{\circ} \times 5^{\circ}$ boxes.

The amplitude and phase (local mean-solar-time of maximum) of the cosine curve are mapped. The phase we report is the maximum of the cosine curve, not necessarily the peak of the daily cycle. The amplitude we report is the amplitude of the cosine curve, which may be more or less than half the range of the eight values. As explained in the land atlas, it is also possible for the amplitude to be larger than the mean reported on the maps.

As an example, Figure 9 shows, for two seasons in a $10^{\circ} \times 20^{\circ}$ box in the North Atlantic, the diurnal cycles of total cloud cover and of the four cloud types contributing most to the total cloud cover. This box was well sampled by transient ships and did not contain any weatherships. The number of compressed observations was about 15,000 at each of the 6-hourly synoptic times $(0,6,12,18 \mathrm{GMT})$ and about 1800 at the 3-hourly times $(3,9,15,21 \mathrm{GMT})$.

For $\mathrm{Ci}$ and As the frequency and awp are shown as well as the amount in Figure 9, illustrating the apparent night-detection" bias in frequency of occurrence. In this example, the awp reported at the 3-hourly times is larger than that at the 6-hourly times, indicating that the observers on ships reporting 8 times per day estimate larger cloud amounts than those on ships reporting only 4 times per day. This causes a zigzag pattern which is especially apparent in awp of As for DJF. We are not certain of the explanation for this difference in cloud amount estimates, but it could partly be due to a foul-weather bias to be discussed in Section 4 .

Cumulus shows the normal pattern of a maximum in early afternoon, and summer stratus shows its typical pattern of a maximum in early morning. 
DJF

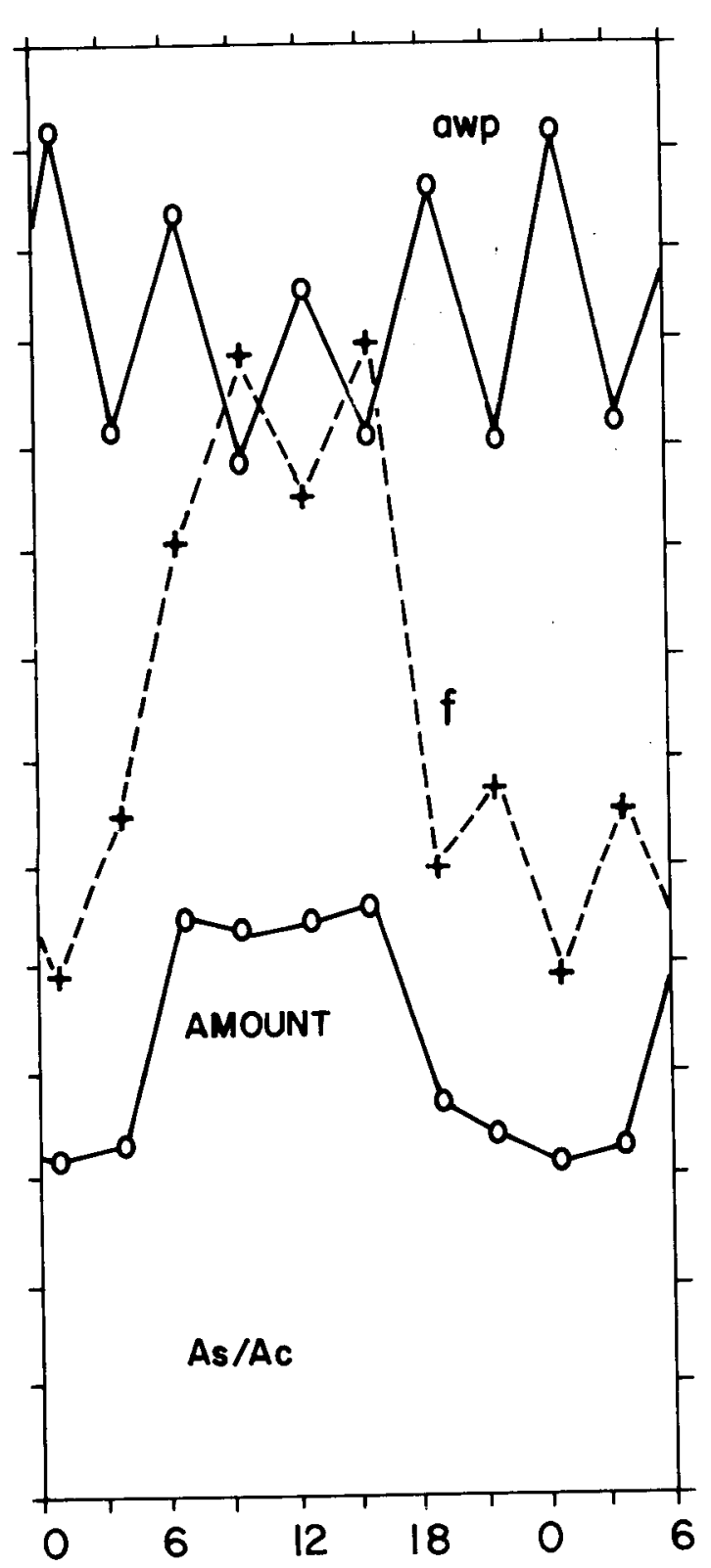

JJA

70

65

60

55

45

40

35

30

25

20

15

10

5

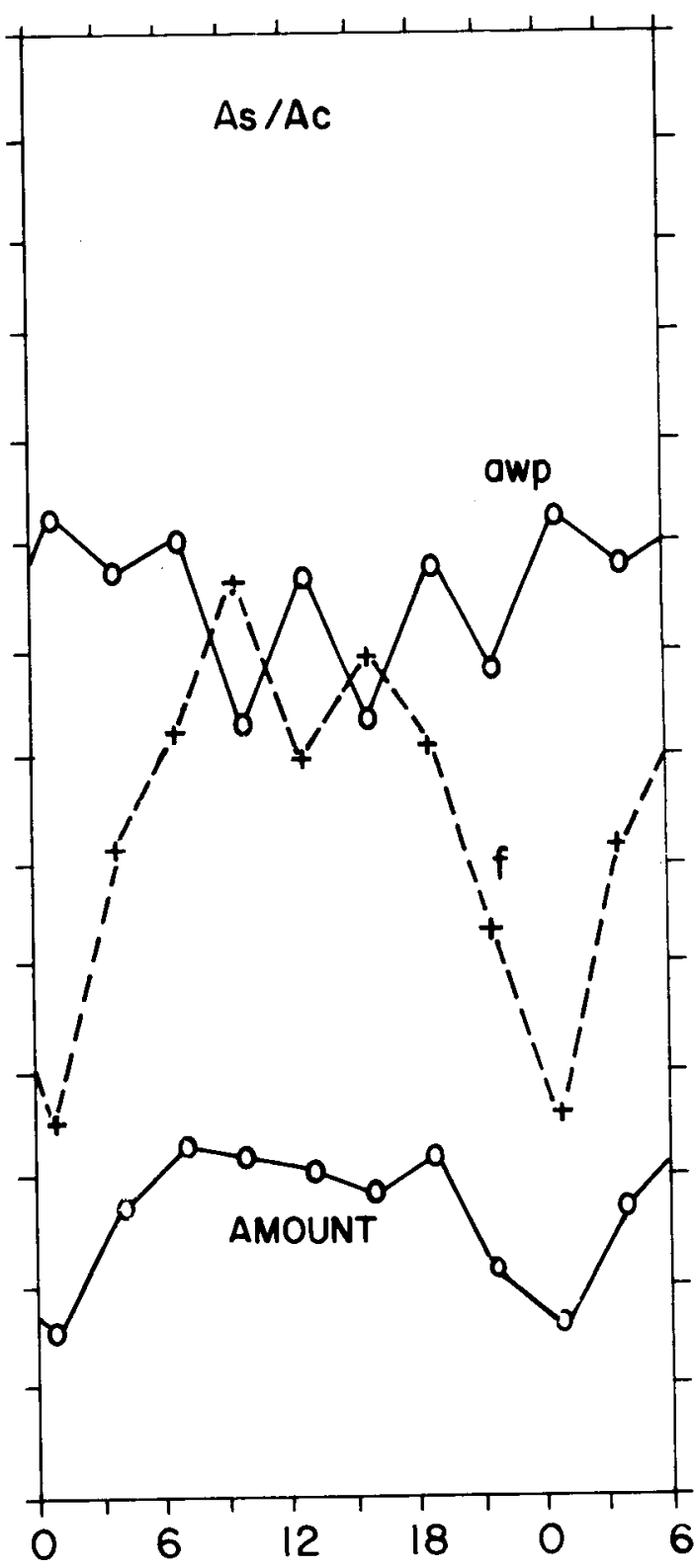

(HOUR)

Figure 9. Examples of diurnal cycles. All are for a grid box in the North Atlantic at 30$40^{\circ} \mathrm{N}, 20-40^{\circ} \mathrm{W}$, for December - January - February (DJF) and June - July August (JJA). Diurnal cycle of total cloud cover is at the top left, followed by the four types with largest diurnal cycles. A cosine curve is fitted to the eight data points, except for $\mathrm{Ci}$ and As/Ac. "Local time" is mean solar time for the center of the box. 


\section{i. Interannual variations and trends}

Values of total cloud cover and cloud-type amounts were computed, at $10^{\circ} \times 20^{\circ}$ resolution only, for individual seasons of individual years which had at least 100 compressed observations. The number of years between 1952 and 1981 which satisfied this criterion is given on Map 111. It is at most 30. A least-squares straight line was fit to the values if at least 15 years were represented, spanning at least 25 years. The difference between the values of this line at 1981 and 1952 is the "trend" mapped in this atlas. (To obtain the change per year, the mapped values should be divided by 29.) The standard deviation of the individual yearly values about the trend line is the (detrended) "interannual variation" (IAV) on the maps. The trend is displayed on the maps only if it is greater than its uncertainty, or if the uncertainty is less than $2 \%$.

The IAV as computed here may be larger than the true IAV in boxes with small numbers of observations, due to the possible error in the seasonal means caused by inadequate sampling (Figure 8).

We computed the trend of the zonal average by computing a zonal average for each year and fitting a trend-line to those values. [The same was done for the global trend.] This is usually a more accurate estimate than would be obtained from a zonal average of the trends for individual boxes. Since this procedure differs from the way zonal averages were formed on other maps, we indicate this in the trend maps by the label "zonal trend" (trend of the zonal average) instead of "zonal average" (zonal average of the trend). This distinction would be unnecessary if all boxes in the zone were represented in each year. A minimum of 100 observations was required to form an average for an individual box in a single year-season. If a box was missing in a particular year, the multi-year cloud amount for that box was used as a bogus value when computing the zonal average cloud amount for that year. This procedure was done because different boxes are missing in different years, which would lead to excessive computed interannual variation and some spurious trends if they were just left out of the computation. Our procedure biases the zonal cloud amounts for individual seasons toward the long-term mean when boxes are missing in some years, so this procedure will probably result in computed interannual variations and trends which are somewhat smaller than the true values.

\section{j. Time series plots}

The individual seasonal means of cloud amounts (from which trends and interannual variations were computed) are plotted on graphs of cloud amount versus year, on the microfiche attachment. For each cloud type, and for clear sky, fog, and total cloud cover, a plot is drawn for each season (DJF, MAM, JJA, or SON) for each $10^{\circ} \times 20^{\circ}$ box. Plotting by season is done so as 
to remove the annual cycle from the plots such that interannual variations are clearly displayed. A point is plotted for a particular year-season if the box contained at least 100 compressed observations in that season in that year. [The later years generally have more observations than the earlier years.]

Time series are also plotted for zonal, hemispheric and global averages. They were computed as described in the previous section ( $3 \mathrm{i}$ ).

The time series for the cloud types, and for clear-sky and fog, cover the years 1952-1981, the same years used for the maps. For total cloud cover, however, the time series cover the 52 year period 1930-1981, because in our inventory of the data (Sec. 2b) we found no compelling reason to exclude the earlier years from the analysis of total cloud cover.

The first 36 microfiche cards contain 251 plots each. Each card contains all the plots for a single cloud type for a single season. The 251 plots are for the 230 boxes, plus 18 zones, plus the two hemispheres and the globe. The 37th card contains plots of annual average cloud amount, for zonal, hemispheric, and global averages only, not for boxes. An annual average value for a particular year was plotted only if all four seasons were represented for that year.

These plots should be useful for the study of climatic anomalies known to have occurred in particular regions and years (e.g. El Ninõ).

\section{$\underline{\text { k. Post-1981 analyses }}$}

The maps in this atlas (except for the analyses of diurnal cycle) resulted from analyses of data from 1952 to 1981 . We will have to change our procedure of rejecting observations with $\mathrm{N}_{\mathrm{h}}=/$ and $\mathrm{C}_{\mathrm{L}}=/$ in our future analysis of the post-1981 data, because under the new rules instituted in 1982 the observer is permitted to omit the ww code if $w w=00,01,02$, or 03 , and is permitted to omit the codes for $\mathrm{N}_{\mathrm{h}}, \mathrm{h}, \mathrm{C}_{\mathrm{L}}, \mathrm{C}_{\mathrm{M}}$, and $\mathrm{C}_{\mathrm{H}}$ if $\mathrm{N}=0$ (no clouds). Thus since $\mathrm{C}_{\mathrm{L}}=/$ no longer (after 1981) necessarily means an observer who never reports cloud types, another test will have to be devised to eliminate this class of observations. A "present-weather indicator," $i_{x}$, has been introduced into the code to make this distinction, but it was not archived in the data source we were using. It will be available in future work.

It was mentioned in Sec. 3 a that observations of $\mathrm{N}=9$ together with $w \mathrm{w}=/$ were converted to $\mathrm{N}=8$ for the analysis of total cloud cover, and that only about $0.1 \%$ of the observations were affected. However, in 1982 and 1983 a substantial fraction of all reports, $2.4 \%$ and $2.9 \%$ respectively, have $\mathrm{N}=9$ and $\mathrm{ww}=/$. This change is probably related to the change in coding procedure instituted in January 1982. It seems unlikely that these are all cases of fog or precipitation, since the frequency of $\mathrm{N}=9$ with ww coded explicitly as fog or precipitation is no less in 1982-3 than in earlier years. Our analysis of the 1982-3 data, which is not included in this atlas but is on the 
archive tape, therefore gives total cloud cover values which are on average $1 \%$ too large because we converted observations of $(\mathrm{N}=9, \mathrm{ww}=/)$ to $\mathrm{N}=8$. The $1982-1983$ data will be reanalyzed in the future.

\section{BIASES}

There are many biases which can affect analyses of cloud amounts from surface weather observations (several of which have already been mentioned), and we have probably not identified all of them. Some biases apply to both land and ocean areas but others are specific to ships or to land stations. The night-detection bias was discussed in Section 3f4; because of its severity we use only daytime observations to establish the climatology of As/Ac and cirrus.

\section{$\underline{\text { a. Day-night sampling bias }}$}

As explained in Section 2, the number of night-time observations in our dataset nearly equals the number of daytime observations through 1979, but in 1980-81 there are relatively fewer night-time observations. Map 110 shows that over the entire period of record, an average of $52.0 \%$ of the compressed observations over the global ocean were made during daytime. Since the daytime average reported cloud cover exceeds the night-time average by $4 \%$, the day-night sampling bias causes our reported cloud cover values to be too large by only $0.1 \%$, on average. However, since the fraction of daytime observations increased from $52 \%$ in $1952-1979$ to $59.4 \%$ in 1980-81 because of our shift to a different data source, spurious trends can result. The computed cloud cover for 1980 and 1981 is, on average, $0.3 \%$ higher than it would be if the fraction of daytime observations had not changed. This correction should be considered when interpreting the values of total cloud cover for 1980 and 1981 shown in the microfiche attachment.

\section{b. Geographical sampling biases}

Ships do not sample all parts of a $5^{\circ} \times 5^{\circ}$ box (or $10^{\circ} \times 20^{\circ}$ box) equally; there are favored shipping routes which may cause part of a box to be over-sampled. The resulting bias in cloud amounts may be less severe than the corresponding bias over land because the ocean surface has uniform topography. This bias would be most significant in the coastal regions, where steep gradients in cloud amount occur. Some ships stop making observations when they come within sight of port; other ships continue to make observations while docked. We did not exclude from our analysis the observations by ships in port, and we do not know what fraction of the observations for coastal boxes are of this type. 


\section{c. Fair-weather bias and foul-weather bias, and observer bias}

There are sampling biases that apply specifically to ships, because ships, unlike land stations, do not normally report from the same fixed position. Ships may slow down because of high waves or poor visibility in storms or fog, thus over-sampling these weather types, causing a "foul-weather bias." There are also ships which do not report regularly but instead record only a few observations per season, as is evident in the lists of number of reports received from each ship given in each issue of the Mariners Weather Log. These rare observations may not be representative of the climate; they may tend to be reports of extreme severe weather events. (However, such ships contribute only a small fraction of the total number of observations.) Furthermore, the US ships are requested by NOAA to record observations routinely every six hours, but also to record observations at the intermediate 3-hourly times if winds exceed 34 knots or visibility is below one-half mile. These practices would all cause a bias toward increased total cloud cover and, particularly, increased nimbostratus. The statistics of the 3-hourly observations do differ sometimes from those of the 6-hourly observations, as Figure 9 shows.

On the other hand, ships may alter their route or delay their departure from port to avoid a forecast storm. If a ship is caught in a storm or in fog the observers may neglect to make weather observations because they are too busy with navigational tasks. These practices cause a "fairweather bias" which counteracts the foul-weather bias. We have evaluated the net result of these biases, as described below, and find that the fair-weather bias prevails but is still quite small. Analyses of the earlier years of COADS (beginning 1854) may be subject to a larger fair-weather bias because sailing ships travel more slowly when the winds are light, the usual condition with fair weather (Wright, 1986).

The fair-weather (or foul-weather) bias is evaluated by comparing observations from the nearly-stationary weatherships (which, when on-station, sample the weather near their assigned point every three hours throughout the year and therefore have no fair-weather bias) to those of transient ships passing near the weatherships. Studies of this sort have been carried out by Bunker (1976) and Quayle (1980). The weatherships whose data we analyzed, and the few weatherships still remaining in operation, are all in the mid-latitudes of the northern hemisphere (Diaz et al., 1987).

We have used the data source described by Quayle (1980), which includes the reports from transient ships passing near a weathership (within $1^{\circ}$ of latitude and longitude). Quayle's study used five weatherships, and he supplied us the selected data for the surrounding transient ships. The results are summarized in Table 8. When individual observations are averaged, the average total cloud cover reported by the transients is $2.0 \%$ less than that reported by the weathership. Use of compressed observations slightly reduces the average bias to $1.8 \%$. There is considerable 
Table 8. Fair-weather bias and observer bias

a. Weatherships used

\begin{tabular}{cl|c|c|c} 
Weathership & \multicolumn{1}{c|}{$\begin{array}{c}\text { period of } \\
\text { record }\end{array}$} & $\begin{array}{l}\text { number of } \\
\text { number } \\
\text { of years }\end{array}$ & $\begin{array}{l}\text { observations from } \\
\text { nearby transient ships }\end{array}$ \\
\hline & & & & \\
$\mathrm{C}$ & $52^{\circ} 45^{\circ} \mathrm{N}, 35^{\circ} 30^{\prime} \mathrm{W}$ & $1949-71$ & 23 & 36,000 \\
$\mathrm{D}$ & $44^{\circ} \mathrm{N}, 41^{\circ} \mathrm{W}$ & $1949-71$ & 23 & 8,000 \\
$\mathrm{E}$ & $35^{\circ} \mathrm{N}, 48^{\circ} \mathrm{W}$ & $1949-71$ & 23 & 26,000 \\
$\mathrm{~N}$ & $30^{\circ} \mathrm{N}, 140^{\circ} \mathrm{W}$ & $1954-73$ & 20 & 45,000 \\
$\mathrm{~V}$ & $34^{\circ} \mathrm{N}, 164^{\circ} \mathrm{E}$ & $1955-71$ & 17 & 58,000
\end{tabular}

\section{b. Bias in total cloud cover}

total bias without pre-averaging (individual observations)

Bias in total cloud cover, transient-minusweathership (average of five weatherships)

total bias after pre-averaging (compressed observations)

$$
\begin{aligned}
& -2.0 \% \\
& -1.8 \% \\
& -1.4 \%
\end{aligned}
$$$$
\text { observer bias (simultaneous observations) }
$$

fair-weather bias (residual)

c. Cloud types contributing to the observer bias. Bias in total cloud cover (transientminus-weathership) when weathership reports the specified cloud type. Other types (at other levels) may be present simultaneously. Units are percent-cloud-cover. Values are

\begin{tabular}{|c|c|c|c|c|c|}
\hline & $\mathrm{C}$ & $\mathrm{D}$ & $\mathrm{E}$ & $\mathbf{N}$ & $\mathrm{V}$ \\
\hline $\mathrm{C}_{\mathrm{L}}=1$ & +0.6 & +0.4 & & +0.8 & +0.7 \\
\hline 2 & & & & +0.3 & \\
\hline 5 & -0.8 & $-1: 3:$ & -0.5 & -0.8 & -0.6 \\
\hline 6 & : -0.3 & . & & & \\
\hline 8 &. & . & -0.4 & -1.8 & -0.8 \\
\hline 9 & & & & & \\
\hline $\mathrm{C}_{\mathrm{M}}=2$ & & -0.4 & -0.3 & & -0.4 \\
\hline 3 & & & -0.5 & & -0.3 \\
\hline 7 & $\because \quad-0.4$ & -0.3 & -0.9 & -0.3 & -0.5 \\
\hline $\mathrm{C}_{\mathrm{H}}=2$ & & $\therefore$ & -0.4 & & -0.4 \\
\hline 6 & & & -0.4 & & \\
\hline 7 & -0.4 & -0.3 & -0.9 & -0.4 & -0.6 \\
\hline 8 & & & -0.4 & & \\
\hline
\end{tabular}
listed only if the difference is at least $0.3 \%$.

\section{Weathership}


variation with season and among weatherships in these values, perhaps because of the limited number of transient ships, so only the average of all five locations is shown in Table 8.

It turns out, however, that only a small part of this bias is a fair-weather bias. Weatherships differ from transients not only because they are fixed in location but also because their weather observers are better trained. To separate these two contributions, we created a subset of the weathership observations by selecting only those that were made at the same time that a transient ship was nearby. There remained a difference of $1.4 \%$ in the average cloud cover, which must be due to the difference in training ("observer bias"), leaving only $0.4 \%$ difference in cloud cover due to fair-weather bias.

The observer bias is significant only for a few particular cloud types. The observations made simultaneously by the weathership and a transient ship were classified according to the cloud types reported by the weathership. The total cloud cover was compared (transient-minusweathership) for each of these groups of observations. The difference was large and consistent for just four of the cloud types, as shown in Table 8: $C_{L}=1, C_{L}=5, C_{M}=7$, and $C_{1 I}=7$. [The contributions of the individual types to the total bias are actually obtained only qualitatively in this way, because in many of these observations more than one cloud layer was present.] The transient ship tends to overestimate the amount of $\mathrm{C}_{\mathrm{L}}=1$ (cumulus of small vertical extent) when it is present. This is to be expected for untrained observers viewing scattered small clouds, based on the psychological study of Young (1967). The transient ship correspondingly underestimates the amount-when-present of $\mathrm{C}_{\mathrm{L}}=5$ (stratocumulus not formed by spreading-out of cumulus), perhaps by exaggerating the area of breaks in a broken cloud layer.

When $\mathrm{C}_{\mathrm{H}}=7$ (cirrostratus covering the whole sky), the transient sometimes does not notice it and reports clear sky. The total (fair-weather plus observer) bias, which averaged $-1.8 \%$, is much larger during the night $(-3.1 \%)$ than during the day $(-0.6 \%)$, suggesting that much of the observer-bias is just the night-detection bias for cirrus, which is more severe for untrained observers. However, the data do not support this idea. The transients' underestimate of the amount of $\mathrm{C}_{\mathrm{H}}=7$ is no greater at night than during day, in this small sample (not shown).

We have no explanation for the bias.shown in Table 8 in the presence of $C_{M}=7$ (altocumulus, or altocumulus together with altostratus or nimbostratus).

The fair-weather bias and observer bias are thus different for different cloud types, so it would not be appropriate to apply a uniform correction to total cloud cover in all areas of the ocean. We also do not know whether these biases have changed with time, because the dataset of nearby ships contained insufficient observations to do this study for each year individually. We did not apply any corrections to our computed average cloud amounts to correct for observer bias or fair-weather bias. 


\section{d. Sky-obscured bias}

Observations of sky obscured $(\mathrm{N}=9)$ due to rain, snow, or fog have $\mathrm{C}_{\mathrm{L}}=/$, but they are not excluded from our analysis. It is important to include these observations to obtain accurate estimates of nimbostratus and fog amounts. However, about $11 \%$ of the ships which routinely report ww never report $C_{L}$ (Table 3), so their observations enter our analysis for cloud types only when $\mathrm{N}=9$, which causes our computed amounts of fog and nimbostratus to be slightly too large in some regions. The bias is normally small: for example, it can cause us to report $11 \%$ fog when the correct value is $10 \%$ in a region which has the global average reporting frequency of $\mathrm{C}_{\mathrm{L}}$. However, in one isolated region, the Great Lakes of North America, about three-quarters of the ships reporting ww do not report $\mathrm{C}_{\mathrm{L}}$, resulting in excessive computed amounts of fog. We therefore do not report cloud-type amounts for the Great Lakes; those areas are represented only on the maps of total cloud cover.

\section{e. Earth-cover versus sky-cover}

The sky-cover is what the ground observer reports. It is the fraction of the celestial hemisphere covered by clouds as viewed from a point on the surface. Except when the sky-cover is $0 \%$ or $100 \%$, it is generally greater than the earth-cover, which is the fraction of earth covered by clouds when the clouds are projected vertically. The difference depends on the ratio of vertical to horizontal dimension of the cloud. This topic was discussed in the land atlas. A relationship between earth-cover $\mathrm{E}$ and sky-cover $\mathrm{S}$, obtained from all-sky photographs by Malick et al (1979), was misprinted on page 18 of the land atlas; the correct equation is $E=(1+3 S) S / 4$. However, Henderson-Sellers and McGuffie (1989) have recently done a more extensive study, using all-sky cameras from a number of locations, and concluded that, on average, earth-cover and sky-cover do not differ from each other as much as that relationship indicates.

Satellite cloud climatologies often attempt to report earth-cover, but satellites also usually have a somewhat oblique view of the clouds so they do not obtain the earth-cover directly. The difference between earth-cover and sky-cover should not really be considered a bias, since in this work our goal is to obtain accurate values of sky-cover, not earth-cover. For different applications one or the other may be more appropriate. 


\section{f. Summary}

Since the discussion of biases has been scattered throughout this atlas and the earlier atlases, it may be useful to list all the biases here together, with references to where they are discussed. There probably still remain other biases in the data, which we have not identified.

1) Biases due to the ground observer's viewpoint, affecting both land and ocean analyses.

(a) Night-detection bias (Section 3f4). To avoid this apparently severe bias, we do not include night-time observations in the computation of $\mathrm{Ci}$ and As amounts, and clear-sky frequency.

(b) Partial-undercast bias (page 12 of the land atlas). This causes $f$ to be underestimated and awp to be overestimated, for As/Ac and $\mathrm{Ci}$. The analysis procedure was designed to reduce this bias (page 12 of the land atlas). However, these opposing biases on $f$ and awp compensate each other so that there should be no bias in the average amount computed for these types.

(c) Earth-cover versus sky-cover (page 18 of the land atlas; Section 4e of this atlas). This is not a bias for applications in which sky-cover is the desired quantity. It is called the "projection bias" when earth-cover is desired, and may be partly responsible for the smaller average cloud cover generally obtained from satellite observations in comparison with ground-based observations.

2) Biases inherent in the synoptic code, affecting both land and ocean analyses

(a) $\mathrm{C}_{\mathrm{L}}$-flowchart bias (page 18 of the land atlas). The synoptic code requires $\mathrm{Cb}$ to be reported as the low cloud type if any $\mathrm{Cb}$ is present, even if other low clouds cover more of the sky. This causes our reported $\mathrm{Cb}$ amounts to be somewhat excessive, and correspondingly causes the amounts of St and $\mathrm{Cu}$ to be slightly underestimated.

(b) $\mathrm{N}$ - endpoint bias (page 18 of the land atlas). In a nearly clear sky, any small amount of clouds, even if less than 0.5 eighths, is to be reported as $\mathrm{N}=1$; and in a near-overcast sky if any gaps, however small, are present, the cloud cover is to be reported as $\mathrm{N}=7$. This is expected to have little effect on our analyses.

\section{3) Biases due to inadequate temporal sampling, affecting both land and ocean analyses}

(a) Day-night sampling bias (Section 4a). The averaging procedure in the land atlas was designed to eliminate this bias (page 14 of the land atlas), but it was impractical to apply that procedure to ocean data. This bias is insignificant for 1952-79 ocean analyses, but causes our computed oceanic total cloud cover to be on average $0.3 \%$ too large in 1980 and 
1981.

(b) Trend bias (Section $3 \mathrm{f} 2$ of the land atlas). The average cloud amounts computed may be more representative of the later years in the period of record, if those years had more observations.

4) Biases due to inadequate temporal sampling, affecting ocean analyses only.

(a) Fair-weather and foul-weather biases (Section 4c). These biases probably vary with location, but on average may together cause our computed total cloud cover to be $0.4 \%$ too low (Table 8).

(b) Interannual variability is probably overestimated in some regions (Section 7k).

(c) Zonal trends are probably underestimated somewhat because the multi-year box average was used in missing years (Section 3i).

5) Bias due to inadequate geographical sampling, affecting both land and ocean analyses (Section 4b)

In the ocean this bias may cause the cloud amounts computed along coastlines not to be representative of the entire area of the box.

\section{6) Errors specific to observations from ships}

(a) Observer bias (Section $4 \mathrm{c}$ ). This bias varies with cloud type. On average it may cause our computed total cloud cover to be $1.4 \%$ too low (Table 8 ).

(b) Mislocated observations can bias the cloud statistics in regions of very light ship traffic toward the climatology for regions of heavy ship traffic (Section 5).

7) Biases and errors specific to our analysis procedure

(a) Sky-obscured bias (Section 4d; affects ocean only). This may cause our computed Ns and fog amounts to be slightly too large in some regions. It is severe only in the Great Lakes; because of this bias we do not report any cloud-type amounts there.

(b) The use of our analysis procedures on post-1981 data, without taking account of the changes in coding procedure, causes our computed total cloud cover to be on average $1 \%$ too large for 1982 and 1983 (Section 3k; affects ocean only). This will be corrected in future work.

(c) Nimbostratus is slightly underestimated in the polar regions because of a mistake in our grouping of the present-weather codes 77 and 79 (Table 4; affects both land and ocean). 


\section{ERRONEOUS REPORTS FROM SHIPS}

In contrast to land stations, individual ships which tend to transmit erroneous cloud reports are not evident in our analysis, because every grid box in the ocean is sampled by many ships. But for the same reason, such ships are not able to do much damage to the cloud climatology in any of the boxes.

A serious problem which does affect our analysis everywhere is that latitude or longitude is often recorded incorrectly or transmitted incorrectly over the radio. As many as 6-8\% of the real-time observations may be affected, according to some estimates (Woodruff et al., 1987), and a smaller fraction of the logbook observations. Many of these reports are mislocated by exactly one degree of latitude or longitude (Lander and Morrissey, 1987; Steurer, 1987); such small mislocations would do little damage to our climatology. However, one reason for mislocations is the specification of the wrong quadrant or octant of the globe, which can cause a gross mislocation. The only way to eliminate or correct mislocated data is to sort the entire dataset by ship identification code and to plot the tracks of each ship. This we did not do. The ship identification code is not always available, particularly in the early years, and also is often not definitive.

An estimate of the fraction of mislocated observations can be made by counting the number of ship reports which appear at land locations (Maps 2-5); this indicates that only $1 \%$ are mislocated, but it is an underestimate because ship observations from land locations unfortunately had been deleted from some of the datasets which entered the COADS compilation. Another estimate may be obtained by considering that if incorrect latitudes and longitudes were randomly distributed, we would expect greater numbers of reports per box at the poles where a $" 5^{\circ} \times 5^{\circ \prime \prime}$ box contains $360^{\circ}$ of longitude. There does seem to be some tendency for this. However, if that is true then the fraction of mislocated reports cannot be larger than $1 \%$, even if the observations at $85^{\circ}-90^{\circ} \mathrm{N}$ in DJF are all mislocated. [Since this is an ocean area, the erroneous data would not have been deleted from the datasets.] As another indication, the sparsely-sampled region west of southem South America has typically 50 observations per multi-year season in a $5^{\circ} \times 5^{\circ}$ box; if all of these are mislocations, and if latitude and longitude are distributed randomly in mislocated observations, then again only $1 \%$ of the observations can be mislocated. [The mislocations due to misreporting of the quadrant of the globe would not be randomly distributed; they should be most common near the equator and near the $0^{\circ}$ and $180^{\circ}$ longitude lines, occurring just after the ship has crossed into a new quadrant.]

Mislocated data add noise to the computation of average cloud amounts. They do the most damage in regions that are rarely sampled by ships, where they can become a substantial fraction of the total number of observations, biasing the climatology there toward the values of regions 
with heavy ship traffic (northern midlatitudes). We are not able to quantify these biases, because we do not know that the mislocated data are randomly distributed geographically. However, such biases are generally not apparent on the maps in this atlas, with the exception of the $85^{\circ}-90^{\circ} \mathrm{N}$ box, which should indeed suffer the most from such biases. Its cumulus frequency seems excessive (5\% in MAM) by comparison to its neighbors (1\%), although its total cloud cover and stratus amount are reasonable.

There are a few boxes whose climatologies do differ appreciably from those of their neighbors. This may be due to a single ship reporting from a harbor and thus biasing its climatology to land (or island) values. This is apparently not the explanation for the large awp(Ci) at $10-15^{\circ} \mathrm{N}$, $165-170^{\circ} \mathrm{E}$ on Map 93 which disagrees with the island station reports for that box. Another example is the large value of $\mathrm{f}(\mathrm{Cb})$ in MAM (Map 41) at $65-70^{\circ} \mathrm{S}, 160-170^{\circ} \mathrm{E}$, which is remote from any land. That value is based on observations which were all from early March, as the seaice edge was approaching the ship's location. Although all the observations are from the early 1950 s, they are not dominated by any one year so should not represent a single anomalous year. Furthermore, in the preceding season (DJF), when sufficient observations are available for the neighboring boxes also to appear on our maps, those neighboring boxes agree in showing $\mathrm{Cb}$ amounts considerably greater than in the rest of the latitude zone.

\section{FORMAT OF THE MAPS}

As stated earlier, the resolution of the $" 5^{\circ} \times 5^{\circ}$ maps is $5^{\circ}$ latitude by $5^{\circ}$ longitude, between $50^{\circ} \mathrm{N}$ and $50^{\circ} \mathrm{S}$. At higher latitudes the size of the boxes is increased in longitude to maintain approximately equal area in each box. The resolution is $5^{\circ} \times 10^{\circ}$ for $50^{\circ}-70^{\circ}$ latitude, $5^{\circ} \times 20^{\circ}$ for $70^{\circ}-80^{\circ}$ latitude, $5^{\circ} \times 40^{\circ}$ for $80^{\circ}-85^{\circ}$, and $5^{\circ} \times 360^{\circ}$ for $85^{\circ}-90^{\circ}$. For convenience, the term " $5^{\circ} \times 5^{\circ}$ box" refers to any of these. The resolution of the " $10^{\circ} \times 20^{\circ}$ maps is $10^{\circ}$ latitude by $20^{\circ}$ longitude for $50^{\circ} \mathrm{N}-50^{\circ} \mathrm{S}, 10^{\circ} \times 40^{\circ}$ for $50^{\circ}-70^{\circ}$ latitude, $10^{\circ} \times 60^{\circ}$ for $70^{\circ}-80^{\circ}$ latitude, and $10^{\circ} \mathrm{x}$ $360^{\circ}$ for $80^{\circ}-90^{\circ}$. Although many of the boxes contain some land area, the values plotted apply only to the ocean portion of the box. The ocean area of each box was determined from the topographic data tape of the US Navy (which is gridded to 10 minutes of latitude and longitude; available at NCAR) but corrected by us so that large Antarctic ice shelves are counted as land rather than ocean. Any box which contains at least $0.1 \%$ ocean is included on the maps. The fraction of each box, and of each zone, which is ocean is given in Map 1 at $5^{\circ} \times 5^{\circ}$ resolution and in Map 108 at $10^{\circ} \times 20^{\circ}$ resolution. Observations from ships in the Great Lakes are included in the total-cloud analysis, and observations from the Caspian Sea are included in all analyses; cloud amounts displayed on the maps for these regions are based on ship observations not land stations. However, they are given an ocean fraction of zero, so they do not contribute to zonal and global 
averages.

For most of the mapped quantities there are four maps: one for each of the four seasons. Blanks occur on the maps where there were insufficient observations to obtain reliable average values by the criteria described earlier.

All the $5^{\circ} \times 5^{\circ}$ maps are grouped together (Maps 1-107), followed by the $10^{\circ} \times 20^{\circ}$ maps (Maps 108-168). The maps of seasonal average total cloud cover, and frequency, amount-whenpresent and amount of the cloud types are mapped at both $5^{\circ} \times 5^{\circ}$ and $10^{\circ} \times 20^{\circ}$ resolution. The $10^{\circ} \times 20^{\circ}$ maps give more complete geographical coverage. The value displayed for a $10^{\circ} \times 20^{\circ}$ box will not necessarily equal the average of the eight values' from the eight $5^{\circ} \times 5^{\circ}$ boxes comprising the $10^{\circ} \times 20^{\circ}$ box, because the $10^{\circ} \times 20^{\circ}$ value is just the average of all compressed observations in the $10^{\circ} \times 20^{\circ}$ box.

Computation of the zonal and global averages printed on the sides and bottoms of the maps was discussed in Sections $3 \mathrm{~h}$ and $3 \mathrm{i}$. Note that for quantities that are mapped at both $5^{\circ} \times 5^{\circ}$ and $10^{\circ} \times 20^{\circ}$, the global average of the $10^{\circ} \times 20^{\circ}$ map is also printed at the bottom of the corresponding $5^{\circ} \times 5^{\circ}$ map (instead of the global average of the $5^{\circ} \times 5^{\circ}$ map) because the world ocean is more fully represented on the $10^{\circ} \times 20^{\circ}$ maps.

Cloud base heights, diurnal cycles, interannual variations and trends are given only on $10^{\circ} \mathrm{x}$ $20^{\circ}$ maps. Except for the diumal cycles, the $10^{\circ} \times 20^{\circ}$ maps are grouped so that the four seasons of a particular quantity are all on one page.

Blank outline maps of both sizes are included at the end of the atlas.

\section{a. Distribution of Reports (Maps 2-5, 109-111)}

Maps 2-5 and 109 show the number of compressed observations (in hundreds). This is the number of 3-hour periods which had some information about clouds, present or absent. The maximum possible number is (30 seasons) $\mathrm{x}$ (91 days per season) $\mathrm{x}$ ( 8 synoptic hours per day) or about 218 hundred in a $5^{\circ} \times 5^{\circ}$ box, or 8 times this ( 1750 hundred) in a $10^{\circ} \times 20^{\circ}$ box. The maximum possible number is approached in some $5^{\circ} \times 5^{\circ}$ boxes in the North Atlantic where weatherships were stationed for much of the 30 -year period. These maps can be used together with Figure 8 to estimate the expected error due to random sampling. On average, there are two individual observations per compressed observation. (In 1979 there were 2.5 on average in the Northern Hemisphere; 1.4 in the Southern Hemisphere.)

The observations from the Arctic Ocean in winter are probably mostly from ice-island stations, which report as ships. 
Maps 110 and 111 do not correspond to maps of the land atlas. Since all compressed observations were averaged here without regard to time of day, the relevant concern is whether a diurnal sampling bias exists. Therefore we present the percent of observations made during daytime (Map 110) rather than the number of synoptic hours with a specified minimum number of observations as in the land atlas. The number of years (out of 30 ) contributing to the analysis of interannual variation and trends is also included (Map 111) for reference in order to judge the significance of trends. Trends were not calculated for land, because the period of record was only 11 years.

\section{b. Total cloud cover}

1) Average cloud cover by season (Maps 6-9, 112)

Values are shown as percent sky cover. The method for computing the average was discussed in Section 3f. Blanks appear on these maps where there were less than 100 compressed observations available (west of southern South America at $5^{\circ} \times 5^{\circ}$ resolution in all seasons, and in the Antarctic Ocean in JJA).

\section{2) Standard deviation of compressed observations (Maps 10-13, 113)}

All compressed observations in the season were pooled irrespective of year or time of day or location within the box. This variation thus includes interannual, geographical (within the box), and diurnal variation of the mean cloud cover, as well as hour-to-hour or day-to-day variation of instantaneous cloud cover. However, this last variation is much larger than the first three (Section 3f2). These values should not be confused with the uncertainty in mean cloud cover, which is usually less than $1 \%$ due to sampling error alone as shown in Figure 8 . The mapped values are in units of percent cloud cover, not percent of the mean; e.g. an average of $60 \%$ and a standard deviation of $30 \%$ means $0.60 \pm 0.30$. The standard deviation of compressed observations rather than individual observations was computed, since it was compressed observations that were used to compute the mean. The standard deviation of individual observations is larger (by $3 \%$ on average), except in regions with few observations where it is the same.

Since the distribution of cloud-cover fractions is rarely gaussian (see Figure 5b), a large standard deviation means a $U$-shaped distribution and a small standard deviation usually means a $\mathrm{J}$-shaped (or reverse - J) distribution.

\section{3) Average cloud cover by month (Maps 14-25)}

Only the average values are given for the twelve months; not the standard deviation (sd) of individual observations nor the number of observations. A minimum of 100 observations was required to compute an average. The sd is very similar to that for the corresponding season, and 
the number of observations is about one-third the value given on Maps 2-5.

The twelve monthly values of average total cloud cover are fitted to a cosine curve with period one year: its amplitude and phase are displayed in Maps 26 and 27. The phase is the month of maximum, given by number $(1=$ mid-January, etc. $)$. It is plotted only if the amplitude is larger than $2 \%$ sky cover.

4) Diurnal cycle (Maps 114,115)

For boxes which had at least 100 observations in four or eight equally-spaced synoptic hours, a cosine curve of period 24 hours was fitted to the cloud cover values as described in Section 3g. The amplitude and phase of this first harmonic function are displayed together on the same page. The phase is the hour (local time) of maximum; it is displayed only if the variance accounted for by the first harmonic is at least $30 \%$, and if the amplitude is either larger than $2 \%$ cloud cover or larger than $10 \%$ of the mean.

\section{5) Interannual variation and trend (Maps 116,117)}

The computation for these maps was fully discussed in section $3 i$.

\section{c. Cloud types (Maps 28-107, 118-168)}

Most of these maps are grouped by cloud type. The same quantities are mapped for each of the six types, and for clear sky and fog, with some omissions as indicated in the Table of Contents and explained below.

\section{1) Frequency of occurrence}

The frequency of occurrence (f) is the number of times that a particular cloud type was reported present, divided by the number of reports in which the level of that type was observable, subject to the modifications discussed in Section 3d. The maps of $\mathrm{f}$ in this atlas should be more accurate than those in Hahn et al. (1982) but are usually very similar. They are different for the following six reasons, the first four of which apply also to the land analysis:
a) Only daylight observations are used here for the maps of $\mathrm{Ci}$, As, and clear-sky (Section 3f4).
b) The partial-undercast bias has been reduced by restricting the analysis of high clouds to reports in which the amount of obscuring lower clouds was at most $6 / 8$ (Section 3d).
c) The definition of Ns was slightly modified (Section $3 \mathrm{c}$ of the land atlas).
d) Reports of (thin) fog together with clear sky are now counted as clear sky (Section $3 c$ of the land atlas).


e) Thirty years, instead of twelve, are used for the present atlas.

f) Compressed observations, instead of individual observations, are used for the present atlas.

\section{2) Amount-when-present}

Amount-when-present (awp) is the average sky cover of a cloud type, when that cloud type is present. It is the total amount, not the non-overlapped amount as seen from below. The method of computing awp was described in Section 3d1 of the land atlas.

\section{3) Average cloud amount}

Average cloud amount is the overall average percent of the sky covered by a cloud type, including times when it was not present. It is the product of frequency of occurrence and average amount-when-present. There are more blank boxes on these maps than on the maps of total cloud cover because we do not use night-time observations for As and $\mathrm{Ci}$, and because in some cases there were not enough observations in which awp of middle or high clouds was computable even if there were sufficient observations to obtain $\mathrm{f}$, and because there are slightly more observations of $\mathrm{N}$ than of $\mathrm{N}_{\mathrm{h}}$.

If the total amount of clouds in each of the three layers is desired, a very good estimate can be made by adding the amounts given in this atlas for $\mathrm{Cu}, \mathrm{St}$ and $\mathrm{Cb}$ to obtain the low cloud amount (including fog), and by adding the Ns and As amounts to obtain the middle cloud amount. The values of low and middle cloud amount thus obtained are not shown on maps, but they are included on the tape. The high cloud amount will be somewhat greater than the amount of $\mathrm{Ci}$ in areas where the tops of $\mathrm{Cb}$ extend to the high level; there the high cloud amount is somewhat less than the sum of $\mathrm{Ci}$ and $\mathrm{Cb}$ amounts (sec discussion of $\mathrm{Cb}$ below).

\section{4) Average base height}

The average base height of the cloud type (when present) is given in tens of meters. It is only computed for the three types whose bases are always less than 2500 meters above the surface: $\mathrm{Cu}, \mathrm{Cb}$, and $\mathrm{St}$. Fog is included in the maps of $\mathrm{St}$ amount but is excluded from maps of $\mathrm{St}$ base height, so that these heights apply only to above-ground St/Sc. Base heights are displayed on the maps if at least 100 observations of base height were reported for that cloud type. The standard deviation of the individual observations of base height is not given here; it is included in the archive on tape.

\section{5) Diurnal cycle; interannual variation}

These quantities have already been discussed for the total cloud cover. Their meanings are the same when applied to cloud types. These variations are shown only for cloud type amount, but the diumal and interannual variations of $f$ and awp are available on tape. The diumal cycle is not mapped for $\mathrm{As}, \mathrm{Ci}$, and clear-sky because of the night-detection bias, but the computed values are also available on the tape. 
The interannual variations and diurnal amplitudes of the cloud type amounts are often 1\% or less, even if they are a significant fraction of the mean. For this reason, both the interannual variation and the diumal amplitude are given to tenths of a percent. Note that although the decimal point is omitted from the individual $5^{\circ} \times 5^{\circ}$ grid values on the map (and in the zonal average) in order to conserve space, it is included in the value of the global average. The zonal and global trends are given to tenths of a percent, but individual box values are given only to the nearest percent because their uncertainty is often that large.

6) Most-frequently occurring cloud type

For each box (for each season) the type with largest $f$ is indicated on Map 167.

\section{7) Cloud type contributing most to total cloud cover}

The type with largest amount is indicated on Map 168. This cloud type may differ from the most frequent type in a particular region if the awp of a slightly less frequent type is larger than that of the more frequent type.

\section{RESULTS}

Global average values of $f$, awp, amount, and base height of the cloud types are summarized in Table 9a, along with their geographical variability (standard deviation of individual box values). This table may be compared with the corresponding Table 7 of the land atlas. Whereas four cloud types $(\mathrm{Cu}, \mathrm{St}, \mathrm{As}$, and $\mathrm{Ci}$ ) are each observed more than $30 \%$ of the time on global ocean average, only two types (St and As) dominate in cloud amount.

The amounts of the six types add to about $30 \%$ more than the observed total cloud cover because clouds frequently overlap each other. The amount of middle and high clouds actually seen by the ground observers can be obtained from Table $9 \mathrm{a}$ or $9 \mathrm{~b}$ as the total cloud cover minus the sum of the low cloud amounts $(\mathrm{Cu}+\mathrm{Cb}+\mathrm{St})$, which is $13.3 \%$ on global average. The amount of middle and high clouds which is inferred to be present, although hidden from view, is the sum of the six cloud-type amounts minus the total cloud cover, or $27.8 \%$ on global average. Thus on average about one-third of the upper cloud amounts we report were actually seen from the ground and two-thirds were inferred to be present behind lower clouds.

Interannual variation of the global average and hemispheric average cloud type amounts is given in Tables $9 \mathrm{~b}$ and $9 \mathrm{c}$ for each season, as well as for the annual mean. A limited description of the total cloud cover and cloud type distributions follows. 


\section{$\underline{\text { a. Total cloud cover }}$}

The global annual average total cloud cover for the ocean areas is $64.8 \%$, whereas for the land it is $52.4 \%$. The ocean (excluding ice shelves) covers $69.7 \%$ of the earth's area, so the whole-earth global average is $61.0 \%$. The largest values of cloud cover, over $90 \%$, are in the Antarctic Ocean at about $65^{\circ} \mathrm{S}$ during most of the year and in the North Pacific at about $50^{\circ} \mathrm{N}$ during JJA. In these locations stratus clouds associated with cold surface waters are dominant. The smallest values are in the nearly landlocked seas: $10 \%$ or less in JJA in the Red Sea, Persian Gulf, and eastern Mediterranean. Secondary minima in total cloud cover (40-50\%) are found in the subtropics, particularly in the Southern Hemisphere, associated with subsiding air east of the anticyclone circulation centers. The largest variations between summer and winter (Map 26) are in the regions of the Indian monsoon, the north-Australian monsoon, and west of Central America.

The standard deviation (sd) of compressed observations (Maps 10-13) is smallest where the average cloud cover is close to $0 \%$ or $100 \%$, as it must be. For example, the sd at the North Pole decreases from $42 \%$ in DJF to $29 \%$ in JJA as the cloud cover increases from $47 \%$ to $82 \%$.

\section{b. Cumulus}

In general, the average amount of cumulus decreases poleward. The largest amounts (about $20 \%$ ) are found in the regions of the trade winds in each hemisphere. At polar latitudes the cumulus amounts are about $3-6 \%$. In most areas the amplitude of the diurnal variation of cumulus amount is about $15 \%$ of the mean, with maximum occurring in the afternoon.

\section{c. Cumulonimbus}

Cumulonimbus amounts are largest (10-14\%) in the region of the intertropical convergence zone (ITCZ) as can clearly be seen in Maps 48-51. There is a second Cb maximum in the Southern Pacific Convergence Zone (SPCZ; Vincent, 1982), particularly during the southemhemisphere summer (DJF) and autumn (MAM). In both the equatorial Pacific and Atlantic Oceans, the $\mathrm{Cb}$ amount tends to decrease from west to east with decreasing sea surface temperatures. The largest amounts of $\mathrm{Cb}$ are reported in the Norwegian Sea during DJF and are associated with snow showers in polar air over warm water. The amplitude of diurnal variation of $\mathrm{Cb}$ is about $10 \%$ of its amount, and the maximum usually occurs at or shortly after local noon, about 5 hours earlier than on land. However, in some regions there is an early moming maximum which probably results from night-time infrared cooling from the cloud tops and consequent continued thermal destabilization of the cloud layer. 
The $\mathrm{Cb}$ amount given on our maps is somewhat larger than the true amount, as discussed in the land atlas, principally because the instructions for coding $\mathrm{C}_{\mathrm{L}}$ require $\mathrm{Cb}$ to be reported as the cloud type even if other low clouds cover more area, but our analysis procedure assigns all of $\mathrm{N}_{h}$ to the single type given by $\mathrm{C}_{\mathrm{L}}$.

\section{d. Stratus + stratocumulus + fog}

Outside the equatorial region, stratus + stratocumulus + fog $(\mathrm{St})$ has the greatest average amount of any cloud type. The fog included here is only the case of sky-obscured due to fog, which is also mapped by itself. The largest amounts of St are at $40^{\circ}-60^{\circ} \mathrm{N}$ in the Pacific in JJA (over 80\%). Large amounts are also reported in the Antarctic Ocean, especially the Weddell Sea, in DJF. These are associated with stable air over the cold water surface. The smallest amounts of St are in areas of nearly cloudless skies (e.g. Persian Gulf and eastern Mediterranean Sea) and at equatorial and subtropical latitudes where there are local $\mathrm{Cu}$ maxima. The diurnal maximum usually occurs in early morning before sunrise when the stability of the boundary layer is maximum.

\section{e. Base heights}

Base heights for the three lower cloud types are about 590 meters for $\mathrm{Cu}, 520$ meters for $\mathrm{St}$ (excluding fog) and 480 meters for $\mathrm{Cb}$. On average these base heights are about 400 meters lower over ocean than over land. There is a tendency for the base heights of all three types to increase slightly with latitude.

\section{f. Nimbostratus}

Except in a small region in the eastern Pacific, nimbostratus is hardly ever reported at equatorial and subtropical latitudes $\left(20^{\circ} \mathrm{N}-30^{\circ} \mathrm{S}\right)$. In many regions there was less than $1 \%$ frequency of occurrence during the 30 -year period covered by this atlas. Ns amount is generally at least $10 \%$ in all seasons in each hemisphere poleward of latitude $40^{\circ}$, and over $20 \%$ in some regions poleward of $60^{\circ}$.

\section{g. Altostratus + altocumulus}

Altostratus + altocumulus amounts vary from less than $10 \%$ near the equator in the central Pacific to about $40 \%$ at subpolar latitudes during summer. The amounts are greatest (about 50\%) in the Indonesian region, which has large amounts of clouds at all levels. This maximum shifts northwestward-southeastward with oscillations of the Southeast Asian monsoon circulation. There is a secondary As maximum along the ITCZ and SPCZ. As/Ac is rare (less than 10\%) just 
Table $9 \mathrm{~b}$. Global average ${ }^{\mathrm{a}}$ seasonal cloud type amounts and their interannual variations ${ }^{\mathrm{b}}$, for ocean areas (1952-1981).

Units are percent cloud amount.

\begin{tabular}{|c|c|c|c|c|c|c|c|c|}
\hline & & $\mathrm{Cu}$ & $\mathrm{Cb}$ & St & Ns & As & $\mathrm{Ci}$ & $\begin{array}{c}\text { total } \\
\text { cloud } \\
\text { cover }\end{array}$ \\
\hline DJF & $\begin{array}{l}\text { amount } \\
\text { IAV } \\
\text { trend }^{\text {d }}\end{array}$ & $\begin{array}{r}12.0 \\
0.4 \\
-0.5\end{array}$ & $\begin{array}{l}5.4 \\
0.4 \\
1.8\end{array}$ & $\begin{array}{r}33.5 \\
0.9 \\
0.5\end{array}$ & $\begin{array}{l}6.6 \\
0.2 \\
0.6\end{array}$ & $\begin{array}{r}23.4 \\
0.6 \\
0.4\end{array}$ & $\begin{array}{r}12.7 \\
0.3 \\
0.5\end{array}$ & $\begin{array}{r}64.8 \\
0.4 \\
1.0\end{array}$ \\
\hline MAM & $\begin{array}{l}\text { amount } \\
\text { IAV } \\
\text { trend }^{\text {d }}\end{array}$ & $\begin{array}{r}12.0 \\
0.3 \\
-0.6\end{array}$ & $\begin{array}{l}5.7 \\
0.3 \\
1.7\end{array}$ & $\begin{array}{r}33.0 \\
0.7 \\
0.7\end{array}$ & $\begin{array}{l}6.4 \\
0.1 \\
0.4\end{array}$ & $\begin{array}{r}21.9 \\
0.4 \\
0.7\end{array}$ & $\begin{array}{r}13.0 \\
0.3 \\
0.3\end{array}$ & $\begin{array}{r}64.2 \\
0.4 \\
1.1\end{array}$ \\
\hline JJA & $\begin{array}{l}\text { amount } \\
\text { IAV } \\
\text { trend }^{d}\end{array}$ & $\begin{array}{c}11.6^{\mathrm{a}} \\
0.3 \\
-0.3\end{array}$ & $\begin{array}{l}6.1^{\mathrm{a}} \\
0.3 \\
1.7\end{array}$ & $\begin{array}{c}34.4^{\mathrm{a}} \\
0.7 \\
0.2 \\
\end{array}$ & $\begin{array}{l}5.3^{\mathrm{a}} \\
0.1 \\
0.1 \\
\end{array}$ & $\begin{array}{c}21.8^{\mathrm{a}} \\
0.5 \\
1.1 \\
\end{array}$ & $\begin{array}{c}12.2^{\mathrm{a}} \\
0.3 \\
0.6 \\
\end{array}$ & $\begin{array}{c}64.6^{\mathrm{a}} \\
0.4 \\
0.9\end{array}$ \\
\hline SON & $\begin{array}{l}\text { amount } \\
\text { IAV } \\
\text { trend }^{d}\end{array}$ & $\begin{array}{r}11.7 \\
0.3 \\
0.3 \\
\end{array}$ & $\begin{array}{l}5.6 \\
0.3 \\
1.9 \\
\end{array}$ & $\begin{array}{r}35.2 \\
0.7 \\
-0.3 \\
\end{array}$ & $\begin{array}{l}6.2 \\
0.1 \\
0.3 \\
\end{array}$ & $\begin{array}{r}22.4 \\
0.5 \\
0.8 \\
\end{array}$ & $\begin{array}{r}12.6 \\
0.3 \\
0.7\end{array}$ & $\begin{array}{r}65.5 \\
0.4 \\
0.7\end{array}$ \\
\hline $\begin{array}{l}\text { average } \\
\text { of four } \\
\text { seasons }\end{array}$ & $\begin{array}{l}\text { amount } \\
\text { IAV } \\
\text { trend }^{d}\end{array}$ & $\begin{array}{r}11.8 \\
0.3 \\
-0.4\end{array}$ & $\begin{array}{l}5.7 \\
0.3 \\
1.8\end{array}$ & $\begin{array}{r}34.0 \\
0.7 \\
0.3\end{array}$ & $\begin{array}{l}6.1 \\
0.1 \\
0.4\end{array}$ & $\begin{array}{r}22.4 \\
0.4 \\
0.8\end{array}$ & $\begin{array}{r}12.6 \\
0.3 \\
0.5\end{array}$ & $\begin{array}{r}64.8 \\
0.3 \\
0.9\end{array}$ \\
\hline
\end{tabular}

${ }^{a}$ These values are the same as the global averages that appear at the bottom of the $10^{\circ} \times 20^{\circ}$ maps. They were obtained (as described in the text) as an area-weighted average of the $10^{\circ}$-zones for which zonal averages could be computed. Missing zones can cause the global average to be inaccurate. In particular, because the Antarctic ocean is insufficiently sampled by ships in JJA, the global and southern hemisphere (SH) average amounts for JJA listed here are probably too high for $\mathrm{Cu}$ and $\mathrm{Cb}$, and too low for the other types and for total cloud cover.

bInterannual variation (IAV) is the standard deviation (detrended) of seasonal means of global average cloud amount. If a box was missing in a particular year the multi-year mean value for that box was used when computing the global average for that year.

'The sum of the six cloud-type amounts is greater than the total cloud cover because of overlap.

${ }^{\mathrm{d}}$ Values of global average cloud amount for each individual year-season were used as data points to fit a straight line. The change along the line from 1952 to 1981 is the "trend." To obtain the change per year, these values should be divided by 29 . 
Table 9a. Annual average global cloud type quantities for ocean arcas (1952-1981)*

\begin{tabular}{|c|c|c|c|c|c|c|c|c|}
\hline \multirow{2}{*}{$\begin{array}{l}\text { cloud } \\
\text { type }\end{array}$} & \multicolumn{2}{|c|}{ frequency (\%) } & \multicolumn{2}{|c|}{ amount-when-present (\%) } & \multicolumn{2}{|c|}{ amount $(\%)$} & \multicolumn{2}{|c|}{ base height $(\mathrm{m})$} \\
\hline & average & geog. sd & average & $\overline{\text { geog. sd }}$ & average & geog. sd & average & $\overline{\text { geog. }}$ sd \\
\hline $\mathrm{Cu}$ & 33 & 18 & 38 & 6 & 11.8 & 5 & 590 & 60 \\
\hline $\mathrm{Cb}$ & 10 & 6 & 57 & 9 & 5.7 & 3 & 480 & 40 \\
\hline $\mathrm{St}$ & 45 & 19 & 73 & 10 & 34.0 & 18 & 520 & 60 \\
\hline Ns & 6 & 5 & 92 & 5 & 6.1 & 5 & - & - \\
\hline As & 46 & 11 & 48 & 11 & 22.4 & 8 & - & - \\
\hline $\mathrm{Ci}$ & 37 & 13 & 34 & 6 & 12.6 & 6 & - & - \\
\hline $\begin{array}{l}\text { clear } \\
\text { sky }\end{array}$ & 3 & 6 & - & - & - & - & - & - \\
\hline $\begin{array}{l}\text { sky ob- } \\
\text { scured } \\
\text { due to } \\
\text { fog }\end{array}$ & 2 & 3 & - & - & - & - & - & - \\
\hline $\begin{array}{l}\text { total } \\
\text { cloud } \\
\text { cover }\end{array}$ & - & - & - & - & 64.8 & 14 & - & - \\
\hline
\end{tabular}

*Values were computed for each season; listed here are the averages of all four seasons. Geographical standard deviation (geog. sd) is the standard deviation of individual $5^{\circ} \times 5^{\circ}$ box values. 
Table 9c. Hemispheric average ${ }^{\text {a }}$ seasonal cloud type amounts and their interannual variations ${ }^{\mathrm{b}}$, for ocean areas (1952-1981)

Units are percent cloud amount.

$(\mathrm{NH}=$ Northern Hemisphere; $\mathrm{SH}=$ Southern Hemisphere; footnotes are below Table $9 \mathrm{~b})$

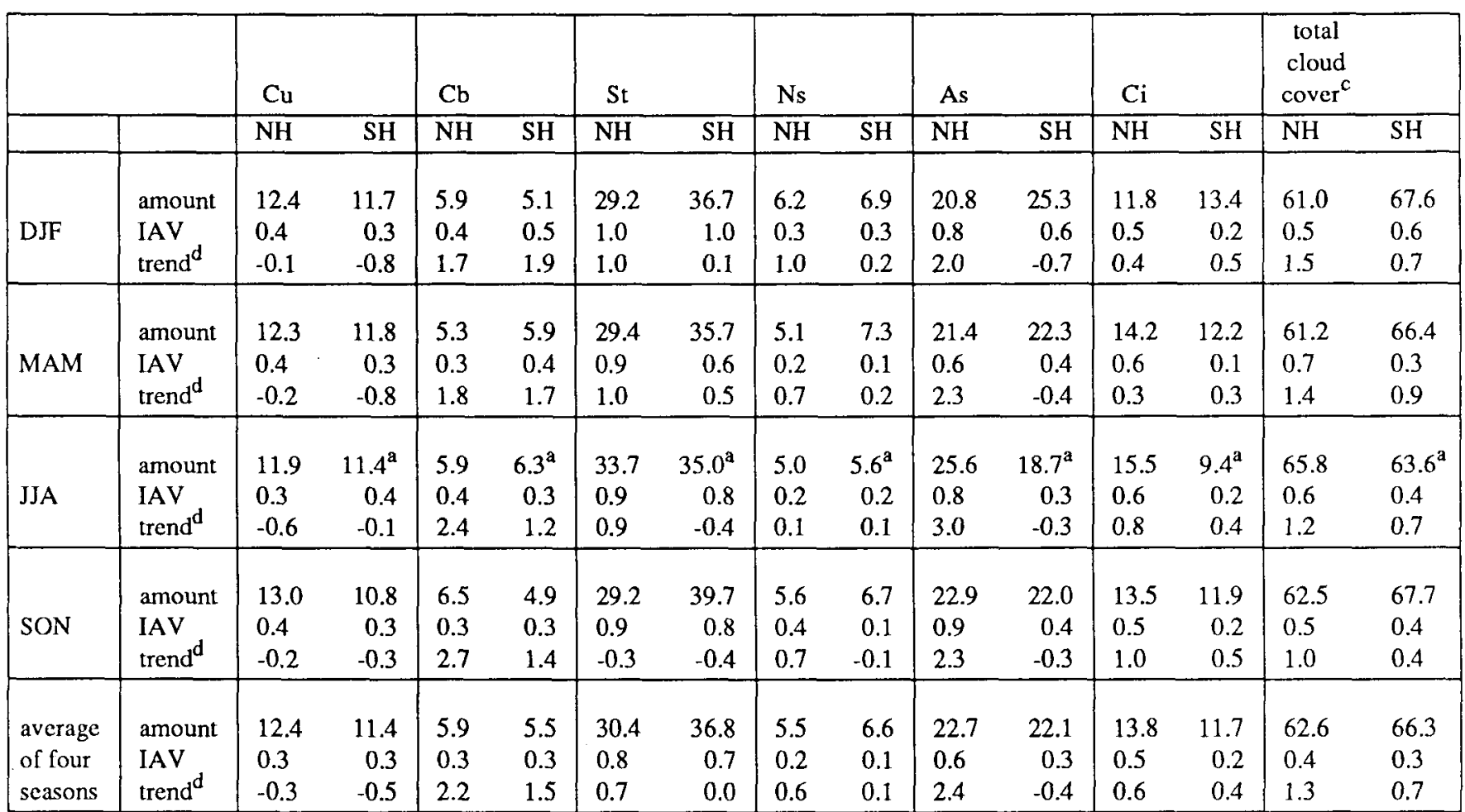


south of the equator in the east-central Pacific, and in a smaller region in the Atlantic just south of the equator, where there are also minima in total cloud cover.

\section{h. Cirrus + cirrostratus + cirrocumulus}

Cirrus + cirrostratus + cirrocumulus have their largest amounts in equatorial (ITCZ) and subpolar regions. $\mathrm{Ci}$ in the former region is associated with the spread of anvil tops of $\mathrm{Cb}$ clouds; in the latter, they are part of the advanced cloud system moving poleward on the western side of the oceanic anticyclonic circulations.

Cirrus is the only cloud type whose global average amount is less over ocean (13\%) than over land (23\%). Where comparisons can be made, this difference seems not to be related to a difference in low cloud amount. For example, in Indonesia the amount of low clouds is the same over ocean as over land, but the cirrus amount is $10-20 \%$ less over ocean than over land. In any case, the largest cirrus amounts in the world ocean are found in the Indonesian region where large amounts of low and middle clouds are also present. Cirrus is relatively rare in the eastern Pacific, with a minimum about $40^{\circ}$ of longitude to the east of the minimum in As/Ac.

The greater reported amount of cirrus over land than over ocean may be due to a difference between land and ocean in the threshold optical thickness of cirrus necessary for ground observers to detect it. Because of the prevalence of haze in the marine boundary layer, only relatively thick cirrus (e.g. originating from cumulonimbus anvils) may normally be observable from ships, whereas thinner cirrus may be included in our average amounts of cirrus over land. The minimum optical thickness necessary for ground observers to detect cirrus in different circumstances (land vs. ocean, day vs. night, dependence on solar elevation angle) is a subject for further research.

\section{i. Skv obscured due to fog}

The maps show not all fog but only the cases of "sky obscured" due to fog, which is responsible for only about one-third of the total number of reports of fog. Fog at a distance, and thin fog through which the sky can be seen, are not included here. Sky-obscured due to fog is reported frequently in the ocean around West Antarctica in DJF (10-20\%) and in the western North Pacific in JJA (20-40\%). The fog in these regions is associated with thermally stable boundary-layer air over cold ocean waters during summer. 


\section{j. Clear sky}

Completely clear sky is rarely reported in the open ocean. Far from the continents, the most common frequency of occurrence of clear sky is $1 \%$. The global average for the oceans is only $3 \%$, in contrast to $18 \%$ for land. Clear sky is of course most frequent in the regions of minimum cloud cover: the Arabian Sea and the Pacific coast of Central America in DJF, and the eastern Mediterranean and Red Sea in JJA.

\section{k. Interannual variations}

The (detrended) interannual variation (IAV) in seasonal total cloud cover for $10^{\circ} \times 20^{\circ}$ boxes is computed to be $4 \%$ on average. Map 116 shows that the IAV is less in the ocean centers than near the coasts. However, in regions of few observations, the mapped values of IAV are larger than the true values, because the seasonal means are in error due to inadequate sampling (Figure 8). Thus the values of 2-3\% shown for the well-sampled North Pacific and North Atlantic may be more representative of the true average for boxes of this size. The same applies to the IAV presented for all the individual cloud types.

\section{$\underline{\text { 1. Trends }}$}

Total cloud cover reported by ships has apparently increased by about $0.7 \%$ from 1952 to 1981. A small part of this increase is artificial, due to the change in our source of data after 1979, as explained above in Section $4 \mathrm{~b}$. The increase in total cloud cover is concentrated at low latitudes. Prior to 1952 the situation is more complicated. The data showed a general increase in cloud cover from 1930 to 1952, but there was a very steep rise during 1940-45, followed by extremely low values in 1946-50. This is true for both hemispheres. We cannot at present explain this behavior. It may be related to the fact that 1940-48 were the years with the smallest numbers of observations (Figure 7) and therefore the poorest geographical coverage.

The only cloud type that has decreased globally (in the thirty years 1952-81) is cumulus. The decline in $\mathrm{Cu}$ could be related to the increase in $\mathrm{Cb}$. However, the decline in $\mathrm{Cu}$ occurs mostly in the first four years of our data, 1952-55, when St/Sc amount also increased rapidly (see microfiche plots), suggesting that perhaps some of the clouds which were formerly called $C_{L}=1$ (cumulus of small vertical extent) are now called $\mathrm{C}_{\mathrm{L}}=4$ (stratocumulus formed by the spreading-out of cumulus). 


\section{$\underline{\text { m. Zonal averages }}$}

The thirty-year zonal averages of total cloud cover and cloud type amounts for the ocean are given in Figures 10 and 11. St is by far the most abundant cloud type over the ocean, and also exhibits the greatest variation with latitude. The seasonal movement of the ITCZ, and the associated Hadley cells, causes the slight shifts of maximum cloud cover near the equator and minimum in the subtropics of both hemispheres which are apparent in both figures. If we define the ITCZ as the latitude of the near-equatorial peak in total cloud cover, then all cloud types except $\mathrm{Cu}$ show a maximum at the ITCZ; cumulus shows a slight minimum right at the ITCZ. The zonal average position of the ITCZ in the ocean is in the Northern Hemisphere in all seasons, unlike the situation on land. Based on Figure 10, the ITCZ moves only about $4^{\circ}$ of latitude with the seasons, much less than on land. The equatorial maximum and subtropical minima in total cloud cover are much less prominent than over land: the difference from maximum to minimum cloud cover is less than $15 \%$ over the ocean but more than $40 \%$ over the land.

\section{COMPARISON WITH EARLIER GROUND-BASED CLOUD CLIMATOLOGIES}

The first world maps of cloud cover were published by Teisserenc de Bort $(1884 ; 1899)$. The first maps of the distribution of the different cloud types over the oceans, and the most similar predecessor to our work, was the Atlas of Climatic Charts of the Oceans (McDonald, 1938), based on weather observations from ships during the years 1885-1933. We have followed McDonald's precedent in grouping the clouds into six types. McDonald's maps of total cloud cover were used by Telegadas and London (1954), together with observations from land stations, to produce contour maps for the Northern Hemisphere for winter and summer seasons. They also computed zonal averages (land plus ocean) for the six cloud types using McDonald's atlas for the ocean part of each zone. We have digitized contour maps from Telegadas and London and computed the zonal and (northern) hemispheric average cloud cover for ocean areas only, for comparison with the present atlas. For comparison in the Southern Hemisphere we have used the cloud climatology of van Loon (1972), which was a "subjective fusion" of climatic atlases based on surface observations as well as Sadler's (1969) atlas based on satellite pictures. More recently, a global climatology of total cloud cover (but not cloud types) was published by Berlyand and Strokina (1980), who combined both surface observations and satellite observations (Sadler's atlas) in unspecified proportions. These and other cloud climatologies have been reviewed by Hughes (1984). The hemispheric annual average cloud cover obtained by these various authors are as follows (for ocean areas only): 
Telegadas and London (based on McDonald), 1885-1933 van Loon

Berlyand and Strokina

Present study(1952-1981)

The reason that our results exceed those of van Loon and of Berlyand and Strokina is partly due to the fact that Sadler's subjective nephanalyses obtained $8 \%$ less cloud cover than reported by ships, as shown by Warren et al. (1981). Since we do not know the relative weight placed on Sadler's results in those two studies, we cannot attempt a quantitative explanation of the difference.

Our results differ from those of Telegadas and London by $9 \%$ over the ocean but only $4 \%$ over land. The $9 \%$ difference is due to several causes:

(1) McDonald's atlas was based on observations mainly from the period 1885-1933, so most of them were not reported in the standard synoptic code. The total cloud cover (in COADS reports) increased with time by $10 \%$ from 1920 to 1950 (Wright, 1986), due to changes in observing and coding procedures or perhaps related to the increase in average sea-surface temperature from 1920 to 1950 (Oort et al, 1987). Our own analysis of the years 1930-1951 gave 2.3\% less total cloud cover than for the years 1952-1981.

(2) McDonald did not count fog as a cloud, accounting for about $1 \%$ difference in total cloud cover.

(3) McDonald used only observations at 12:00 GMT, which is night in the Pacific. Since reported cloud cover is greater during the day than at night, and since the Pacific Ocean is larger than the Atlantic, a difference of about $0.5 \%$ in the hemispheric average would result.

The difference between our analysis and McDonald's is much more substantial for cloud types than for total cloud cover. McDonald did not account for obscuration of upper clouds by low overcast when computing frequency of occurrence of upper clouds (Telegadas and London did attempt a correction for this), and his computation of the frequency of each cloud type was based on the total number of observations, not on the number of observations that included information on clouds present or absent.

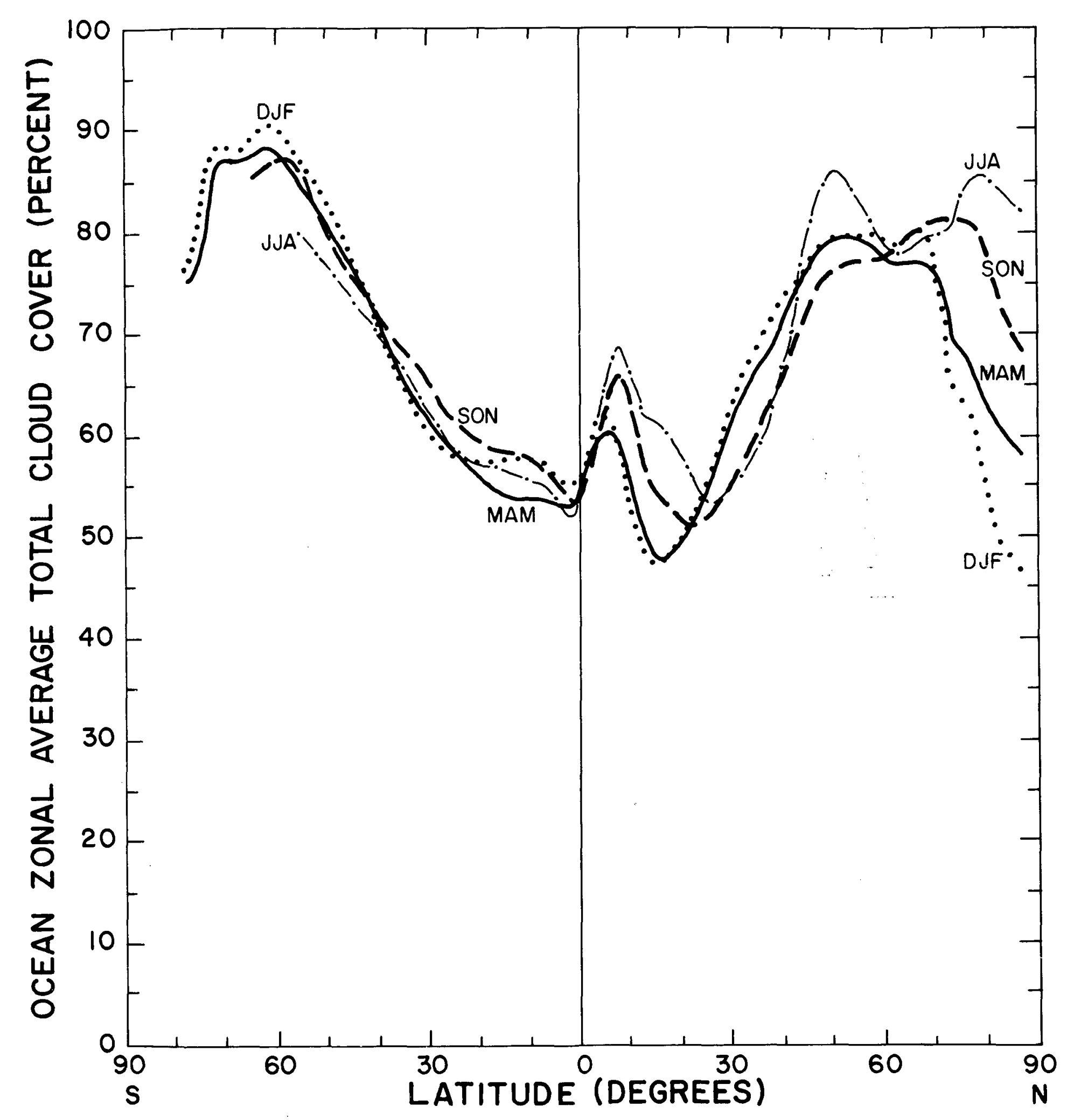

Figure 10. Zonal average total cloud cover over ocean as a function of latitude, for four seasons. Smooth curves were drawn through the data points for 5-degree zones listed on the right side of maps 6-9. Values for 10-degree zones (from the $10^{\circ} \times 20^{\circ}$ maps) were used where 5 -degree values were missing. 

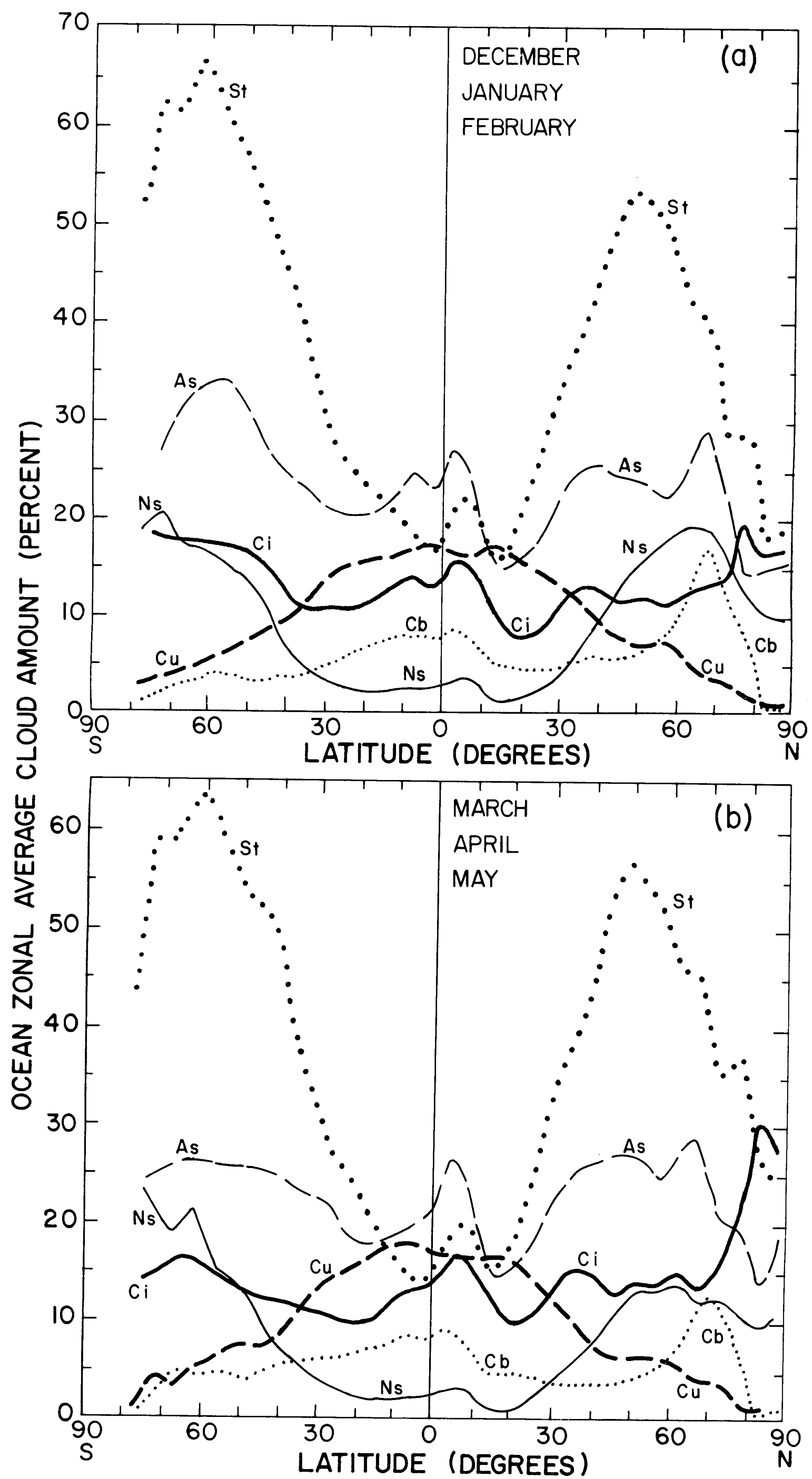

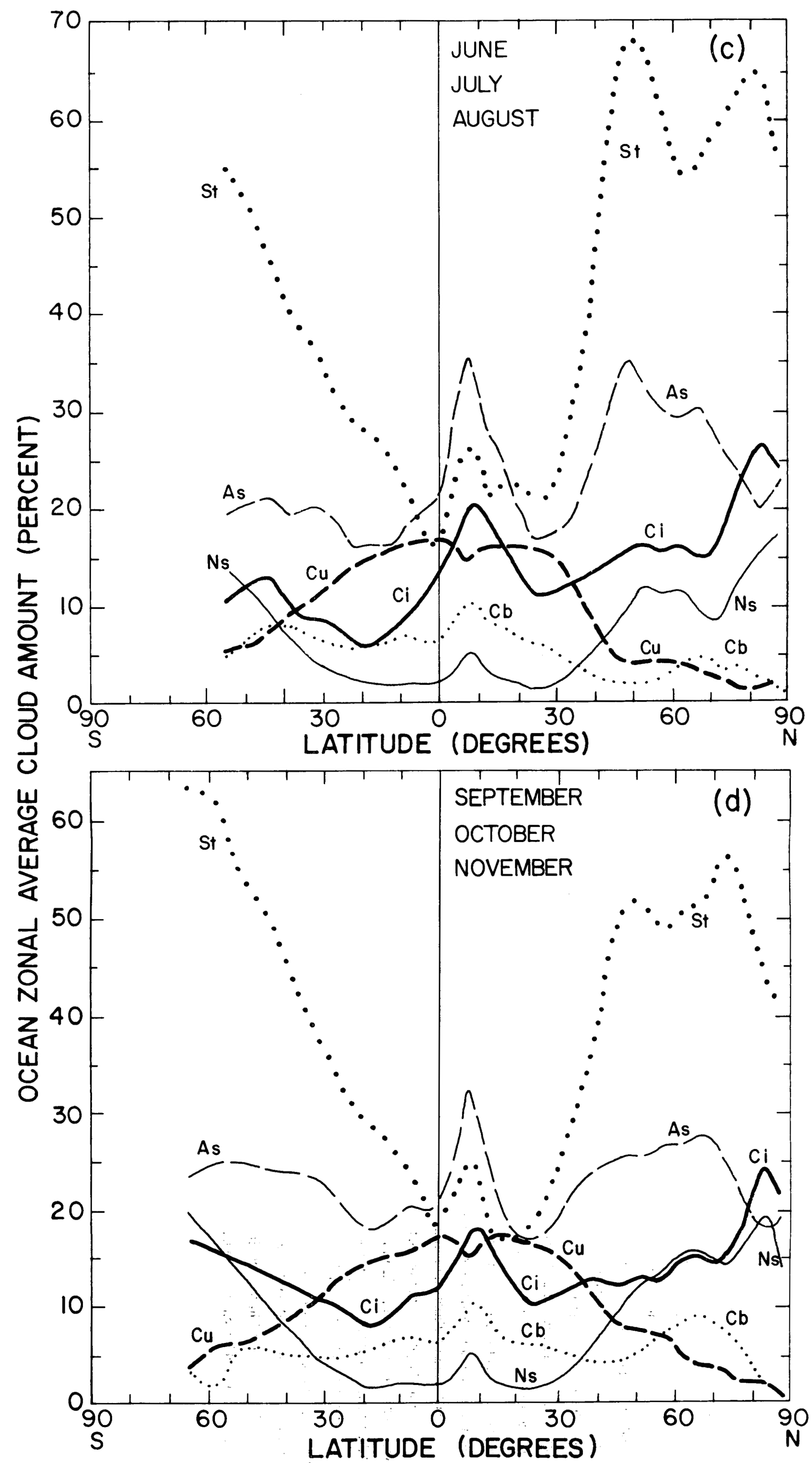

Figure 11. Zonal average amount of each cloud type over ocean as a function of latitude. Smooth curves were drawn through the data points for 5-degree zones listed on the right side of maps $36-39,48-51,60-63,72-75,84-87$, and 96-99. Values for 10-degree zones (from the $10^{\circ} \times 20^{\circ}$ maps) were used where 5-degree values 
Satellite cloud climatologies will differ from our results for many reasons: cloud types are defined in satellite observations using radiance statistics rather than pattem recognition; the clouds are projected in a different manner so that something intermediate between earth-cover and sky-cover is usually obtained; clouds much smaller than the pixel may go undetected; thin cirrus at night may be mistaken for thick altostratus, and many other reasons; a review of this problem is outside the scope of this atlas.

\section{RESULTS ON DATA TAPE}

The numbers plotted on the maps, as well as more detailed information listed in Table 10 , are available on magnetic tape from the Data Support Section at NCAR (Boulder, CO 80307; tel. 303-497-1215) and from the Carbon Dioxide Information Analysis Center (CDIAC, MS-050, Oak Ridge National Laboratory, Post Office Box 2008, Oak Ridge, TN 37831-6050; tcl. 615574-0390; request Numeric Data Package NDP-026). It is also available from the Nationa Climatic Data Center (Federal Building, Asheville, NC 28801; tel. 704-259-0682)

The cloud climatologies for both ocean and land areas are on the same tape. The long-term average monthly and seasonal total cloud cover is given, along with the standard deviation and number of observations. The average for each of the eight individual synoptic hours and for each of the thirty years is given; these values were the basis for our analysis of the diurnal cycle and interannual variation. The same is done for seasonal values for each of the cloud types. The total amount of low level clouds and of middle level clouds, and annual average total clou cover and cloud type amounts, are given on tape but not in the atlas.

Values of total cloud cover for 1982 and 1983 are not used in this atlas (except for the diurnal analysis) but are included on the archive tape. We now know that they are too large by an average of $1 \%$ as explained in Section 3k. The values on the tape should therefore not be used they will be superseded by our future reanalysis of the 1982-83 data.
Table 10. Outline of Quantities Archived on Magnetic Tape for Land and Ocean Grid Boxes

A. Total Cloud Cover

1. Four seasons

a) long-term average

1) all times*

2) daytime only ${ }^{* 1}$

3) eight individual synoptic hours ${ }^{* 1}$

b) individual year averages

c) diurnal cycle

d) interannual variations and trends

2. Twelve months

a) long-term average*

b) individual year averages

3. Annual

a) long-term average

b) annual cycle

B. Cloud Types (for 6 type classes and clear-sky and fog; for frequency of occurrence, amount, and amount-when-present where appropriate)

1. Four seasons

a) long-term average

1) all times (upper clouds daytime only)*

2) eight individual synoptic hours

b) individual year averages

c) diurnal cycle

d) interannual variations and trends

e) base heights of low clouds

f) co-occurrence probabilities

2. Annual

a) long-term average

C. Low and Middle Cloud Levels

1. Four seasons

a) long-term average

D. Nine Individual Low Cloud Types*

1. Two seasons (December-January-February and June-July-August)

a) average amount, amount-when-present, and frequency

b) base heights

*also for FGGE year (Dec 1978-Nov 1979) at higher spatial resolution

**for FGGE year only

${ }^{1}$ FGGE land averages are computed monthly 


\section{ACKNOWLEDGMENTS}

The observations from ships were obtained principally from COADS. We appreciate the great effort by the COADS workers to create this dataset, and especially thank Scott Woodruff (NOAA-ERL) for discussions concerning the data quality. Will Spangler (NCAR) facilitated our access to COADS-CMR in 1984 before it was ready for general release. Rob Quayle (NCDC) provided the special dataset of transient ships passing near the weatherships.

Discussions with Roger Barry (CIRES), Tom Charlock (NASA-Langley), Tony Gordon (NOAA-GFDL), Garth Paltridge (CSIRO-Melboume), Rob Quayle, Tom Schlatter (NOAAERL), Ralph Slutz (CIRES), Starley Thompson (NCAR) and Bruce Wielicki (NASA-Langley) helped in our development of the analysis procedure. SGW thanks the meteorologists on the "Icebird" (Warwick Bromham and Jeff Wilson) and on the "Polar Star" (Brian Branson, Mark Lewack, Jeff Newton, Dave Stanberry, and John Sullivan) for helpful discussion about observing practices during cruises between Australia and Antarctica.

The cloud maps were generated on the DICOMED Graphic System located in the NCAR Scientific Computing Division, with programming help from David Kennison. Ginger Hein of the NCAR Photographics staff produced the final prints. The cover photographs on both land and ocean atlases were printed by Bill Warren. The photograph of oceanic cumulus was taken by John Porter (Univ. Hawaii). We thank Rob Quayle, Tony Slingo (NCAR), Mike Wallace (Univ. Washington) and Scott Woodruff for review of the original manuscript.

The figures were drafted by Suzanne Whitman at NCAR. The text was typed at CIRES by Julie McKie, Alice Rhodes, and Claudia Rogers. Carol Rasmussen and Anatta (NCAR) assisted with the page-layout.

Printing and distribution of the atlas were arranged by Tom Boden, Mike Farrell, Tom Gross, Bob Kleppner, and Mike Riches, all of the Department of Energy.

The ground-based global cloud climatology project was supported by the National Climate Program Office of NOAA and the Carbon Dioxide Assessment Program of the Department of Energy, under NOAA grant number NA 80 AA-D-00030 to the University of Colorado, in order to provide a complementary data set for evaluating the results of the International Satellite Cloud Climatology Project. Additional support was provided by NASA Grant NAGW-1002. We thank Martin Yerg (NOAA; National Climate Program Office) for his efforts to ensure continuity of funding support for this project. 


\section{REFERENCES}

Berlyand, T.G. and L.A. Strokina, 1980: Global Distribution of Total Cloud Amount (in Russian). Leningrad, Gidrometeoizdat, 71 pp. (English translation available from S.G. Warren.)

Bunker, A.F., 1976: Computations of surface energy flux and annual air-sea interaction cycles of the North Atlantic Ocean. Mon. Wea. Rev., 104, 1122-1140.

Diaz, H.F., C.S. Ramage, S.D. Woodruff and T.S. Parker, 1987: Climatic Summaries of Ocean Weather Stations. NOAA-ERL Report, 400 pp.

Hahn, C.J., S.G. Warren, J. London, R.M. Chervin, and R. Jenne, 1982: Atlas of Simultaneous Occurrence of Different Cloud Types over the Ocean, NCAR Technical Note TN-201+STR, Boulder, CO, 212 pp. (NTIS number PB83-152074).

Hahn, C.J., S.G. Warren, J. London, R.M. Chervin, and R. Jenne, 1984: Atlas of Simultaneous Occurrence of Different Cloud Types over Land, NCAR Technical Note TN-241+STR, Boulder, CO, 216 pp. (NTIS number PB88-118641/AS).

Henderson-Sellers, A., and K. McGuffie, 1989: Basis for integration of conventional observations of cloud into global nephanalyses. Submitted to Atmos. Chem.

Hughes, N.A., 1984: Global cloud climatologies: a historical review. J. Clim. Appl. Meteor., 23, $724-751$.

Lander, M.A., and M.I. Morrissey, 1987: Unexpected duplicate ship reports in the Comprehensive Ocean-Atmosphere Data Set (COADS). Tropical Ocean-Atmosphere Newsletter, March 1987, 13-15.

McDonald, W.F., 1938: Atlas of Climatic Charts of the Oceans. USDA Weather Bureau Pub. No. 1247. US Government Printing Office, Washington, D.C., 130 pp.

Malick, J.D., J.H. Allen and S. Zakanycz, 1979: Calibrated analytical modeling of cloud-free intervals, Proc. Soc. Photo-optical Instrumentation Engineering, 195, 142-147.

National Climatic Data Center (NCDC), 1962: History of the international code, in TDF-13 Reference Manual, pp. 0.6-0.10 (Available from NCDC, Asheville, NC).

Oort, A.H., Y.H. Pan, R.W. Reynolds, and C.F. Ropelewski, 1987: Historical trends in the surface temperature over the oceans based on the COADS. Climate Dynamics, 2, 29-38.

Quayle, R.G., 1980: Climatic comparison of estimated and measured winds from ships. J. Appl. Meteor., 19, 142-156.

Riehl, H., 1947: Diurnal variation of cloudiness over the subtropical Atlantic Ocean. Bull. Am. Meteorol. Soc., 28, 37-40. 
Riehl, H., 1979: Climate and Weather in the Tropics, Academic Press, London, 611 pp.

Sadler, J.C., 1969: Average Cloudiness in the Tropics from Satellite Observations. Honolulu, East-West Center Press, 22 pp. and maps.

Steurer, P.M., 1987: Reply: Unexpected duplicate ship reports in the Comprehensive OceanAtmosphere Data Set (COADS). Tropical Ocean-Atmosphere Newsletter, July 1987, 12 14.

Sverdrup, H.U., 1933: The Norwegian North Polar Expedition with the "Maud", 1918-1925, Scientific Results, Vol. II: Meteorology, Part I, Discussion, pub. John Griegs, Bergen, 331 pp.

Teisserenc de Bort, L., 1899: Mean monthly and annual cloudiness. Plates 17 and 18 of Atlas of Meteorology, Bartholomew's Physical Atlas, Vol. III (eds. J.G. Bartholomew, A.J. Herbertson and A. Buchan), Archibald Constable pub., Westminster. (Reprinted from Annales $d u$ Bureau central meteórologique de France, Vol. IV, 1884)

Telegadas, K., and J. London, 1954: A Physical Model of the Northern Hemisphere Troposphere for Winter and Summer. New York University College of Engineering Scientific Report No. 1 [AF 19(122)-165], 55 pp.

Tian, L., and J.A. Curry, 1989: Cloud overlap statistics. Submitted to J. Geophys. Res.

U.S. Navy, 1974-1979: Marine Climatic Atlas of the World, Volumes 1-5. U.S. Government Printing Office.

van Loon, H., 1972: Cloudiness and precipitation in the Southem Hemisphere. Meteorological Monographs, 13, 101-111.

Vincent, D.G., 1982: Circulation features over the South Pacific during 10-18 January 1979, Mon. Wea. Rev., 110, 981-993.

Warren, S.G., C. Hahn and J. London, 1981: Ground-based observations of cloudiness for crossvalidation of satellite observations. In Clouds in Climate (W. Rossow, ed.), NASA-GISS, New York, 174-179.

Warren, S.G., C.J. Hahn, and J. London, 1985: Simultaneous occurrence of different cloud types. J. Clim. Appl. Meteorol., 24, 658-667.

Warren, S.G., C.J. Hahn, J. London, R.M. Chervin and R.L. Jenne, 1986: Global Distribution of Total Cloud Cover and Cloud Type Amounts over Land. NCAR Technical Note TN273+STR, Boulder, CO 29 pp. + 200 maps (NTIS number DE87-006903).

Woodruff, S.D., R.J. Slutz, R.L. Jenne and P.M. Steurer, 1987: A comprehensive oceanatmosphere data set. Bulletin Amer. Meteorol. Soc., 68, 1239-1250. 
World Meteorological Organization, 1956: International Cloud Atlas, Abridged Atlas, WMO, Geneva, 62 pp. +72 Plates.

World Meteorological Organization, 1974: Manual on Codes, Volume 1. (WMO Publ. No. 306), WMO, Geneva.

Wright, P.B., 1986: Problems in the use of ship observations for the study of interdecadal climate changes. Mon. Wea. Rev., 114, 1028-1034.

Young, M.J., 1967: Variability in estimating total cloud cover from satellite pictures. J. Appl. Meteor., 6, 573-579. 
$90^{\circ} \mathrm{N}$

$60^{\circ} \mathrm{N}$
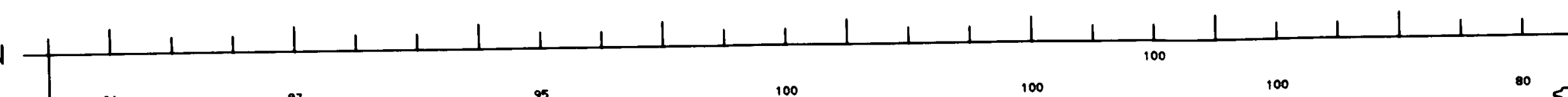

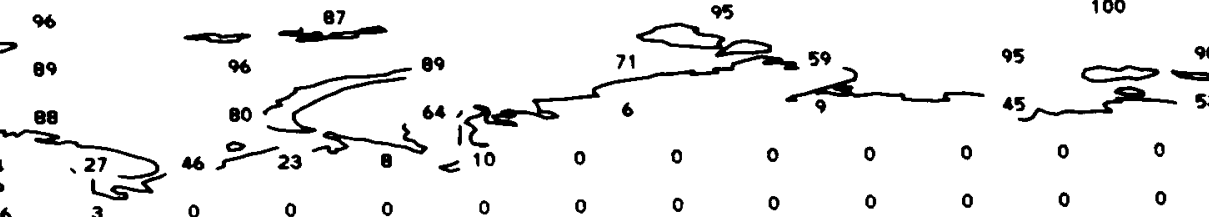

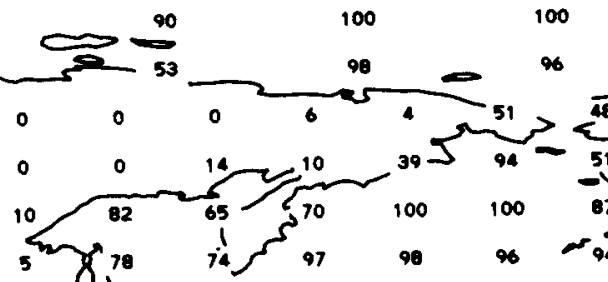

100
100
86
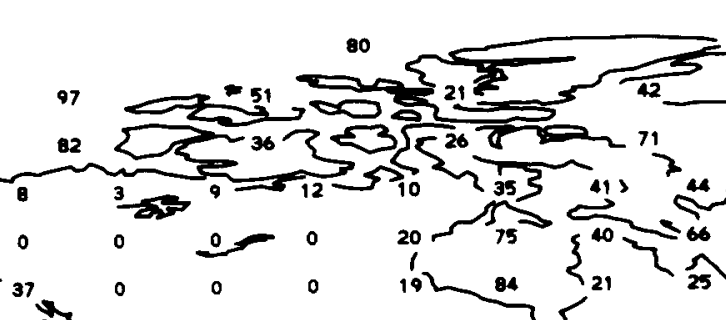

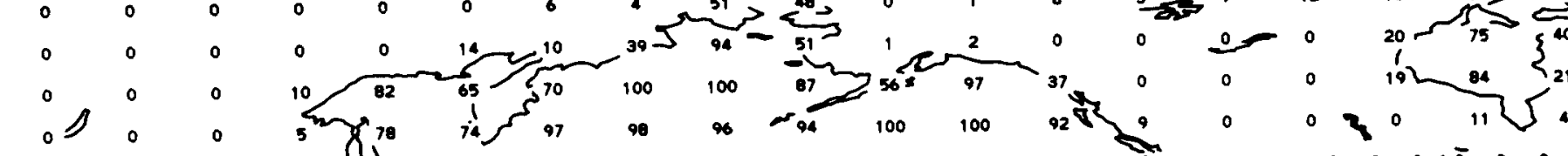

93

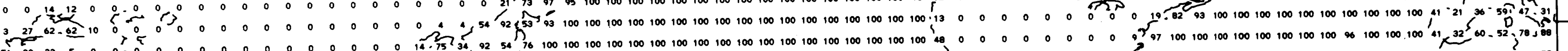

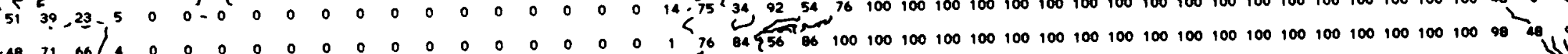

$30^{\circ} \mathrm{N}$

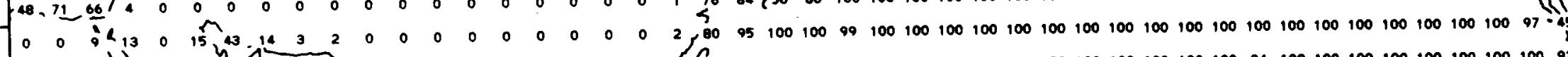

S O

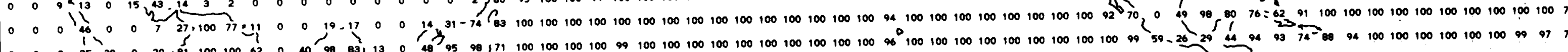

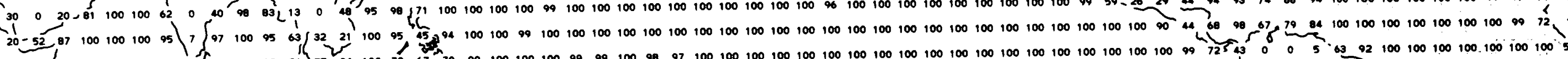

$\begin{array}{lll}9 & \\ 9\end{array}$

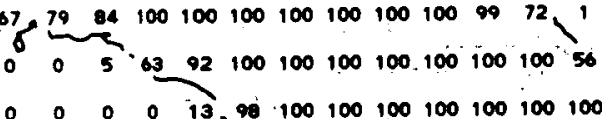

?

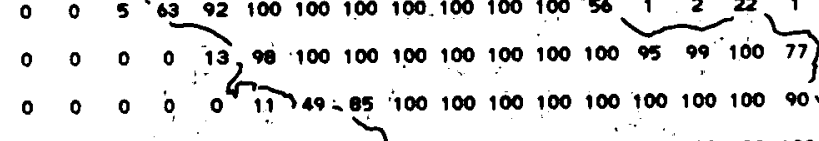

o

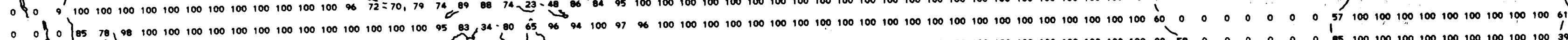

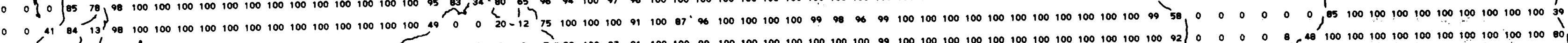

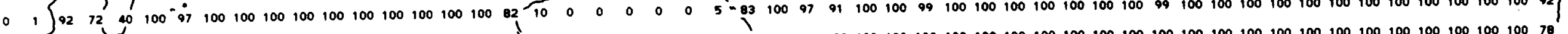

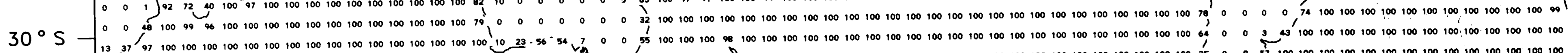

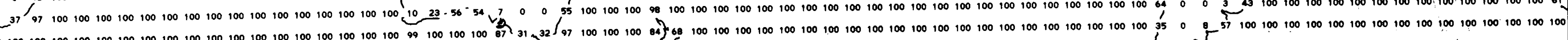

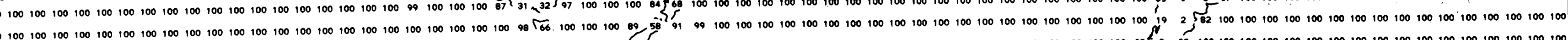

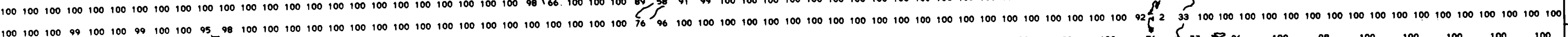

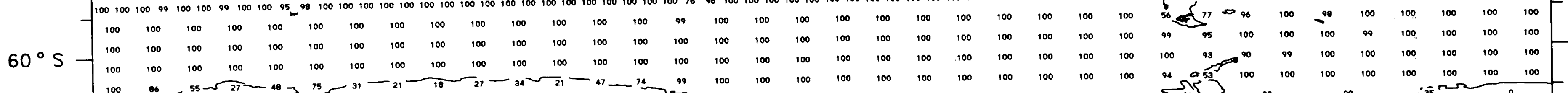

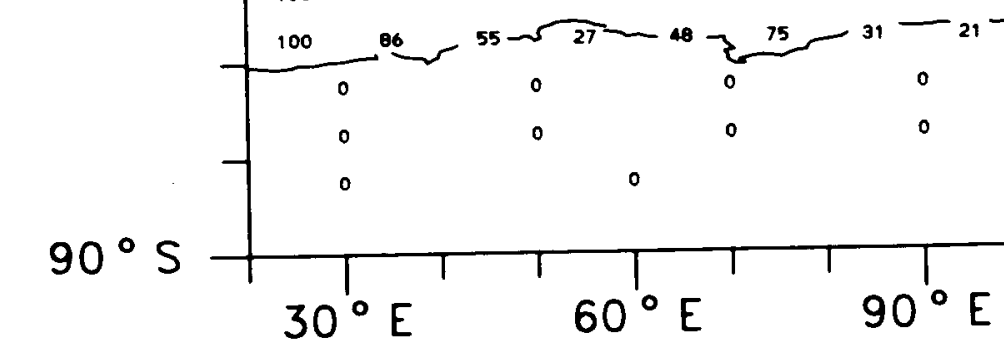
$0 \quad 0 \quad 055^{50}$ $100 \quad 100$ ${ }_{33}^{100}$ 87 ح 273

${ }_{150^{\circ} \mathrm{E}}{ }_{180^{\circ}}{ }_{150^{\circ} \mathrm{W}}$

$120^{\circ} \mathrm{E} \quad 150^{\circ} \mathrm{E}$

GLOBAL AVERAGE $69.7 \%$

$120^{\circ} \mathrm{w} \quad 90^{\circ} \mathrm{W}$

$60^{\circ} \mathrm{W}$

$w^{\prime}$

$30^{\circ}$ 
December, January, February (1952-1981)

Ship Observations Only

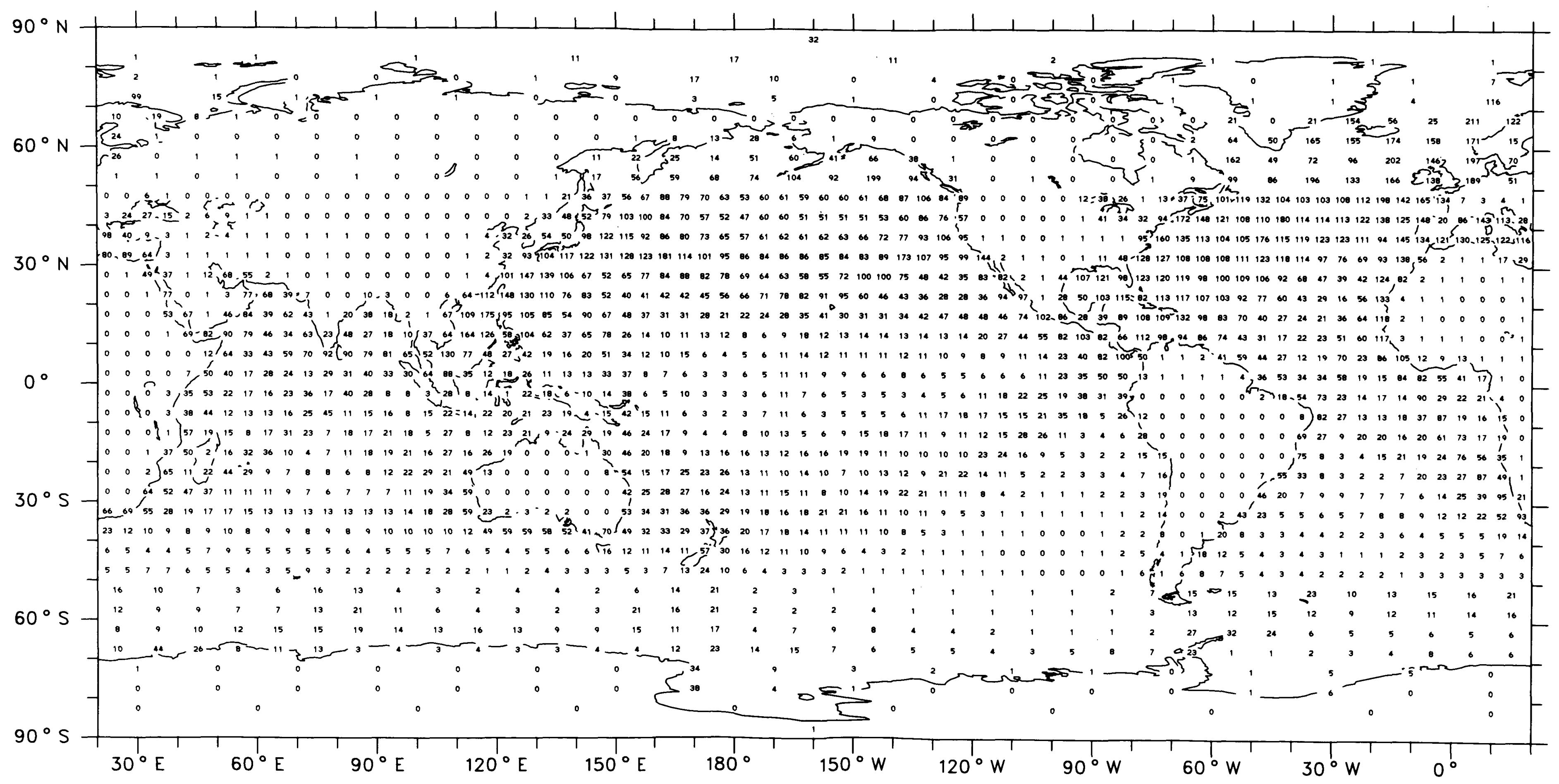

Map 2 


\section{Number of 3-Hour Periods with At Least One Cloud Report}

\section{(Number of "Compressed Observations") (hundreds)}

March, April, May (1952-1981)

Ship Observations Only

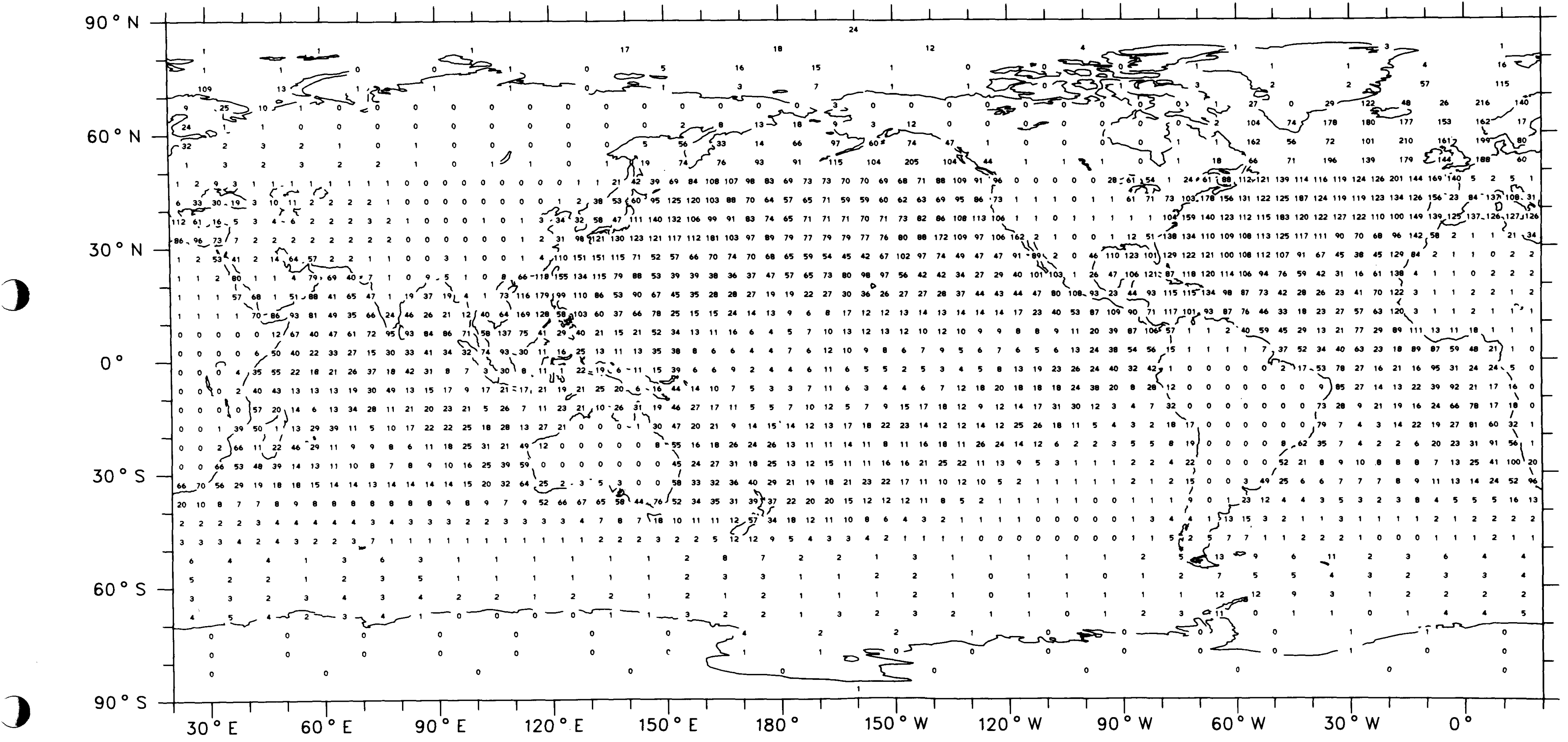




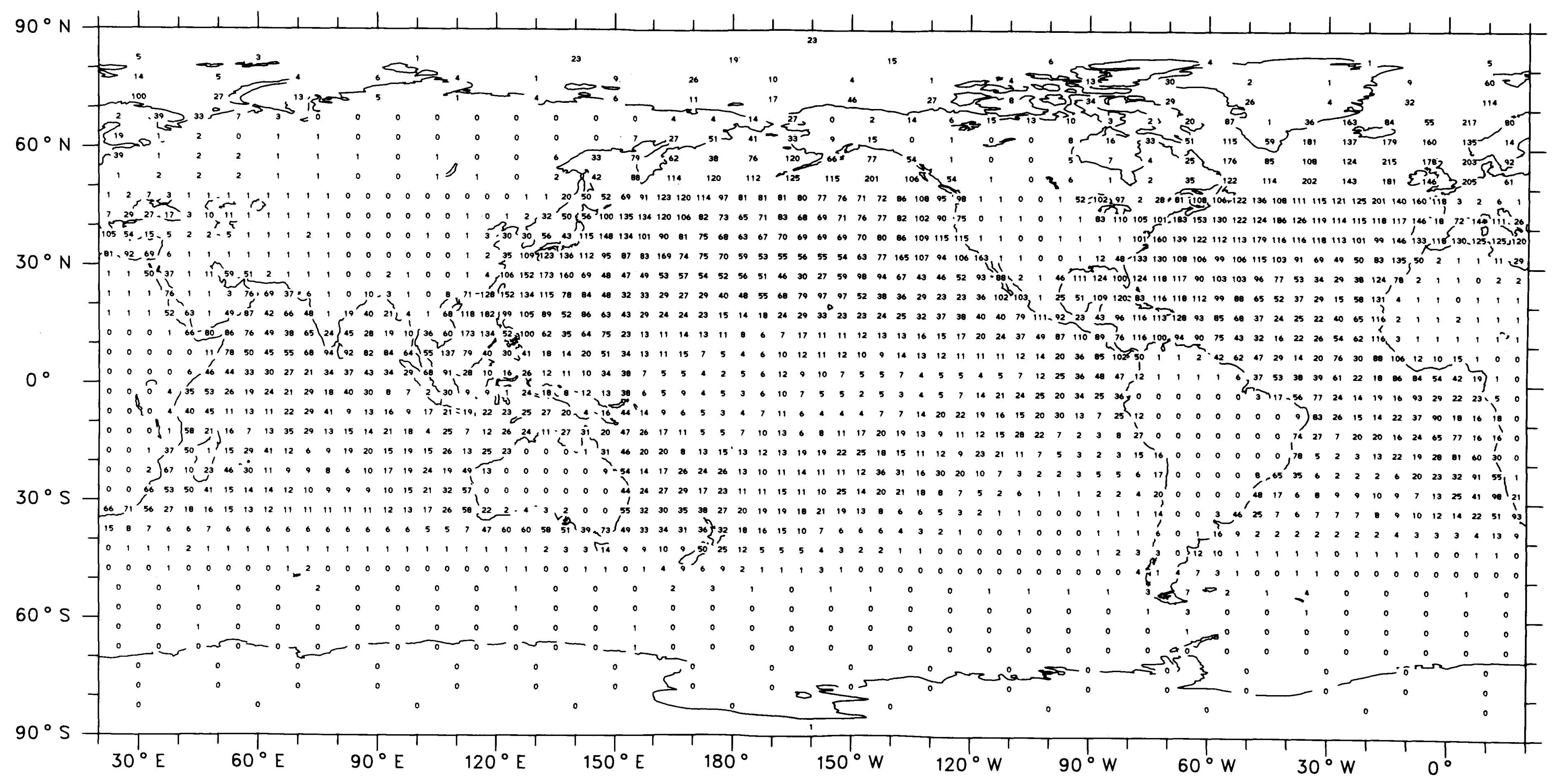

Map 4 


\section{Number of 3-Hour Periods with At Least One Cloud Report}

\section{(Number of "Compressed Observations") (hundreds)}

September, October, November (1952-1981)

Ship Observations Only

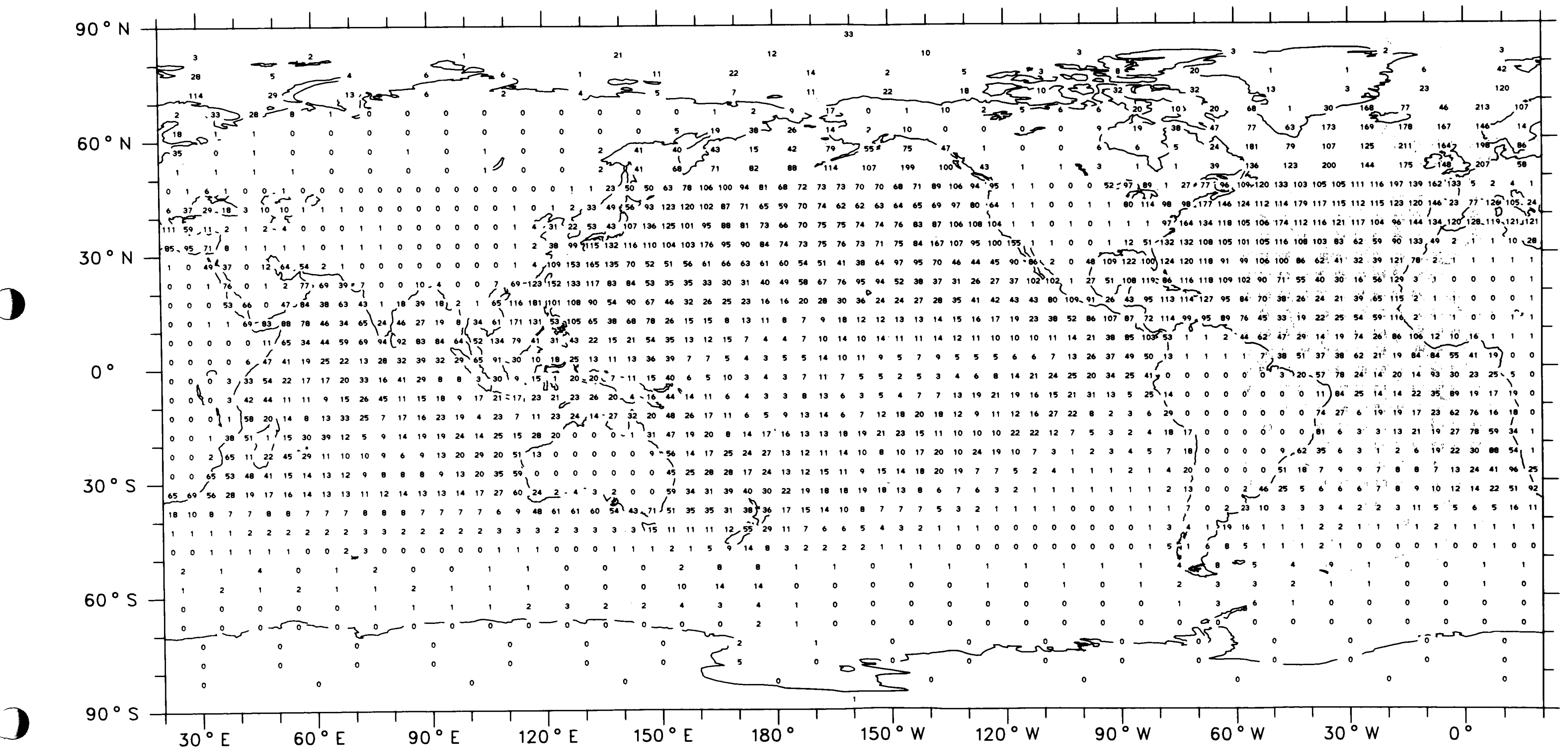

Map 5 
December, January, February (1952-1981)

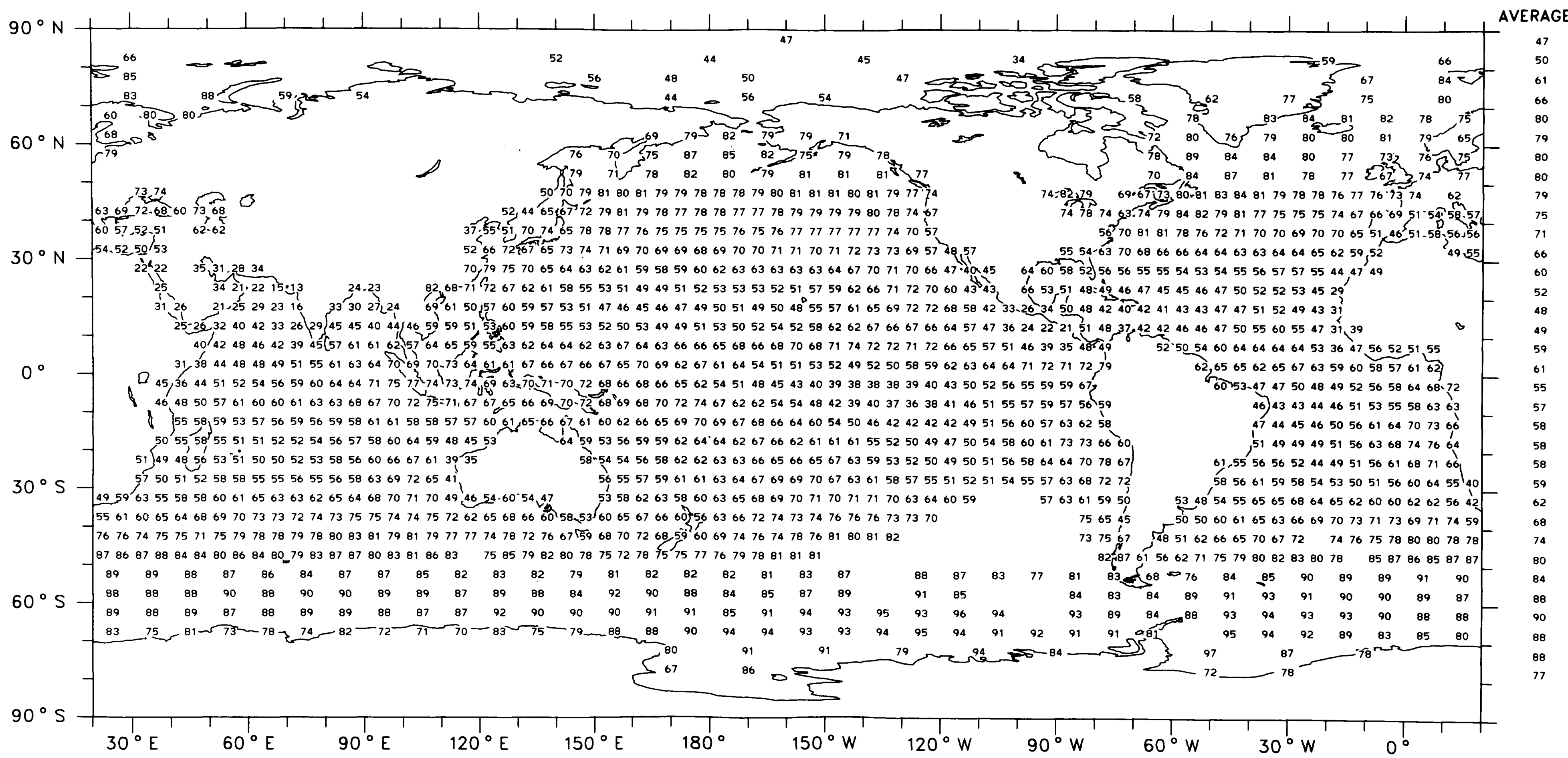

Map 6

global AVERAGE (OCEAN) $65 \%$ 
March, April, May (1952-1981)

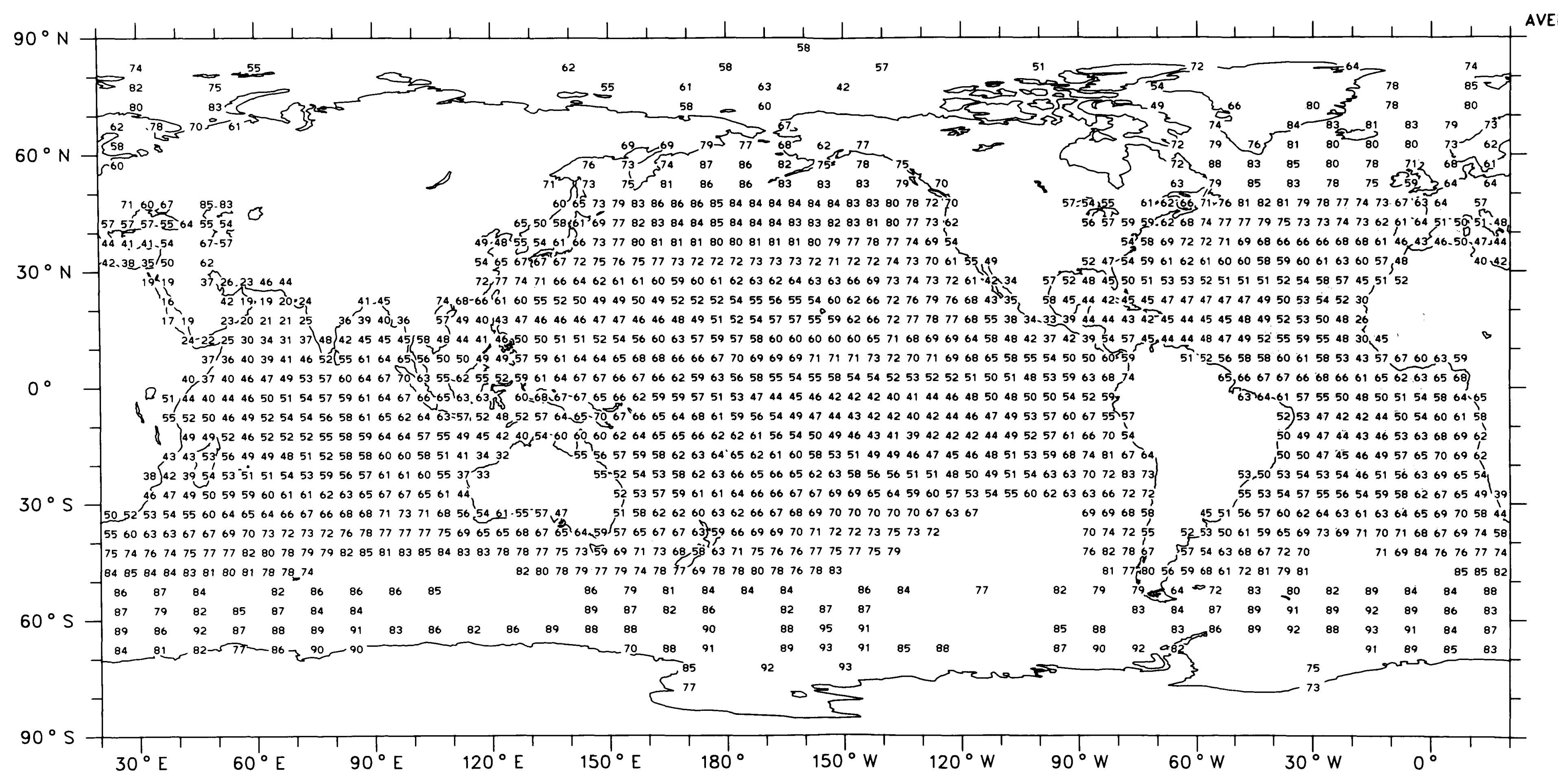


June, July, August (1952-1981)

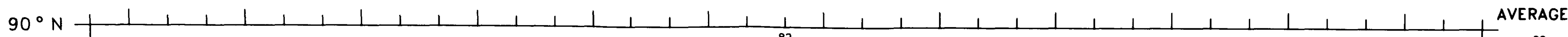
$58 \frac{41.52}{252} \leftarrow \frac{77}{30} 0$

14 $10,19-38 \quad 57-41$ $64,7373<76838791$

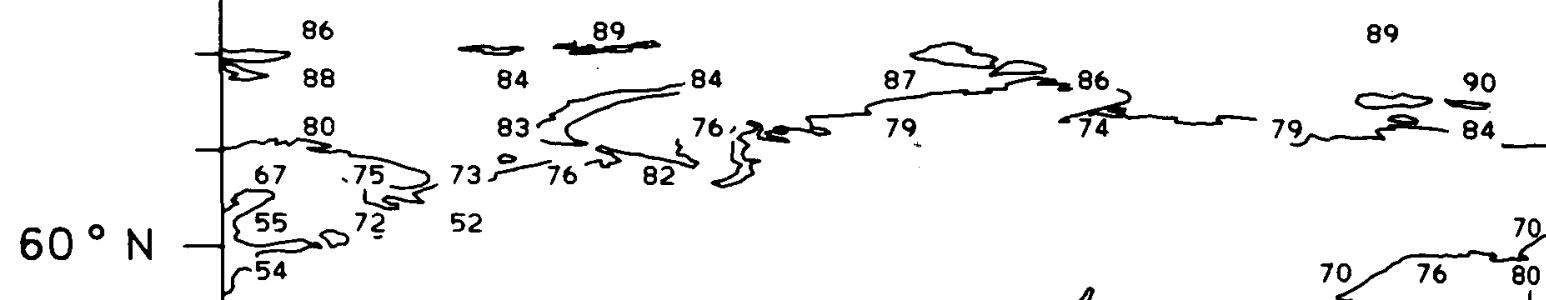

$30^{\circ} \mathrm{N}$

í 1310

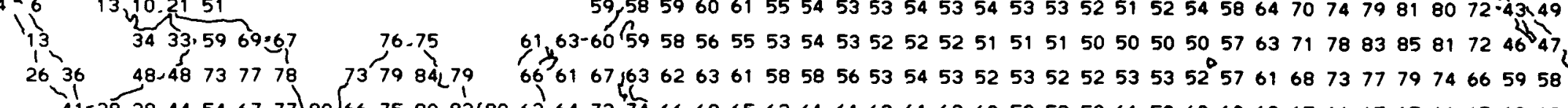

1-2628445467 77)

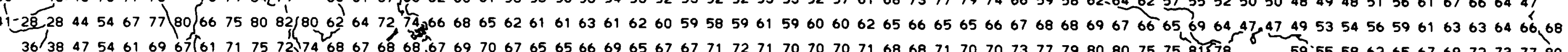

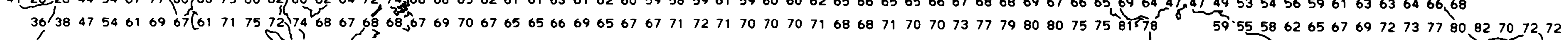

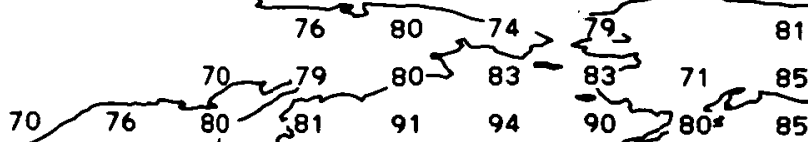

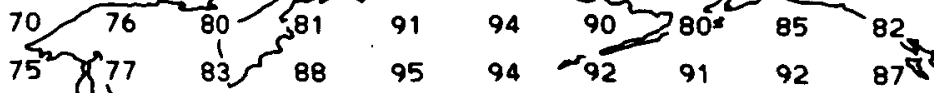

7575829092949595959595959494939291898573.88 55.636765677073777980207977777574737374757670767062

4848515962646265676974736764.6761596467656163616261595861575151514952504649464749596061637478858684

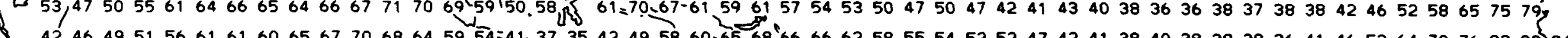

$42,4649515661616065677068645954=41,373564249$

J5

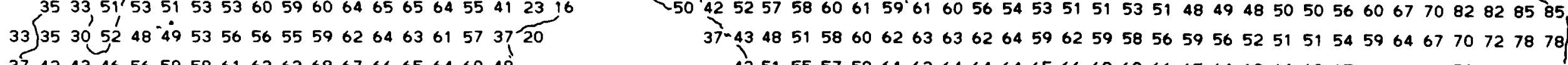

$425155575861636464646566686866656463646065 \quad 70696466$

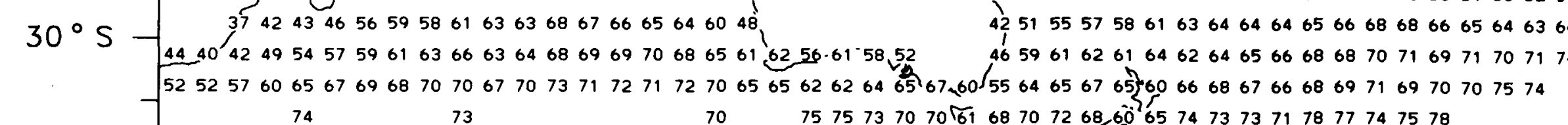

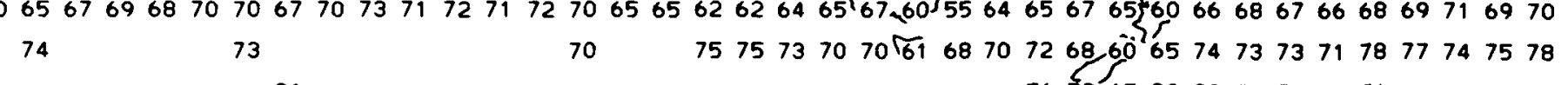

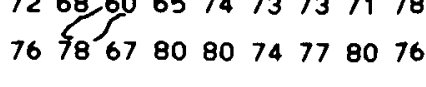

837864

52,505148475251576264687070

(48)41 45 4440393637394755 62.72

59) 52404076373947556272

53) 52464746535607737361 4846474955606777808376 4484925155606074797567 57.474952555846616369726548 $58545557565960596268706546 \quad 37$

AVERAGE

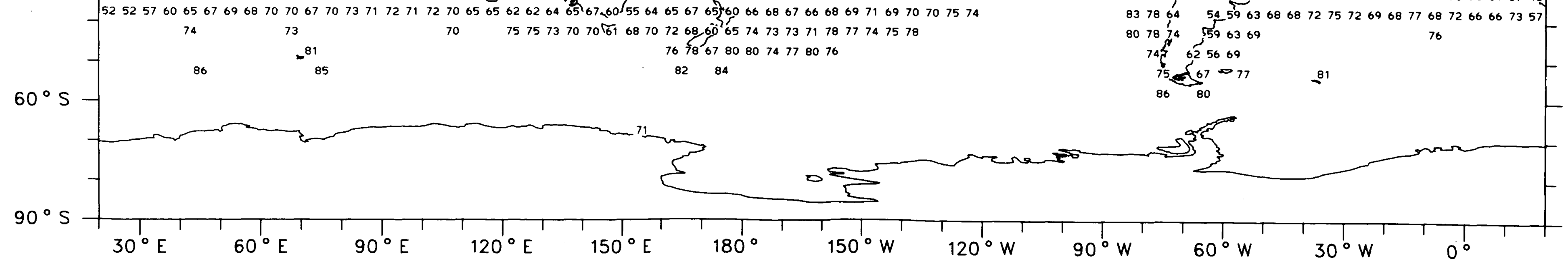

Map 8

GLOBAL AVERAGe (OCEAN) $65 \%$ 
Average Total Cloud Cover (\%)

September, October, November (1952-1981)

Ocean Areas Only

ZONAL

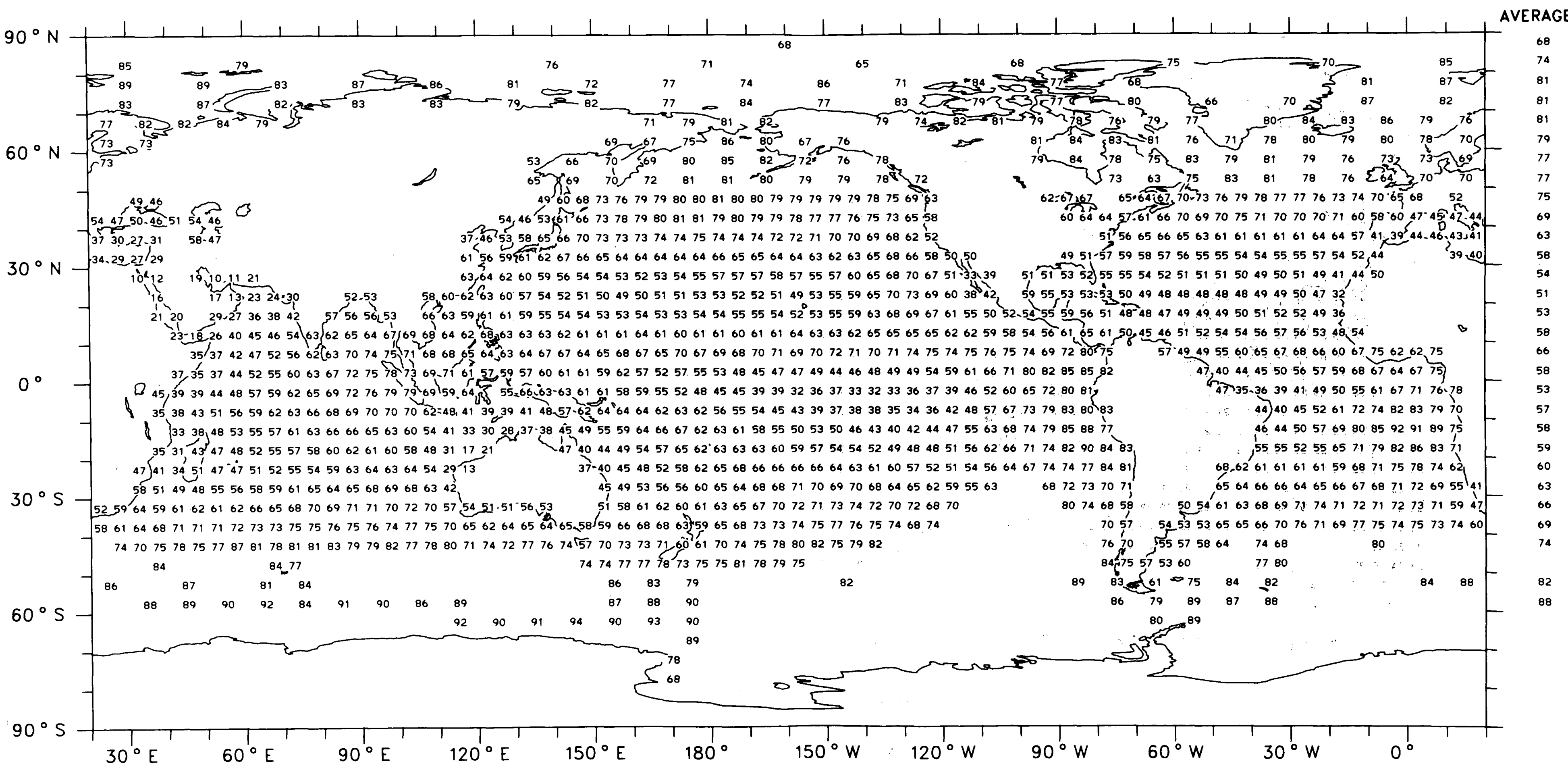




\section{Standard Deviation of Compressed Observations of Total Cloud Cover (\%)}

December, January, February (1952-1981)

Ocean Areas Only

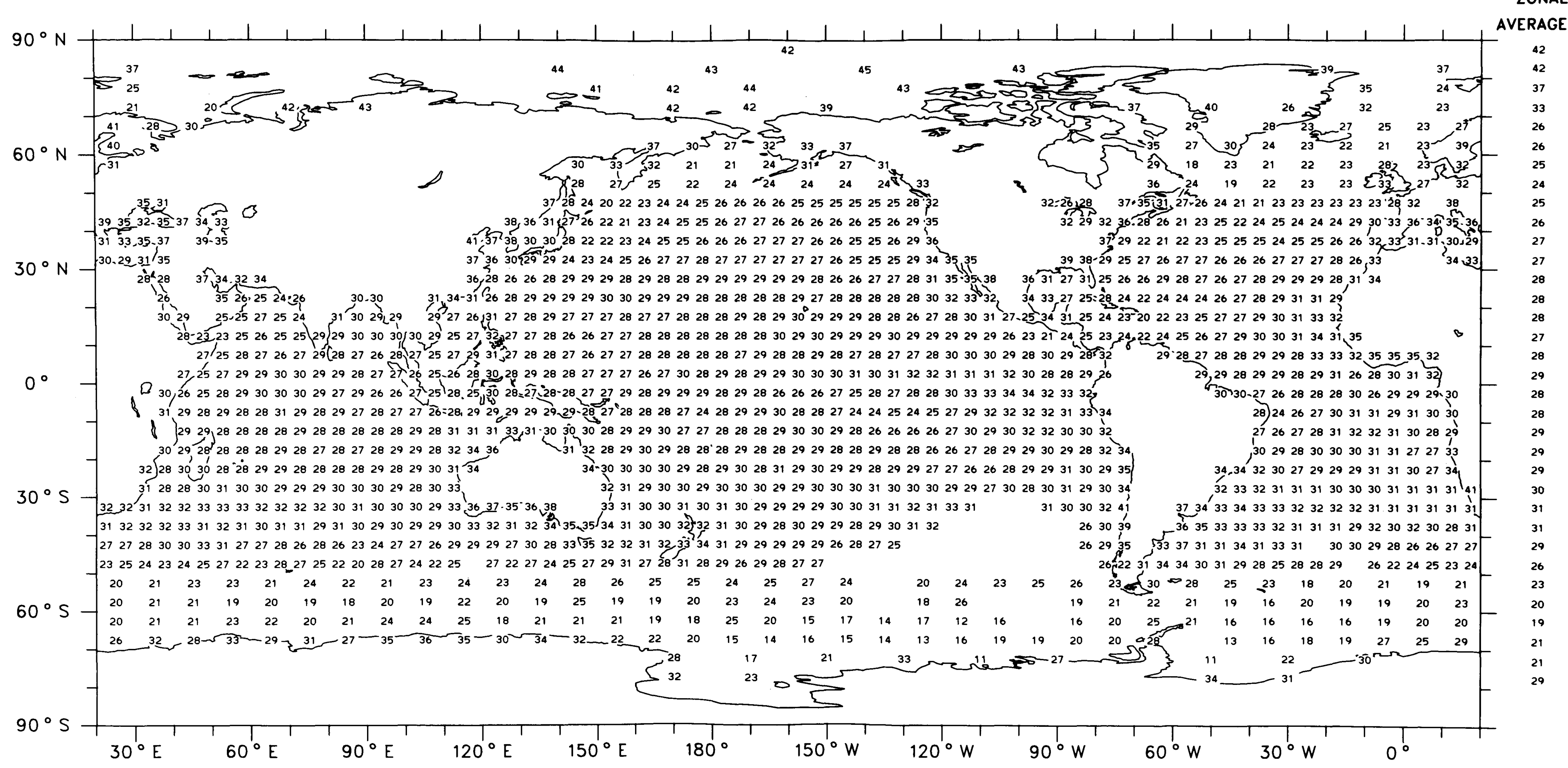

Map 10

global average (ocean) $28 \%$ 


\section{Standard Deviation of Compressed Observations of Total Cloud Cover (\%)}

March, April, May (1952-1981)

Ocean Areas Only

ZONAL AVERAGE

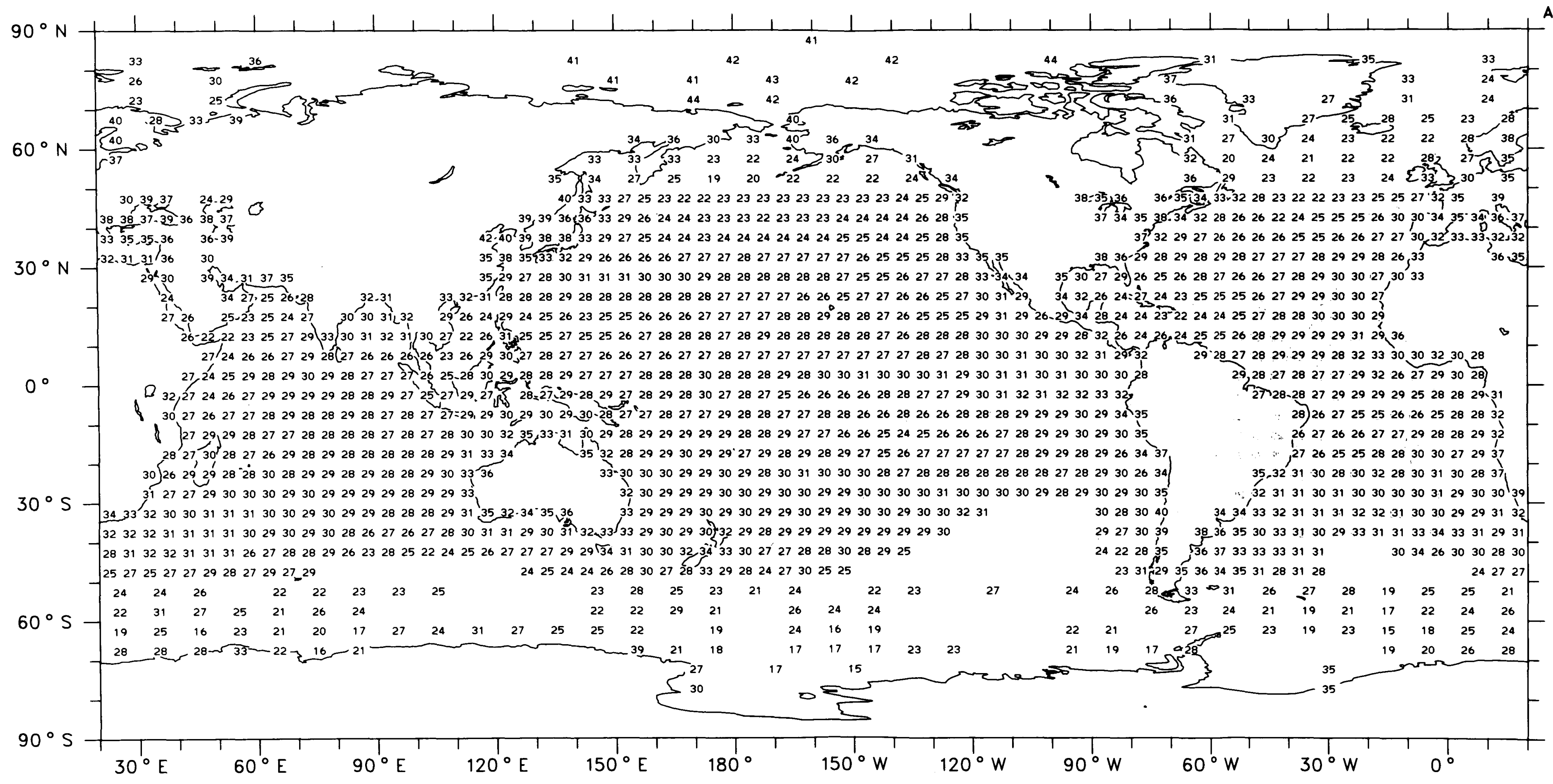

41

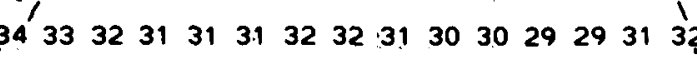

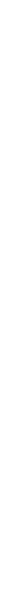

$60^{\circ} \mathrm{S}$
$90^{\circ} \mathrm{S}$

$30^{\circ} \mathrm{E}$

$60^{\circ} \mathrm{E}$

$90^{\circ} \mathrm{E}$

$120^{\circ} \mathrm{E}$

GLOBAL AVERAGE (OCEAN) $28 \%$

Map 11 


\section{Standard Deviation of Compressed Observations of Total Cloud Cover (\%)}

June, July, August (1952-1981)

Ocean Areas Only

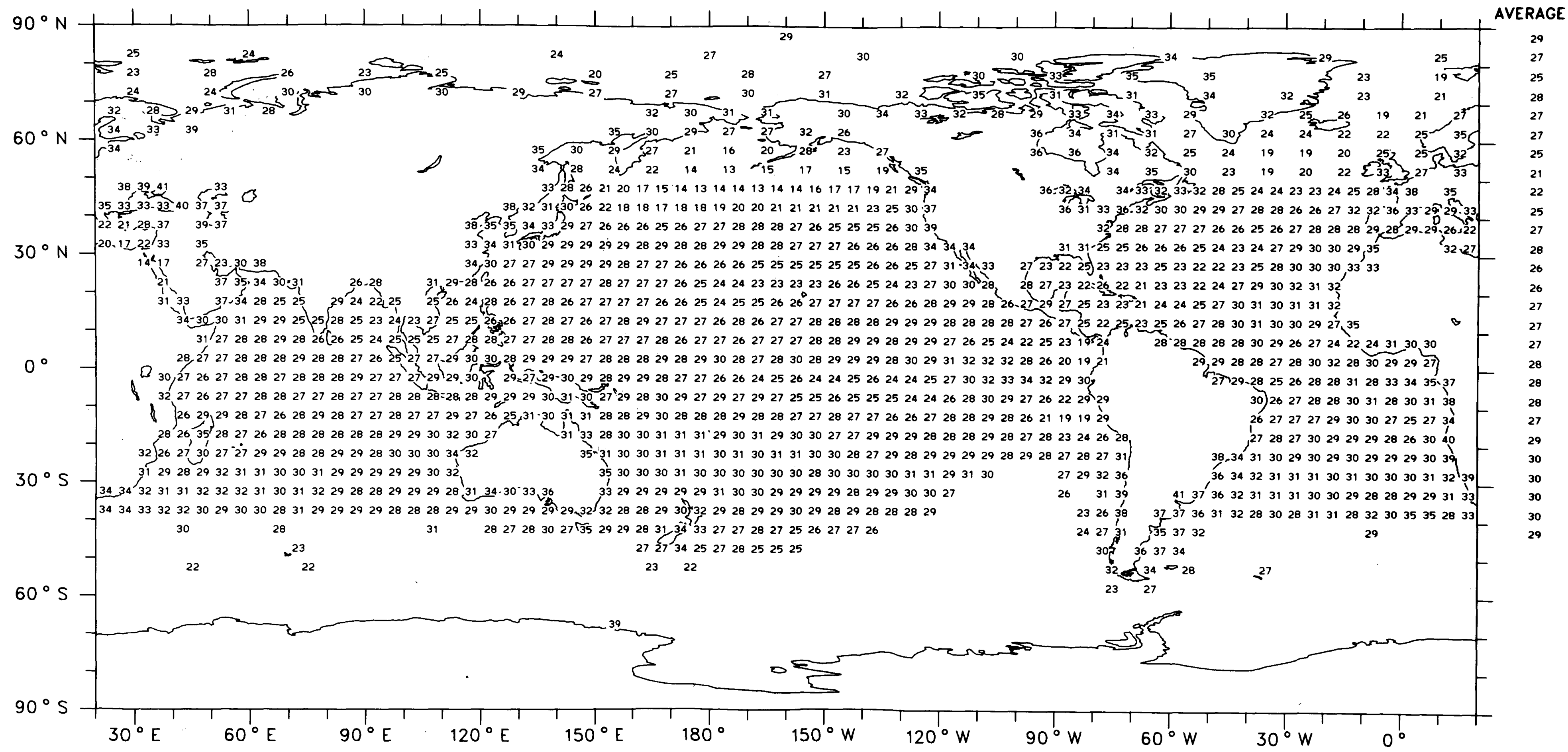

Map 12

GLOBAL AVERAGE (OCEAN) $28 \%$ 


\section{Standard Deviation of Compressed Observations of Total Cloud Cover (\%)}


Average Total Cloud Cover (\%)

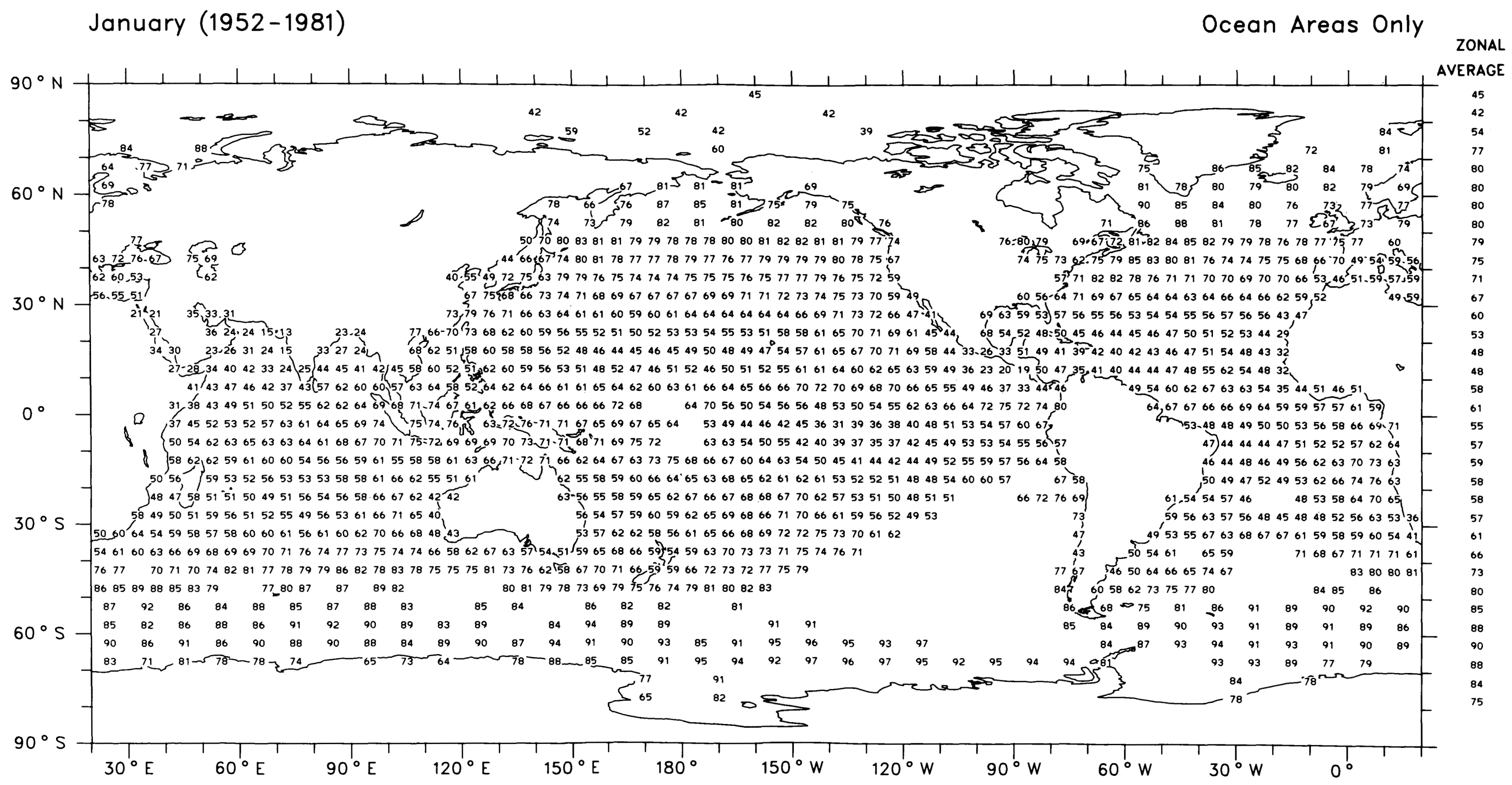

Map 14

GLOBAL AVERAGE (OCEAN) $65 \%$ 
Average Total Cloud Cover (\%)

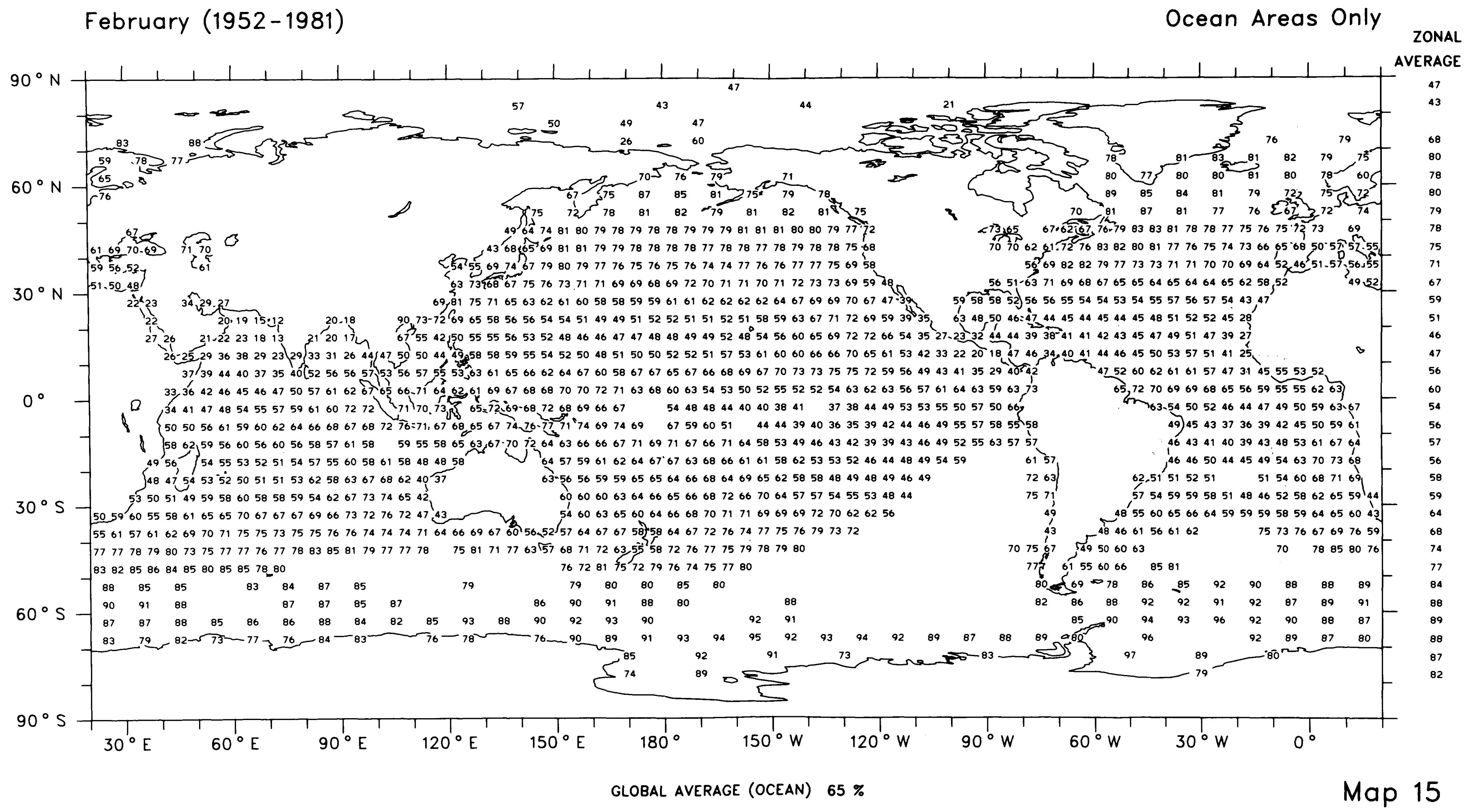




\section{Average Total Cloud Cover (\%)}

March (1952-1981)

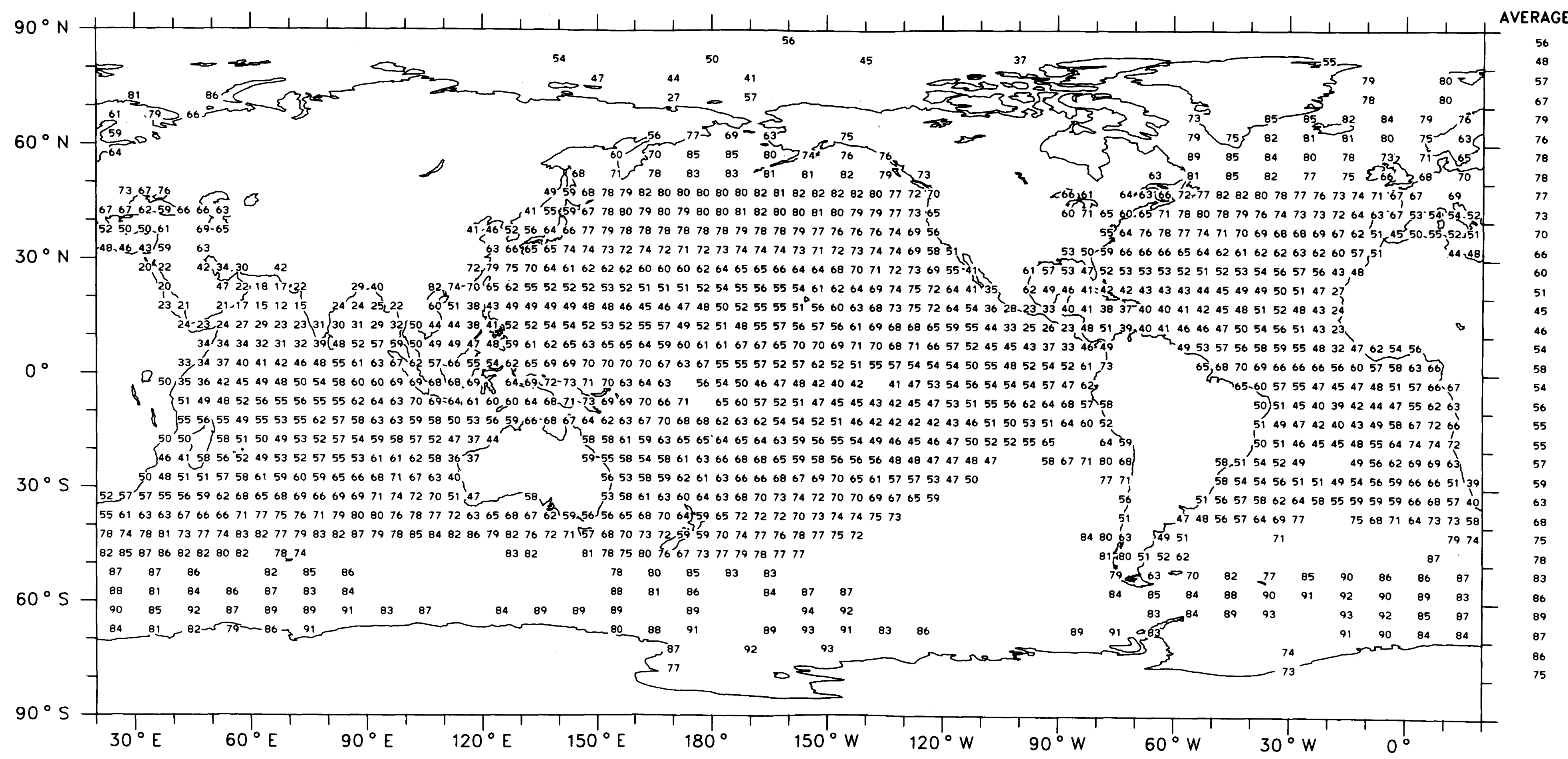

Map 16

GLOBAL AVERAGE (OCEAN) $64 \%$ 
April (1952-1981)

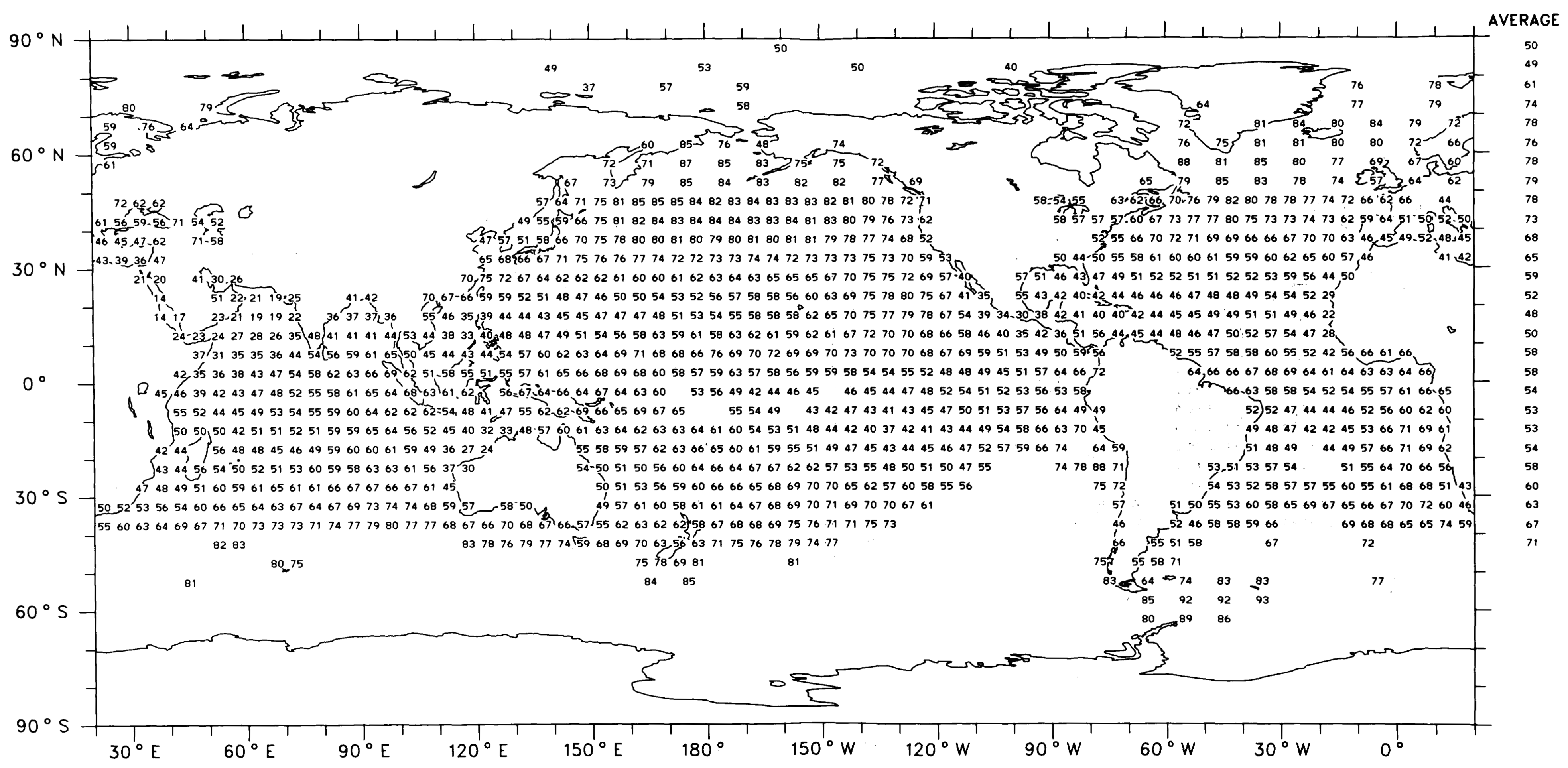




\section{Average Total Cloud Cover (\%)}

May $(1952-1981)$

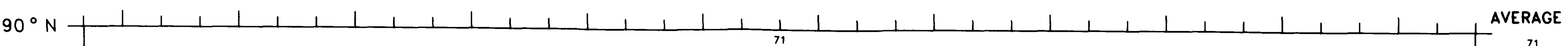

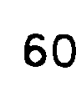

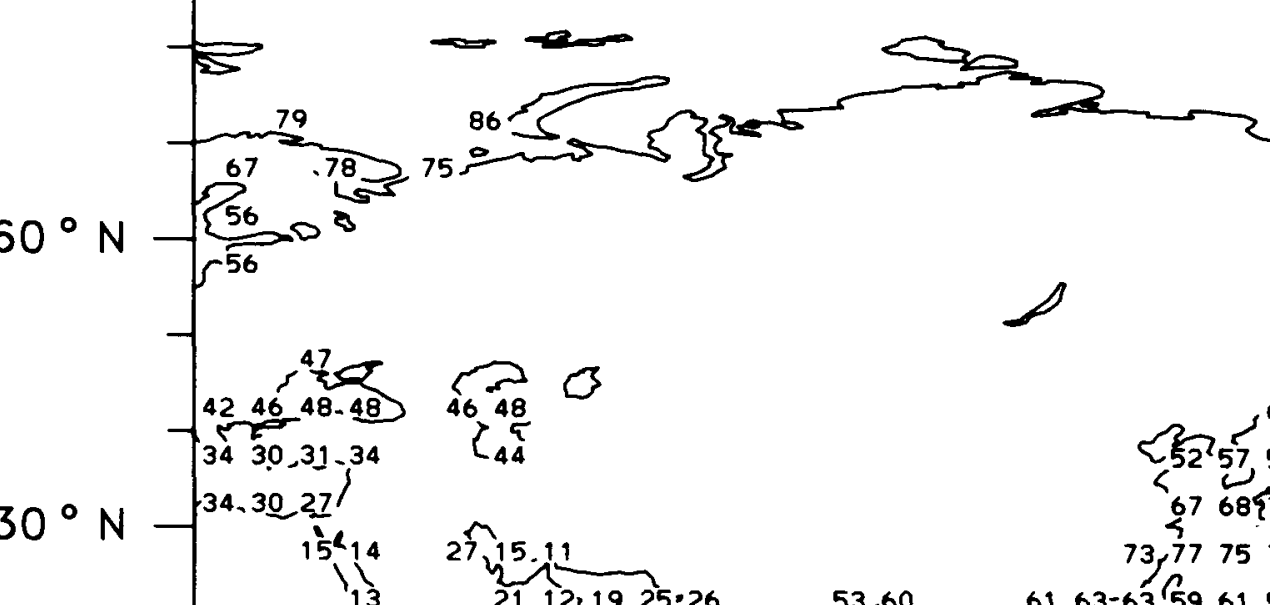
$77 \quad 76^{69} \quad 32 \quad 89$ 作 60 6056 C4 $^{73} 7884878888898788878686858483817973.61$ 6840070 72788284848482828382838179777878756955

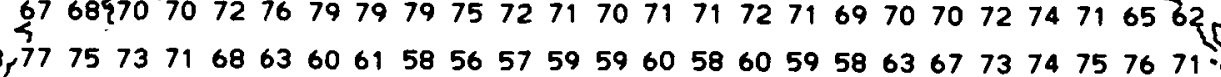

75

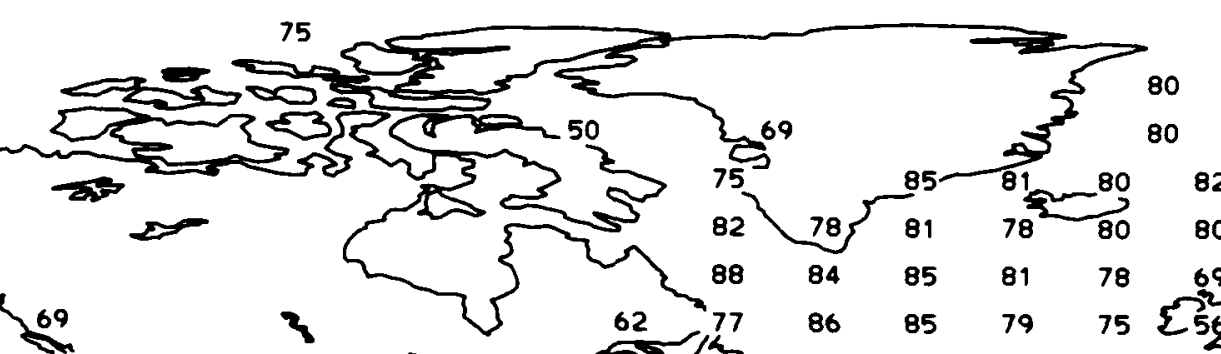

3

$56-53,54$

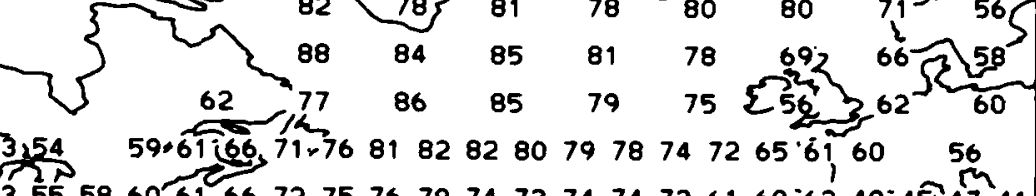
555860.67667275767974737474736160 .6249 .45747 .4 $5556646869686665636364676759400^{37}$ $53474444) 5052545351494949505356604855$

$56454444=50555351504948495155585733$ ?

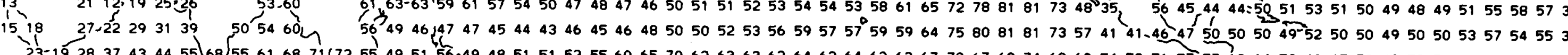

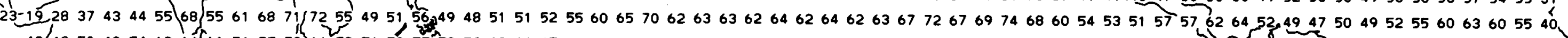

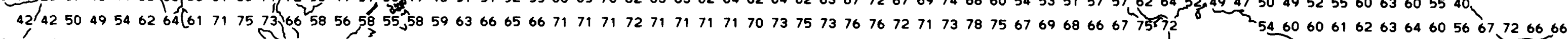

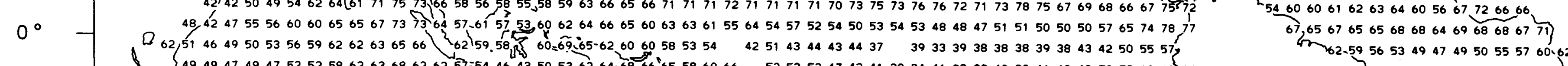

1) $49494749475252586263686262577544464350536264.6866 \% 65586066 \quad 5253524742413934413838403941424953586960964$ 841 40 $504850504954596164665454514337,28,50.5554576164656265546357535645464341413843423944475359748265$

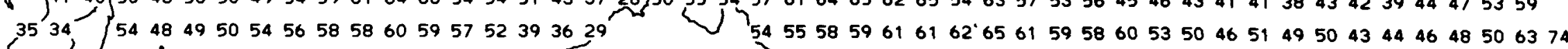

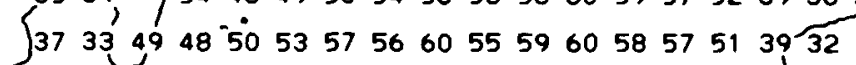

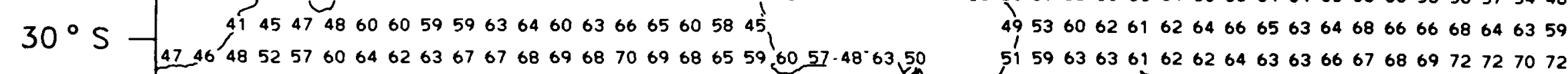

$50=505155606364666364646568635856575448525252$ $5 4 \longdiv { 5 5 4 9 4 2 4 4 4 5 5 3 5 9 6 3 5 9 5 1 }$ 5150494646485765676557 4952474549505865666352 495360626162646665636468666668646359575862

- $535961626669716868687074767472767469686564666666868,63 / 5967686862 f^{5} 5966666668696871747475$

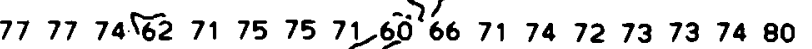
787871838182 $79 \quad 83$

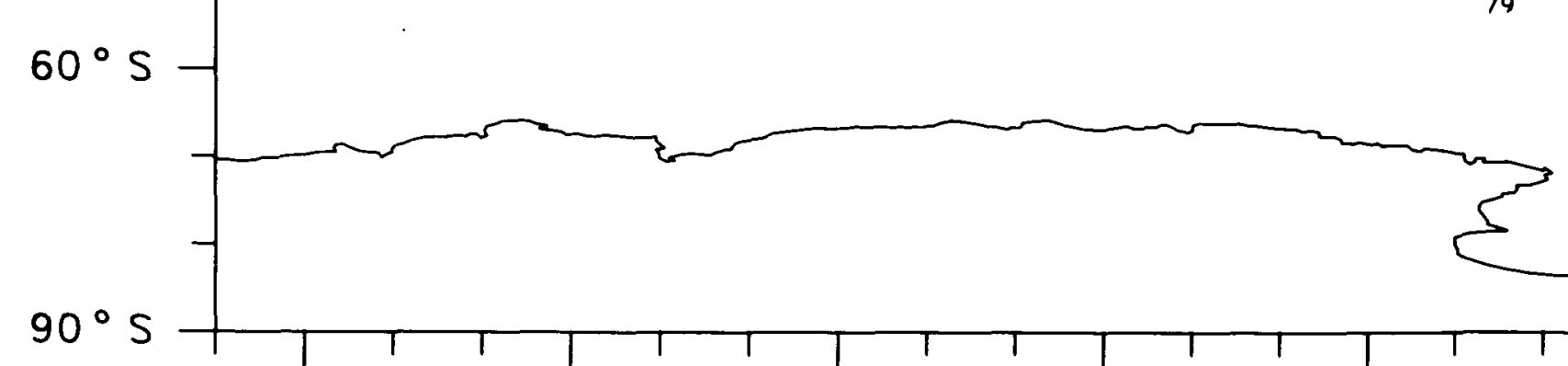

$30^{\circ}$
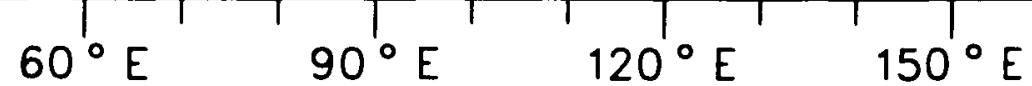

$150^{\circ} \mathrm{E}$
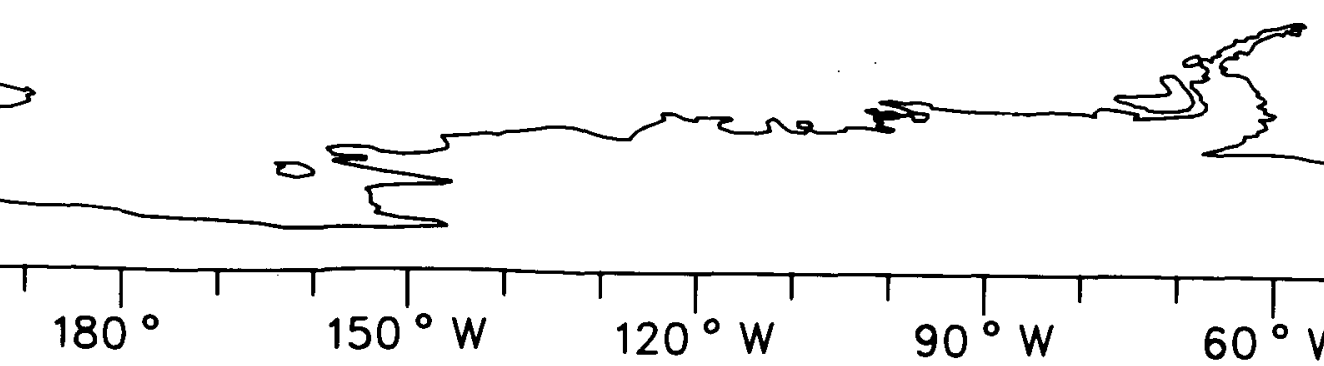
525763675944 53515557576050020206670245 525660636764636066686871705747
-515671617074 69688270 6474 $8077 \int_{75}^{68} 56764$ 6870 88

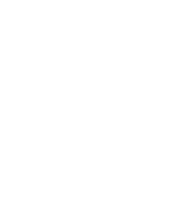

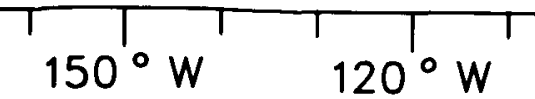
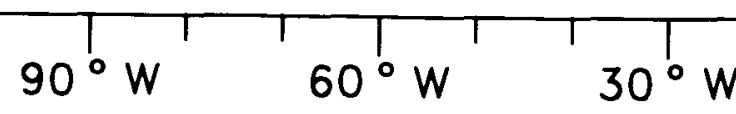

79

Map 18

GLOBAL AVERAGE (OCEAN) $61 \%$ 


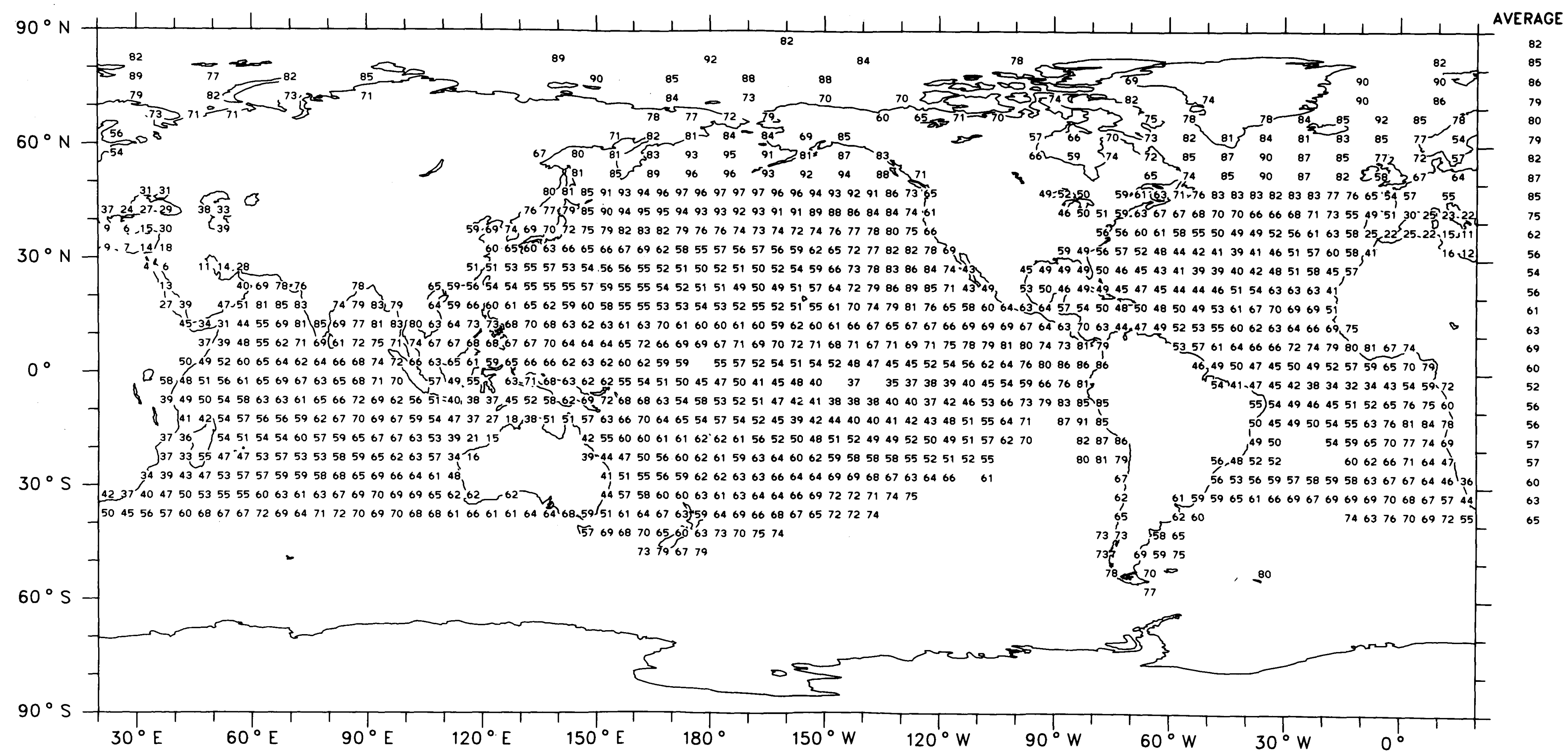

Map 20 


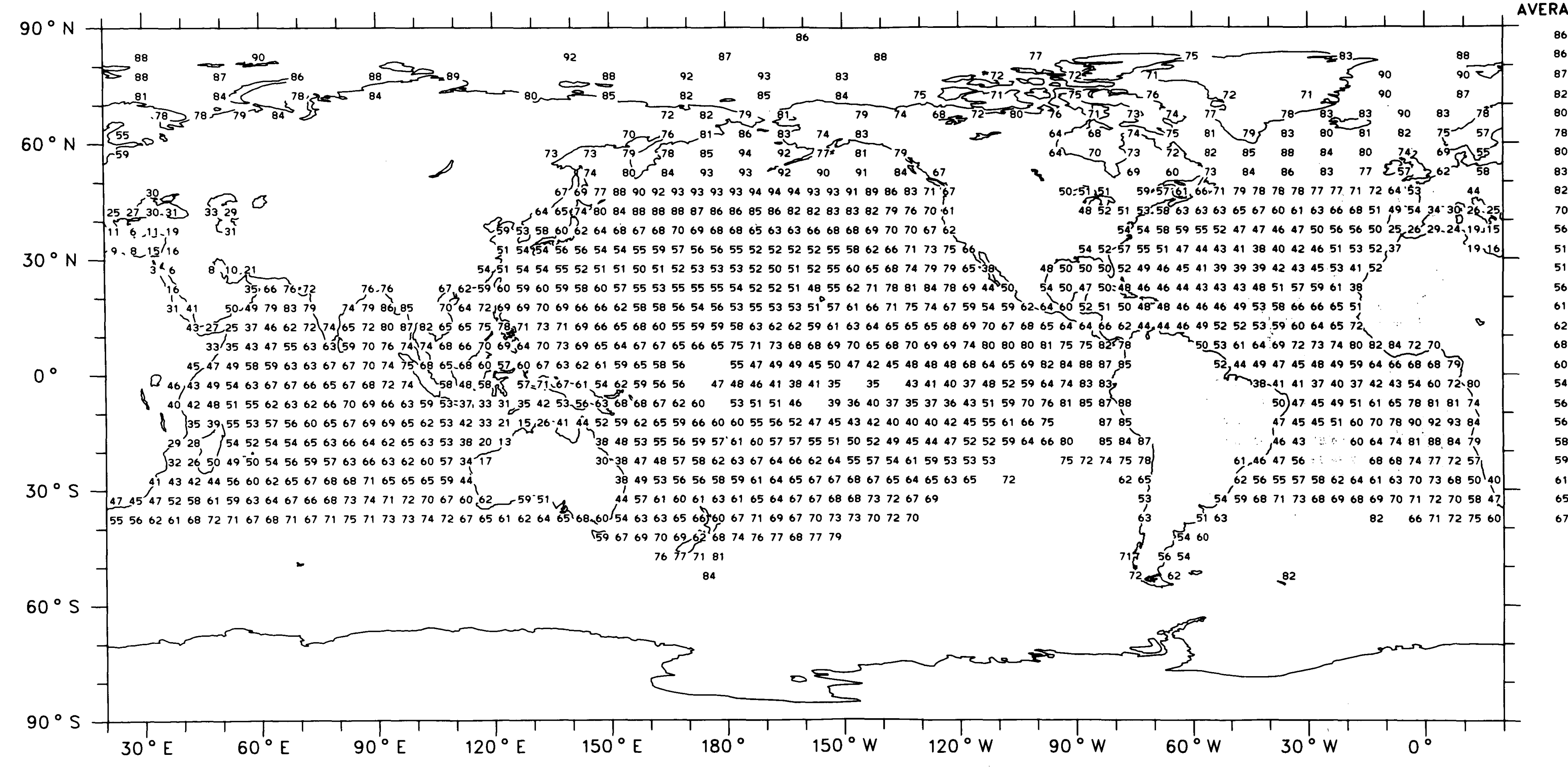




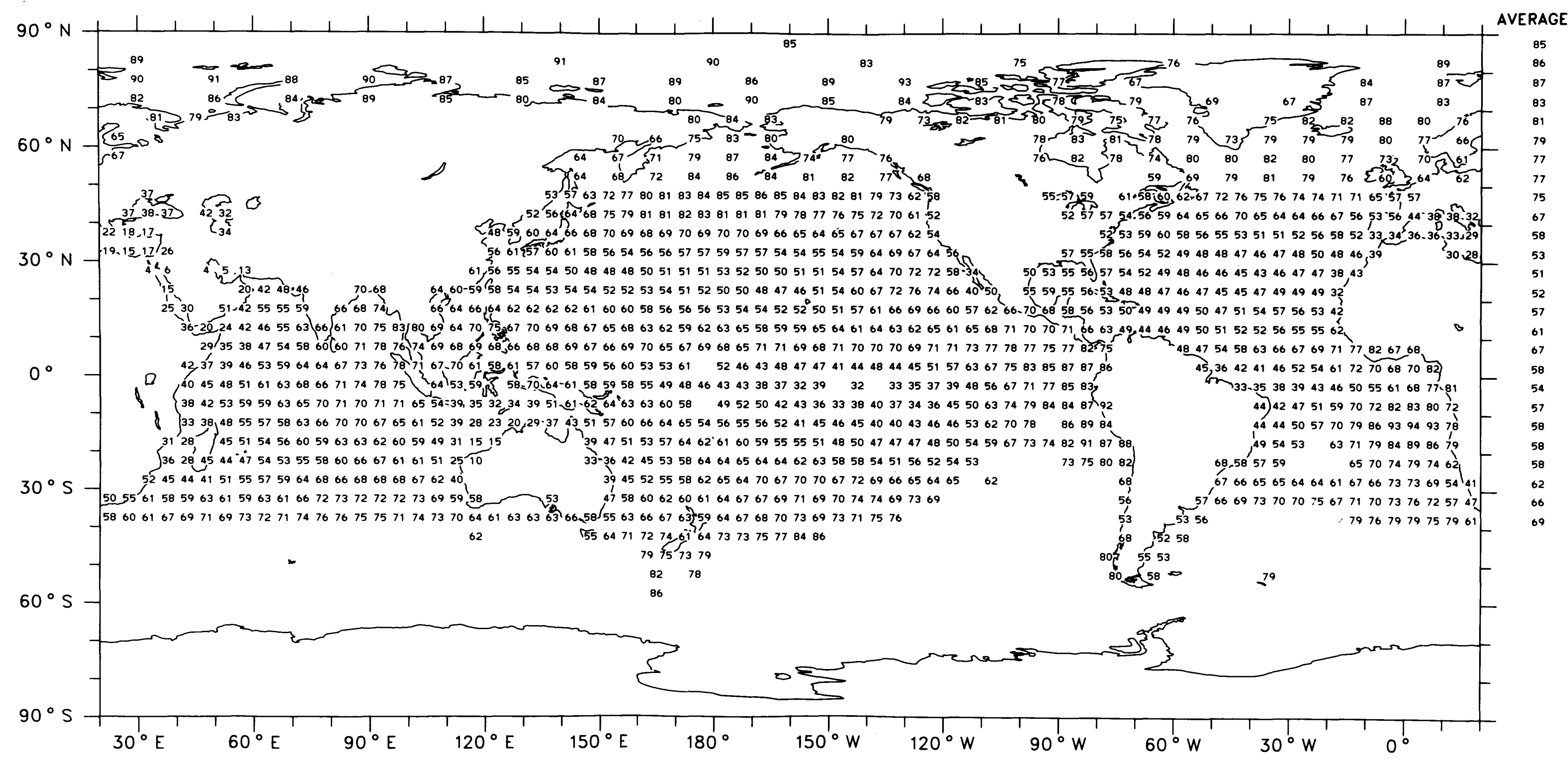

Map 22

global average (ocean) $62 \%$ 


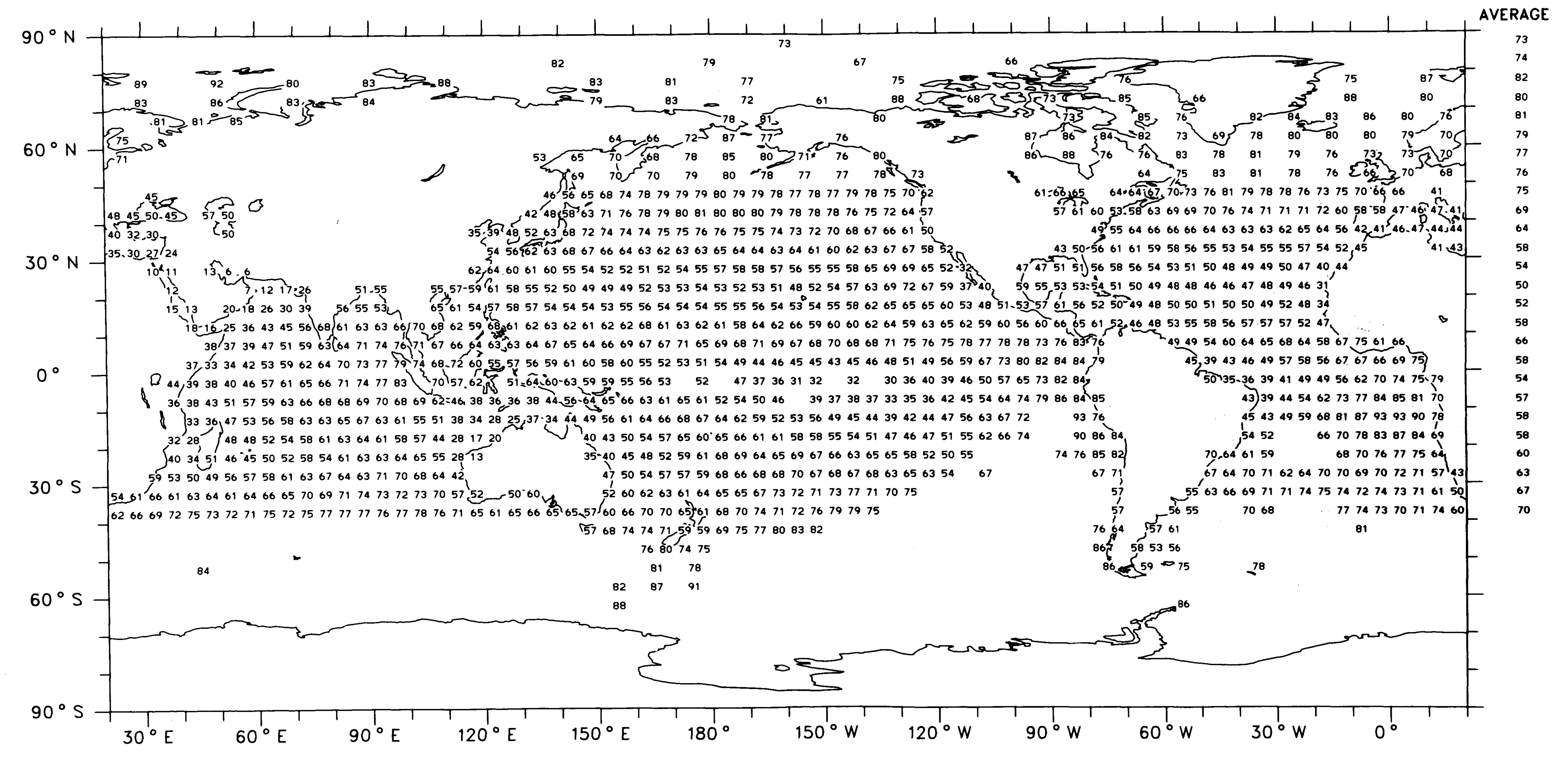


Average Total Cloud Cover (\%)

November (1952-1981)

Ocean Areas Only

ZONAL

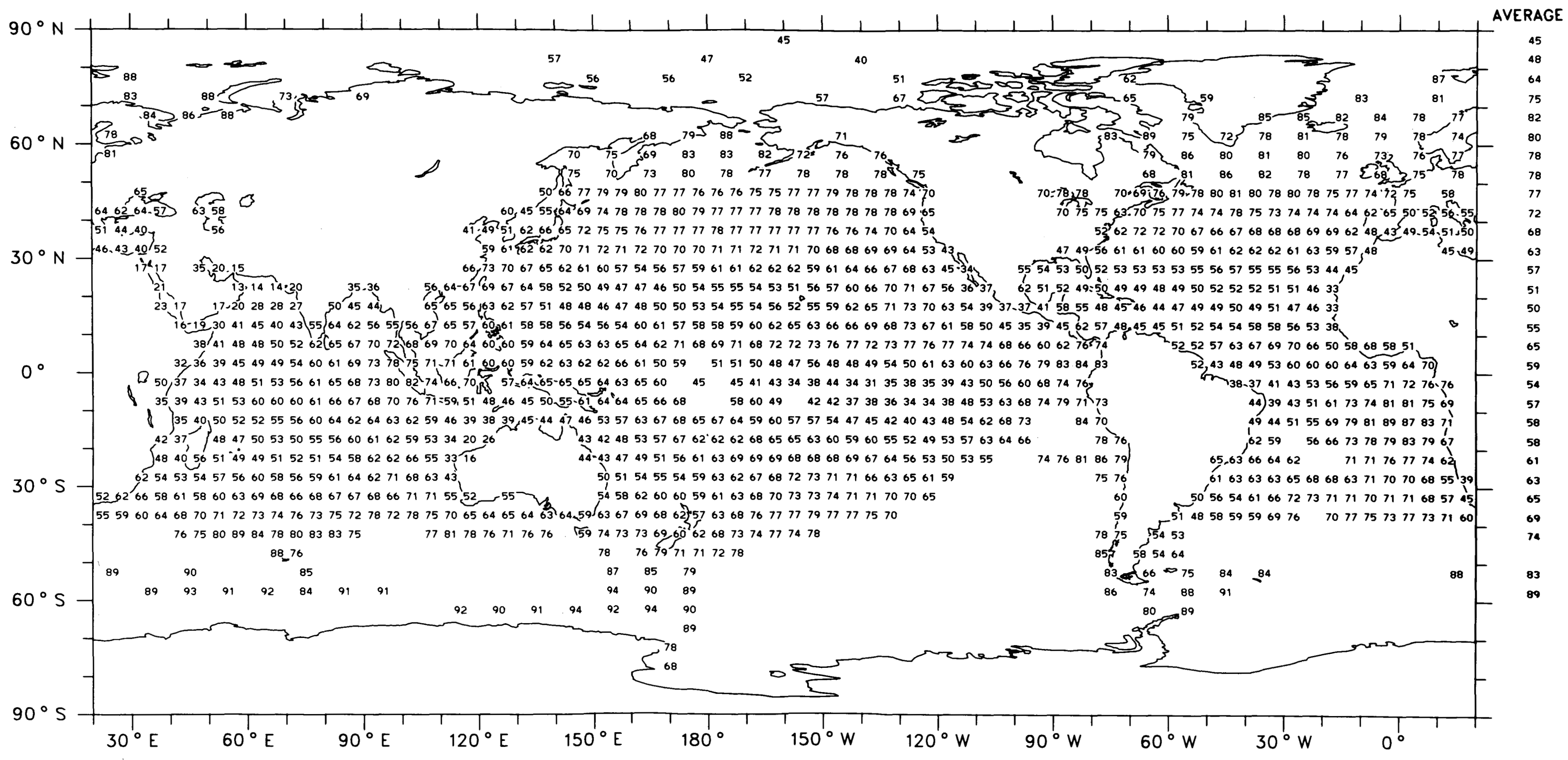

Map 24

GLOBAL AVERAGE (OCEAN) $64 \%$ 


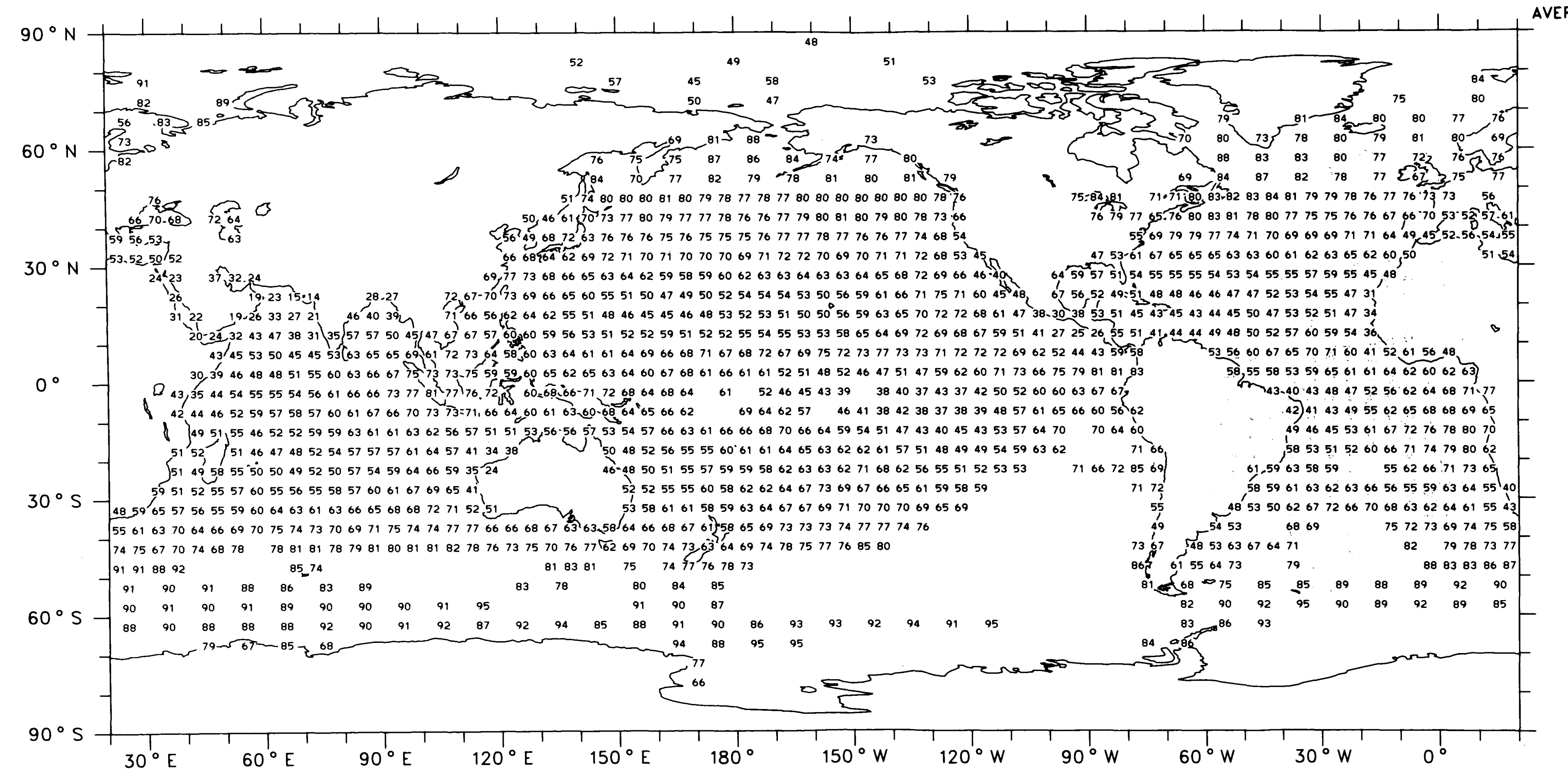

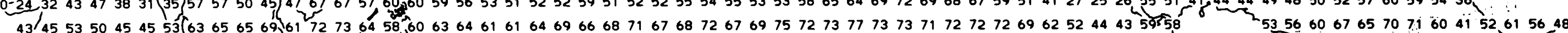
$43,35445455555456616666737781,7776.72,3600=68666-717268646864 \quad 61 \quad 5246454339 \quad 38403743374250526060636767 \%$ $69646257 \quad 464138423837383948576165666056602$ 4 $4951554652525959636161636256575151,53,56 \cdot 5655555457666361666668706664595451474340454353576470 \quad 706460$

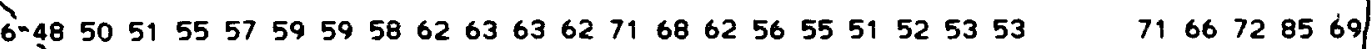
48,59655756555960646361636665686872715251 51

74 756770746069707574737069717574747777606060676367676269707473,63646974787577768580

83

$\begin{array}{ll}84 & 85 \\ 90 & 87\end{array}$ 


\section{Total Cloud Cover}

\section{Amplitude of Annual Cycle (\% Cloud Cover)}

Ocean Areas Only

ZONAL AVERAGE

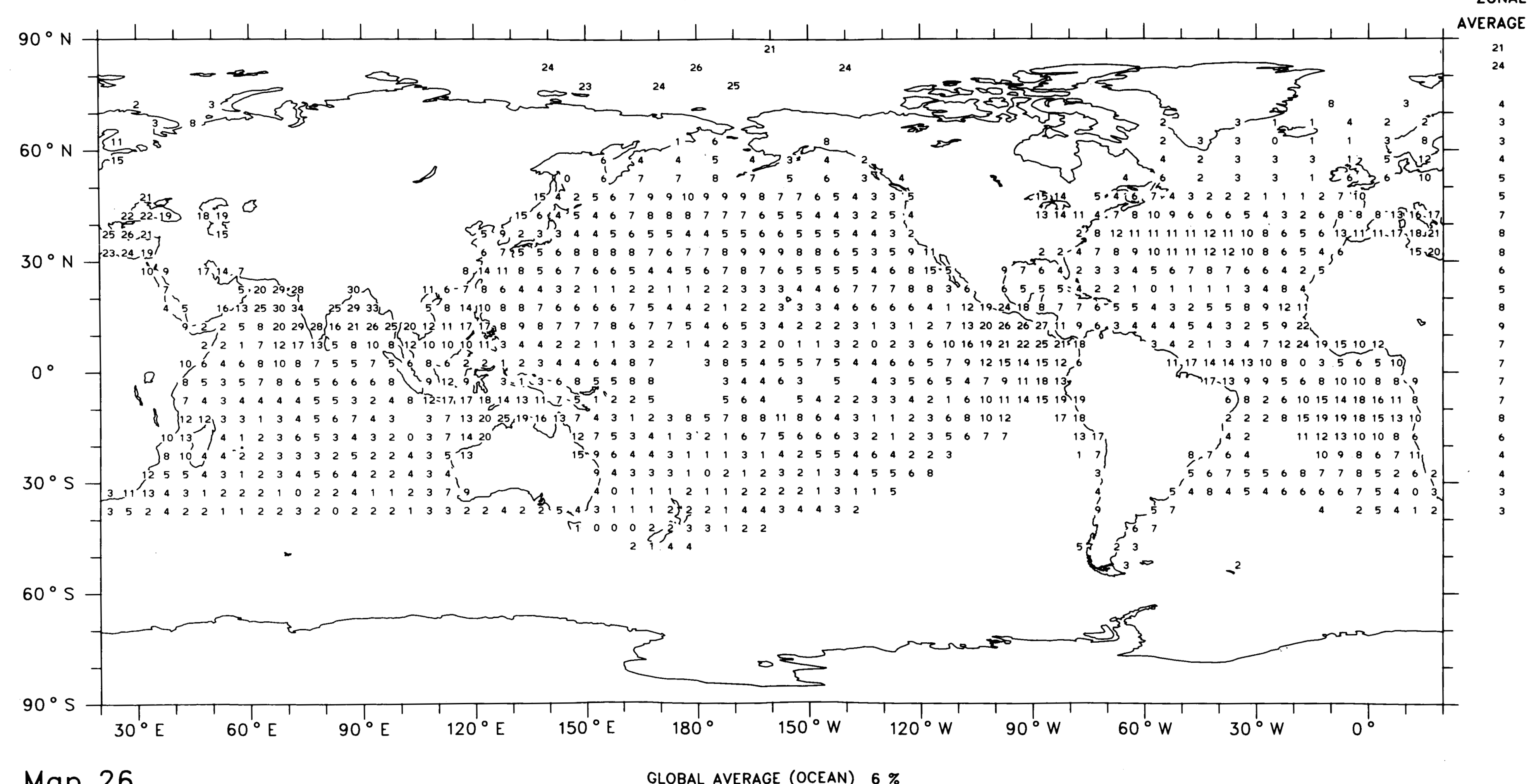


Total Cloud Cover

Phase of Annual Cycle (Month of Maximum)

Ocean Areas Only

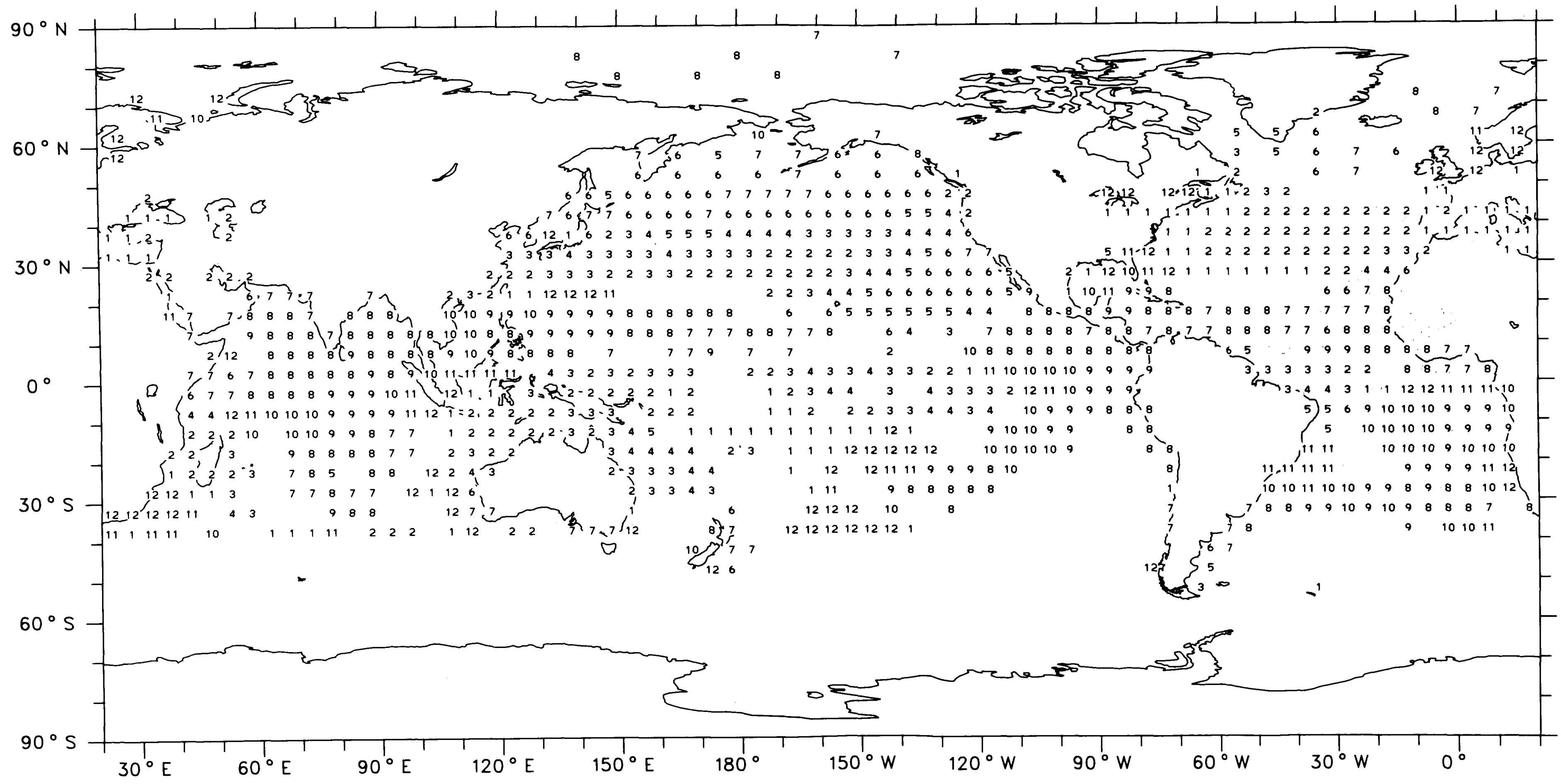

Map 27 


\section{Cumulus}

Frequency of Occurrence (\%)

December, January, February (1952-1981)

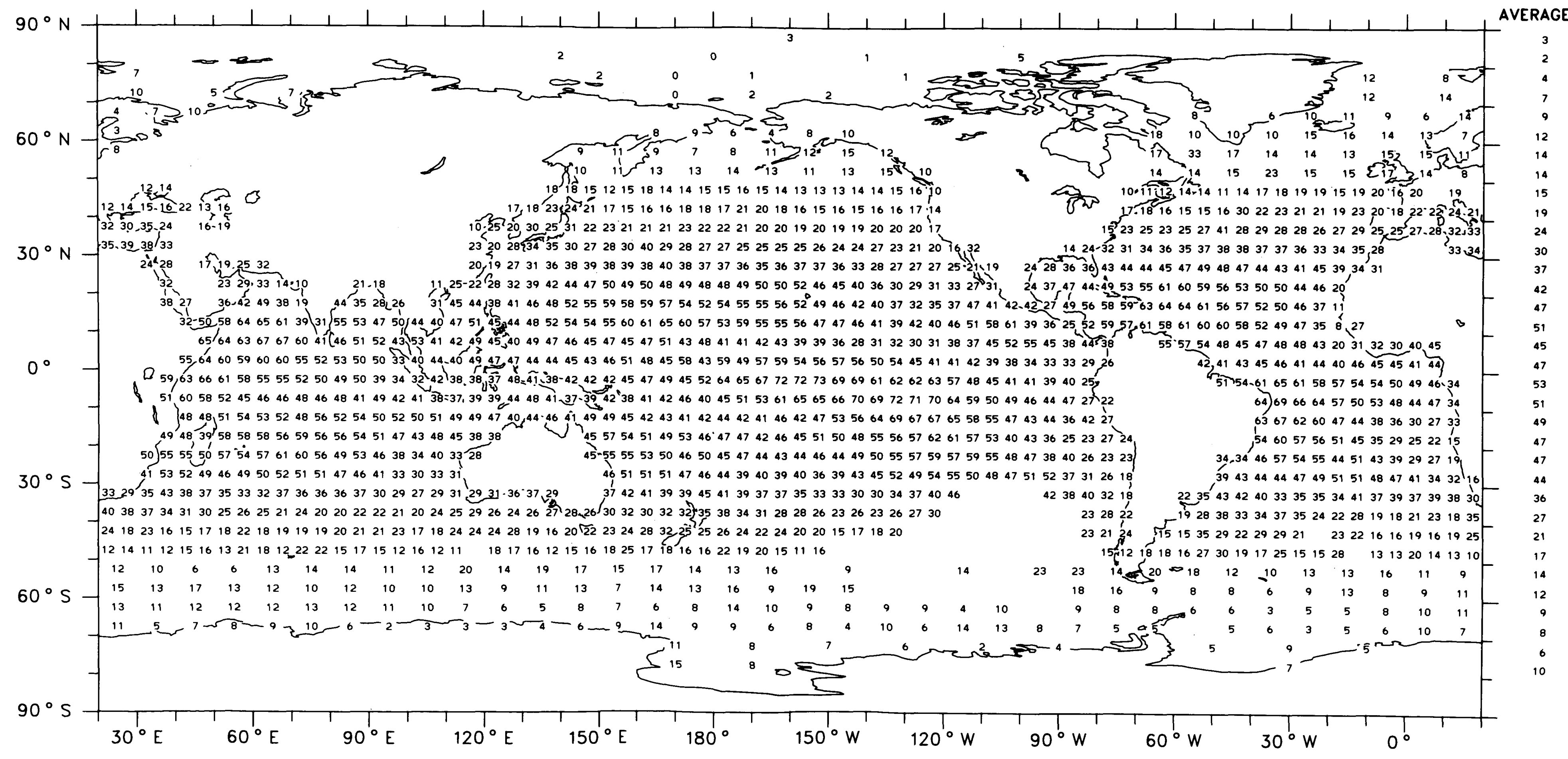

Map 28

global average (OCEAN) $34 \%$ 
Cumulus

Frequency of Occurrence (\%)

March, April, May (1952-1981)

Ocean Areas Only

ZONAL

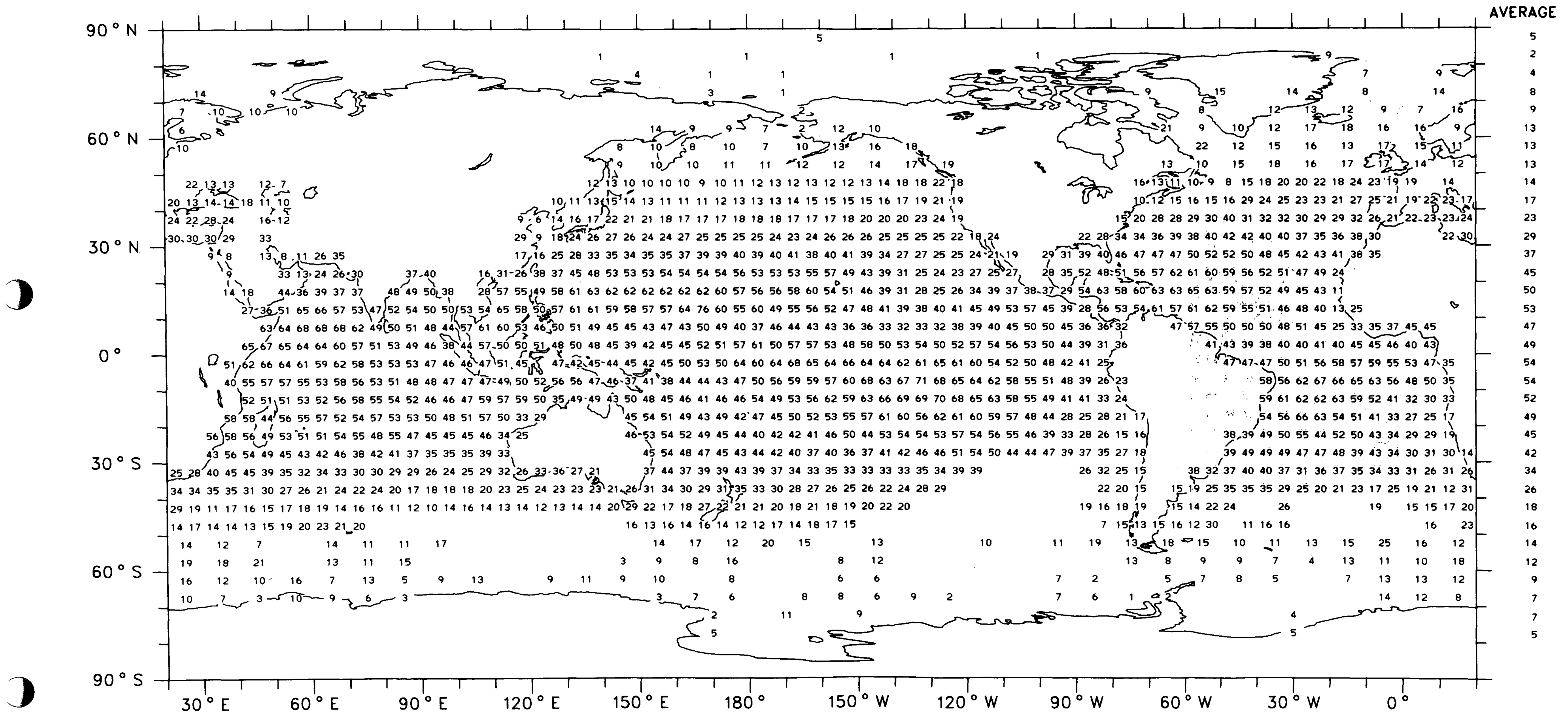

GLOBAL AVERAGE (OCEAN) $34 \%$

Map 29 
Cumulus

Frequency of Occurrence (\%)

June, July, August (1952-1981)

Ocean Areas Only

ZONAL

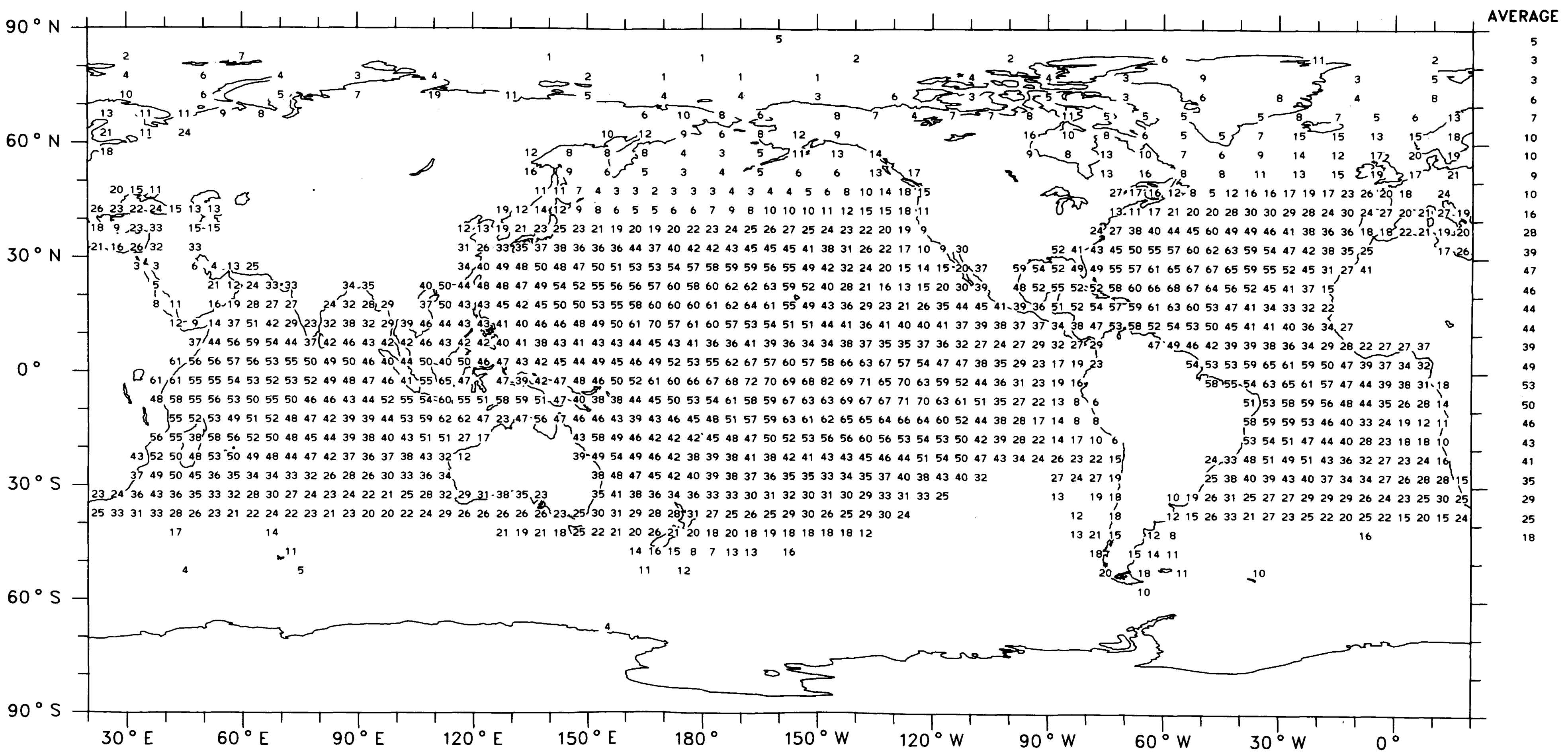

Map 30

GLOBAL AVERAGE (OCEAN) $33 \%$ 


\section{Cumulus}

\section{Frequency of Occurrence (\%)}

September, October, November (1952-1981)

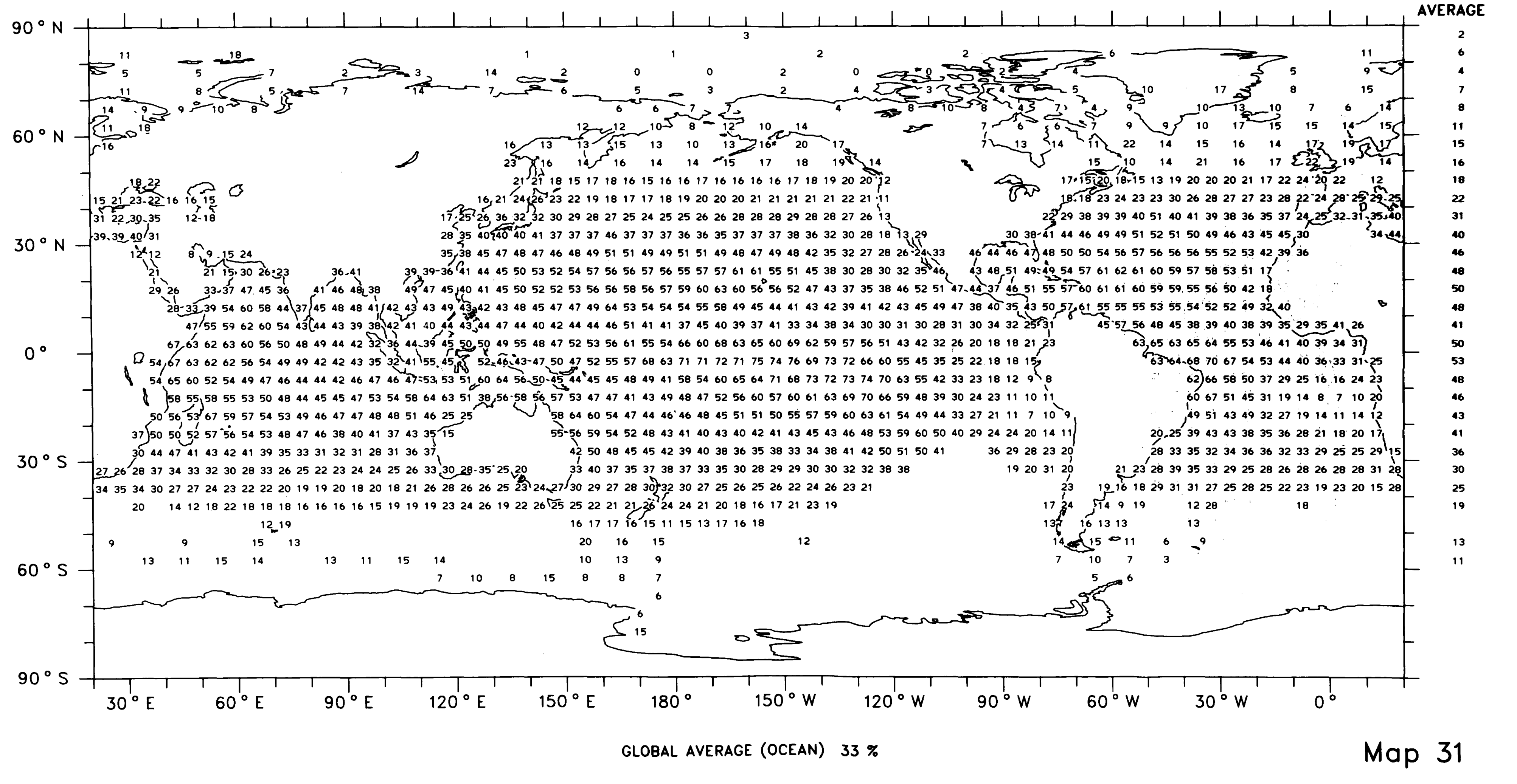




\section{Cumulus}

\section{Amount-When-Present (\%)}

December, January, February (1952-1981)

Ocean Areas Only

ZONAL

AVERAGE

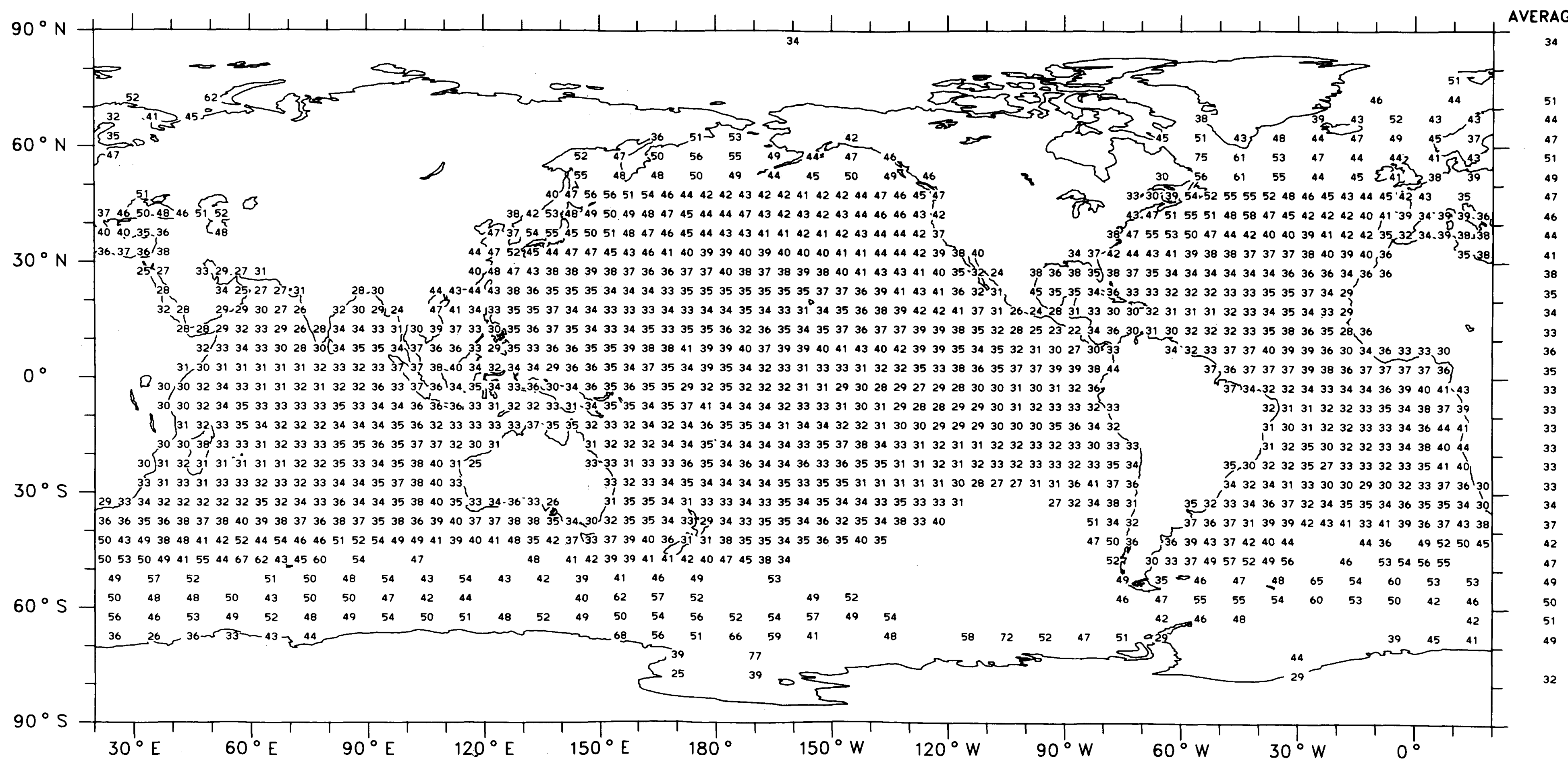

Map 32

GLOBAL AVERAGe (OCEAN) $38 \%$ 


\section{Cumulus}

\section{Amount-When-Present (\%)}

March, April, May (1952-1981)

Ocean Areas Only

ZONAL AVERAGE

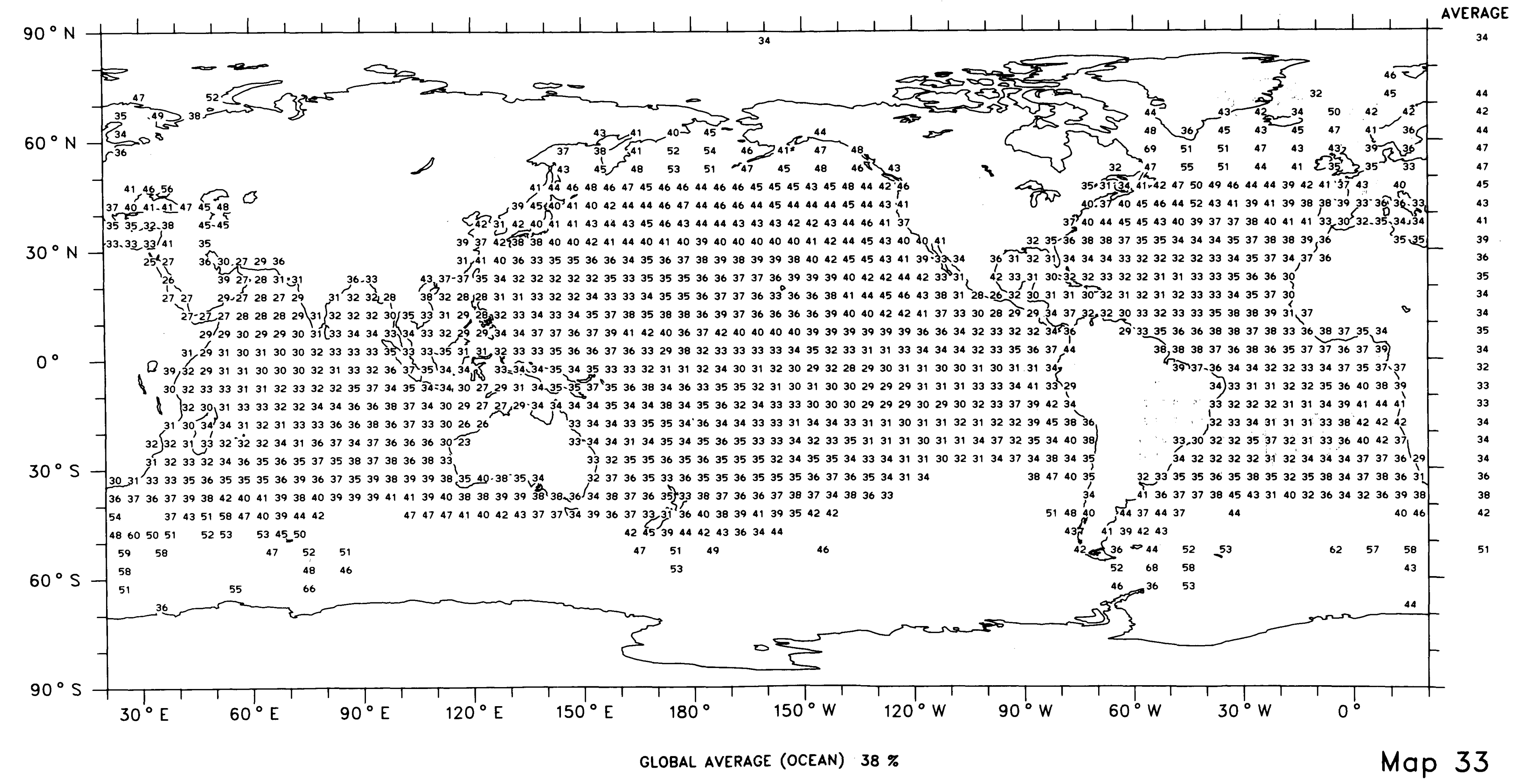


Cumulus

Amount-When-Present (\%)

June, July, August (1952-1981)

Ocean Areas Only

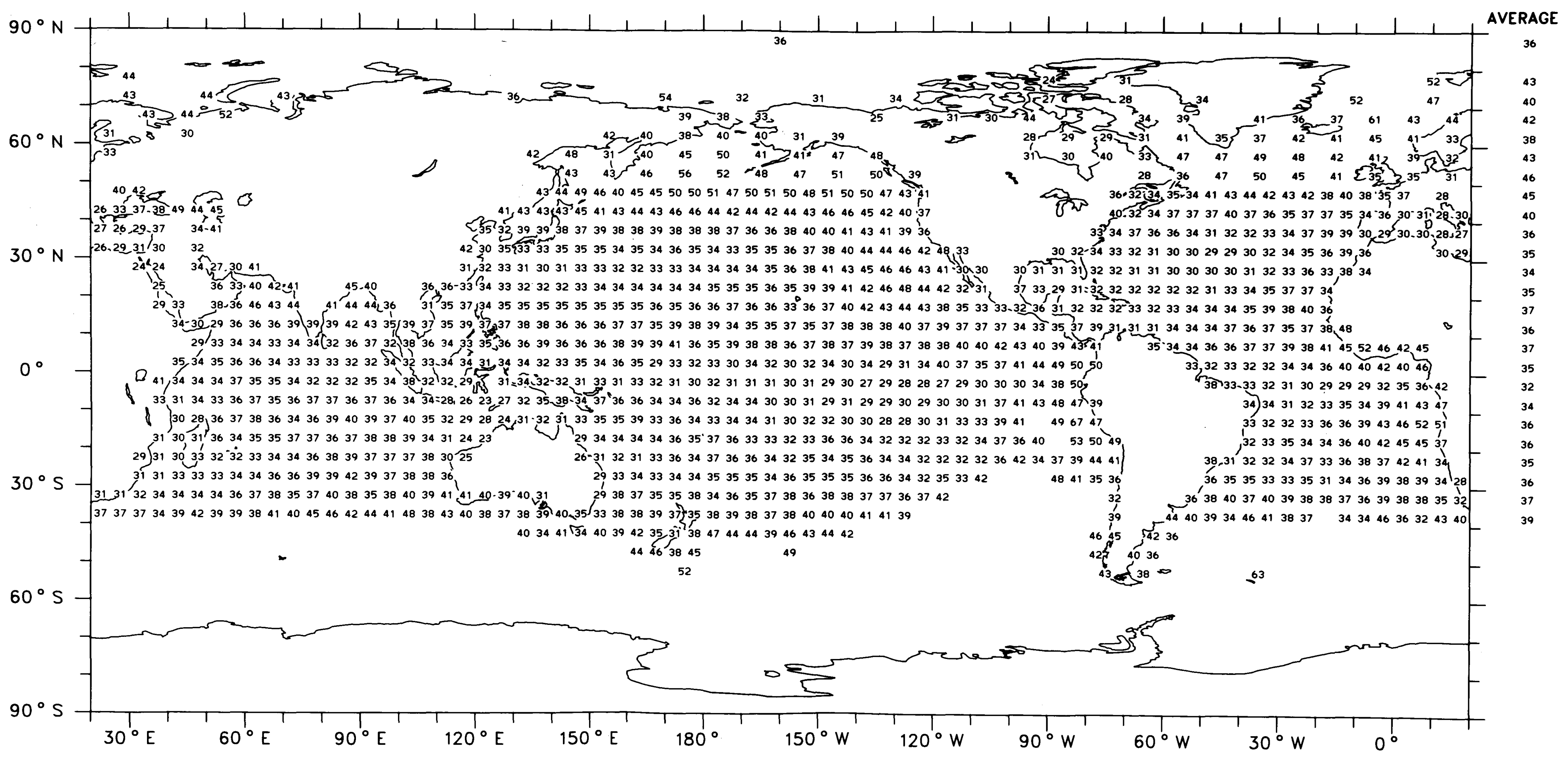

Map 34

GLOBAL AVERAGE (OCEAN) $38 \%$ 


\section{Cumulus}

\section{Amount-When-Present (\%)}

September, October, November (1952-1981) 
Cumulus

Average Cloud Amount (\%)

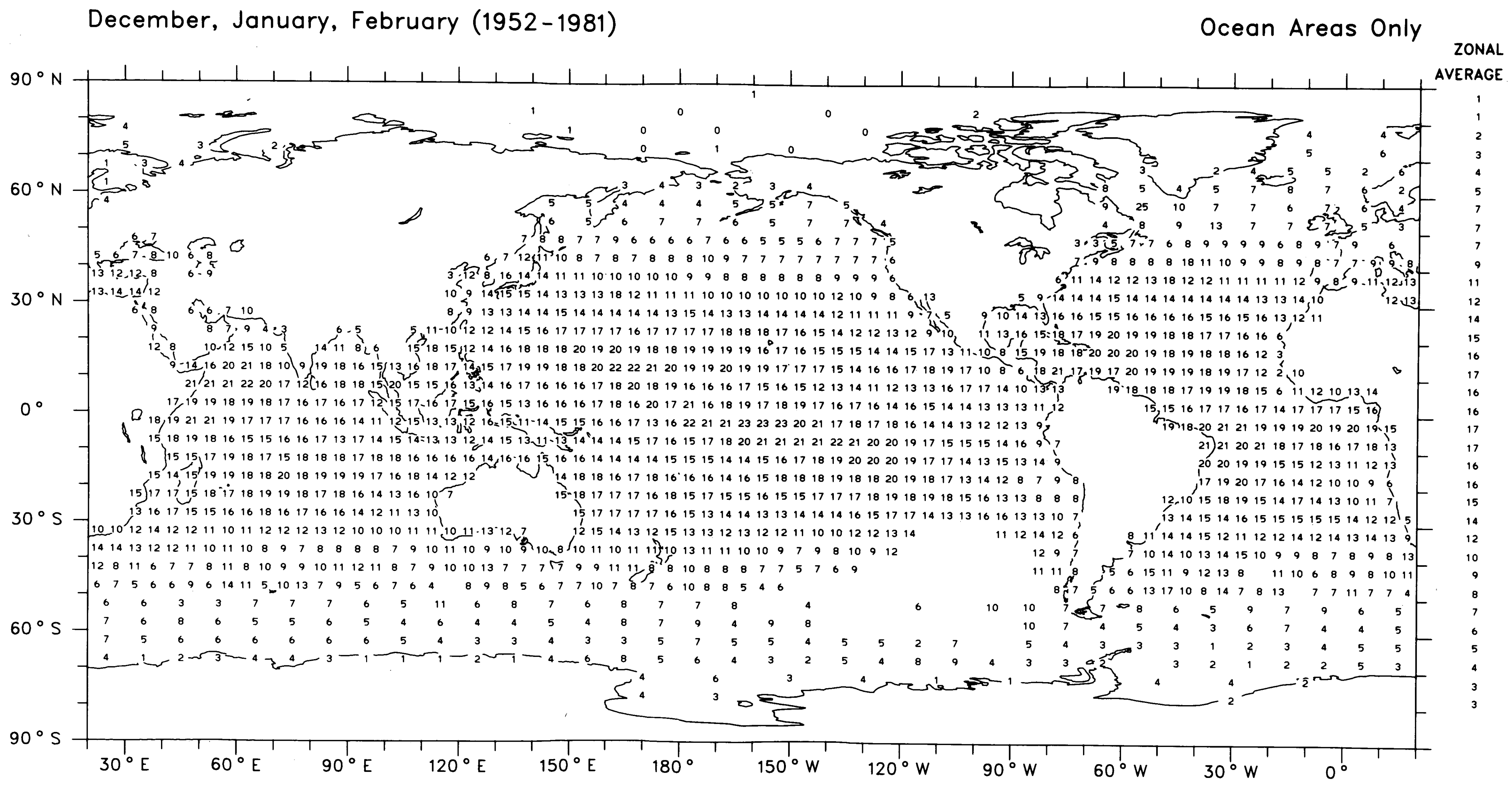

Map 36

global average (ocean) $12 \%$ 


\section{Cumulus}

\section{Average Cloud Amount (\%)}

March, April, May (1952-1981)

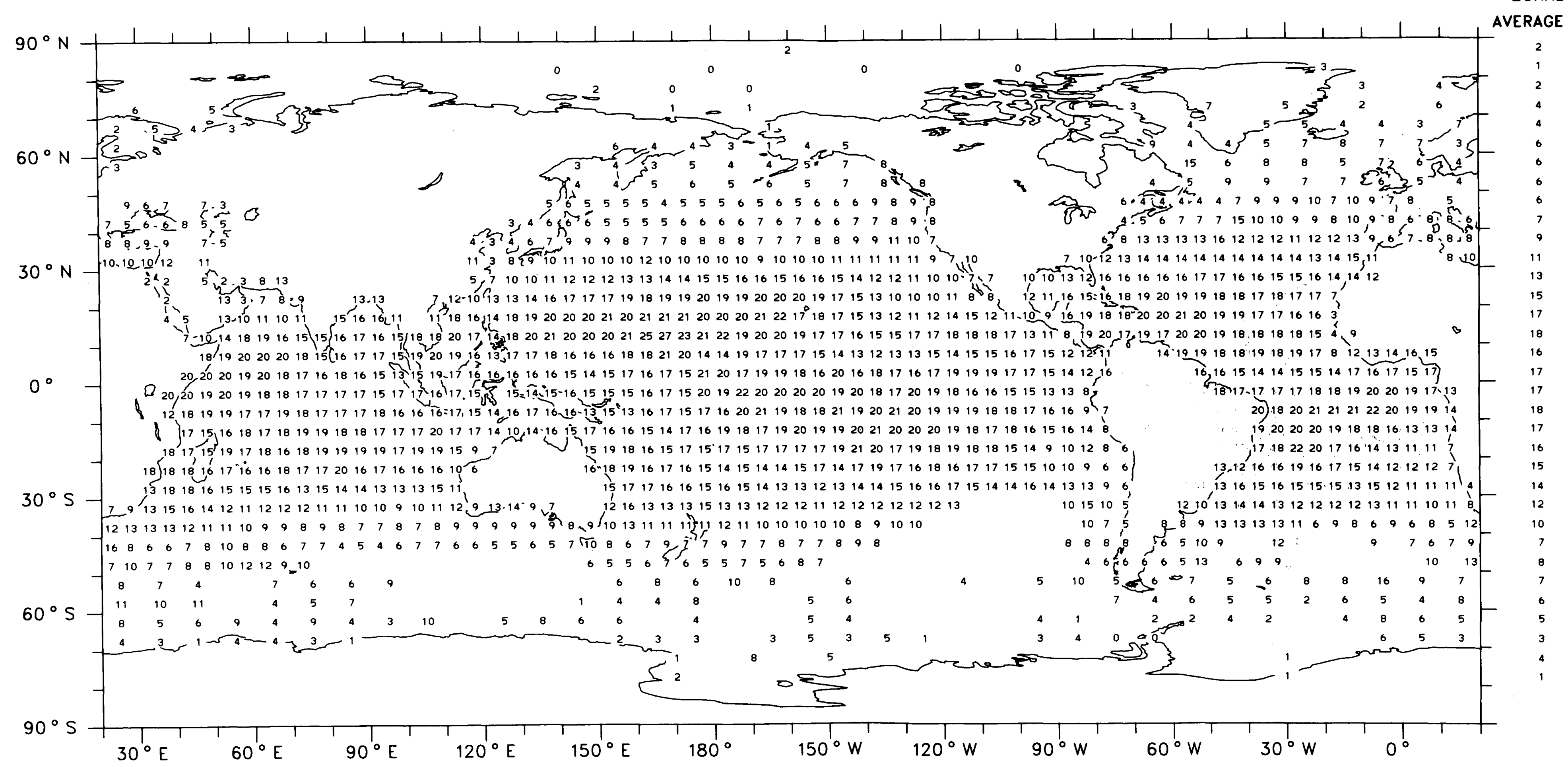


Cumulus

Average Cloud Amount (\%)

June, July, August (1952-1981)

Ocean Areas Only

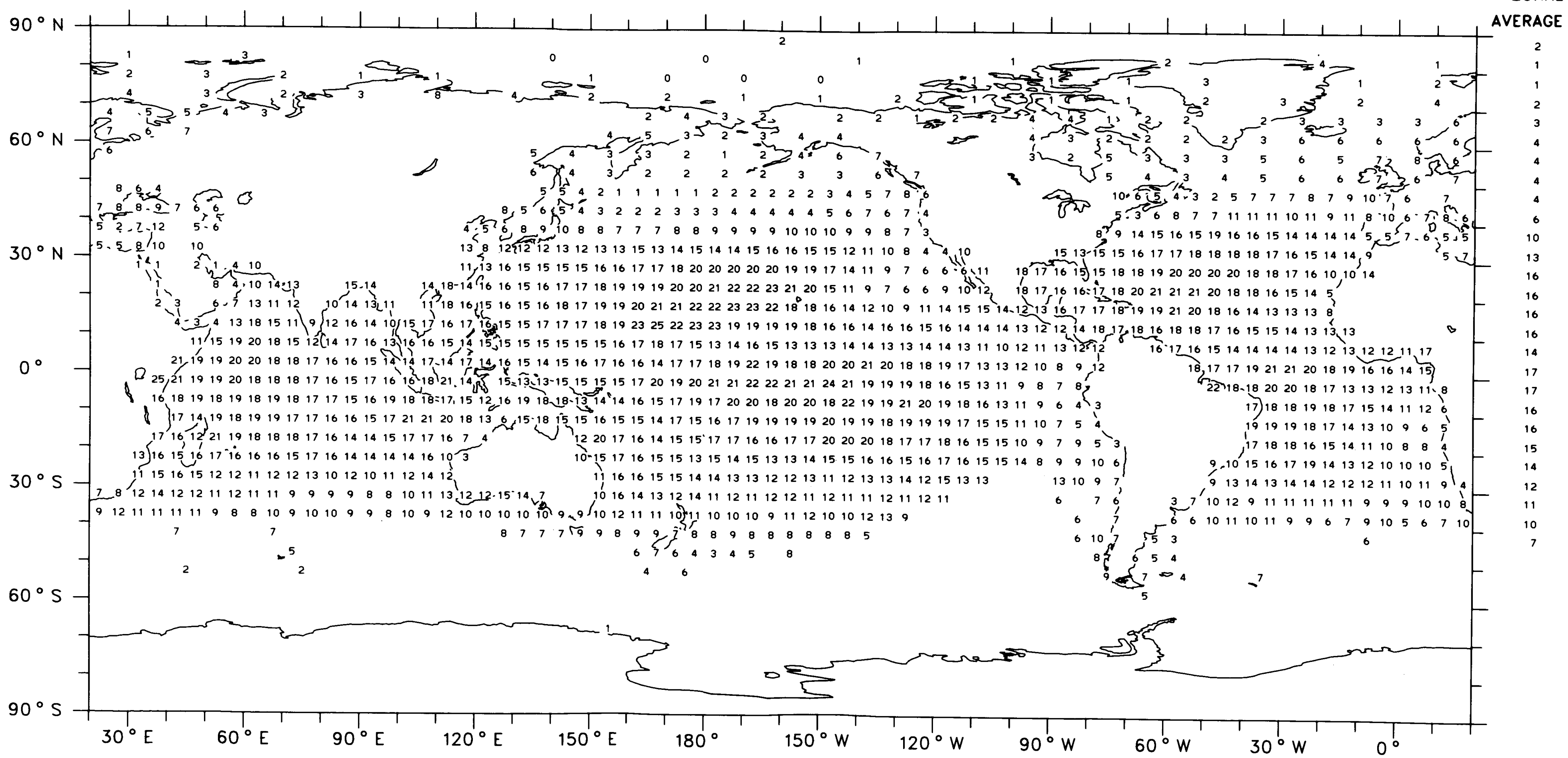

Map 38

GLOBAL AVERAGE (OCEAN) $12 \%$ 


\section{Cumulus}

\section{Average Cloud Amount (\%)}

September, October, November (1952-1981)

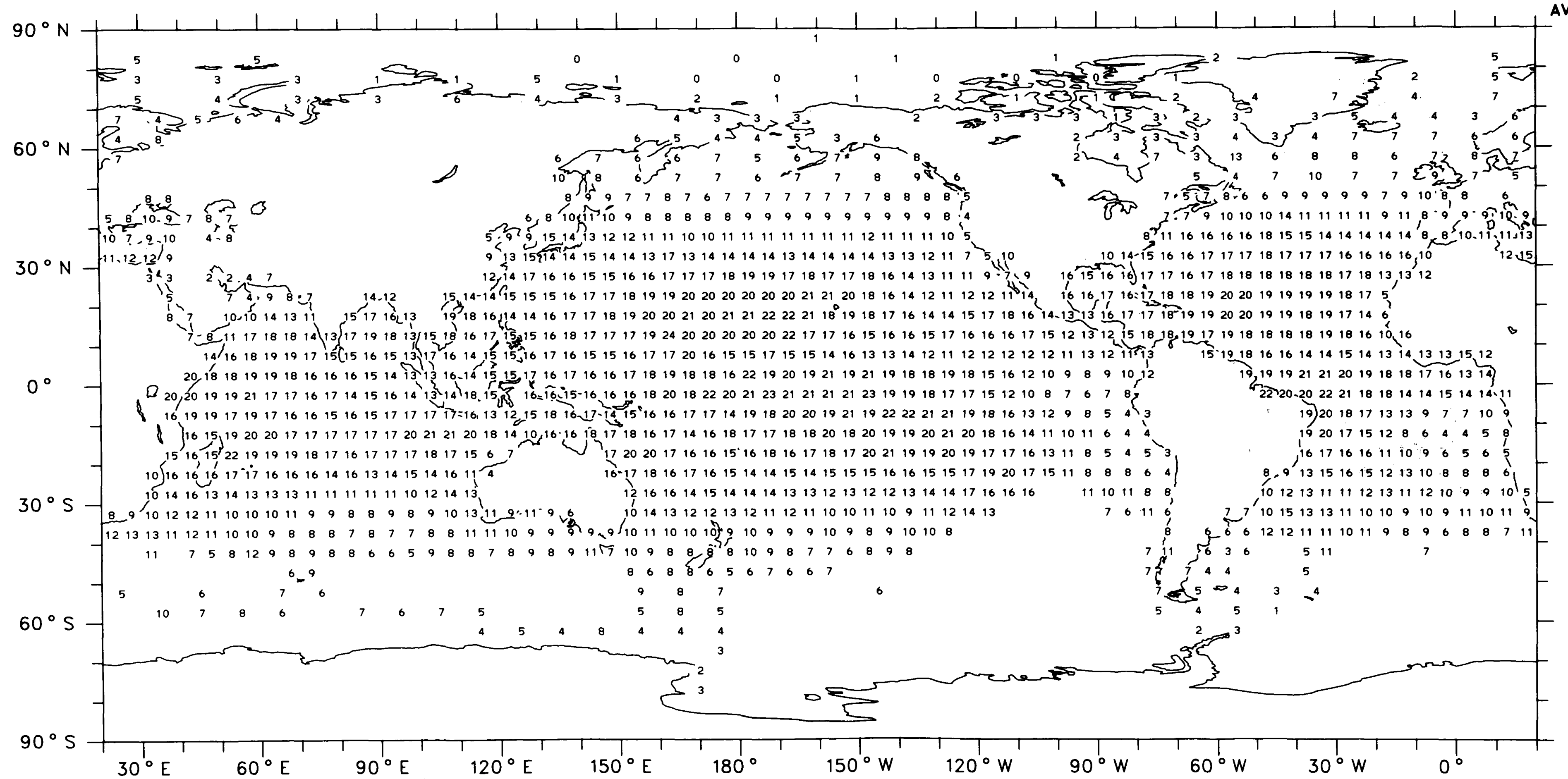


Cumulonimbus

Frequency of Occurrence (\%)

December, January, February (1952-1981)

Ocean Areas Only

ZONAL

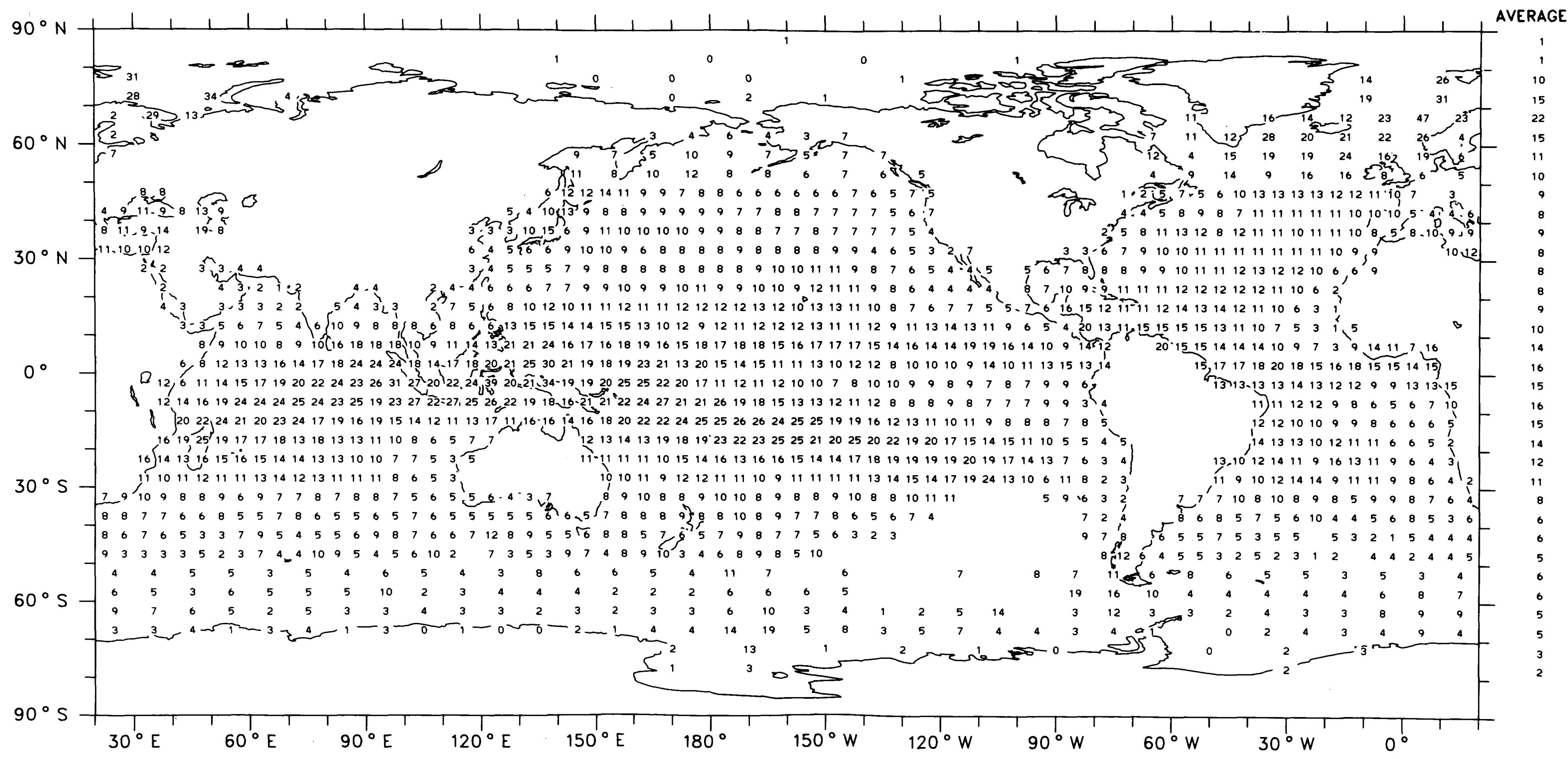

Map 40

global average (ocean) $10 \%$ 


\section{Cumulonimbus}

\section{Frequency of Occurrence (\%)}

March, April, May (1952-1981)

Ocean Areas Only

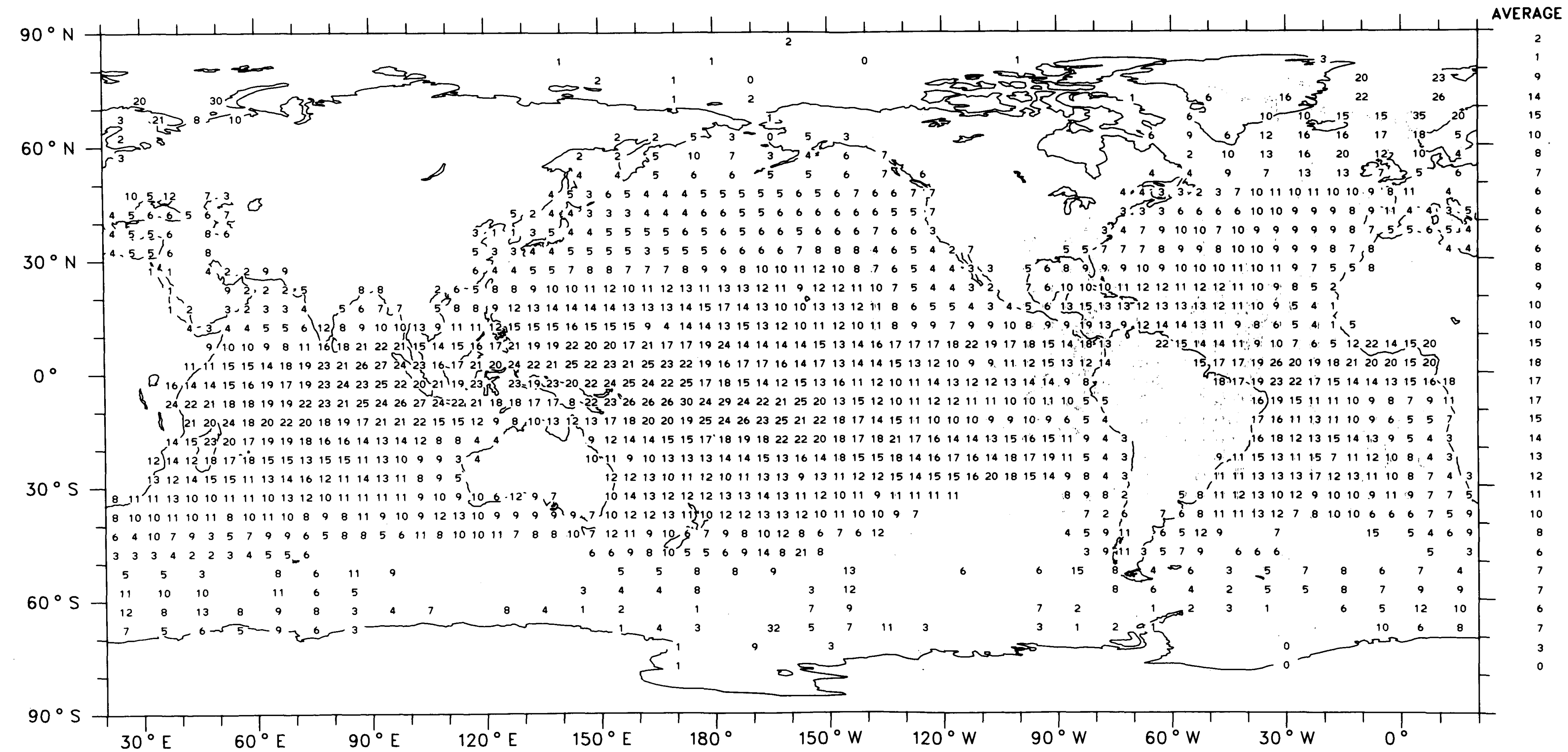




\section{Cumulonimbus}

\section{Frequency of Occurrence (\%)}

June, July, August (1952-1981)

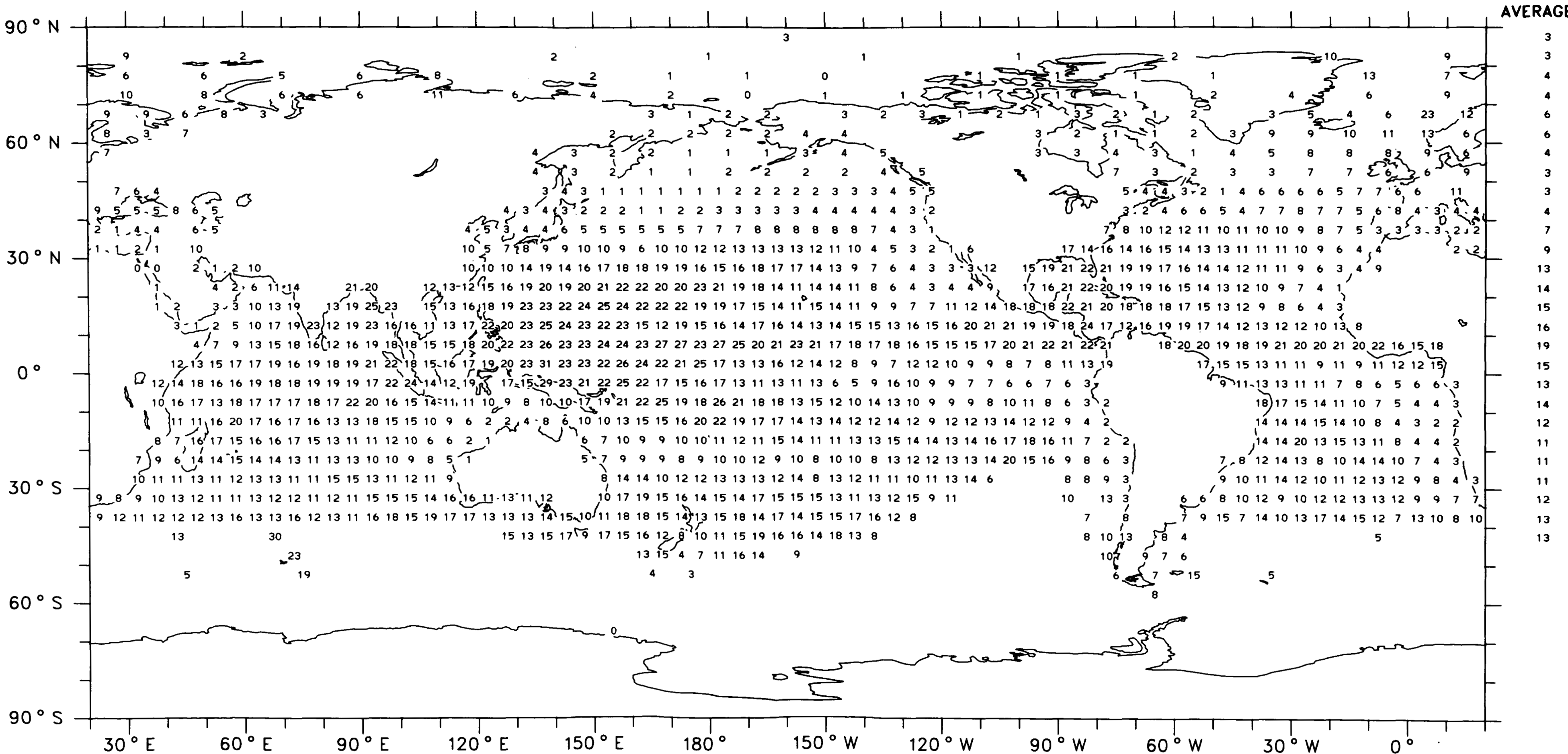


Cumulonimbus

Frequency of Occurrence (\%)

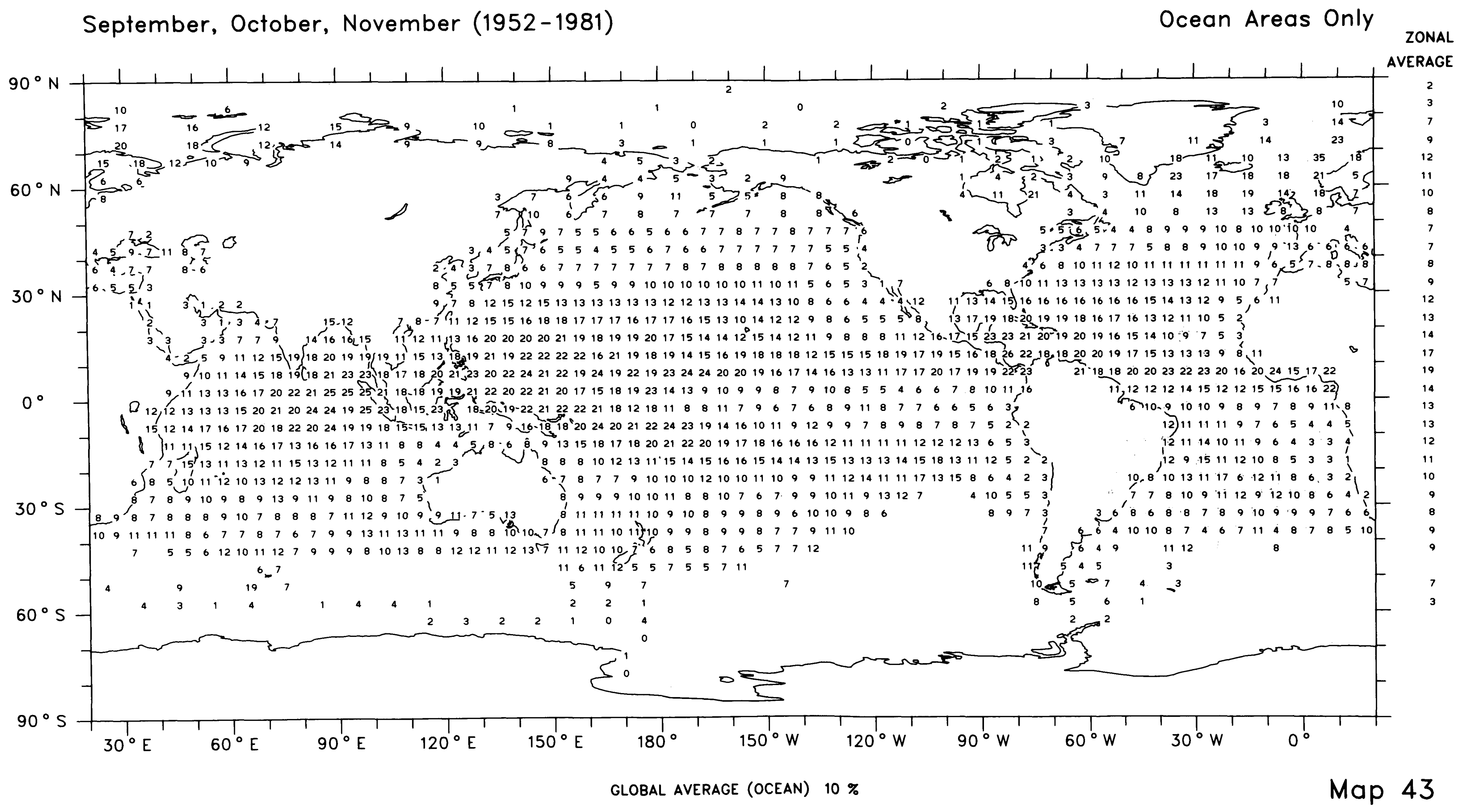




\section{Cumulonimbus}

Amount-When-Present (\%)

December, January, February (1952-1981)

Ocean Areas Only

ZONAL

AVERAGE

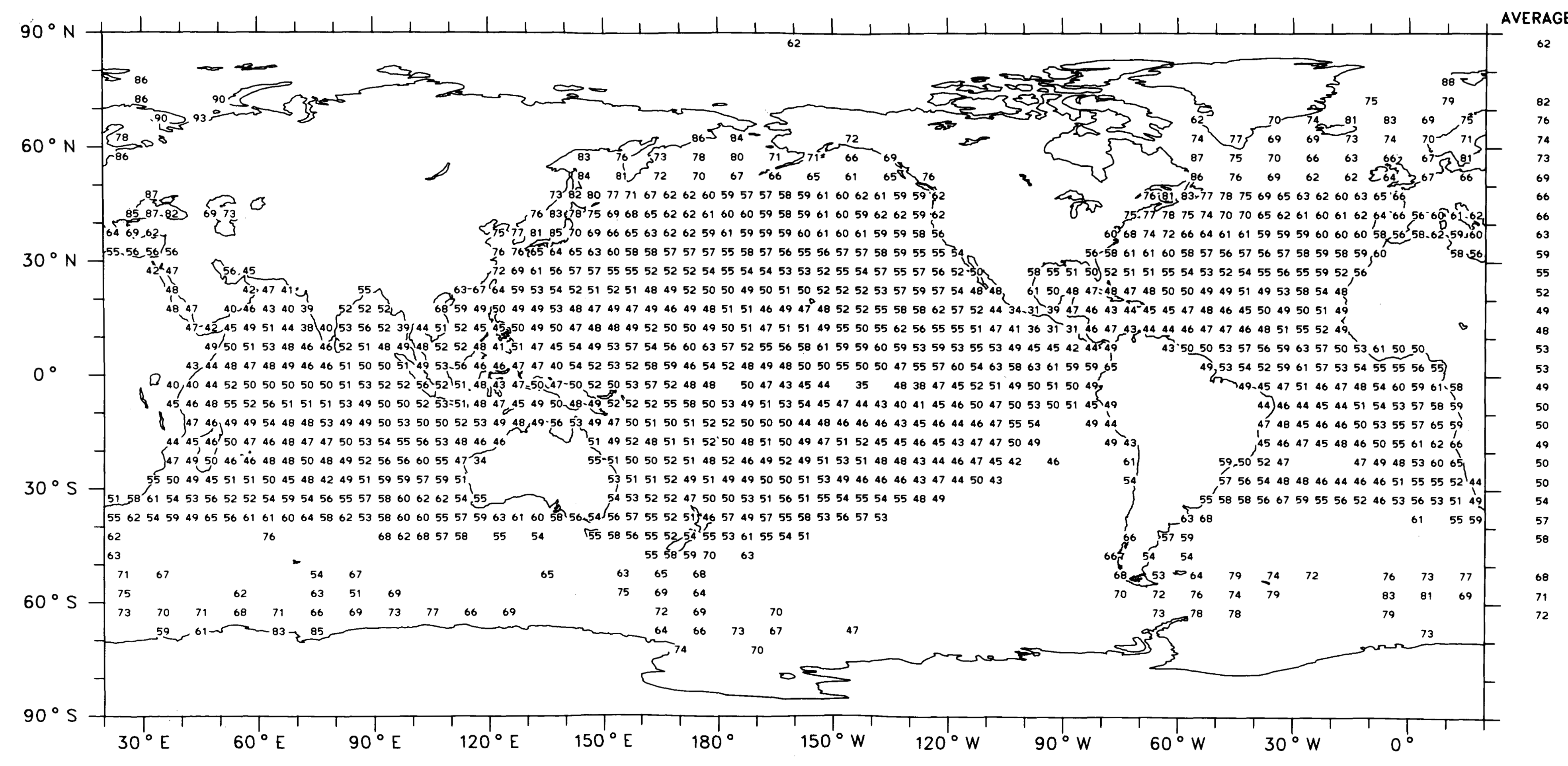

Map 44

global average (OCEAN) $57 \%$ 


\section{Cumulonimbus}

\section{Amount-When-Present (\%)}

March, April, May (1952-1981) 


\section{Cumulonimbus}

\section{Amount-When-Present (\%)}

June, July, August (1952-1981)

Ocean Areas Only

ZONAL

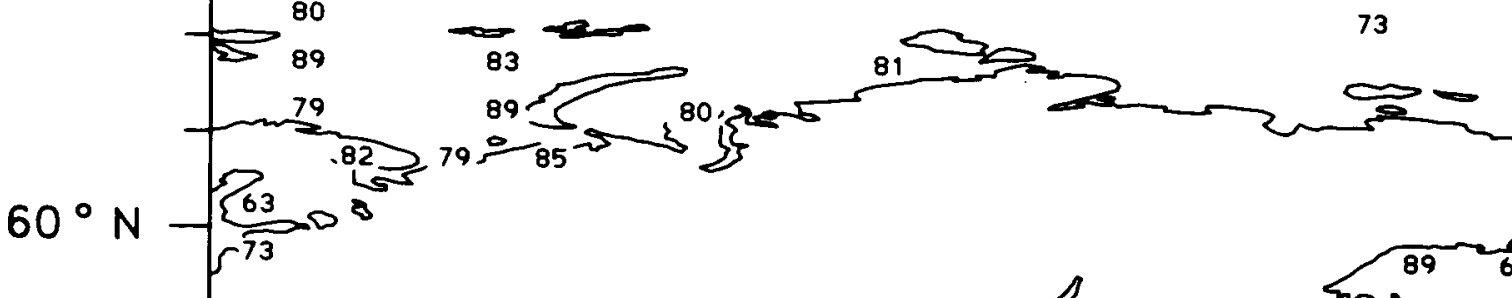

$59 \sum$

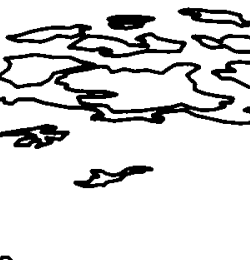
ती $797966 \quad 6867 \quad 78 \quad 76 \quad 70 \quad 67 \quad 68 \quad 658768$

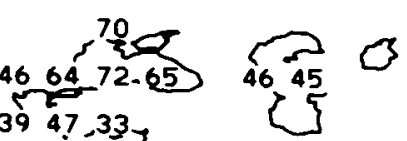
$30^{\circ} \mathrm{N}-\left[\begin{array}{ccc}39 & 47.33 \\ -41.43 & 46\end{array}\right]$ $71764727665656867656766626461636564676560620 \%$

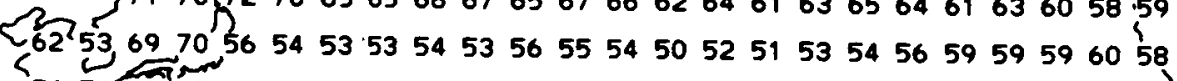
54544847504847474547504745464647475054555861626657 $45,44454342424242434343434345434346495155565962686760 \% 4$

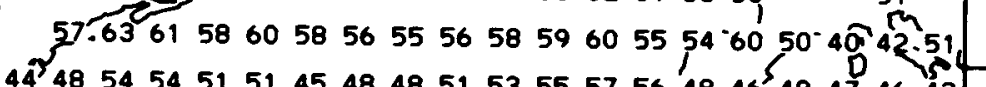
$44485451514548485153555756 \quad 48,46 \quad 48.47,46542$ $3440-4645444544434344454854555556,56$ AVERAGE 5146

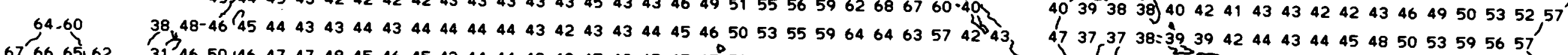

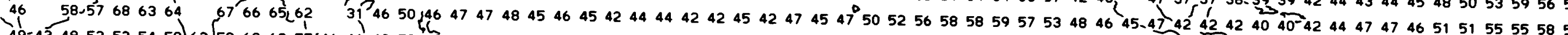

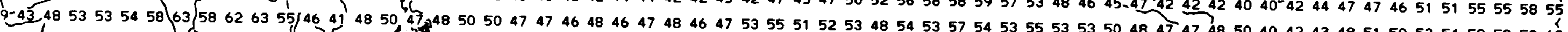

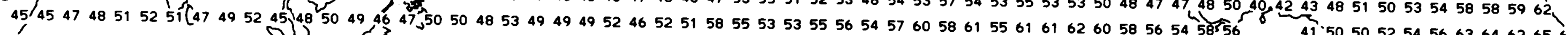

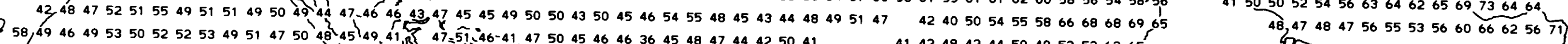
\$ $564749525560555453555353525045=41,3737425156,4147504546463645484744425041 \quad 4142484244504953536265$ ?

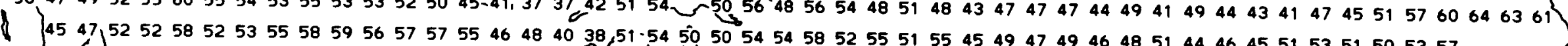
$4946-5951535461555658545657545844$ (2)

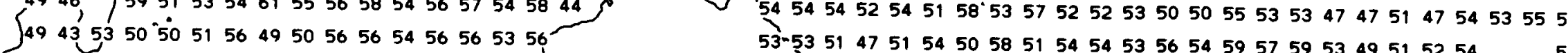
$30^{\circ} \mathrm{S}-\begin{aligned} 5344515053515555555556595755545454 \\ 54545352525553575554565661565957565557 \\ 57\end{aligned}$ $565349505348475750525051515553525351505548 \quad 5055565464$ $46-48494646414746575359$
55554495345515459746065
5154504952555765697870 51525753464956606869 ! $64.535348 \quad 545155616159$ 65535354535254525554545452152

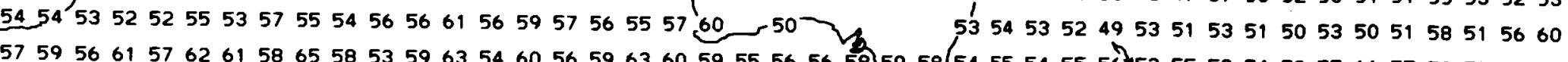
60 $58535963546056596360595556565859,585455545556) 53555354535561555052$

$$
\begin{array}{r}
52595954575758,566067 \\
-84 \\
{ }_{88}
\end{array}
$$

$60^{\circ}$

$90^{\circ}$

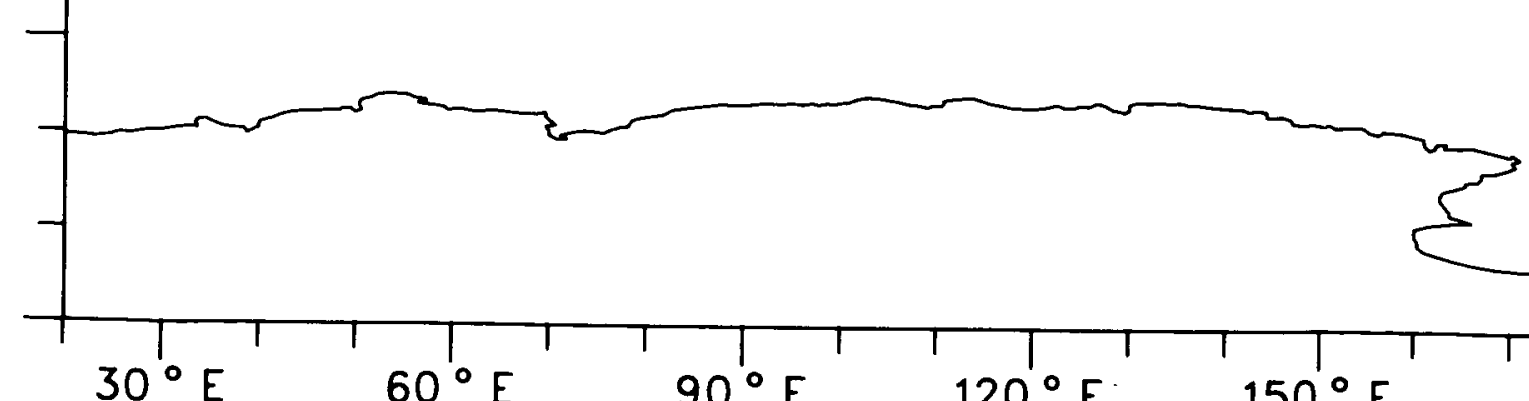

\section{Map 46}


Cumulonimbus

Amount-When-Present (\%)

September, October, November (1952-1981)

Ocean Areas Only

ZONAL

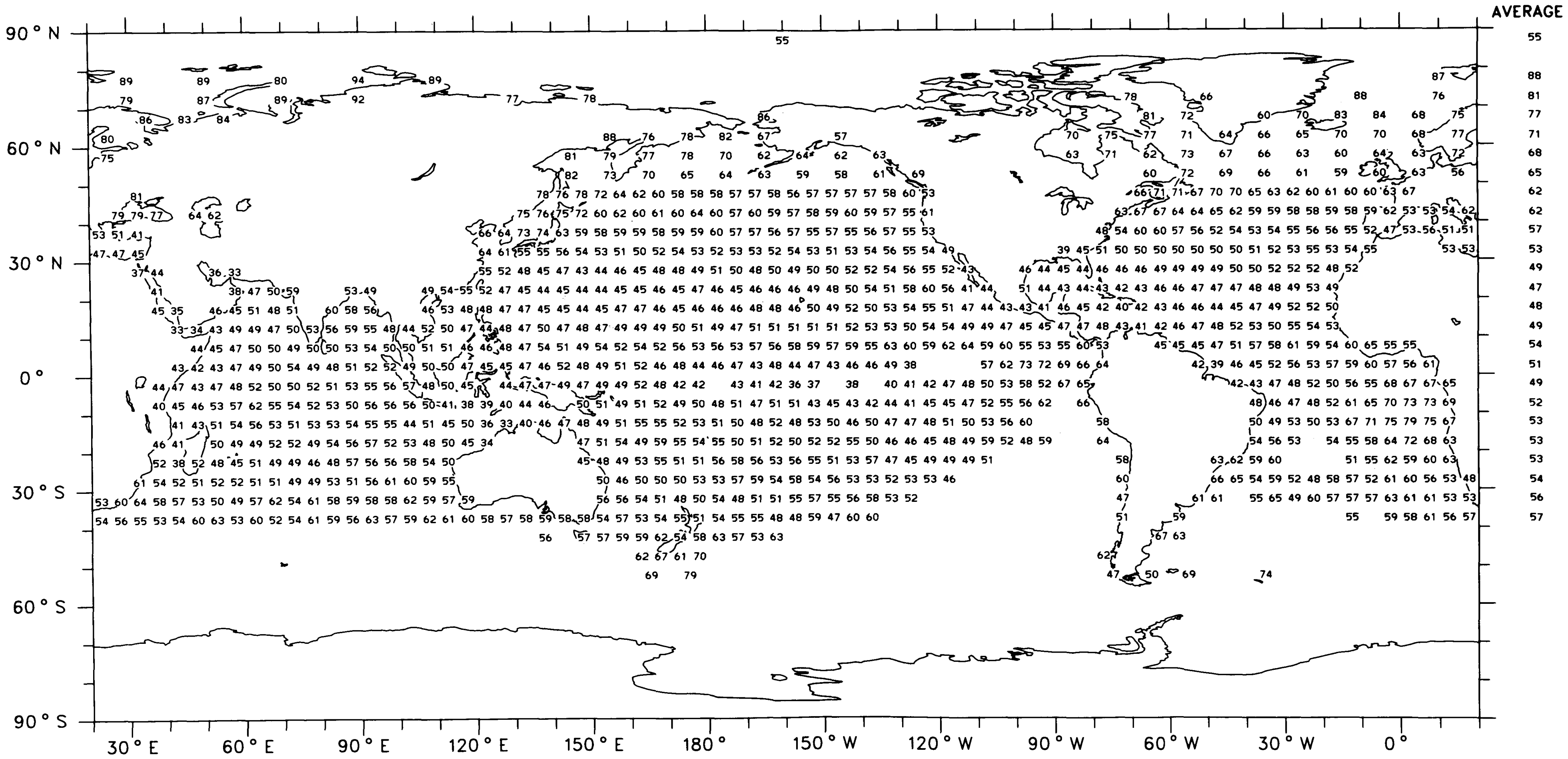

global AVERAGe (OCEAN) $56 \%$

Map 47 


\section{Cumulonimbus}

\section{Average Cloud Amount (\%)}

December, January, February (1952-1981)

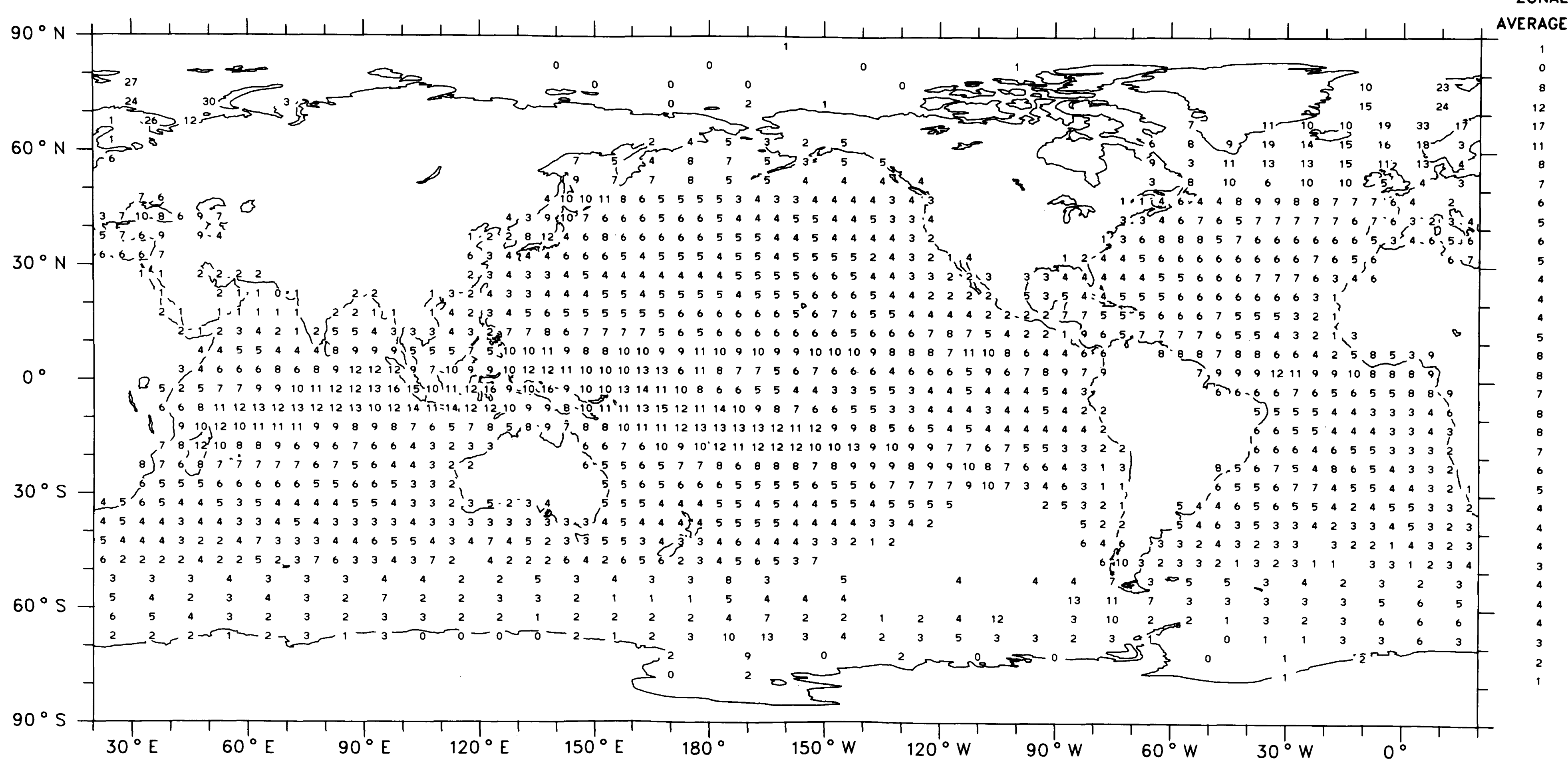




\section{Cumulonimbus}

\section{Average Cloud Amount (\%)}

March, April, May (1952-1981)

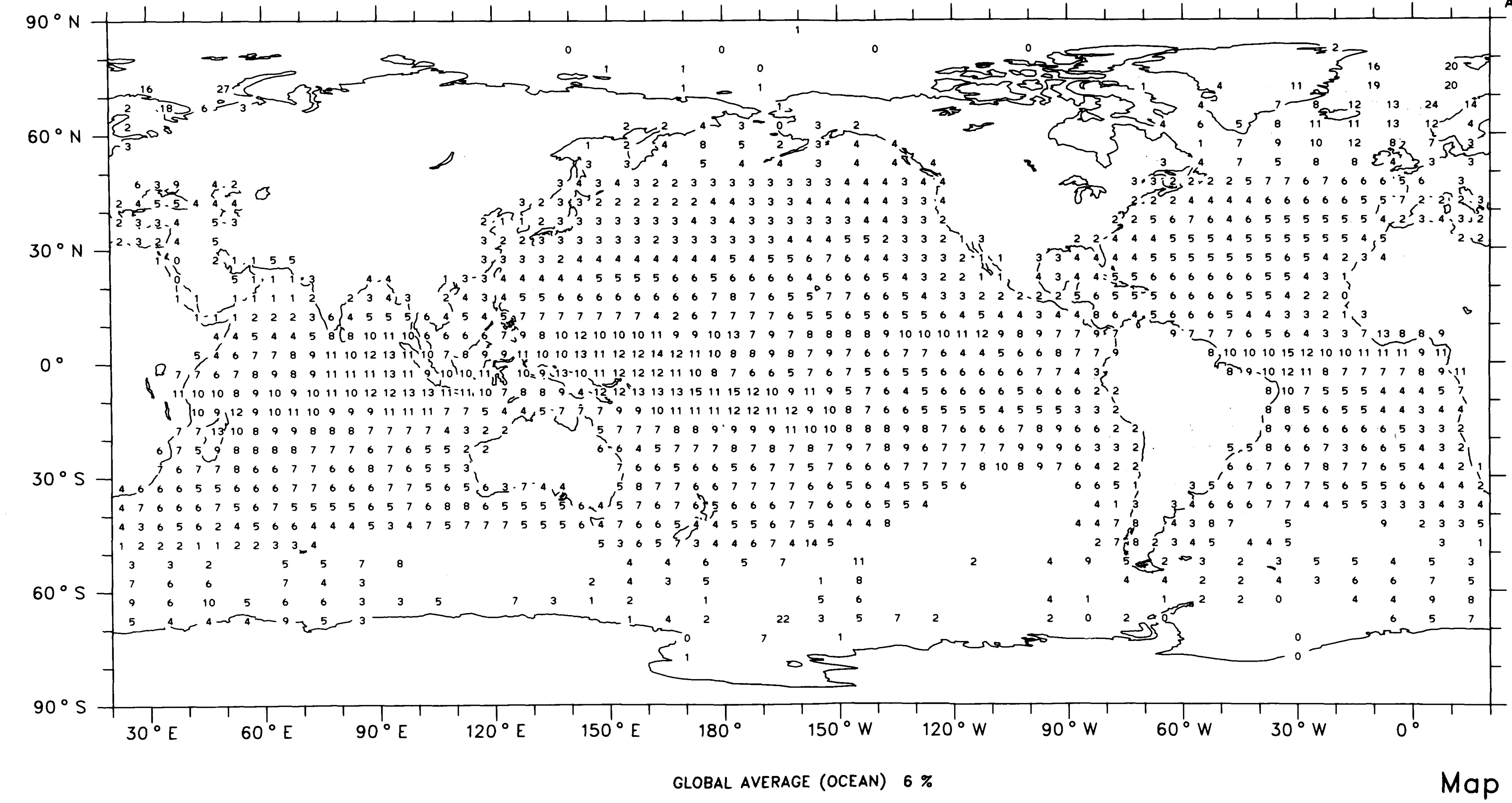




\section{Cumulonimbus}

\section{Average Cloud Amount (\%)}

June, July, August (1952-1981)

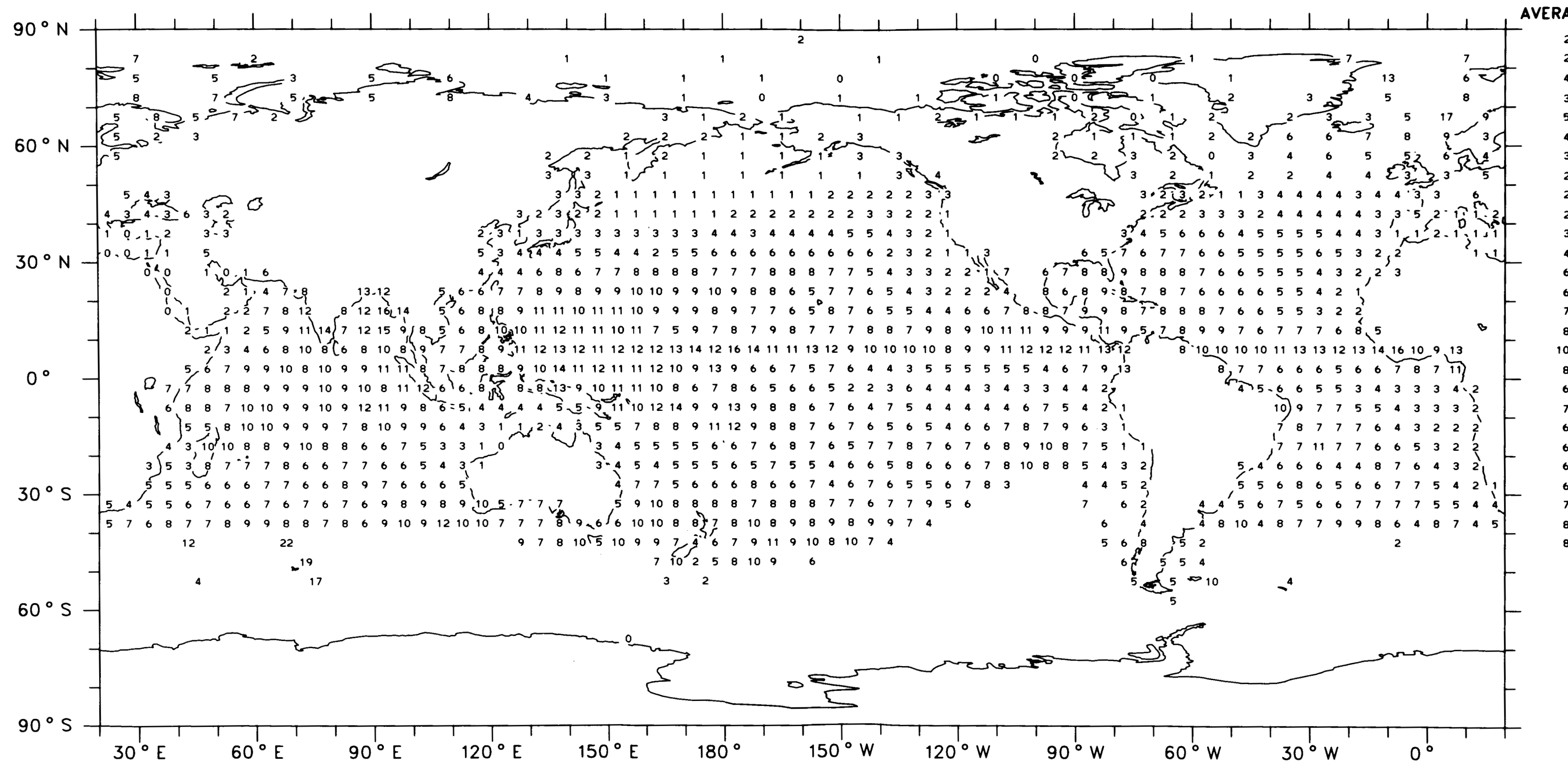




\section{Cumulonimbus}

\section{Average Cloud Amount (\%)}

September, October, November (1952-1981)

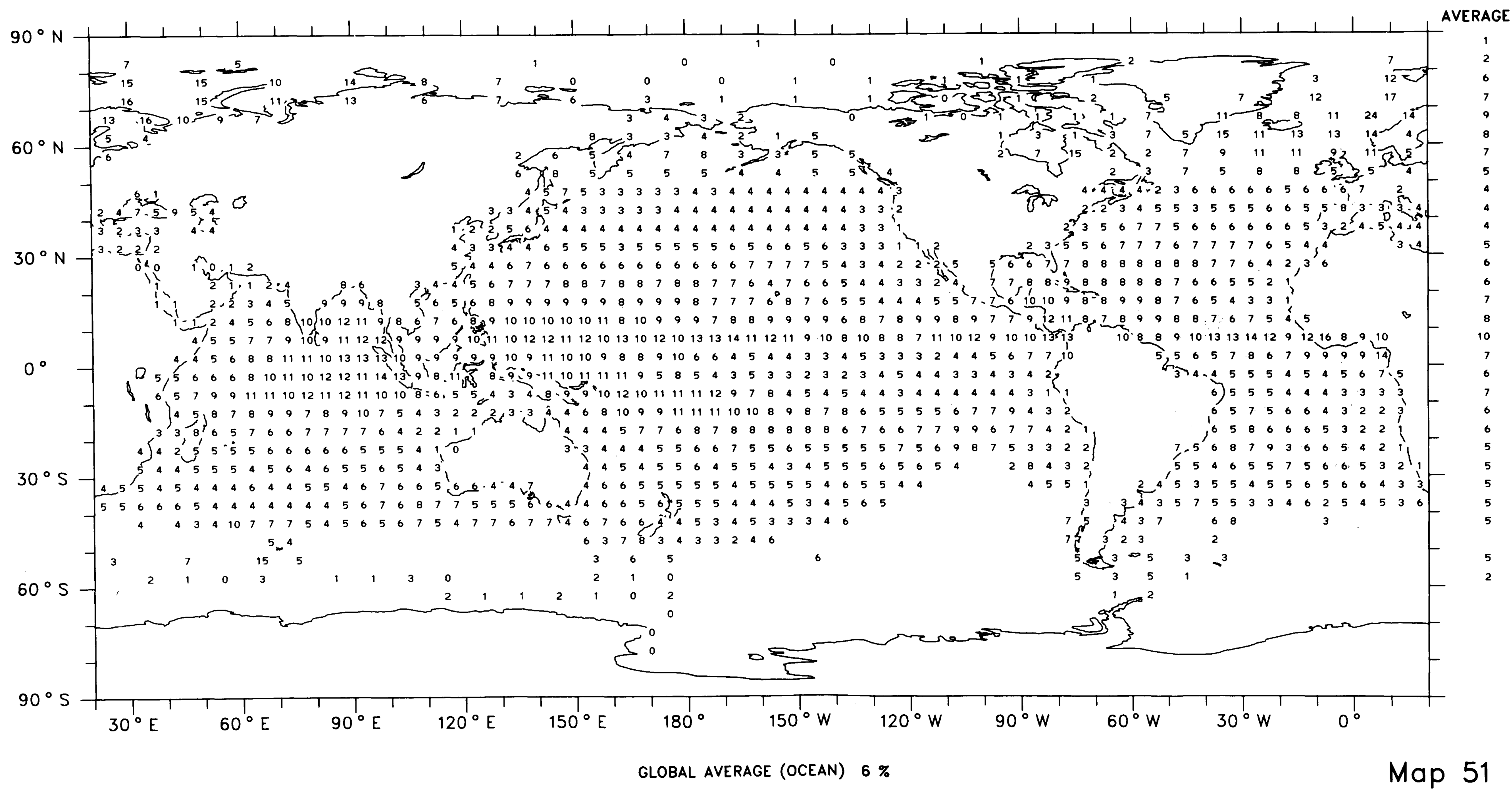




\section{Stratus + Stratocumulus + Fog}

Frequency of Occurrence (\%)

December, January, February (1952-1981) 


\section{Stratus + Stratocumulus + Fog}

\section{Frequency of Occurrence (\%)}

March, April, May (1952-1981) 


\section{Stratus + Stratocumulus + Fog}

Frequency of Occurrence (\%)

June, July, August (1952-1981)

Ocean Areas Only

ZONAL AVERAGE

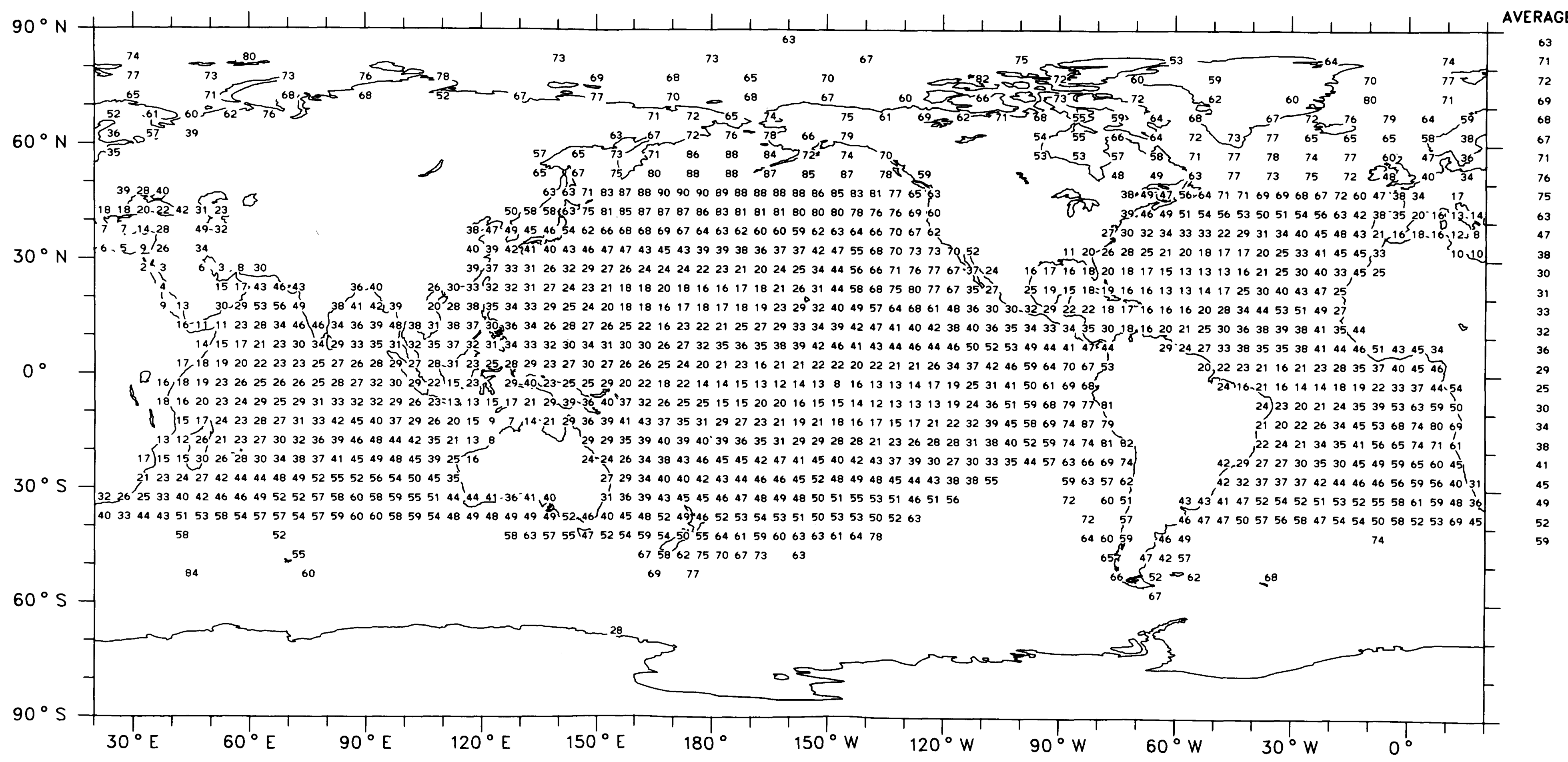

Map 54

global average (OCEAN) $45 \%$ 


\section{Stratus + Stratocumulus + Fog}

Frequency of Occurrence (\%)

September, October, November (1952-1981)

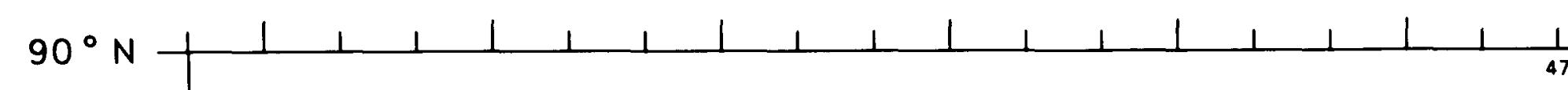

$$
\begin{array}{lll}
1 & 1 \\
47 & & 1
\end{array}
$$
$65 \approx \frac{66}{63}$ $47 \quad 51$ 70
72 70 435

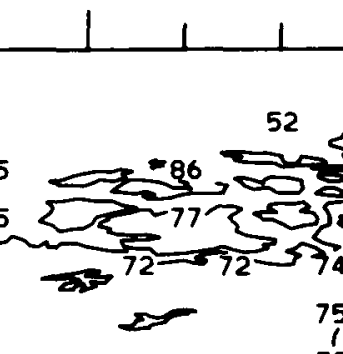
$253-64572-\frac{71}{72} 67,62$ $60^{\circ} \mathrm{N}$

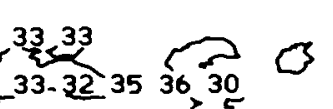
$30^{\circ} \mathrm{N}-17,14,13 / 16$ $\begin{array}{ll}16,11,17 & 44-32 \\ 14-13 / 16 & 0\end{array}$

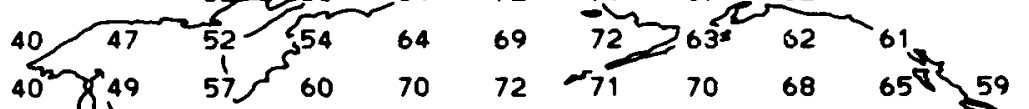
${ }_{33}^{4} \int_{42}^{49} 48596770727373727171707069696868 \quad 6557 \quad 5075$ 3234 43 526469717172706867676766666566666557,52 (1) 43.4741363943484847434949474948494747474548605860564935 2

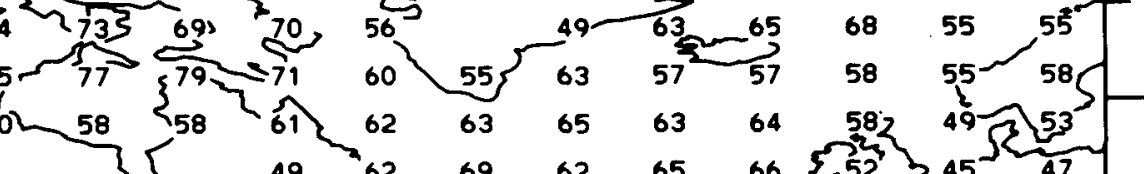
(10 Co.50047 $53.59636463636362696054 \cdot 4548 \quad 33$ चेग $41.455054555556565455556043 \quad 42 \cdot 3728.27 \% 28.28$ 33 $38414242403240404142454638 \quad 27,266^{6} 26.28,24 J 21$

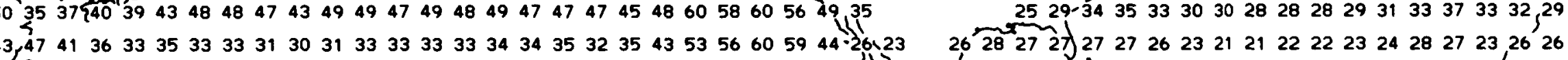
$\begin{array}{llllllllll} & \end{array}$

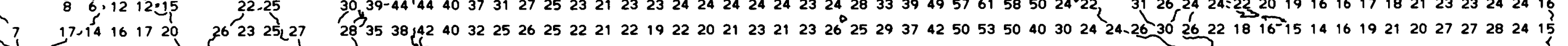

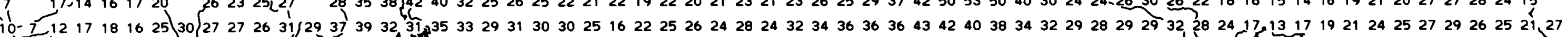

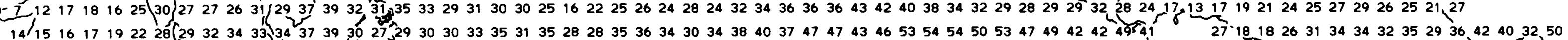
D

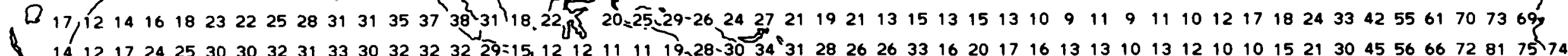
$1412172425303032313330323232 \quad 29=15,1212111119,28-30034312826263316201716131310131210101521304556 \quad 6672817574$ 1) 111620282829323937373331312914118 8 11 10.12 20 24 283432363528282724221921201915131419243646566262818471 1510191524252931333838373737341479 .

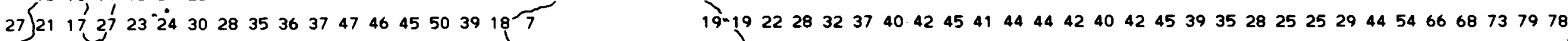 40434650545660606162636666636561646258494951525050,4344495454477455056616061586260606259 $5 9 7 2 6 7 6 4 6 1 6 6 6 0 6 0 6 8 6 7 7 1 6 9 7 0 6 3 6 3 6 6 6 4 5 8 5 6 6 4 5 8 5 4 \longdiv { 4 7 } 5 4 5 6 6 0 5 8,47^{7} 48576665687572666569$

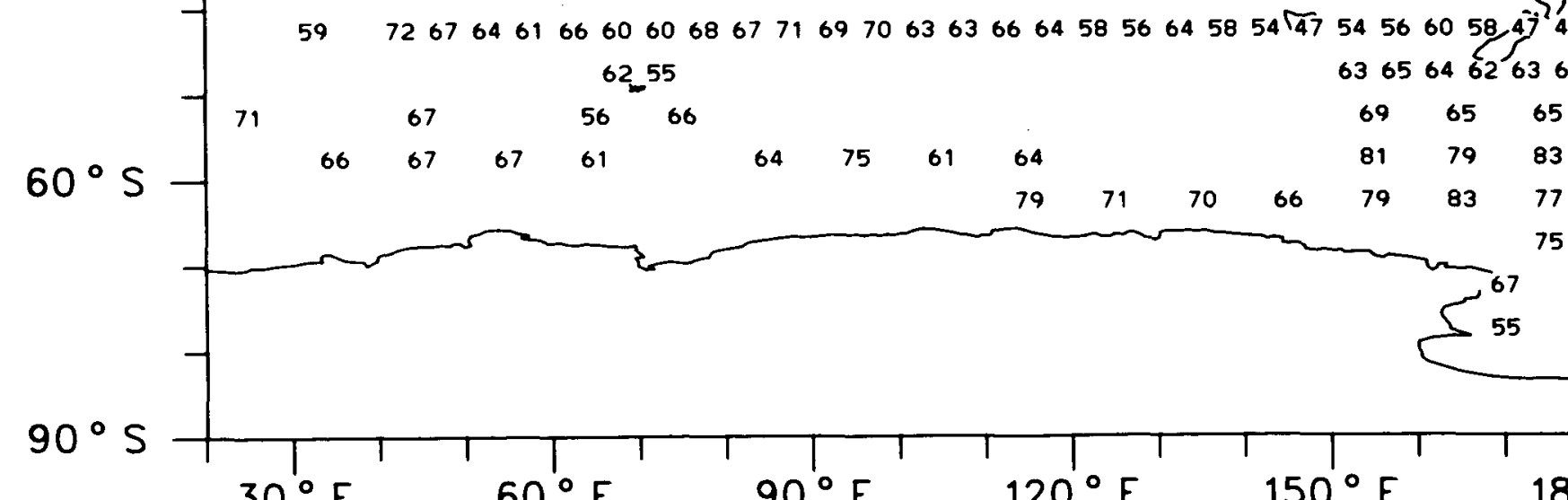
$69 \quad 65 \quad 65$ \begin{tabular}{lll}
79 & 83 & 77 \\
\hline
\end{tabular} 


\section{Stratus + Stratocumulus + Fog}

\section{Amount-When-Present (\%)}

December, January, February (1952-1981)

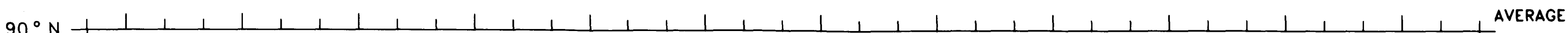

60

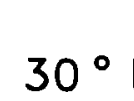

$\rho$

$\overbrace{85}^{85} \overbrace{79}^{80} \int_{863}^{80} 5_{87}^{80}-\sum_{86}^{86}$

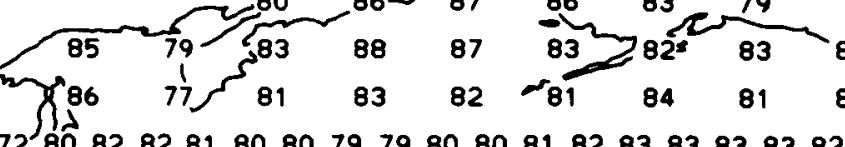

2279676778081808079798080818283838383828181

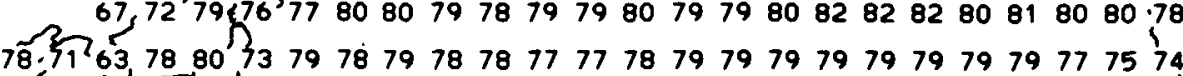
6777777272767674737072737273747474747373747275747064

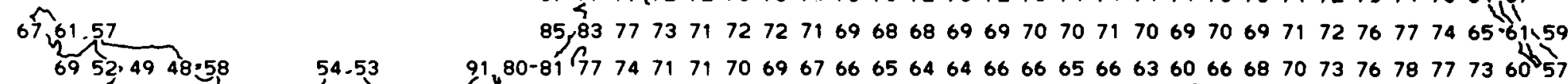

$\begin{array}{lllll} & \end{array}$

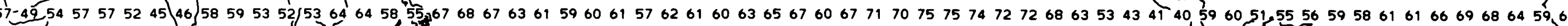

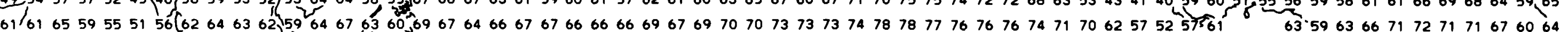

$0^{\circ} \quad 4655606563616163646465666669,70 \quad 5663,6773706770727071746566636863616066607167727272737474757778787777$

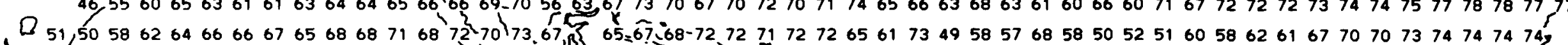

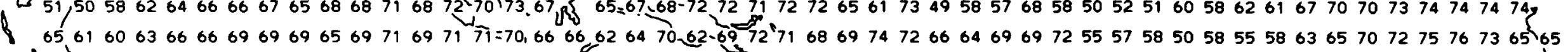

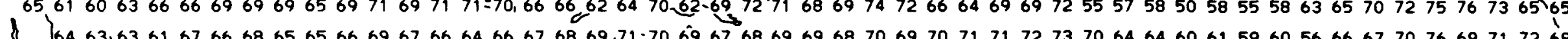
( 646363636167666865656669676664606768,6971706967686969687069707171727370646460615960566667707669717268 $6364,61,626262616269676669697368656368 \quad 7066687063676868687168676967726963626260616869706776777768$ $7 3 6 6 4 6 6 6 6 6 3 6 1 6 2 5 9 6 3 6 3 6 8 6 9 7 0 7 5 7 6 7 1 5 7 \longdiv { 5 1 }$

7169676866687071706975767175706666686361626468646877778581 7164656572716768686670717277797661

68696870726874737374757674757372696771656069686372768085

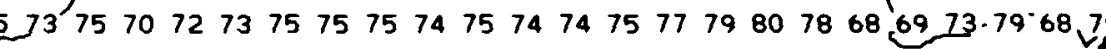
67697372697073737375777779767978737682

6771746580
777171

778180

59636671727171676064676662,50

65,697071757271686767626768

3763.59616261 $55) 5657606669727272727$ 5859626069747678808173 6559636565707479818278 70.676770575555656975787988 67687270666665646471747772 65646570767575697374717173767263 64676978737375787376767876807006 $-70747477757878797979818079828082807977757577767573,6872757776734677275798080828381827781$

$\begin{array}{llll}8786 & 88 & 87858379848284,7990868781797982 \quad 78 \quad 758276797972737680 \quad 888082838184858685\end{array}$

$60^{\circ} \mathrm{S}-\begin{array}{llllllllllllllllllll}87 & 89 & 89 & 88 & 87 & 80 & 85 & 80 & 81 & 81 & 80 & 79 & 79 & 78 & 84 & 84 & 77 & 81 & 87 \\ 86 & 85 & 87 & 86 & 85 & 86 & 87 & 83 & 83 & 85 & 86 & 83 & 82 & 92 & 87 & 86 & 83 & 84 & 92 & 90\end{array}$

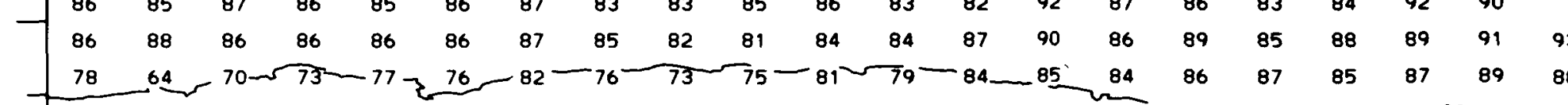
$\circ \mathrm{s}$ 1

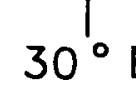

(1)

$$
\begin{array}{lll}
85 & 88 \\
87 & 85
\end{array}
$$$$
87 \quad 85 \quad 87
$$$$
84
$$$$
90^{89}
$$

93

89

$5_{58}^{74}$

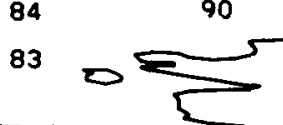

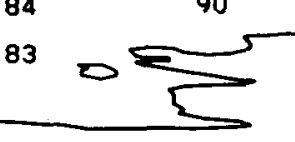

$92 \quad 89 \quad 87$

$78 \quad 86$

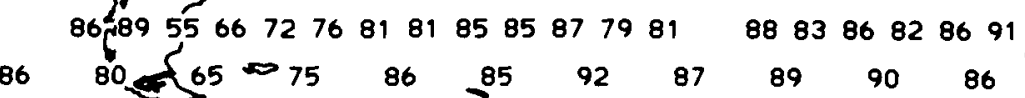

$87 \quad 81 \quad 86$

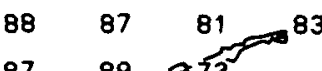

$\begin{array}{lllllll}90 & 90 & 88 & 88 & 90 & 89 & 88\end{array}$

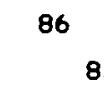

\begin{tabular}{lllll|}
88 & 85 & 78 & 87 & 80 \\
\hline
\end{tabular} ${ }_{75}^{83}$
$82 \quad 80 \begin{array}{lllllllll}82 & 86 & 96 & 85 & 92 & 87 & 89 & 90 & 86 \\ 80 & 88 & 88 & 90 & 89 & 80\end{array}$

\section{Map 56}




\section{Stratus + Stratocumulus + Fog}

\section{Amount-When-Present (\%)}

March, April, May (1952-1981)

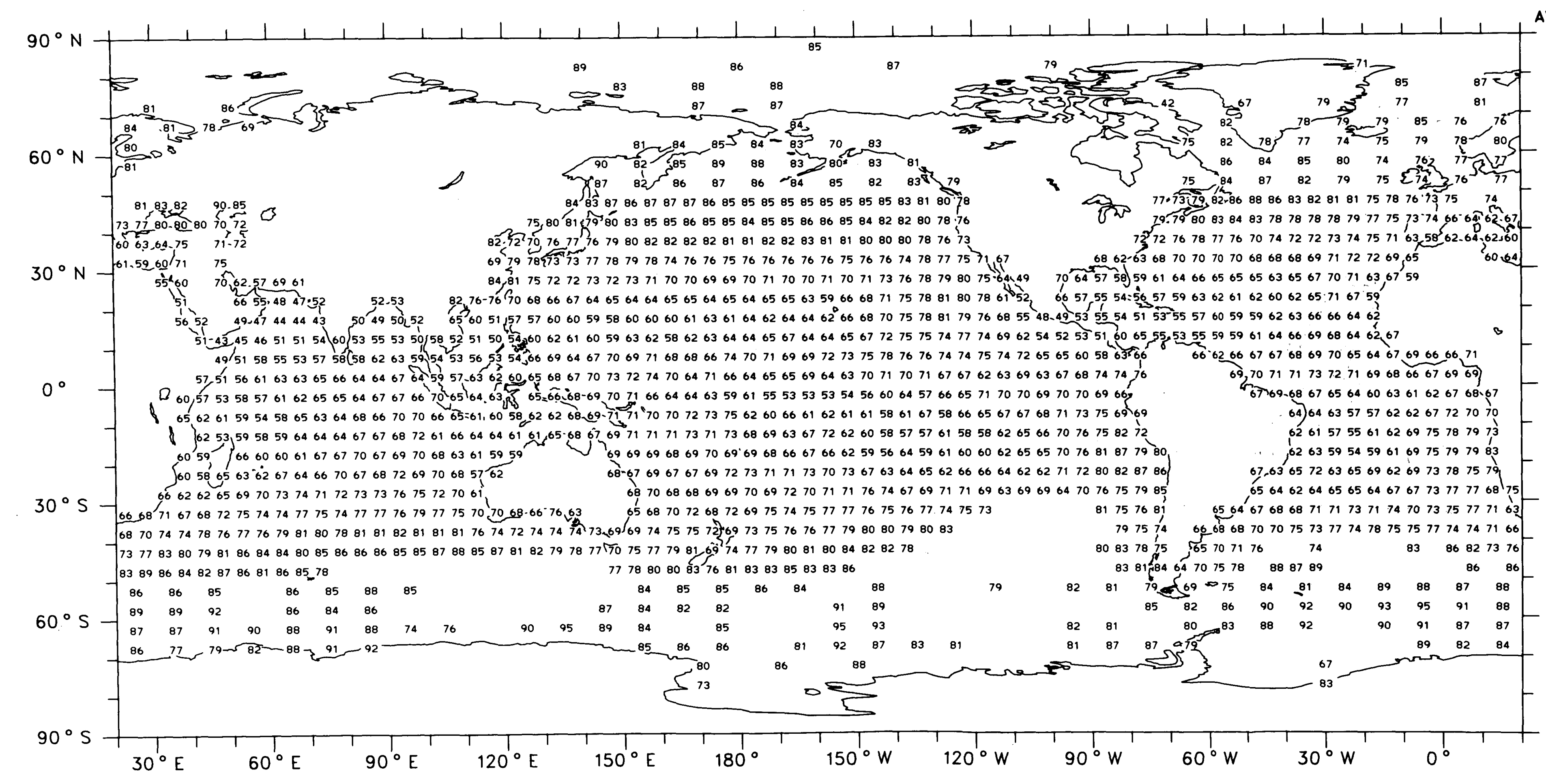




\section{Stratus + Stratocumulus + Fog}

\section{Amount-When-Present (\%)}

June, July, August (1952-1981)

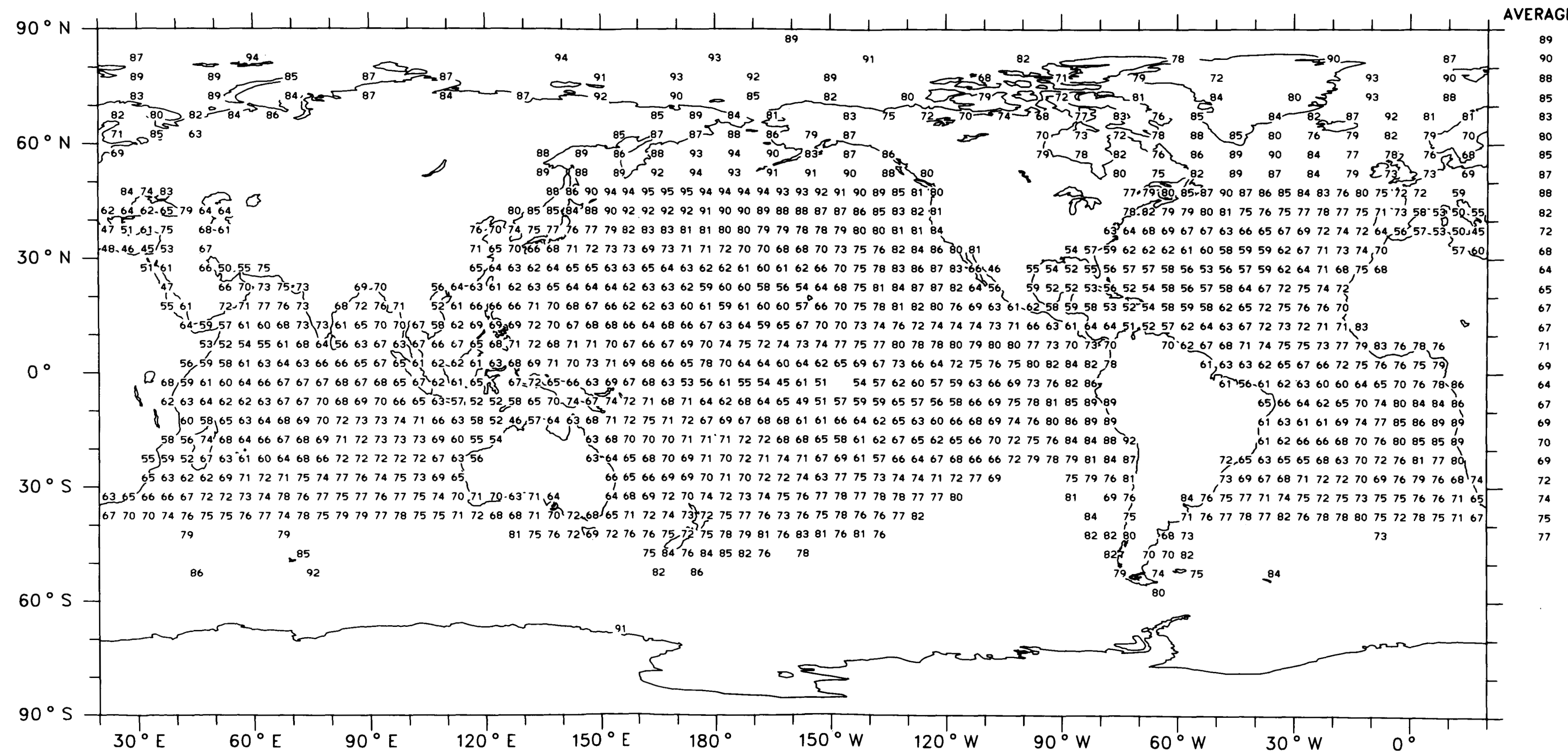




\section{Stratus + Stratocumulus + Fog}

\section{Amount-When-Present (\%)}

September, October, November (1952-1981) 
Stratus + Stratocumulus + Fog

Average Cloud Amount (\%)

December, January, February (1952-1981)

Ocean Areas Only

ZONAL

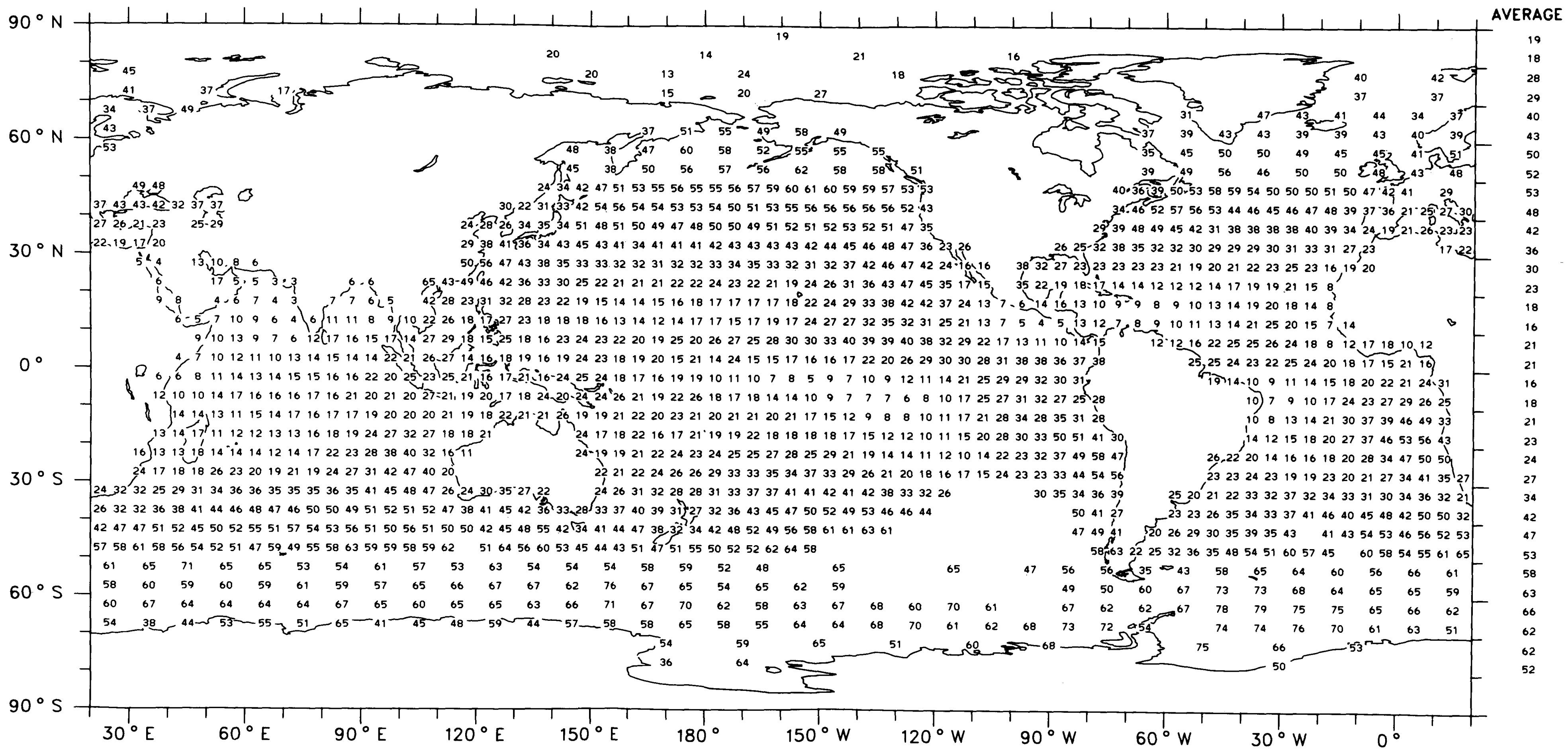

Map 60

GLOBAL AVERAGE (OCEAN) $34 \%$ 


\section{Stratus + Stratocumulus + Fog}

\section{Average Cloud Amount (\%)}

March, April, May (1952-1981) 


\section{Stratus + Stratocumulus + Fog}

\section{Average Cloud Amount (\%)}

June, July, August (1952-1981)

Ocean Areas Only

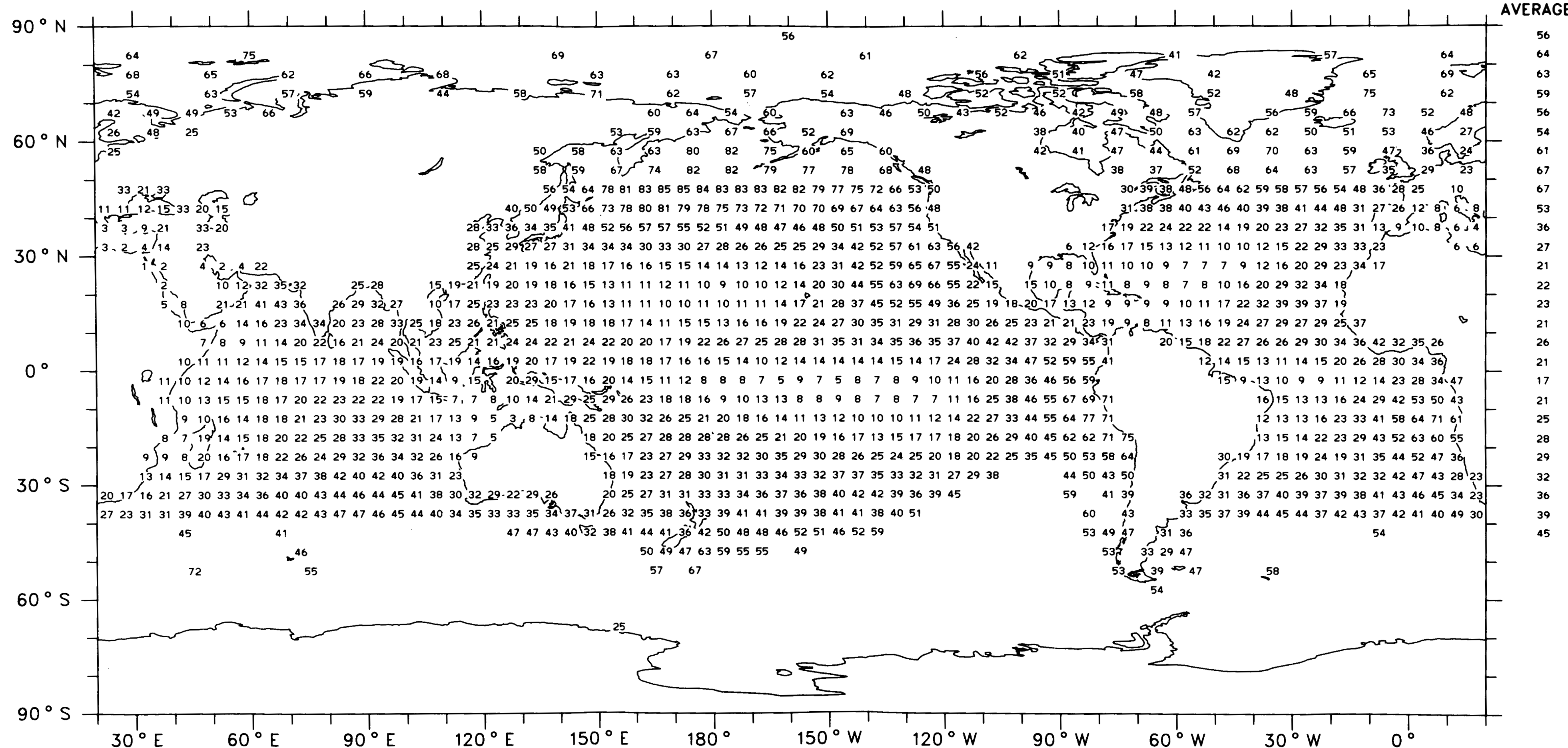

Map 62 


\section{Stratus + Stratocumulus + Fog}

Average Cloud Amount (\%)

September, October, November (1952-1981)
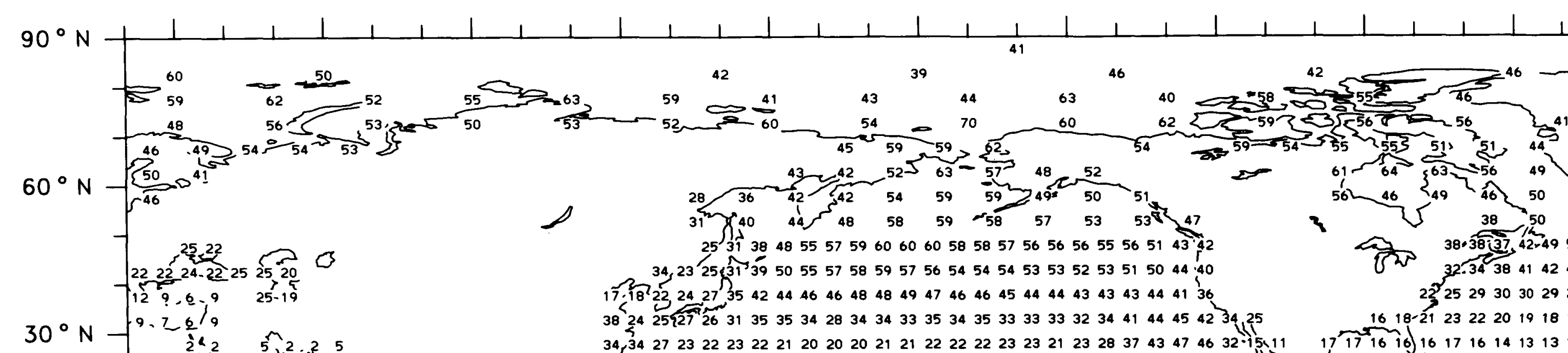

61-

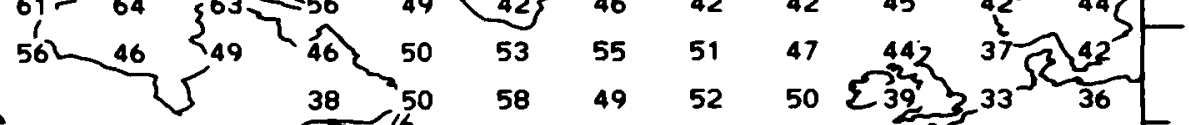

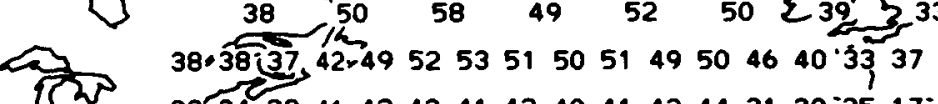
22. 252930302921272720293232 (1) 2. 22,243542 8)

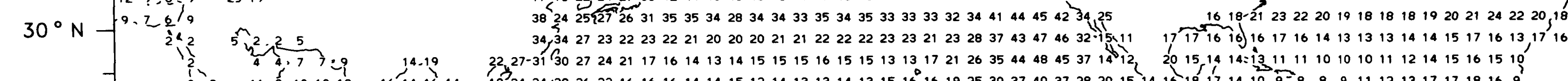

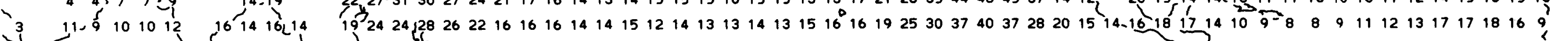

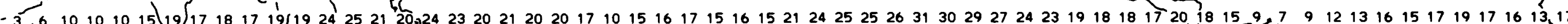

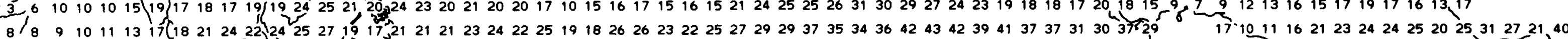

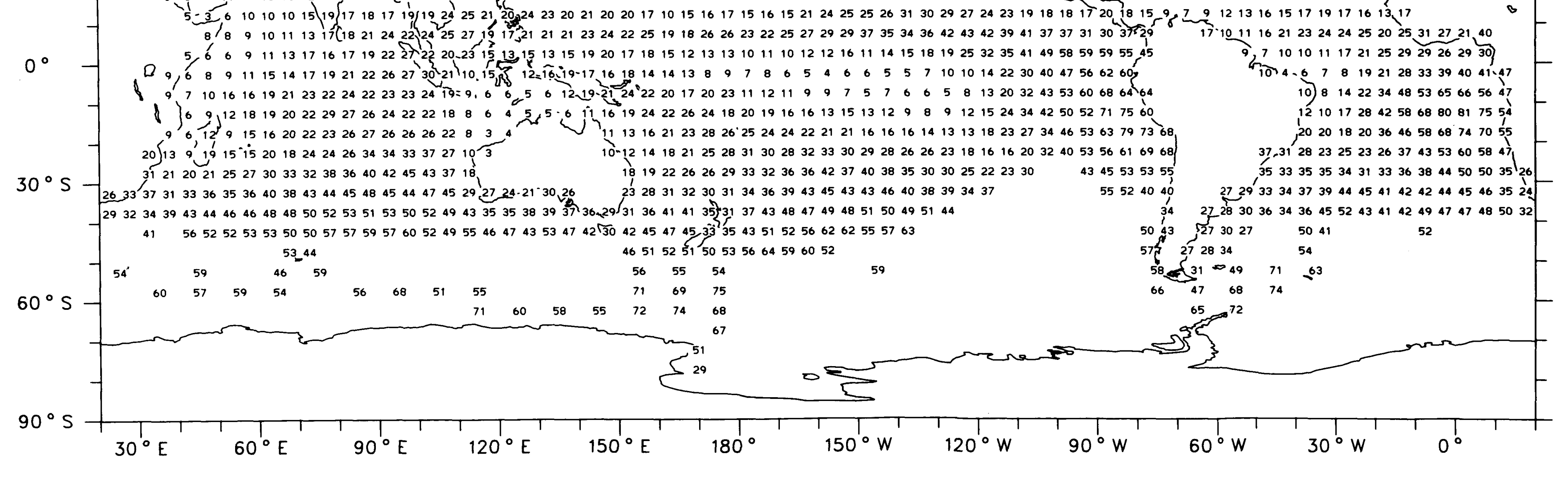
$6 \quad 7 \quad 819212833394041.47$ 10) 8142234485365665647 1210172842586880817554 3128232523063743535058 96,12915162022232627262626228334 (1) 11131621232826252424222121161616141313182327344653637973 $181922262629333236364237403835303025222330 \quad 4345535355$ 
Nimbostratus

Frequency of Occurrence (\%)

December, January, February (1952-1981)

Ocean Areas Only

ZONAL

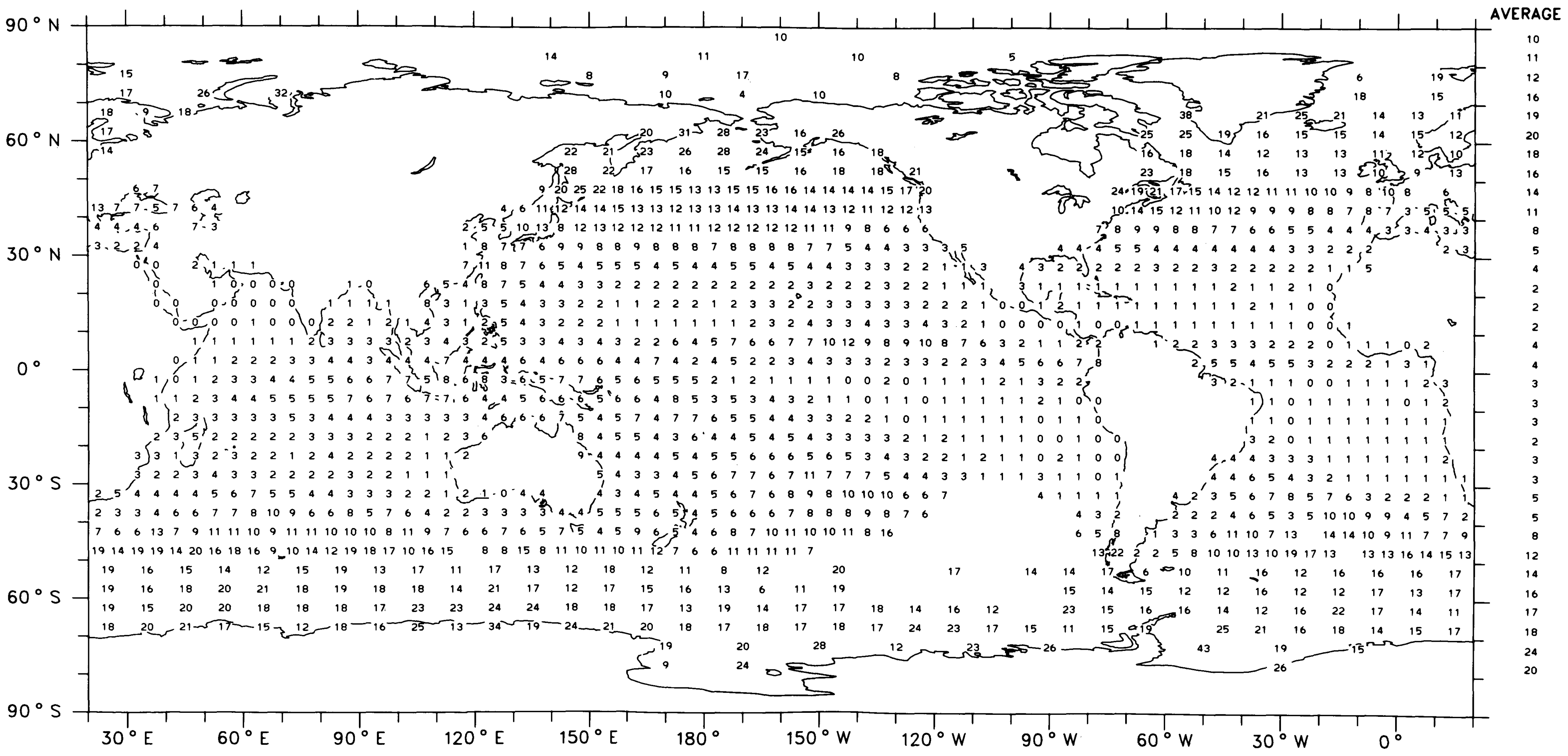

Map 64

GLOBAL AVERAGE (OCEAN) $7 \%$ 


\section{Nimbostratus}

\section{Frequency of Occurrence (\%)}

March, April, May (1952-1981)

$$
90^{\circ} \mathrm{N}
$$

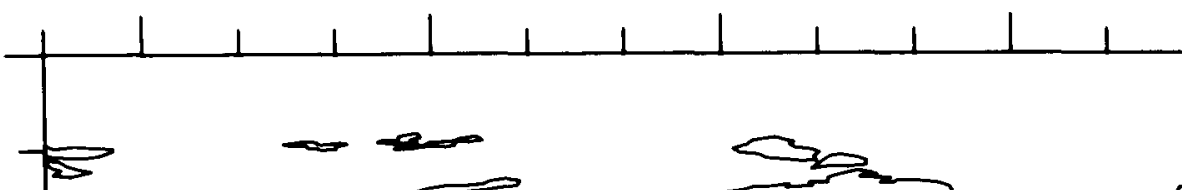

10
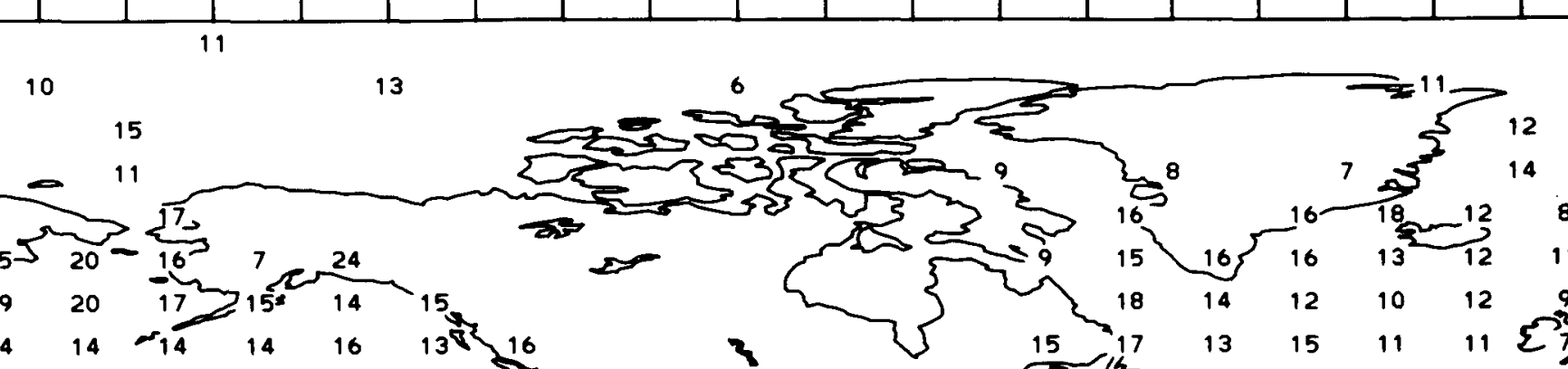


\section{Nimbostratus}

Frequency of Occurrence (\%)

June, July, August (1952-1981)

Ocean Areas Only

ZONAL

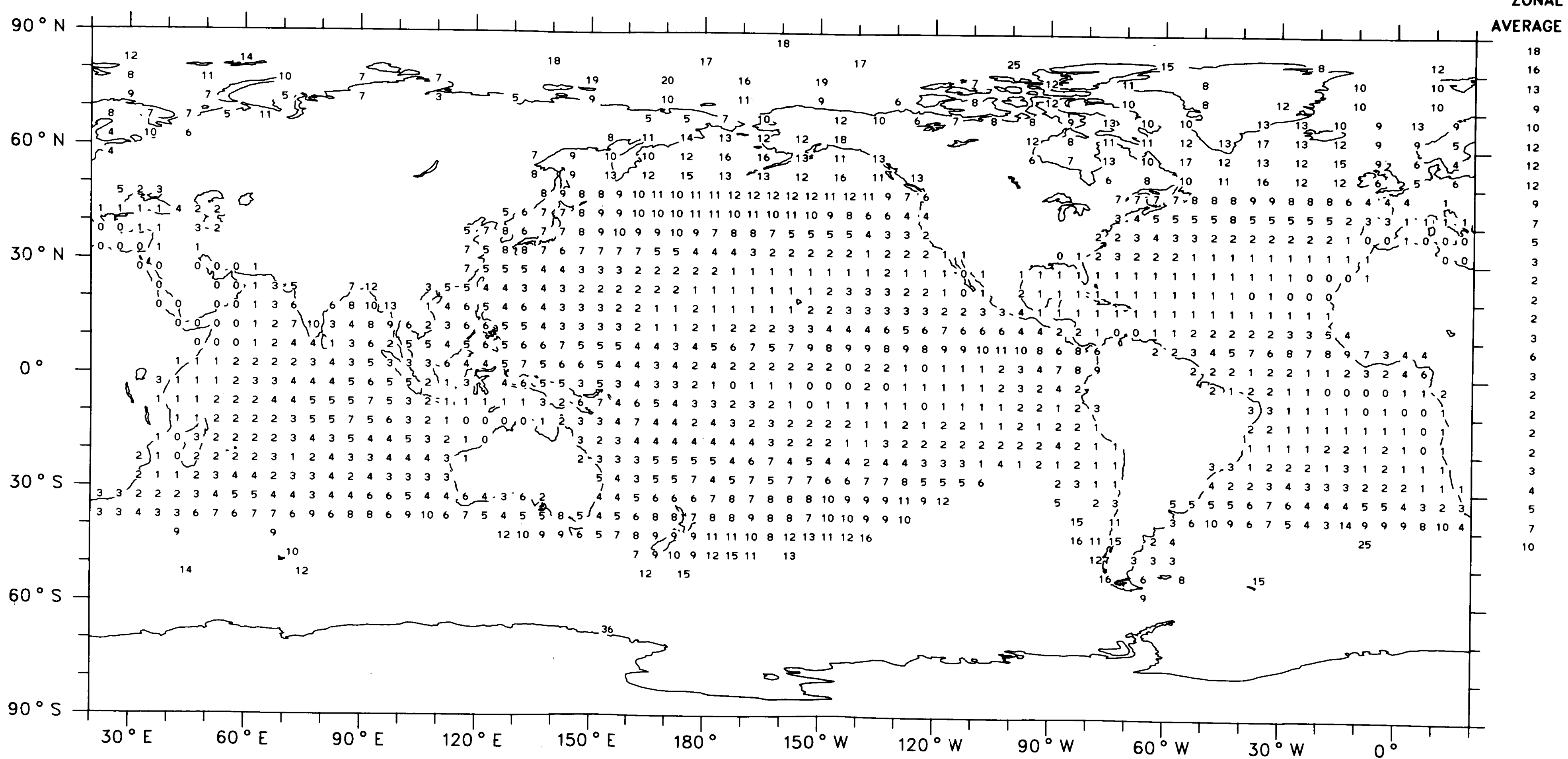

Map 66

GLOBAL AVERAGE (OCEAN) $6 \%$ 


\section{Nimbostratus}

\section{Frequency of Occurrence (\%)}

September, October, November (1952-1981)

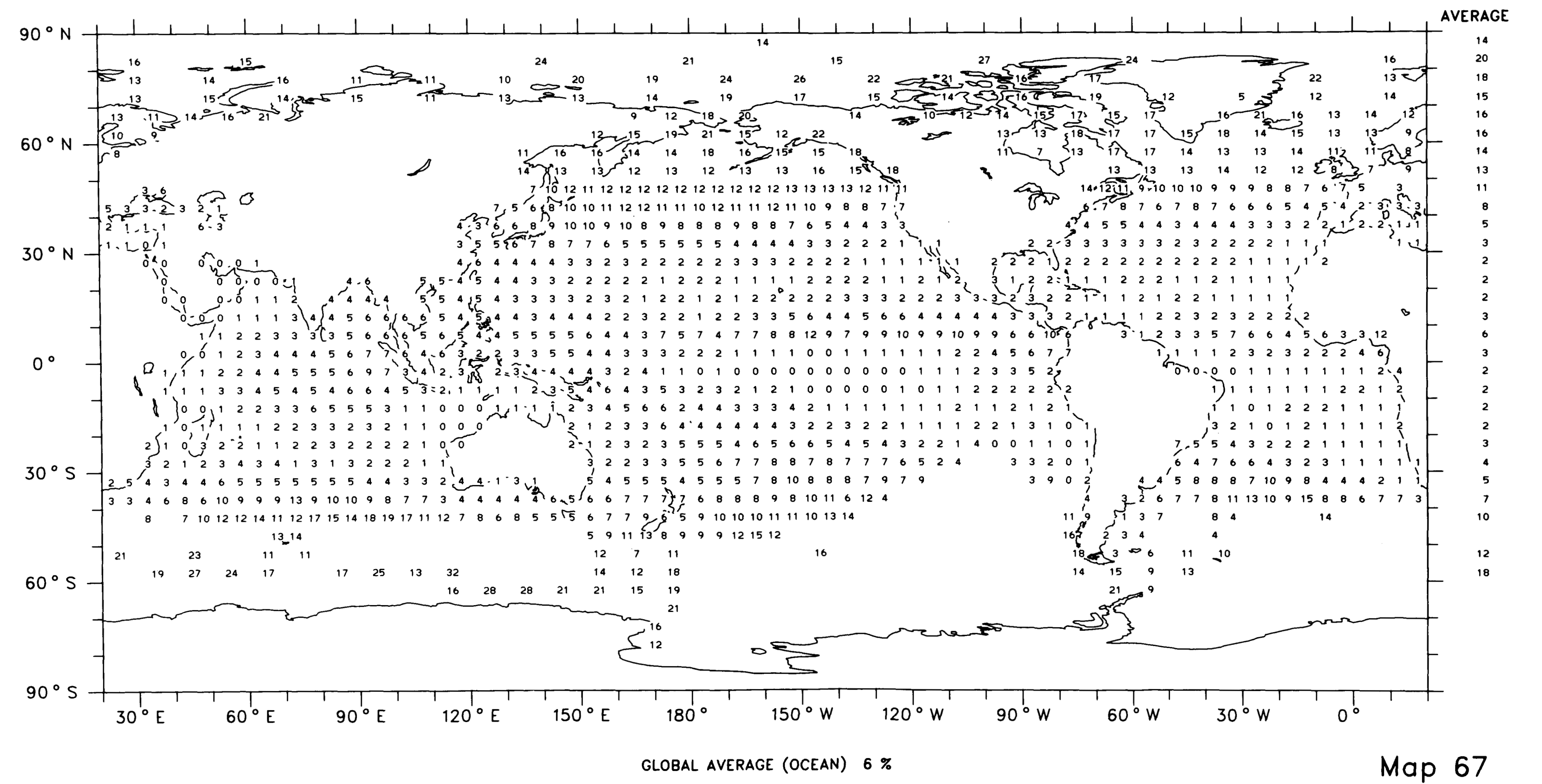




\section{Nimbostratus}

\section{Amount-When-Present (\%)}

December, January, February (1952-1981)

Ocean Areas Only

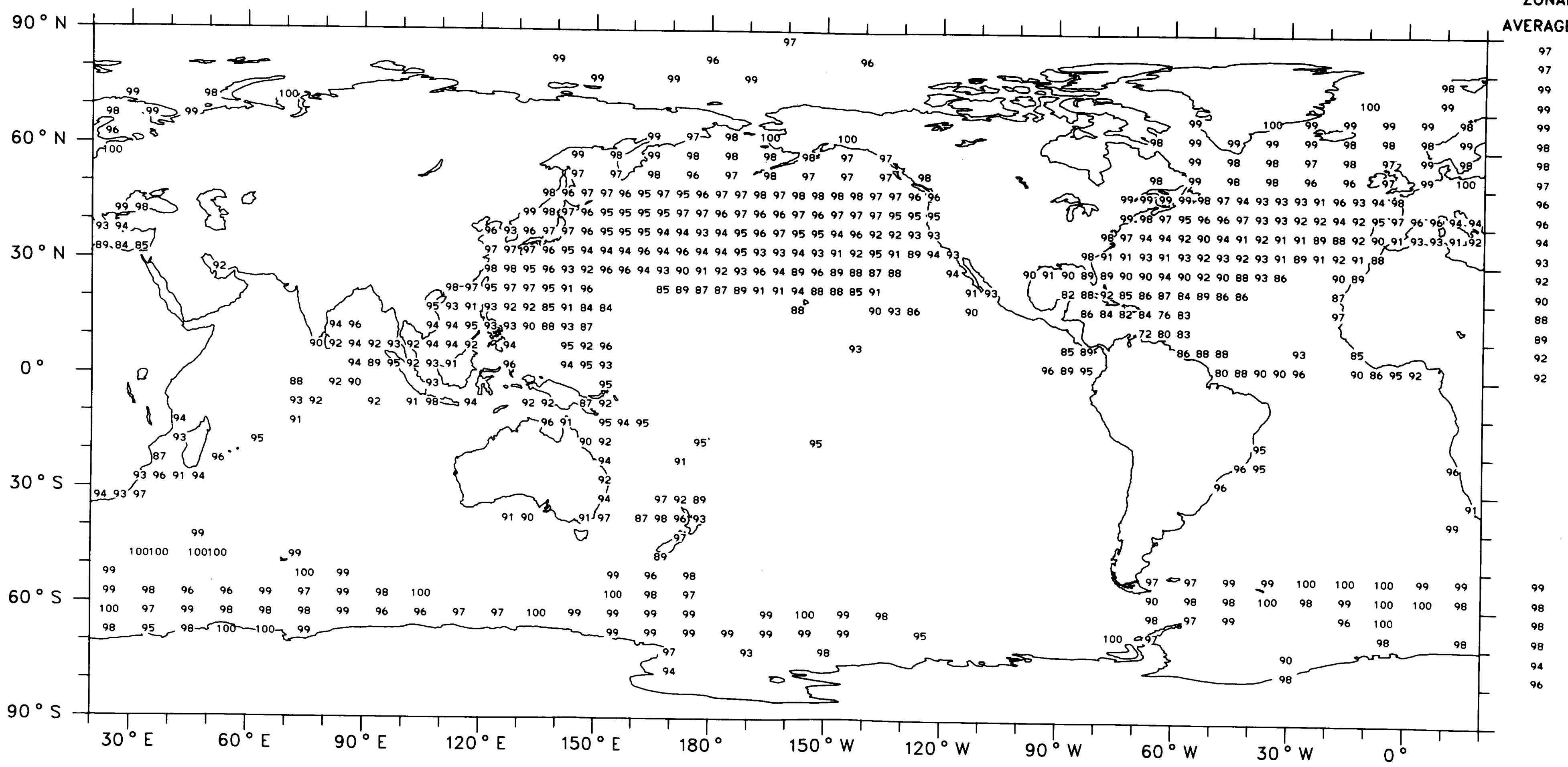




\section{Nimbostratus}

\section{Amount-When-Present (\%)}

March, April, May (1952-1981)

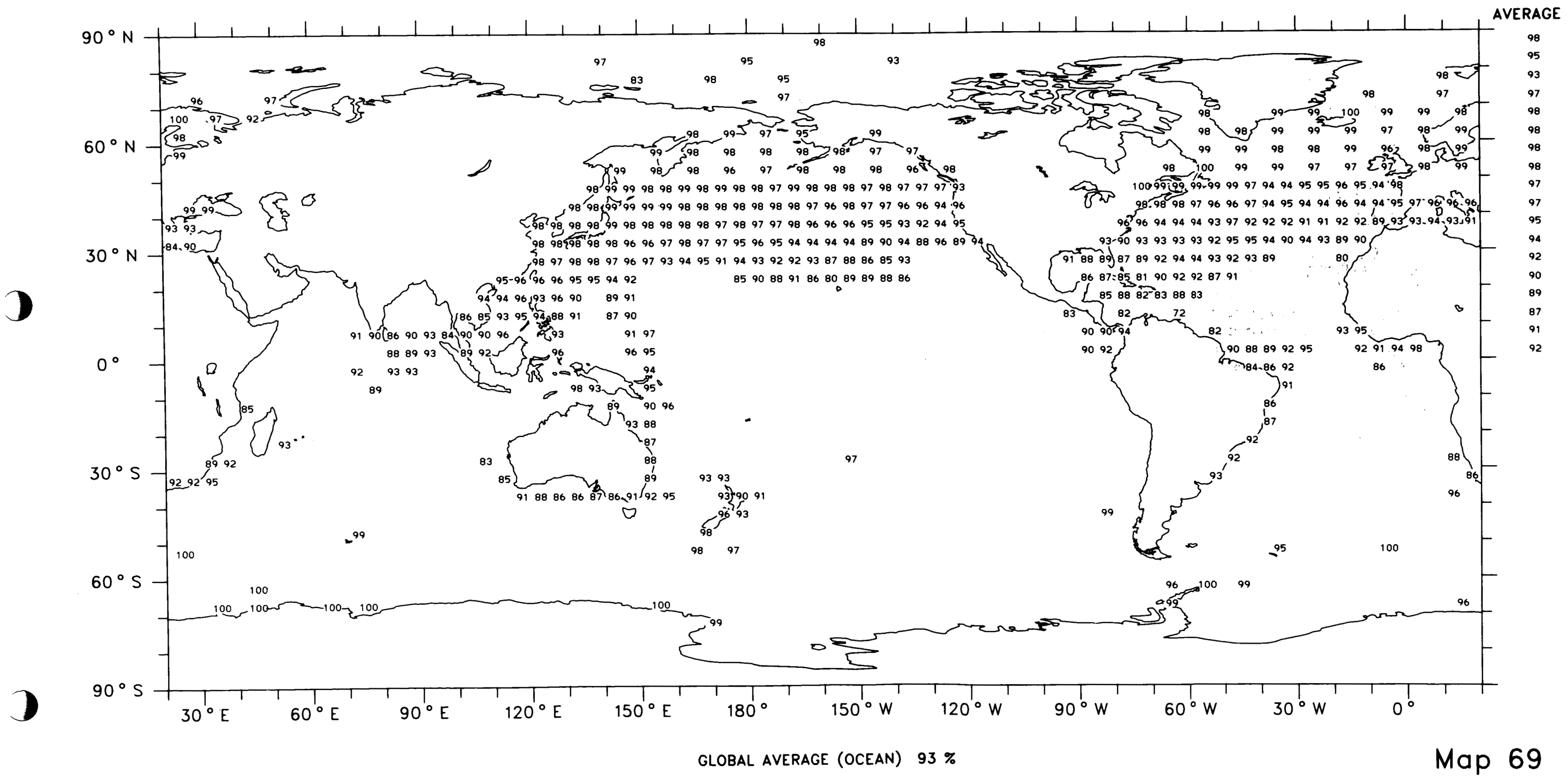




\section{Nimbostratus}

\section{Amount-When-Present (\%)}

June, July, August (1952-1981)

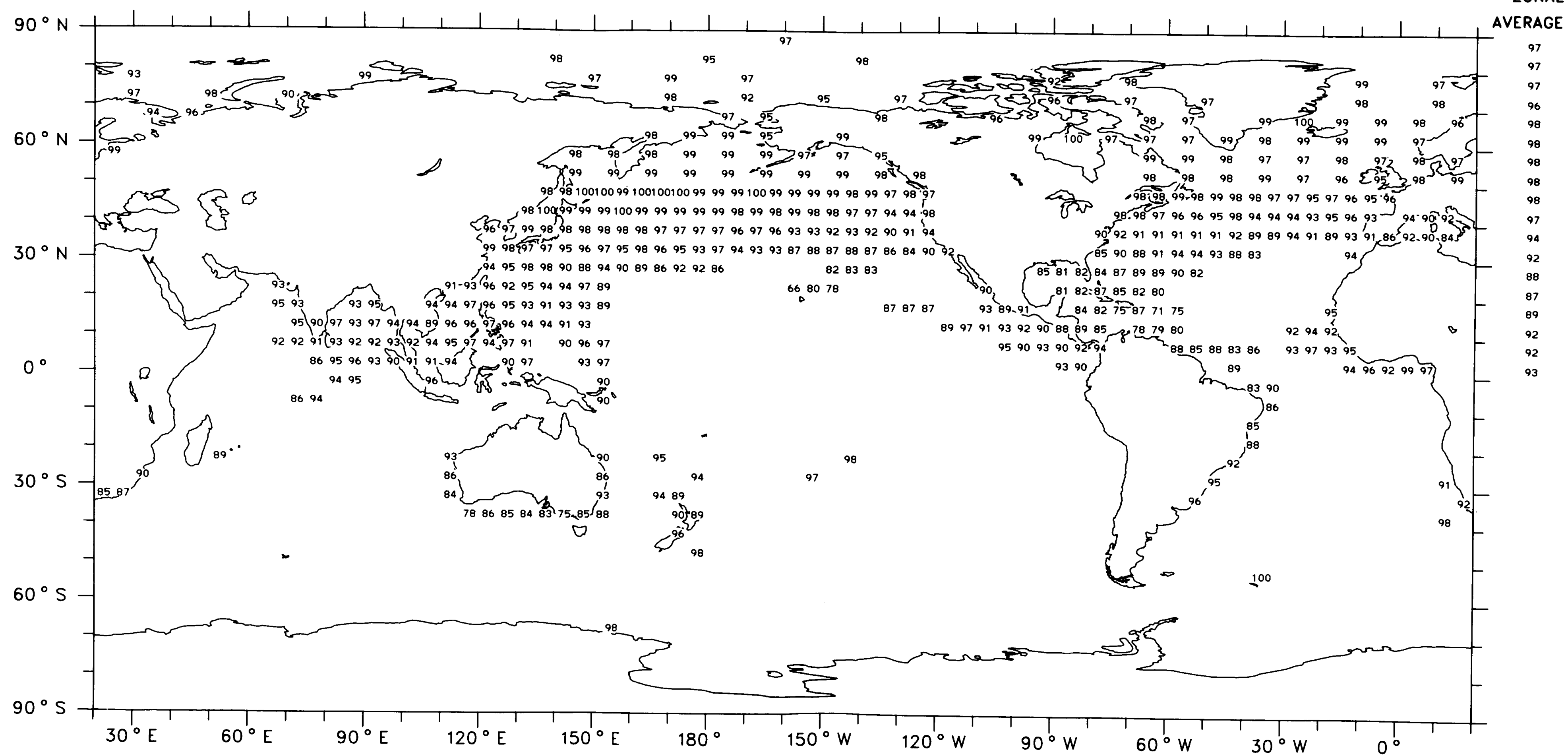

Map 70

GLOBAL AVERAGE (OCEAN) $91 \%$ 
Nimbostratus

Amount-When-Present (\%)

September, October, November (1952-1981)

Ocean Areas Only

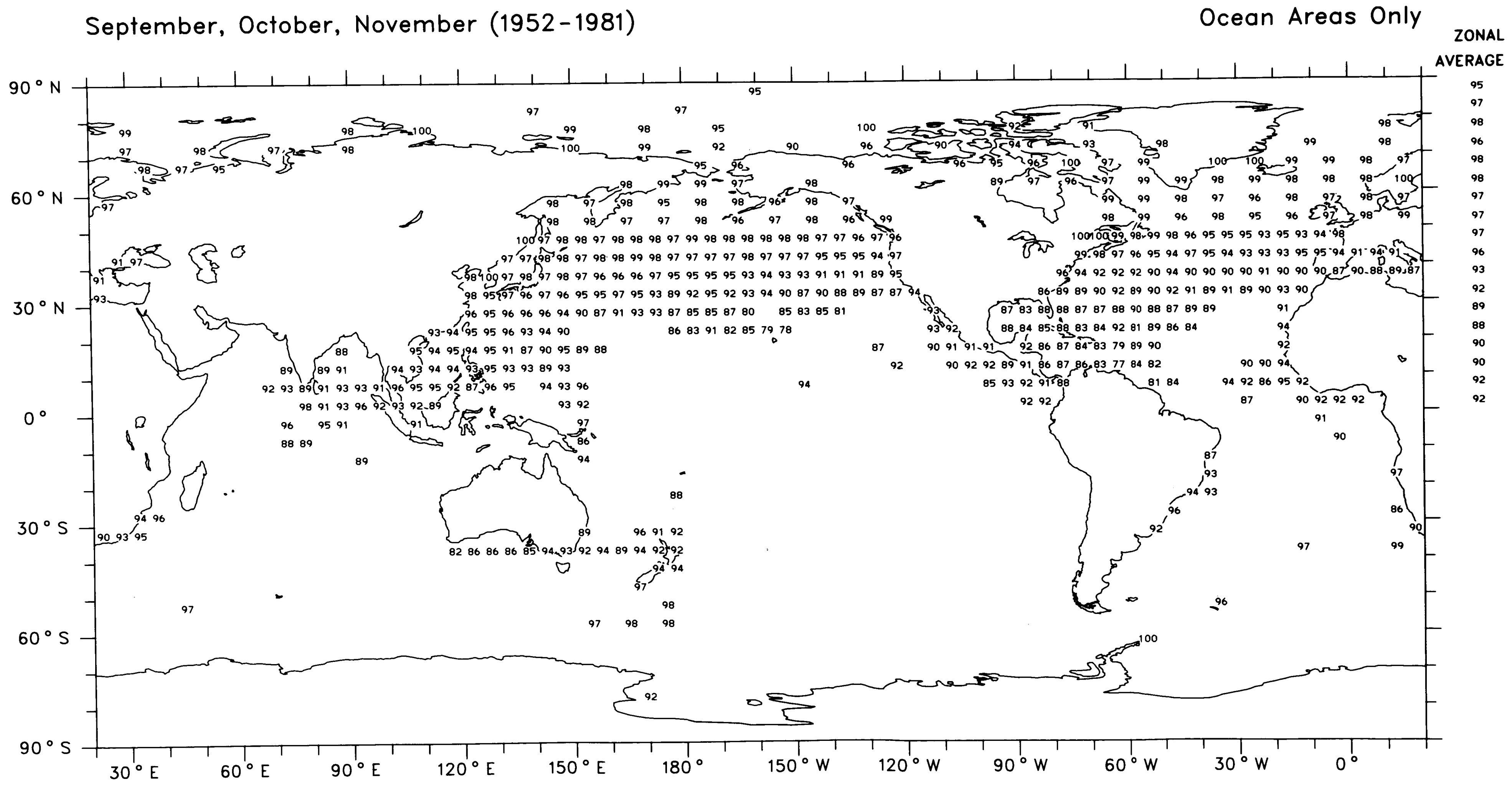

GLOBAL AVERAGE (OCEAN) $93 \%$

Map 71 


\section{Nimbostratus}

\section{Average Cloud Amount (\%)}

December, January, February (1952-1981)

Ocean Areas Only

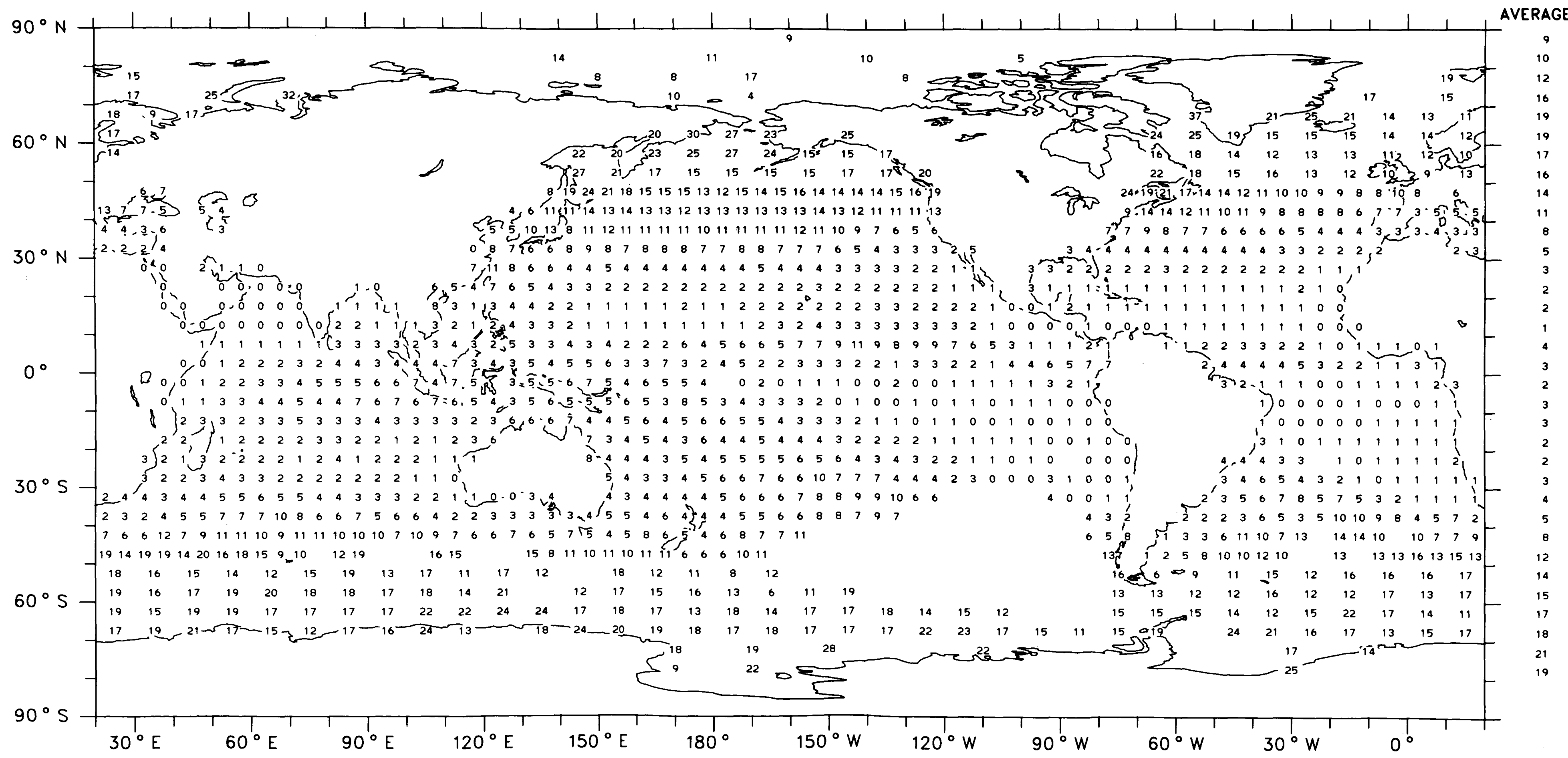

Map 72

GLobAL AVERAGE (OCEAN) $7 \%$ 
Nimbostratus

Average Cloud Amount (\%)

March, April, May (1952-1981)

Ocean Areas Only

ZONAL

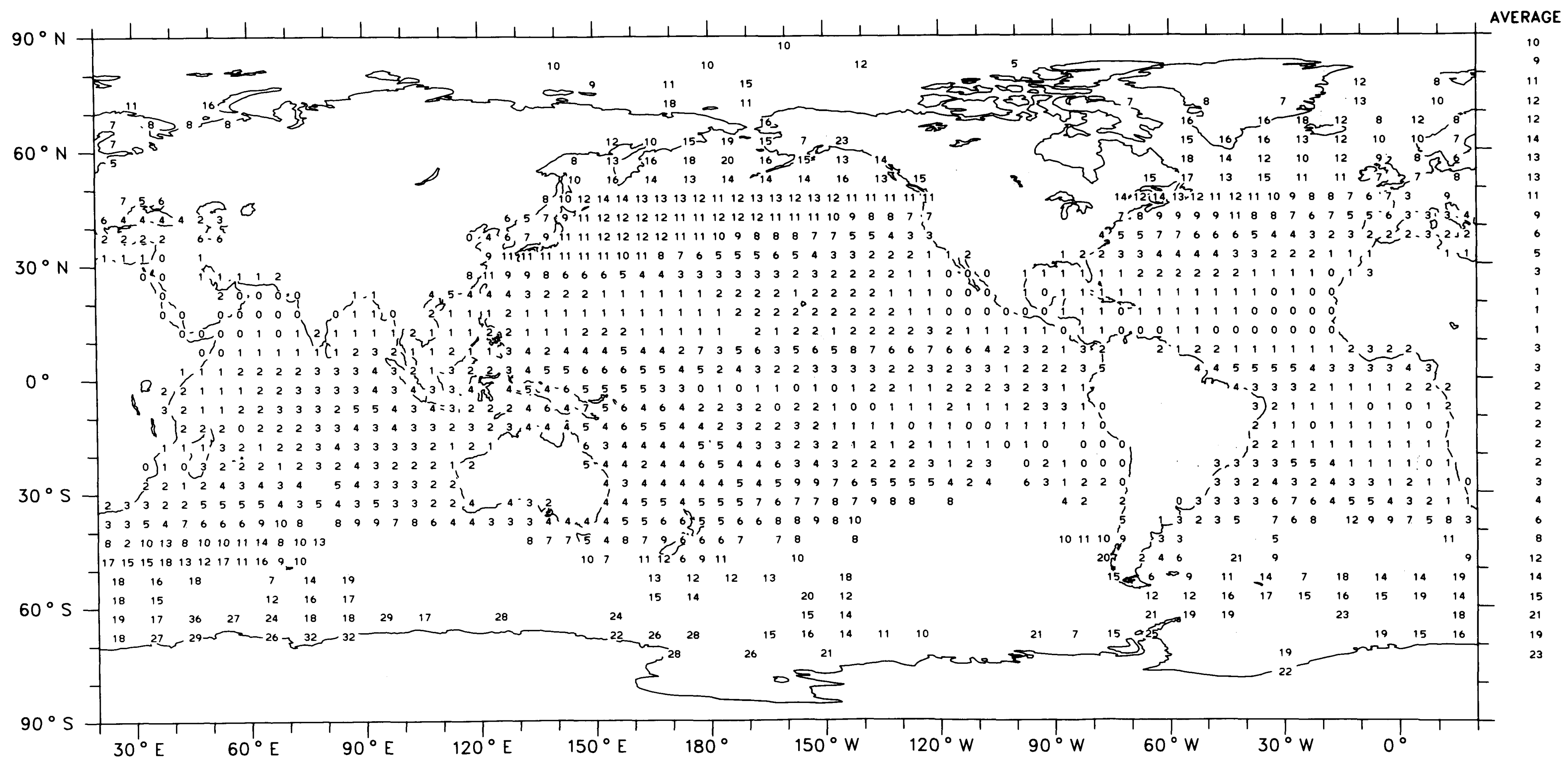

GLOBAL AVERAGE (OCEAN) $6 \%$

Map 73 


\section{Nimbostratus}

Average Cloud Amount (\%)

June, July, August (1952-1981)

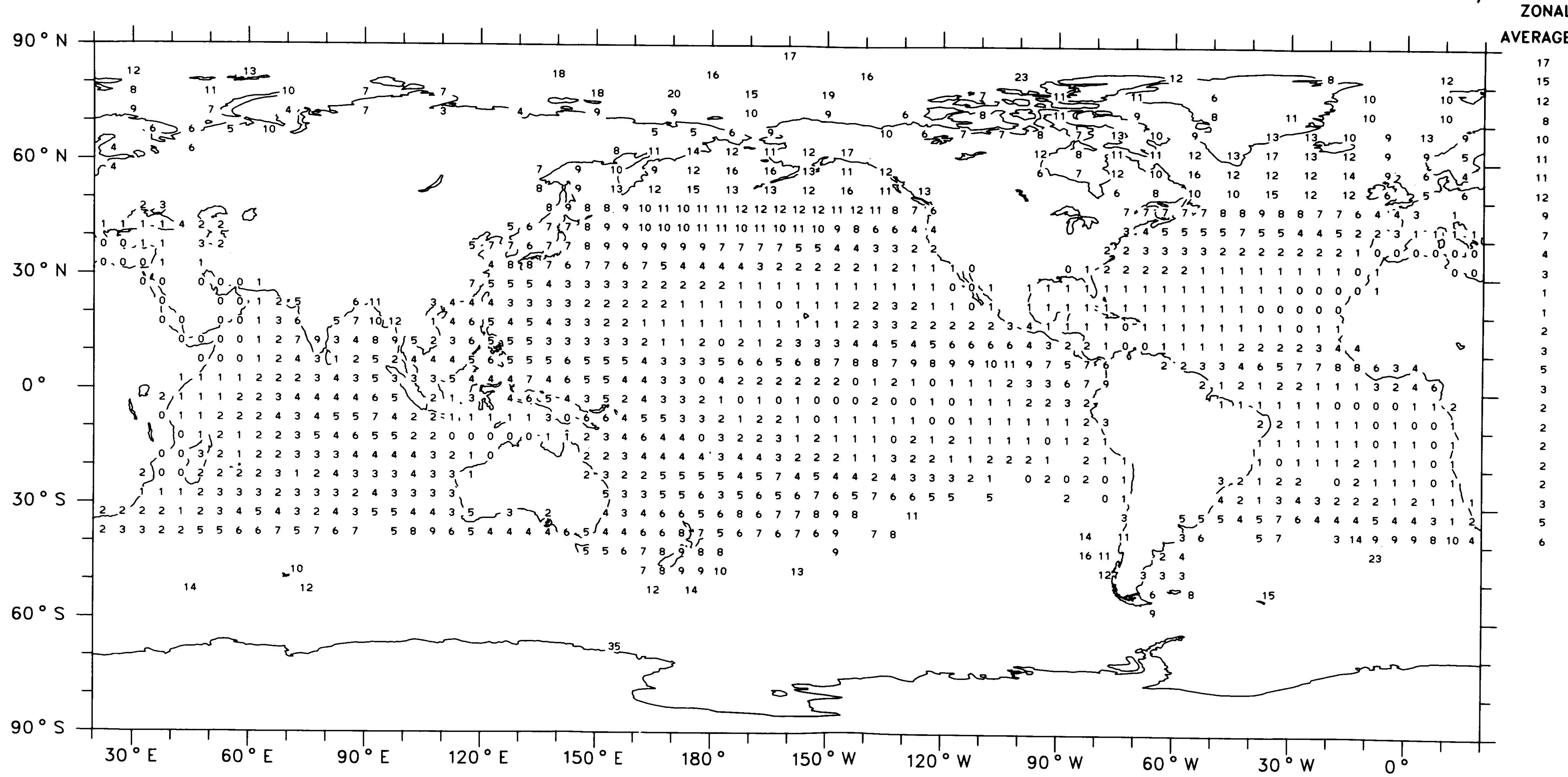

Map 74

global aVerage (oCEAN) $5 \%$ 


\section{Nimbostratus}

\section{Average Cloud Amount (\%)}

September, October, November (1952-1981)

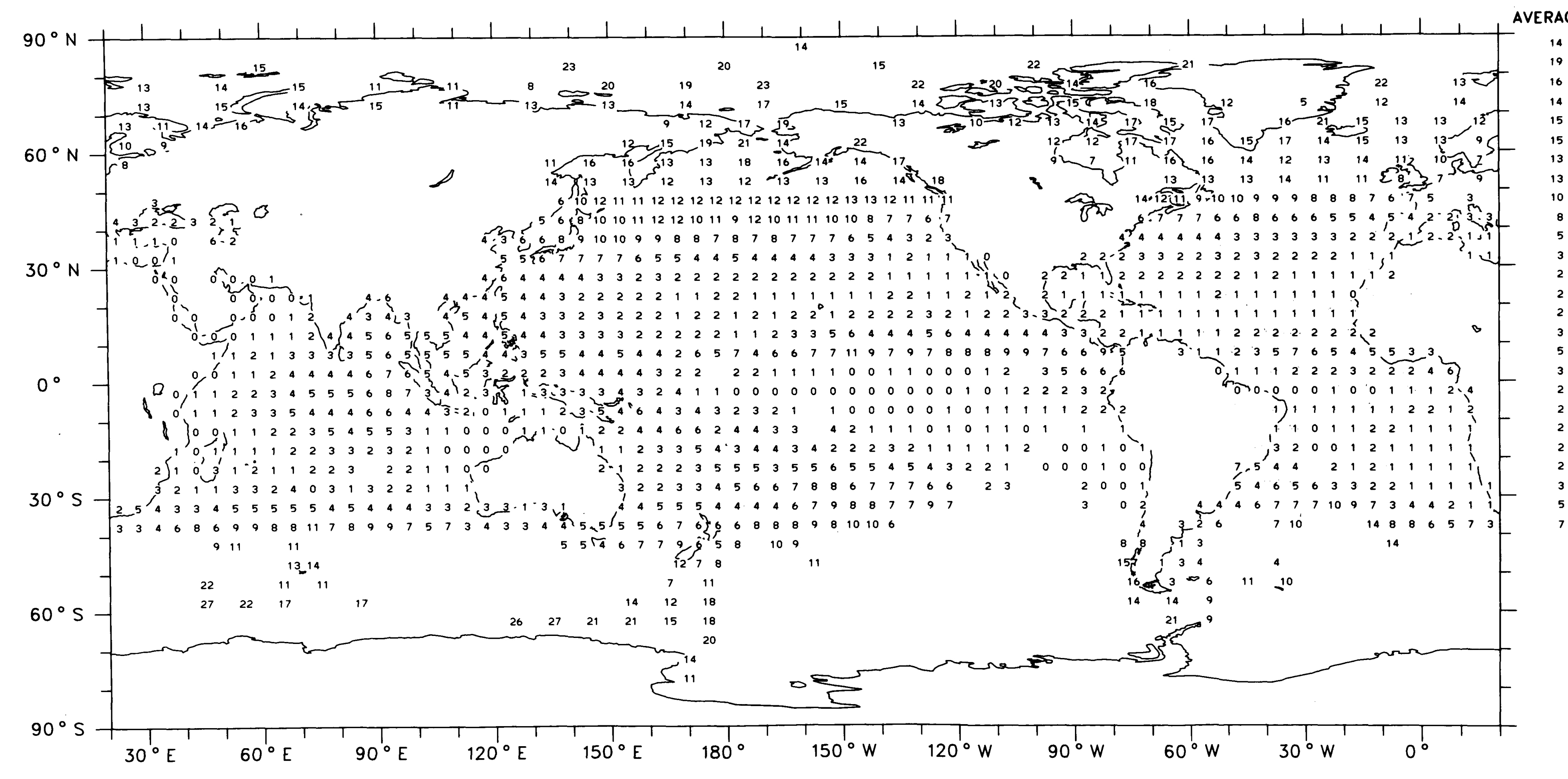


Altostratus + Altocumulus

Frequency of Occurrence (\%), 6-18 LT

December, January, February (1952-1981)

Ocean Areas Only

ZONAL

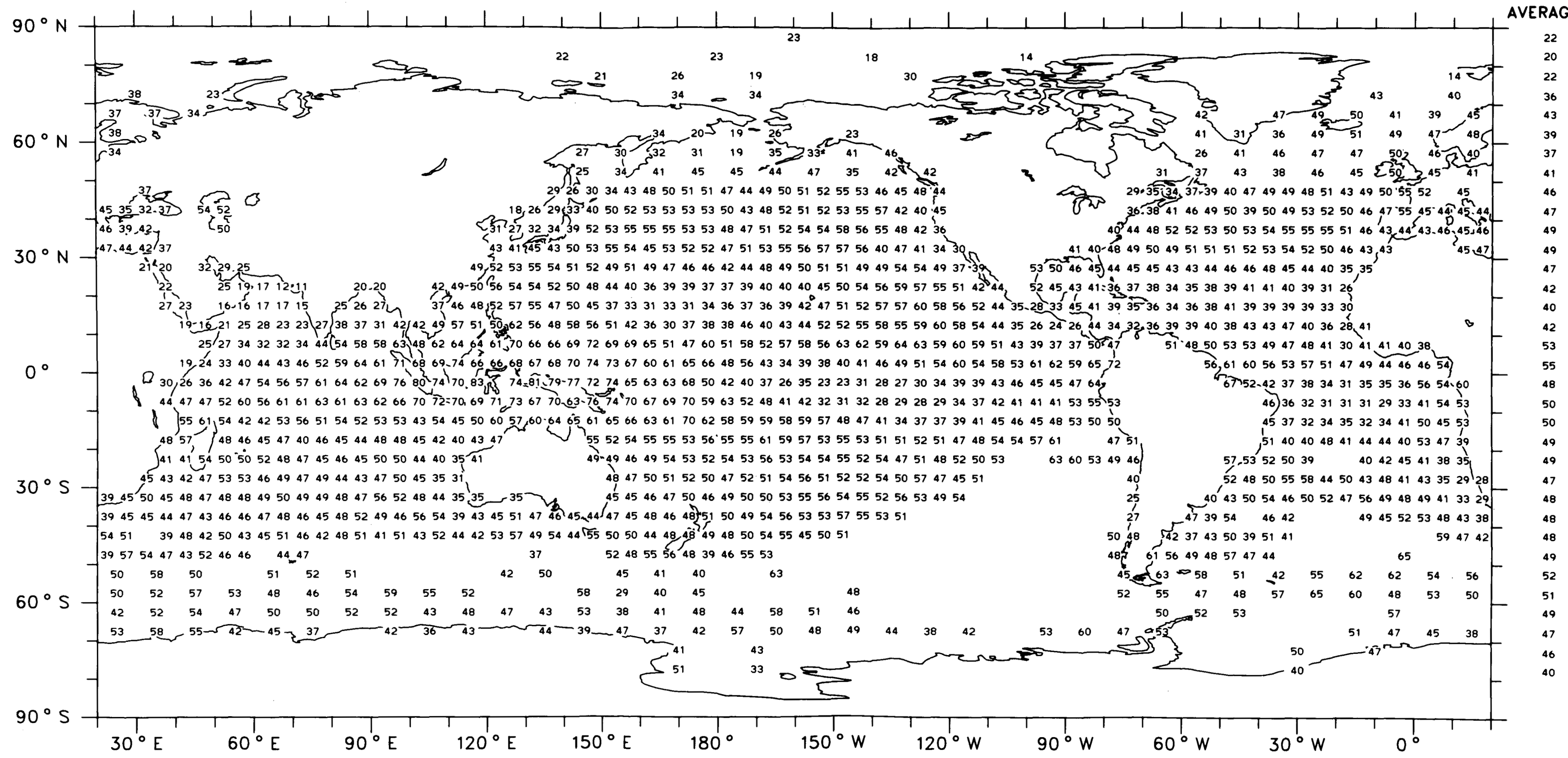

Map 76

global average (OCEAN) $47 \%$ 


\section{Altostratus + Altocumulus}

\section{Frequency of Occurrence (\%), 6-18 LT}

March, April, May (1952-1981)

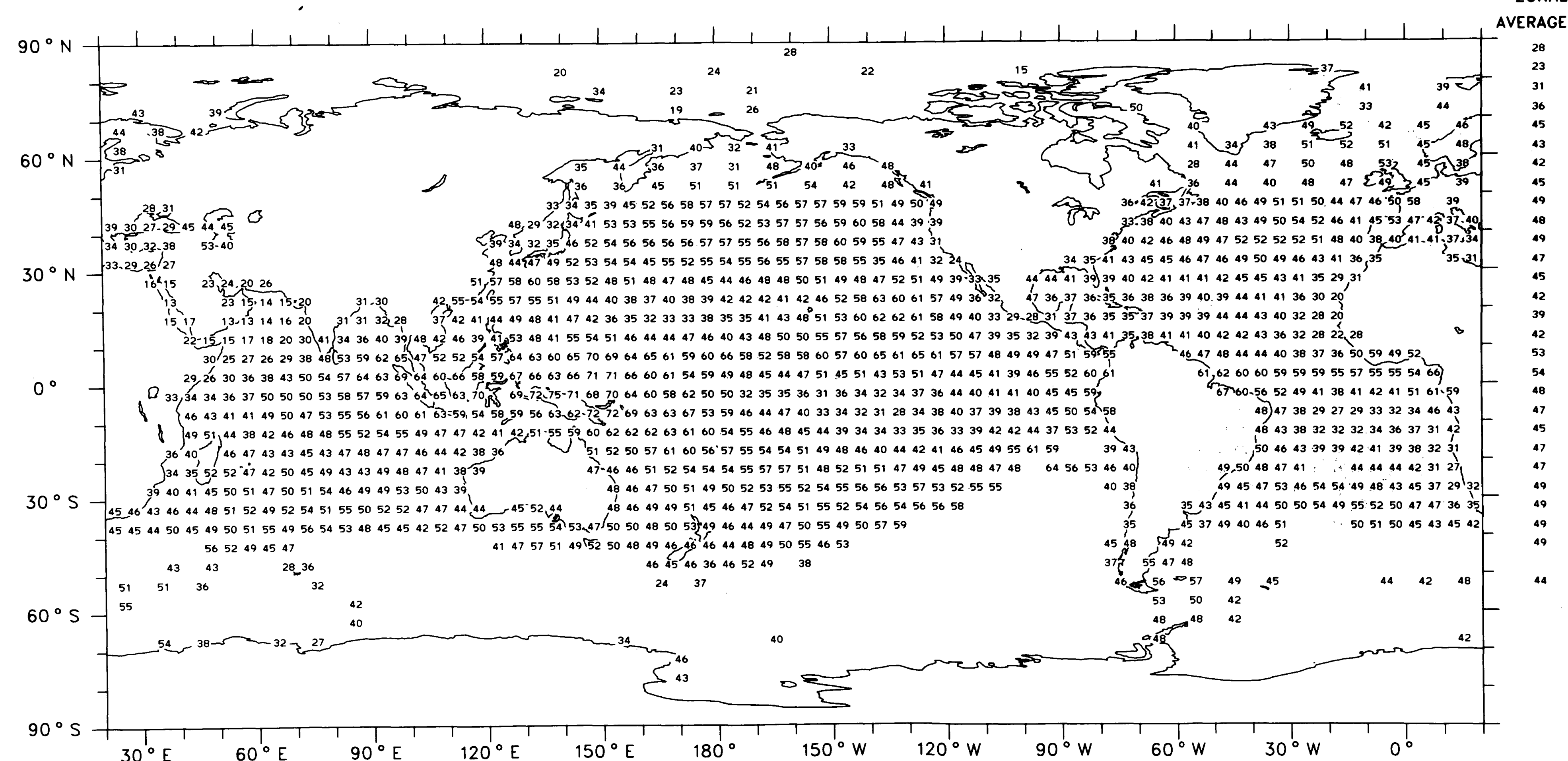




\section{Altostratus + Altocumulus}

\section{Frequency of Occurrence (\%), 6-18 LT}

June, July, August (1952-1981)

Ocean Areas Only

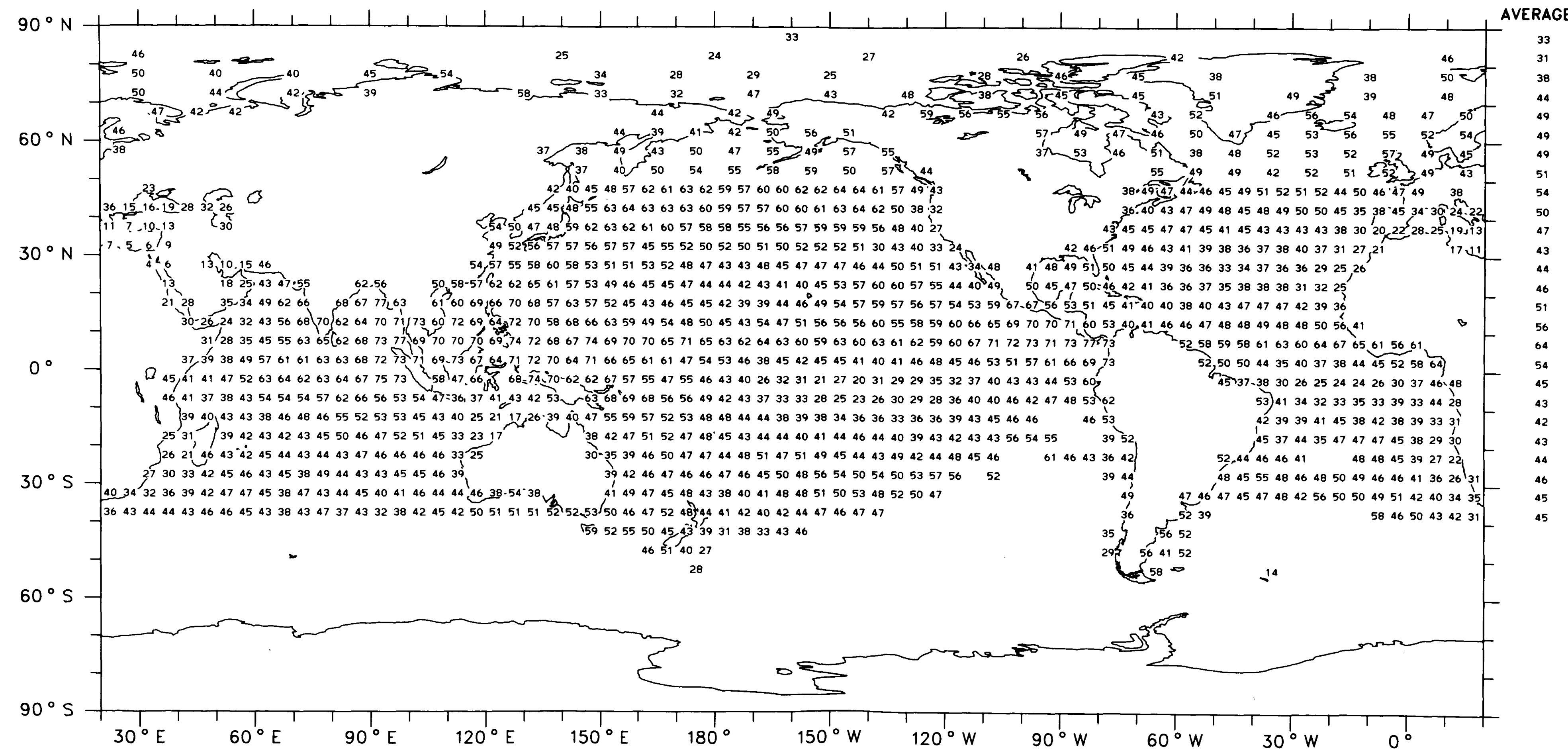

Map 78

global AVERAGe (OCEAN) $46 \%$ 


\section{Altostratus + Altocumulus}

\section{Frequency of Occurrence (\%), 6-18 LT}

September, October, November (1952-1981)

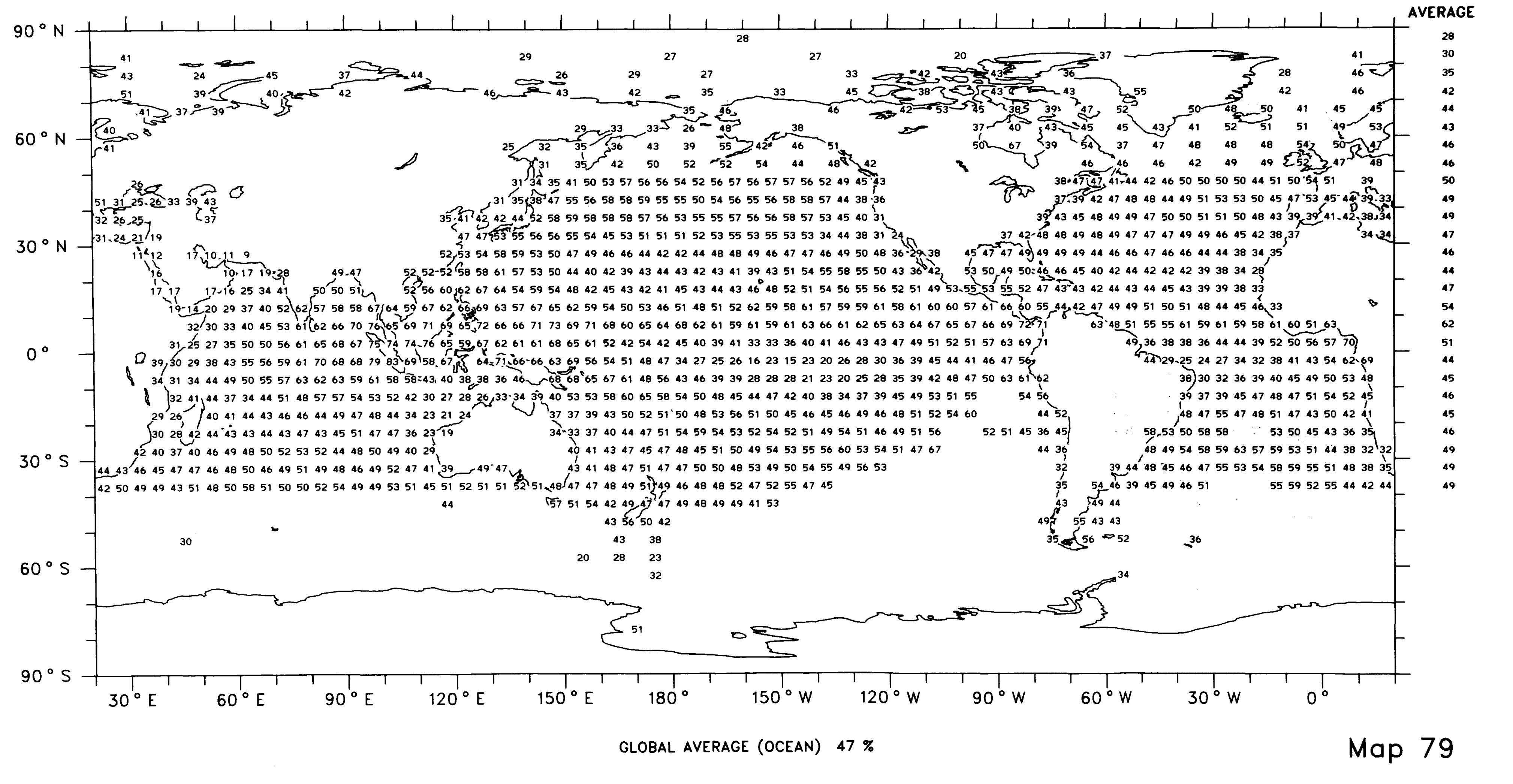




\section{Altostratus + Altocumulus}

\section{Amount-When-Present (\%), 6-18 LT}

December, January, February (1952-1981)

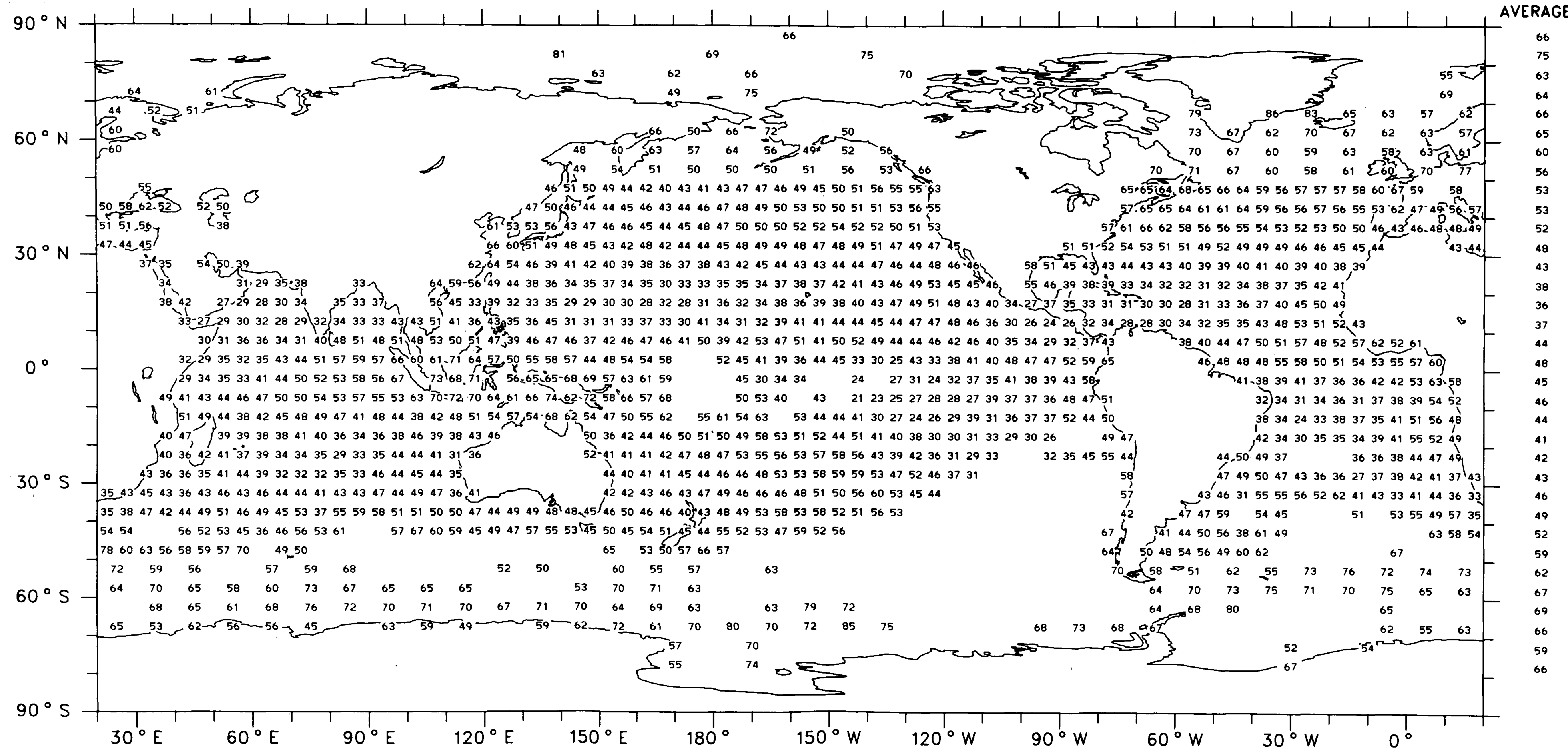




\section{Altostratus + Altocumulus}

\section{Amount-When-Present (\%), 6-18 LT}

March, April, May (1952-1981)

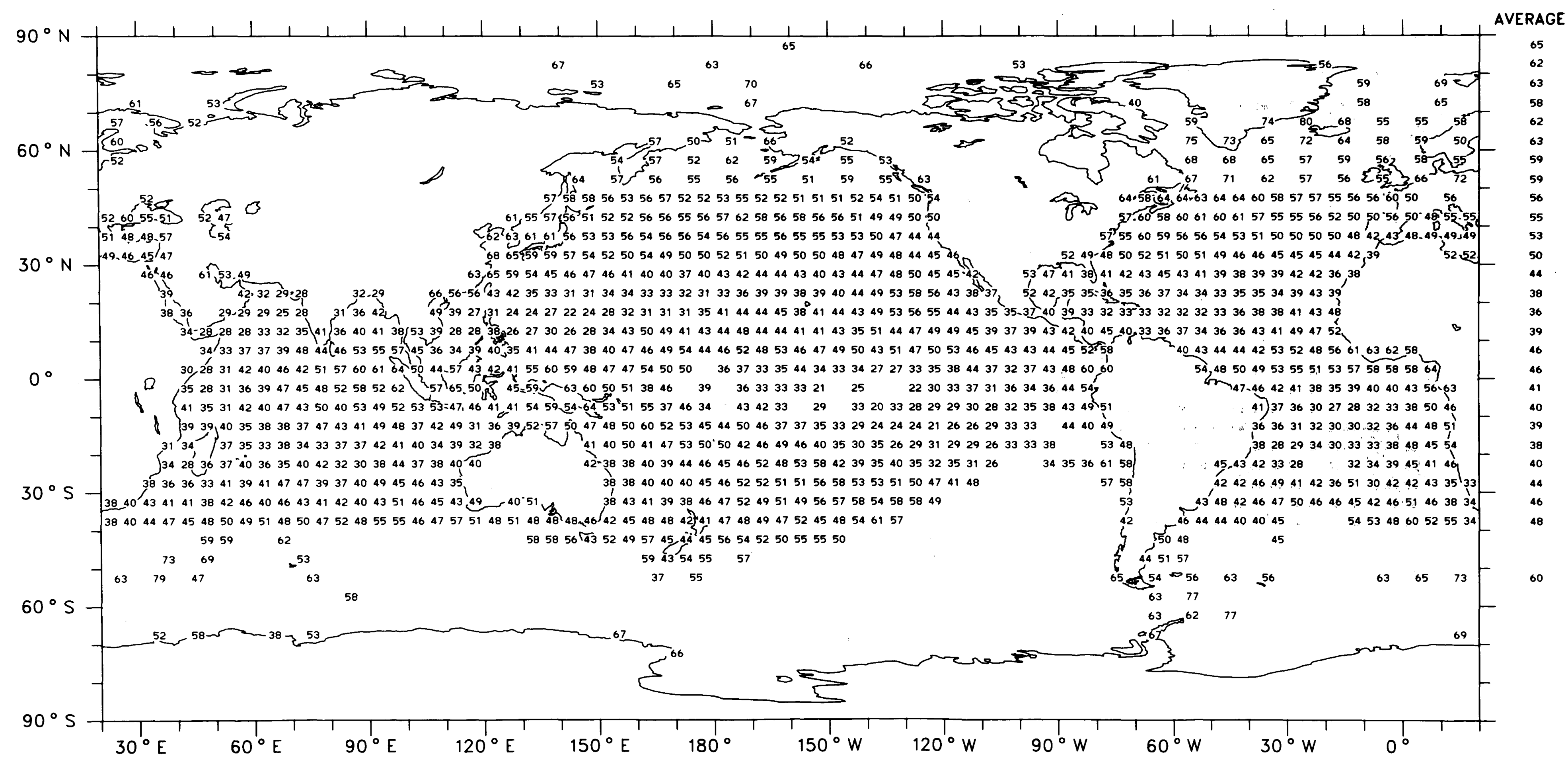




\section{Altostratus + Altocumulus}

\section{Amount-When-Present (\%), 6-18 LT}

June, July, August (1952-1981)

Ocean Areas Only

ZONAL

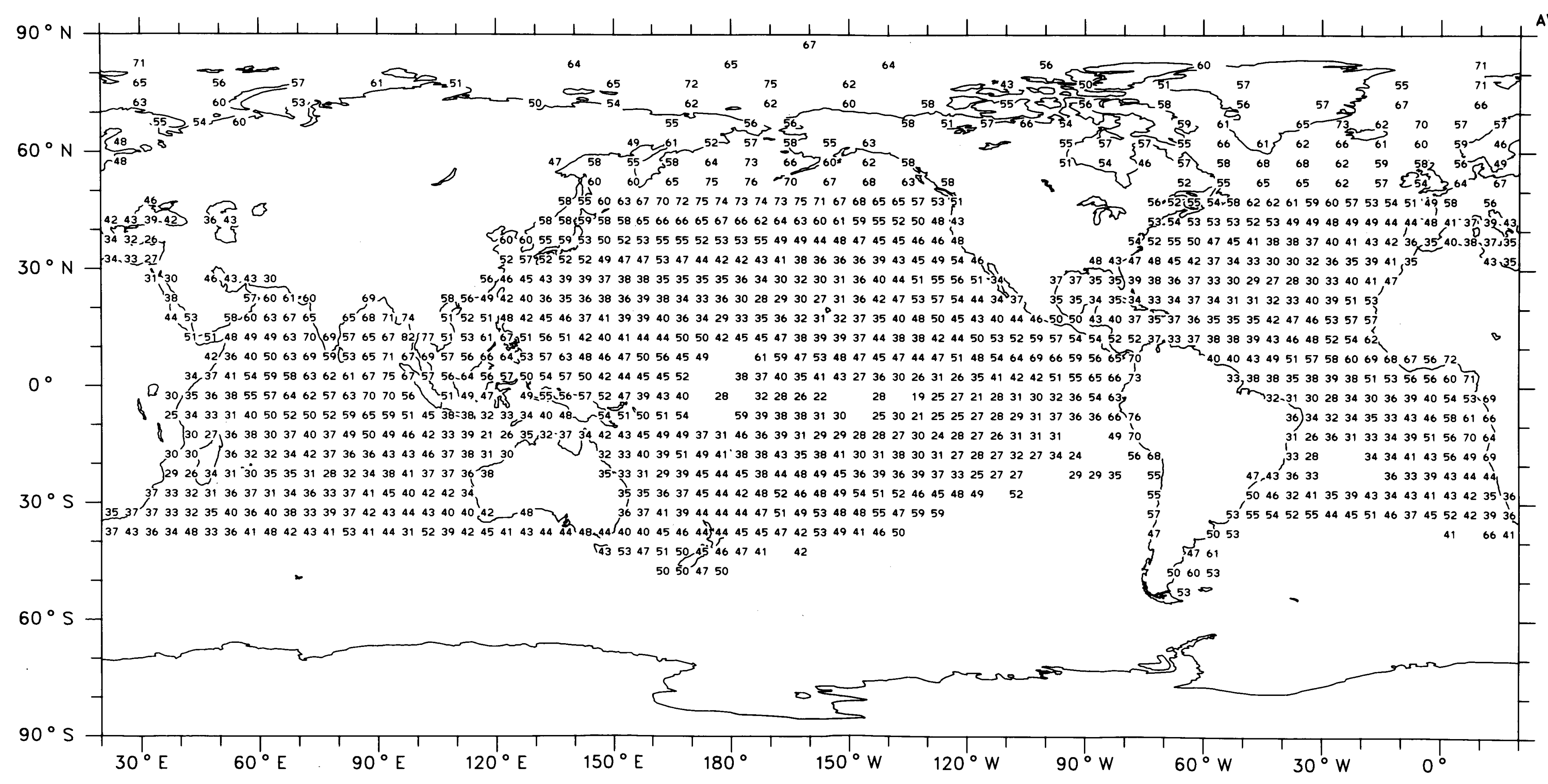
AVERAGE 


\section{Altostratus + Altocumulus}

\section{Amount-When-Present (\%), 6-18 LT}

September, October, November (1952-1981)

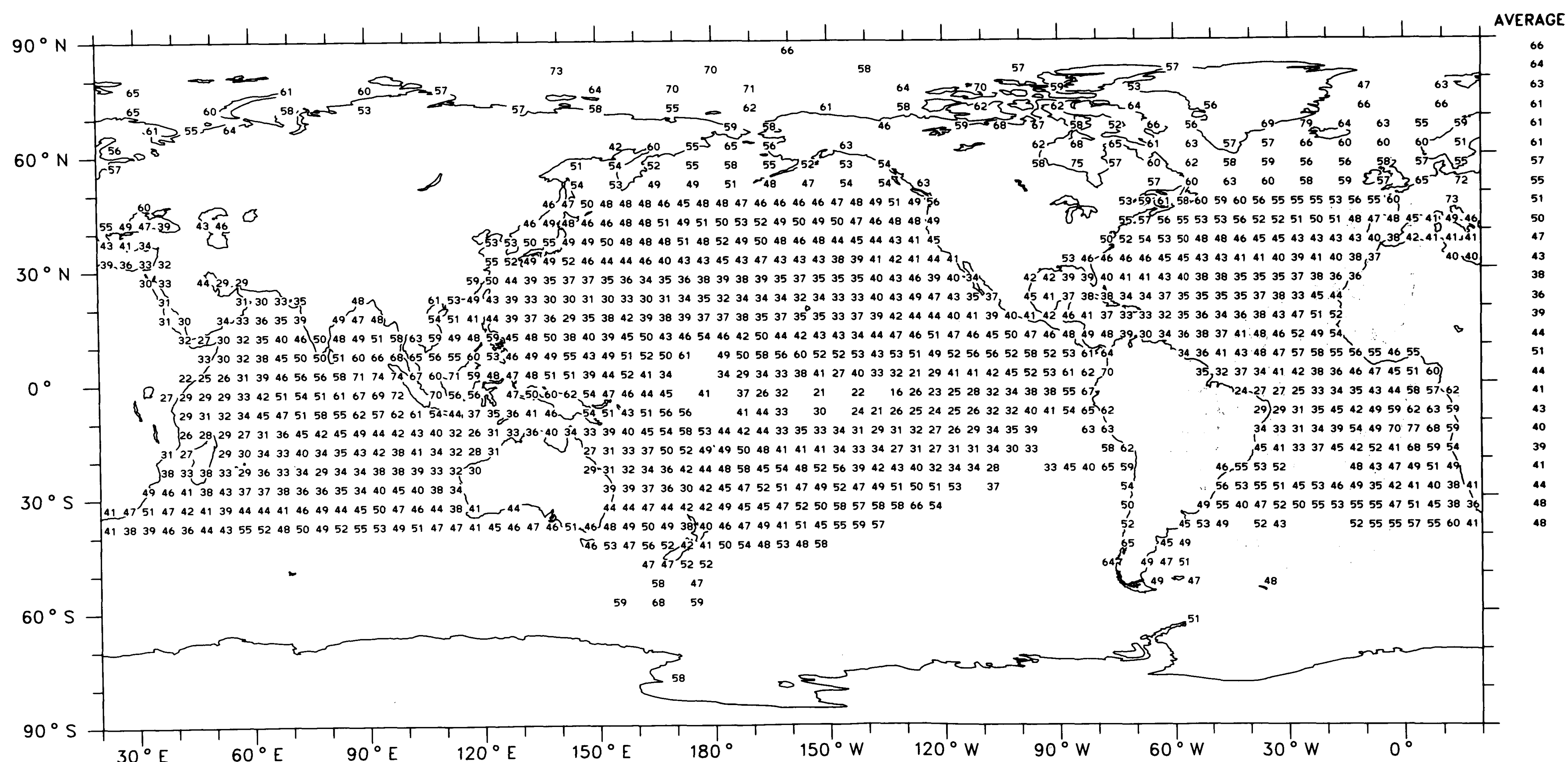




\section{Altostratus + Altocumulus}

\section{Average Cloud Amount (\%), 6-18 LT}

December, January, February (1952-1981)

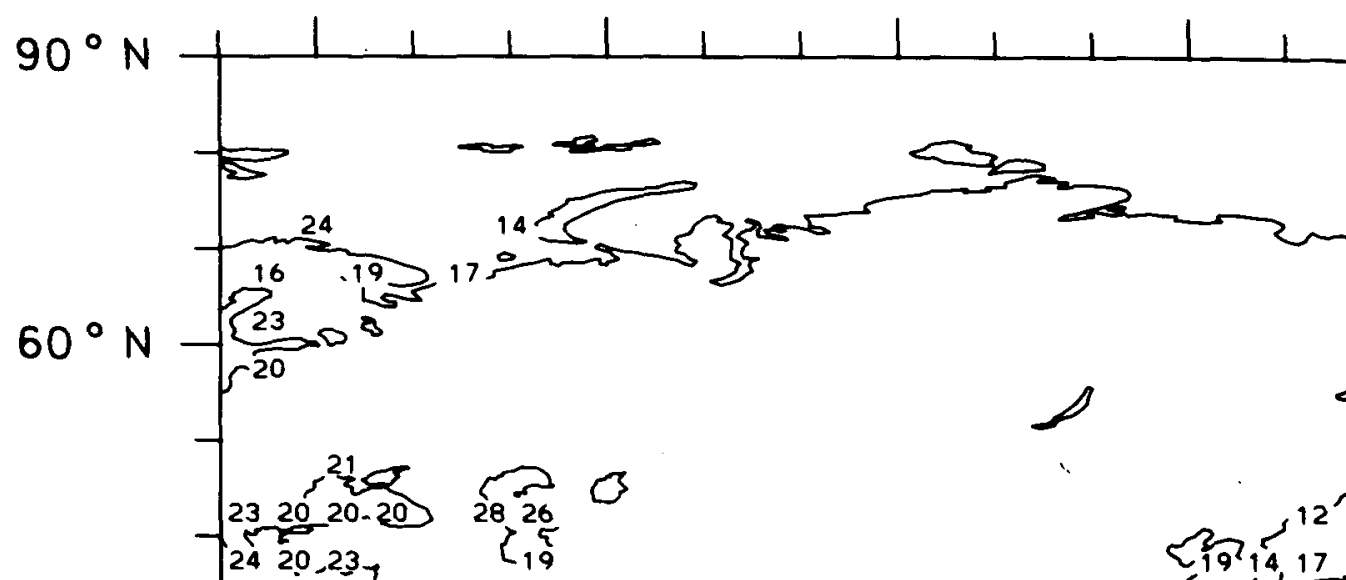

(1)

作

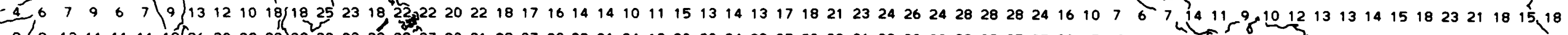

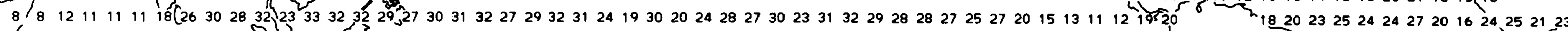

$0^{\circ}-\quad 0 \quad 6,7121316192027343835474142.524237,343639403235363336 \quad 252618131417181414122218222223262929313946$

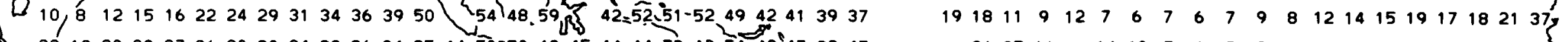

$121920232726303034323634354450=50,49454444452,40.5443^{\circ} 473847 \quad 262516$

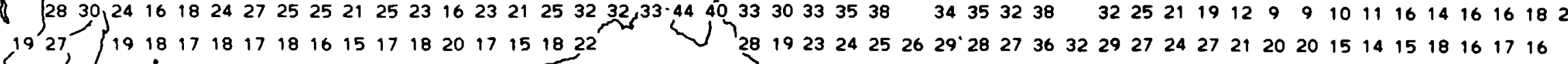

$26,29292933 \quad 25242724 \quad 262632)$ 15) $12101111 \quad 9 \quad 1112162927$ 1

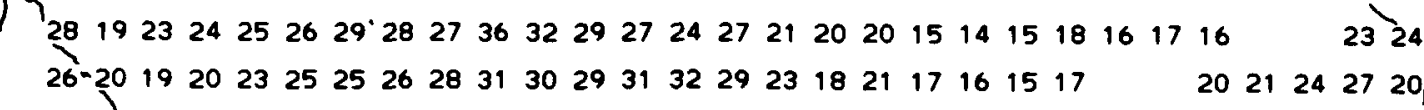

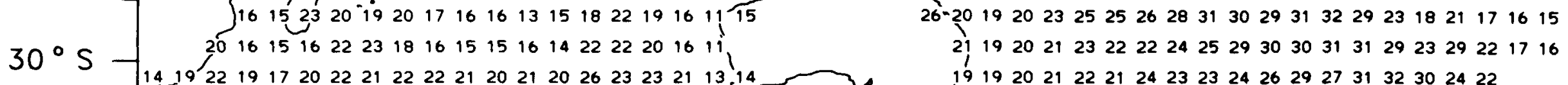
14. 192219172022 212222 21 20212026232321 13 14 191920212221242323242629273132302422

13172119212124212322241726312823292719202025232221,2021222221 19े22 24242932283130283027

$2928 \quad 18272226201623262230 \quad 2629293126192627283024 \sqrt{25} 25222424322^{2} 2127262926272628$

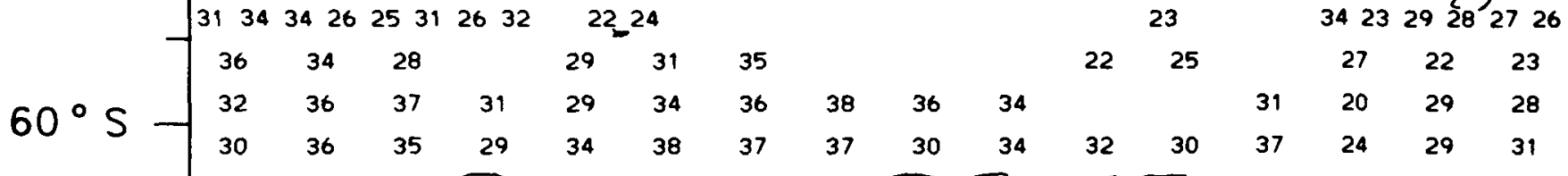

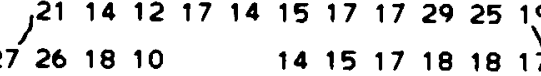

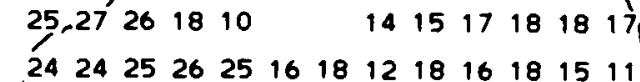
172015302528272923211620181210 22 $1832 \quad 2519$

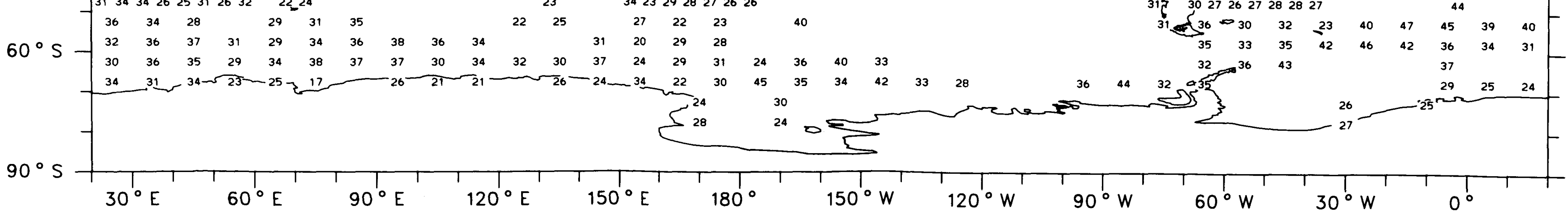

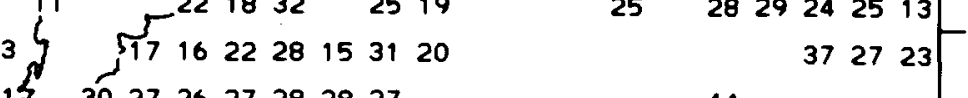




\section{Altostratus + Altocumulus}

\section{Average Cloud Amount (\%), 6-18 LT}

March, April, May (1952-1981)

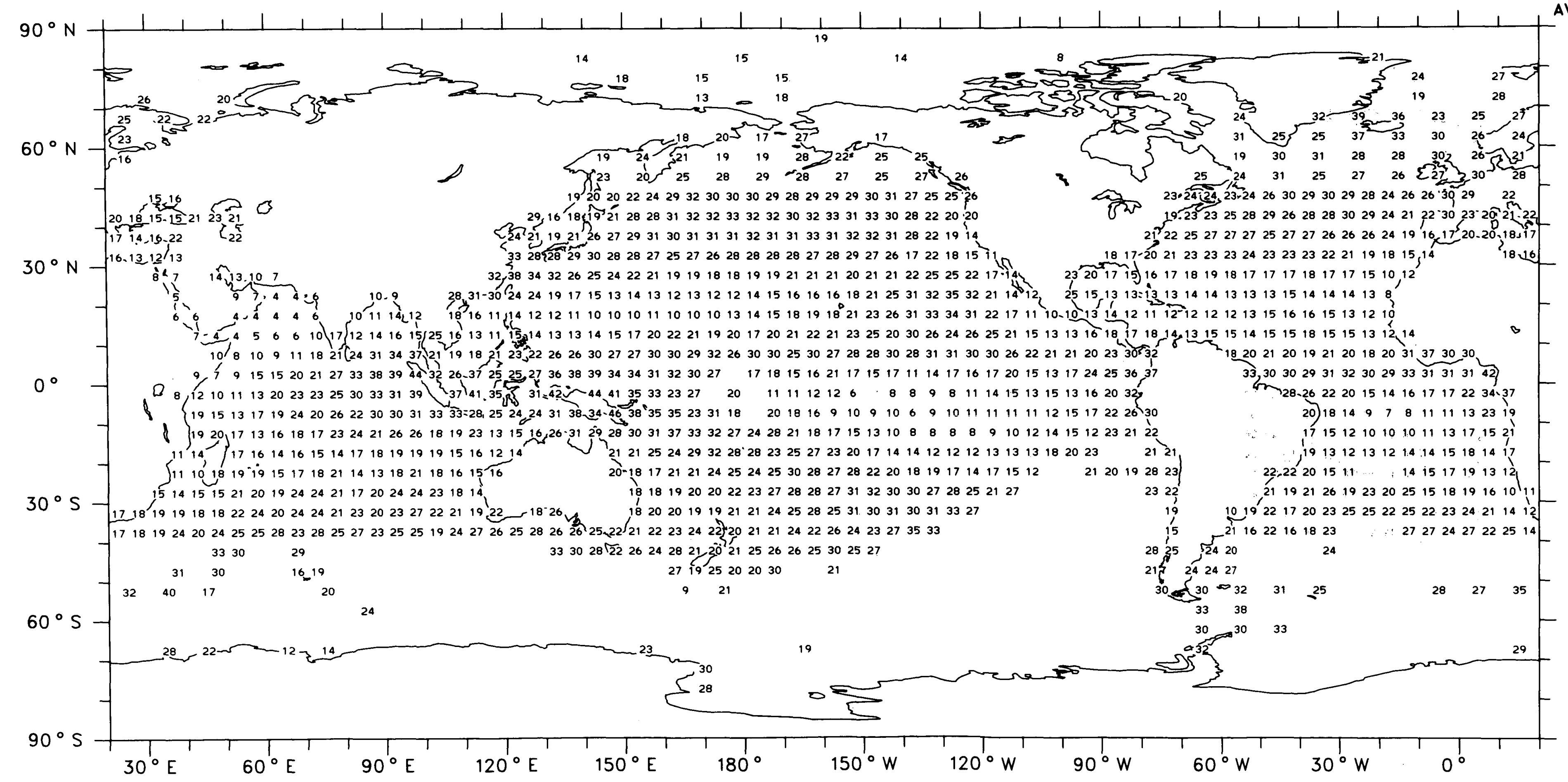


Altostratus + Altocumulus

Average Cloud Amount (\%), 6-18 LT

June, July, August (1952-1981)

Ocean Areas Only

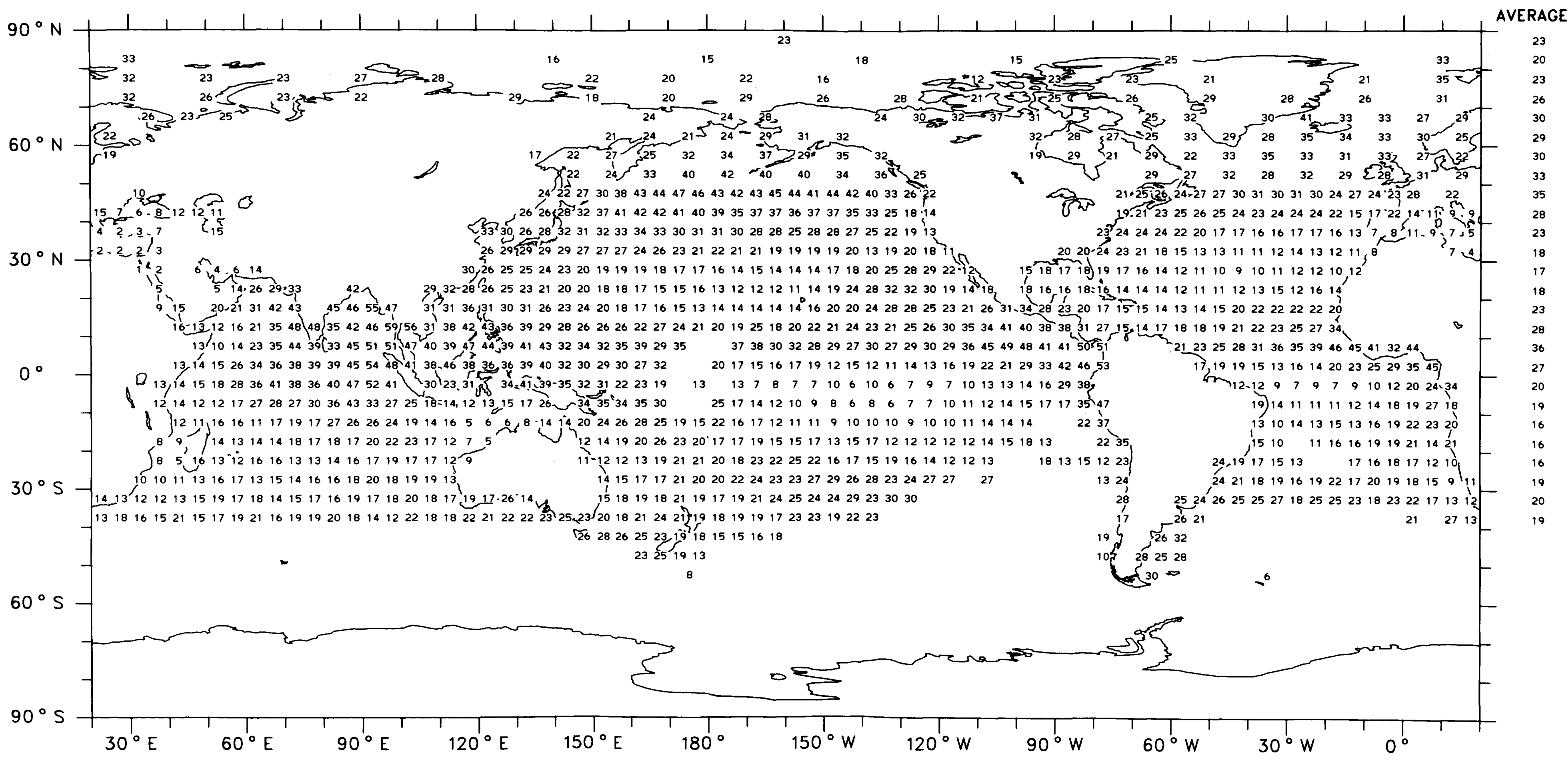

Map 86

GLOBAL AVERAGE (OCEAN) $22 \%$ 


\section{Altostratus + Altocumulus}

\section{Average Cloud Amount (\%), 6-18 LT}

September, October, November (1952-1981)

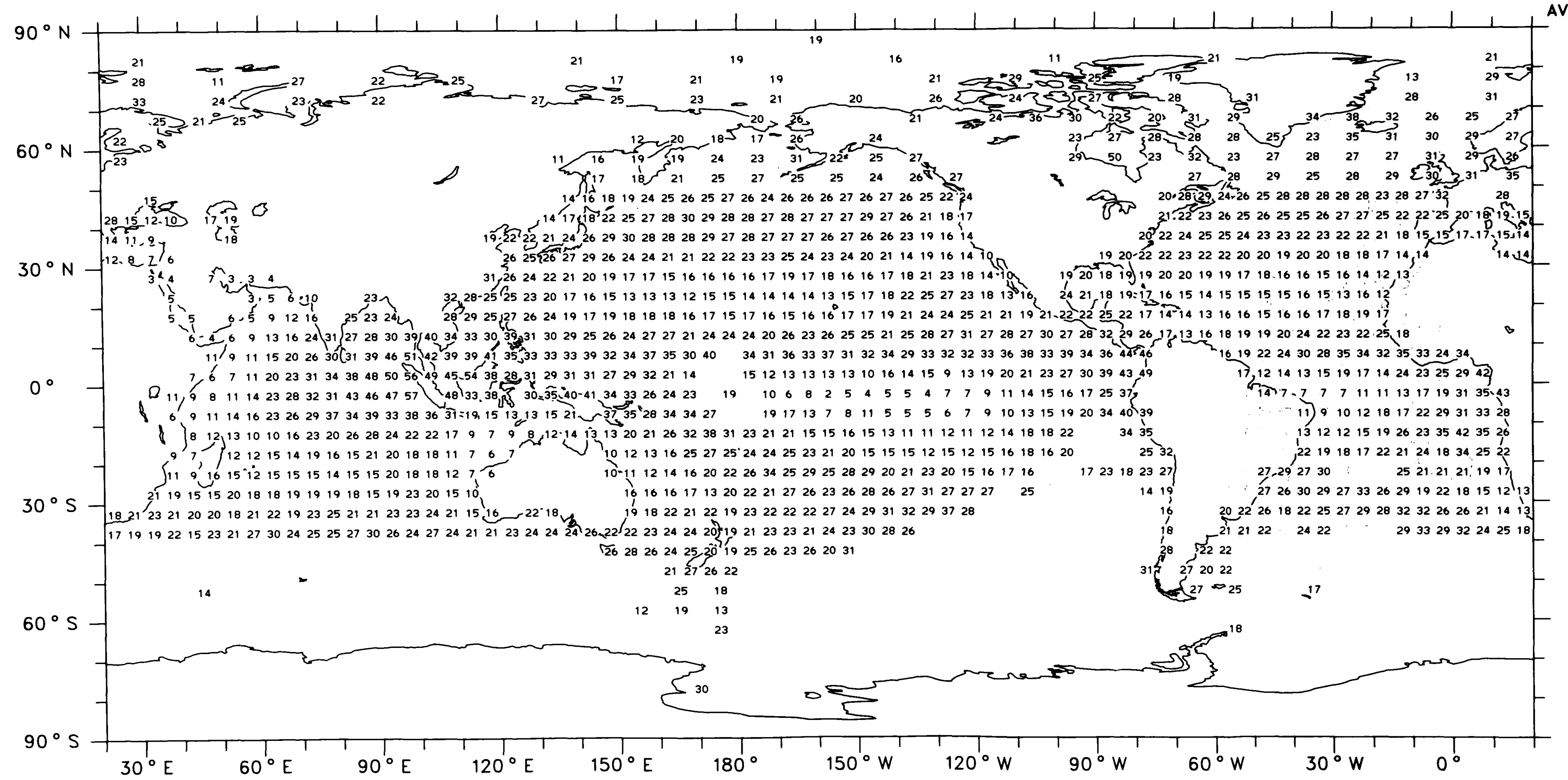




\section{Cirrus + Cirrostratus + Cirrocumulus}

Frequency of Occurrence (\%), 6-18 LT

December, January, February (1952-1981)

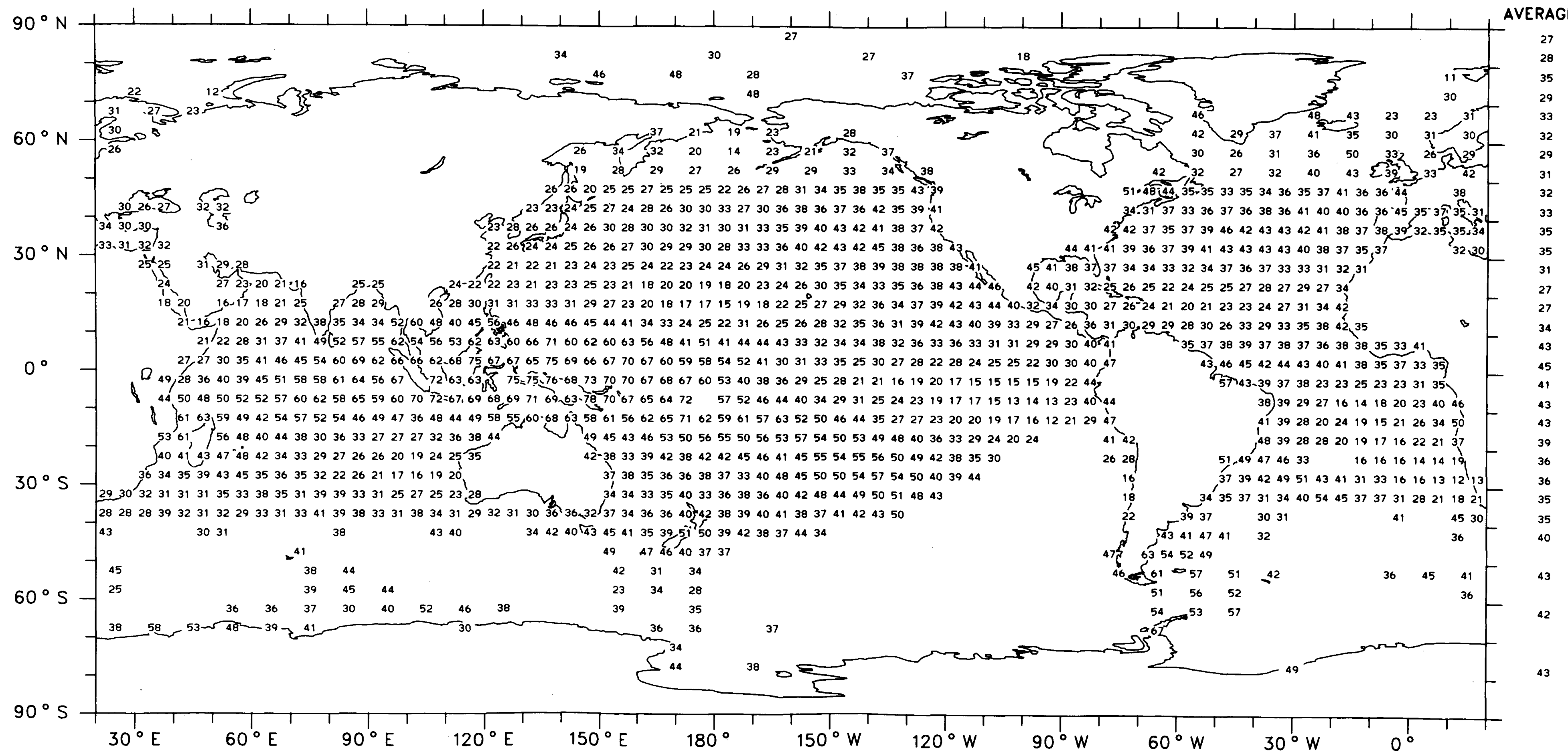




\section{Cirrus + Cirrostratus + Cirrocumulus}

\section{Frequency of Occurrence (\%), 6-18 LT}

March, April, May (1952-1981)

$$
90^{\circ}
$$

$60^{\circ} \mathrm{N}$
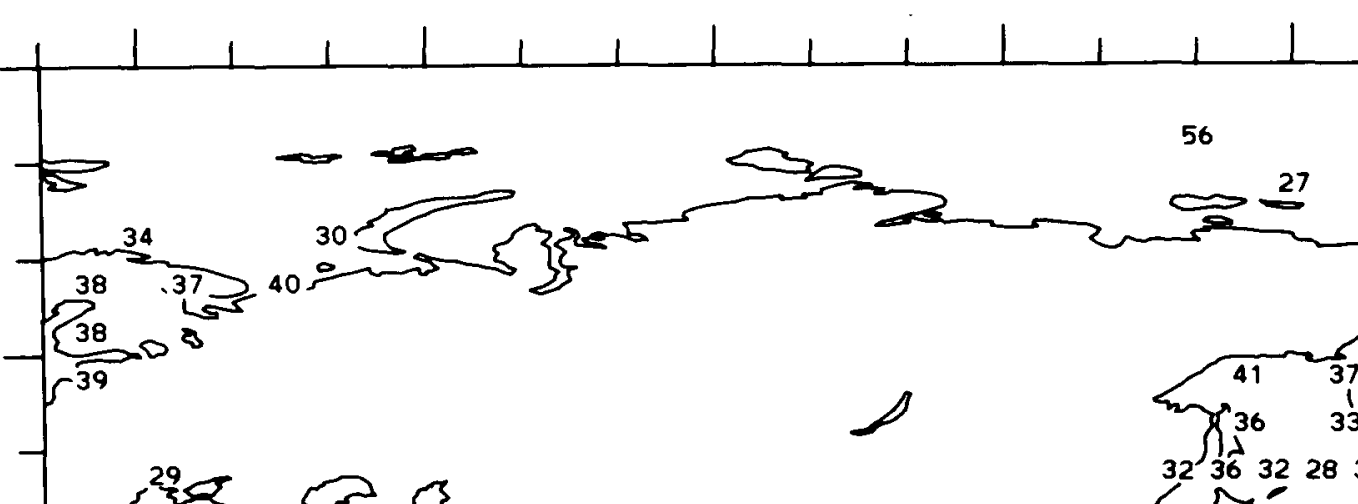

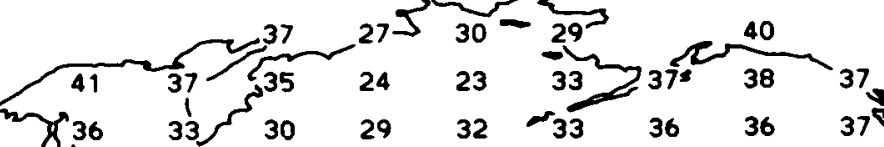

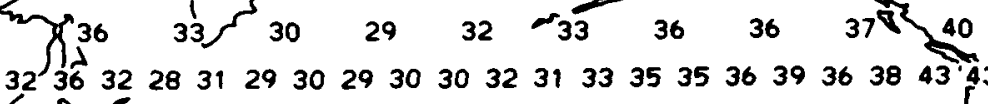
$3132 \widehat{333} 32 \quad 3532343537353837393838414037393137$ ?

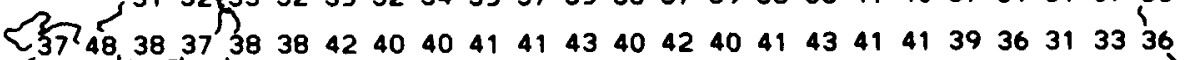

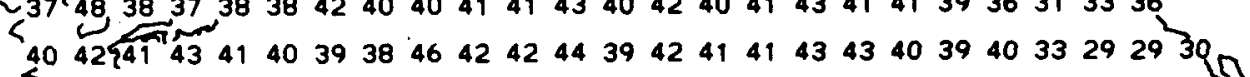

40 $394341 \quad 3838 \quad 353736353534343434353635353535 \quad 353232 \quad 32-3845$

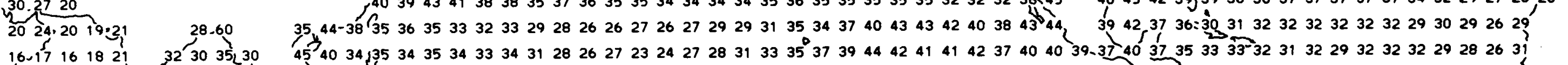

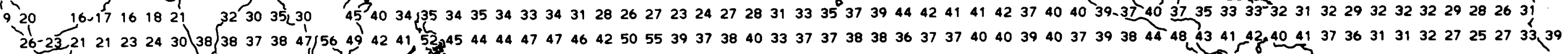

$36 / 293131344151$ (56 61 6369 69555525960558586162596262585258475742374144493840373938424946394345475055552

(1)

$0^{\circ}$

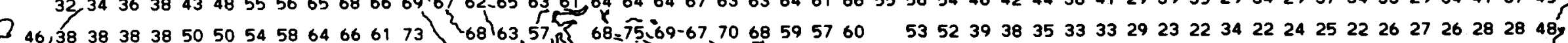

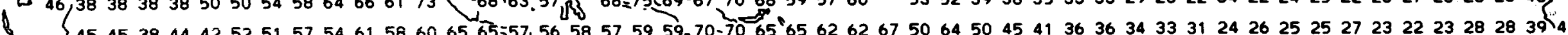

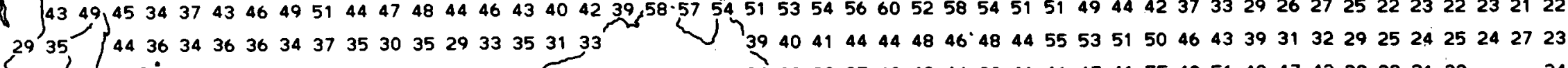
$2935, \begin{array}{ll}443634363634373530352933353133 \\ 24\end{array}$ 24283638392926272623252426262629 33

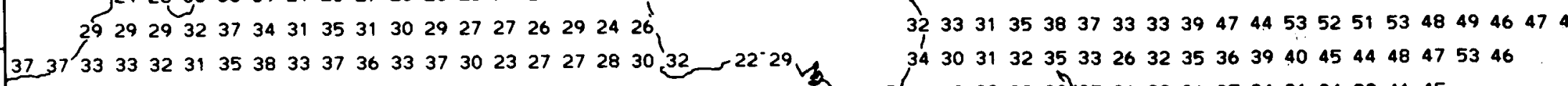

$30^{\circ} \mathrm{S}$

$3432383634353337374041344228332736353237363735 \quad 3641,37 / 40403838$ 38 37 37 31283135343634384145

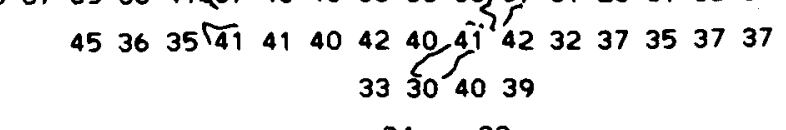

$60^{\circ} \mathrm{S}$

$90^{\circ} \mathrm{S}$

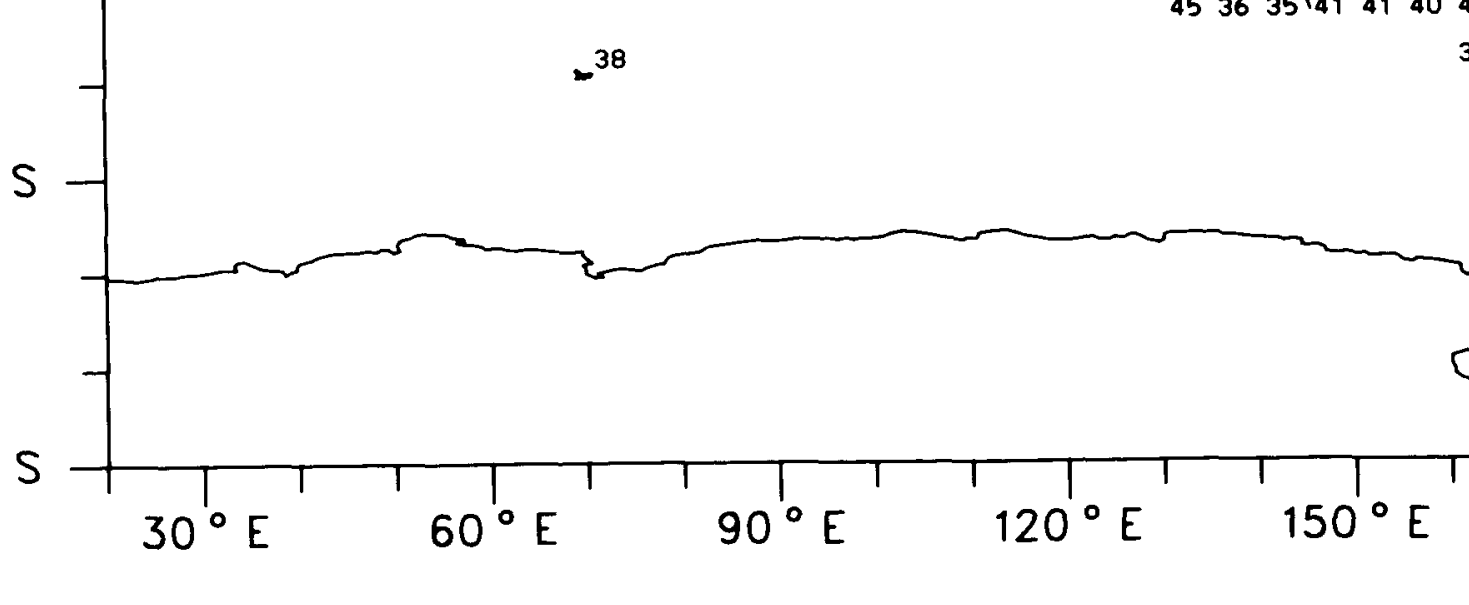

$24 \quad 22$
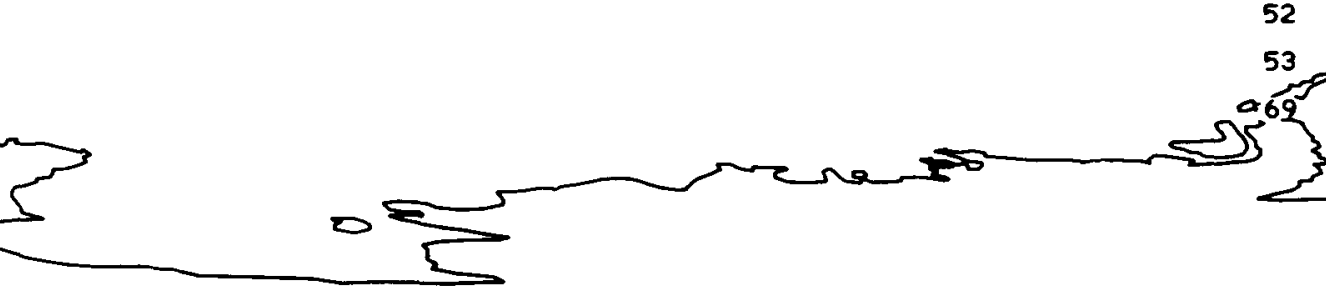

$180^{\circ}$

$150^{\circ} \mathrm{W}$

$120^{\circ} \mathrm{W}$

$90^{\circ} \mathrm{W}$

4038313535313339485346,48
394847445248484755535348

(n) 50.46474538343843394145 .56

$40) 44362727263230284036$ 4342312721211726212337

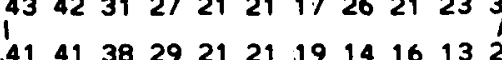
$35.40433636: \quad 212520151415$ $353237404137 \quad 36353024 \quad 241918$

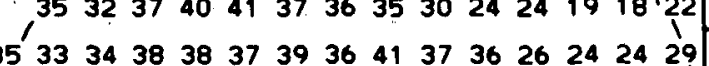

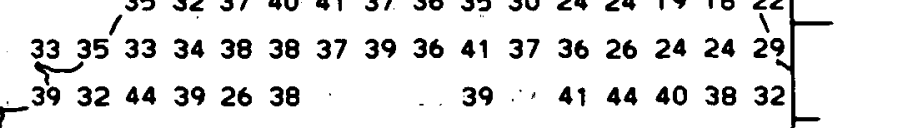


Cirrus + Cirrostratus + Cirrocumulus

Frequency of Occurrence (\%), 6-18 LT

June, July, August (1952-1981)

Ocean Areas Only

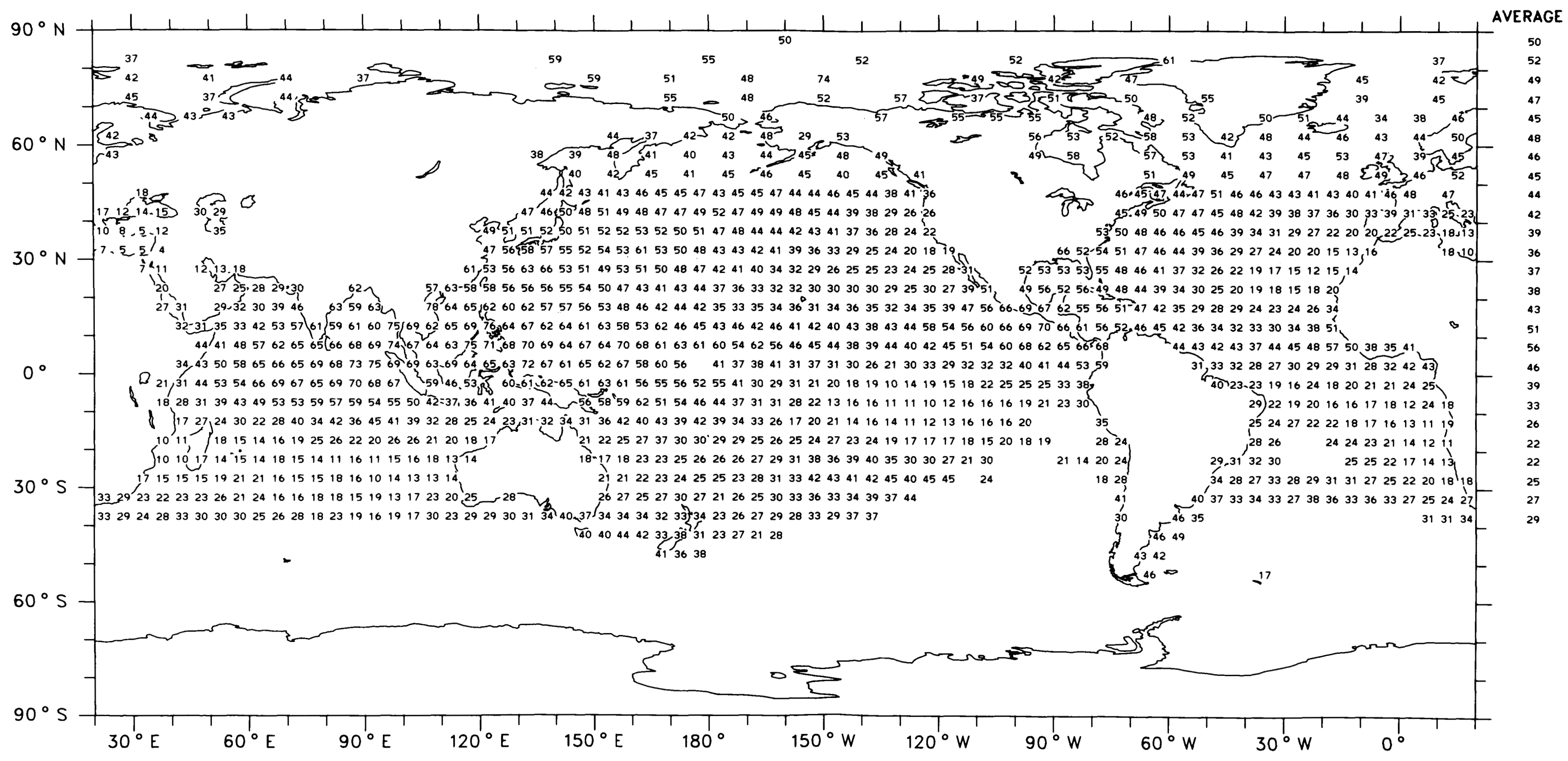

Map 90

GLOBAL AVERAGE (OCEAN) $36 \%$ 


\section{Cirrus + Cirrostratus + Cirrocumulus}

Frequency of Occurrence (\%), 6-18 LT

September, October, November (1952-1981)

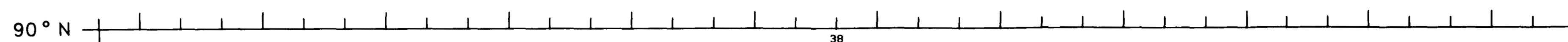
38

$60^{\circ}$

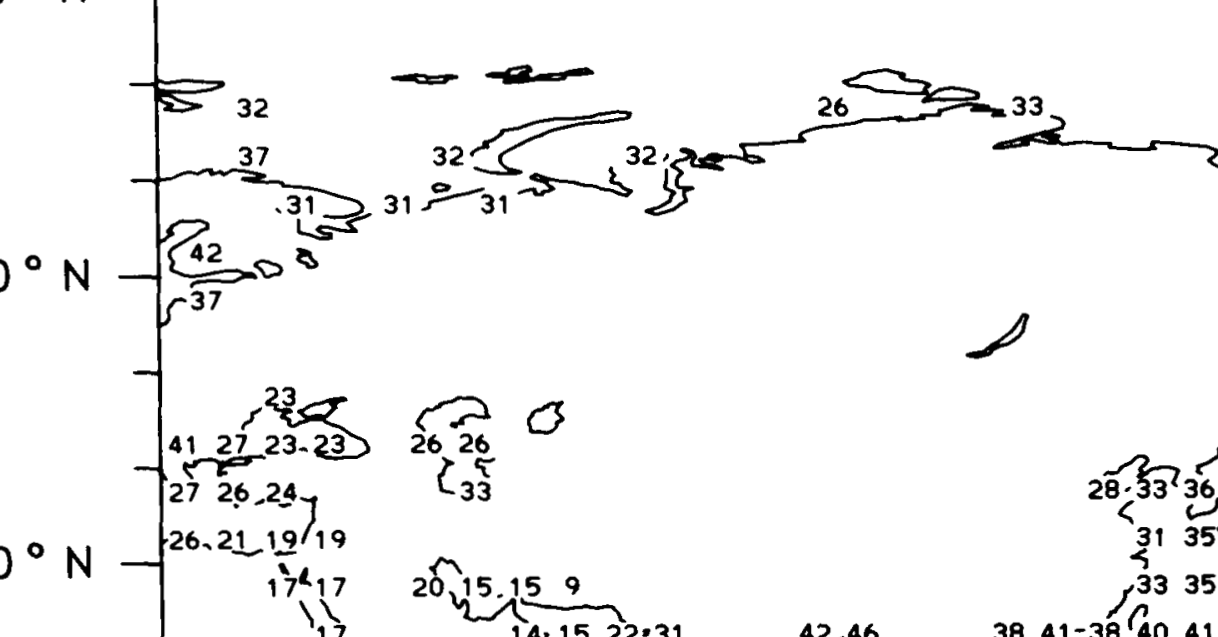

53 32 $\underbrace{53} \underbrace{32}-{ }^{60}-28$ 43.

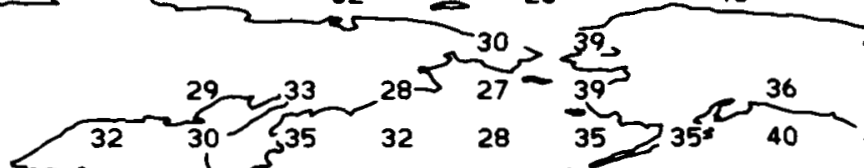

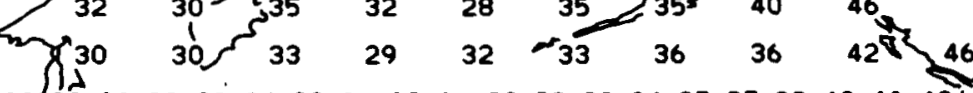
30 3029303234333132312933333437373840404340 33 363537394143414243424137404141424241403631303

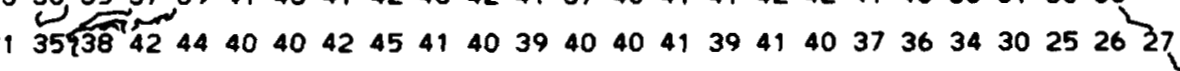
3028303028

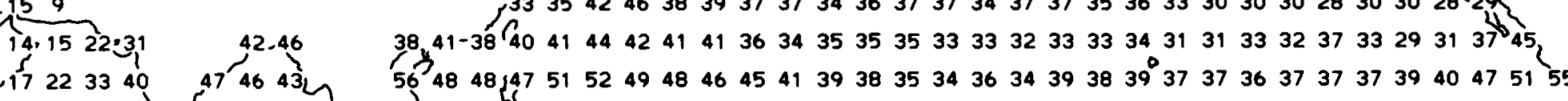
18 18 14017223340

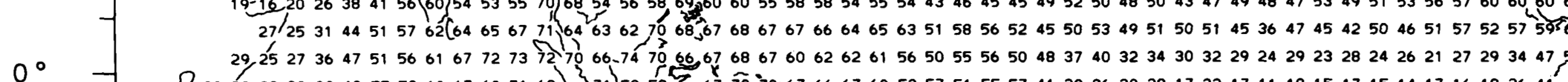

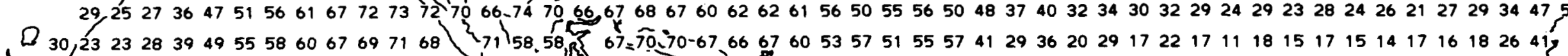

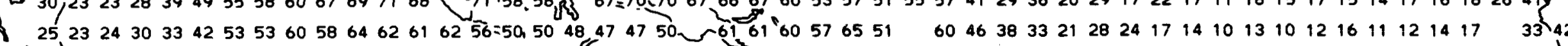

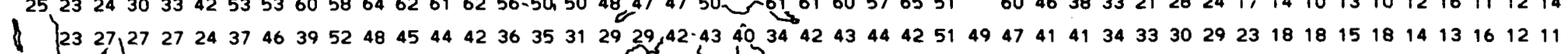
$2323, \lcm{26} 2325272730292825262317191821$ \{24 $252427 \not 27222221211818191815141113$ $30^{\circ} \mathrm{S}-\begin{array}{rl}30 & 30262727292726282922172017161616 \\ 3736 & 3231353130343328293325292727252223 \\ 34 & 30\end{array}$

$\sqrt{26} 2423273736 \quad 373636404339403432332526 \quad 6 \quad 23192021 \quad 23$ $20-212125282830363938354237425051504035343326$
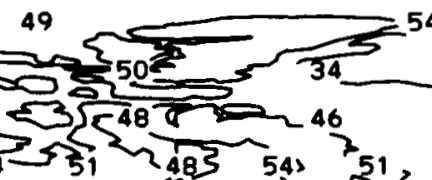

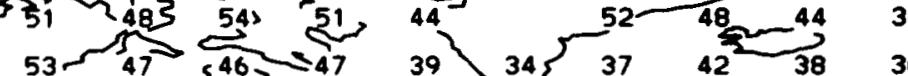

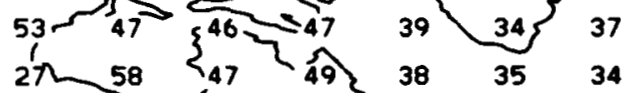
325

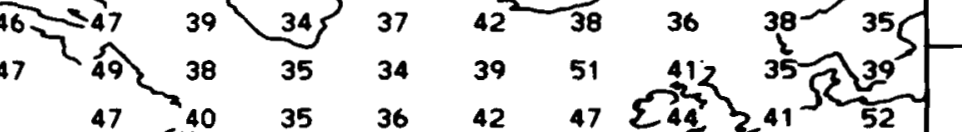

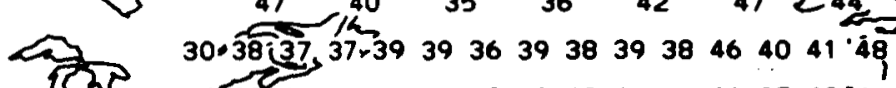

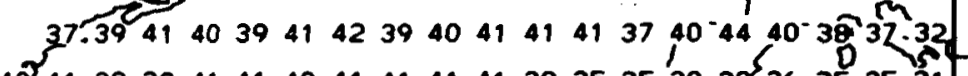
$44,11304394141494141414138353539,58$ $4441-4342414444424442403838343332,35$ $434444) 4545454243434339373535293131$ $28252830323127303837384336444644495046 \quad 40$

$$
32464145
$$

$\begin{array}{lll} & 36 & 33 \\ 22 & 21 & 18\end{array}$

$60^{\circ} \mathrm{S}$
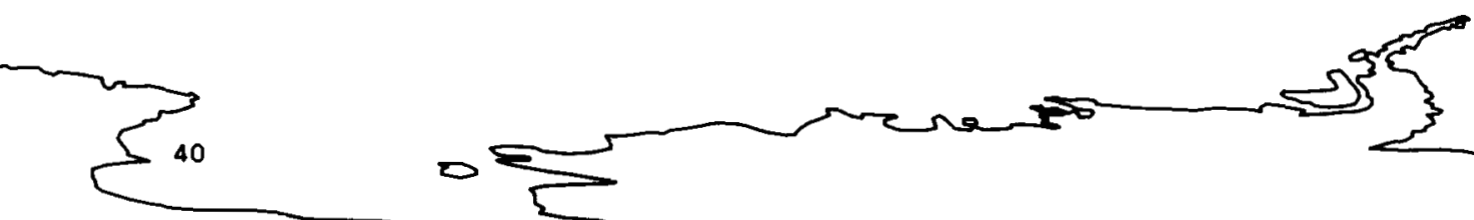

$90^{\circ} \mathrm{S}$

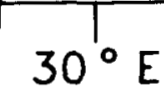

$60^{\circ}$

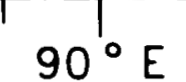

$120^{\circ} \mathrm{E}$

$150^{\circ} \mathrm{E}$

$180^{\circ}$

$150^{\circ} \mathrm{W}$

$120^{\circ} \mathrm{W}$

$90^{\circ} \mathrm{W}$

$60^{\circ} \mathrm{W}$

$30^{\circ} \mathrm{W}$

$0^{\circ}$ 
Cirrus + Cirrostratus + Cirrocumulus

Amount-When-Present (\%), 6-18 LT

December, January, February (1952-1981)

Ocean Areas Only

ZONAL

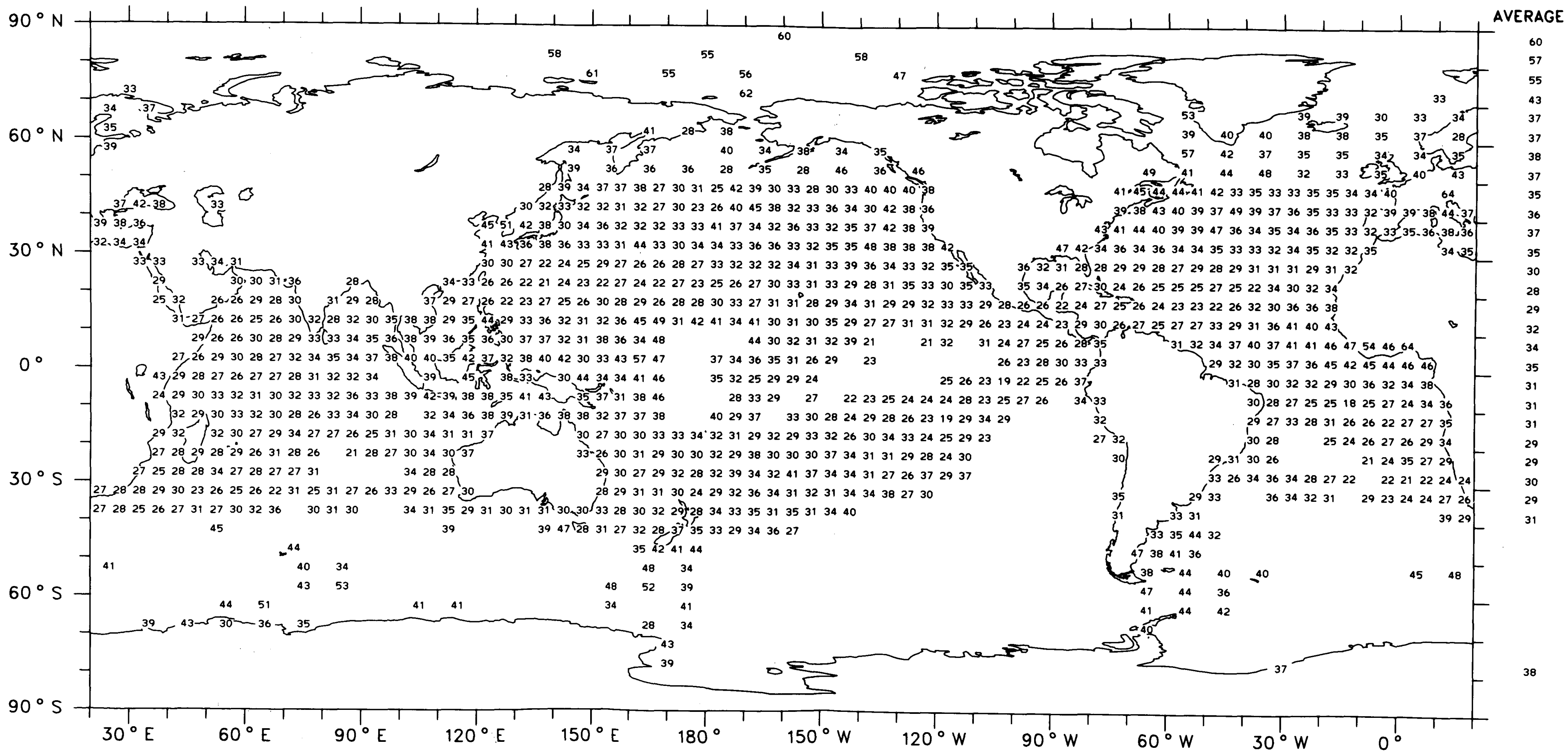

Map 92

GLOBAL AVERAGE (OCEAN) $34 \%$ 


\section{Cirrus + Cirrostratus + Cirrocumulus}

\section{Amount-When-Present (\%), 6-18 LT}

March, April, May (1952-1981)
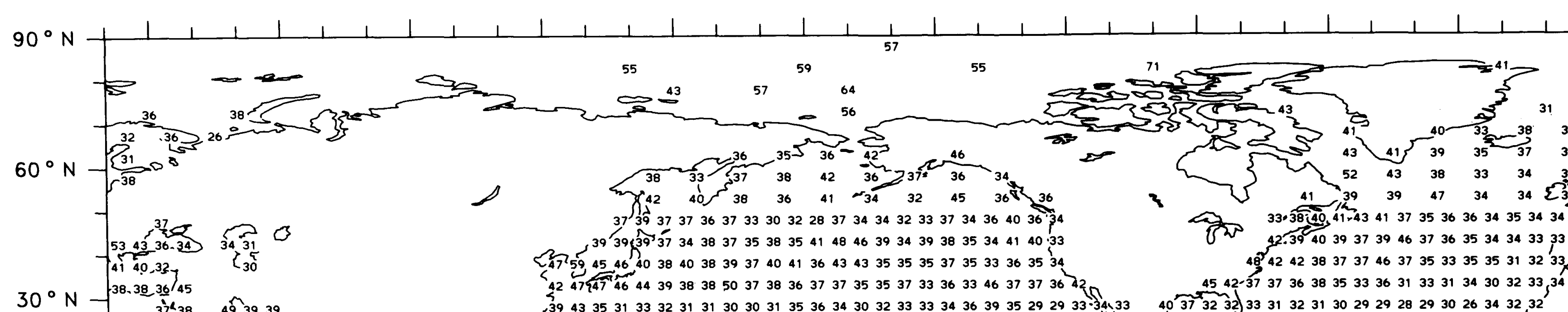

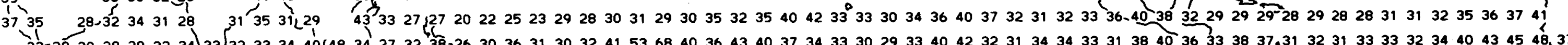

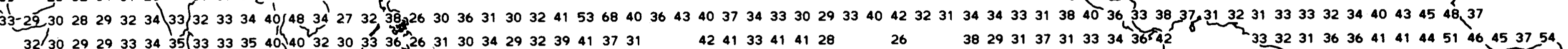

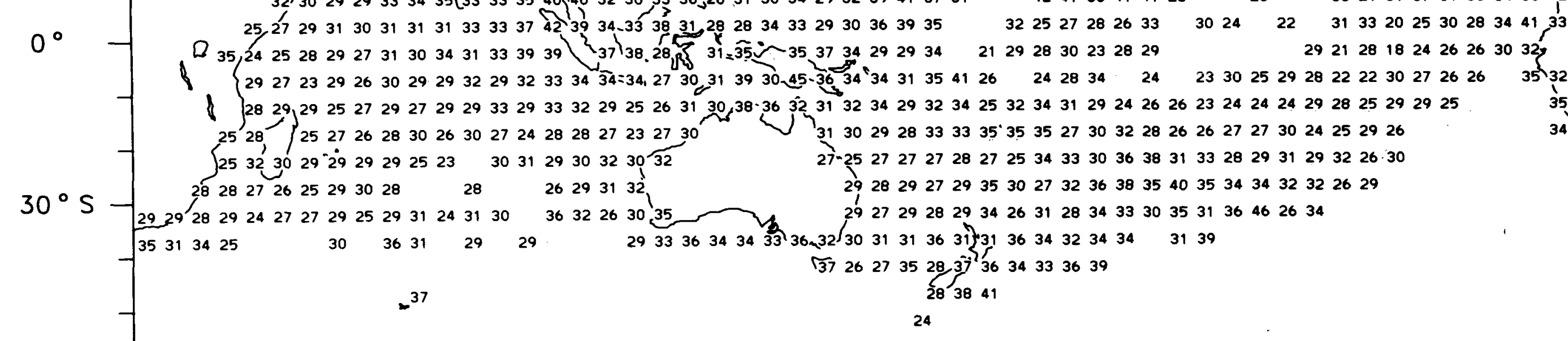
$25,2729313031313133 \quad 333742,3934.33 \quad 3831282834332930363935 \quad 32 \quad 2527282633 \quad 3024 \quad 22 \quad 313320253028344133$

24

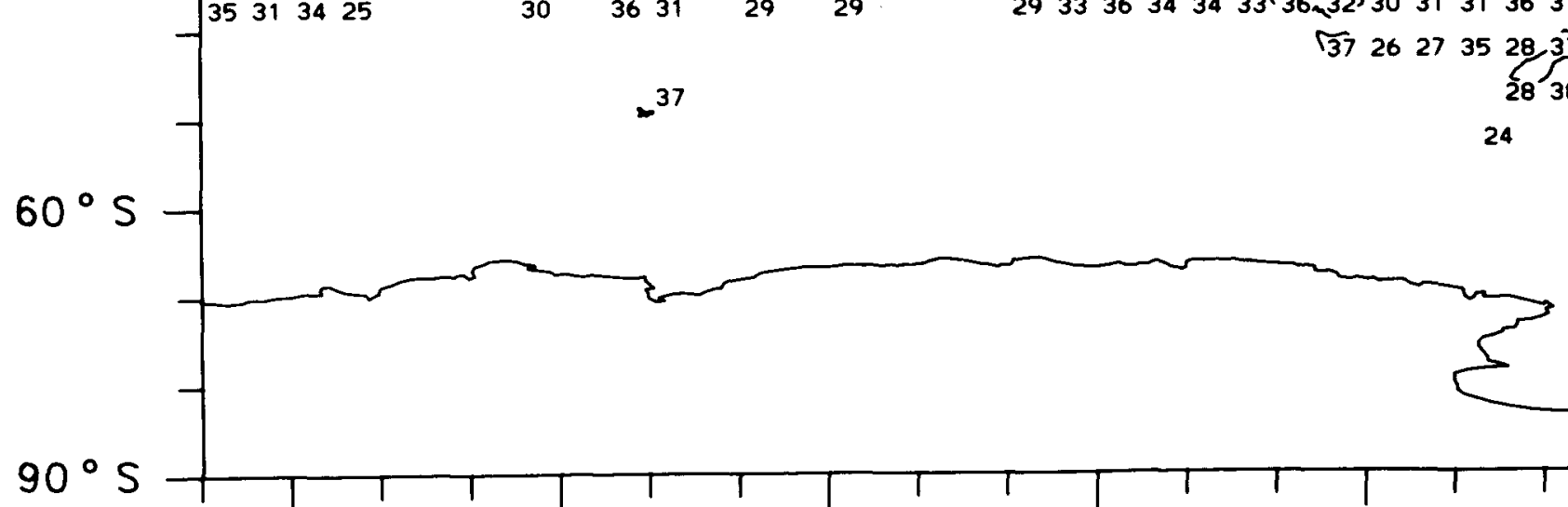

333233323738373737393945 $31282930283131293138 \cdot 36$ 


\section{Cirrus + Cirrostratus + Cirrocumulus}

\section{Amount-When-Present (\%), 6-18 LT}

June, July, August (1952-1981)

Ocean Areas Only

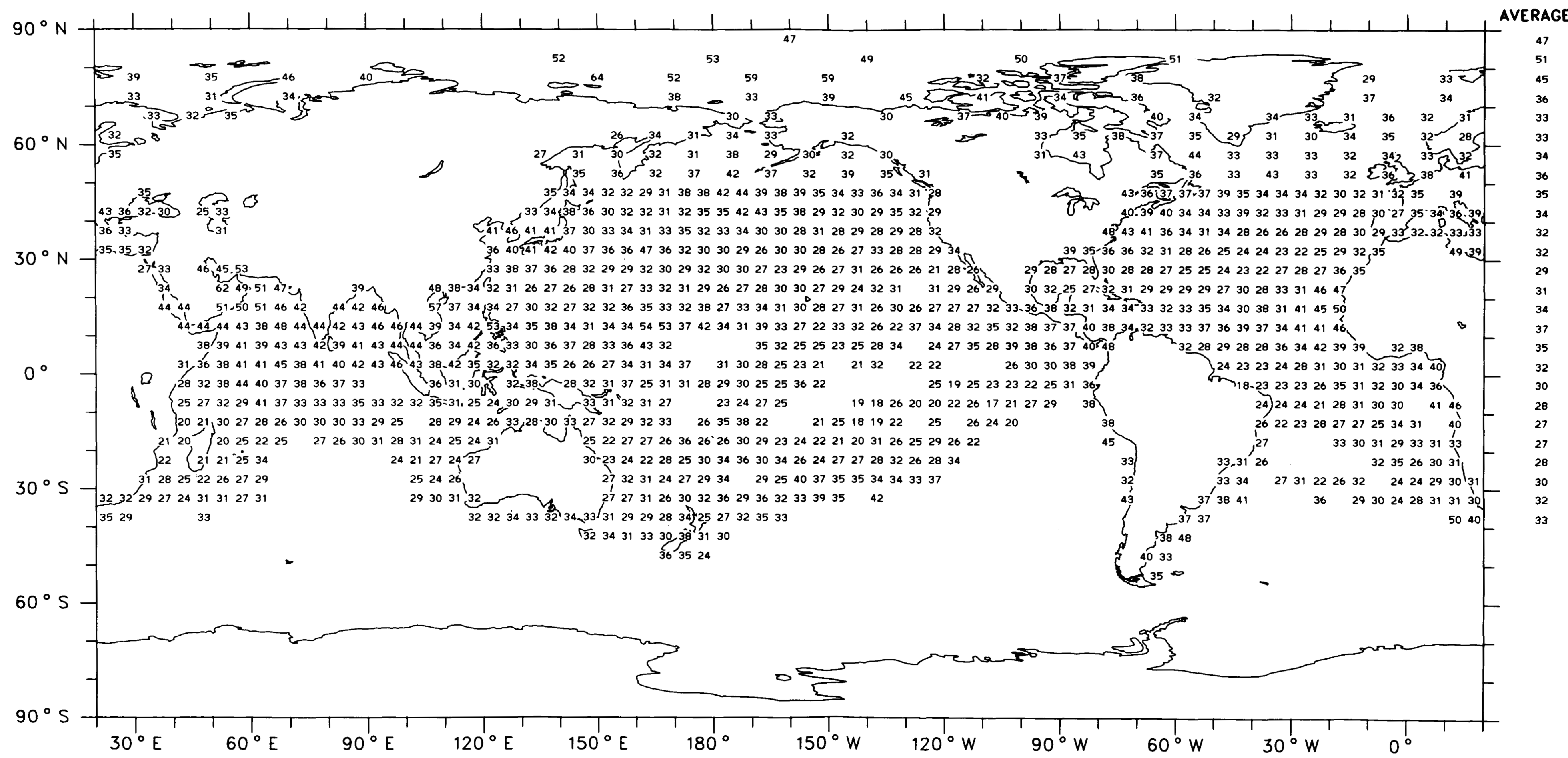

Map 94

global average (ocean) $32 \%$ 


\section{Cirrus + Cirrostratus + Cirrocumulus}

\section{Amount-When-Present (\%), 6-18 LT}

September, October, November (1952-1981)

Ocean Areas Only

ZONAL AVERAGE

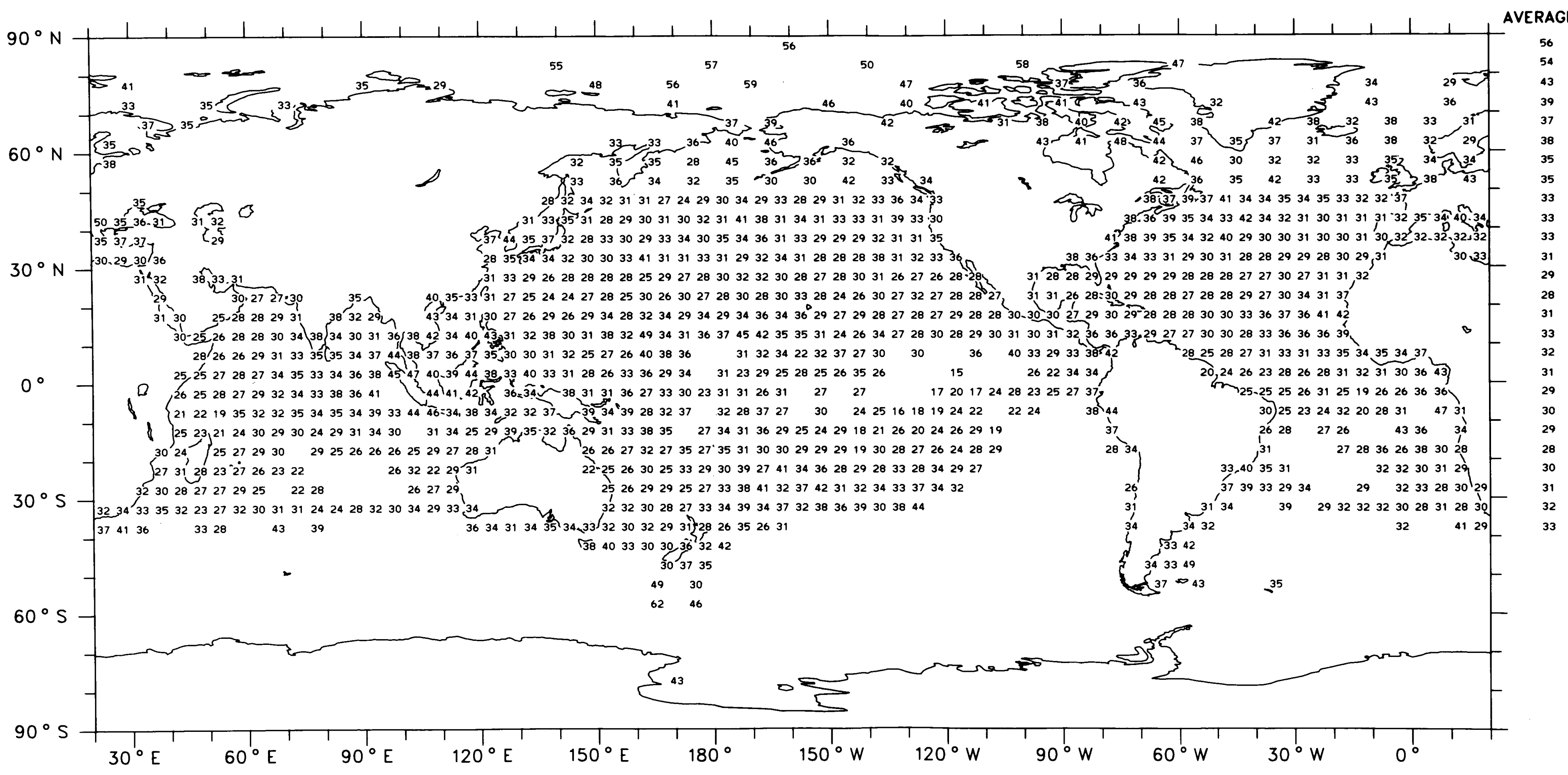


Cirrus + Cirrostratus + Cirrocumulus

Average Cloud Amount (\%), 6-18 LT

December, January, February (1952-1981)

Ocean Areas Only

ZONAL

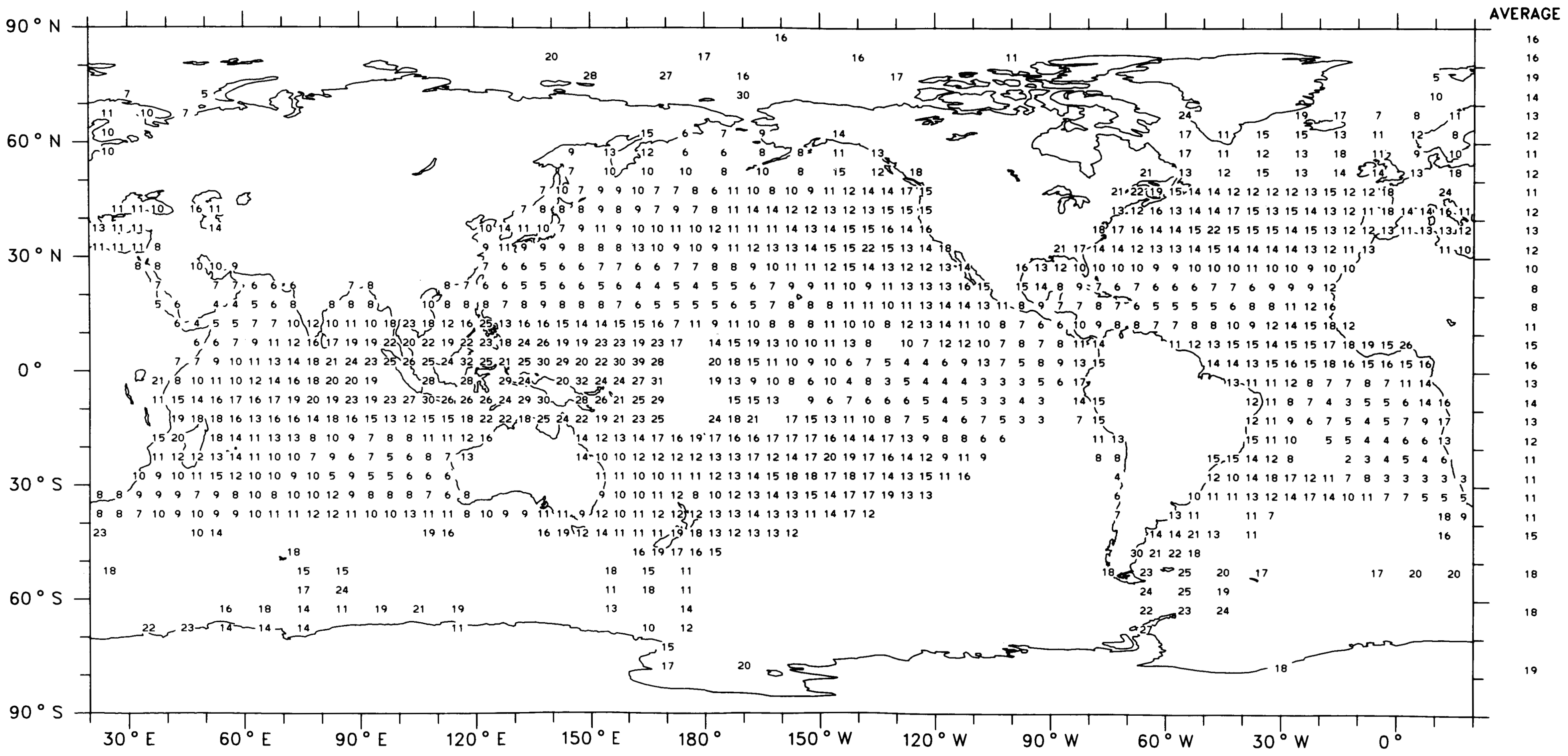

Map 96

GLOBAL AVERAGE (OCEAN) $13 \%$ 


\title{
Cirrus + Cirrostratus + Cirrocumulus
}

\section{Average Cloud Amount (\%), 6-18 LT}

March, April, May (1952-1981)

$90^{\circ} \mathrm{N}$

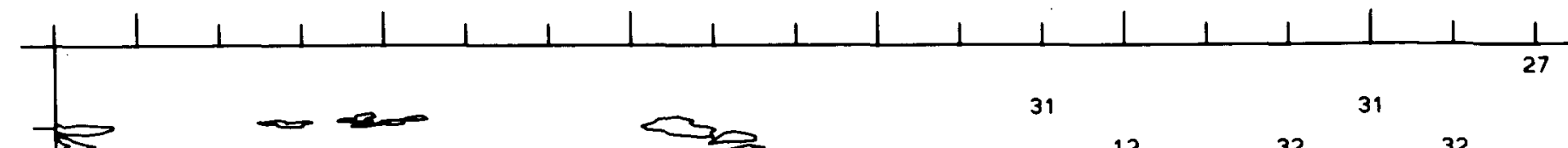

29

$$
60^{\circ}
$$

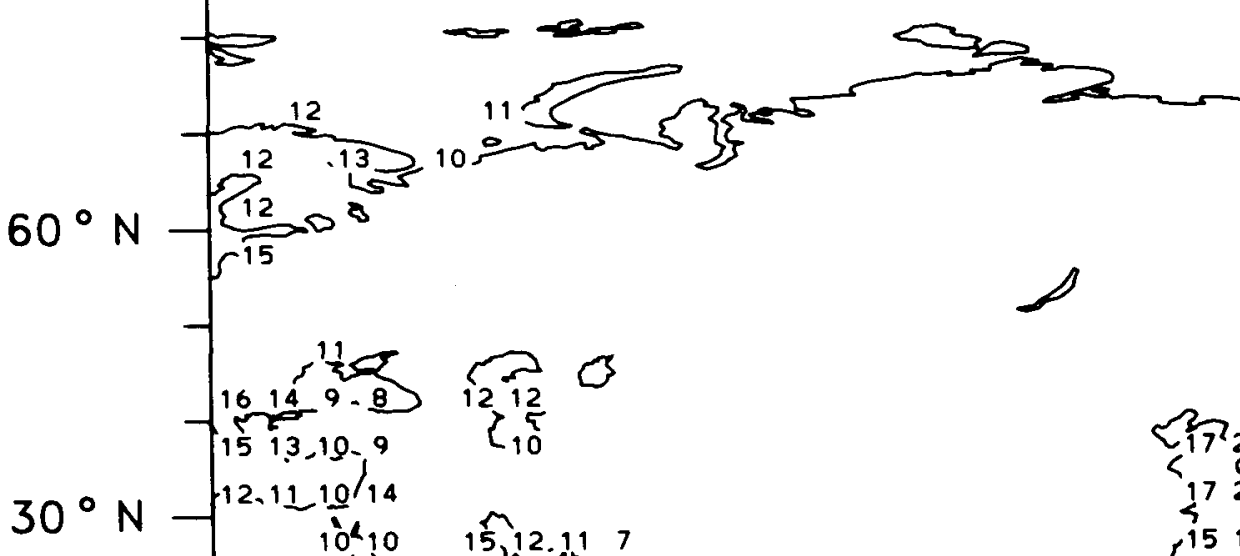

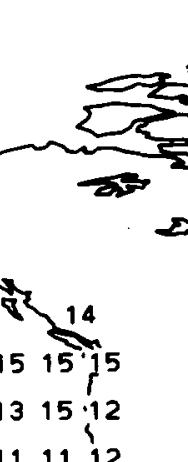

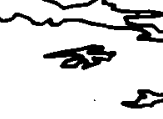

33

\author{
3
} $1 \quad 1$

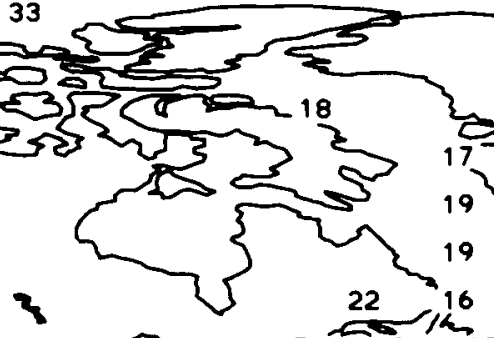

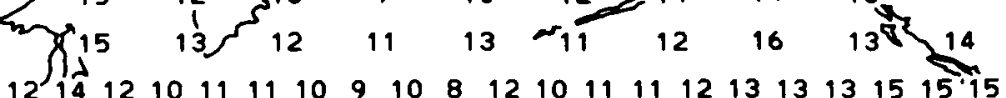

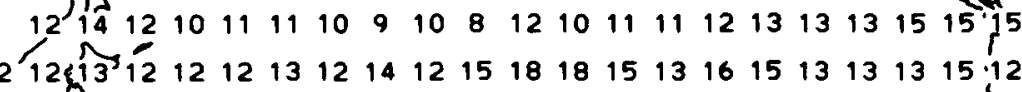

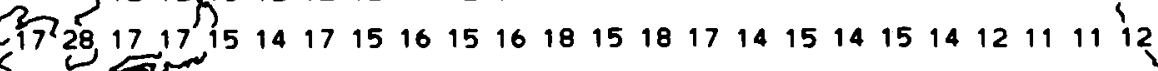

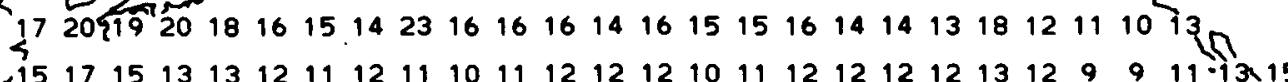

ass $22=16$ $\begin{array}{lllll}15 & 13 & 13 & 15 & 14\end{array}$ 11

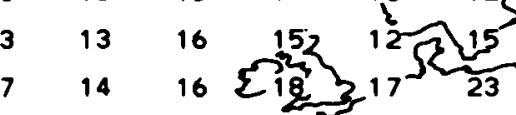

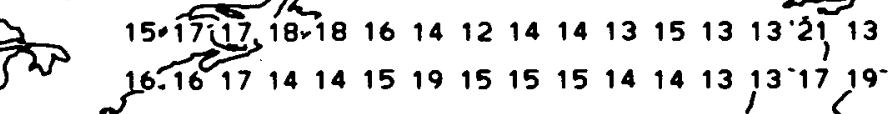
21 18 1614141422161514141411111315 19. 2518 - 1615131514141613131212101010,12 19711412) 1311111211111110101089989 $141110: 9999999889998999910$

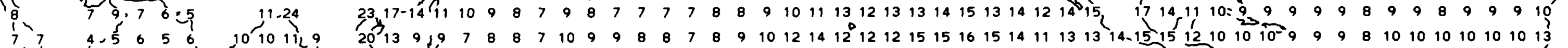
$\begin{array}{rl}-7 & 6 \\ 11 & 6\end{array}$ 8.

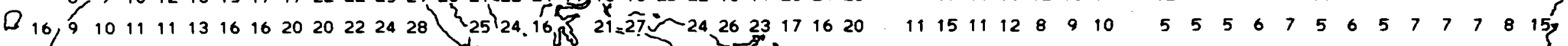

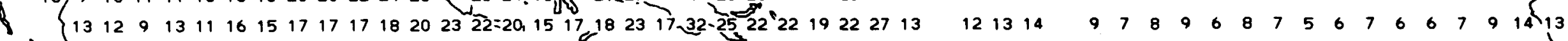

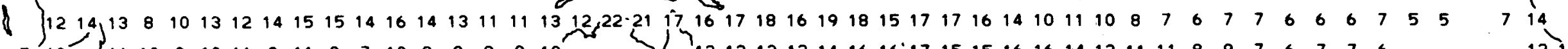

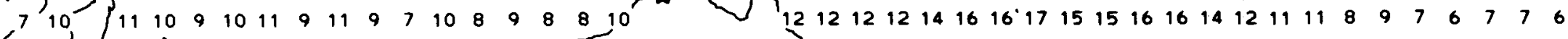
Jo 9 111119977606877888 8 $9711 \quad 9-8991112121014151415211517141413910810$

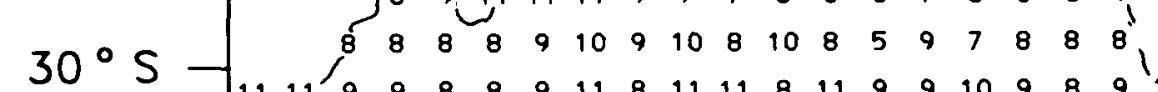

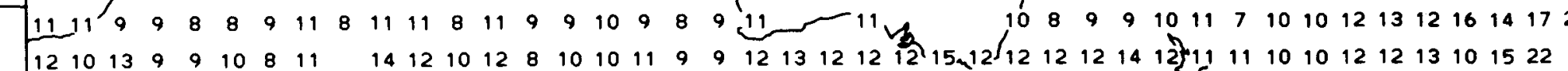

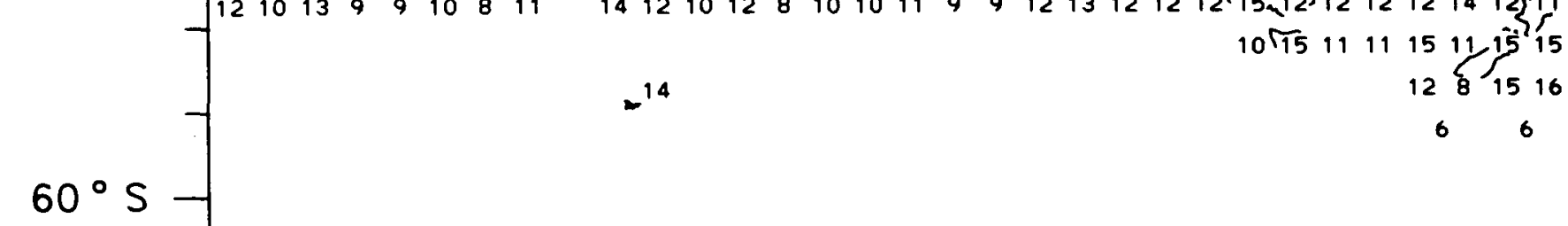
$60^{\circ}$

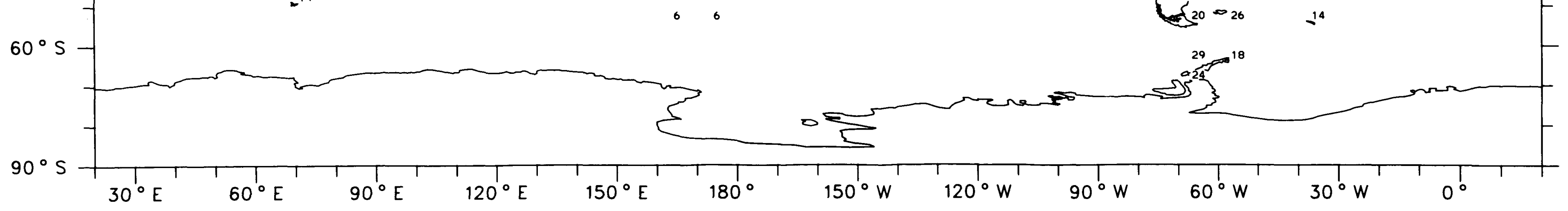




\section{Cirrus + Cirrostratus + Cirrocumulus}

\section{Average Cloud Amount (\%), 6-18 LT}

June, July, August (1952-1981)

Ocean Areas Only

ZONAL AVERAGE

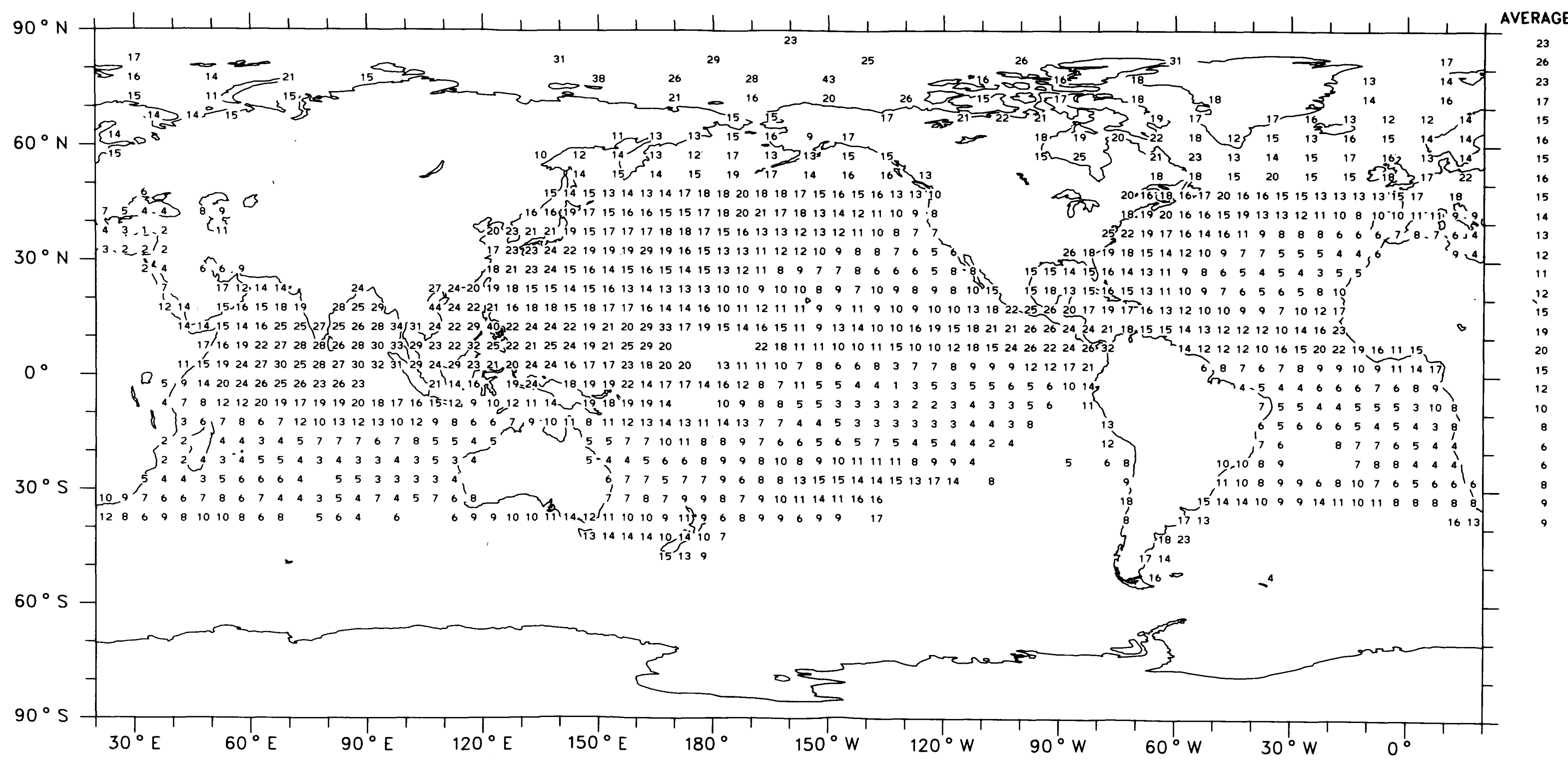

Map 98

global average (OCEAN) $12 \%$ 


\section{Cirrus + Cirrostratus + Cirrocumulus}

Average Cloud Amount (\%), 6-18 LT

September, October, November (1952-1981)

$$
90^{\circ}
$$

$$
\infty
$$
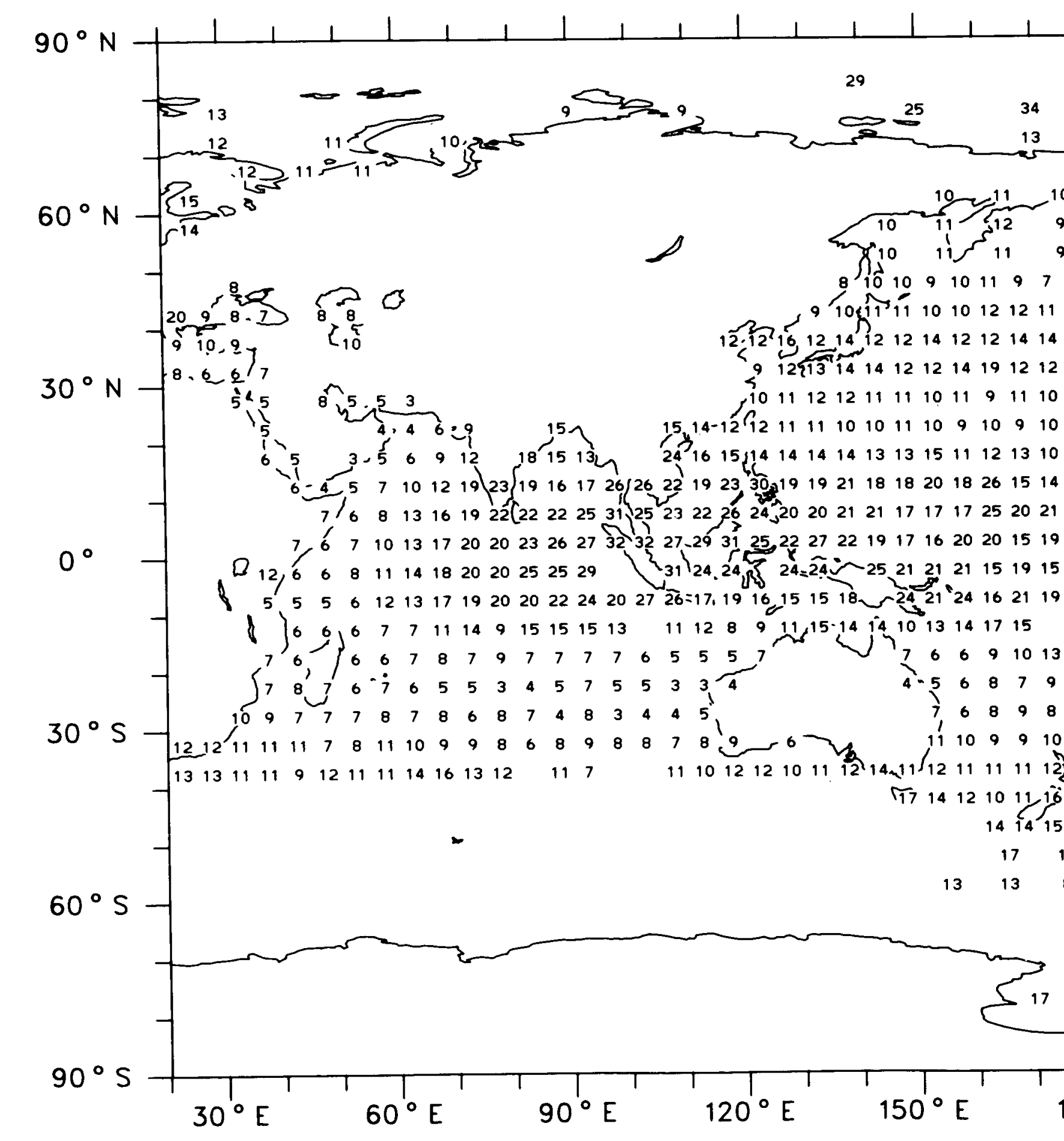
Sky Obscured Due to Fog

Frequency of Occurrence (\%)

December, January, February (1952-1981)

Ocean Areas Only

ZONAL

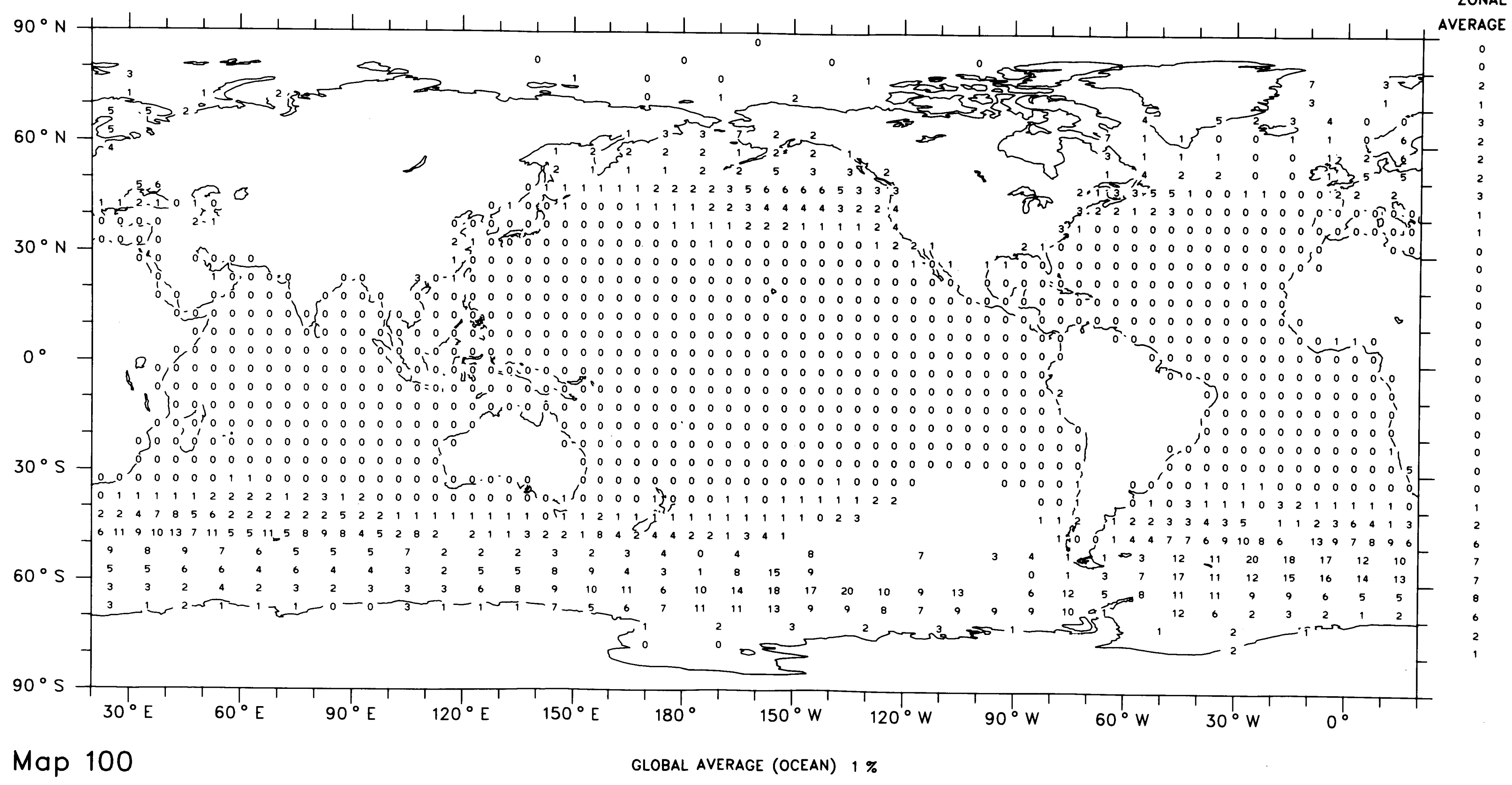


March, April, May (1952-1981)

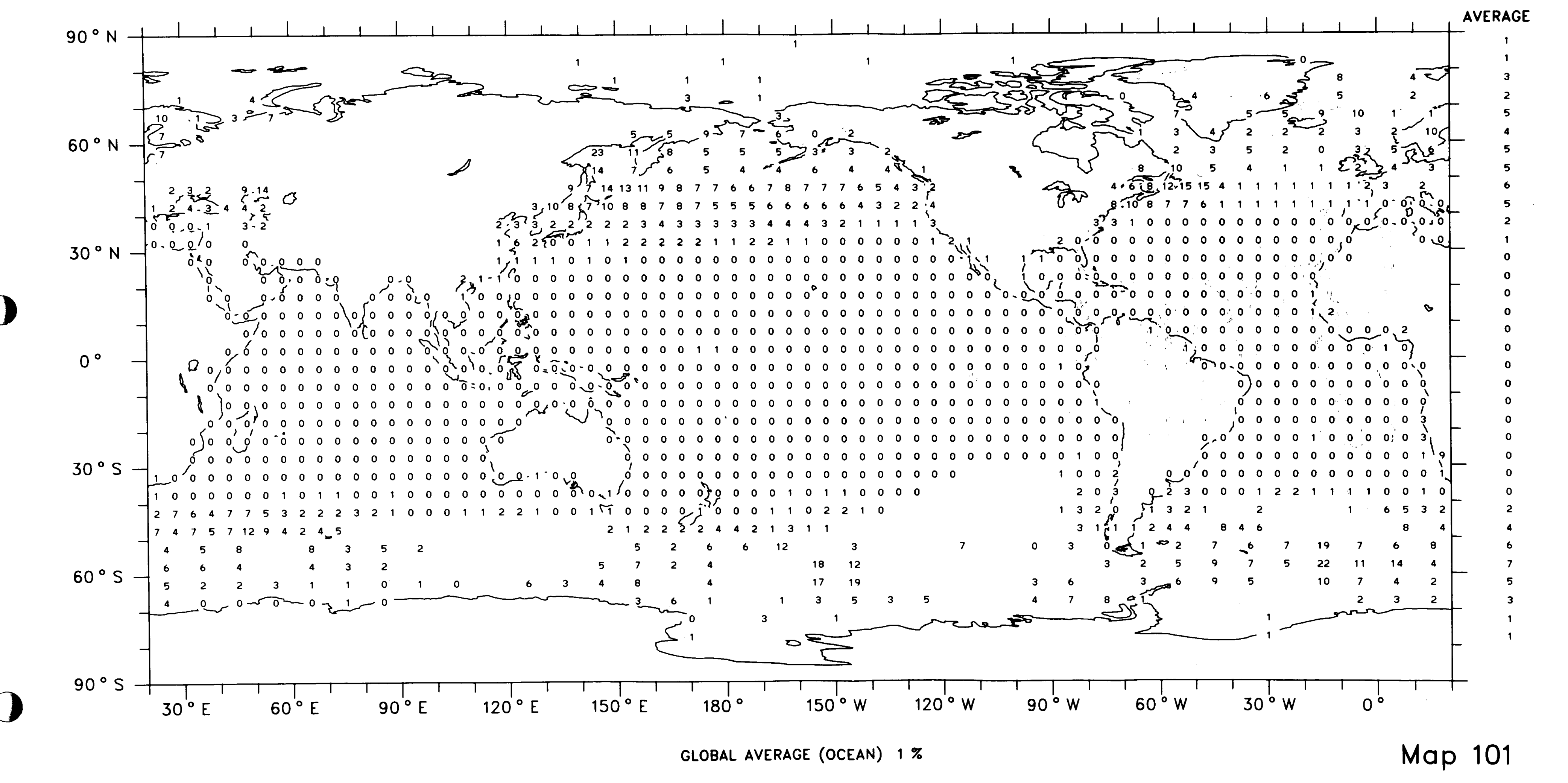




\section{Sky Obscured Due to Fog}

\section{Frequency of Occurrence (\%)}

June, July, August (19,52-1981)

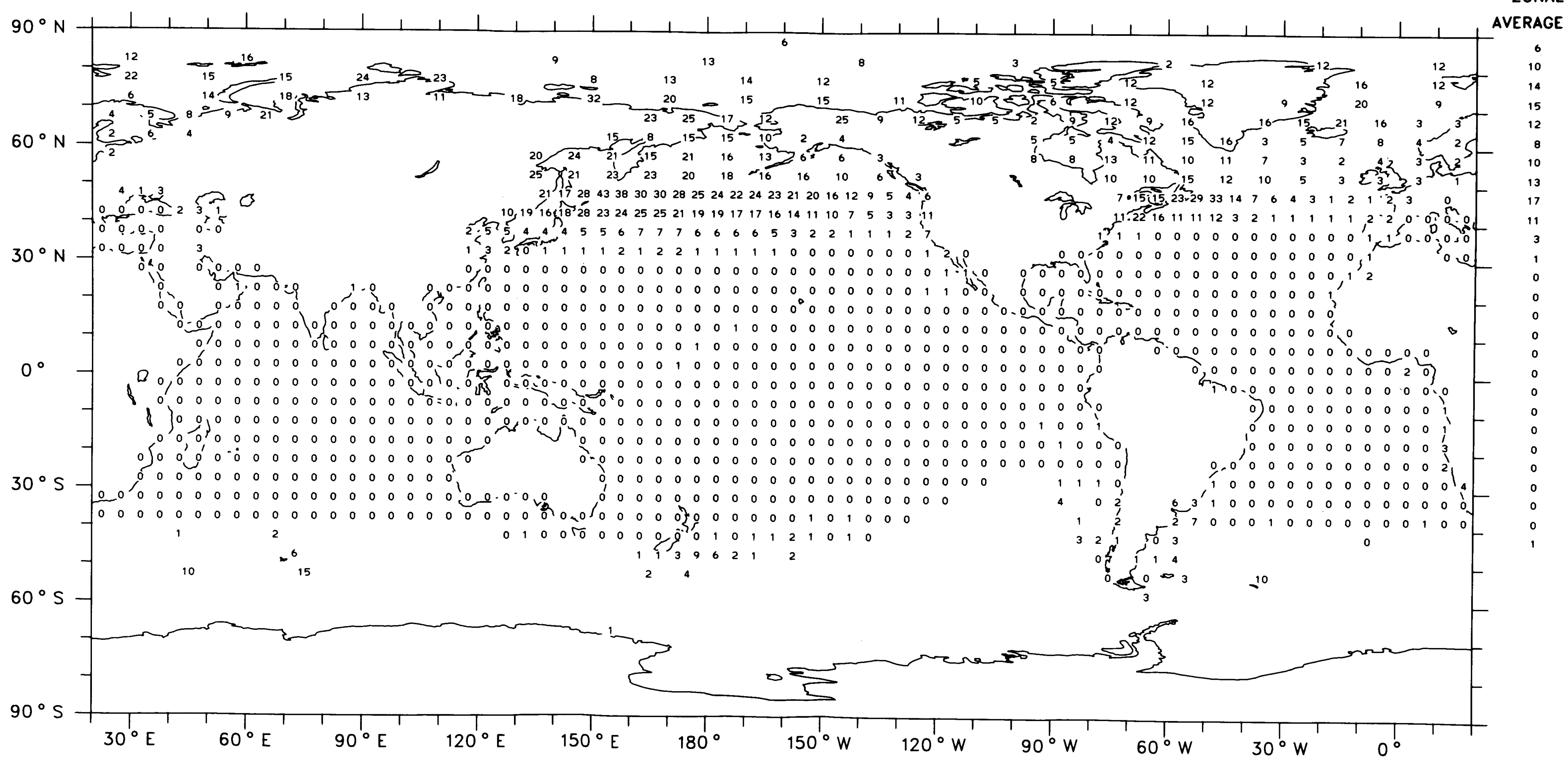

Map 102 
Sky Obscured Due to Fog

Frequency of Occurrence (\%)

September, October, November (1952-1981)

Ocean Areas Only

ZONAL

AVERAGE

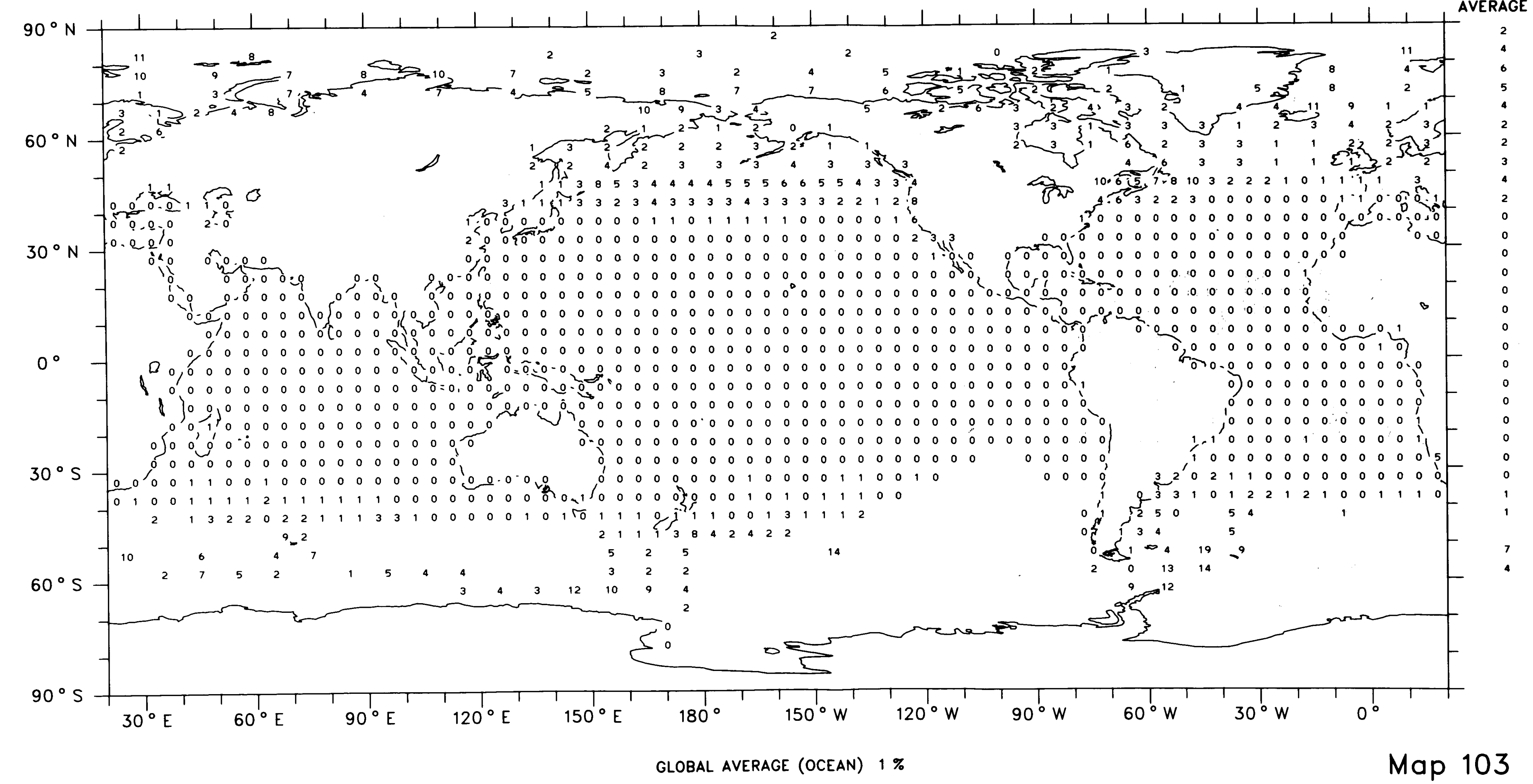




\section{Completely Clear Sky}

\section{Frequency of Occurrence (\%), 6-18 LT}

December, January, February (1952-1981)

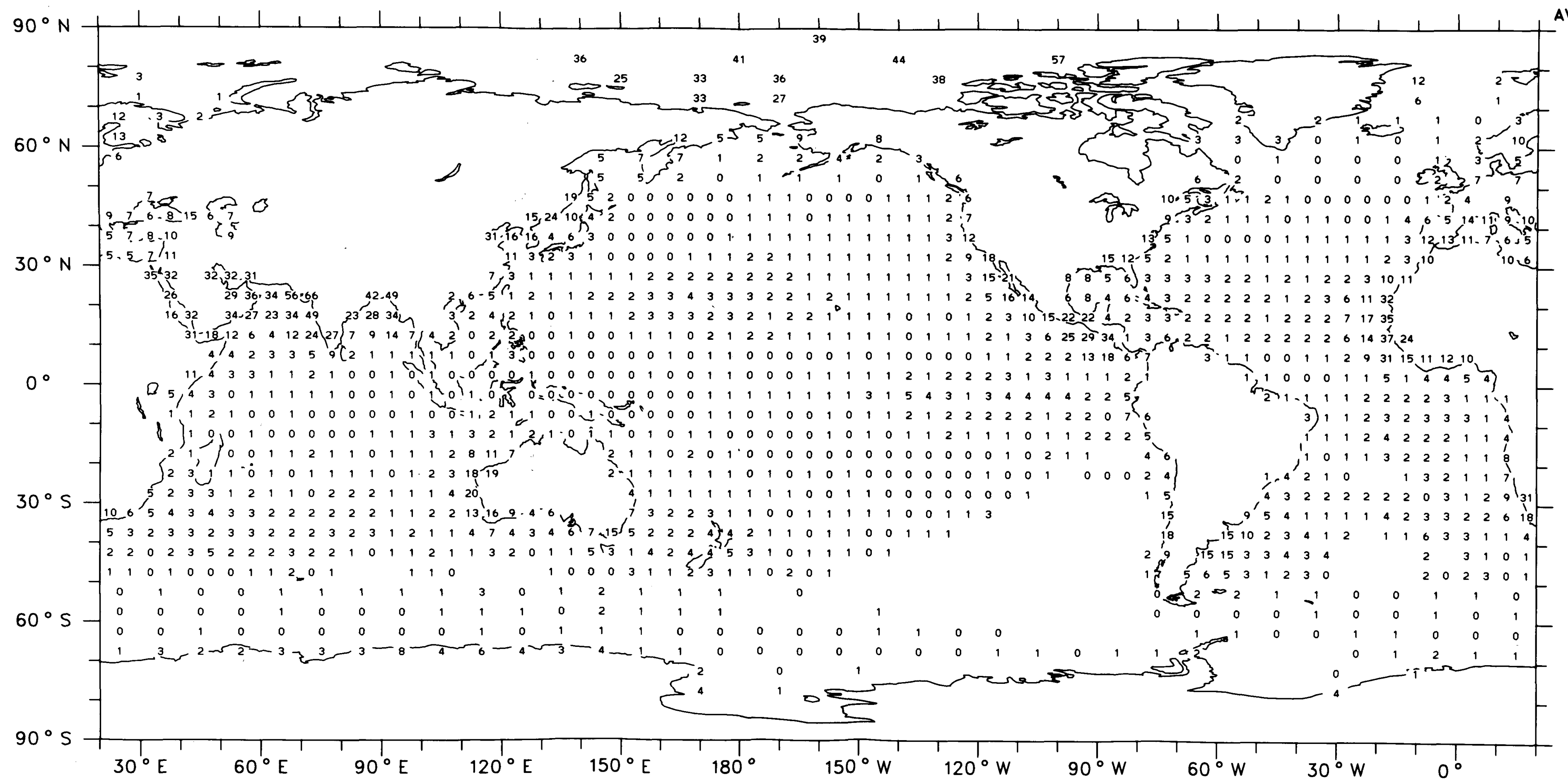




\section{Completely Clear Sky}

\section{Frequency of Occurrence (\%), 6-18 LT}

March, April, May (1952-1981)

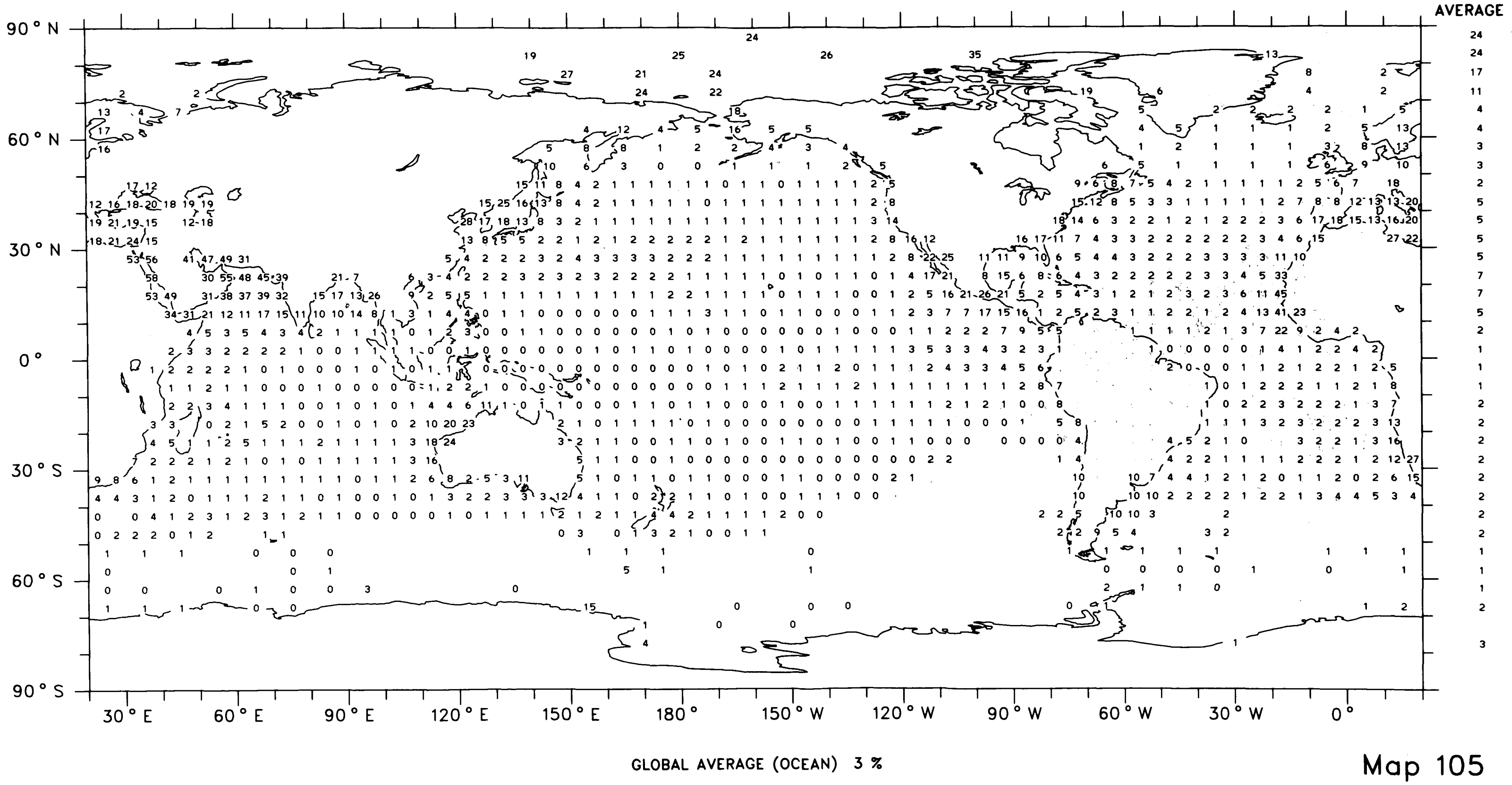




\section{Completely Clear Sky}

\section{Frequency of Occurrence (\%), 6-18 LT}

June, July, August (1952-1981)

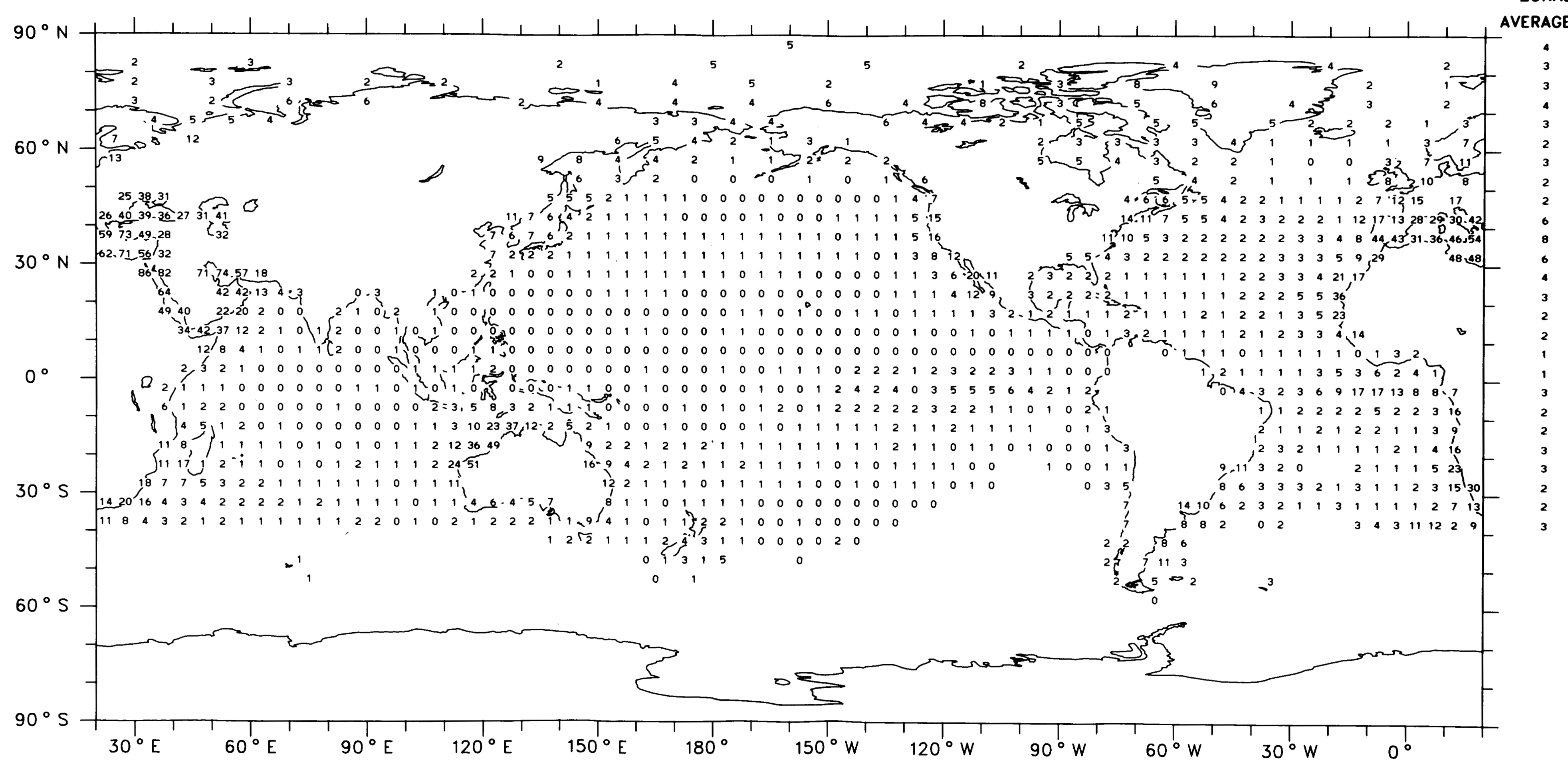




\section{Completely Clear Sky}

September, October, November (1952-1981)

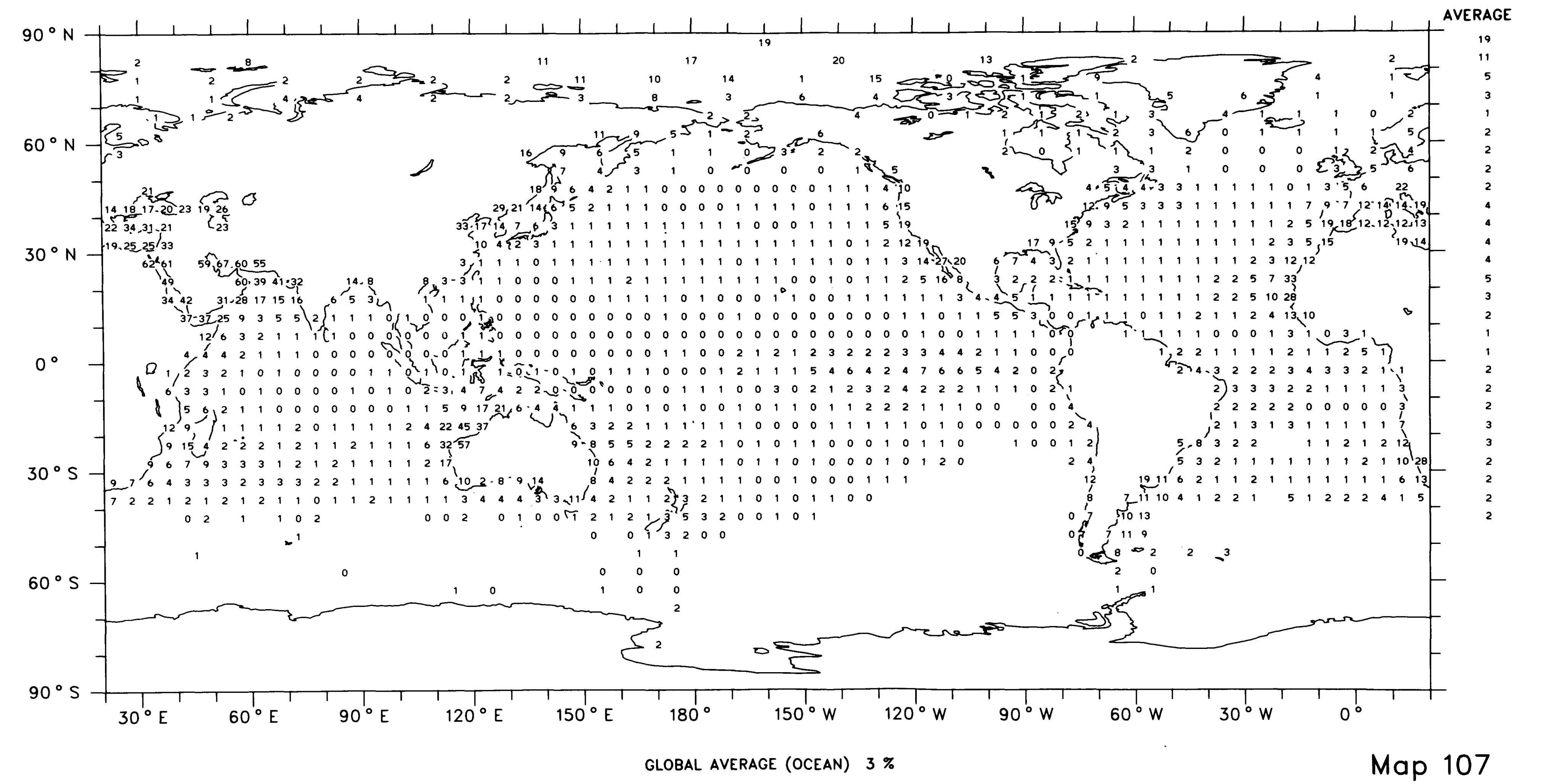


Fraction of Area Which is Ocean (\%)

ZONAL

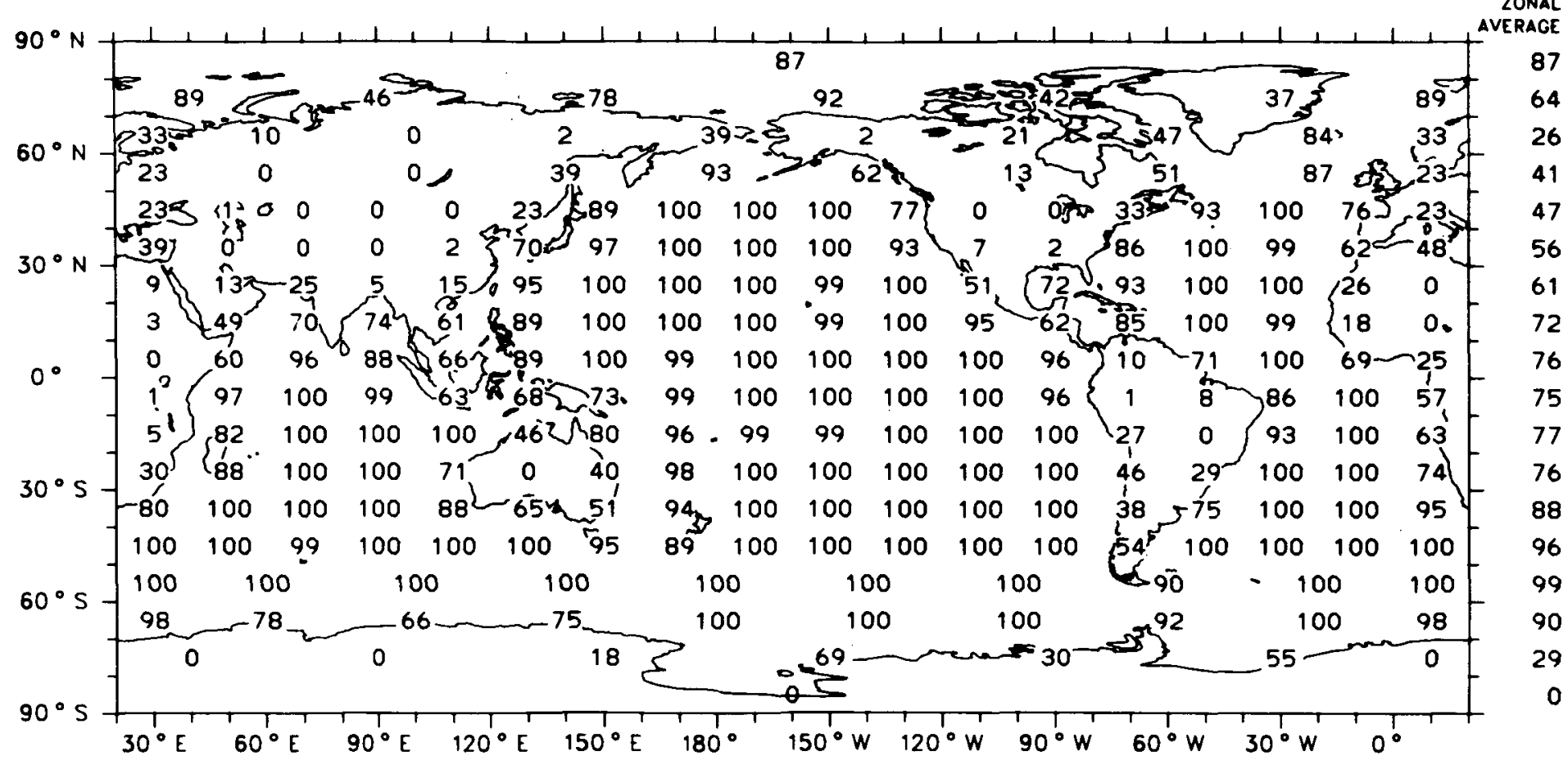

Map 108

Global Averoge $69.7 \%$ 
Number of 3-Hour Periods with At Leasł One Cloud Report (Number of "Compressed Observations") (hundreds)

December. January. Februory (1952-1981)

Ship Observations Only

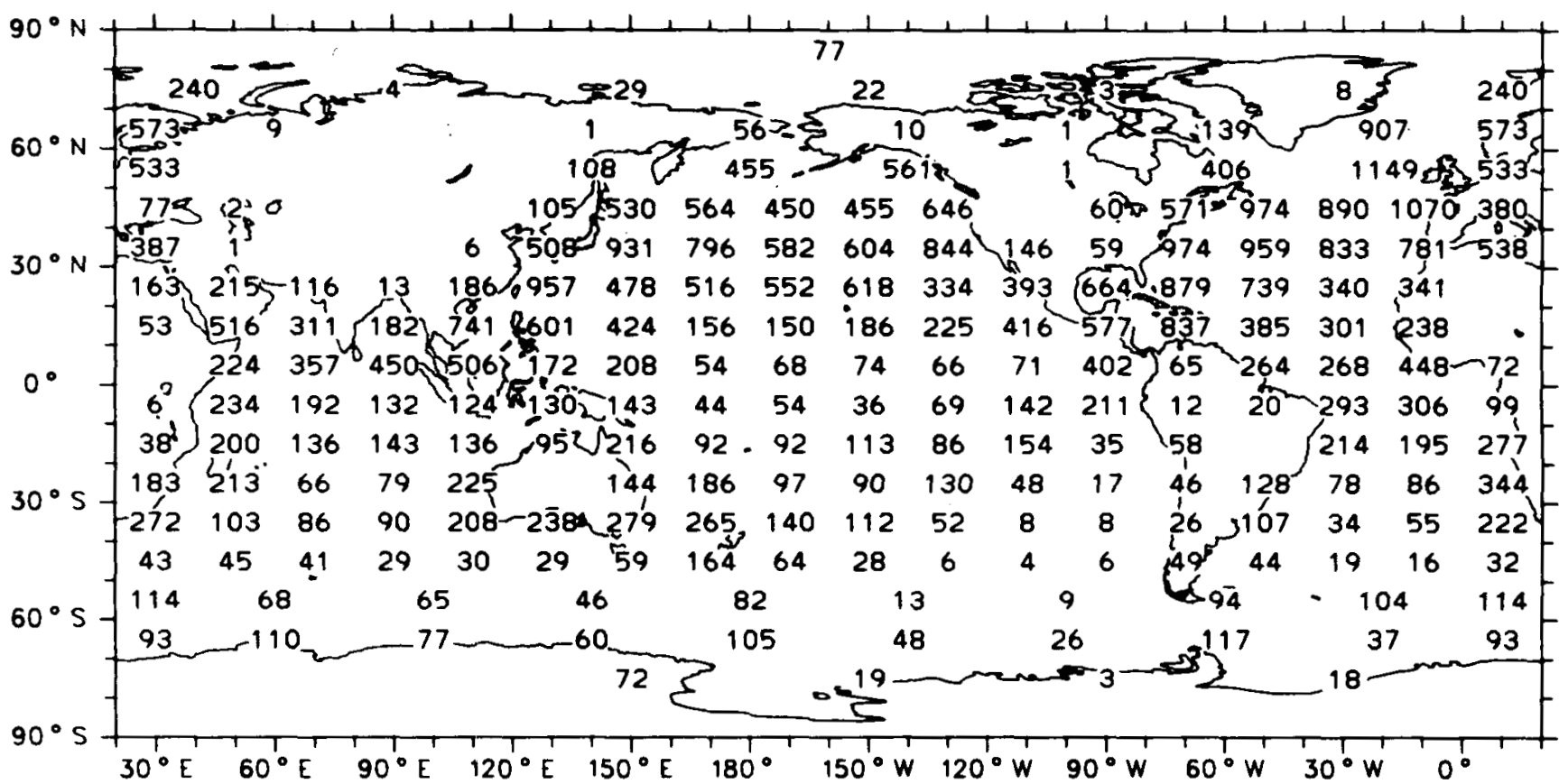

Map 109a

Number of 3-Hour Periods with At Least One Cloud Report

(Number of "Compressed Observations") (hundreds)

March. April. May (1952-1981)

Ship Observations Only

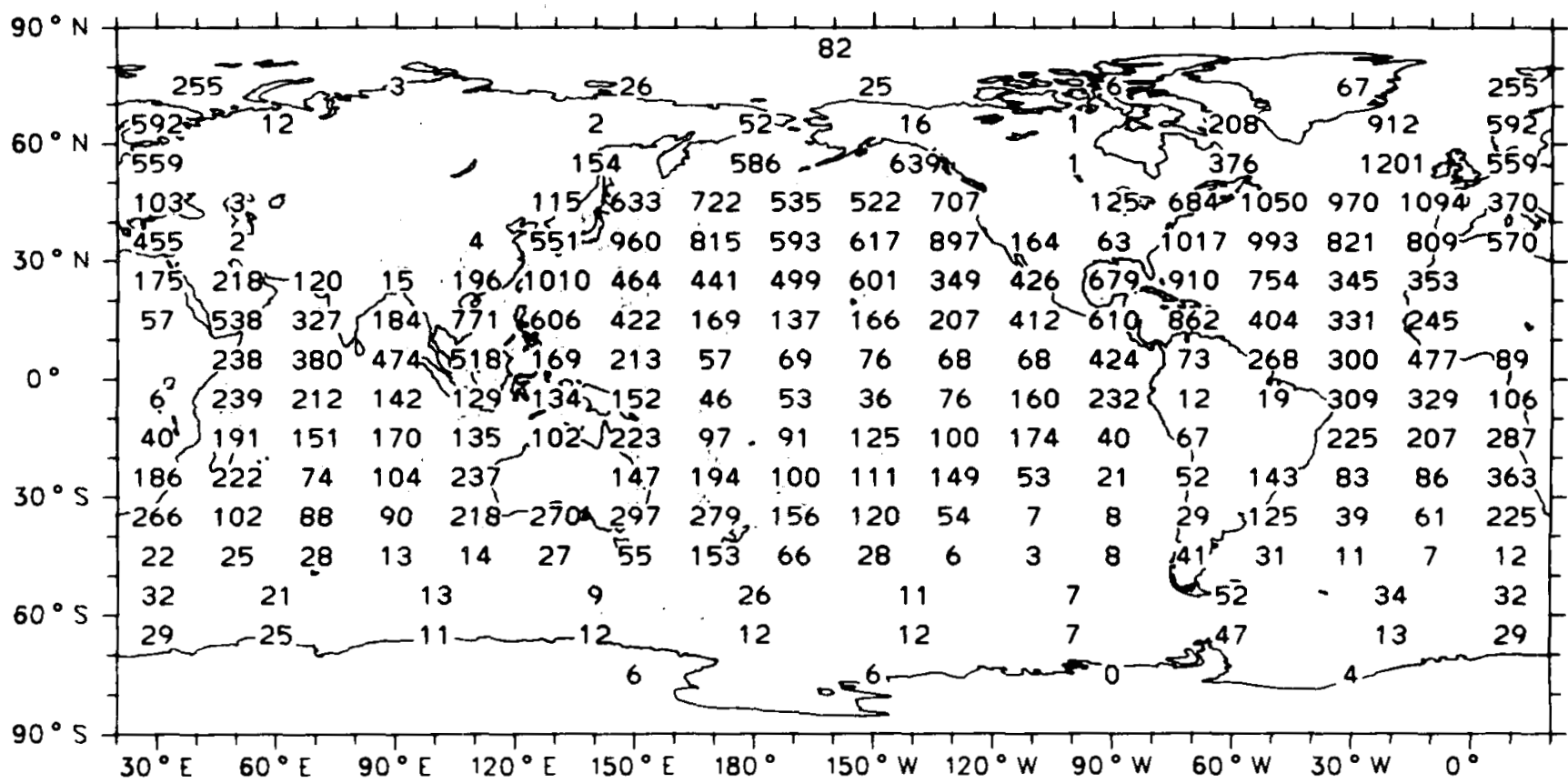

Mop 109b 
Number of 3-Hour Periods with At Leost One Cloud Report

(Number of "Compressed Observations") (hundreds)

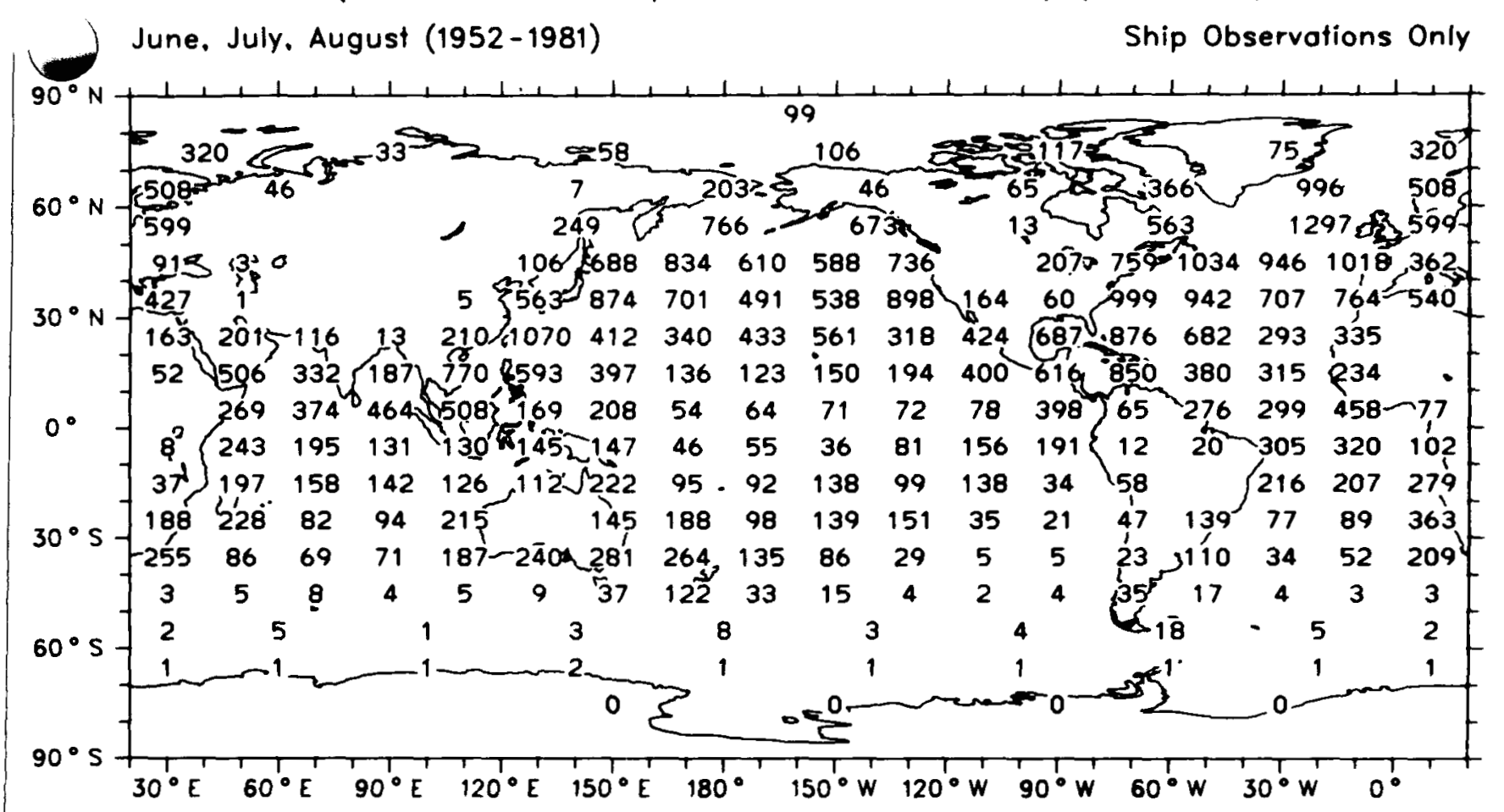

Map 109c

Number of 3-Hour Periods with At Leost One Cloud Report

(Number of "Compressed Observations") (hundreds)

September. October. November (1952-1981) Ship Observations Only

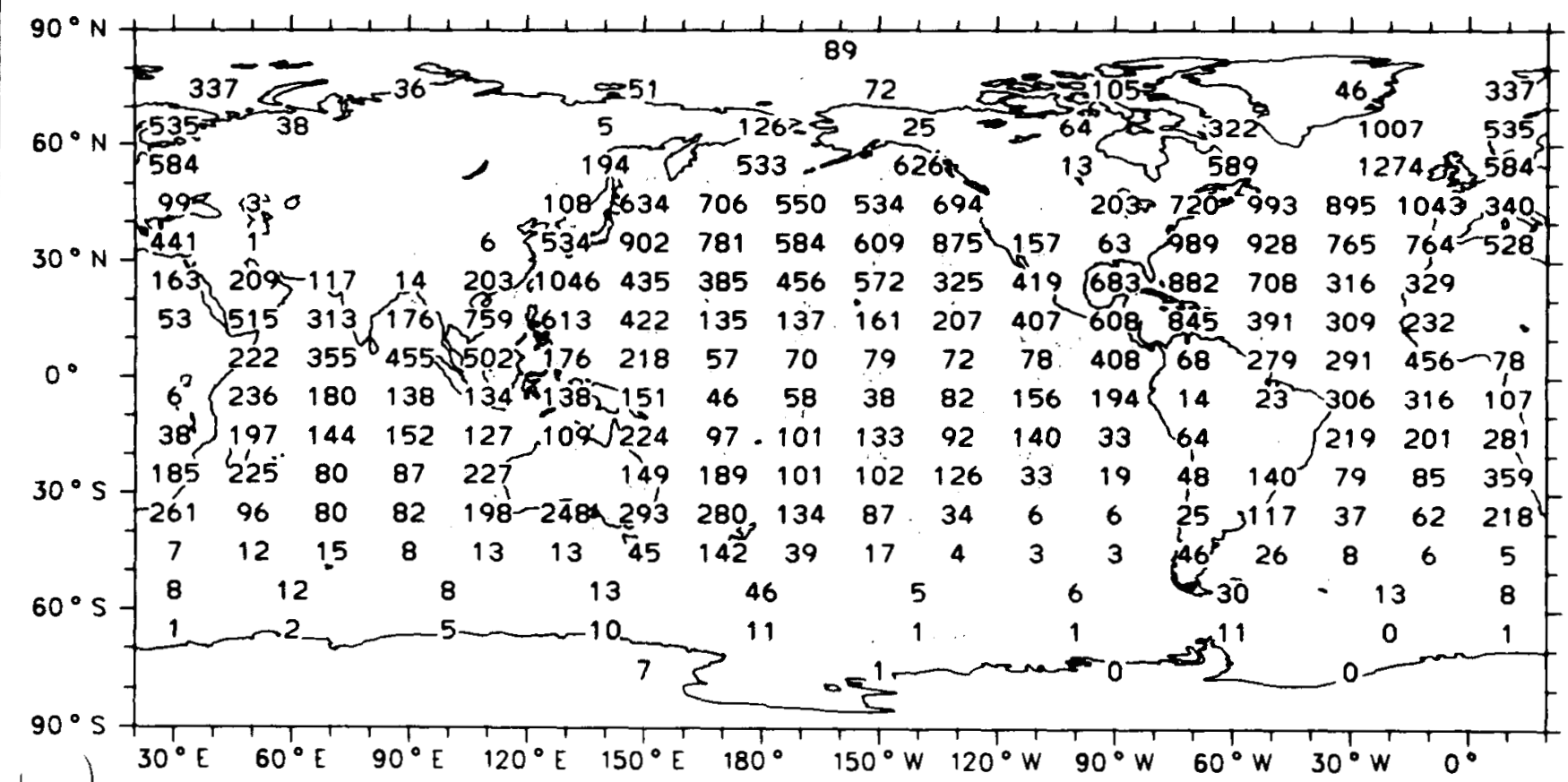

Map 109d 
Percent of (Compressed) Observations Made During Daytime Hours (6-18 LT) December, January, February (1952-1981) Ship Observations Only

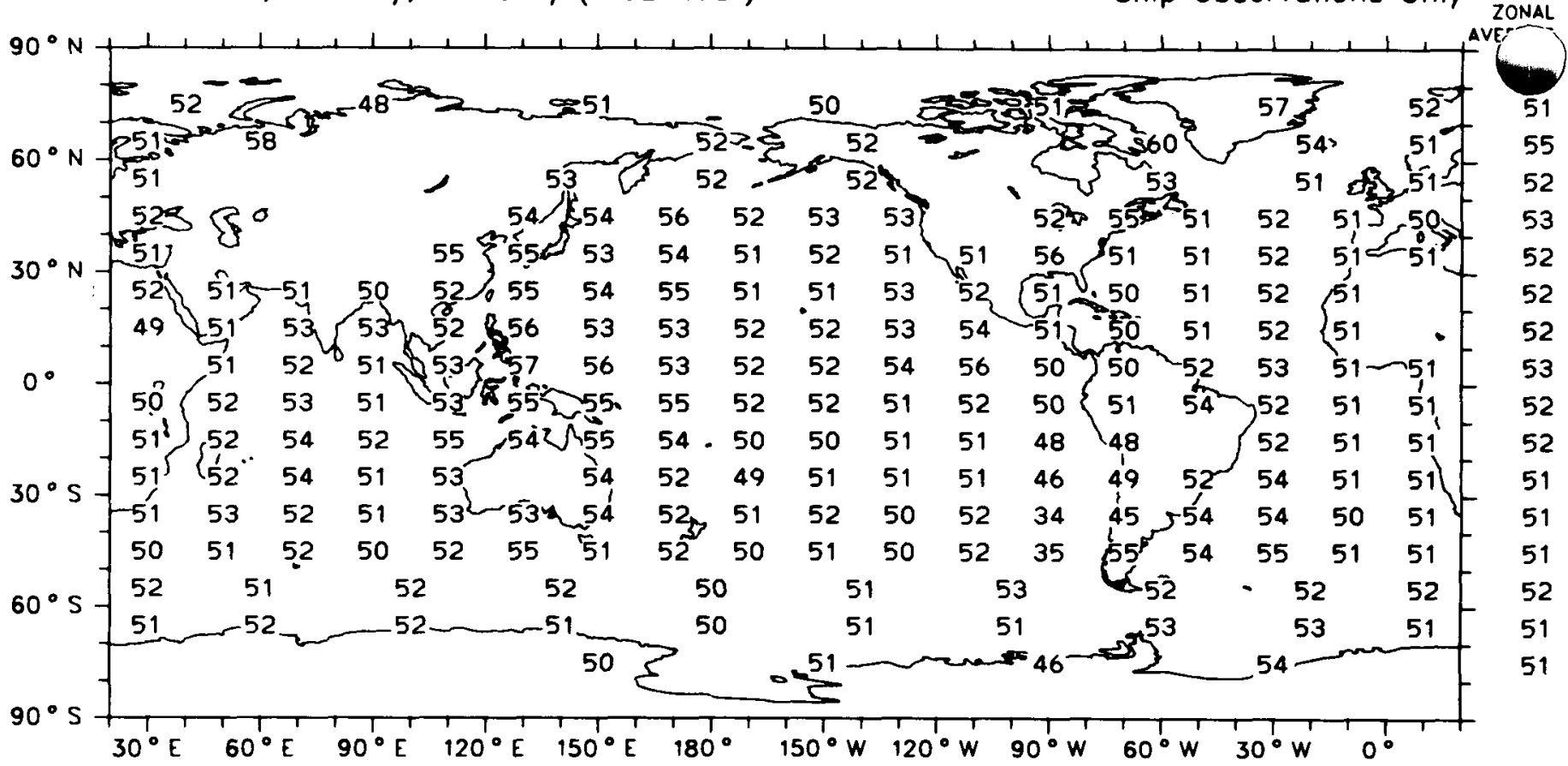

Map 110a

Global Average (Ocean) 52

Percent of (Compressed) Observations Made During Daytime Hours (6-18 LT) March, April, Moy (1952-1981) Ship Observations Only

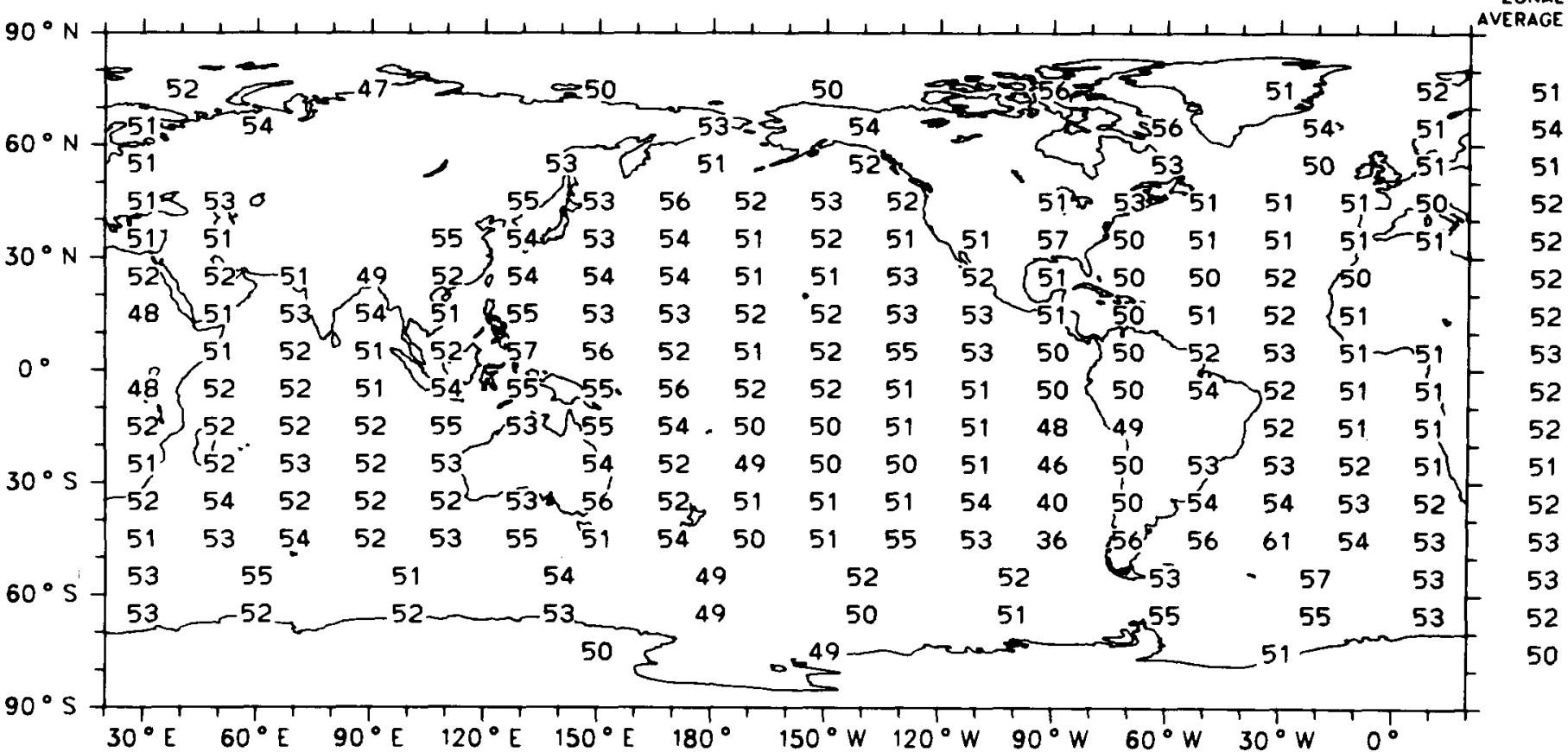

Map 110b

Global Average (Ocean) 52 
Percent of (Compressed) Observations Made During Daytime Hours (6-18 LT) June, July, August (1952-1981)

Ship Observations Only

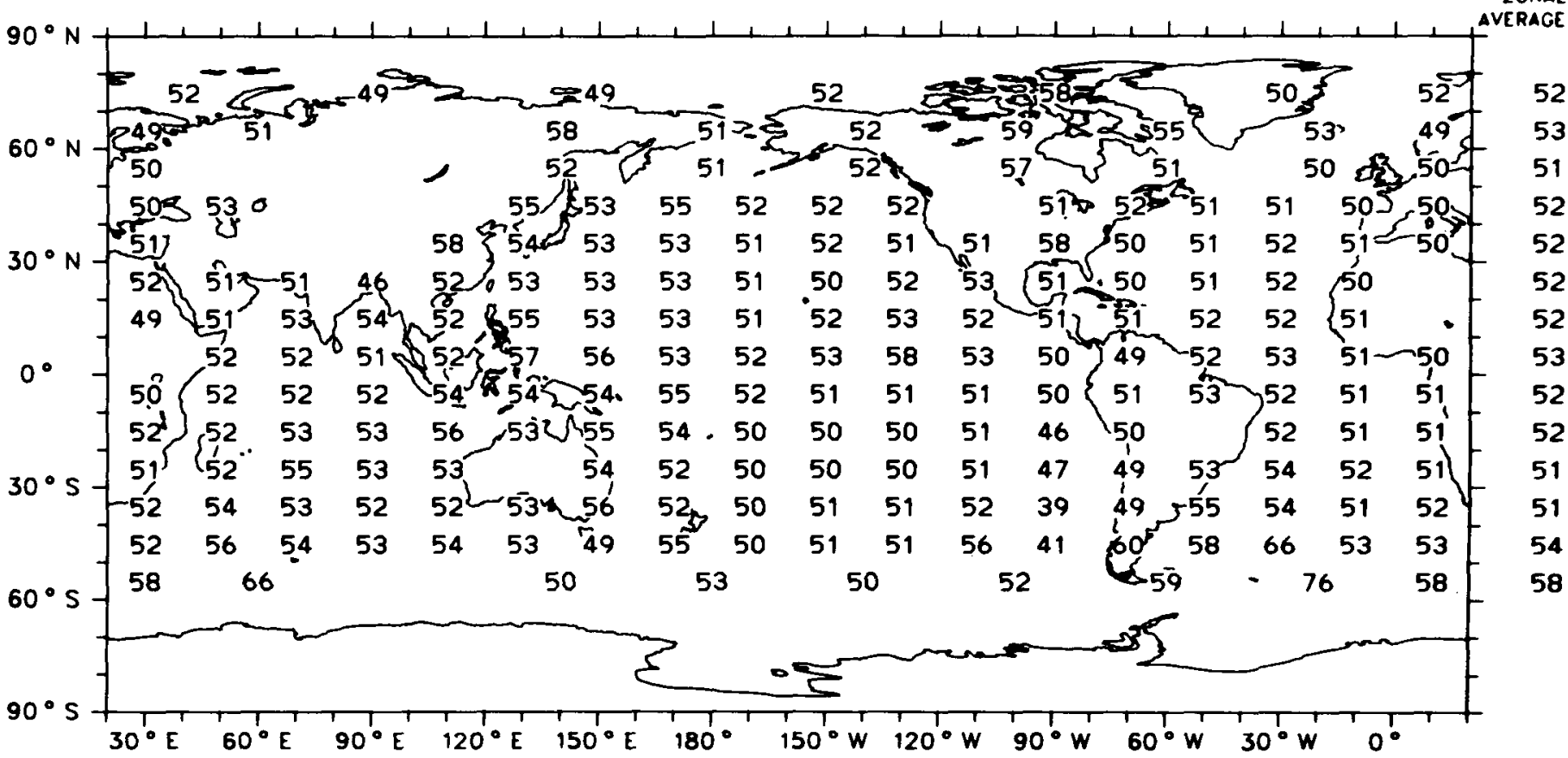

Map 110c

Global Averoge (Ocean) 52

Percent of (Compressed) Observations Made During Daytime Hours (6-18 LT) September, October, November (1952-1981) Ship Observations Only

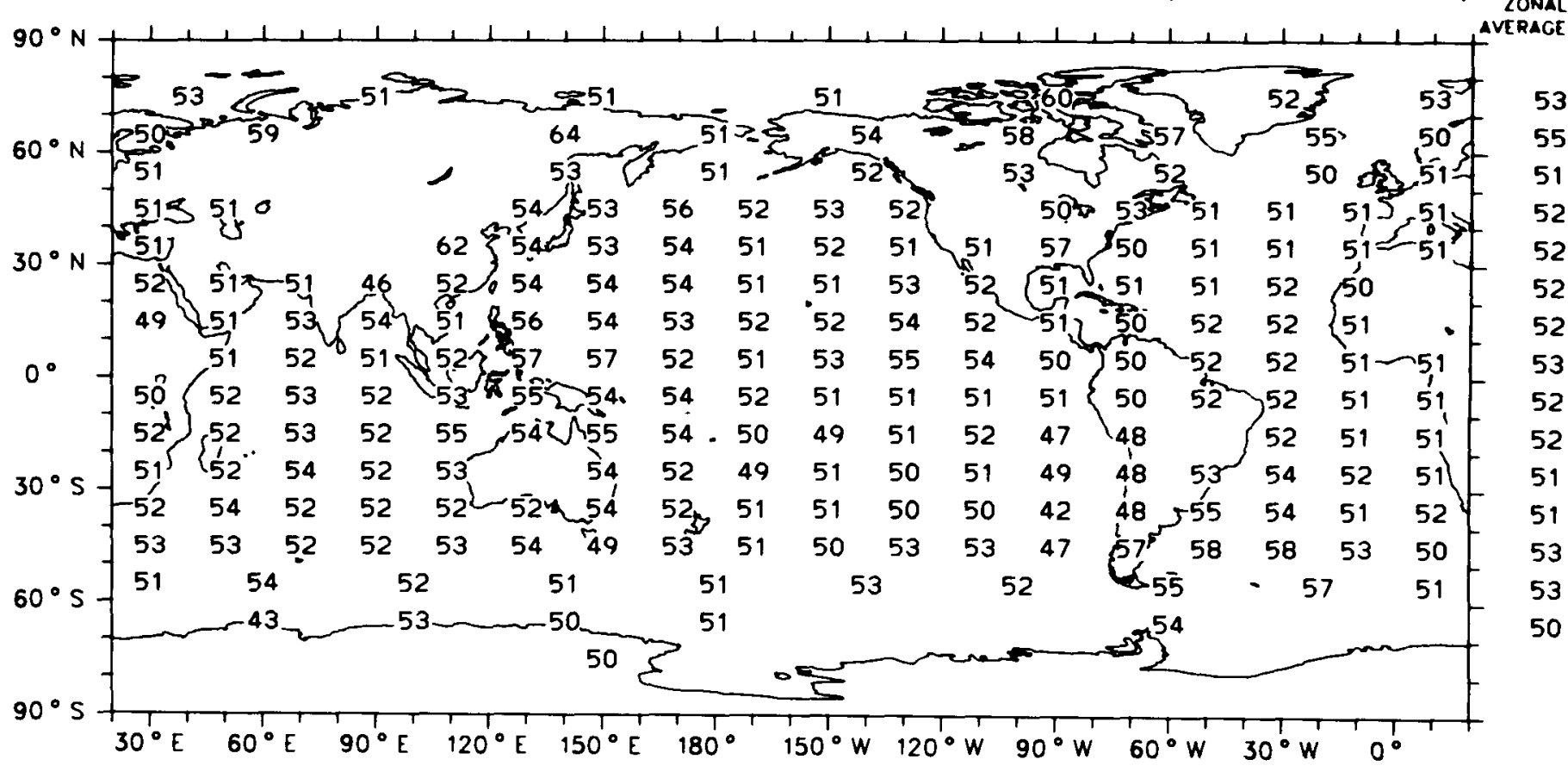

Map 110d

Global Average (Oceon) 52 
Number of Years with At Least 100 Compressed Observations

December, January, February $(1952-1981)$

Ship Observations Only

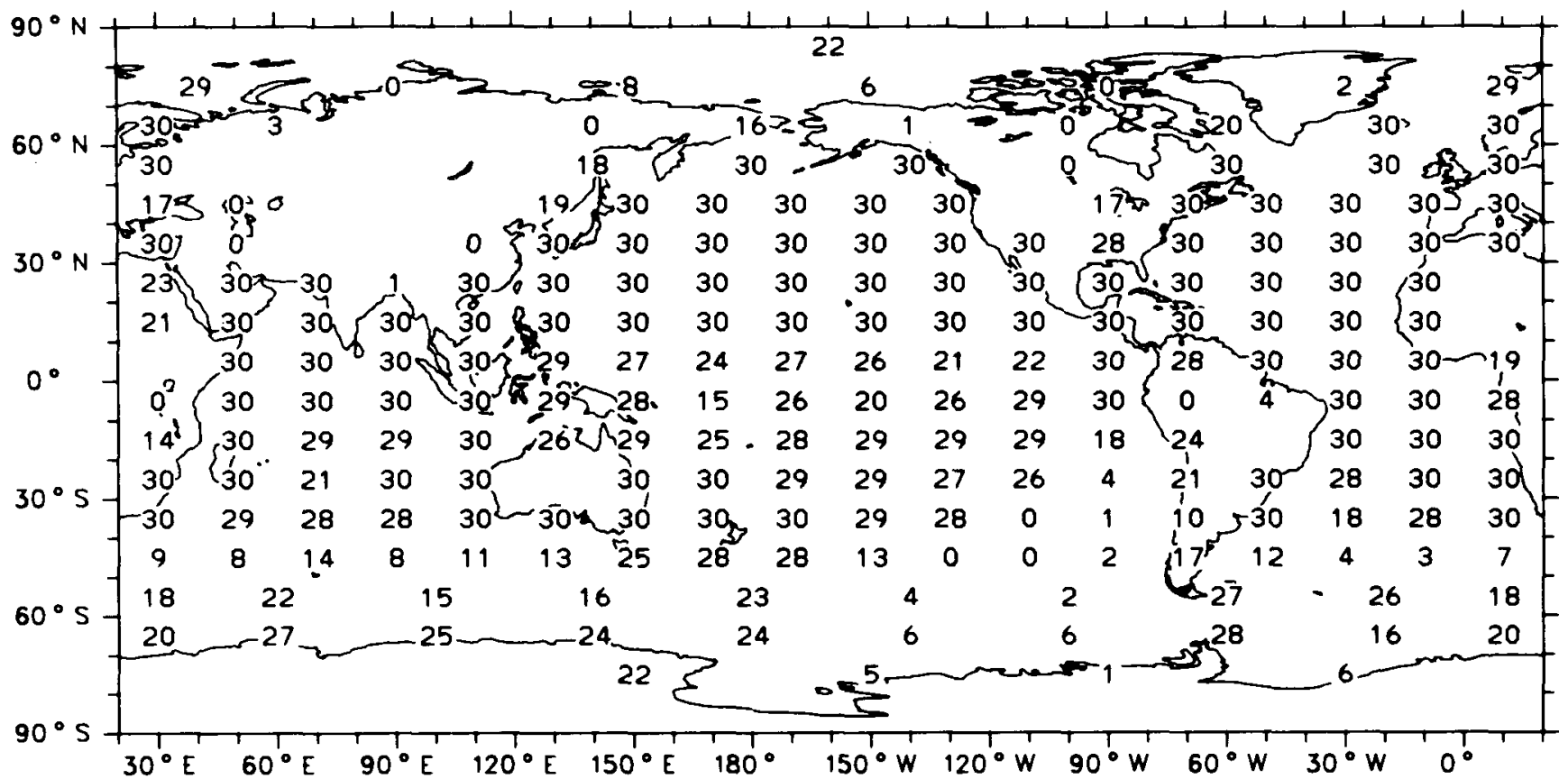

Map 111a

\section{Number of Years with At Least 100 Compressed Observations} March. April, May (1952-1981)

Ship Observations Only

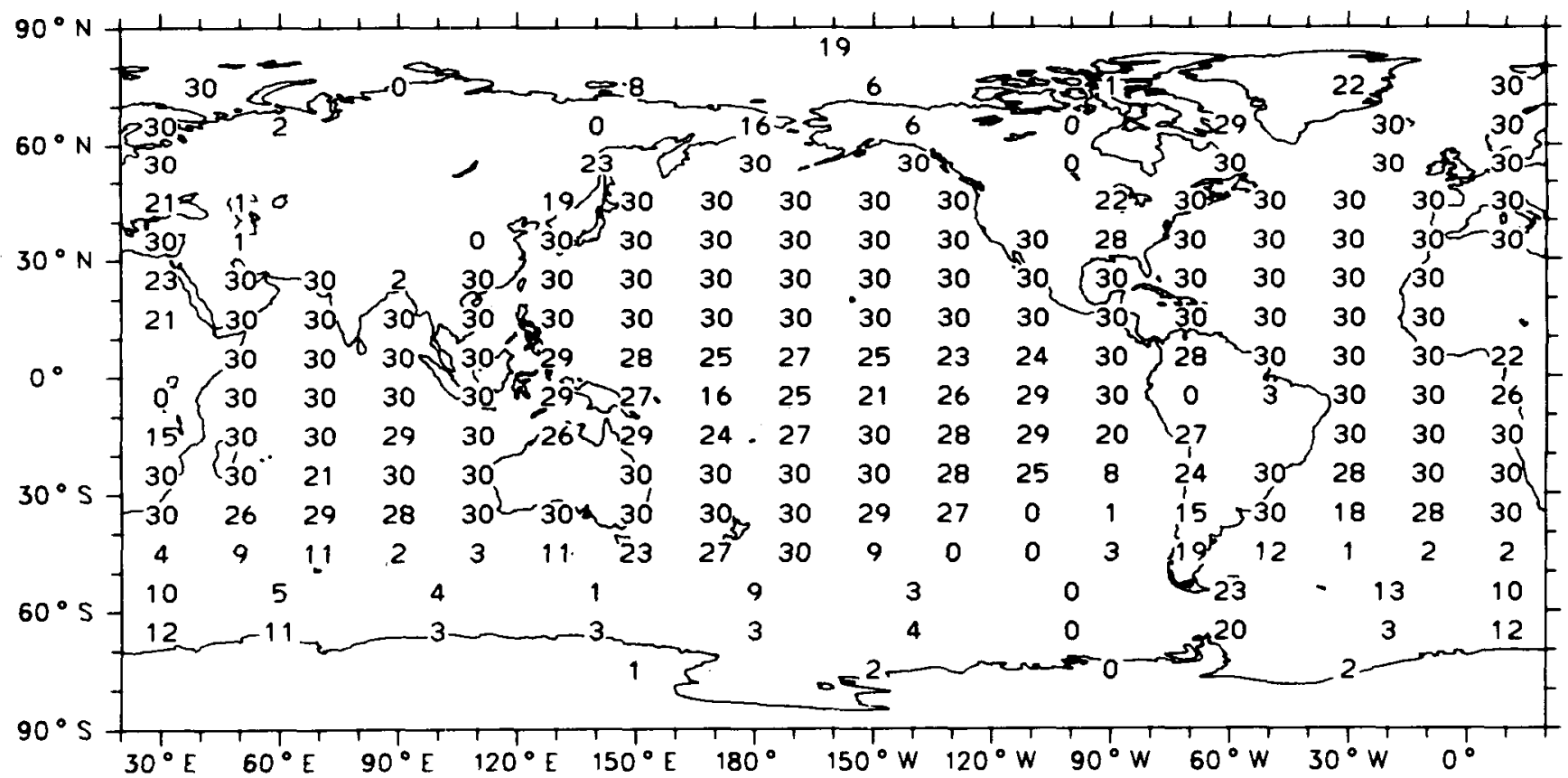

Map 111b 
Number of Years with At Least 100 Compressed Observations June, July, August (1952-1981)

Ship Observations Only

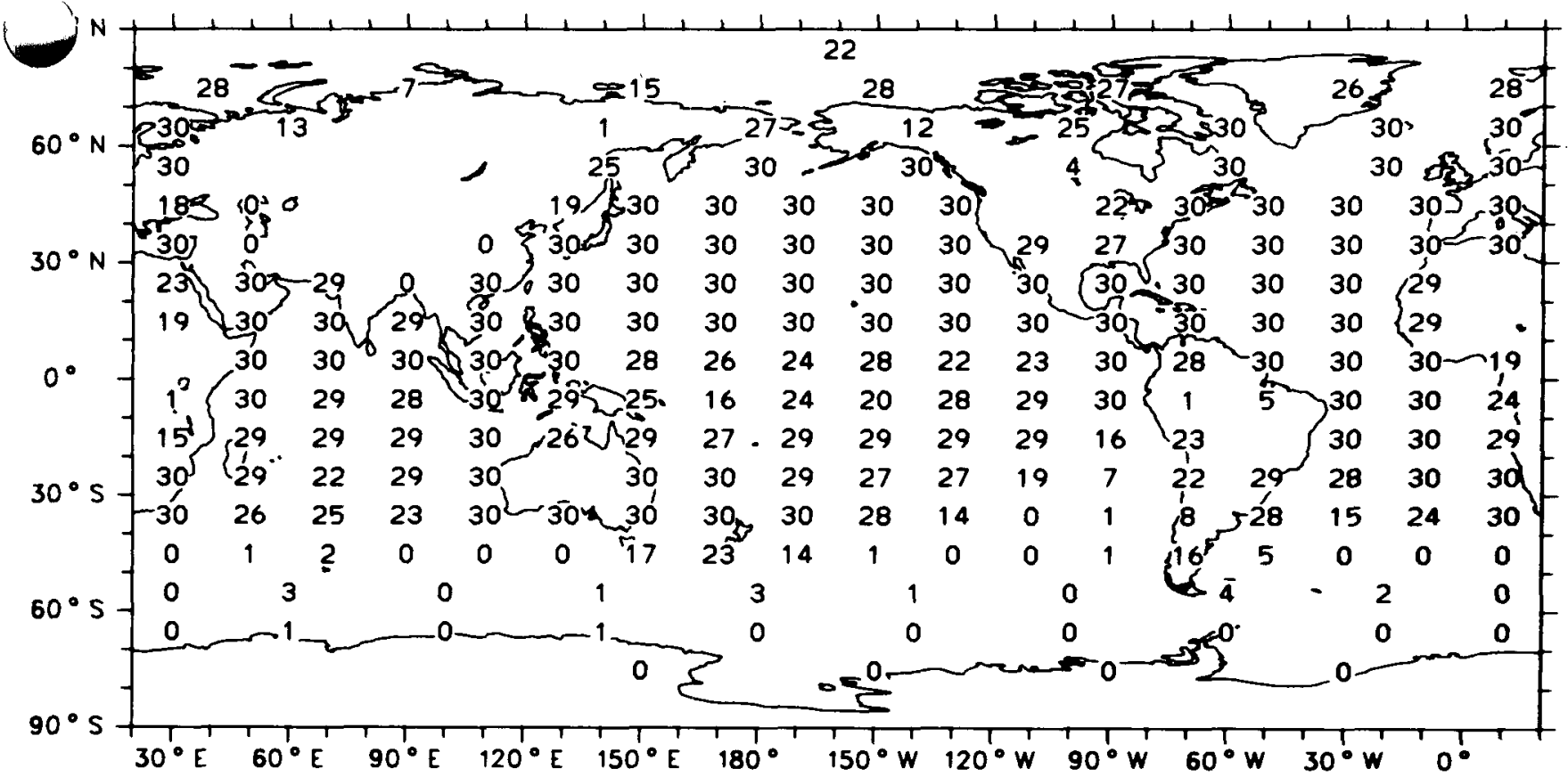

Map 111c

Number of Years with At Least 100 Compressed Observations

September, October. November (1952-1981)

Ship Observations Only

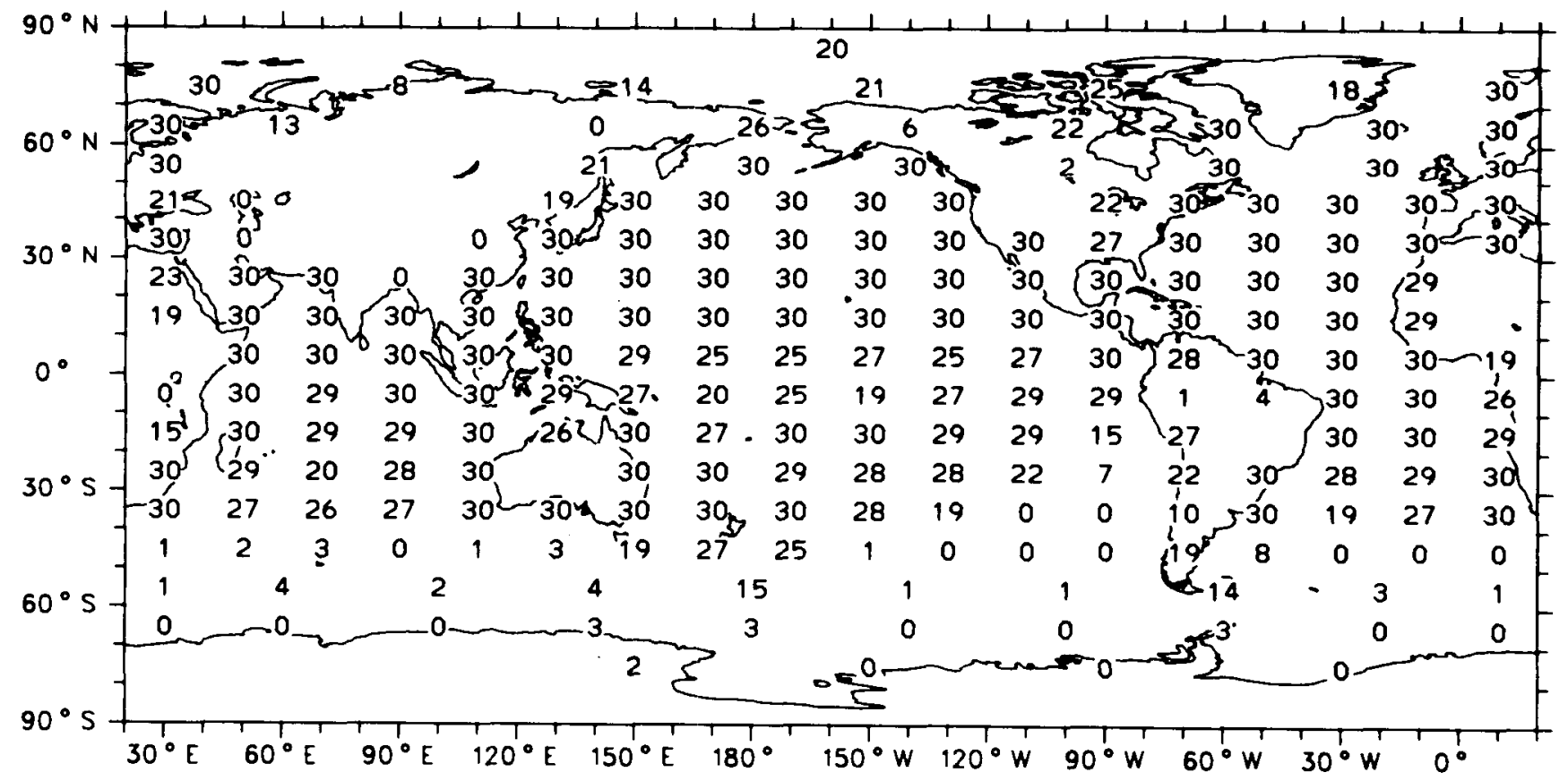

Map 111d 


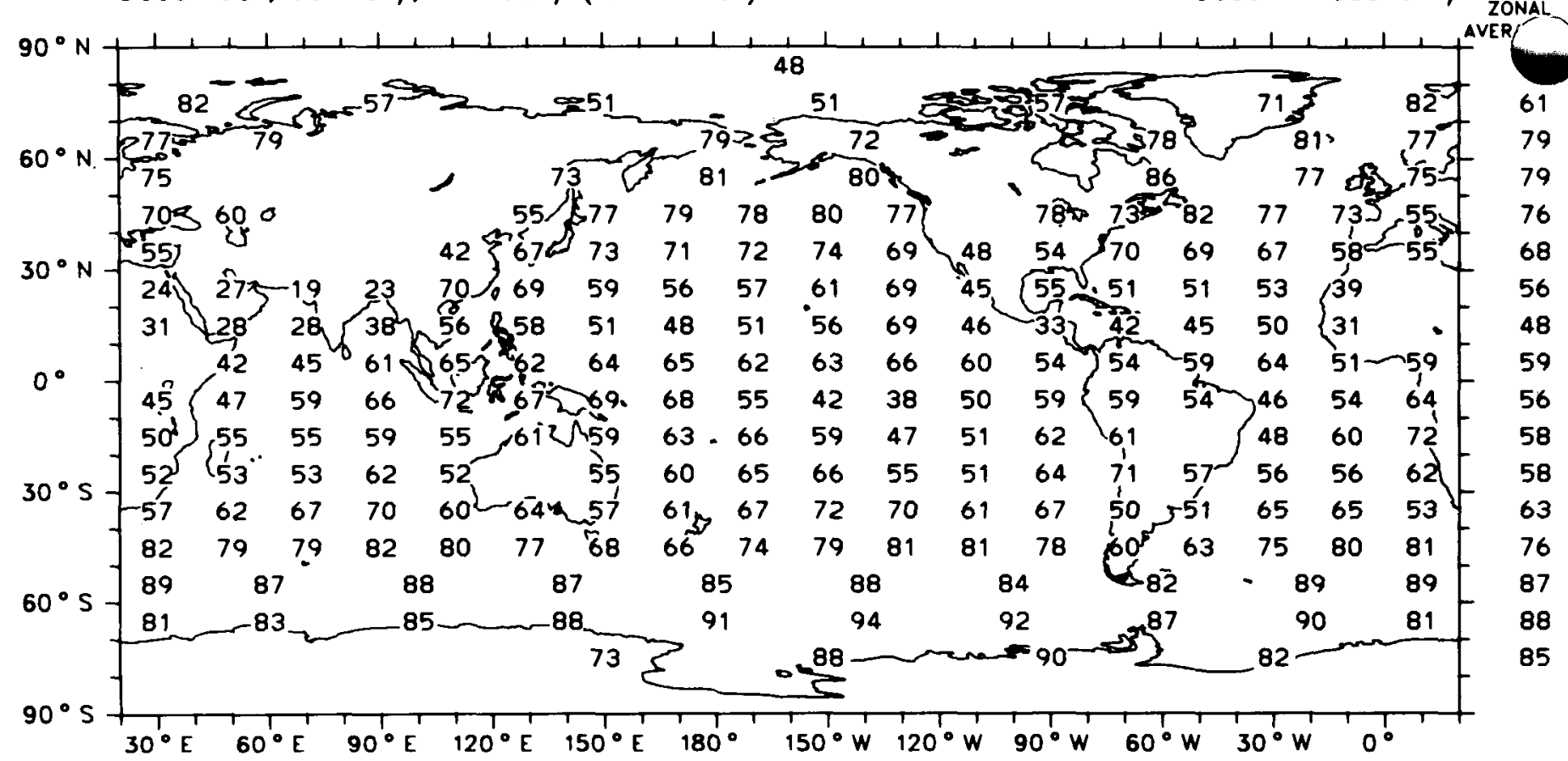

Map $112 a$

Globol Averoge (Ocean) $65 \%$

Average Total Cloud Cover (\%)

March, April, May (1952-1981)

Ocean Areos Only

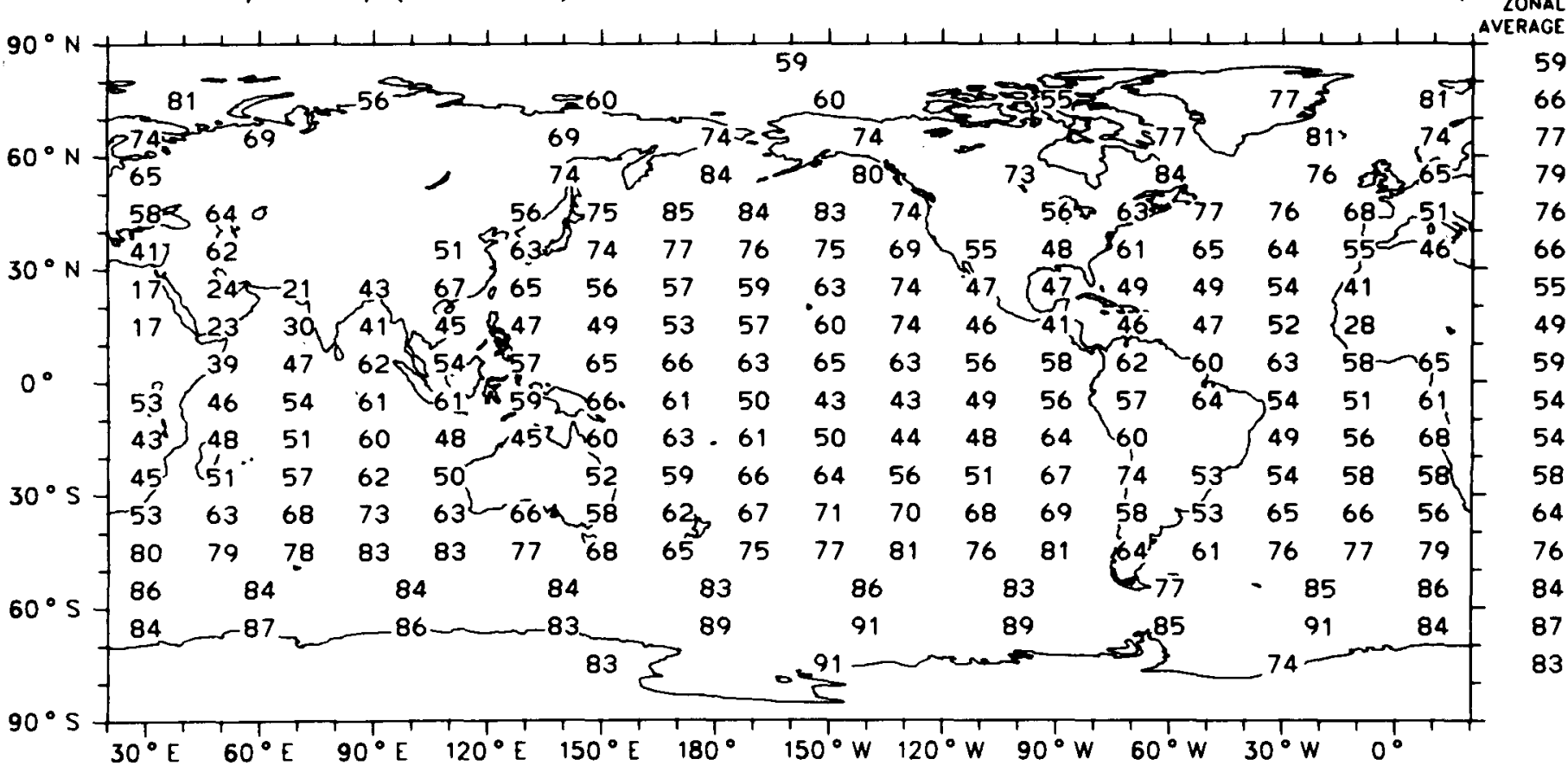

Map 112b 


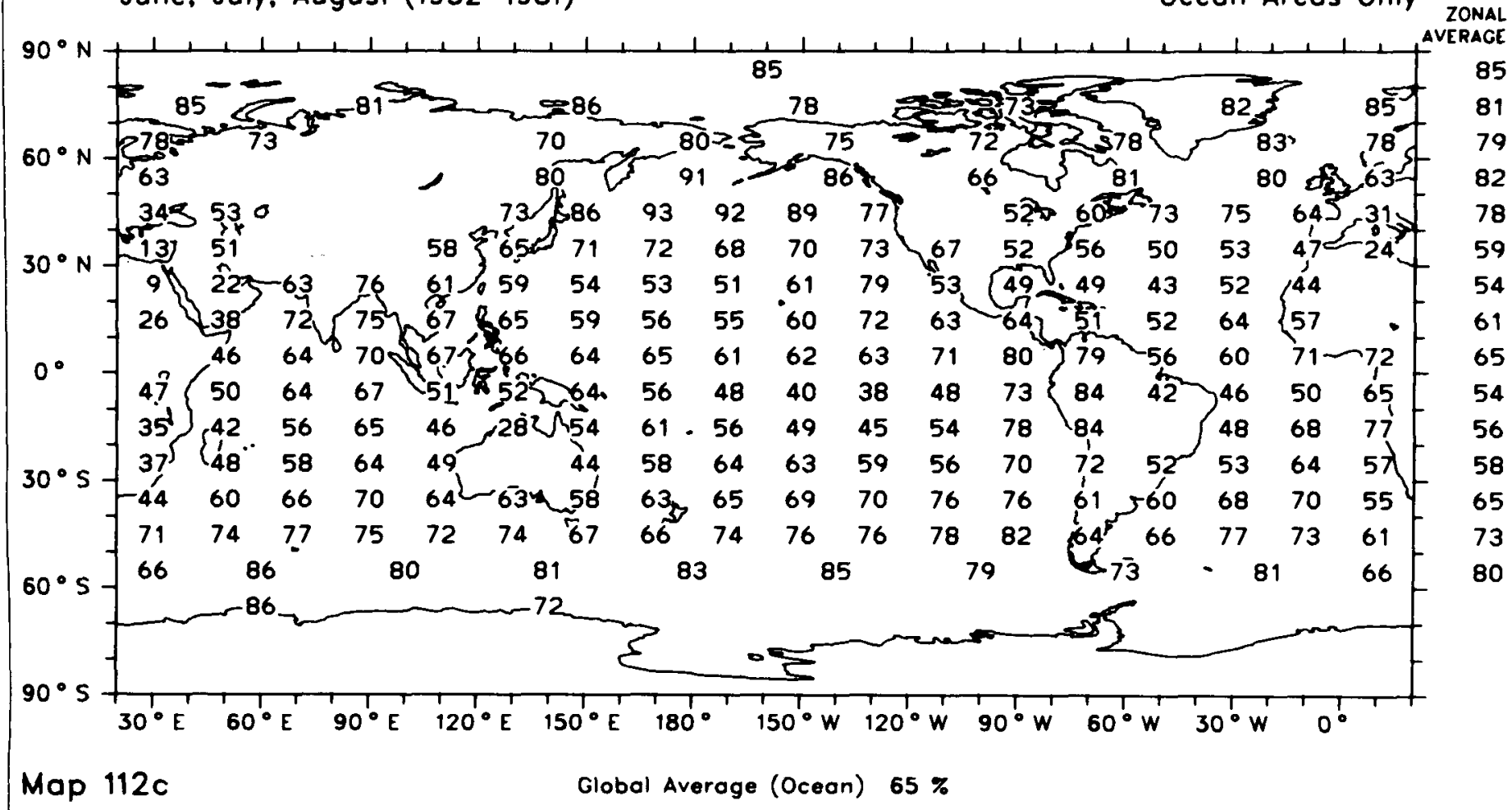

\section{Average Total Cloud Cover (\%)}

September, October, November (1952-1981)

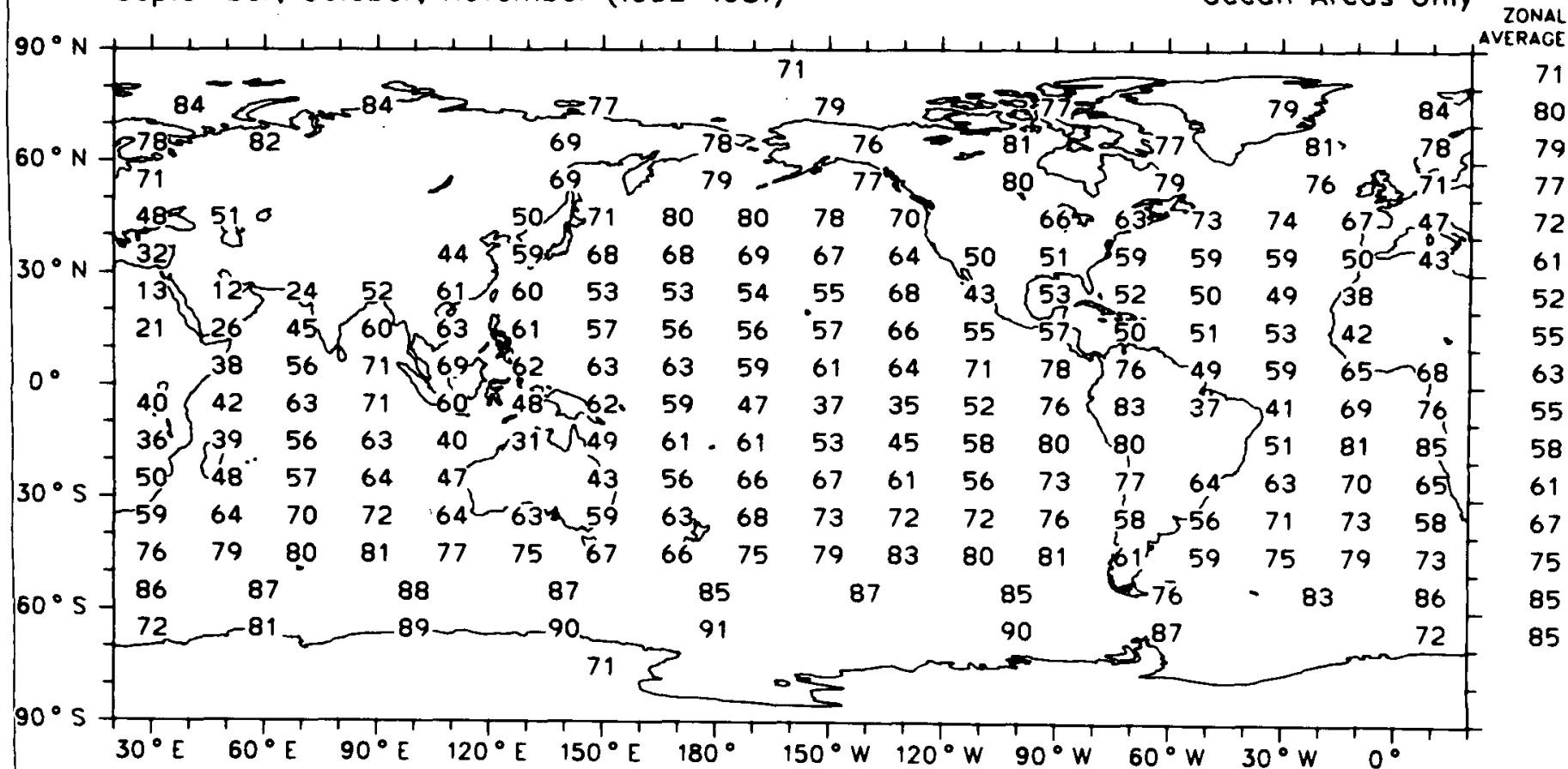

Map 112d 
Standard Deviation of Compressed Observations of Total Cloud Cover (\%) December. January. February (1952-1981)

Ocean Areas Only

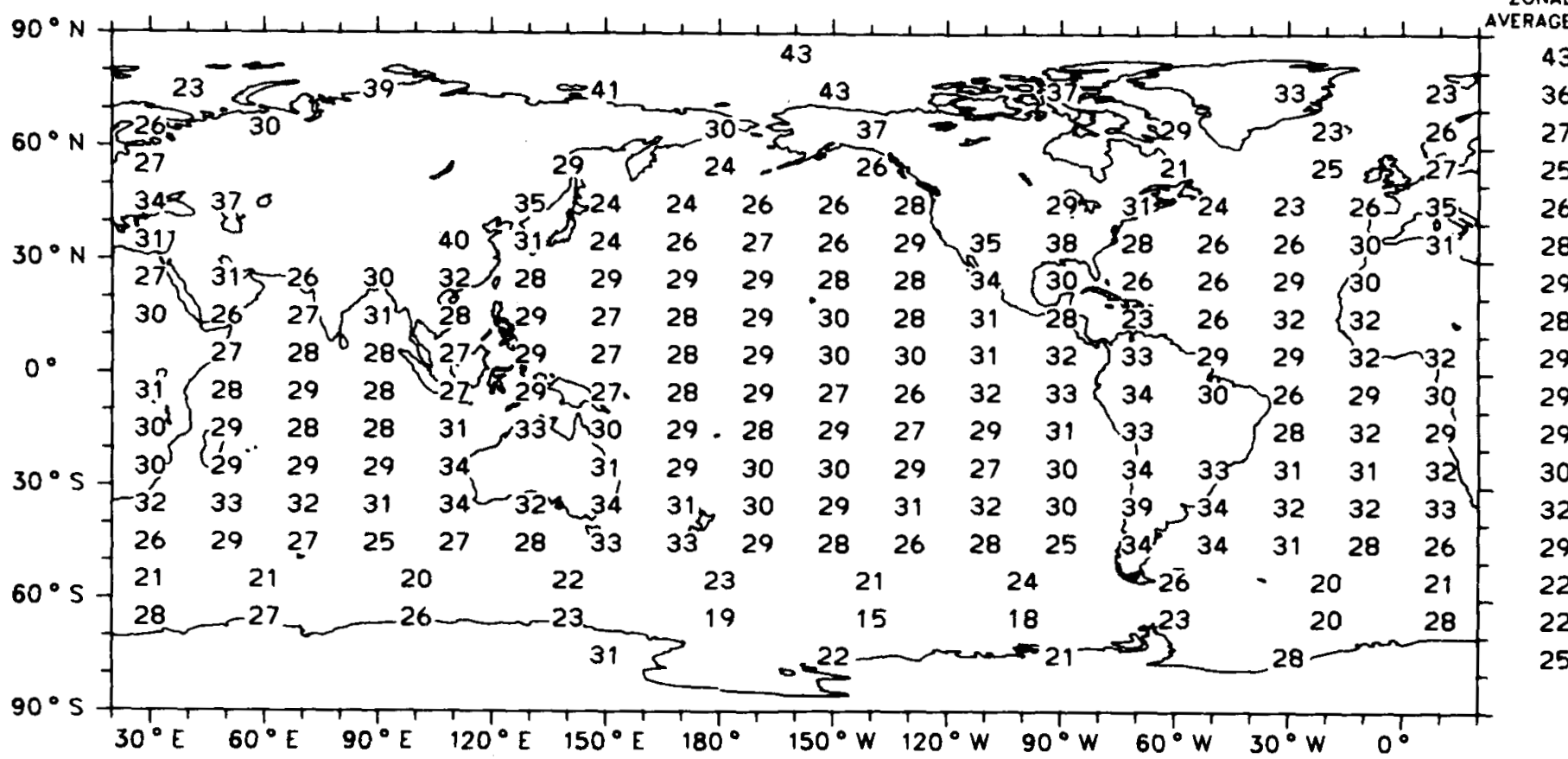

Global Average (Ocean) $28 \%$

Map 113o

Standard Deviation of Compressed Observations of Total Cloud Cover (\%) March. April, May (1952-1981)

Ocean Areas Only

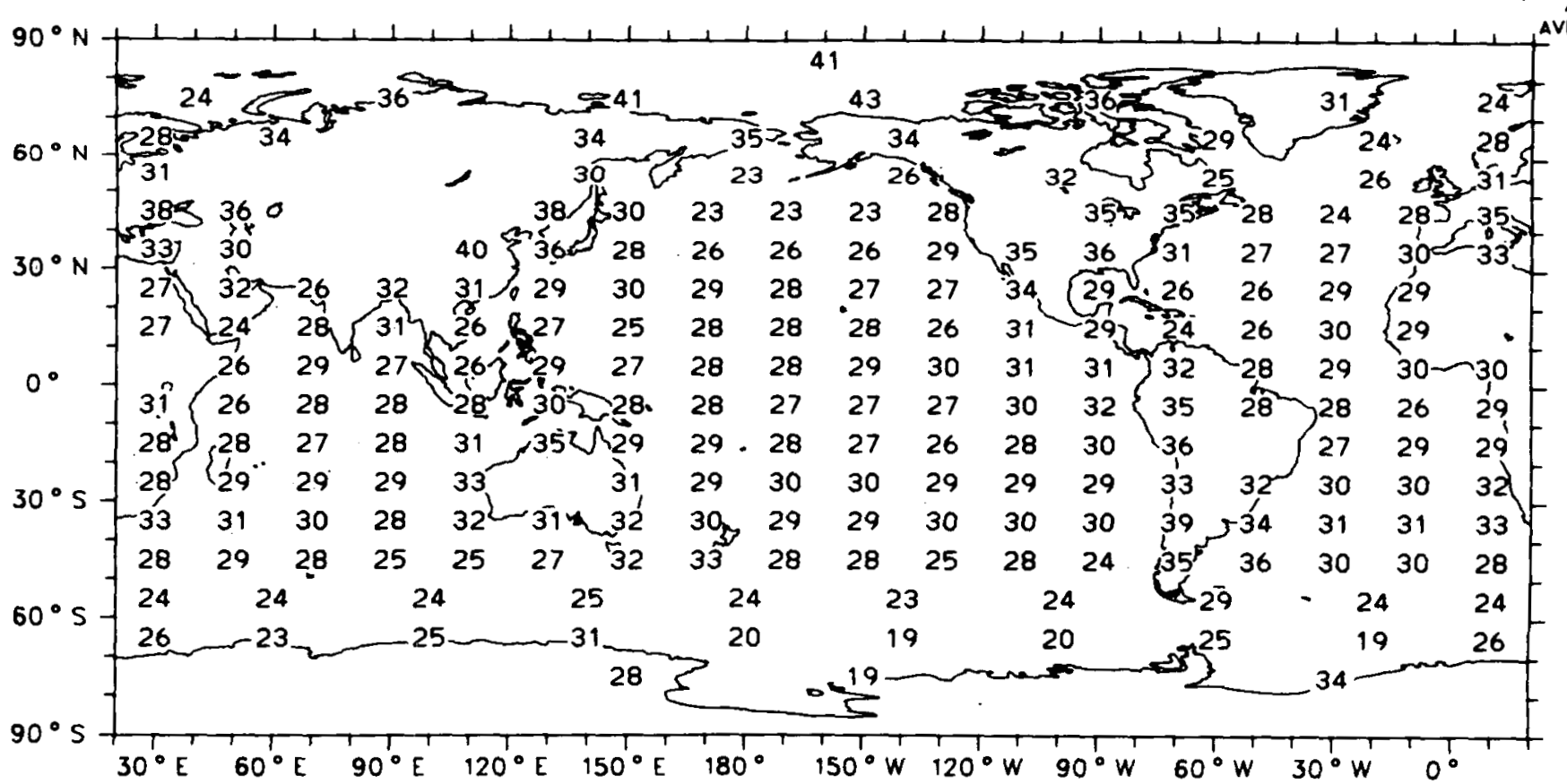

41

35

28

26

28

27

29

28

29

30

31 
Standard Deviation of Compressed Observations of Total Cloud Cover (\%) June. July. August (1952-1981)

Ocean Areos Only
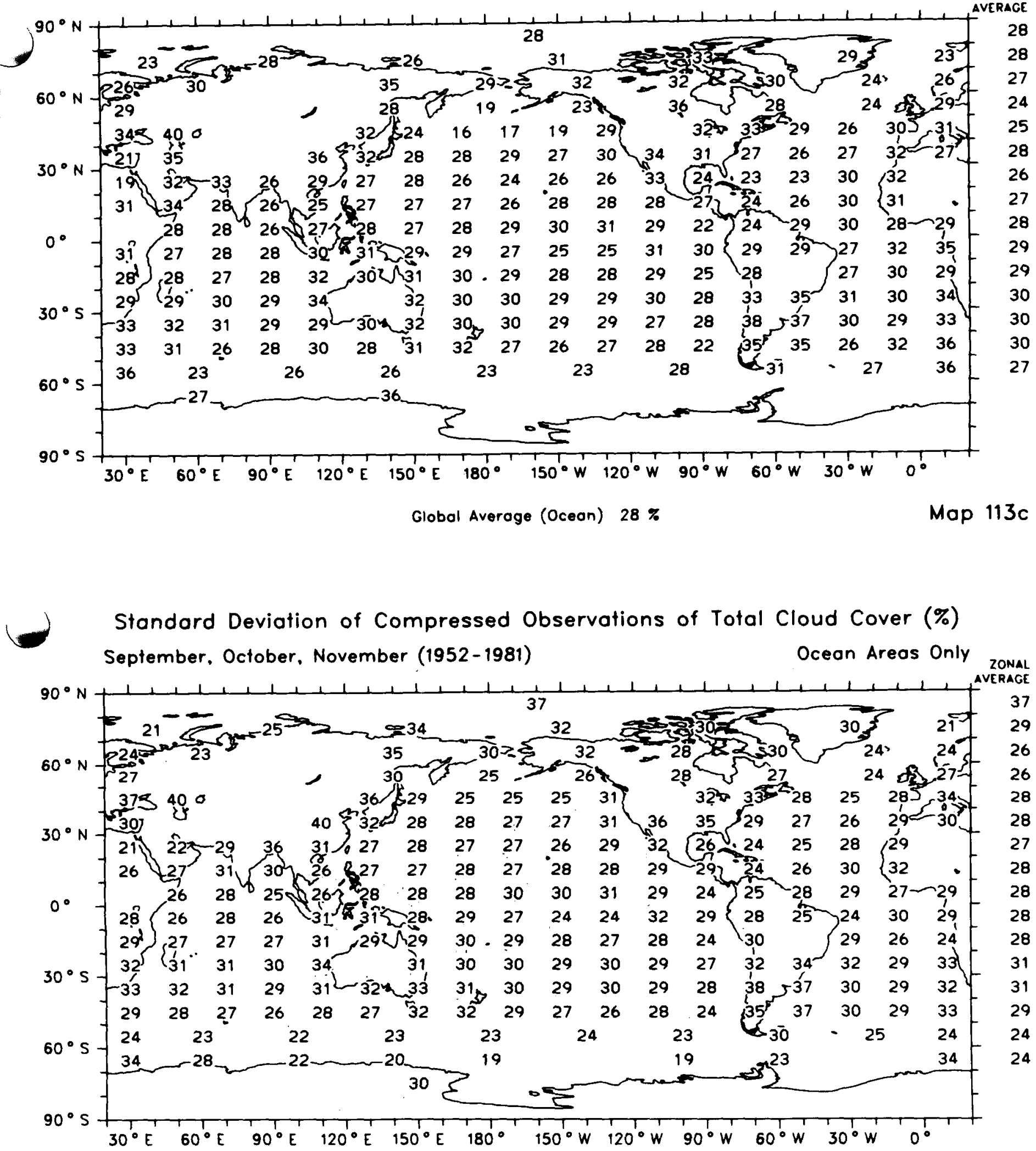
Total Cloud Cover

Amplitude of Diurnal Cycle (\% Cloud Cover)

December, January, February (1954-1983)

Ocean Areas Only

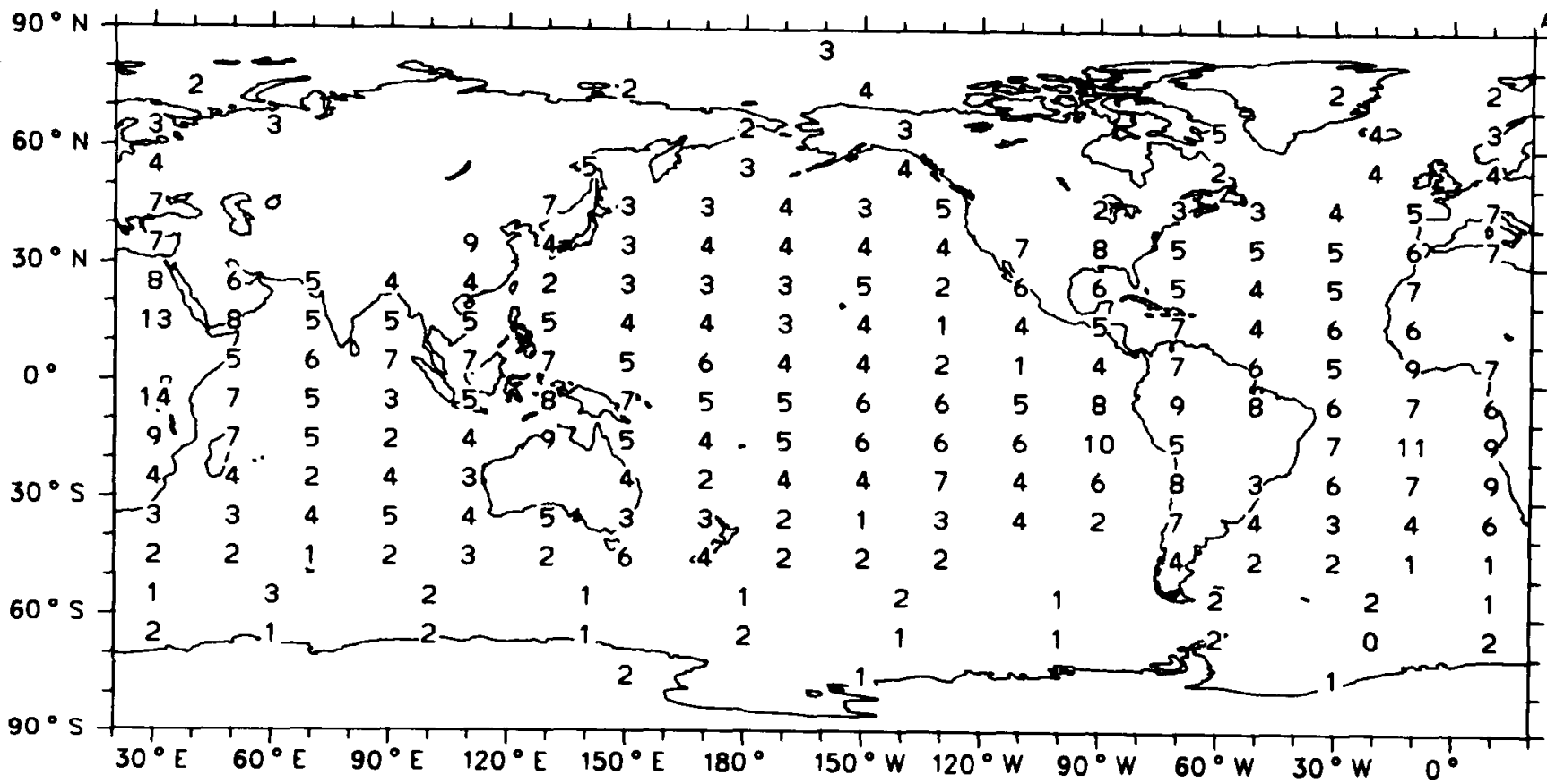

AVERAGE

Map 114a

Global Averoge (Ocean) $4 \%$

Total Cloud Cover

Phase of Diurnal Cycle (Local Time of Maximum )

December. Jonuary. February (1954-1983)

Ocean Areas Only

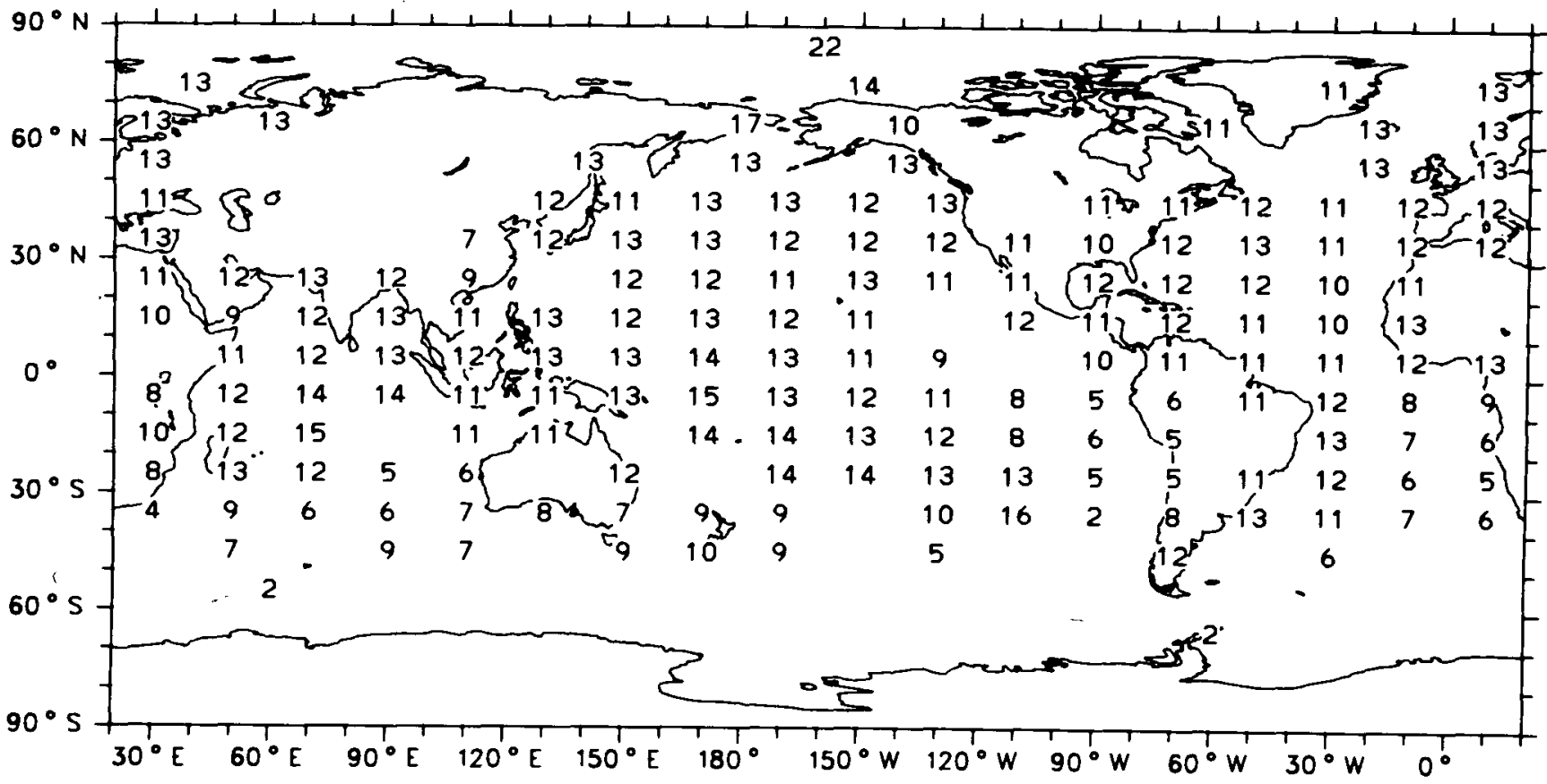

Map $114 b$ 
Total Cloud Cover

Amplitude of Diurnal Cycle (\% Cloud Cover)

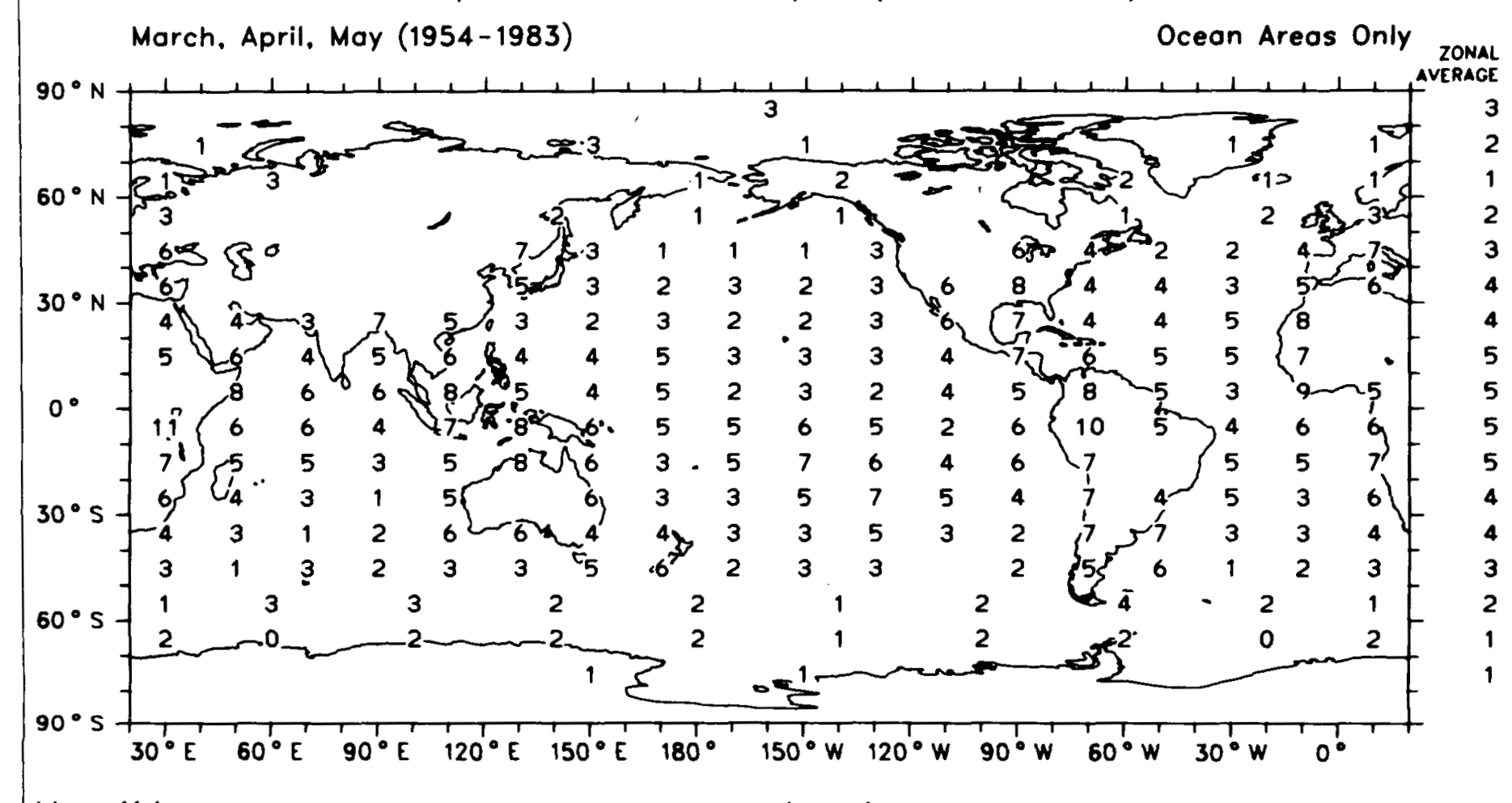

Map 114c

Global Average (Ocean) $4 \%$

Total Cloud Cover

Phase of Diurnal Cycle (Local Time of Maximum )

Morch, April, Moy (1954-1983)

Ocean Areos Only

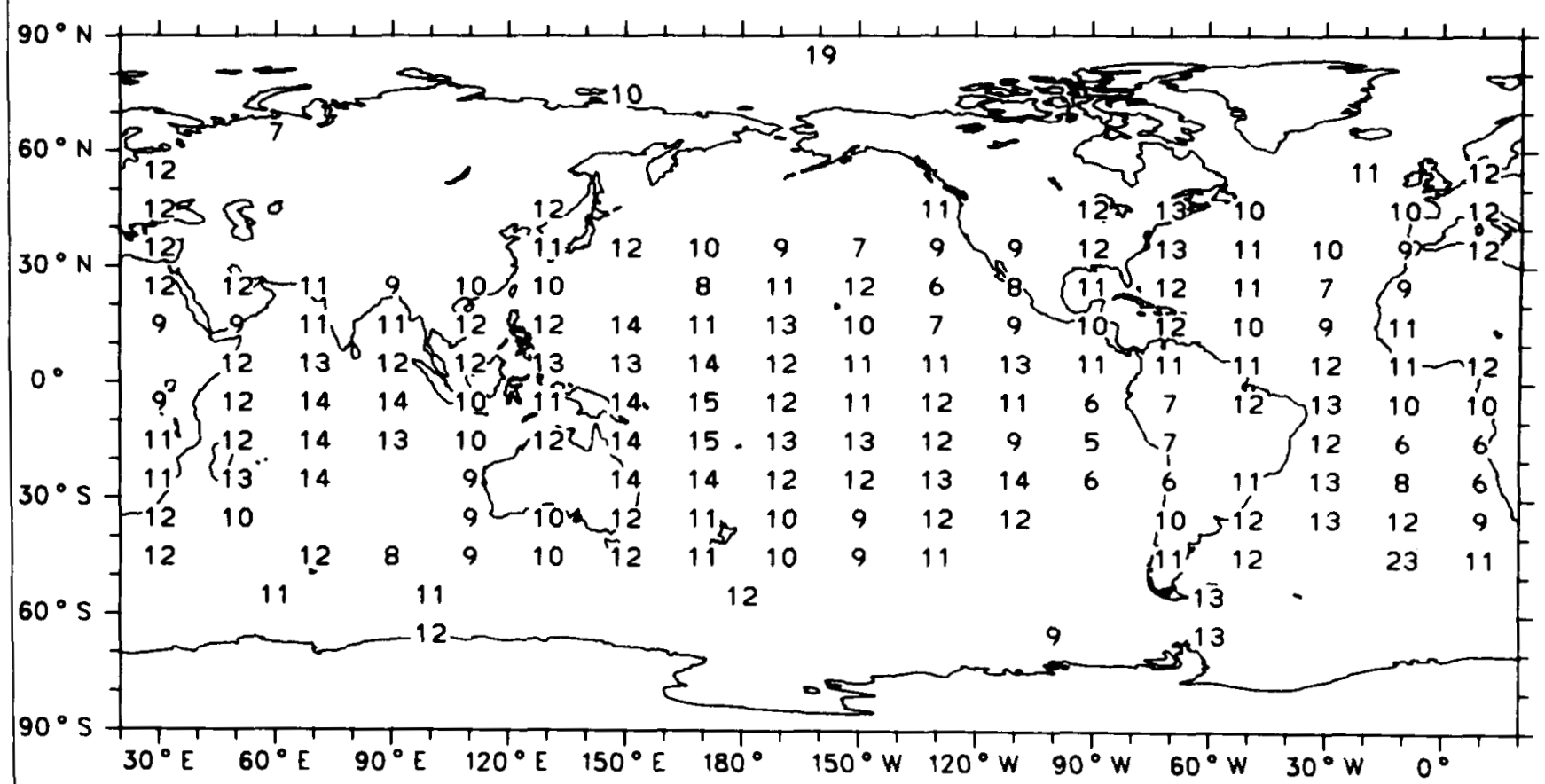

Map 114d 
Total Cloud Cover

Amplitude of Diurnal Cycle (\% Cloud Cover)

June. July, August (1954-1983)

Ocean Areos Only

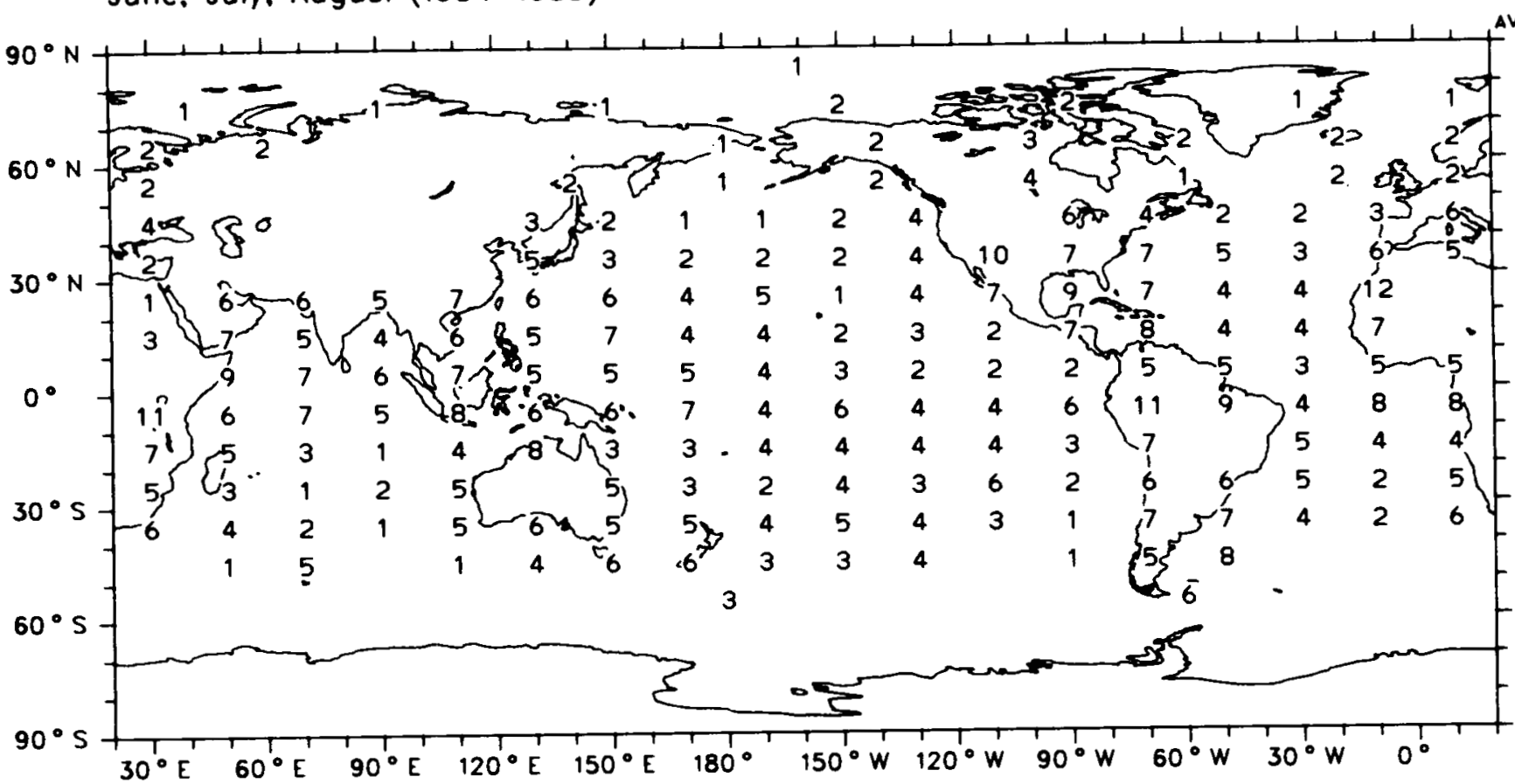

Map 115a

Total Cloud Cover

Phase of Diurnal Cycle (Local Time of Maximum ) June, July, August (1954-1983)

Ocean Areas Only

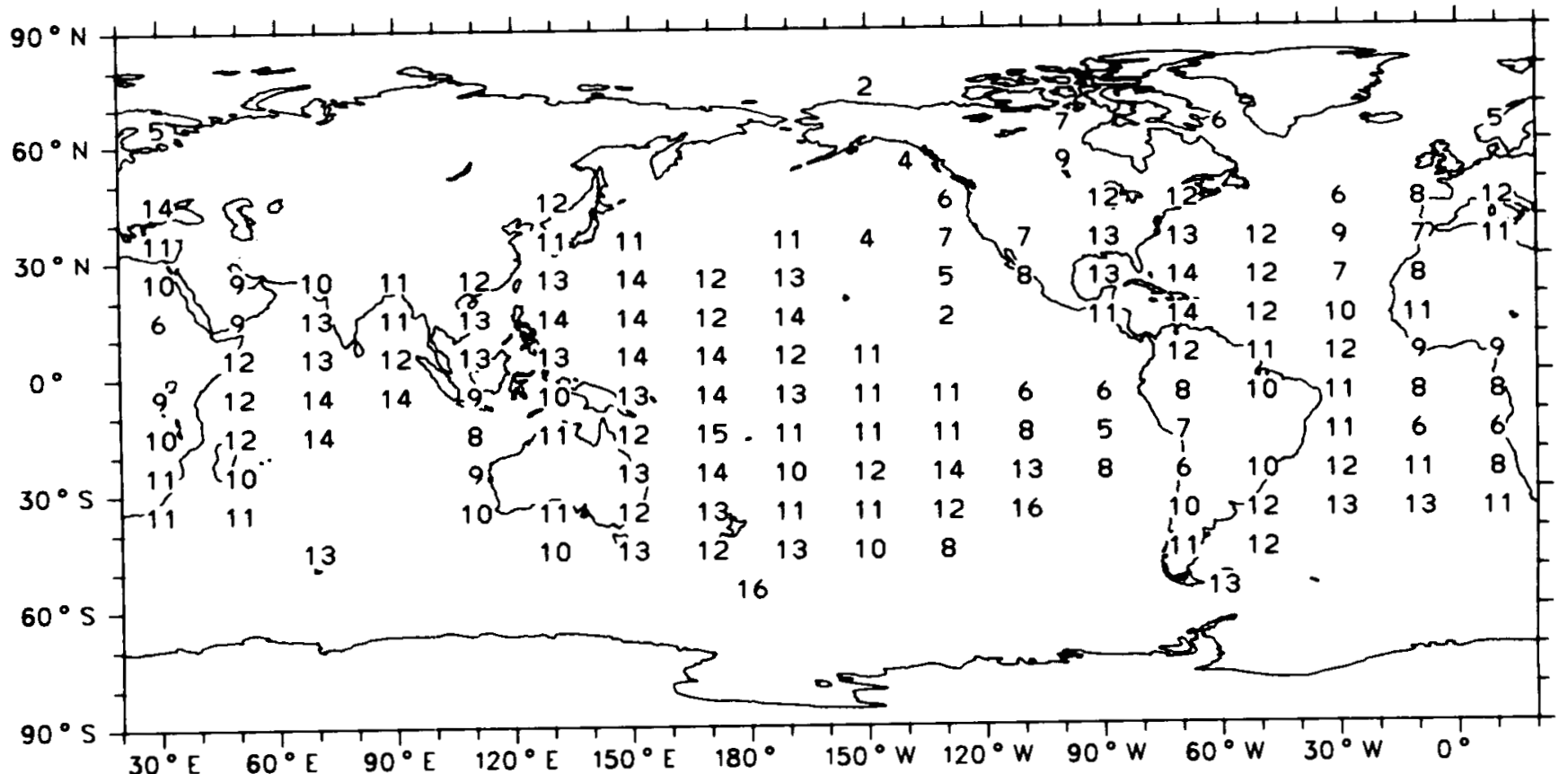

Map 115b 
Total Cloud Cover

Amplitude of Diurnal Cycle (\% Cloud Cover)

September. October. November (1954-1983)

Ocean Areas Only

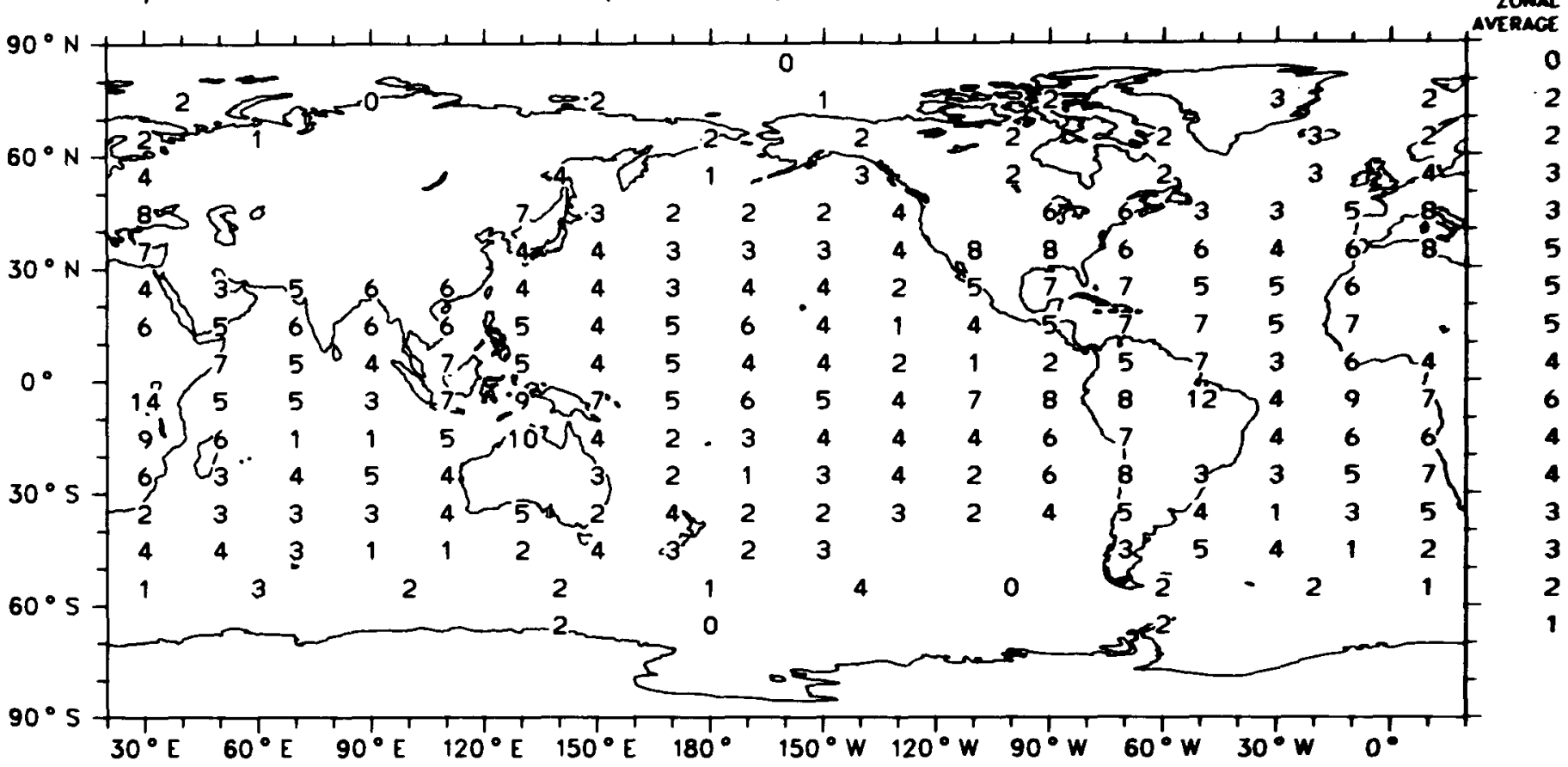

Global Averoge (Oceon) $4 \%$

Map 115c

Total Cloud Cover

Phase of Diurnal Cycle (Local Time of Maximum )

September, October, November (1954-1983)

Ocean Areas Only

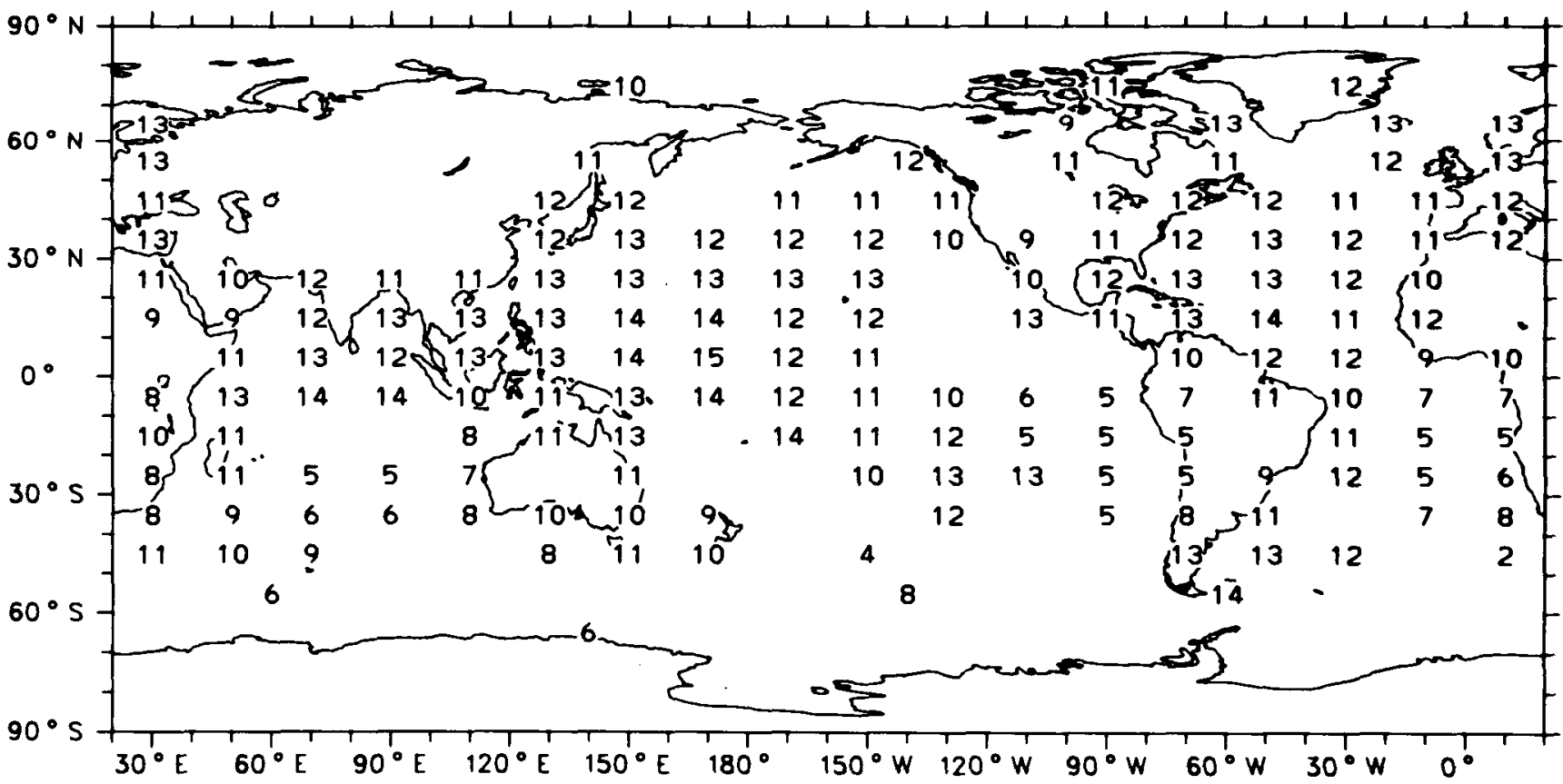

Map 115d 
Interannual Variation of Total Cloud Cover :

Standard Deviation (detrended) of Seasonal Means (\% Cloud Cover)

December. Januory. February (1952-1981)

Ocean Areas Only

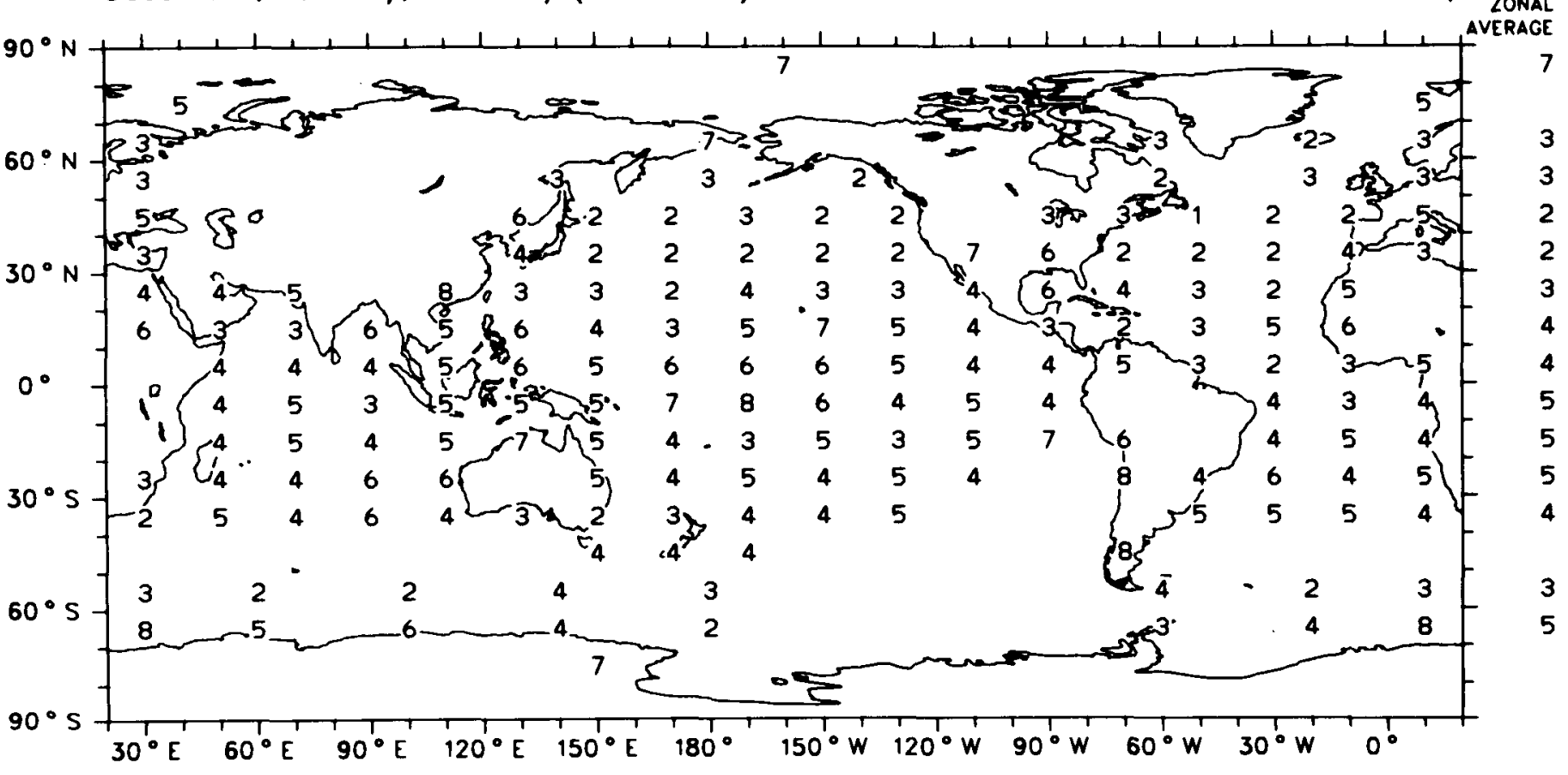

Map 116a

Globol Averoge (Oceon) $4 \%$

Interannual Variation of Total Cloud Cover :

Standard Deviation (detrended) of Seasonal Means (\% Cloud Cover) March. April. May (1952-1981)

Ocean Areas Only

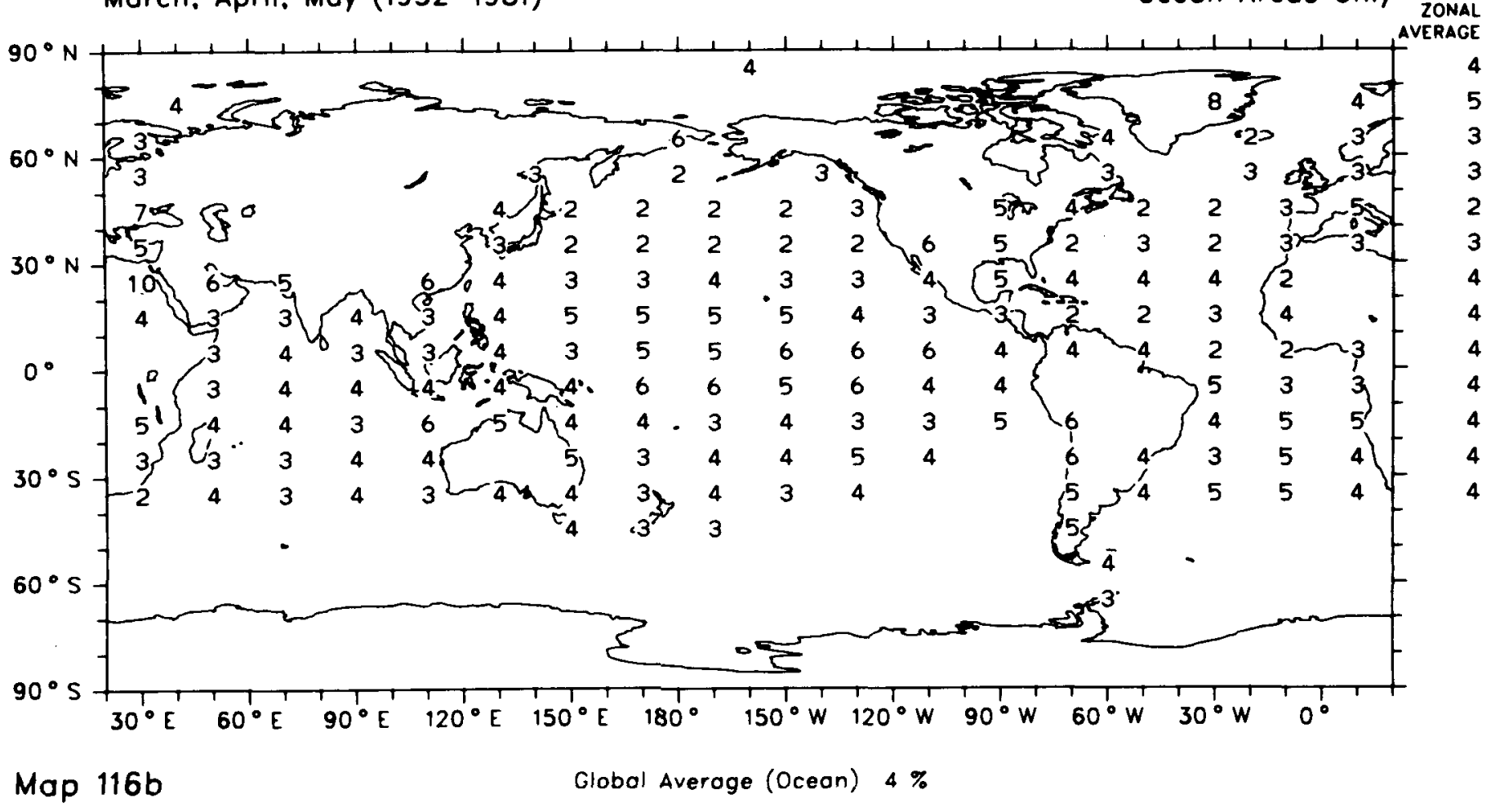


Interannual Variation of Total Cloud Cover:

Standard Deviation (detrended) of Seasonal Means (\% Cloud Cover) June. July, August (1952-1981)

Oceon Areos Only

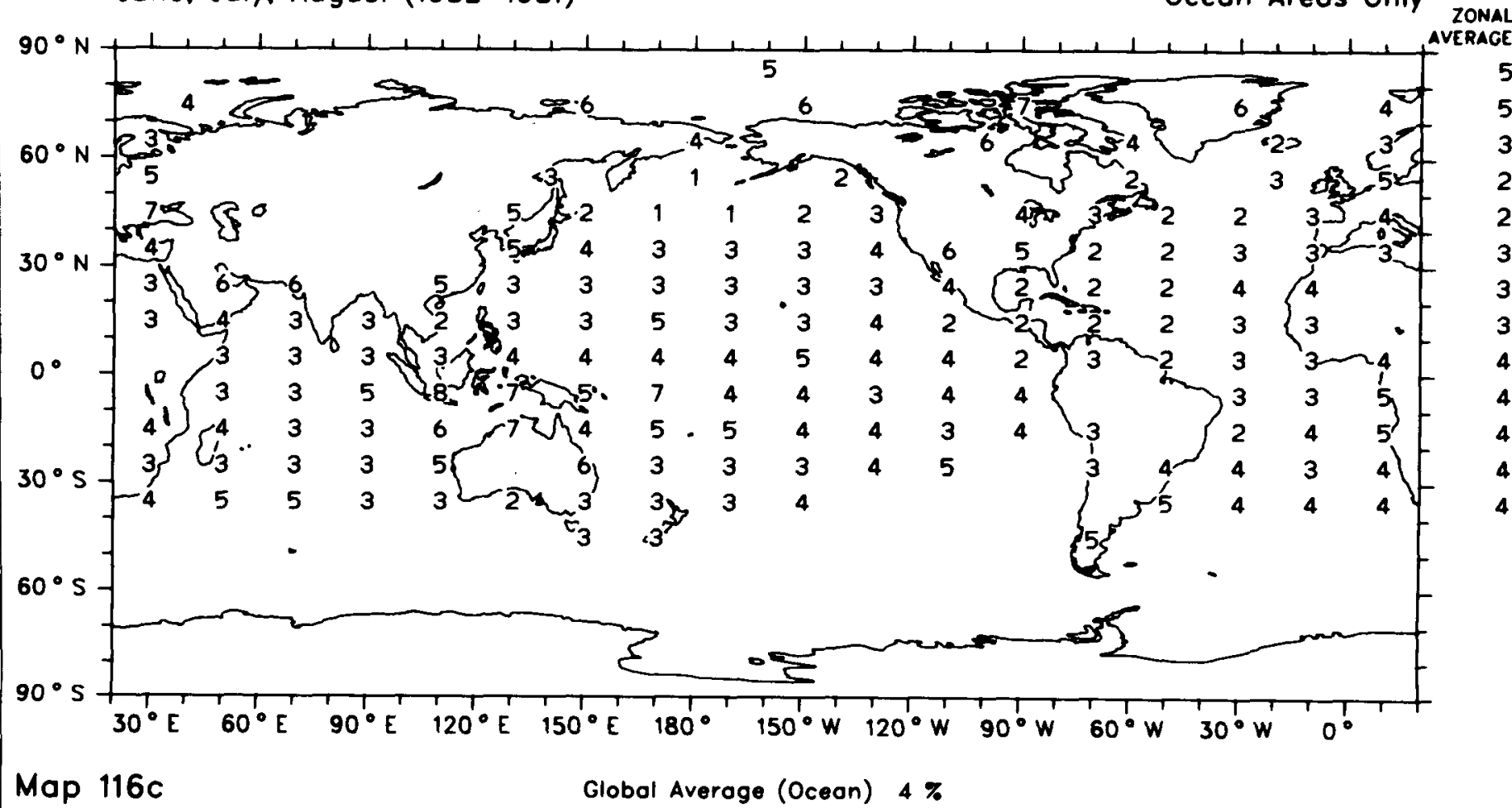

Interannual Variation of Total Cloud Cover :

Standard Deviation (detrended) of Seasonal Means (\% Cloud Cover) September. October. November (1952-1981)

Ocean Areas Only

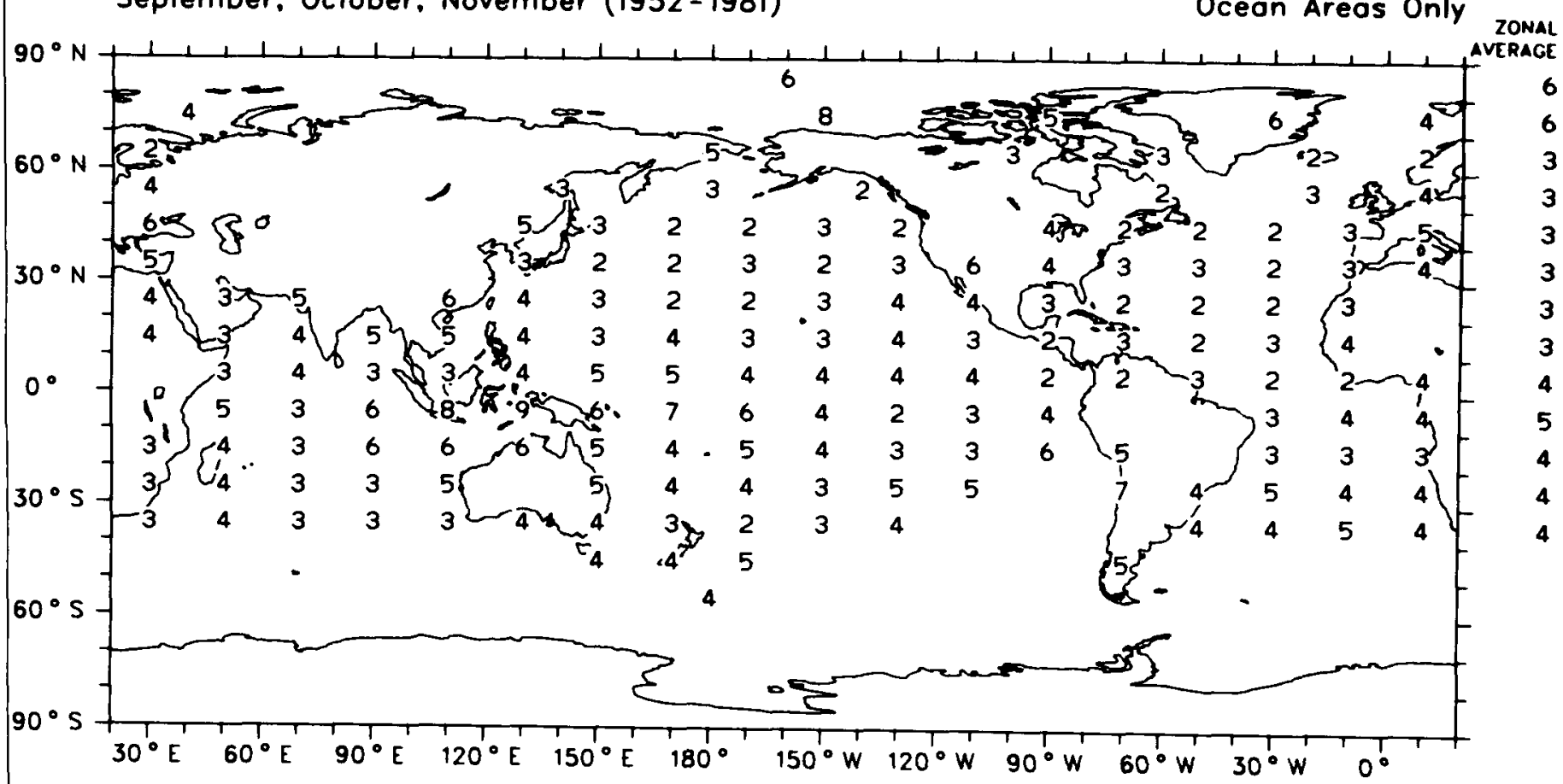

Map 116d

Global Average (Ocean) $4 \%$ 
Trend of Total Cloud Cover :

Change in \%-Cloud-Cover from 1952 to 1981

December, January. February (1952-1981)

Ocean Areos Only

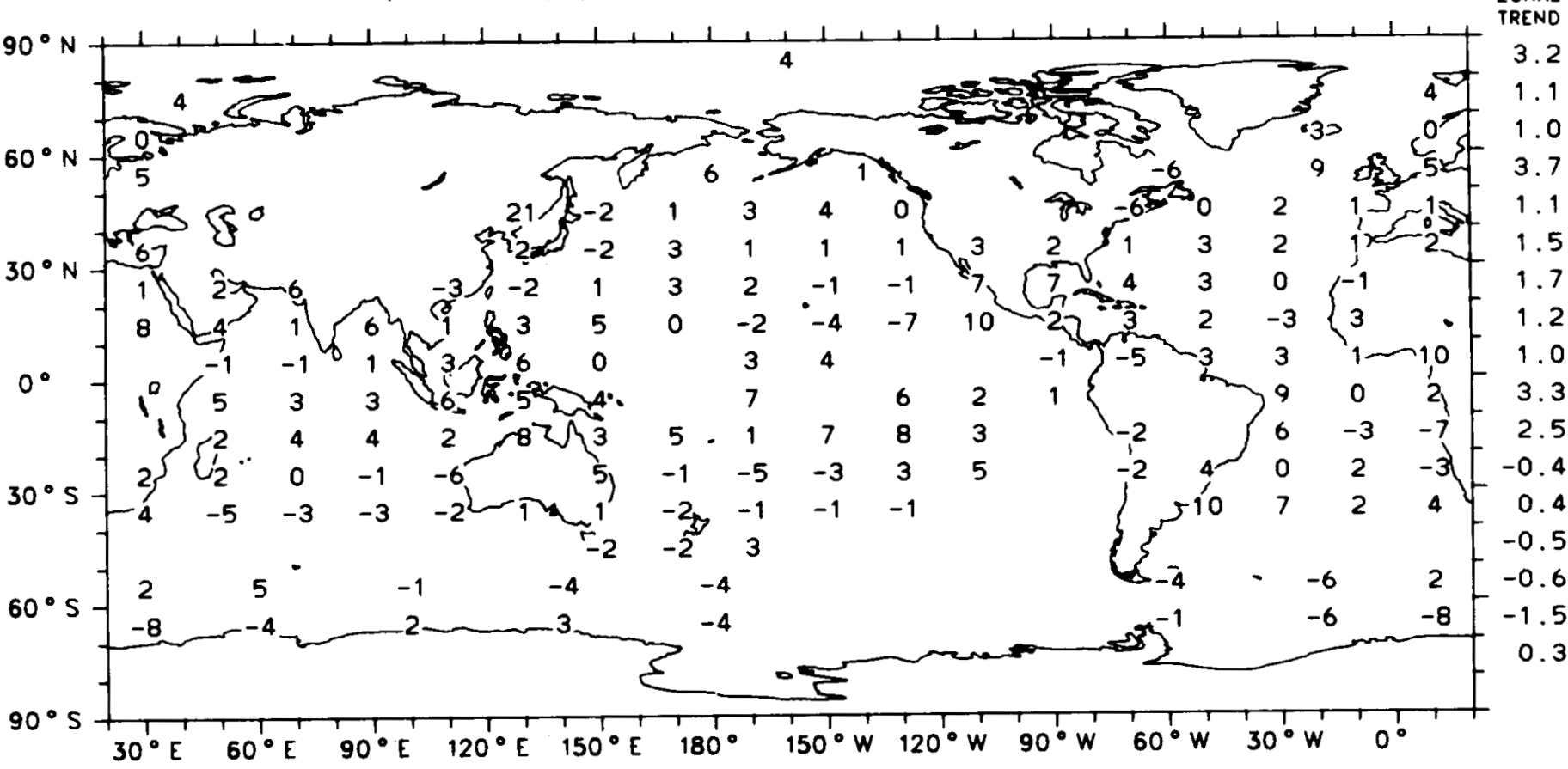

Global Trend (Ocean) $1.0 \%$

Map 117a

Trend of Total Cloud Cover :

Change in \%-Cloud-Cover from 1952 to 1981

Morch, April, May (1952-1981)

Ocean Areos Only

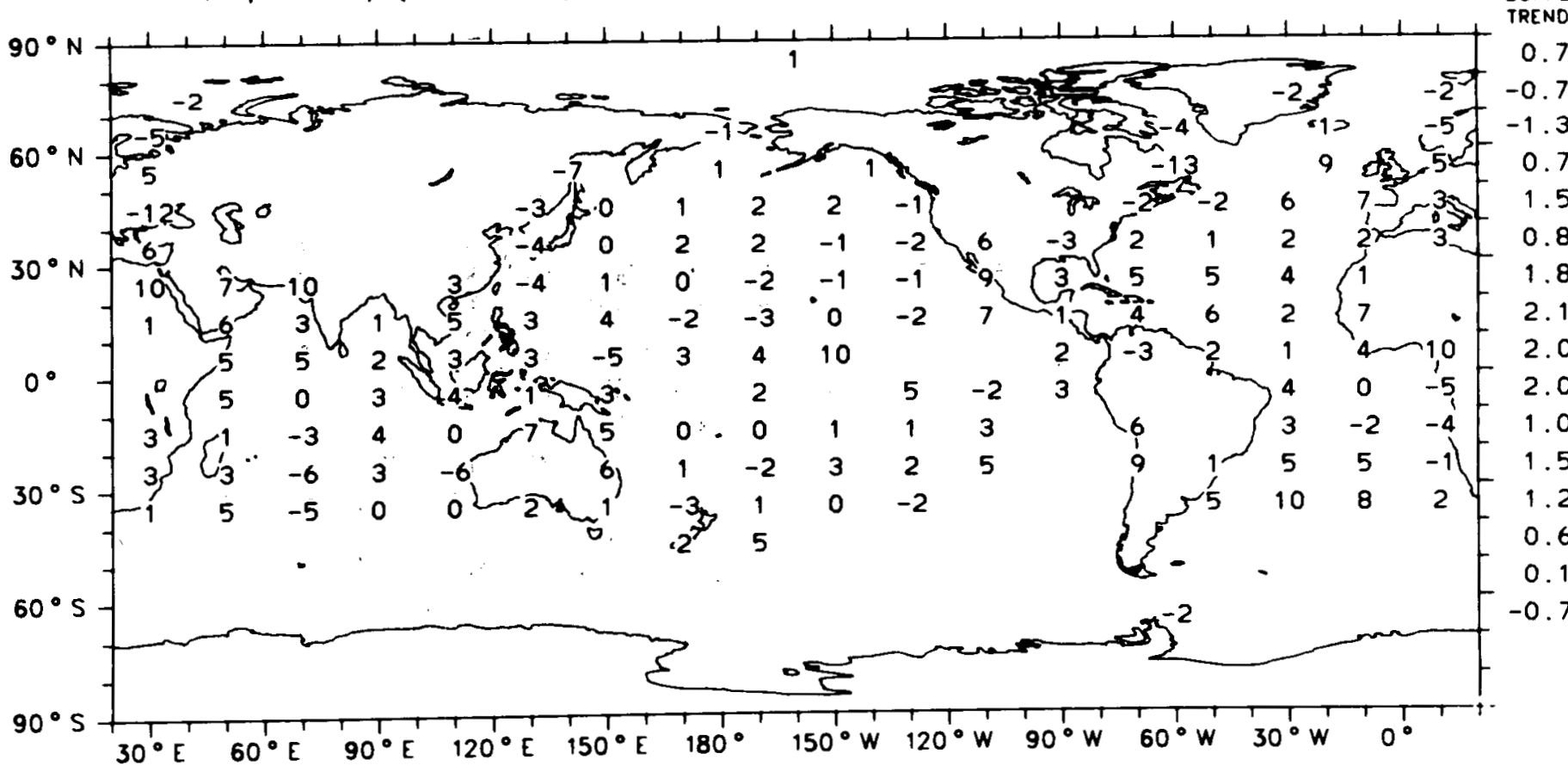


Trend of Total Cloud Cover:

Change in \%-Cloud-Cover from 1952 to 1981

June, July. August (1952-1981)

Oceon Areas Only

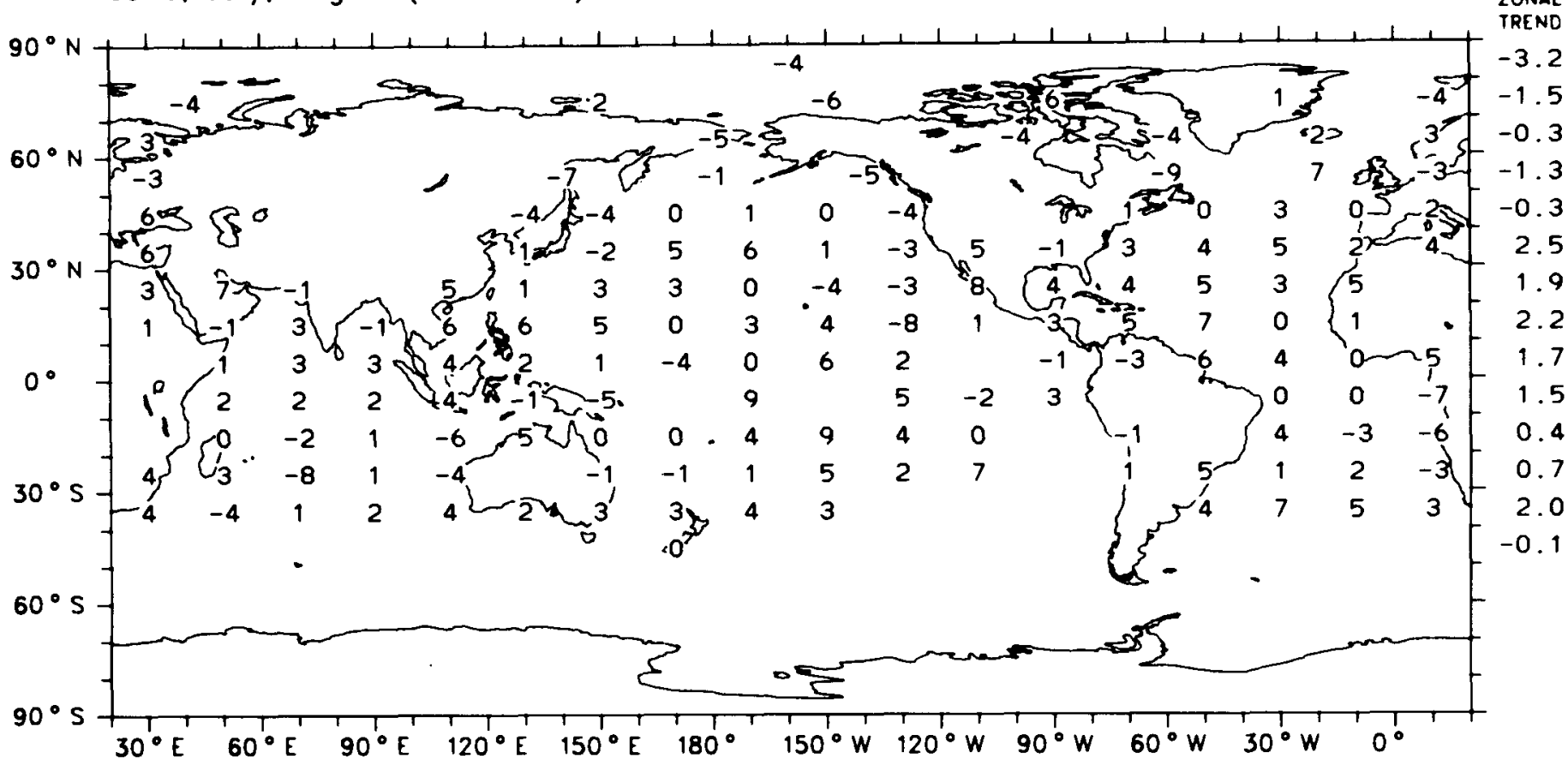

Global Trend (Ocean) $0.9 \%$

Map 117c

Trend of Total Cloud Cover :

Change in \%-Cloud-Cover from 1952 to 1981

September, October, November (1952-1981)

Ocean Areas Only

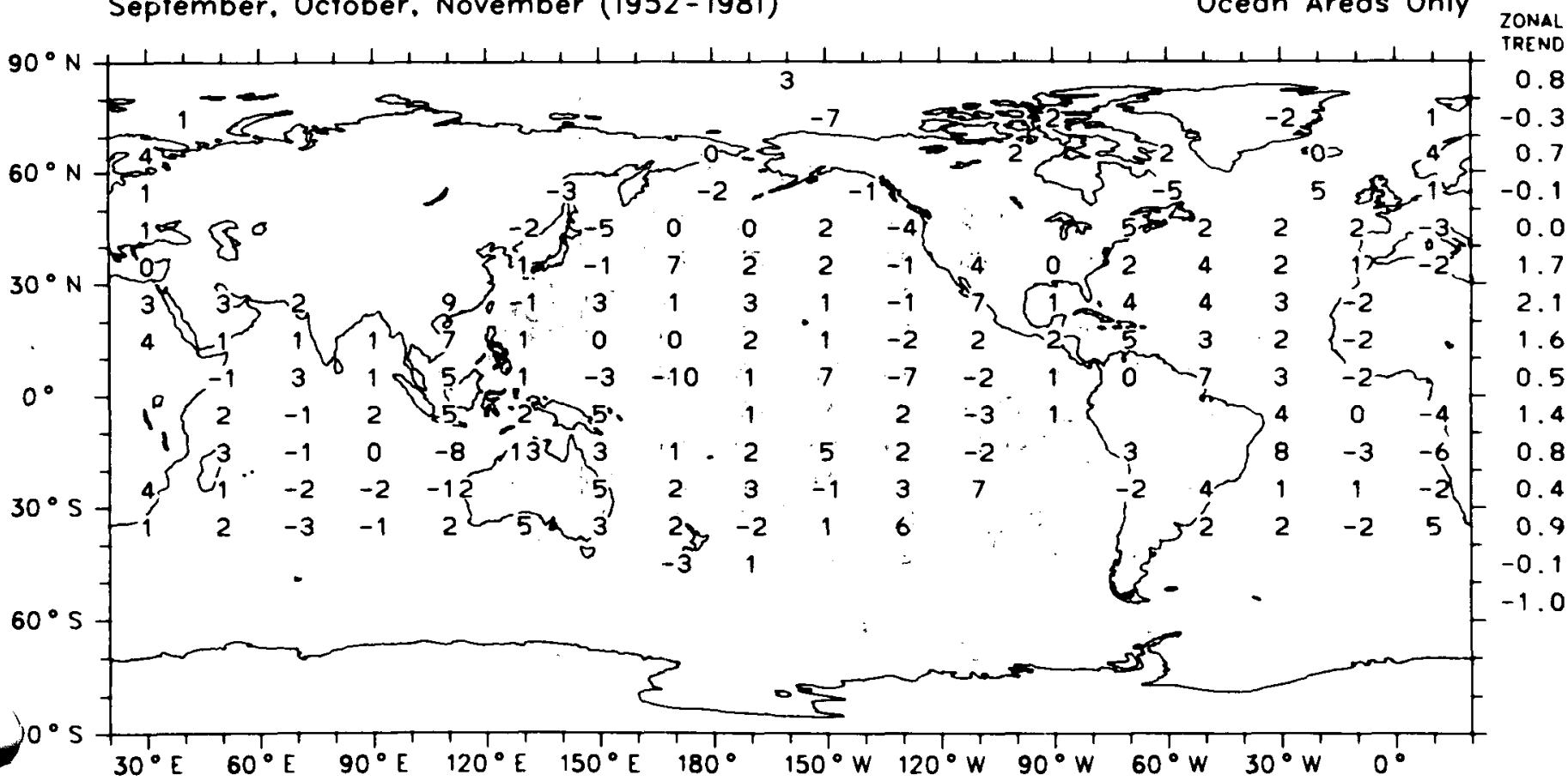

Global Trend (Ocean) $0.7 \%$

Map 117d 


\section{Cumulus}

\section{Frequency of Occurrence (\%)}

December, January. February (1952-1981)

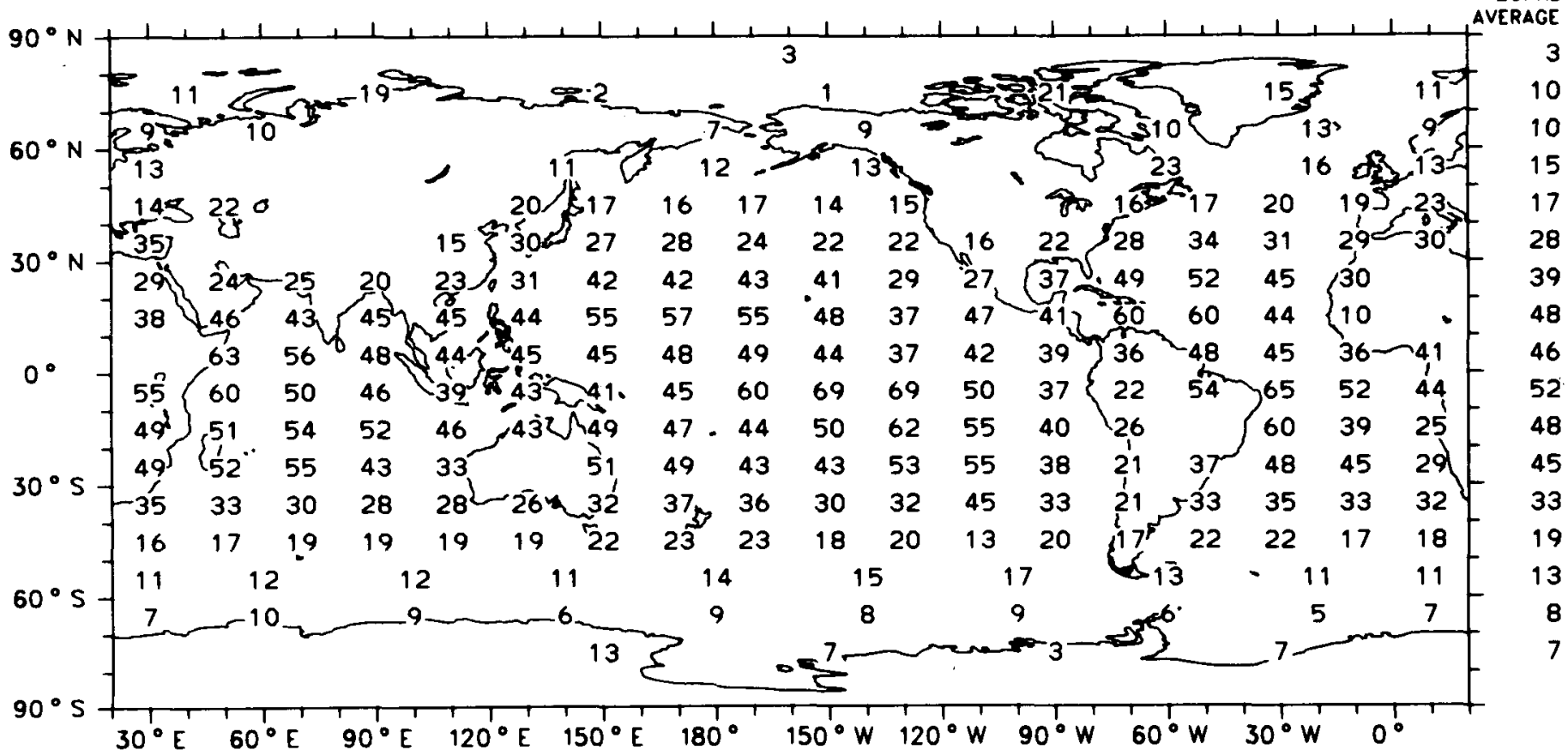

Map $118 a$

Global Averoge (Ocean) $34 \%$

\section{Cumulus}

\section{Frequency of Occurrence (\%)}

March. April. May (1952-1981)

Ocean Areas Only

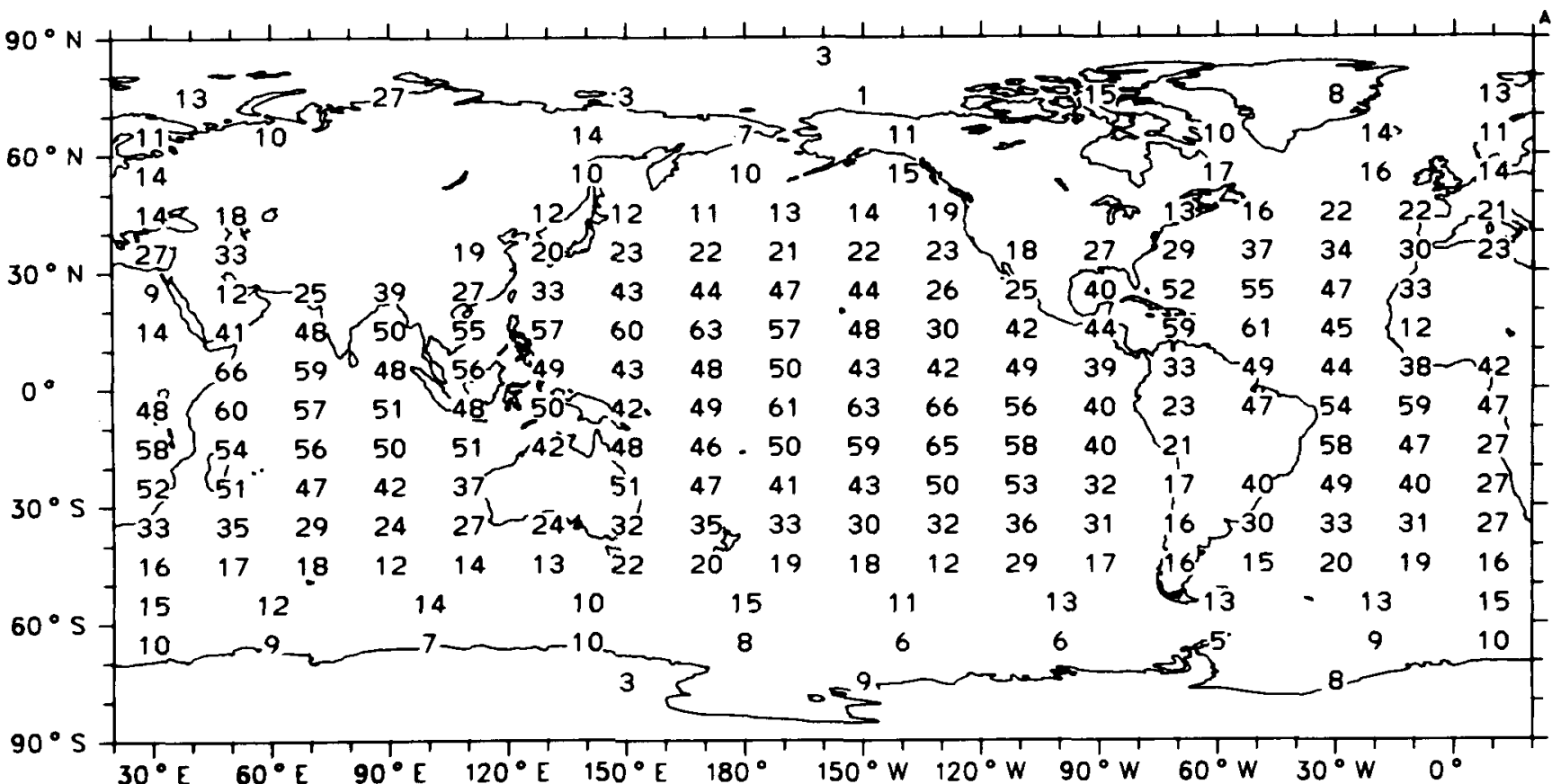




\section{Cumulus}

Frequency of Occurrence (\%)

June, July, August (1952-1981)

Oceon Areos Only

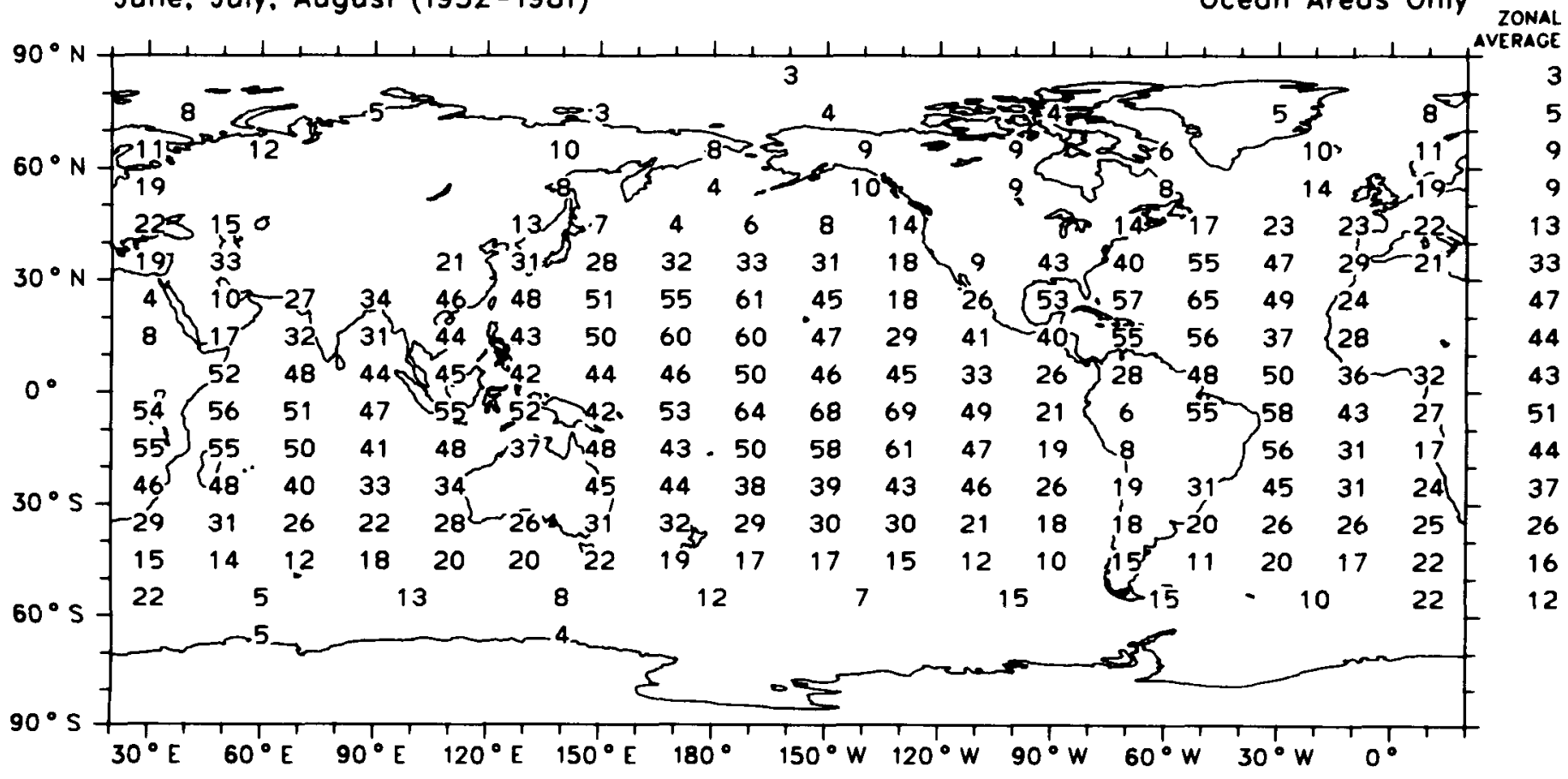

Map 118c

Global Average (Ocean) $33 \%$

\section{Cumulus}

Frequency of Occurrence (\%)

September, October, November (1952-1981)

Oceon Areos Only

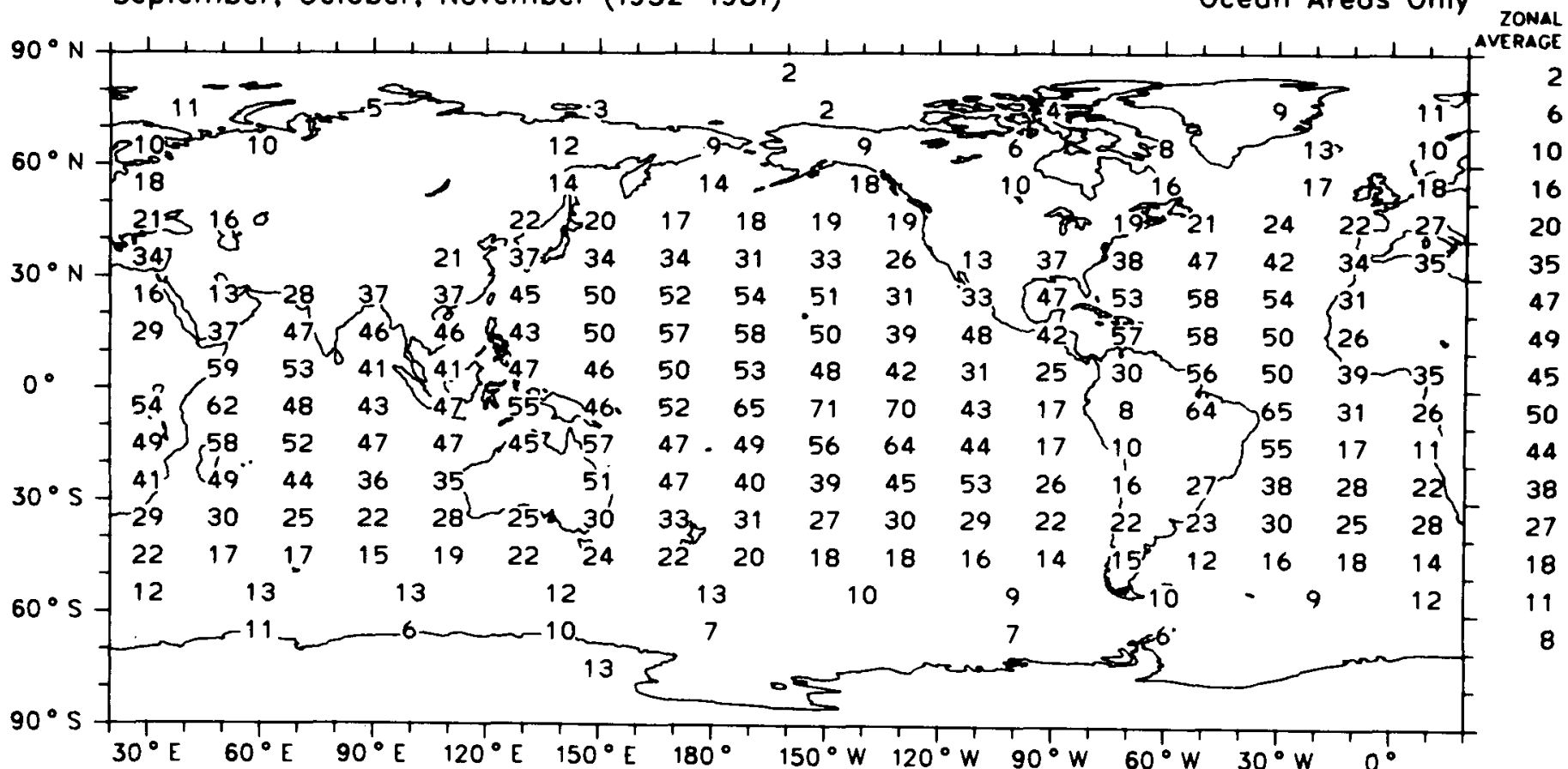

Map 118d

Global Averoge (Ocean) $33 \%$ 
Cumulus

Amount-When-Present (\%)

December, January, February (1952-1981)

Ocean Areas Only

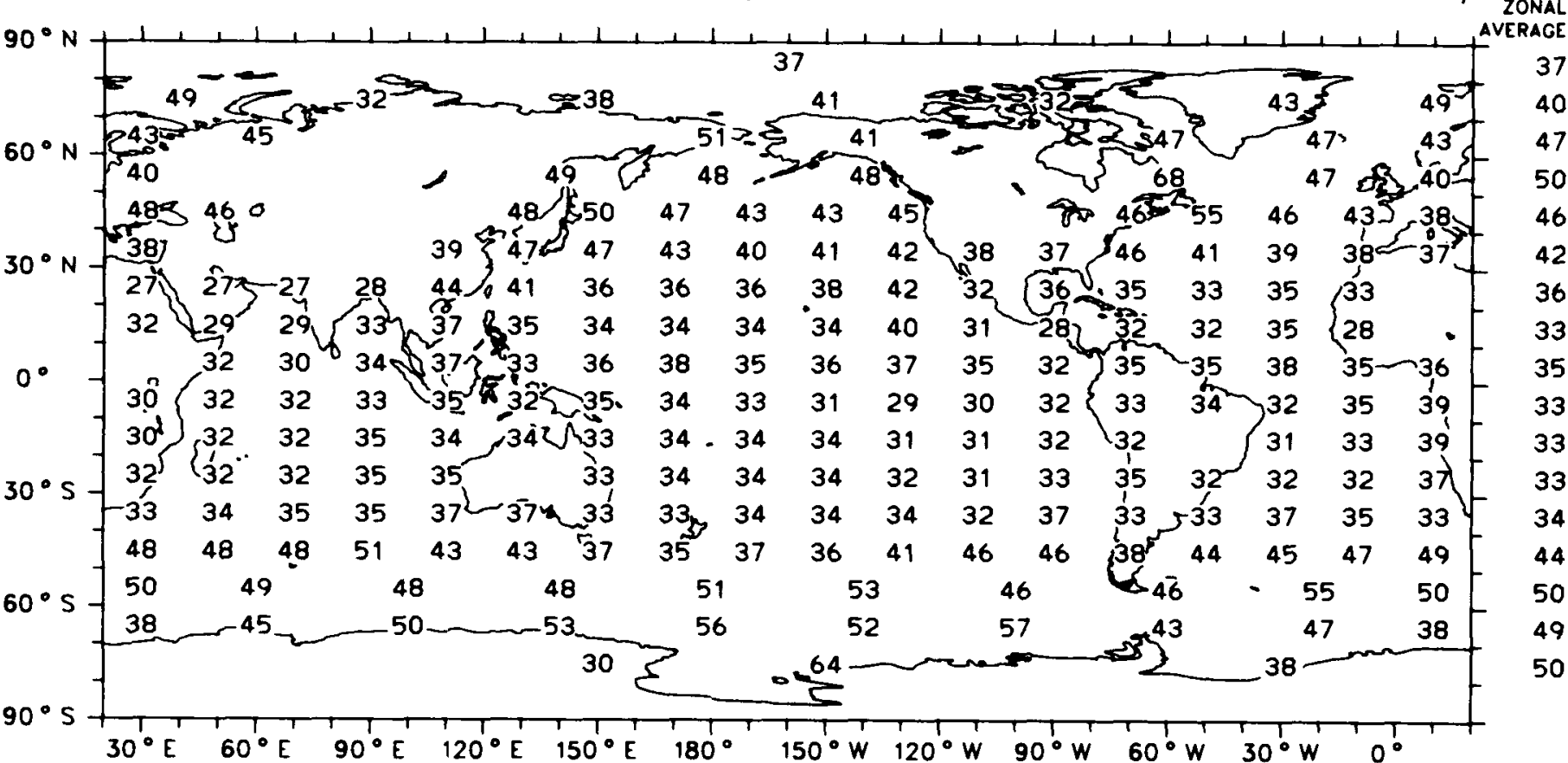

Global Average (Ocean) $38 \%$

Map 119a

Cumulus

Amount-When-Present (\%)

March. April. May (1952-1981)

Ocean Areas Only

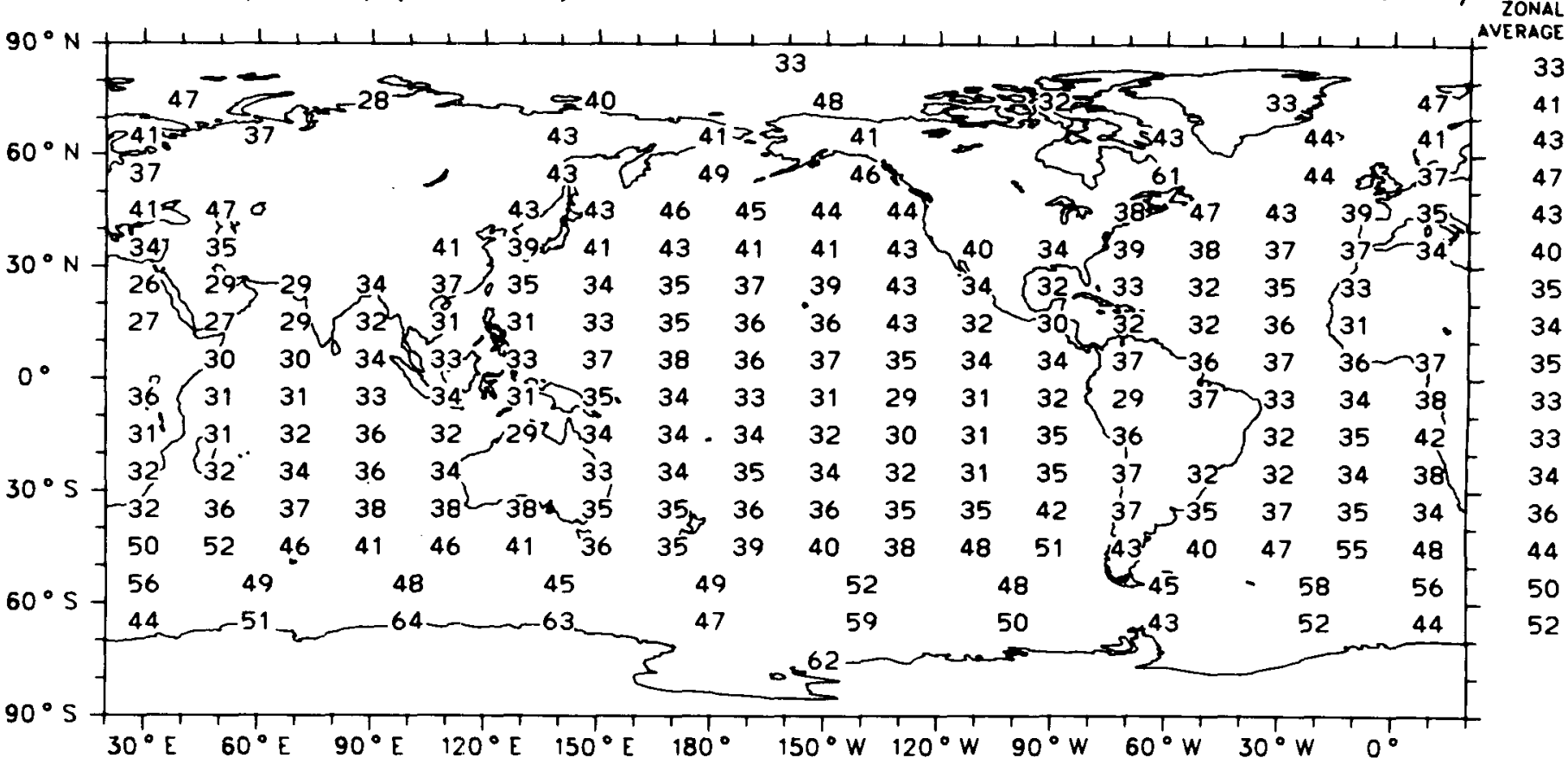


Cumulus

Amount-When-Present (\%)

June, July, August (1952-1981)

Oceon Areas Only

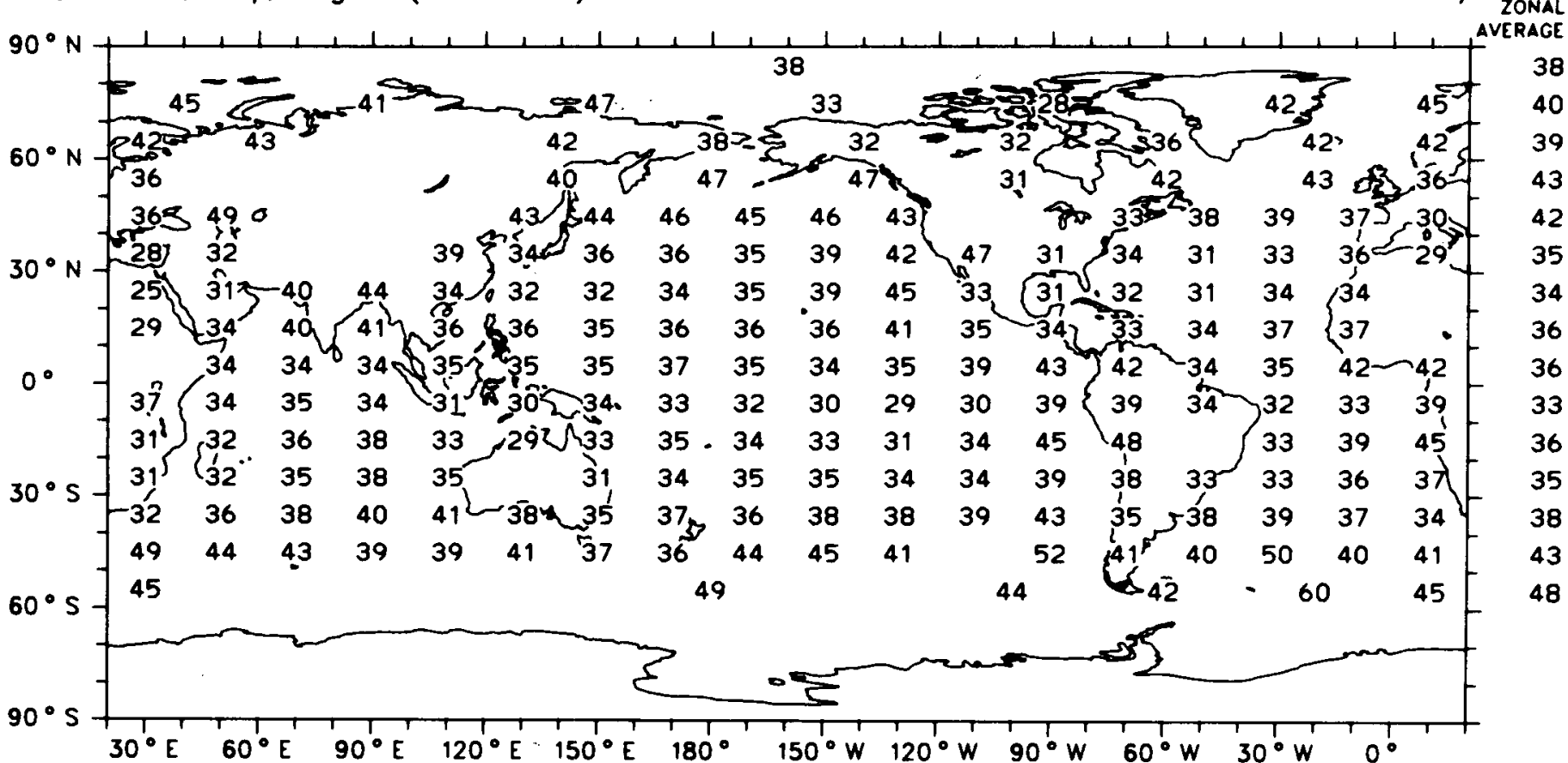

Global Average (Oceon) $38 \%$

Map 119c

\section{Cumulus}

Amount-When-Present (\%)

September, October, November (1952-1981)

Ocean Areas Only

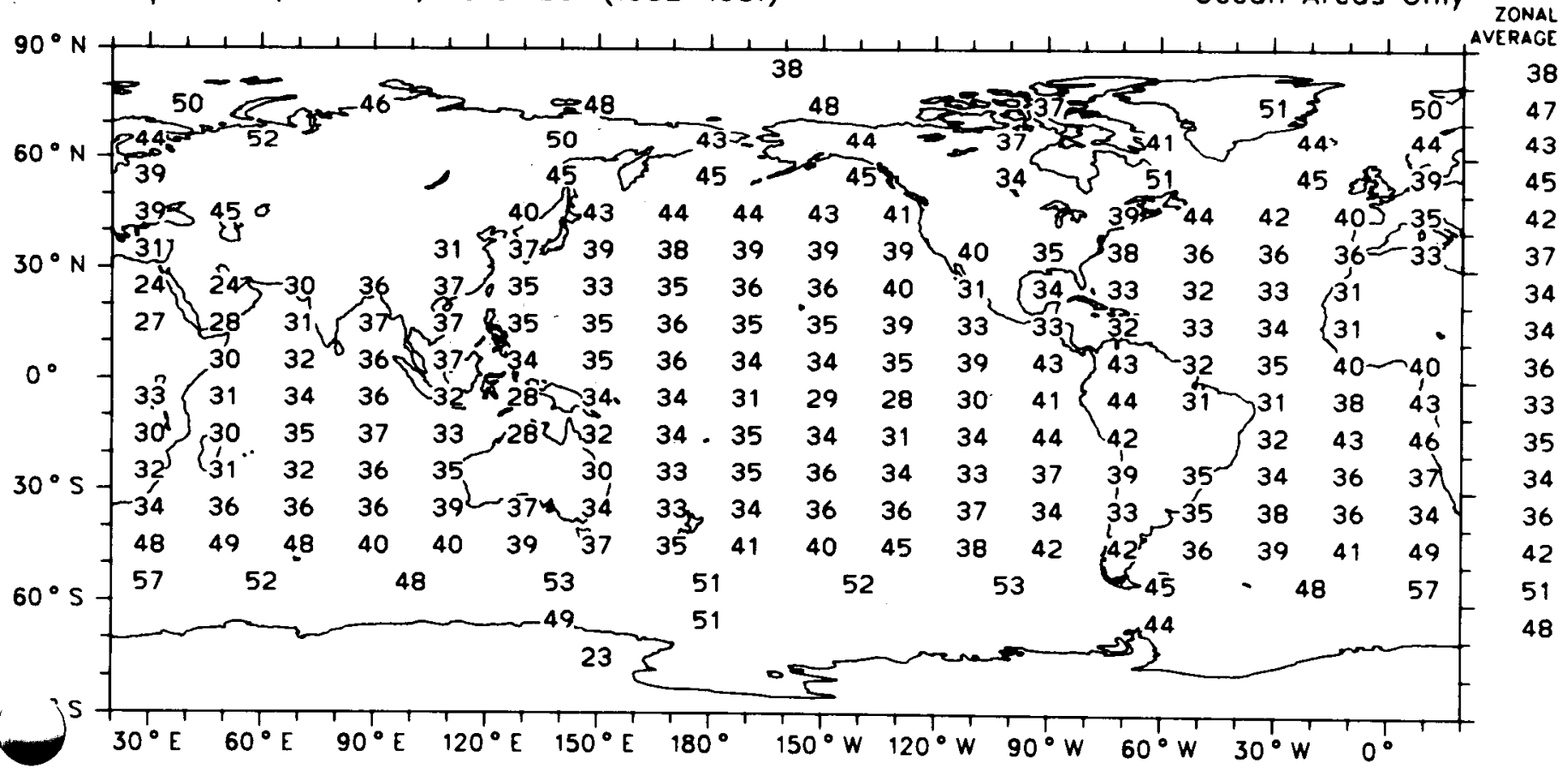

Global Average (Ocean) $38 \%$

Map 119d 
Cumulus

Average Cloud Amount (\%)

December, January. February (1952-1981)

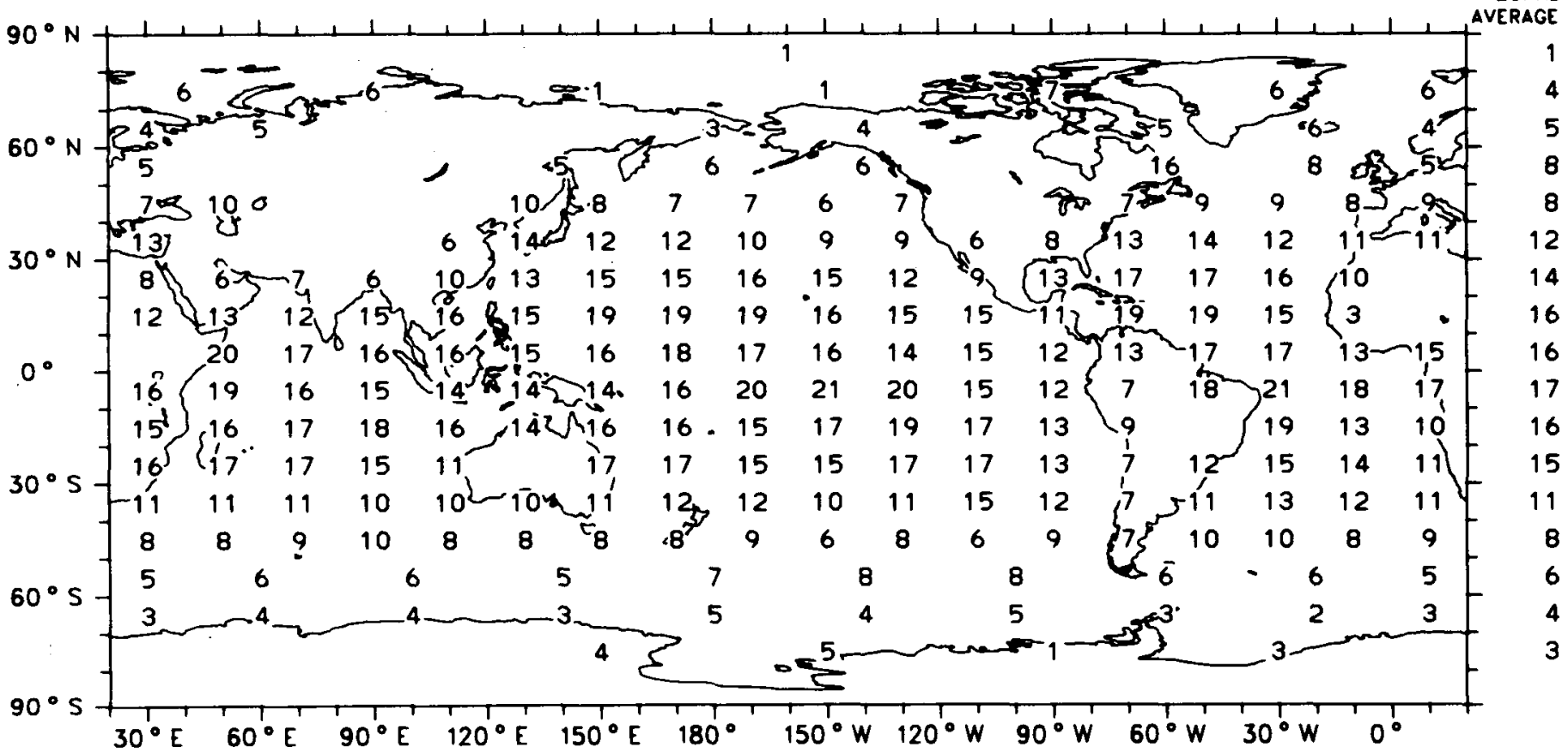

Map 120a

Global Average (Ocean) $12 \%$

Cumulus

Average Cloud Amount (\%)

March. April, May (1952-1981)

Ocean Areas Only

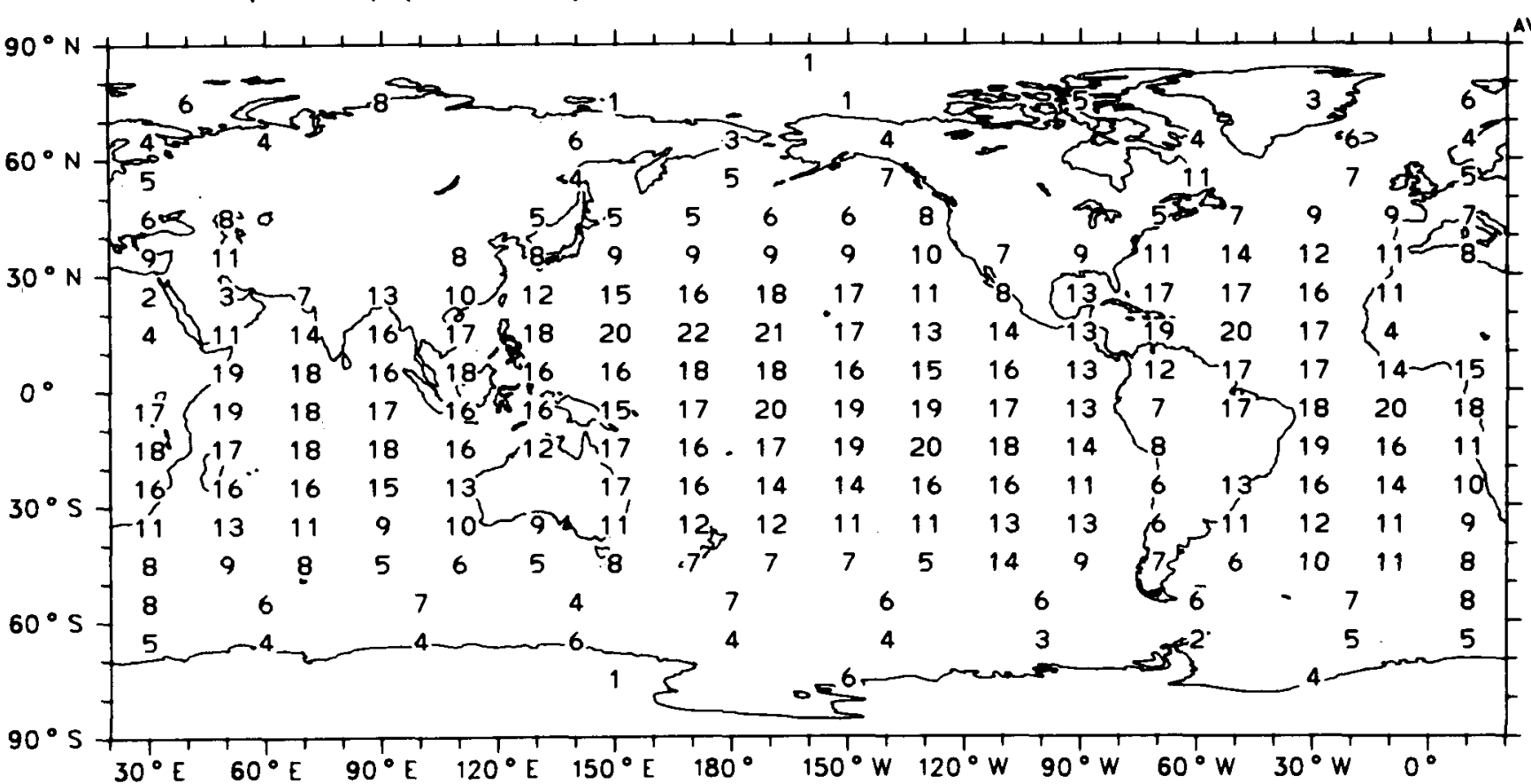

ZONAL VERAGE

Map $120 b$

Global Average (Oceon) $12 \%$ 
Cumulus

Average Cloud Amount (\%)

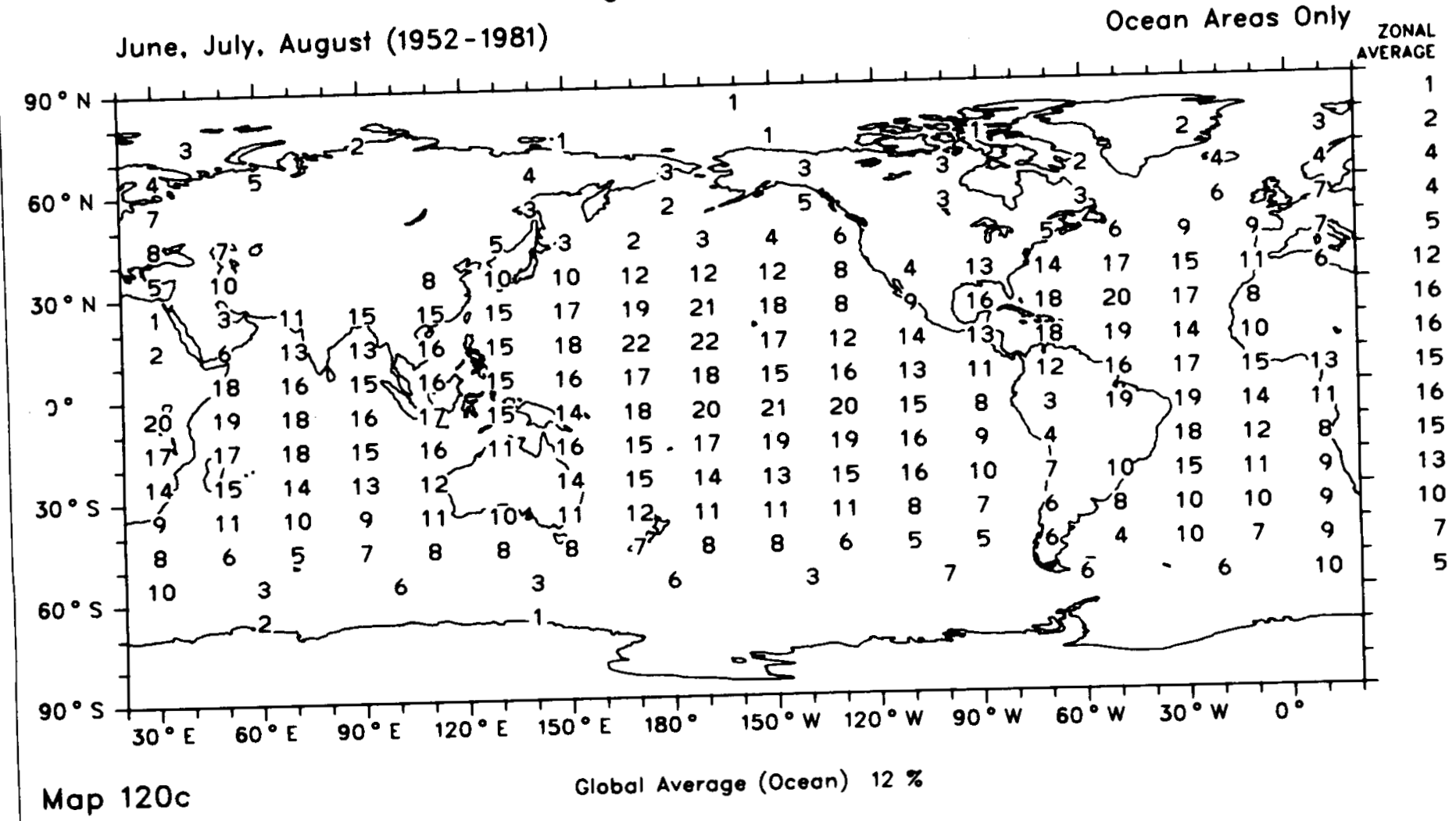

Cumulus

Average Cloud Amount (\%)

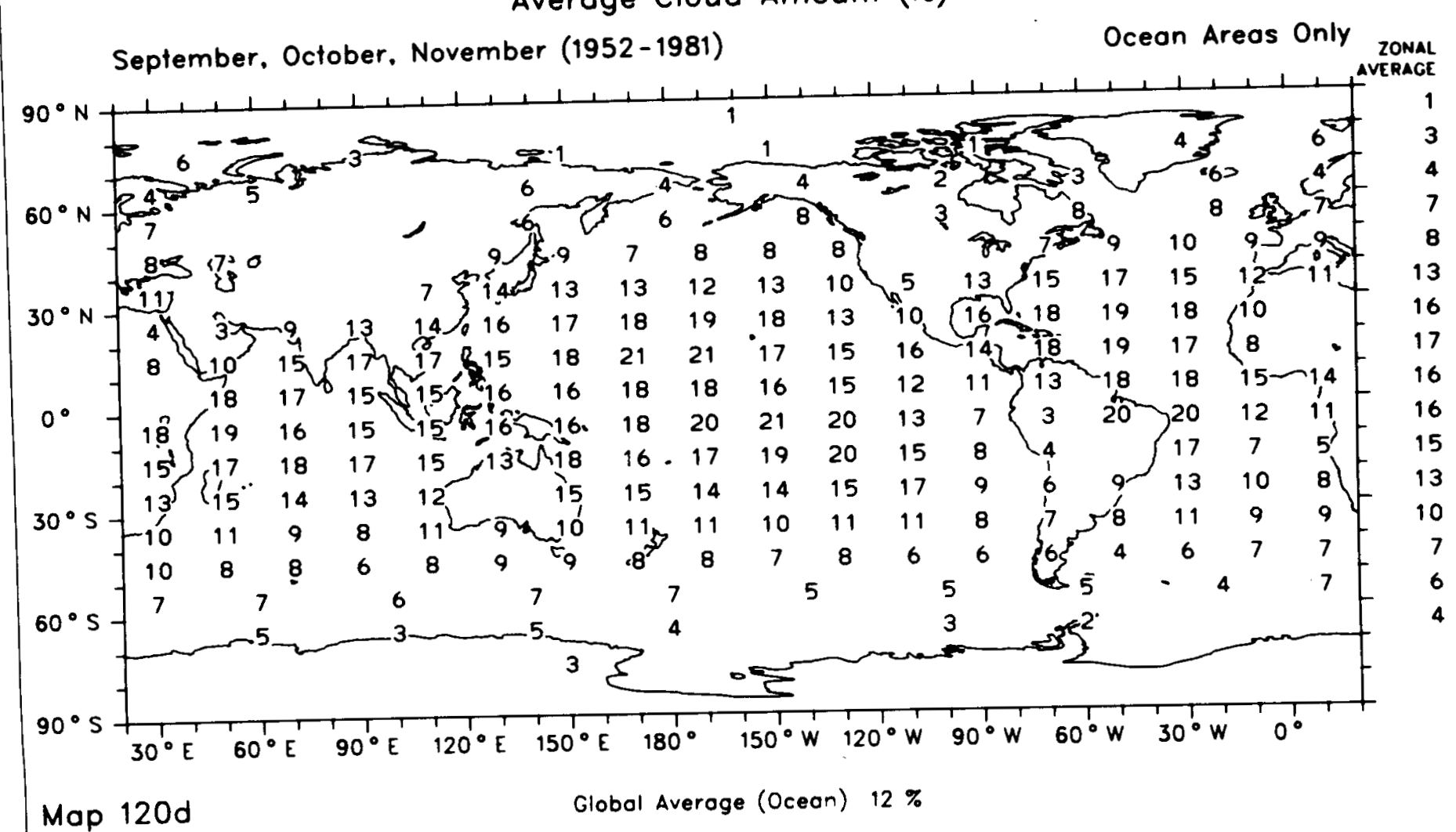


Cumulus

Average Base Height (decometers)

December, Januory. February (1954-1981)

Ocean Areas Only

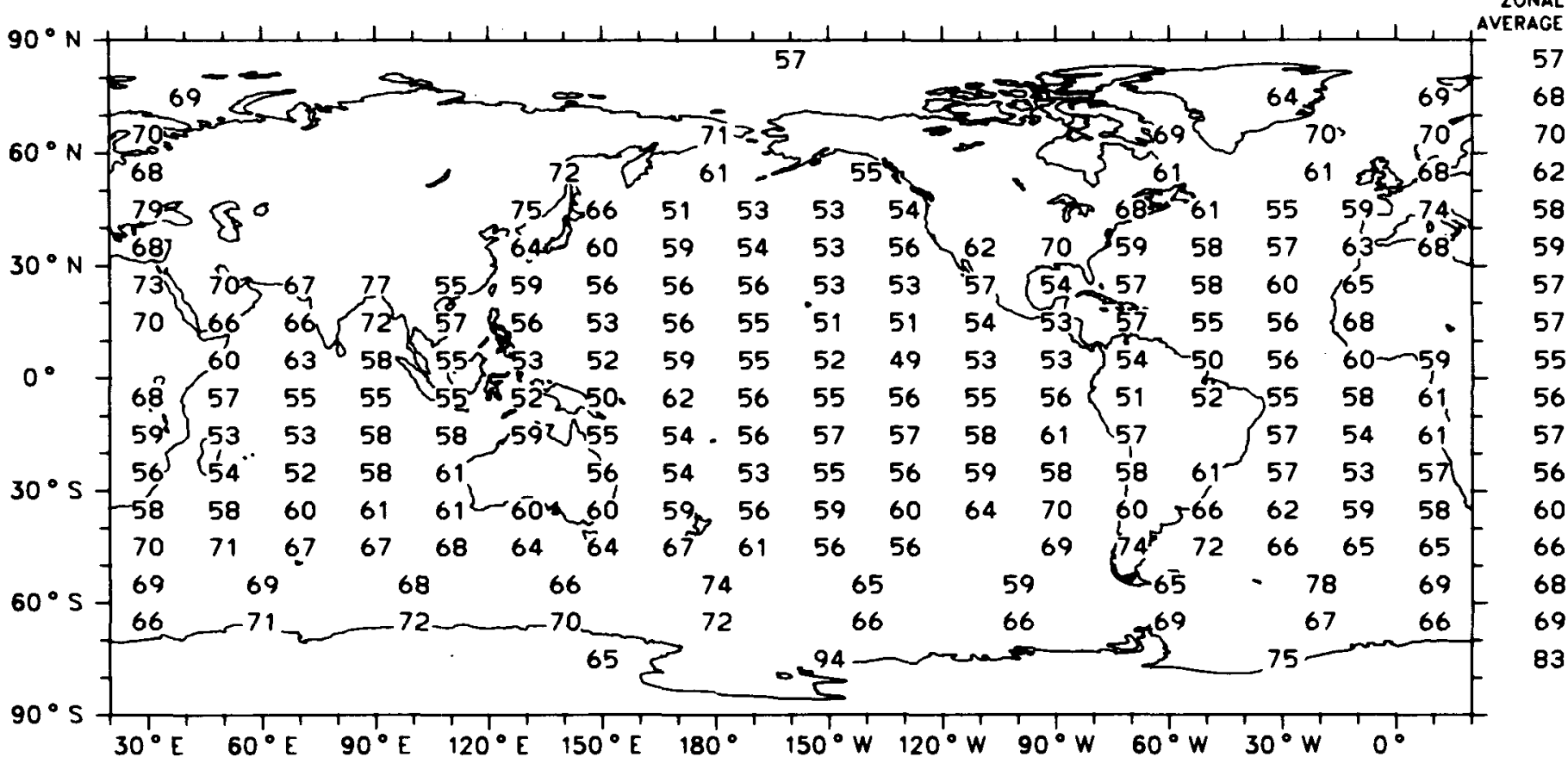

Global Averoge (Ocean) 599 meters

Map 121a

Cumulus

Average Base Height (decameters)

March, April. Moy (1954-1981)

Ocean Areas Only

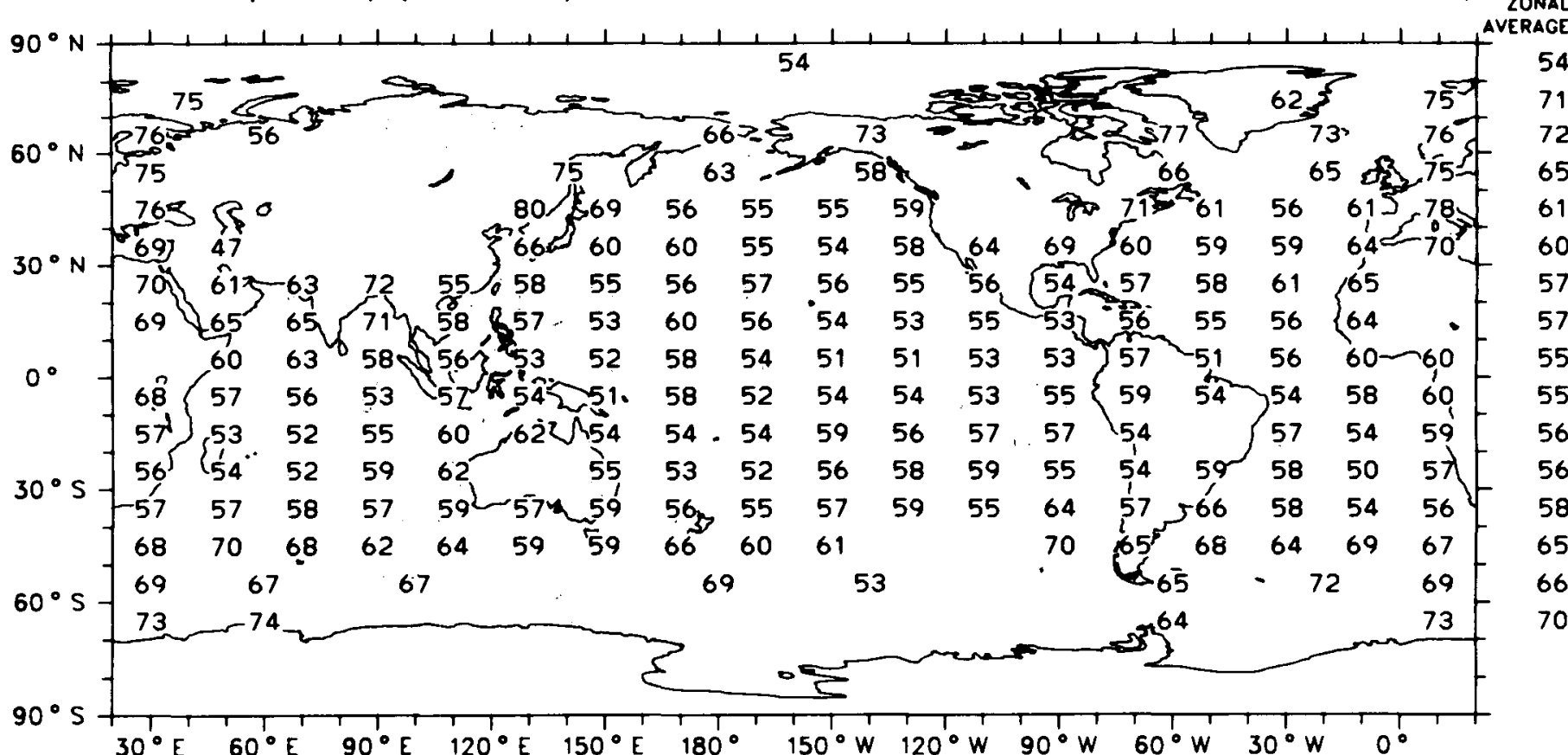




\section{Cumulus}

Average Base Height (decameters)

$\int$ June, July, August (1954-1981)

Oceon Areos Only

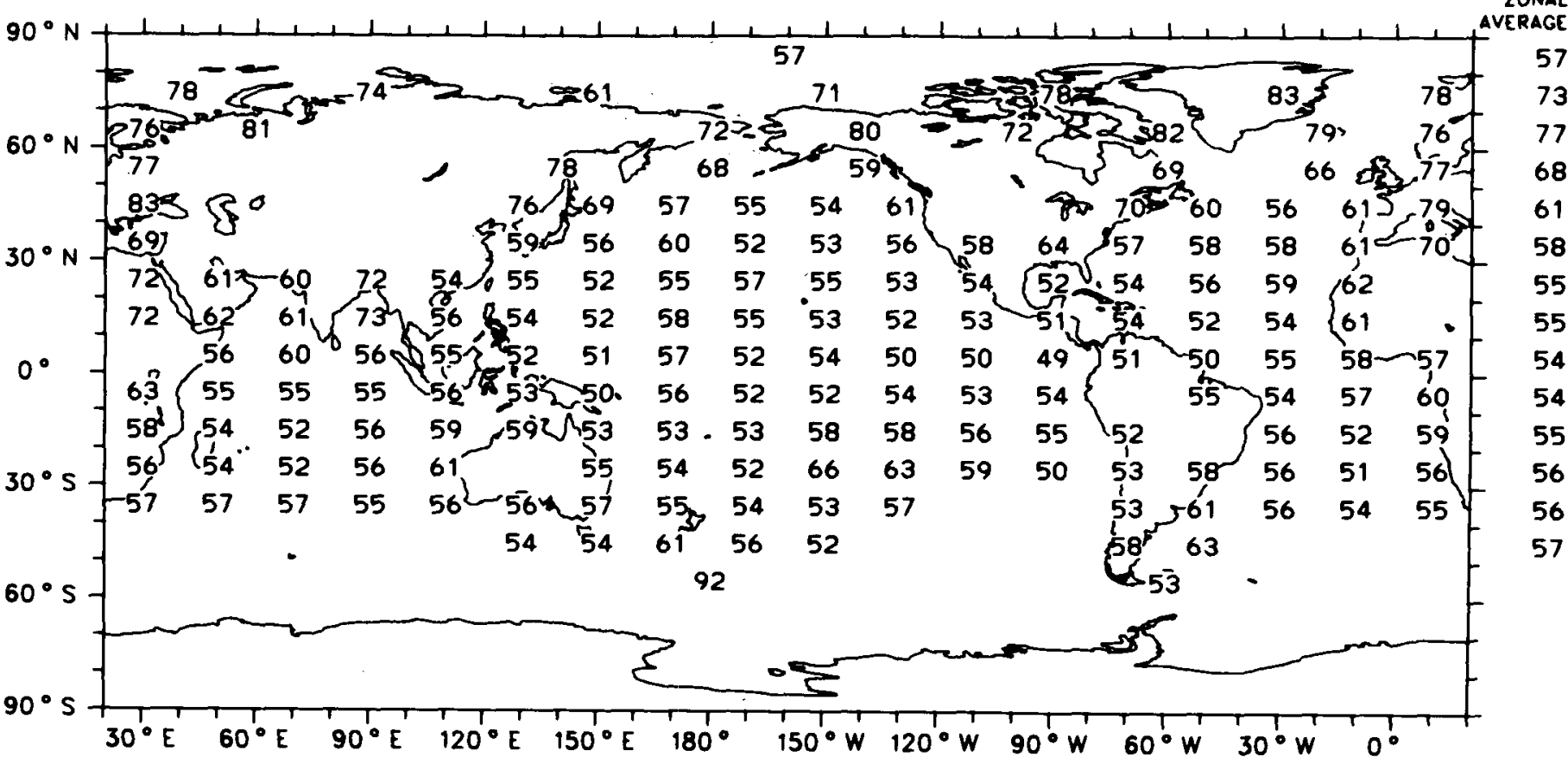

Global Averoge (Ocean) 569 meters

Mop 121c

\section{Cumulus}

Average Base Height (decameters)

September, October, November (1952-1981)

Ocean Areas Only

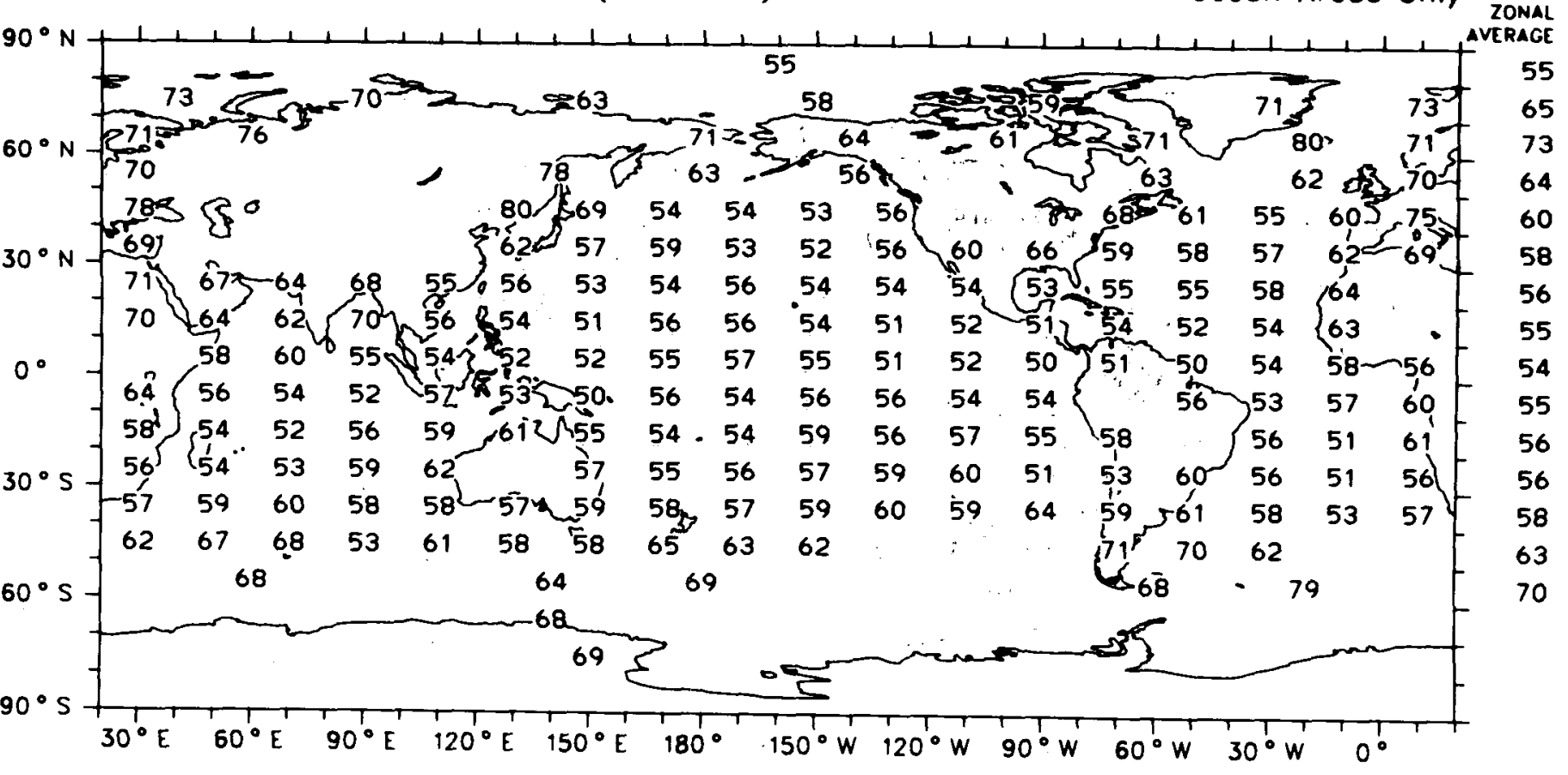




\section{Cumulus}

Amplitude of Diurnal Cycle (0.1\% Cloud Amount)

December, January. February (1952-1981)

Ocean Areas Only

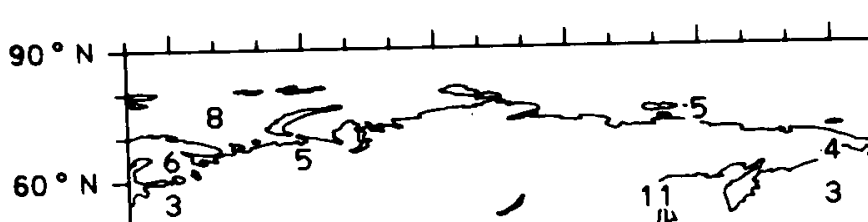

$$
30
$$

$\frac{805}{30} \varepsilon^{\circ}$ $17 / 147$

$\left\{\begin{array}{llll}17 & 14 & 7 & 4 \\ 21 & 16 & 14 & 12 \\ 22 & 25 & 22 & 19\end{array}\right.$
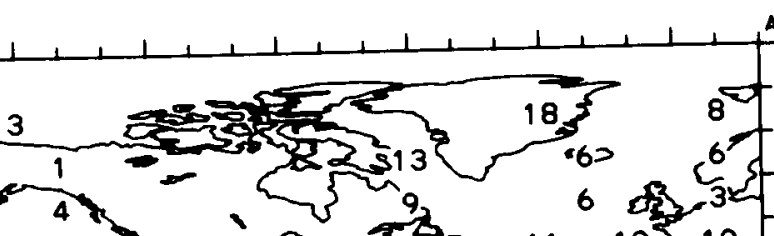

ZONAL

$30^{\circ}$

30

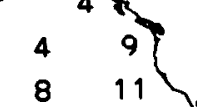

of 98

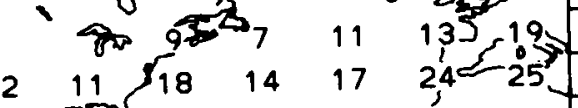

$6144529 \sqrt{29} 23, \frac{6}{23}, 24 \quad 23 \quad 26 \quad 21$

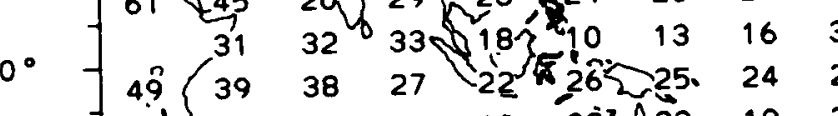

29. $3332 \quad 32$

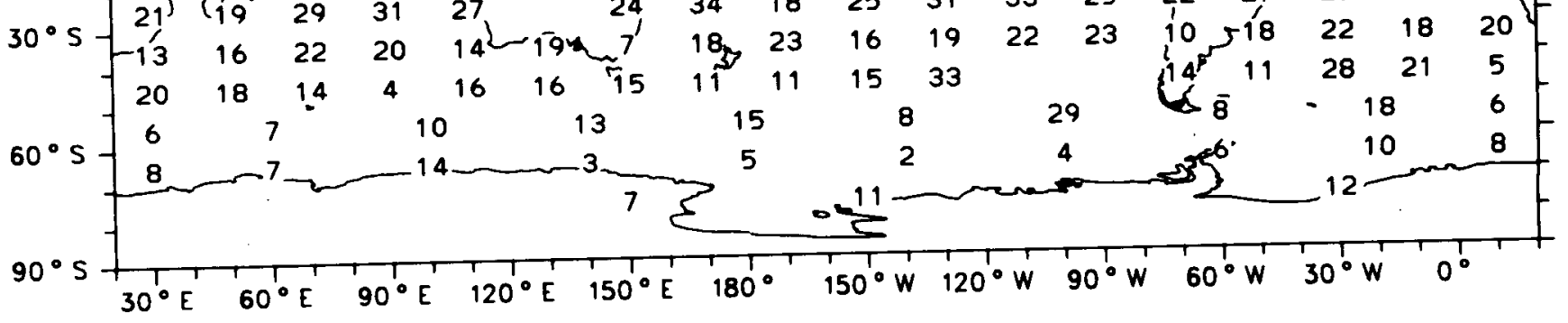

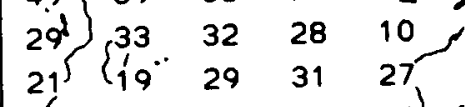

$\bigwedge 23$

19.24

19

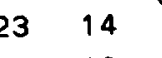

$23 \quad 27 \quad 30 \quad 37$ 22 30

$30 \begin{array}{lllllll}22 & 14 & 36 \\ 34 & 40 & 31 & 34\end{array}$

$28 \quad 39$

$39 \quad 27$

$2733 \quad 17$

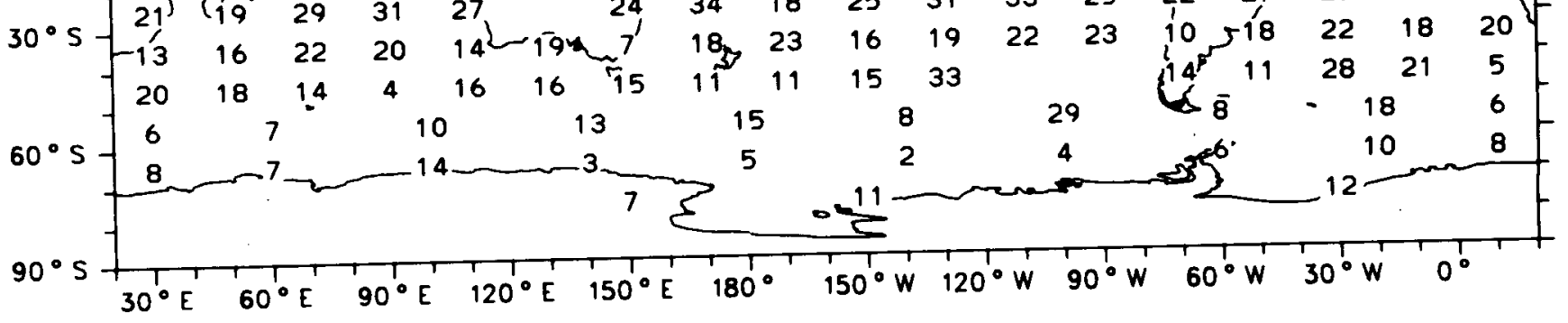

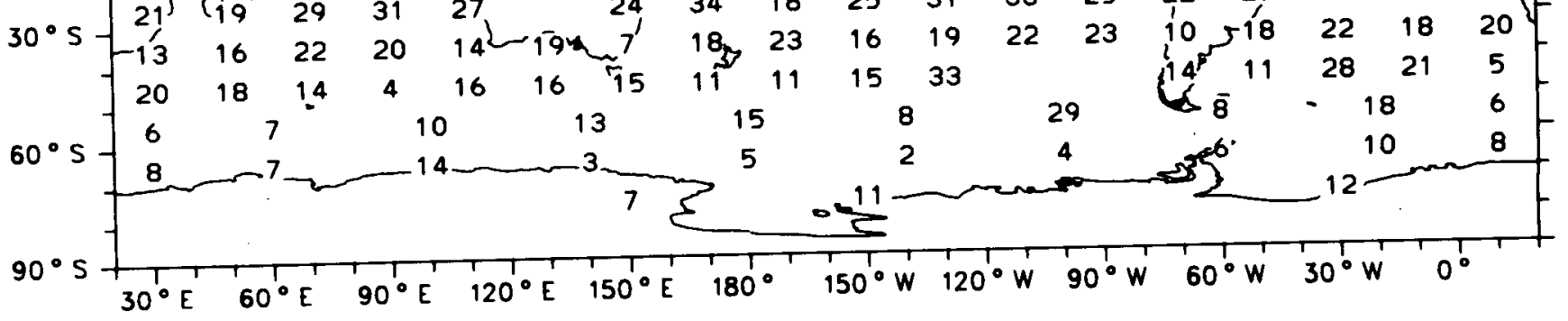

Map 122a

Global Average (Ocean) $2.0 \%$

\section{Cumulus}

Phase of Diurnal Cycle (Local Time of Maximum Cloud Amount) December. January. February (1952-1981)

Ocean Areas Only

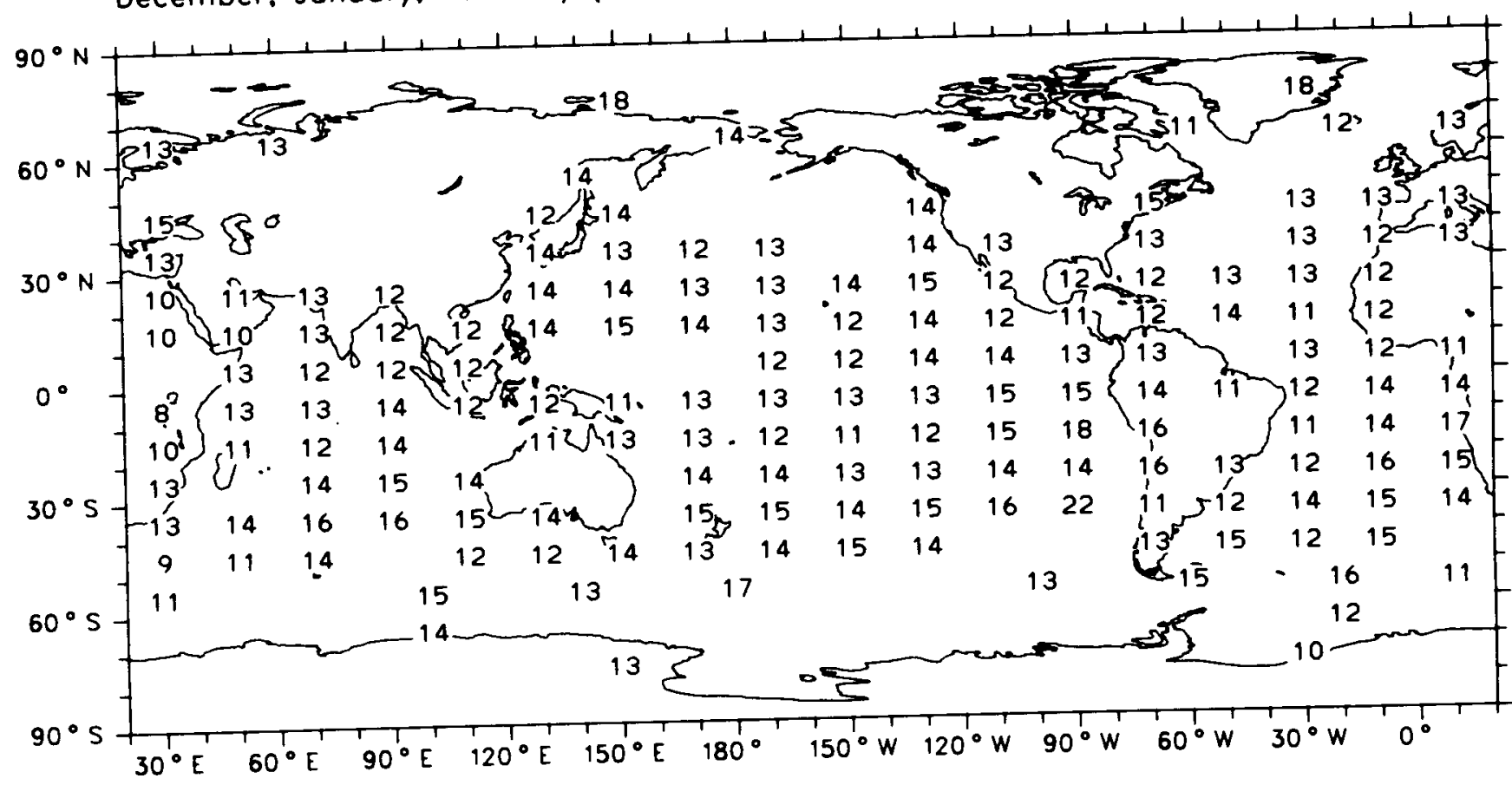

Map 122b 


\section{Cumulus}

Amplitude of Diurnal Cycle ( $0.1 \%$ Cloud Amount)

Morch. April. Moy (1952-1981)

Ocean Areas Only ZONAL

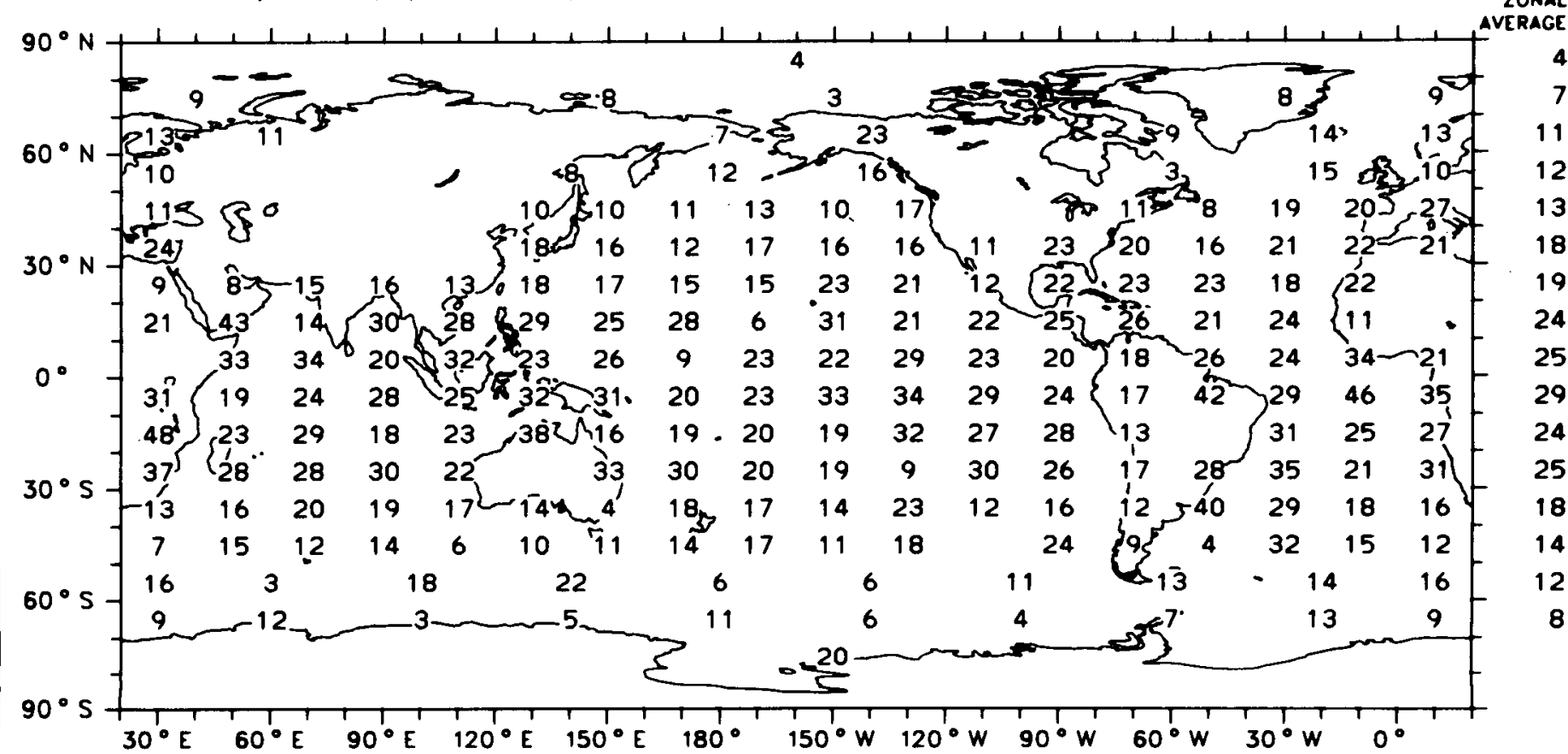

Map 122c

Global Average (Ocean) $1.9 \%$

Cumulus

Phase of Diurnal Cycle (Local Time of Maximum Cloud Amount) March, April, May (1952-1981)

Oceon Areas Only

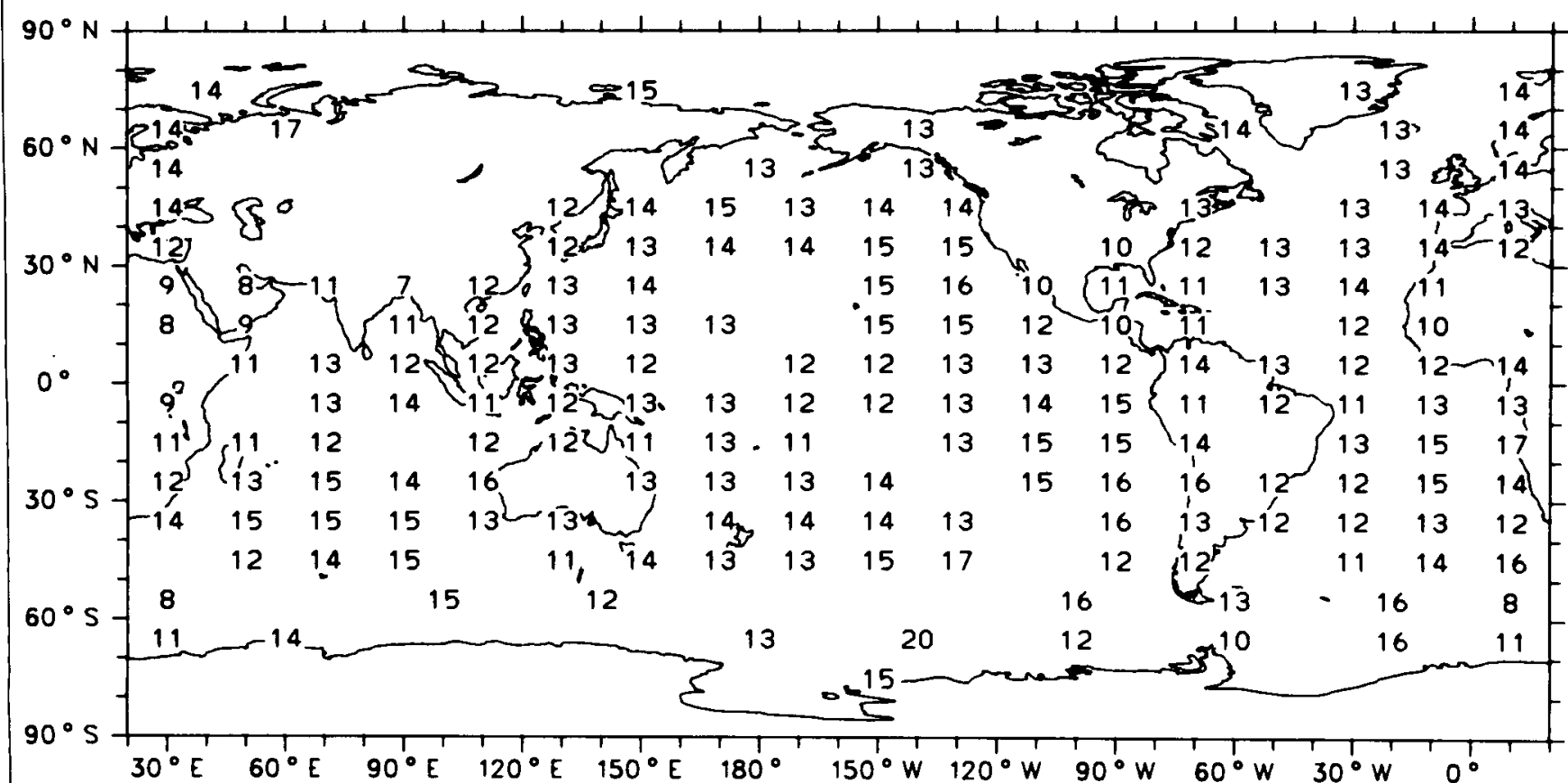

Map $122 d$ 
Cumulus

Amplitude of Diurnal Cycle ( $0.1 \%$ Cloud Amount)

June. July, August (1952-1981)

Ocean Areas Only

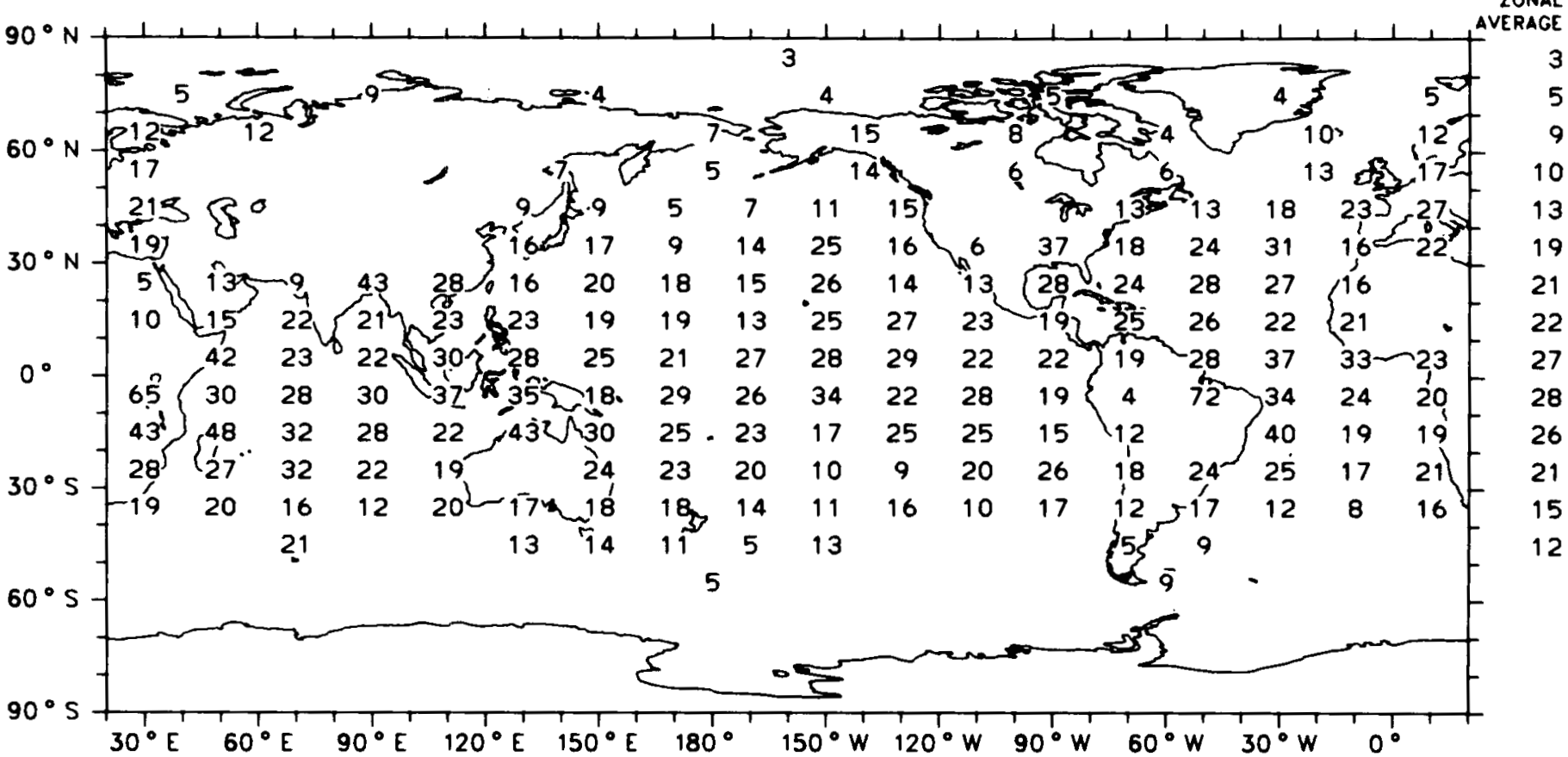

Global Averoge (Ocean) $2.0 \%$

Map 123a

Cumulus

Phase of Diurnal Cycle (Local Time of Maximum Cloud Amount) June. July, August (1952-1981)

Oceon Areos Only

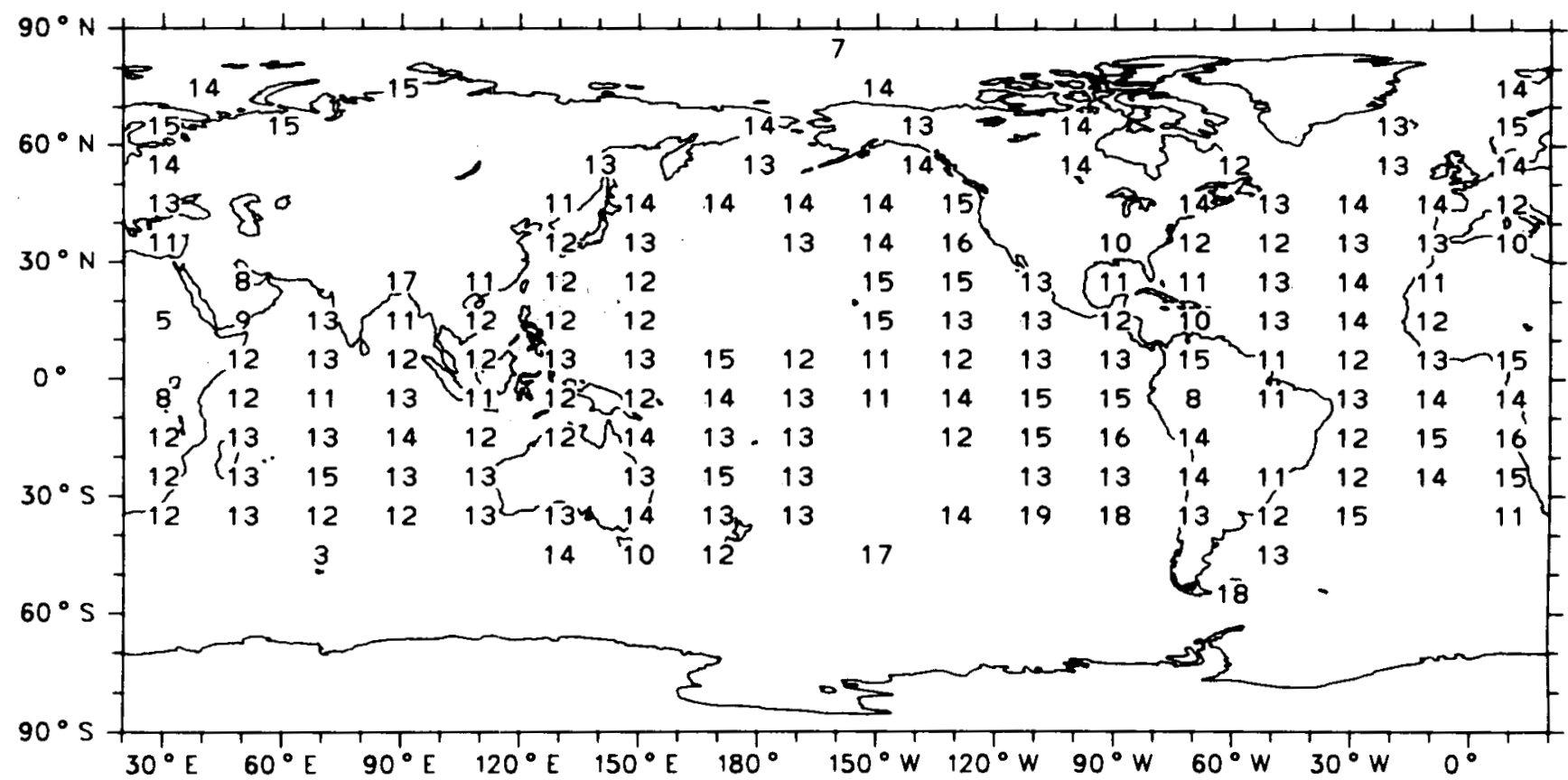

Map 123b 


\section{Cumulus}

Amplitude of Diurnal Cycle (0.1\% Cloud Amount)

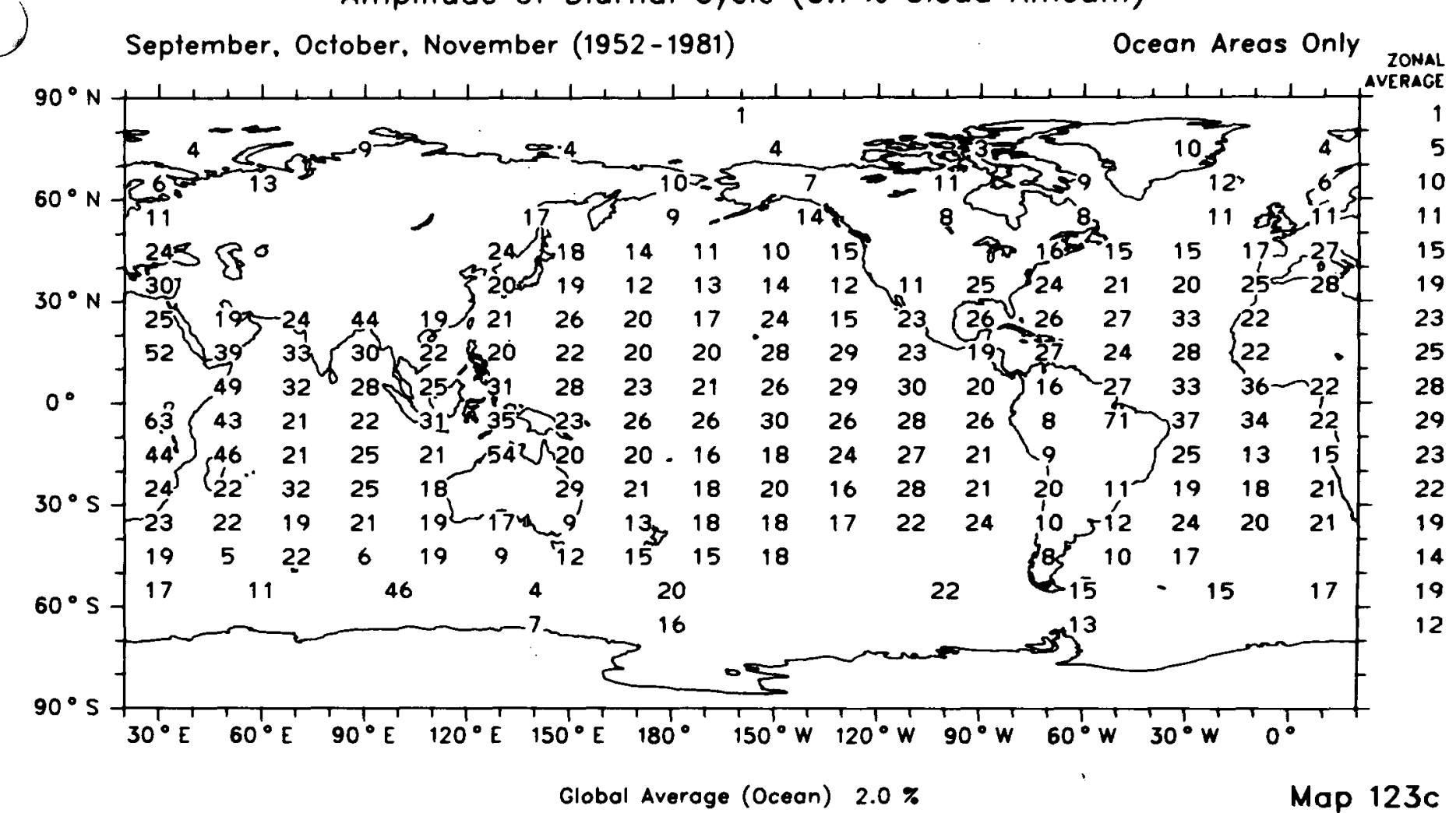

\section{Cumulus}

Phase of Diurnal Cycle (Local Time of Maximum Cloud Amount) September. October. November (1952-1981)

Ocean Areas Only

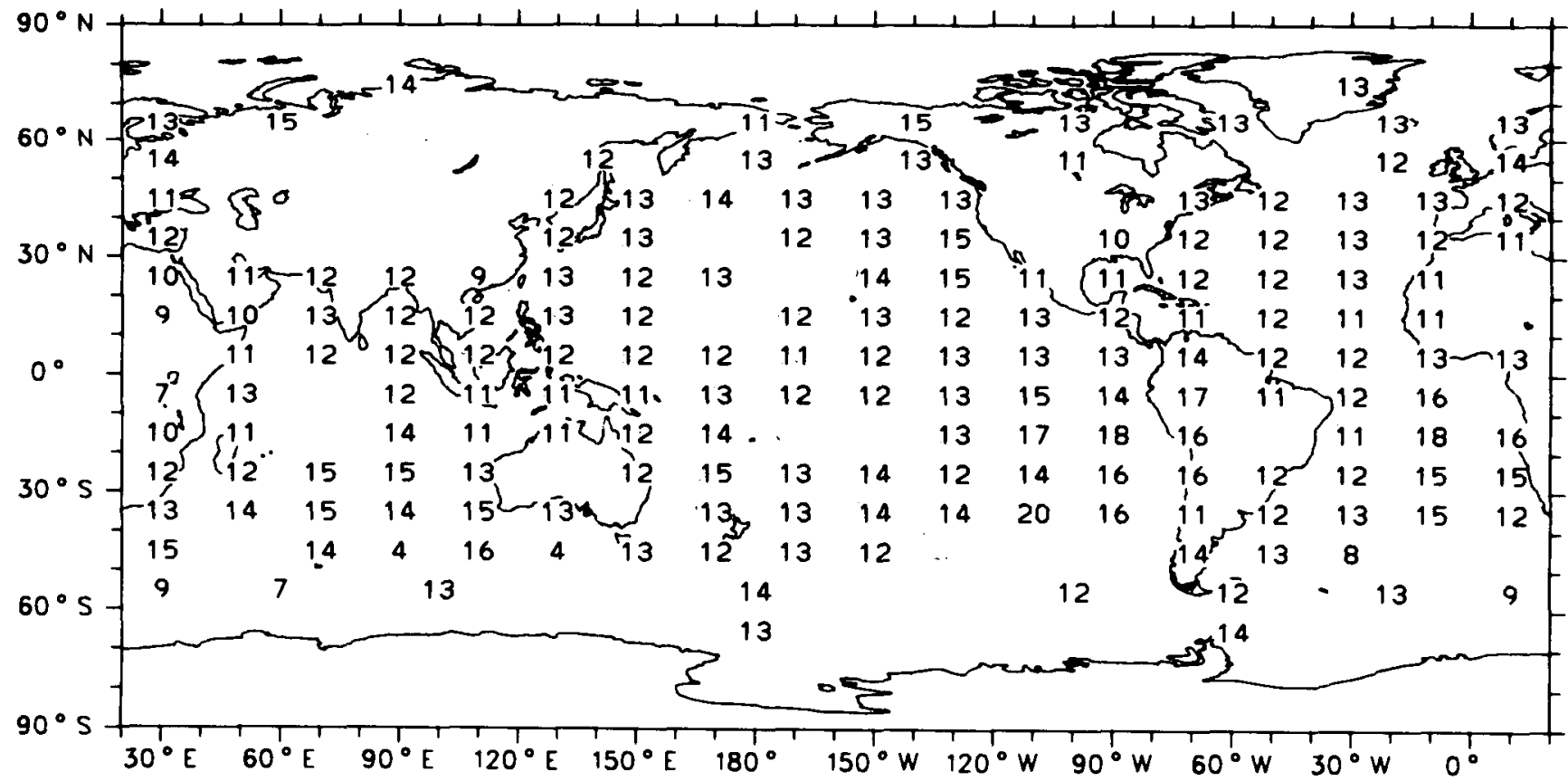

Map 123d 
Interannual Variation of Cumulus :

Standard Deviation (detrended) of Seasonal Means (0.1\% Cloud Amount)

December. January. February (1952-1981)

Ocean Areas Only

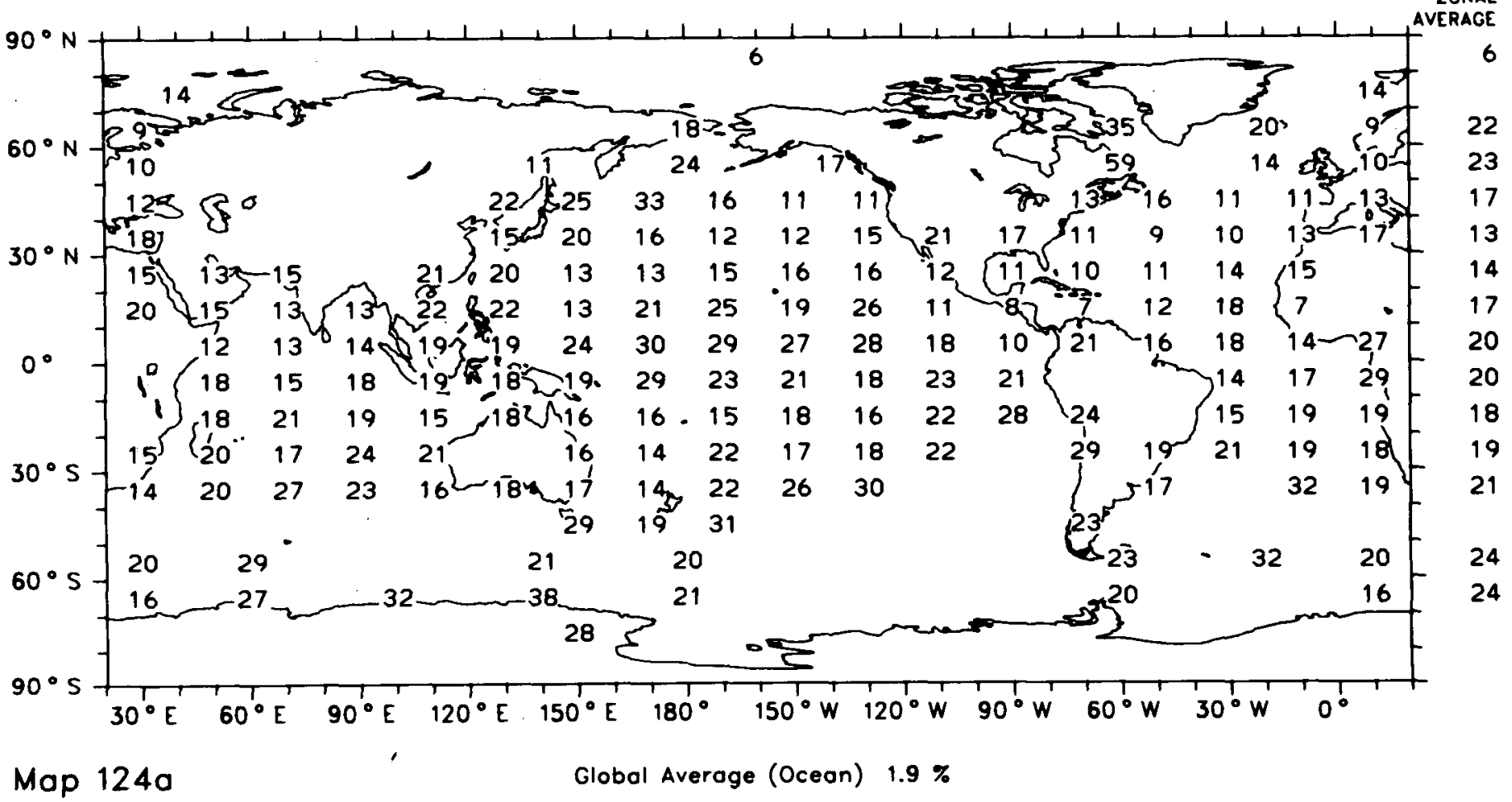

Interannual Variation of Cumulus :

Standard Deviation (detrended) of Seasonal Means (0.1\% Cloud Amount) March. April, May (1952-1981)

Ocean Areas Only

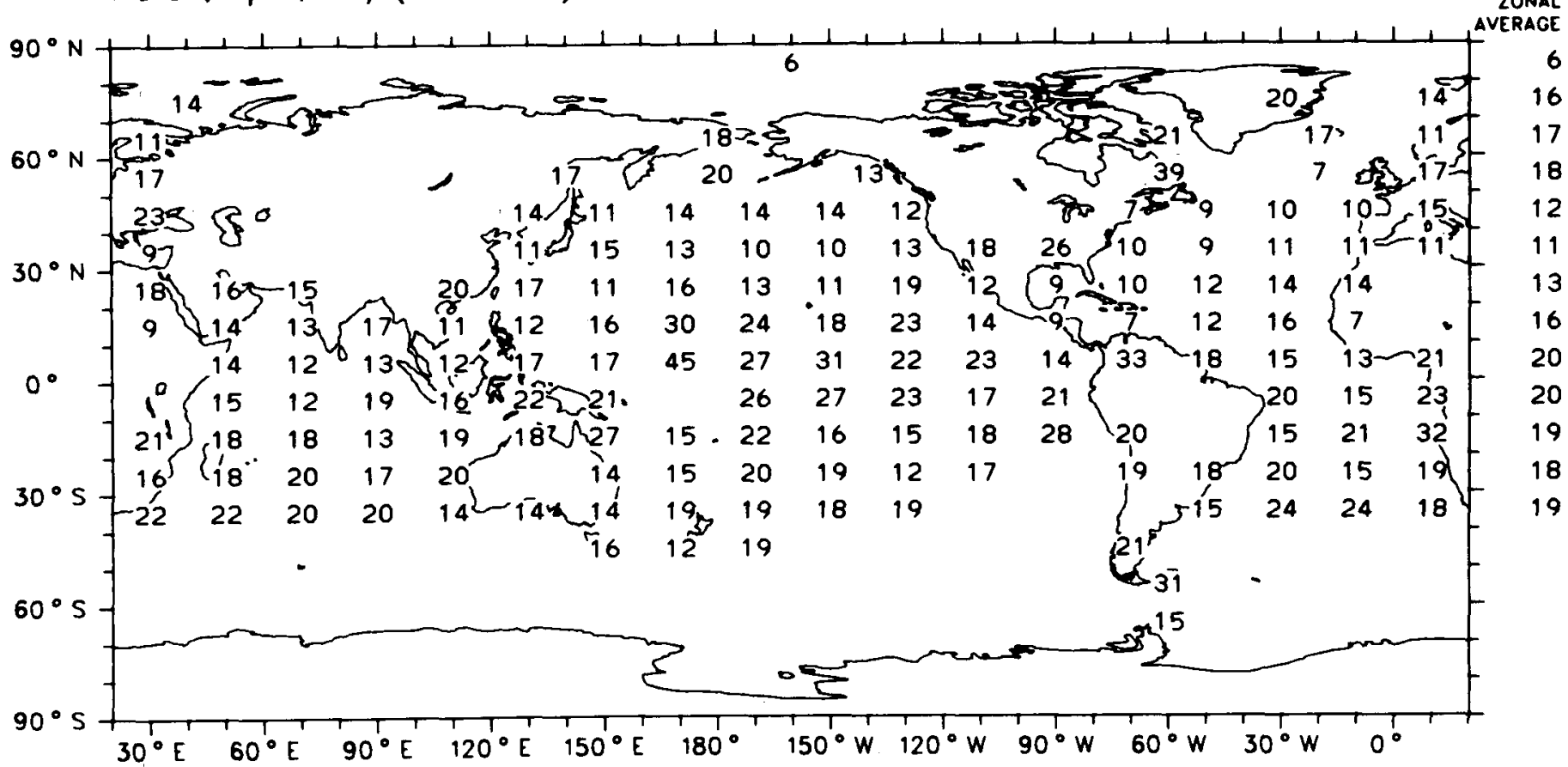

Map 124b

Global Average (Ocean) $1.7 \%$ 
Interannual Variation of Cumulus :

Standard Deviation (detrended) of Seasonal Means (0.1\% Cloud Amount) June. July, August (1952-1981)

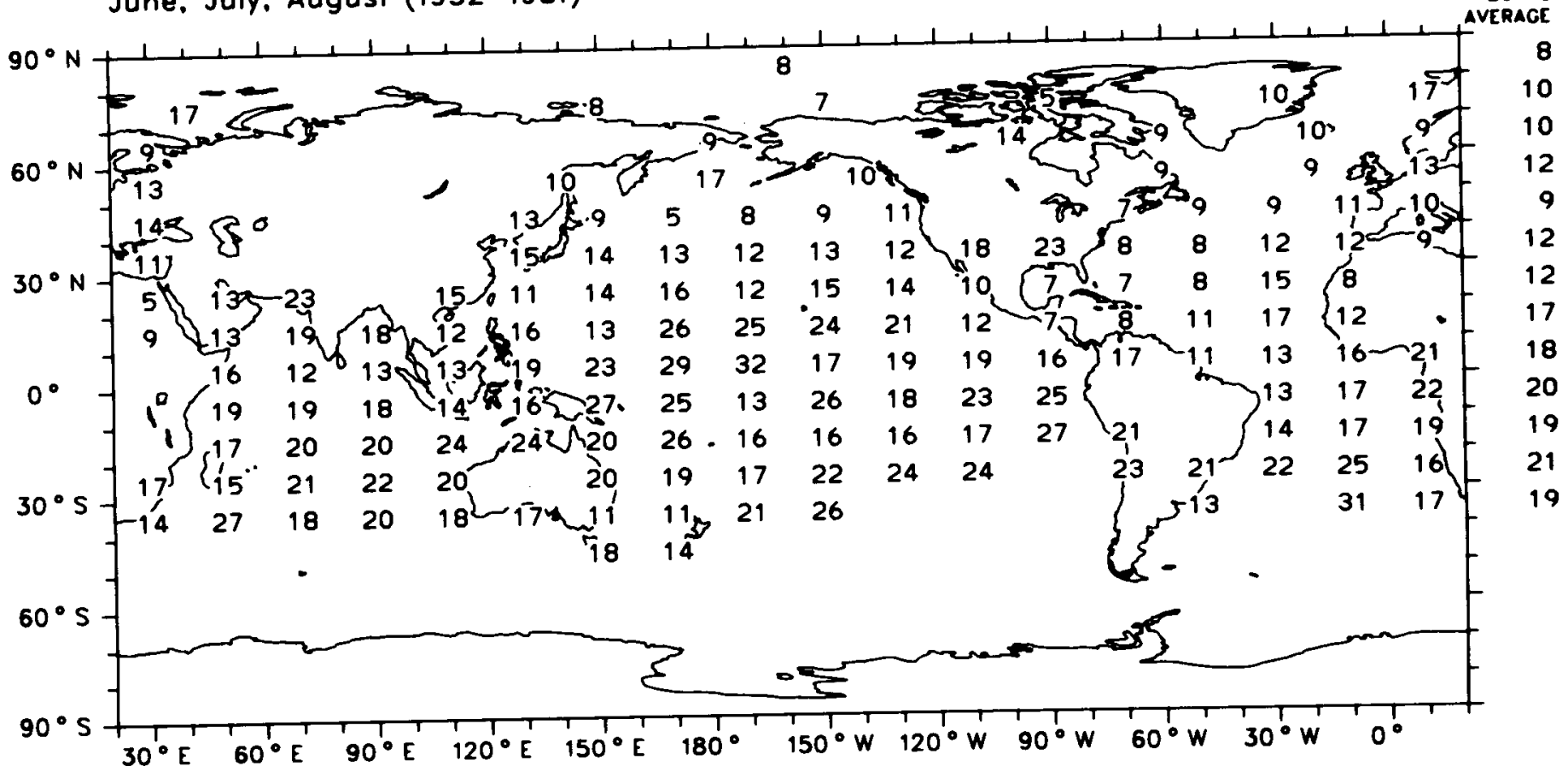

Map 124c

Global Average (Ocean) $1.6 \%$

Interannual Variation of Cumulus :

Standard Deviation (detrended) of Seasonal Means (0.1\% Cloud Amount) September, October, November (1952-1981)

Ocean Areos Only

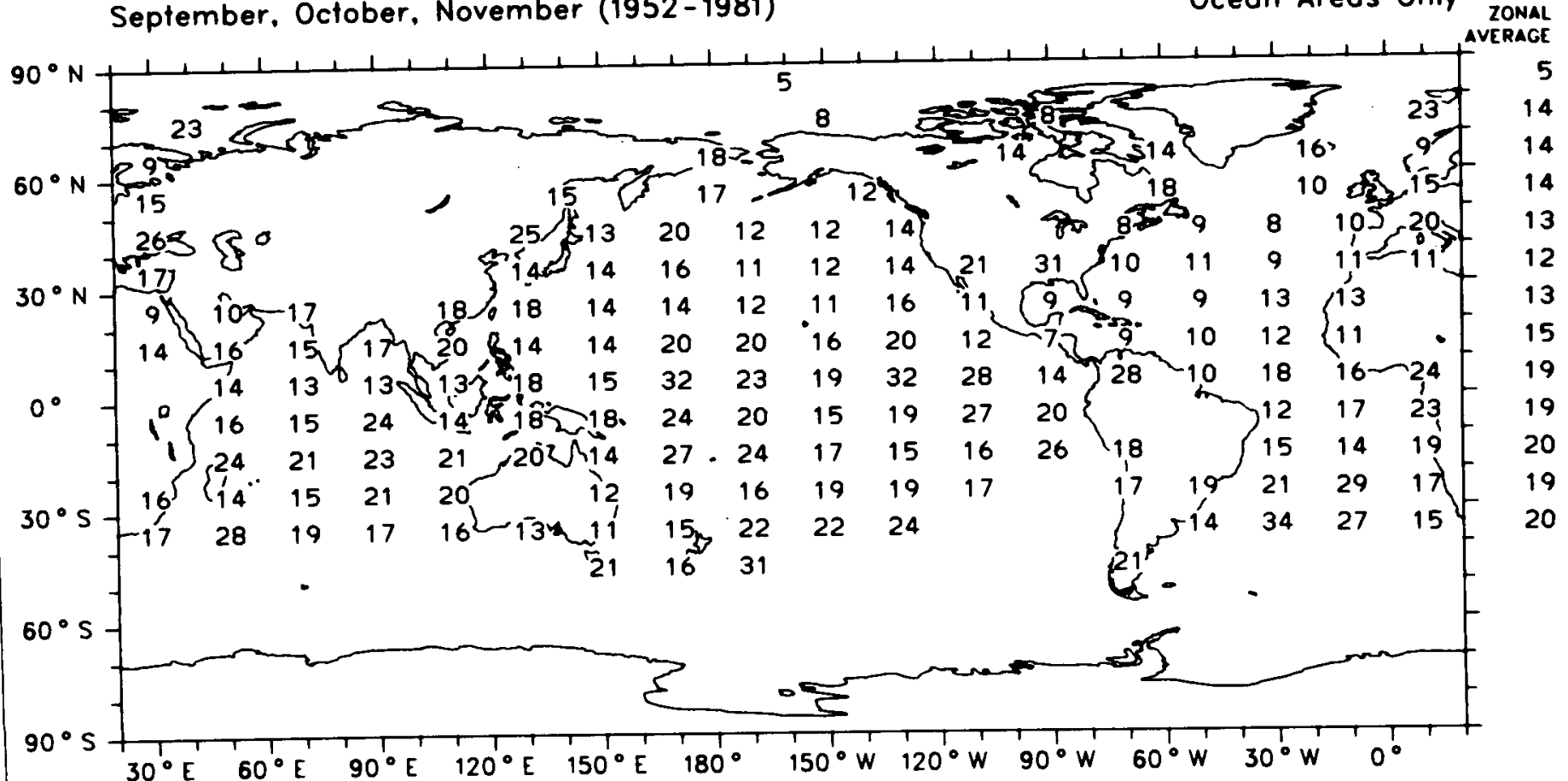

Map 124d

Global Averoge (Ocean) $1.7 \%$ 
Trend of Cumulus :

Change in \%-Cloud-Amount from 1952 to 1981

December, January, February (1952-1981)

Oceon Areas Only

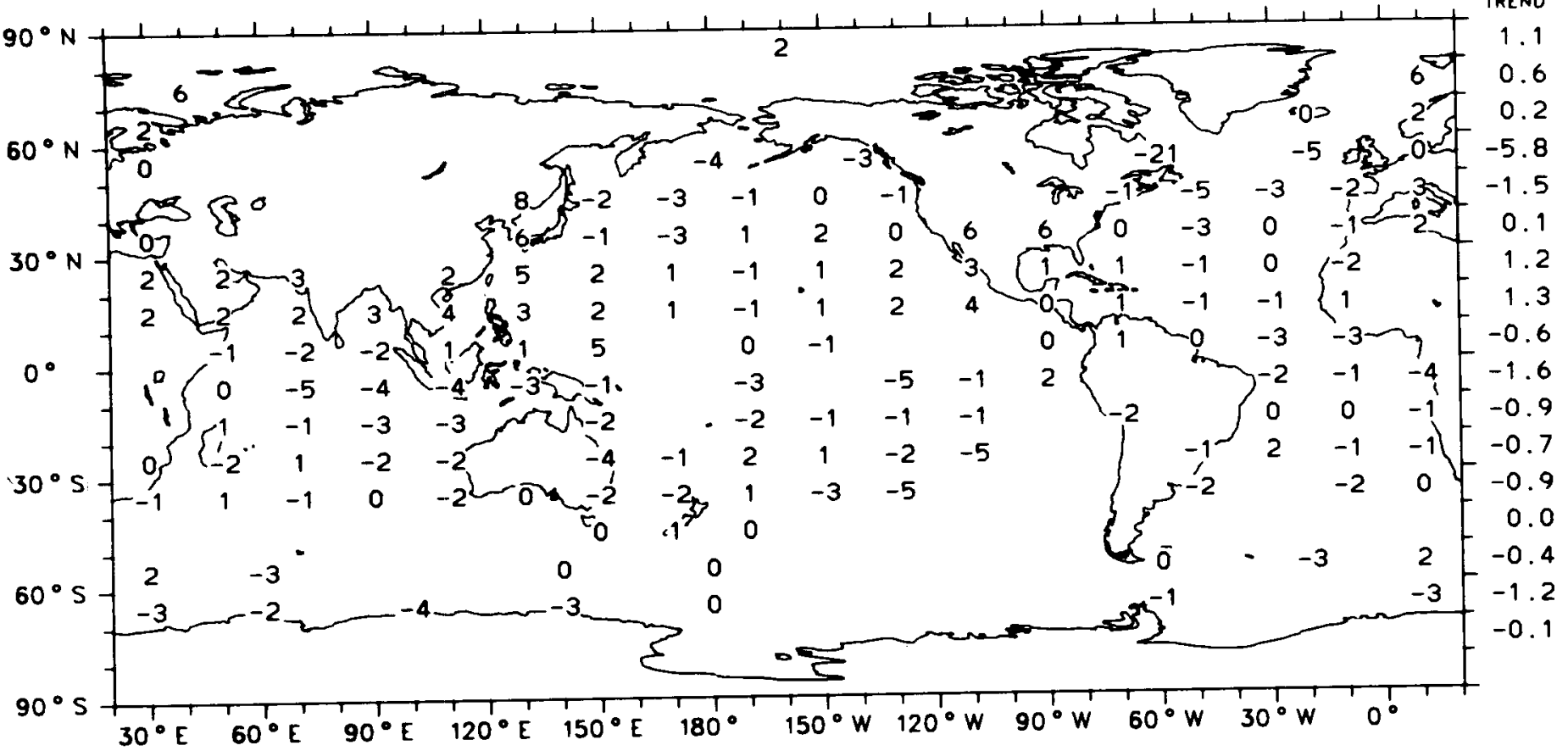

Global Trend (Ocean) - $0.5 \%$

Map 125a

Trend of Cumulus :

Change in \%-Cloud-Amount from 1952 to 1981

Morch. April. Moy (1952-1981)

Ocean Areas Only

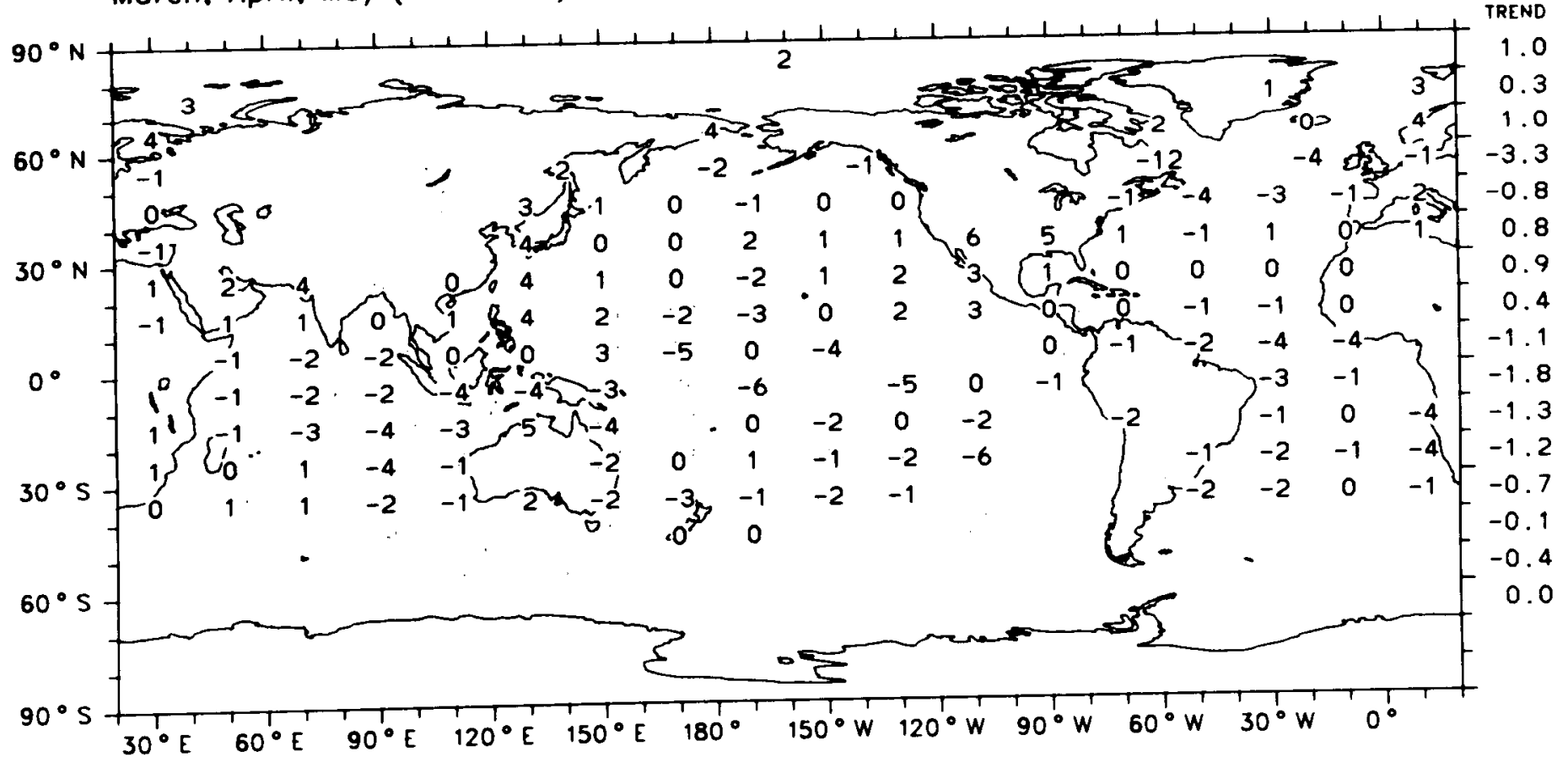


Trend of Cumulus :

Change in \%-Cloud-Amount from 1952 to 1981

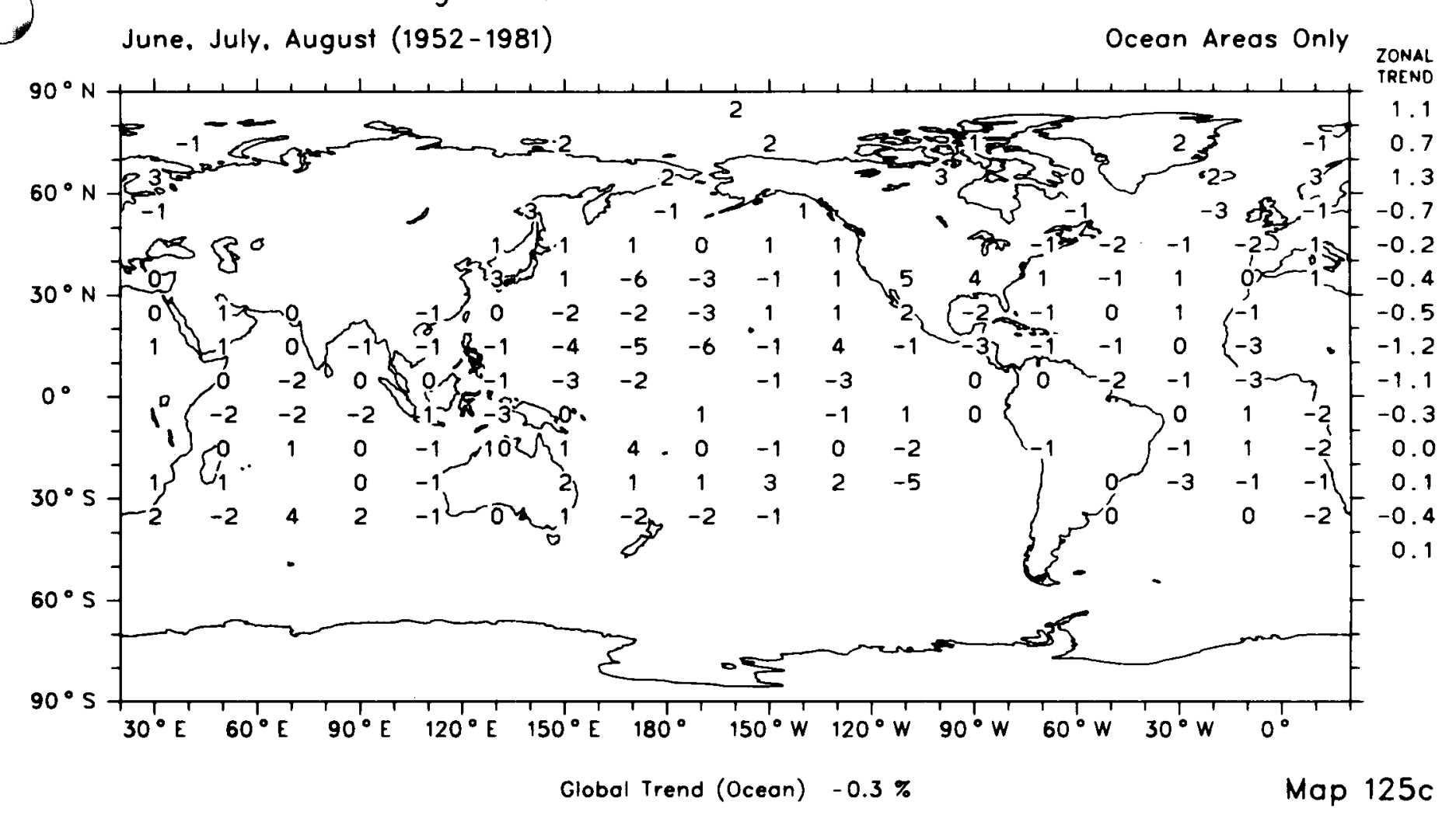

Trend of Cumulus :

Change in \%-Cloud-Amount from 1952 to 1981

September, October, November (1952-1981)

Ocean Areas Only

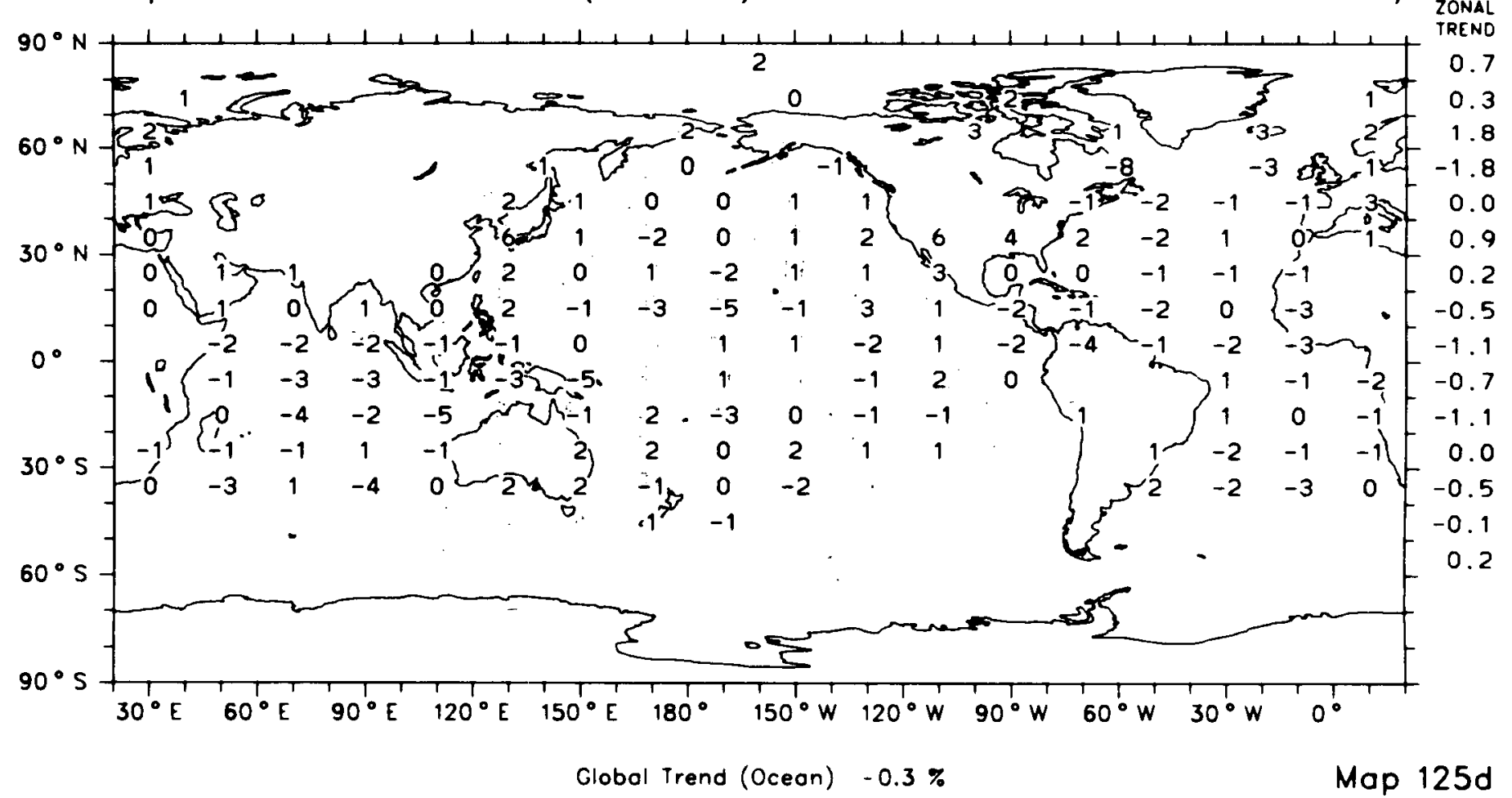


Cumulonimbus

Frequency of Occurrence (\%)

December. January. February (1952-1981)

Ocean Areas Only

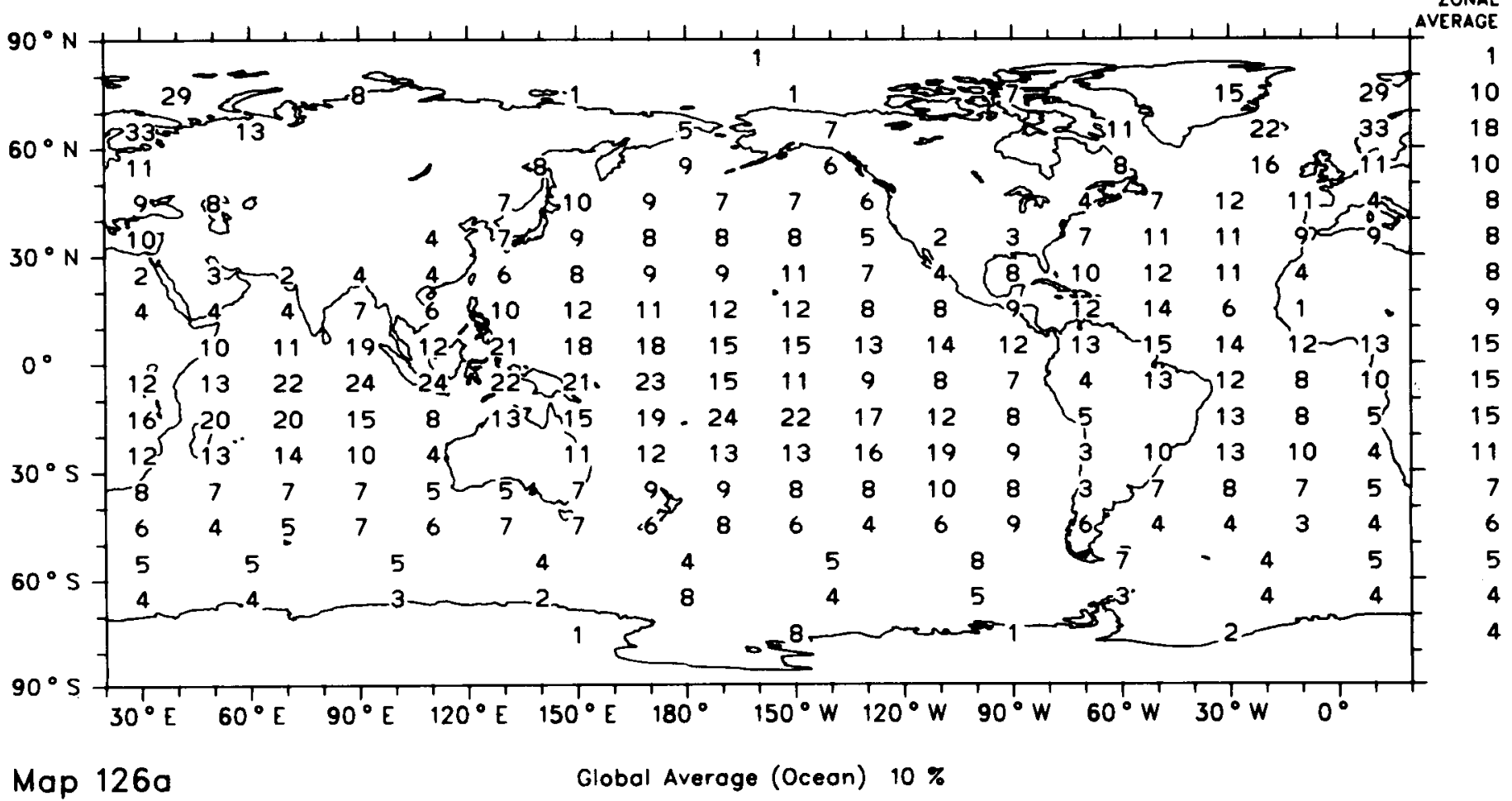

Cumulonimbus

Frequency of Occurrence (\%)

March, April, Moy (1952-1981)

Ocean Areas Only

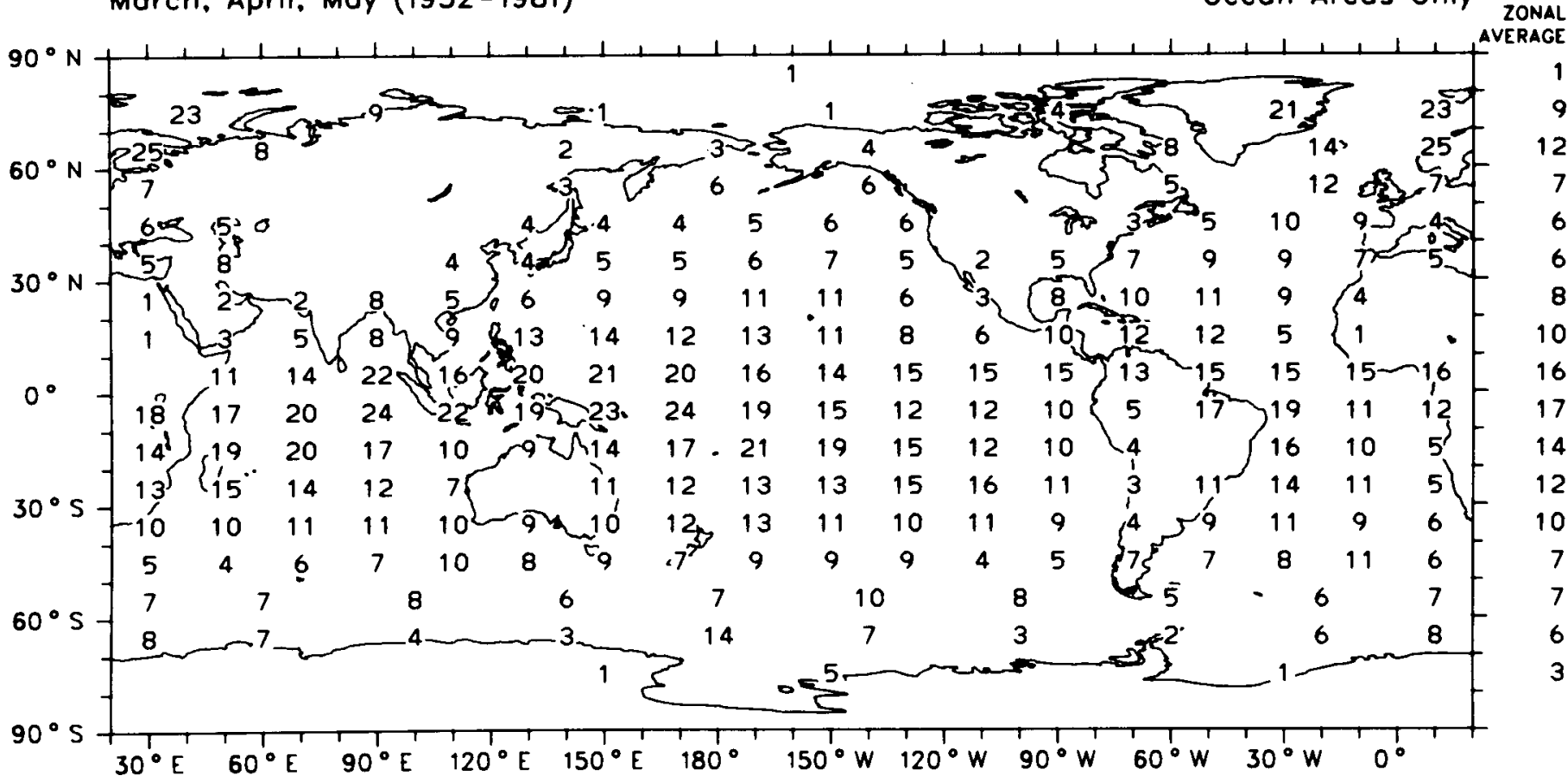

Map 126b

Global Average (Ocean) $10 \%$ 


\section{Cumulonimbus}

Frequency of Occurrence (\%)

June, July. August (1952-1981)

Ocean Areas Only

ZONAL

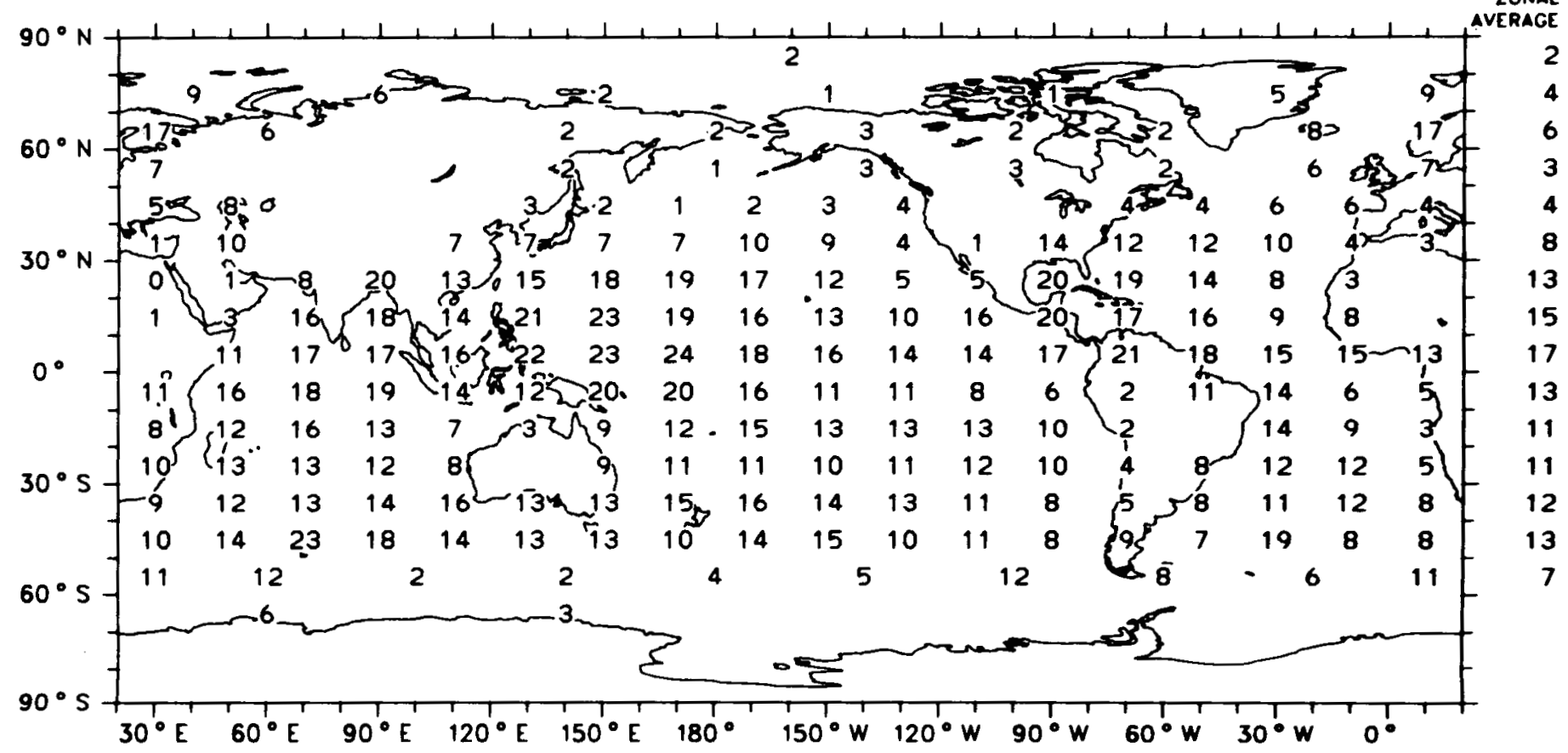

Map 126c

Global Average (Ocean) $11 \%$

Cumulonimbus

Frequency of Occurrence (\%)

September. October. November (1952-1981)

Ocean Areas Only

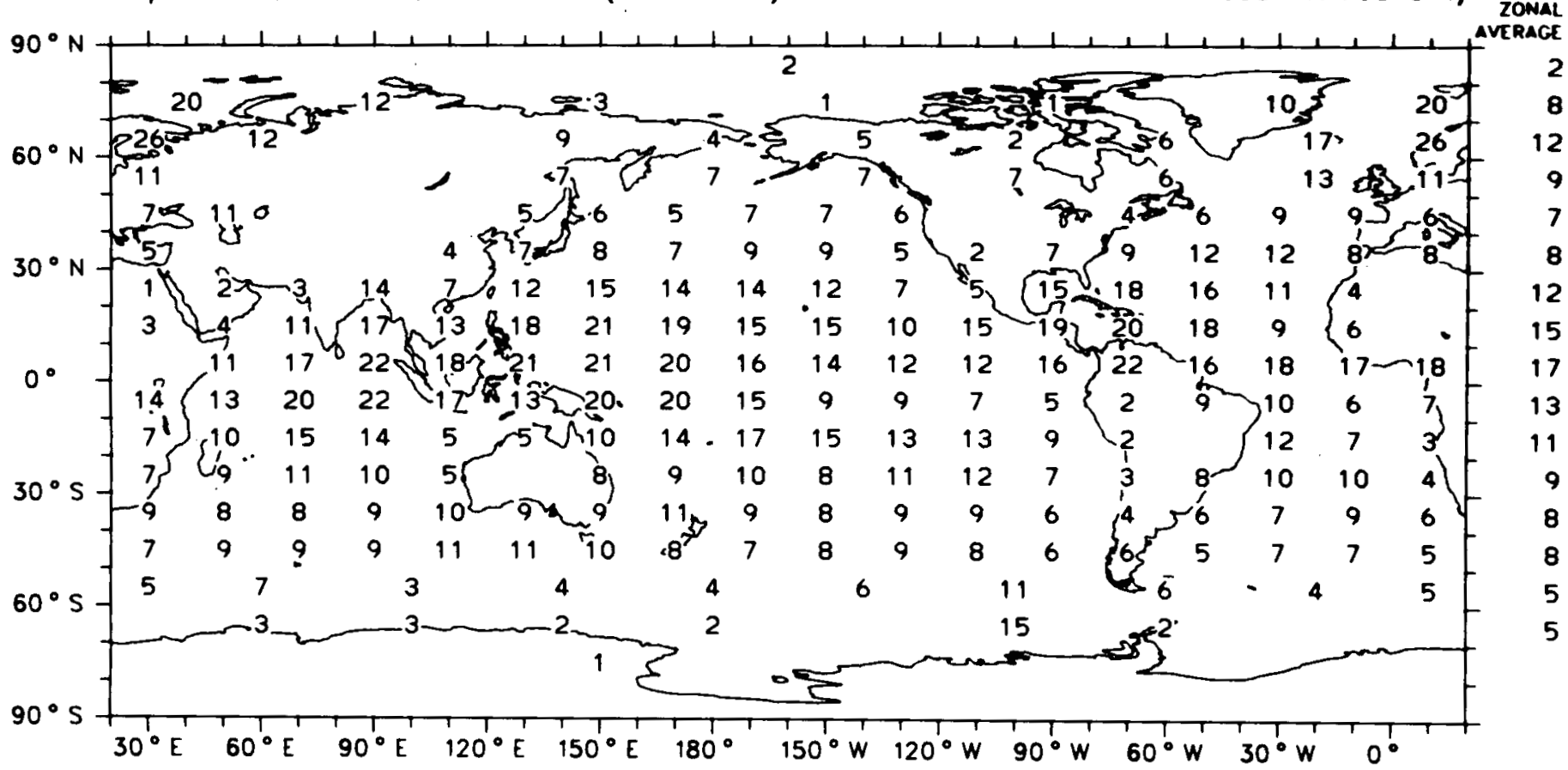

Map 126d

Global Average (Ocean) $10 \%$ 


\section{Cumulonimbus}

Amount-When-Present (\%)

December. January, February (1952-1981)

Ocean Areas Only

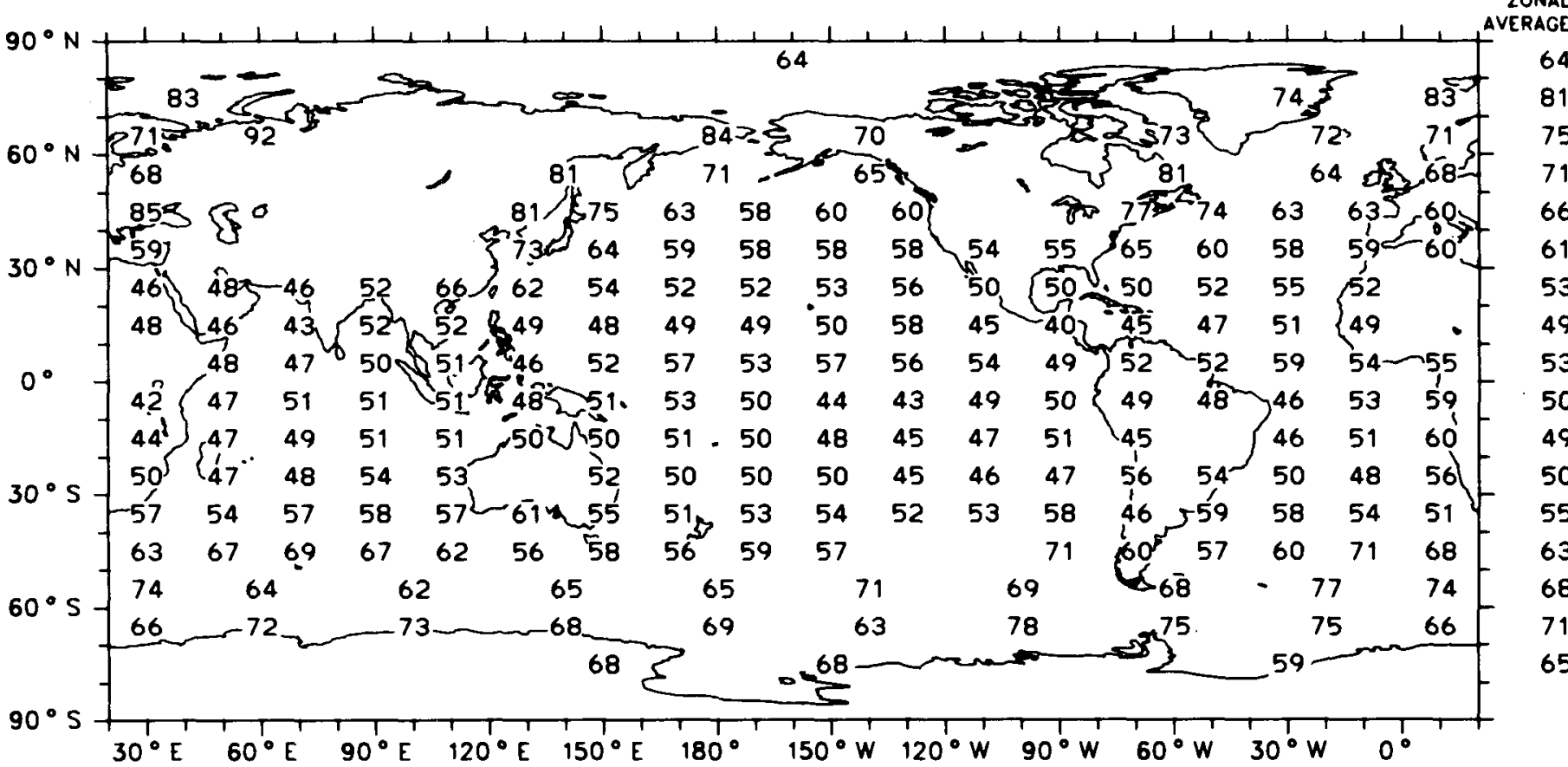

Globol Average (Ocean) $57 \%$

Map $127 a$

\section{Cumulonimbus}

Amount-When-Present (\%)

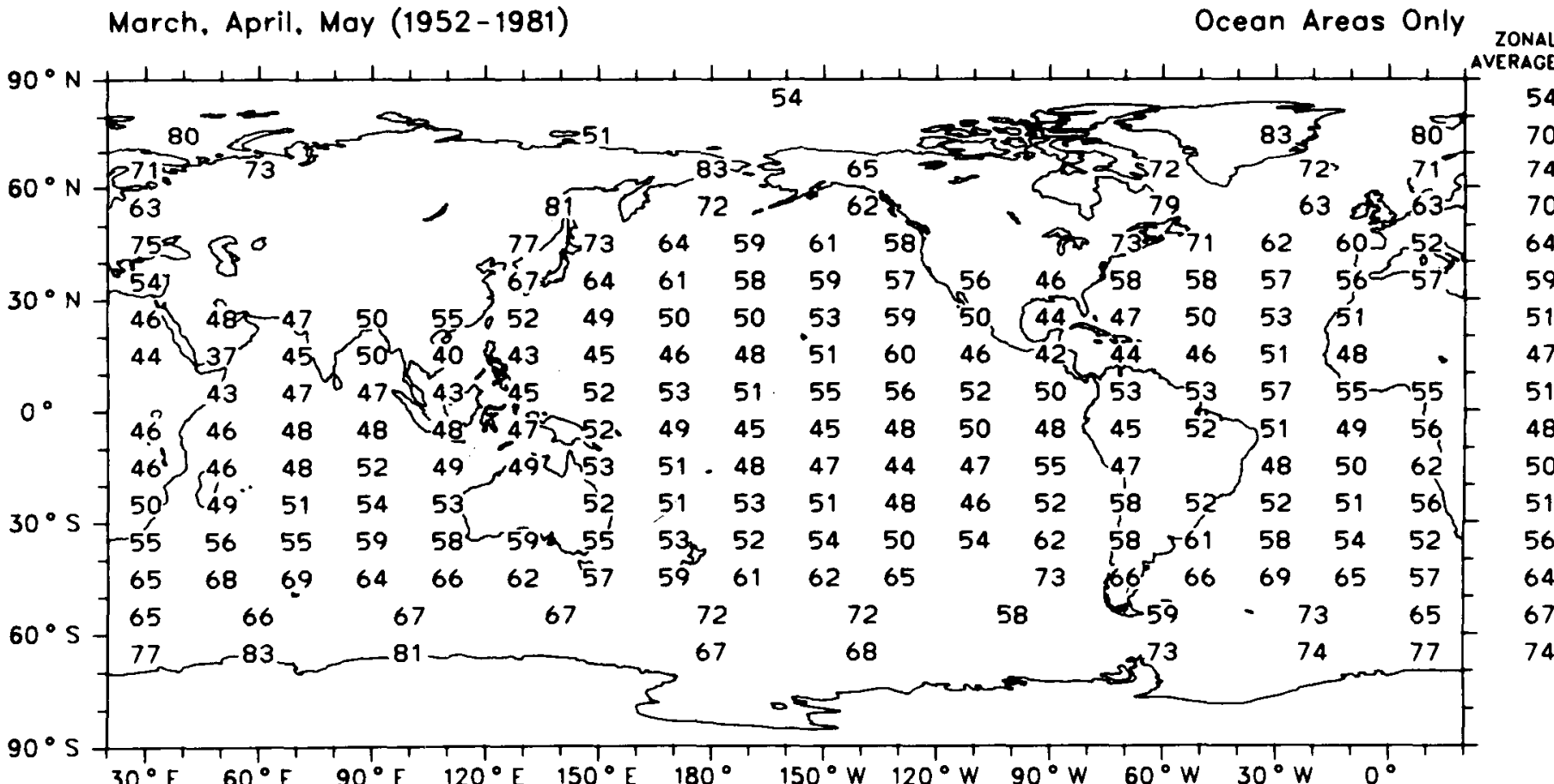

Global Average (Oceon) $56 \%$

Map 127b 
Cumulonimbus

Amount-When-Present (\%)

June. July. August (1952-1981)

Oceon Areas Only

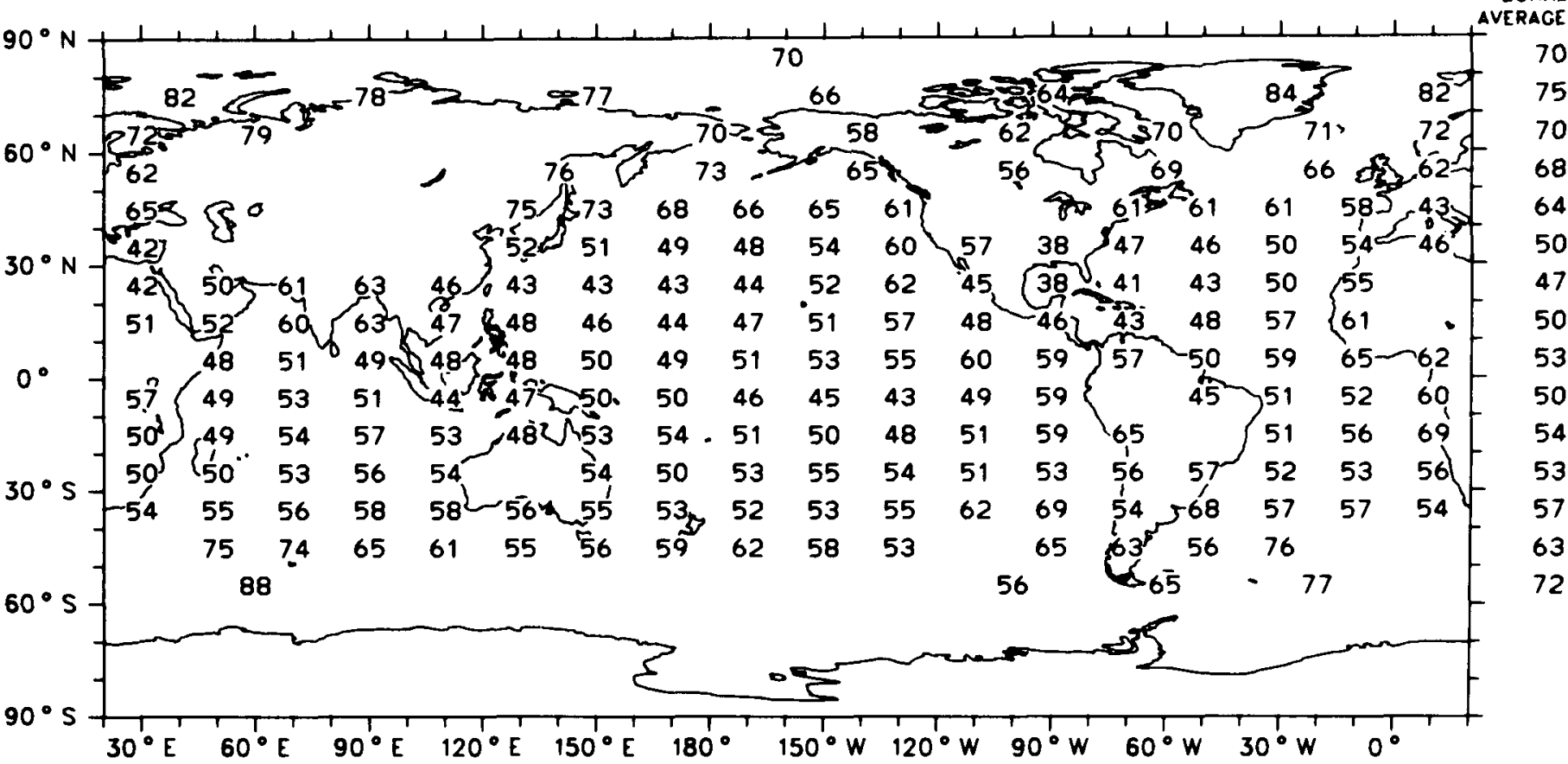

Global Averoge (Ocean) $56 \%$

Map 127c

\section{Cumulonimbus}

Amount-When-Present (\%)

September, October, November (1952-1981)

Ocean Areas Only

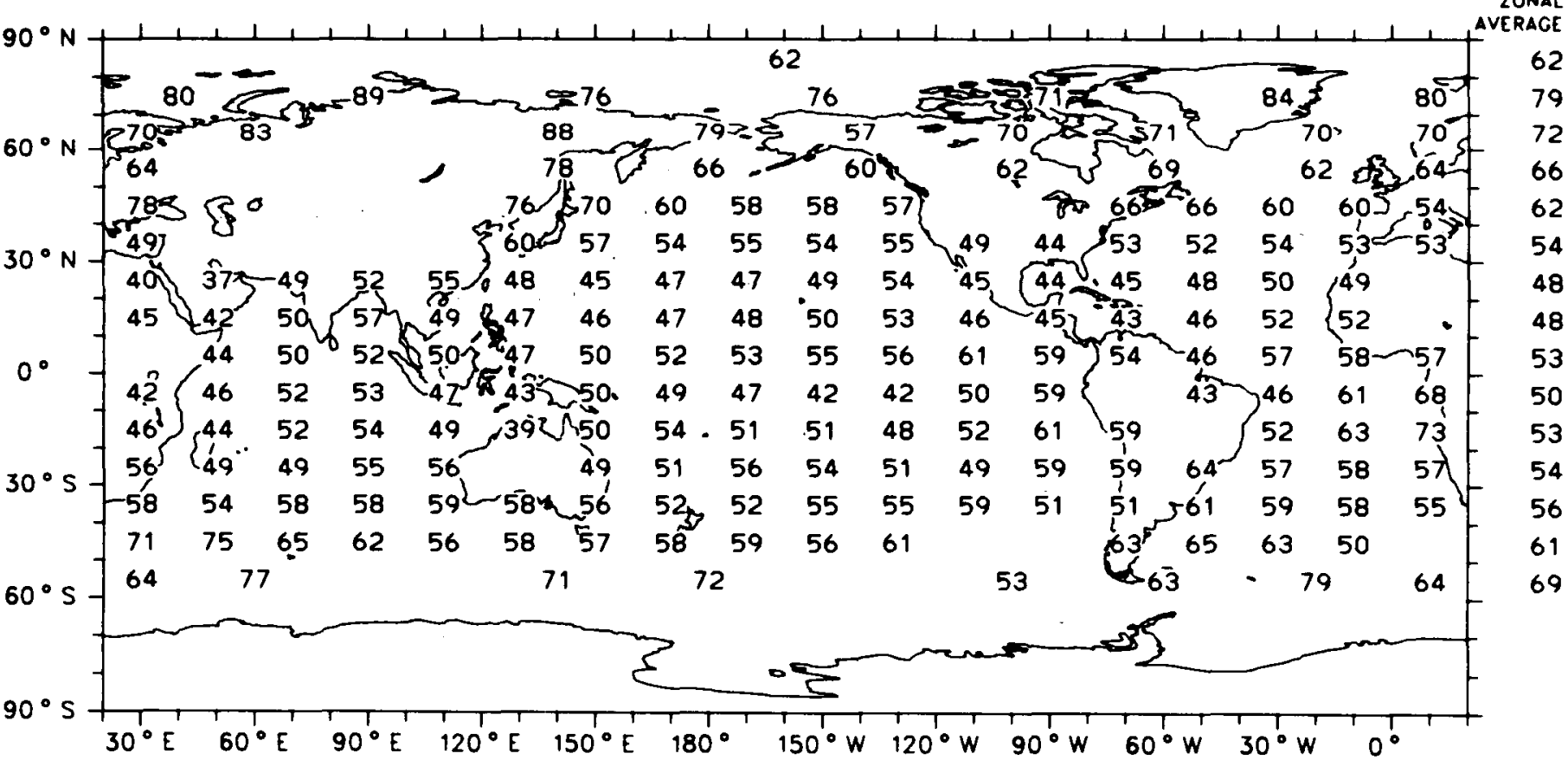

Globol Averoge (Ocean) $56 \%$

Map 127d 


\section{Cumulonimbus}

Average Cloud Amount (\%)

December. January. February (1952-1981)

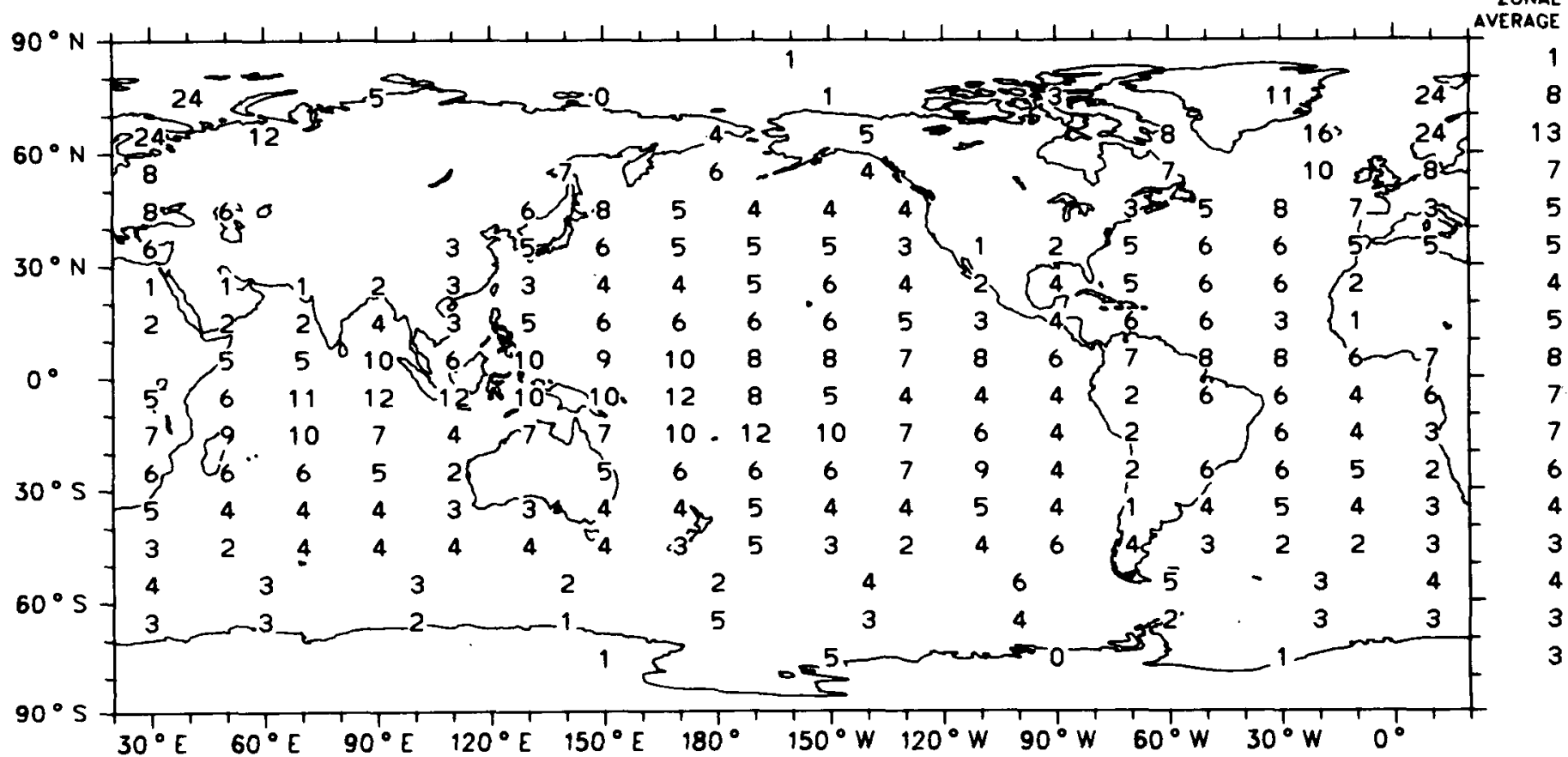

Map 128a

Global Average (Ocean) $5 \%$

\section{Cumulonimbus}

Average Cloud Amount (\%)

Morch. April. Moy (1952-1981)

Oceon Areas Only

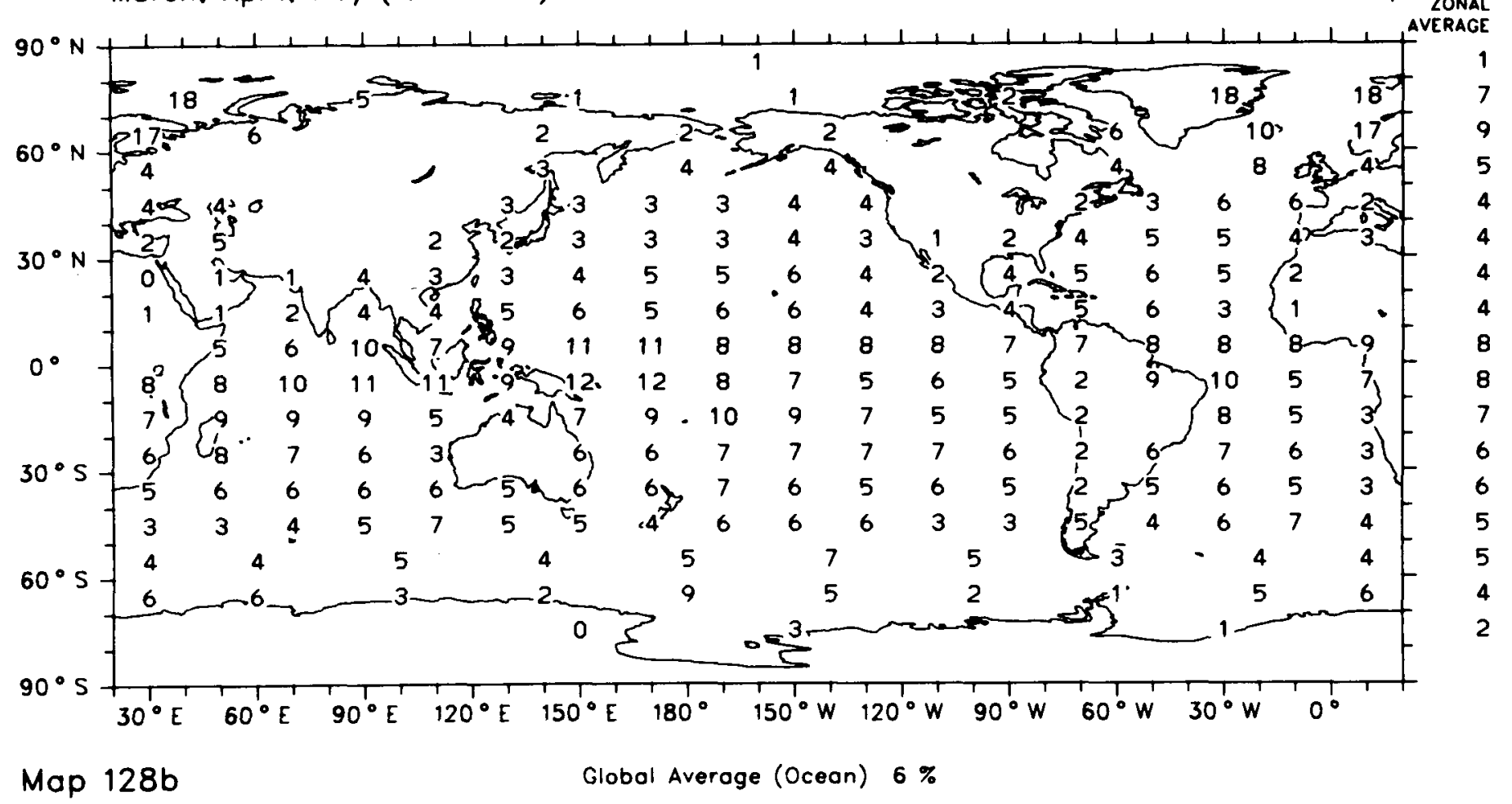




\section{Cumulonimbus}

Average Cloud Amount (\%)

June. July. August (1952-1981)

Ocean Areas Only

ZONAL

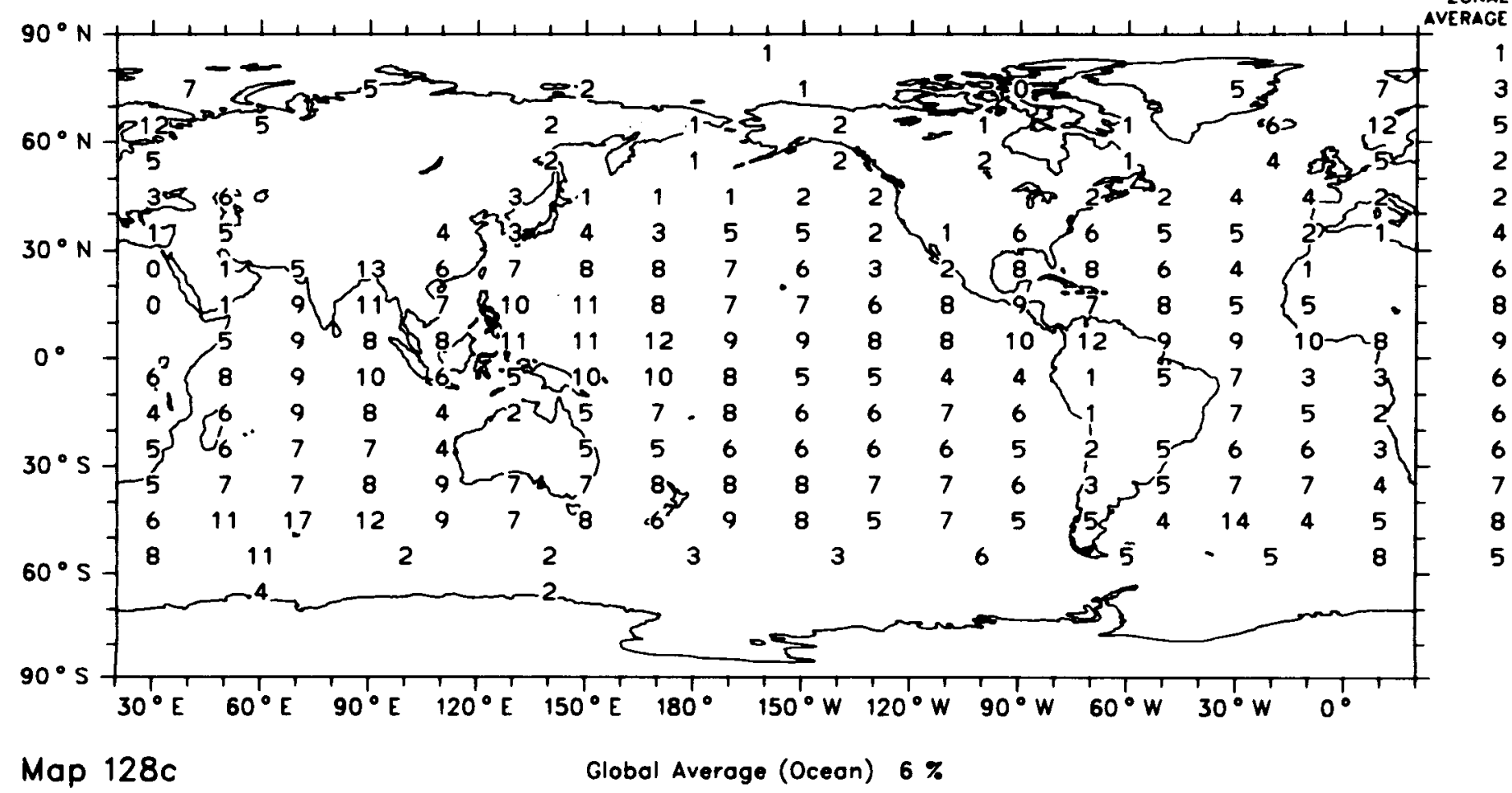

\section{Cumulonimbus}

Average Cloud Amount (\%)

September, October, November (1952-1981)

Ocean Areos Only

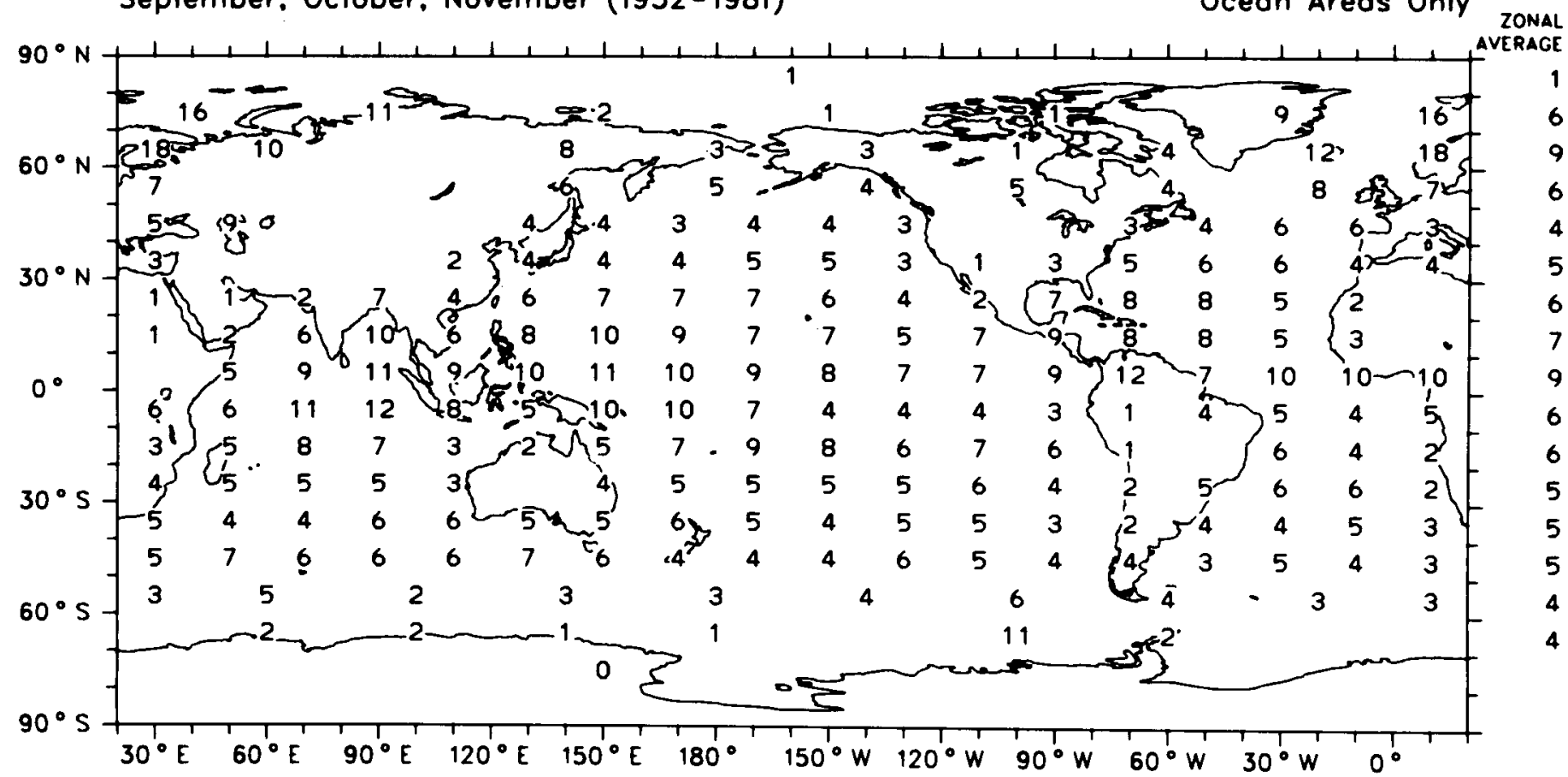

Map 128d

Global Average (Ocean) $6 \%$ 


\section{Cumulonimbus}

Average Base Height (decameters)

December, January. February (1954-1981)

Ocean Areas Only

ZONAL

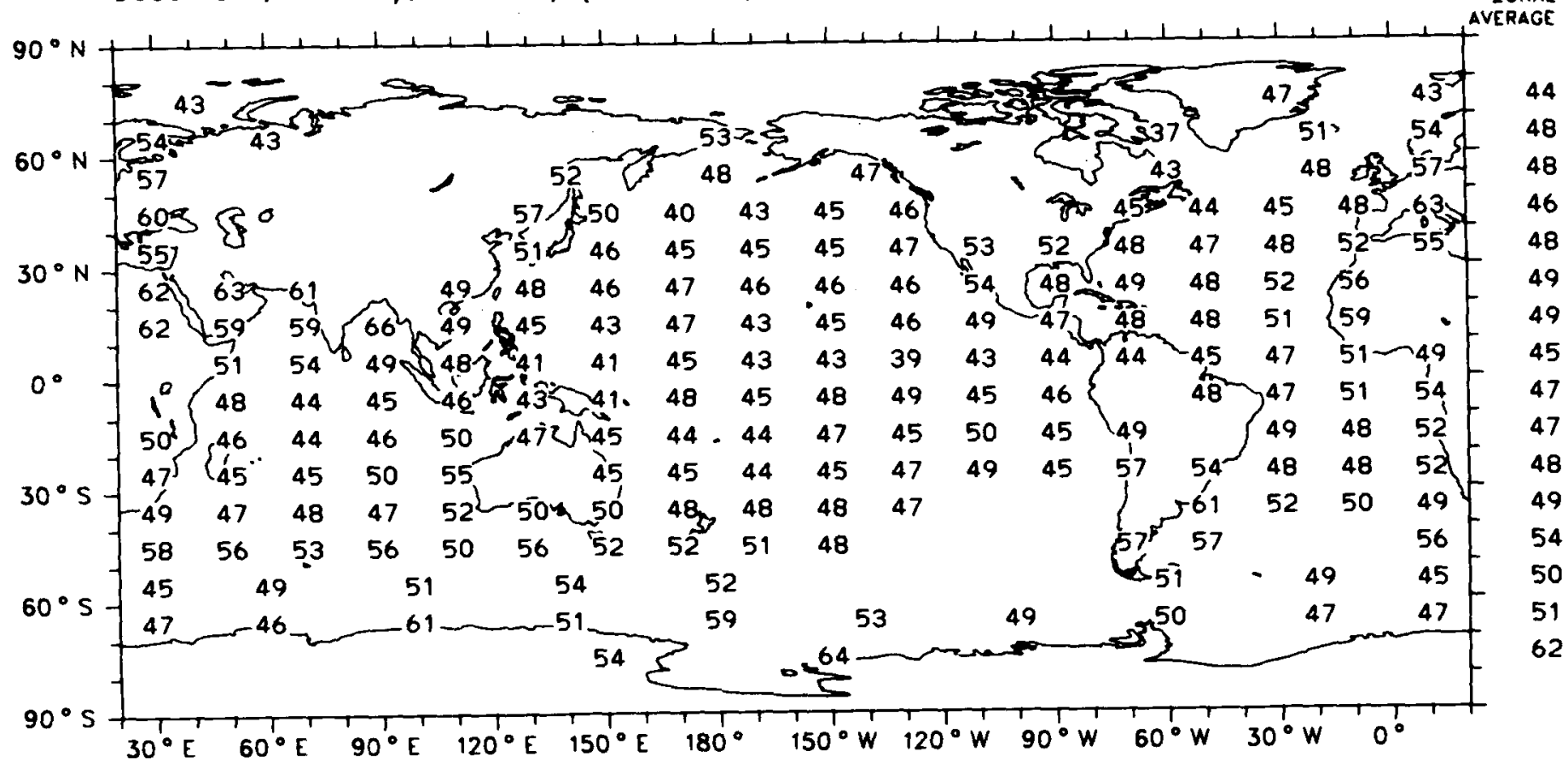

Global Average (Ocean) 484 meters

Map 129a

\section{Cumulonimbus}

Average Base Height (decameters)

March. April. May (1954-1981)

Ocean Areas Only

ZONAL

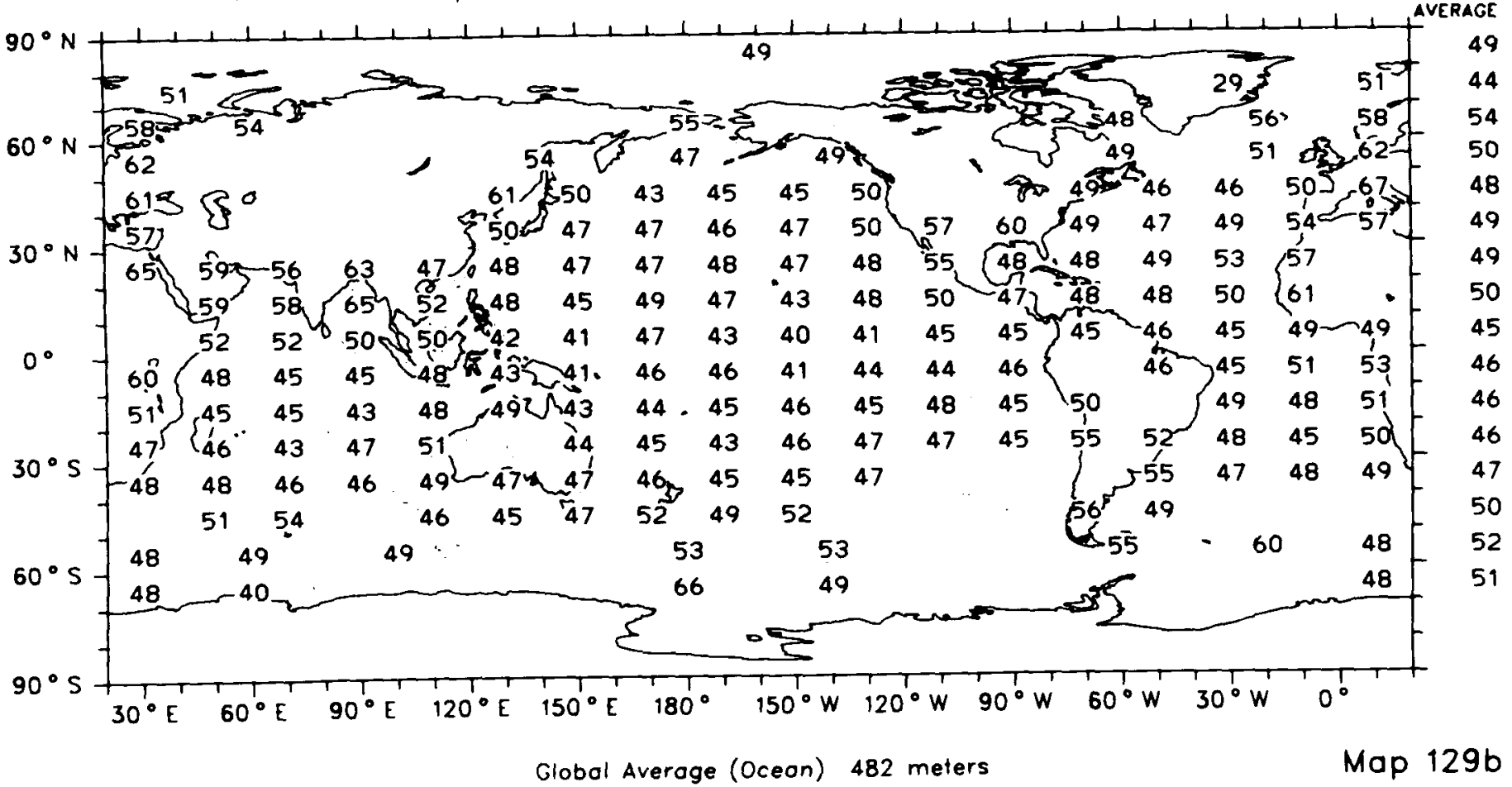




\section{Cumulonimbus}

Average Base Height (decameters)

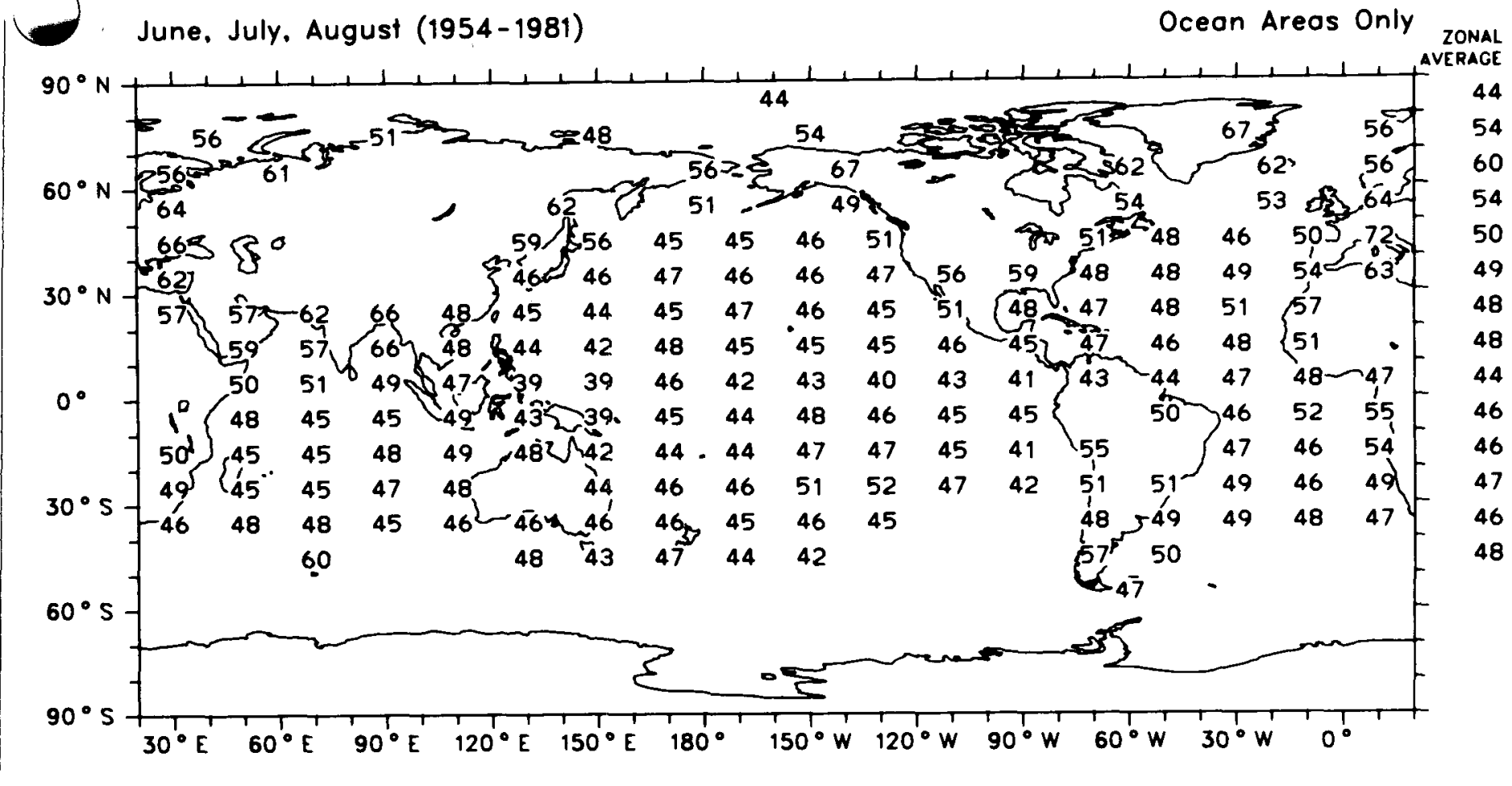

Global Average (Oceon) 476 meters

Map 129c

Cumulonimbus

Average Base Height (decameters)

September, October, November (1952-1981)

Oceon Areas Only

ZONAL

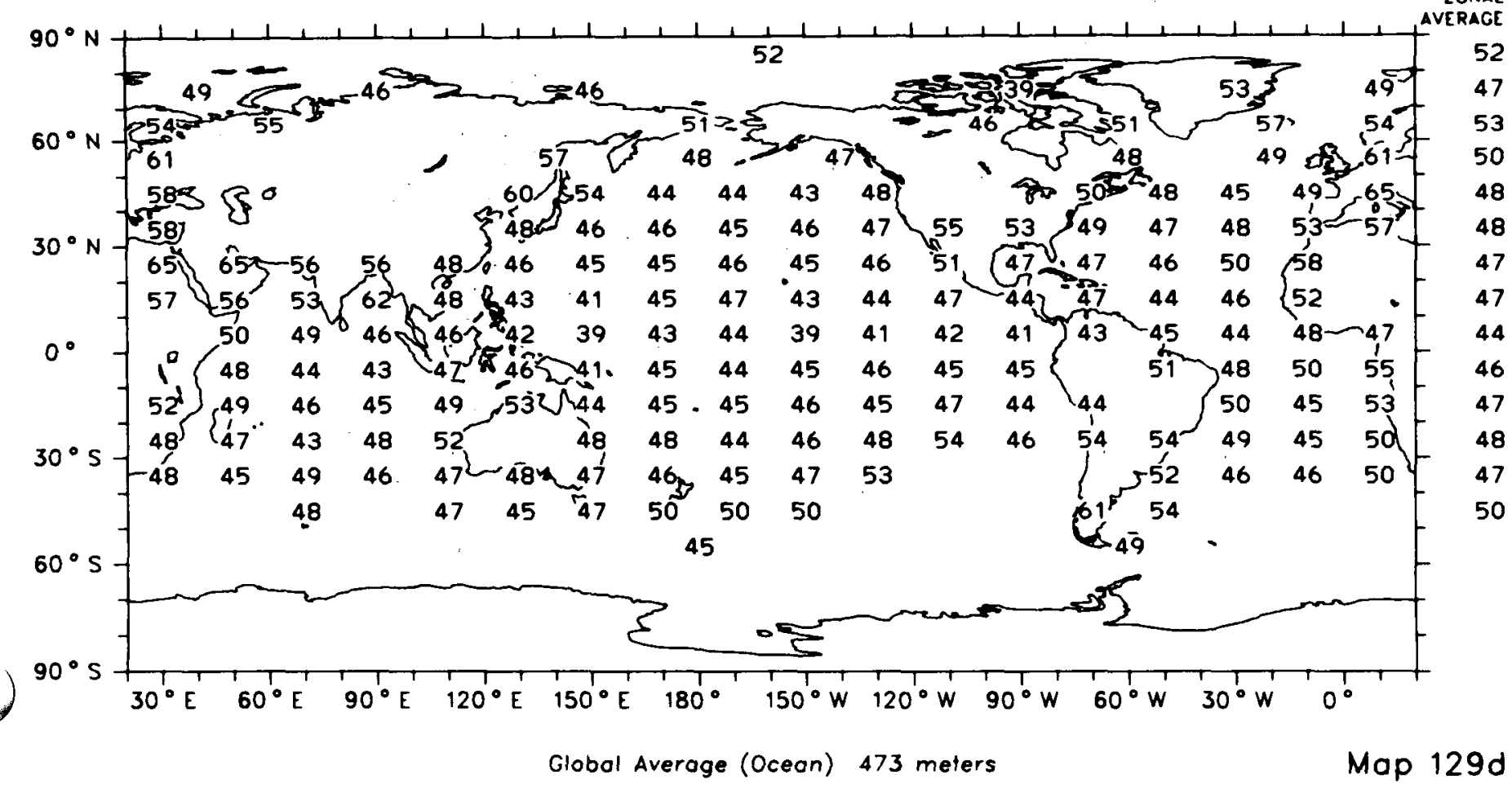




\section{Cumulonimbus}

Amplitude of Diurnal Cycle ( $0.1 \%$ Cloud Amount) December, January, February (1952-1981)

Ocean Areas Only

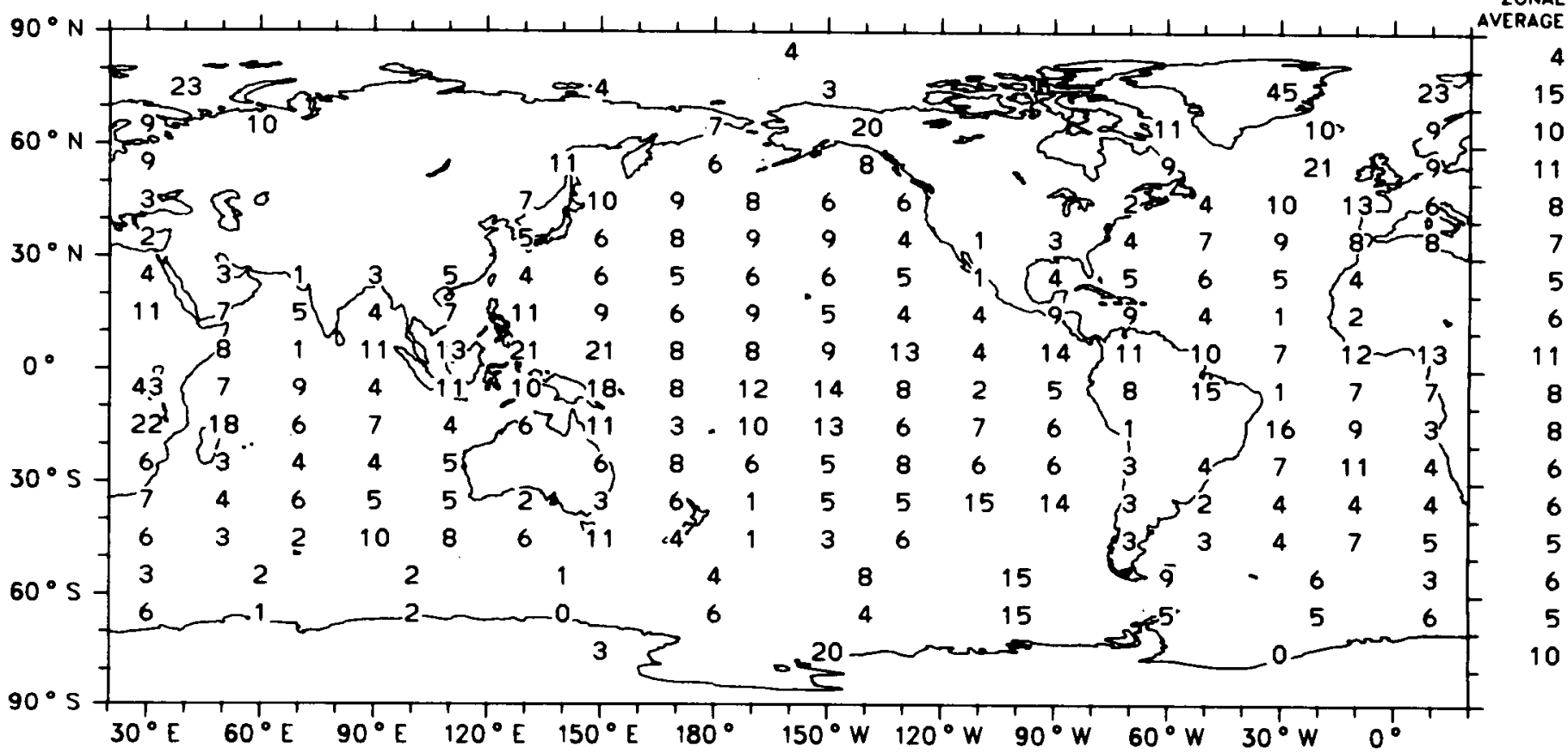

Map 130a

Globol Average (Ocean) $0.7 \%$

\section{Cumulonimbus}

Phase of Diurnal Cycle (Local Time of Maximum Cloud Amount) December, January. February (1952-1981)

Ocean Areas Only

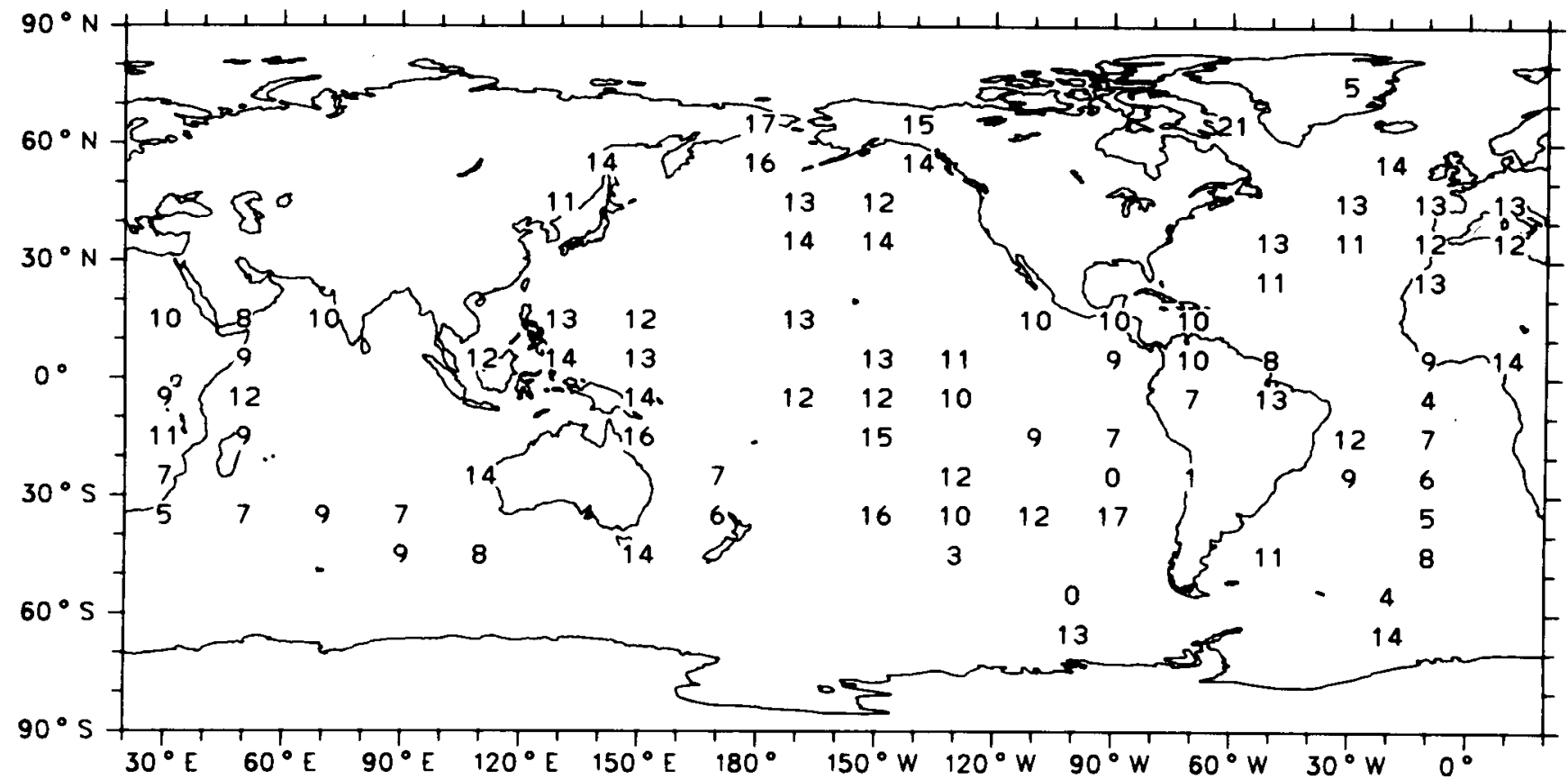

Map 130b 


\section{Cumulonimbus}

Amplitude of Diurnal Cycle (0.1\% Cloud Amount)

March, April, May (1952-1981)

Ocean Areas Only

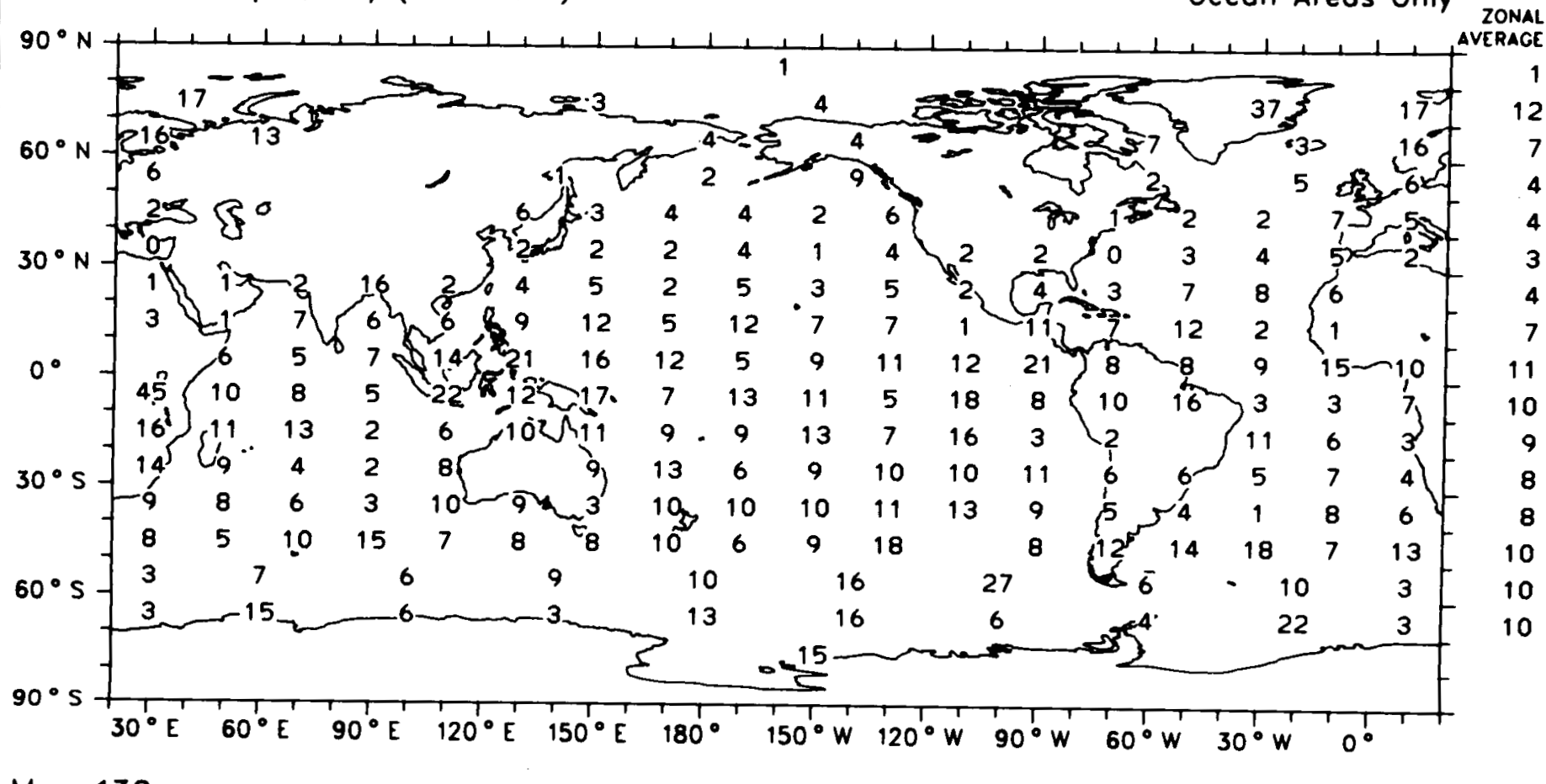

Map 130c

Global Averoge (Ocean) $0.8 \%$

\section{Cumulonimbus}

Phase of Diurnal Cycle (Local Time of Maximum Cloud Amount) Morch. April. May (1952-1981)

Ocean Areas Only

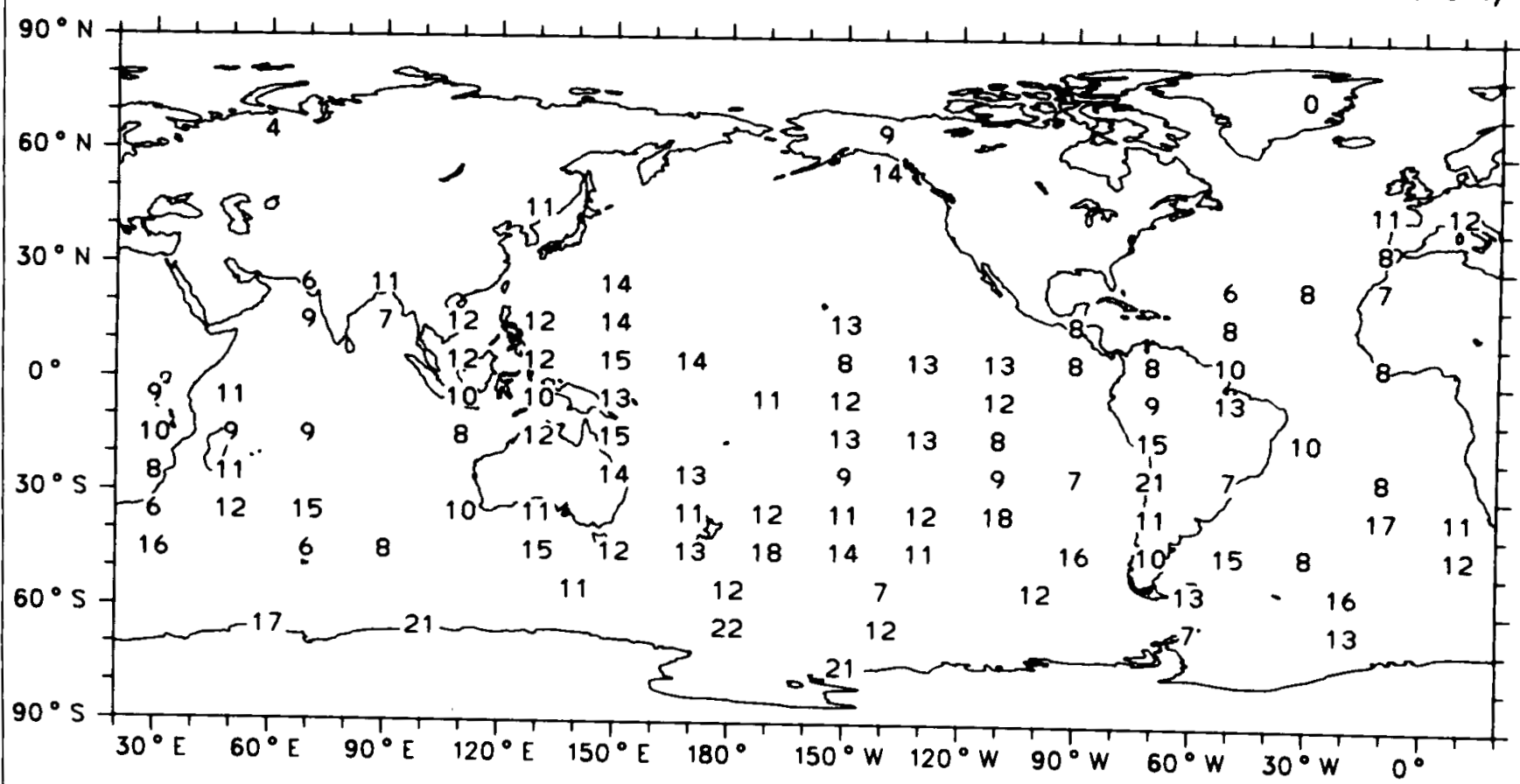

Map 130d 


\section{Cumulonimbus}

Amplitude of Diurnal Cycle (0.1\% Cloud Amount)

June, July. August (1952-1981)

Ocean Areas Only

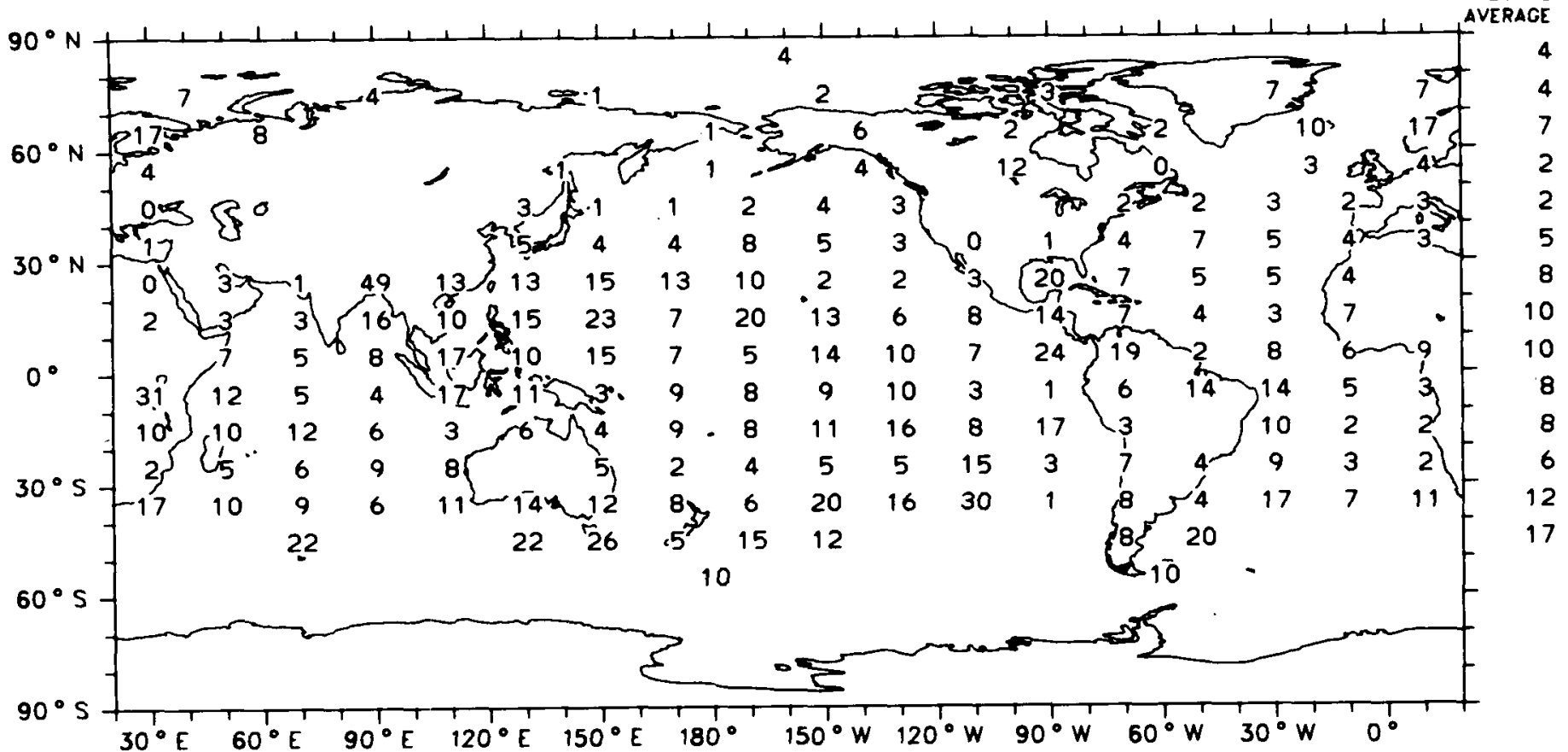

Globol Average (Oceon) $0.9 \%$

Map 131a

Cumulonimbus

Phase of Diurnal Cycle (Local Time of Maximum Cloud Amount) June. July. August (1952-1981)

Ocean Areas Only

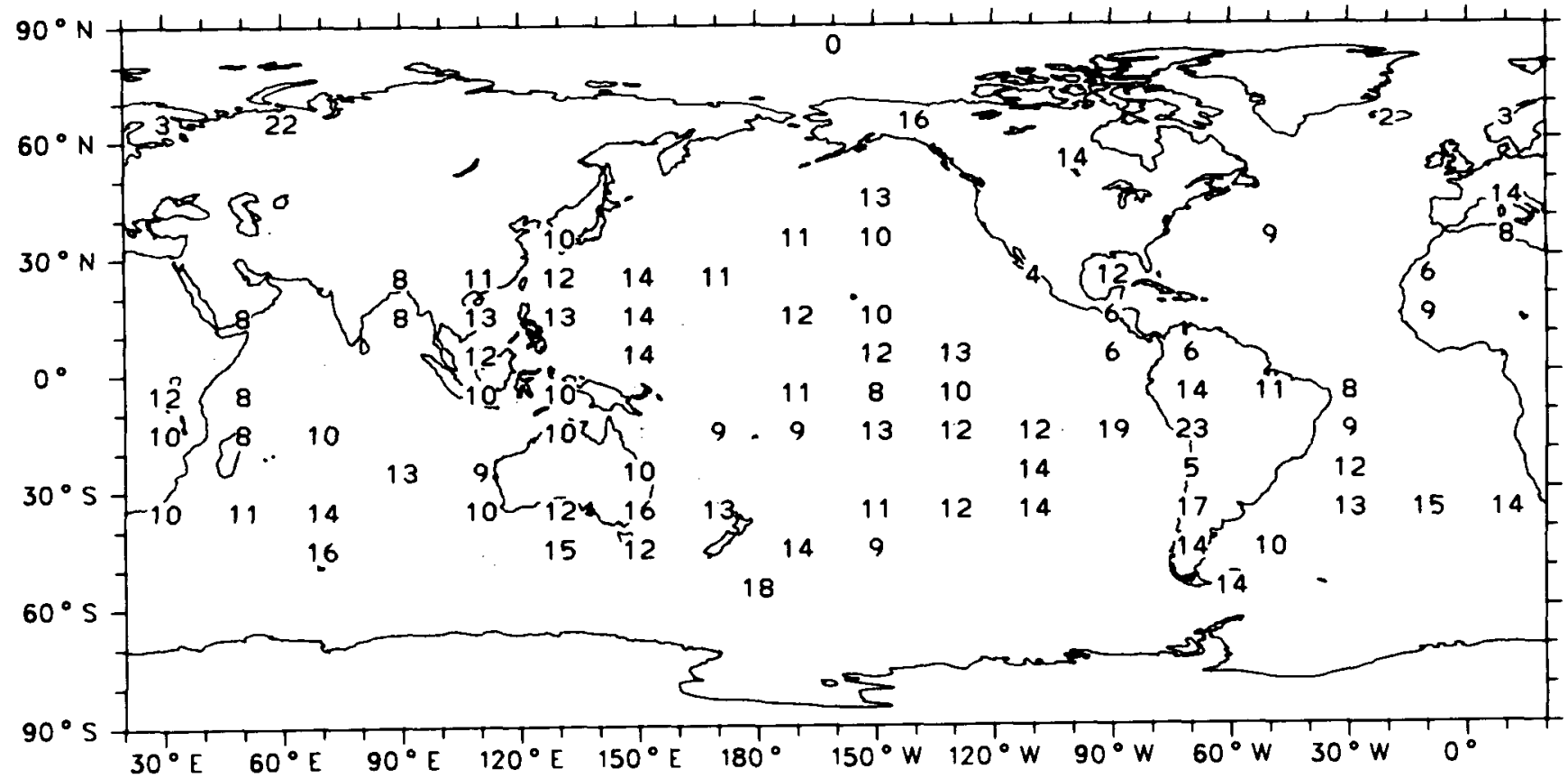

Map 131b 


\section{Cumulonimbus}

Amplitude of Diurnal Cycle (0.1\% Cloud Amount)

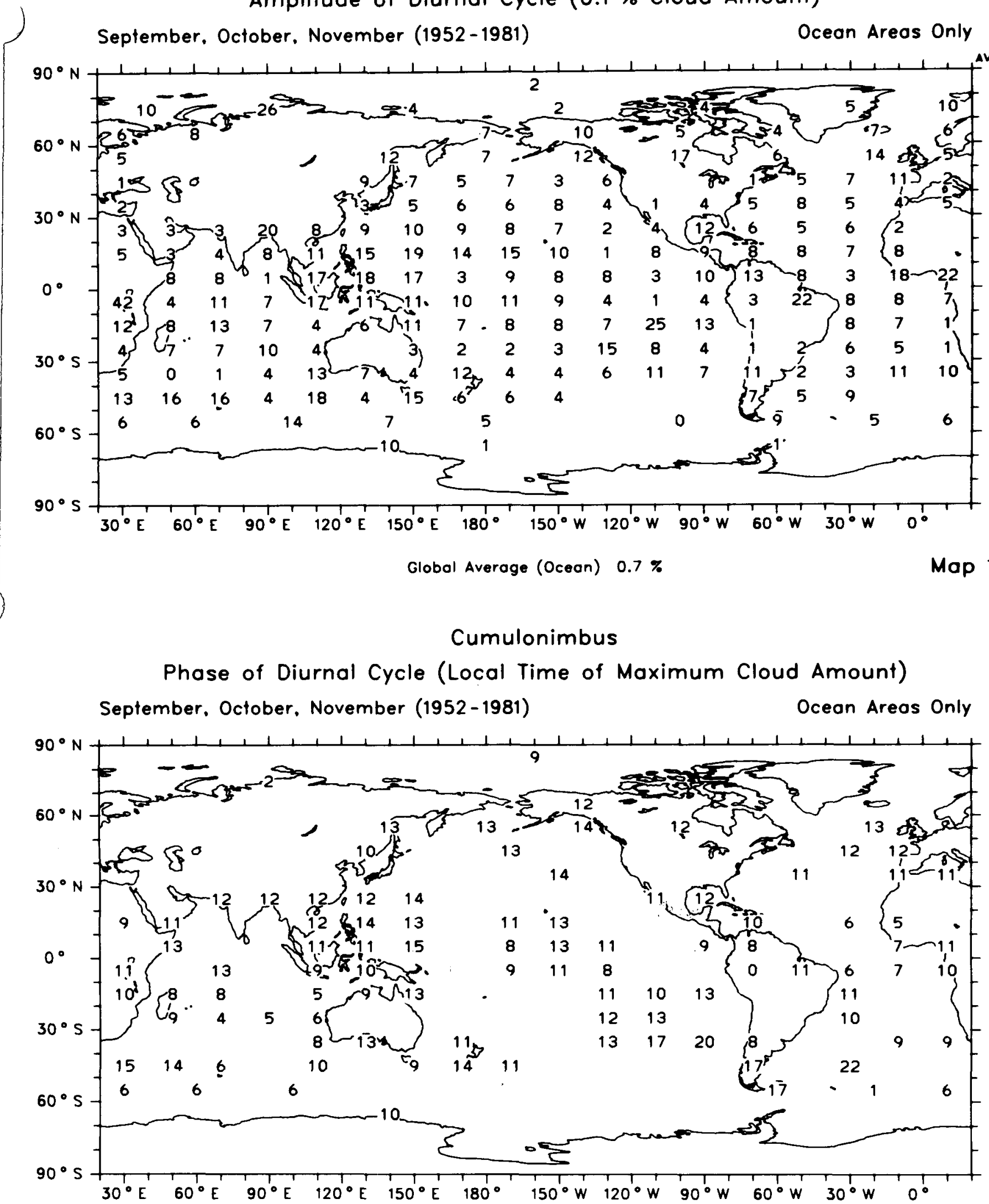

Map 131d 
Interannual Variation of Cumulonimbus :

Standard Deviation (detrended) of Seasonal Means (0.1\% Cloud Amount) December, January, February (1952-1981)

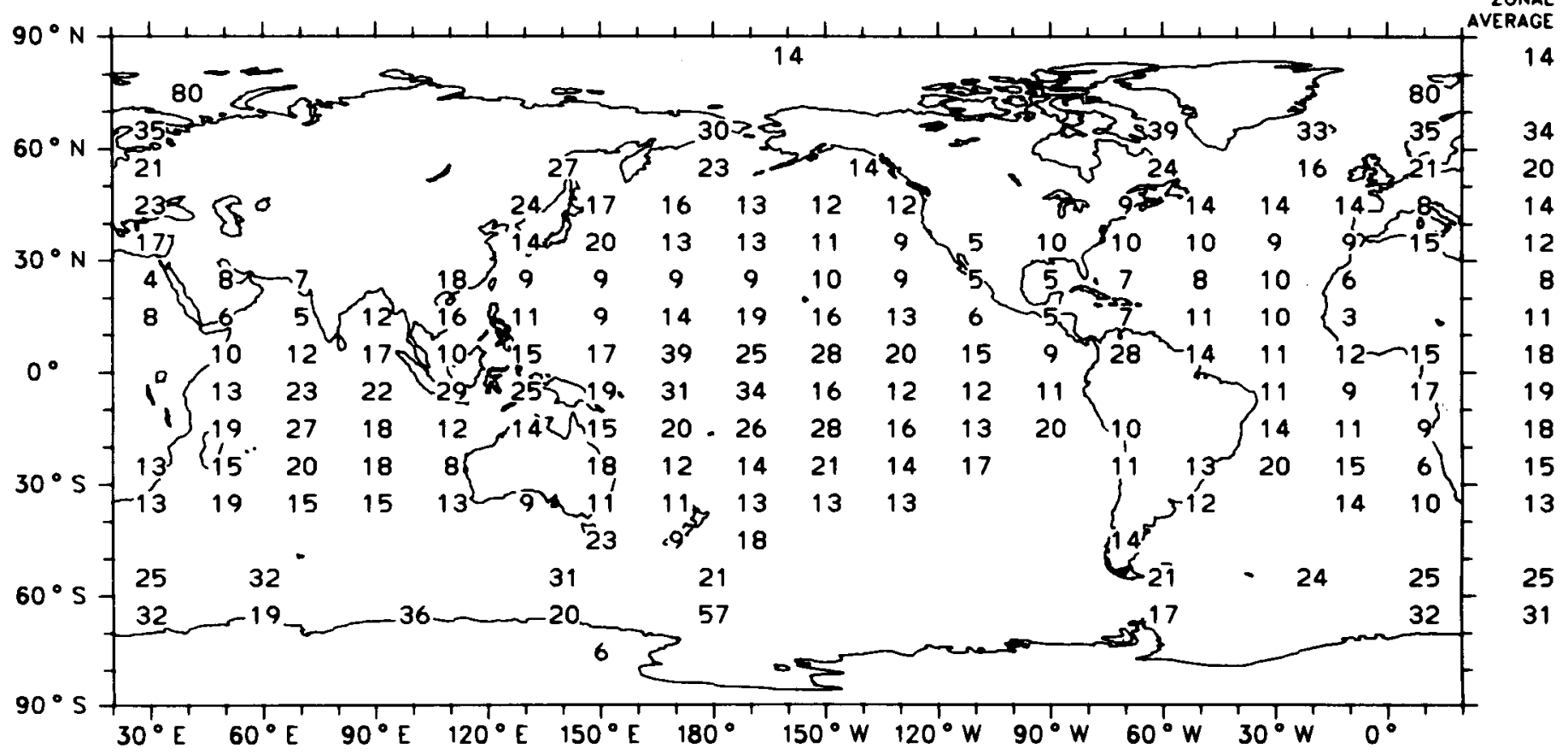

Map $132 a$

Global Average (Ocean) $1.7 \%$

Interannual Variation of Cumulonimbus :

Standard Deviation (detrended) of Seasonal Means (0.1\% Cloud Amount) March. April, May (1952-1981)

Ocean Areas Only

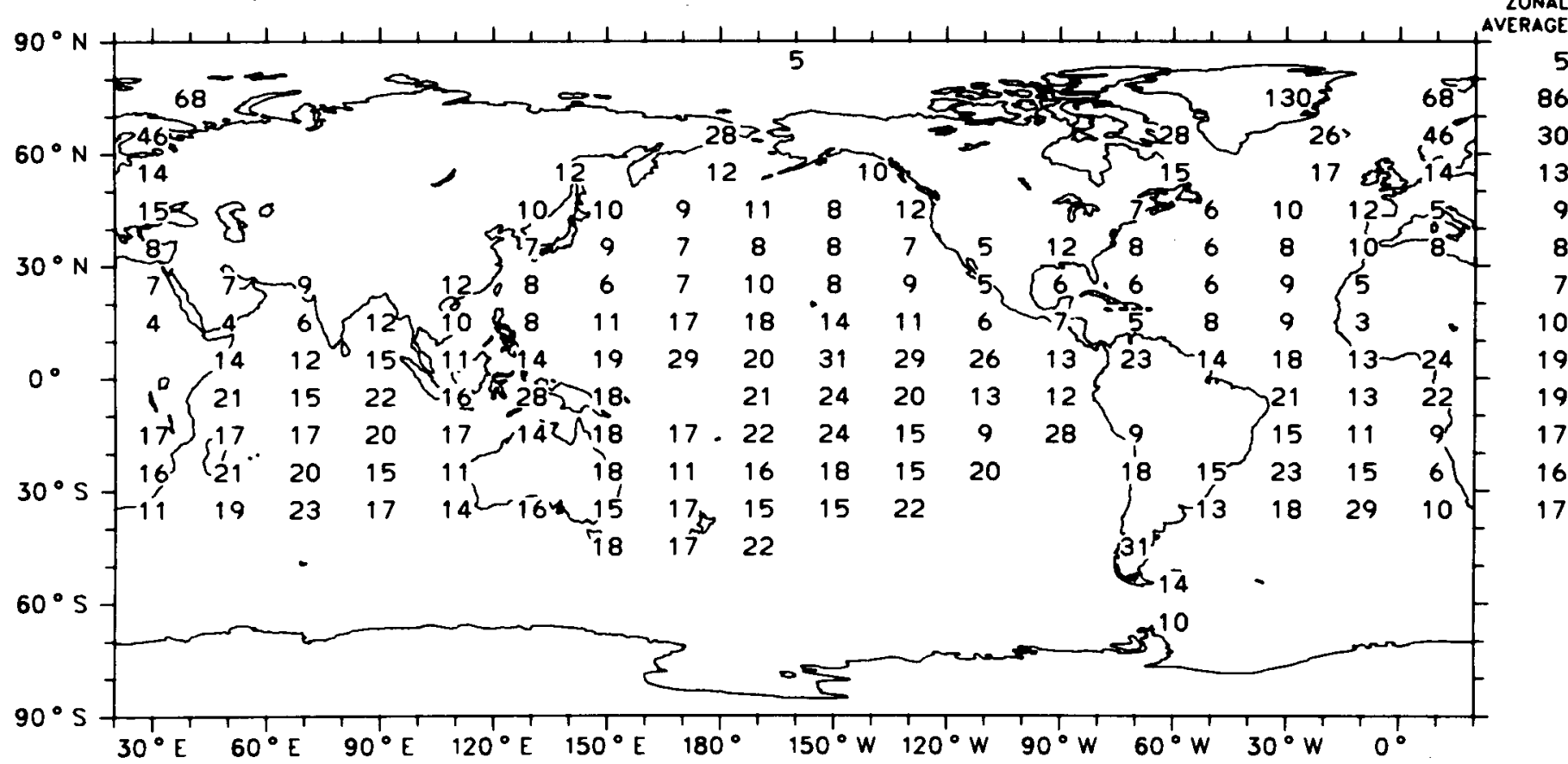

Map 132b

Global Averoge (Ocean) $9.7 \%$ 
Interannual Variation of Cumulonimbus :

Standard Deviation (detrended) of Seasonal Means (0.1\% Cloud Amount) June, July, August (1952-1981)

Ocean Areas Only

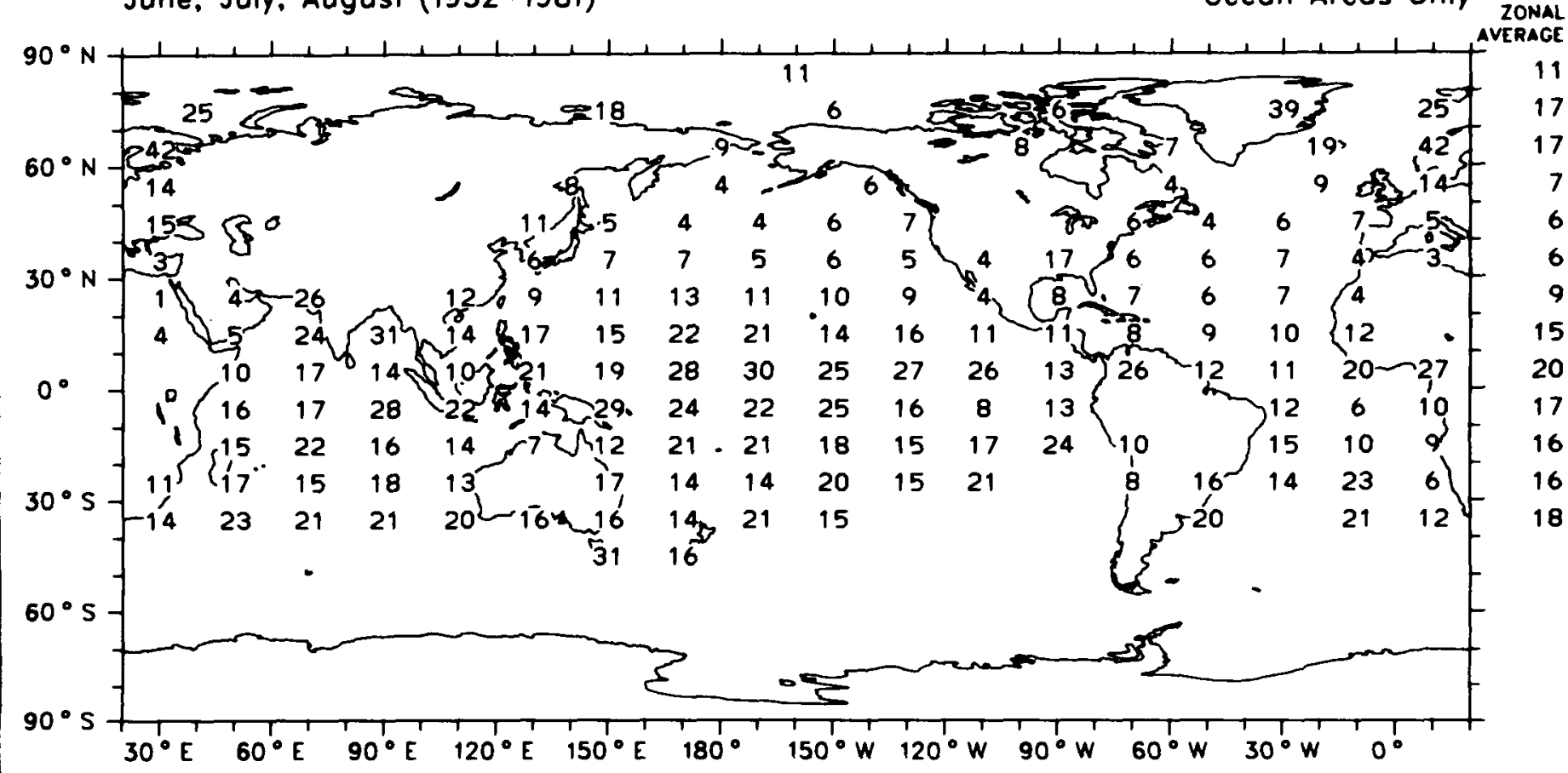

Map 132c

Globol Average (Ocean) $1.4 \%$

Interannual Variation of Cumulonimbus :

Standard Deviation (detrended) of Seasonal Means (0.1\% Cloud Amount)

September, October, November (1952-1981)

Ocean Areas Only

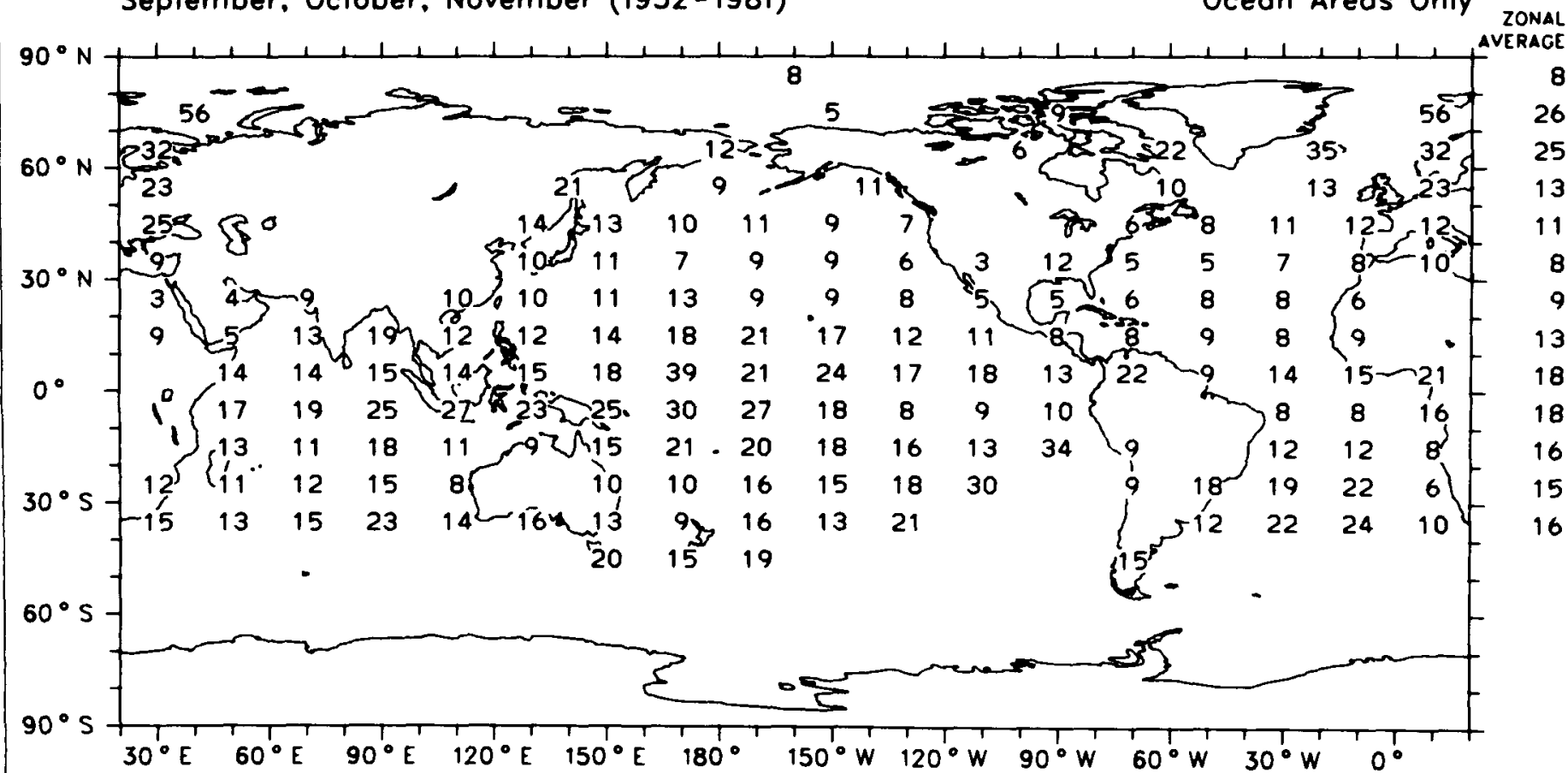

Map 132d

Global Average (Oceon) $1.5 \%$ 
Trend of Cumulonimbus :

Change in \%-Cloud-Amount from 1952 to 1981

December, January. February (1952-1981)

Ocean Areas Only

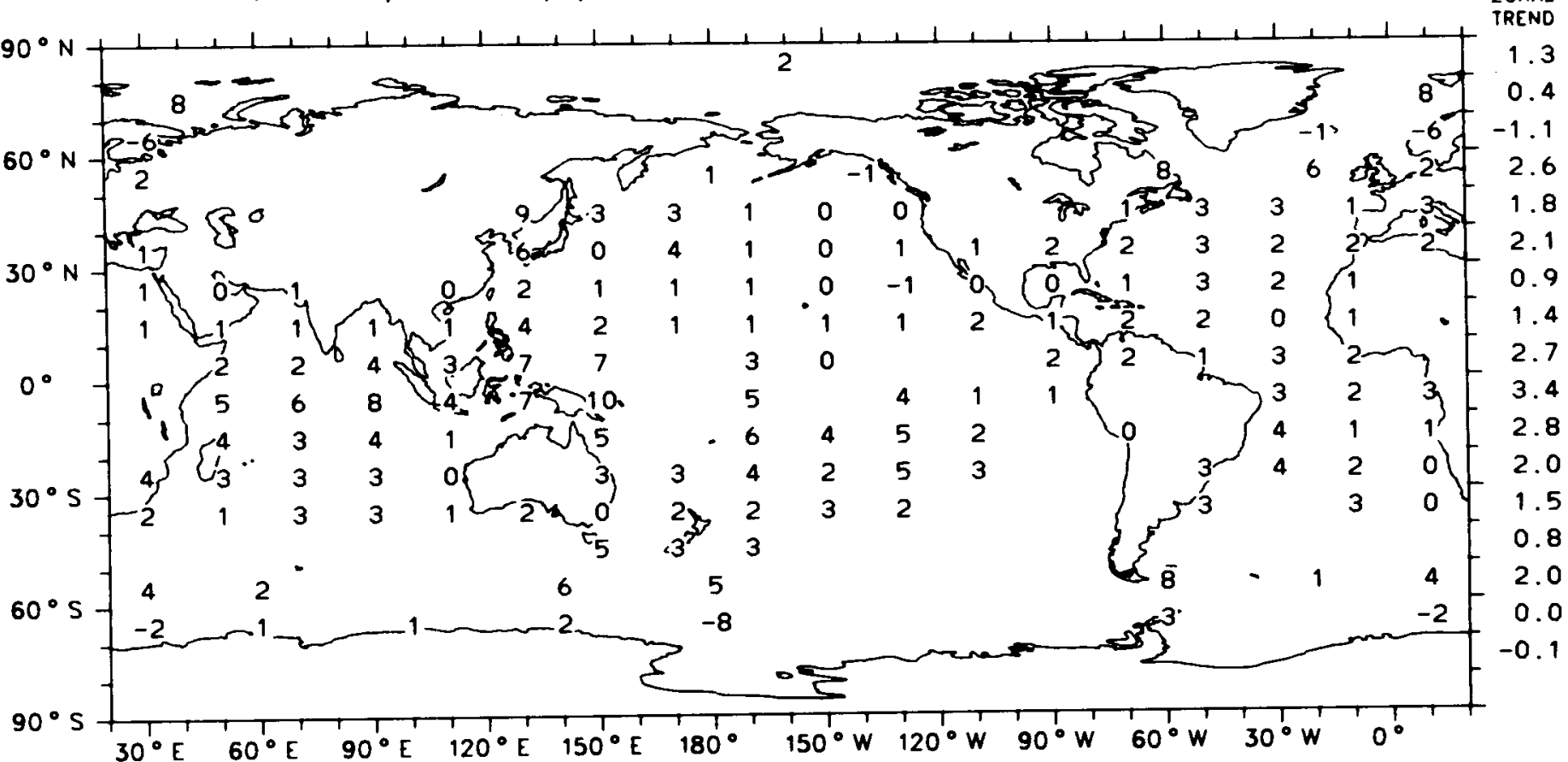

Global Trend (Ocean) $1.8 \%$

Map 133a

Trend of Cumulonimbus :

Change in \%-Cloud-Amount from 1952 to 1981

March. April. May (1952-1981)

Ocean Areas Only

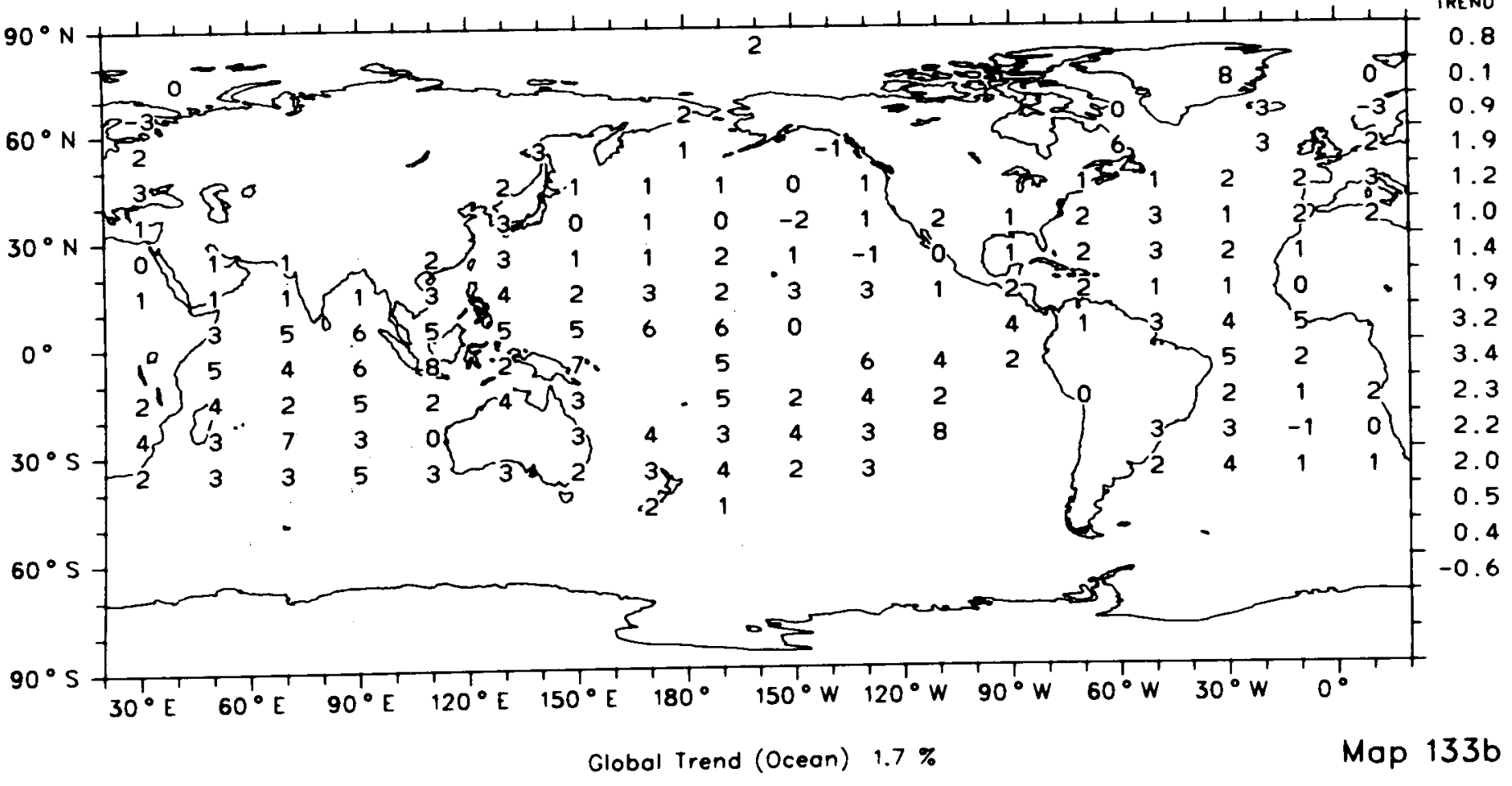


Trend of Cumulonimbus :

Change in \%-Cloud-Amount from 1952 to 1981 June. July, August (1952-1981)

Ocean Areos Only

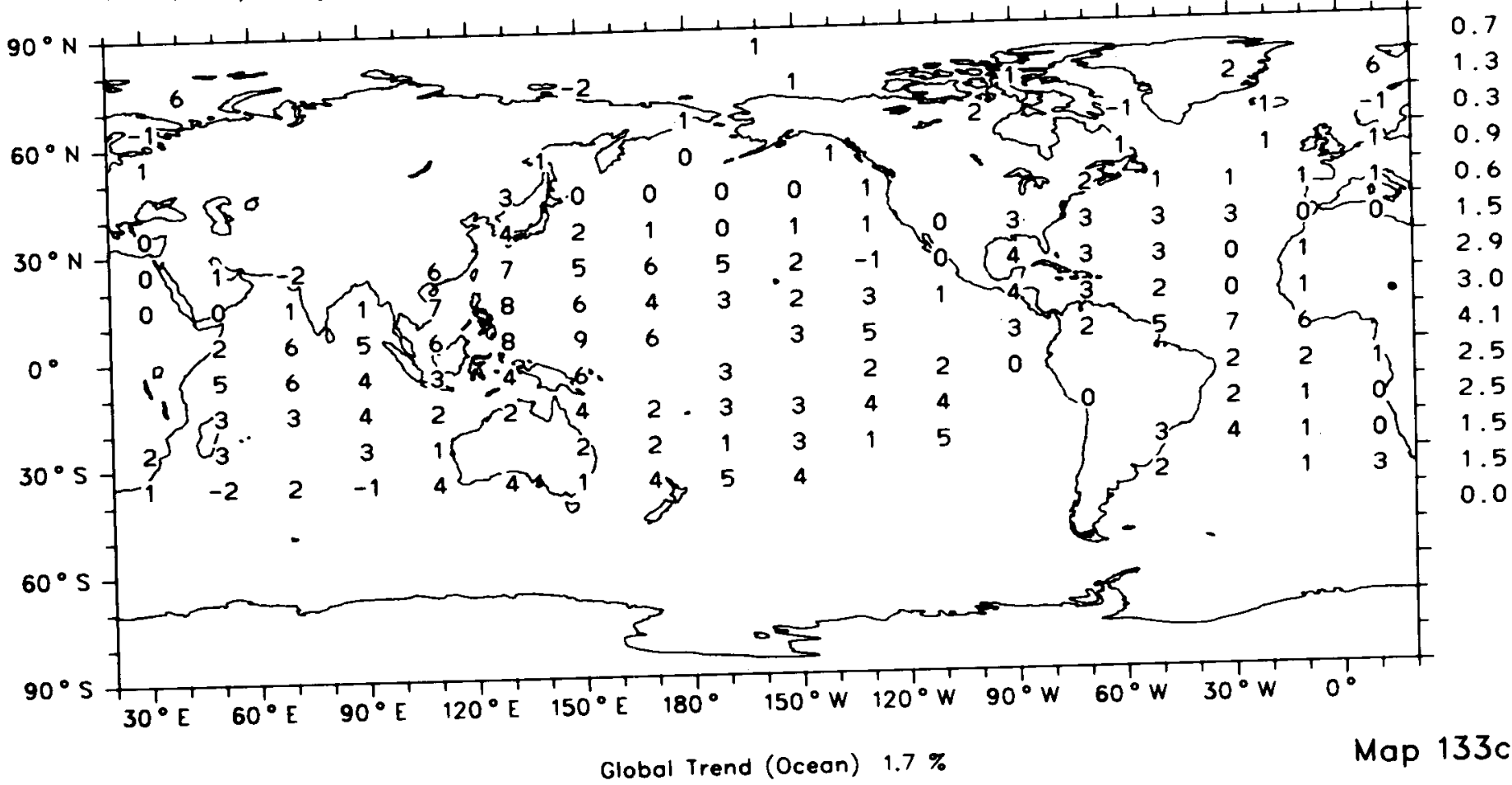

Trend of Cumulonimbus :

Change in \%-Cloud-Amount from 1952 to 1981

September, October, November (1952-1981)

Ocean Areas Only

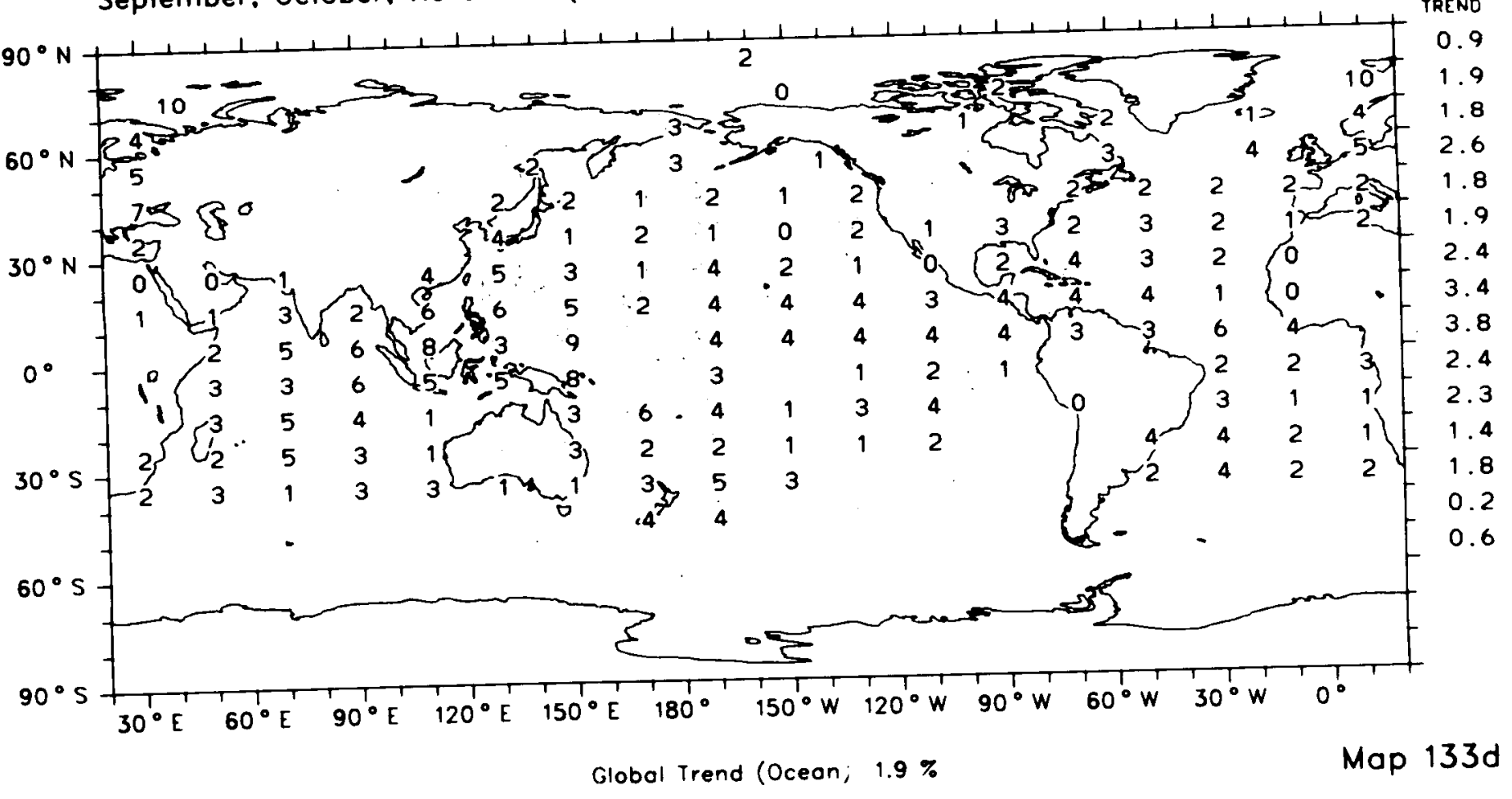




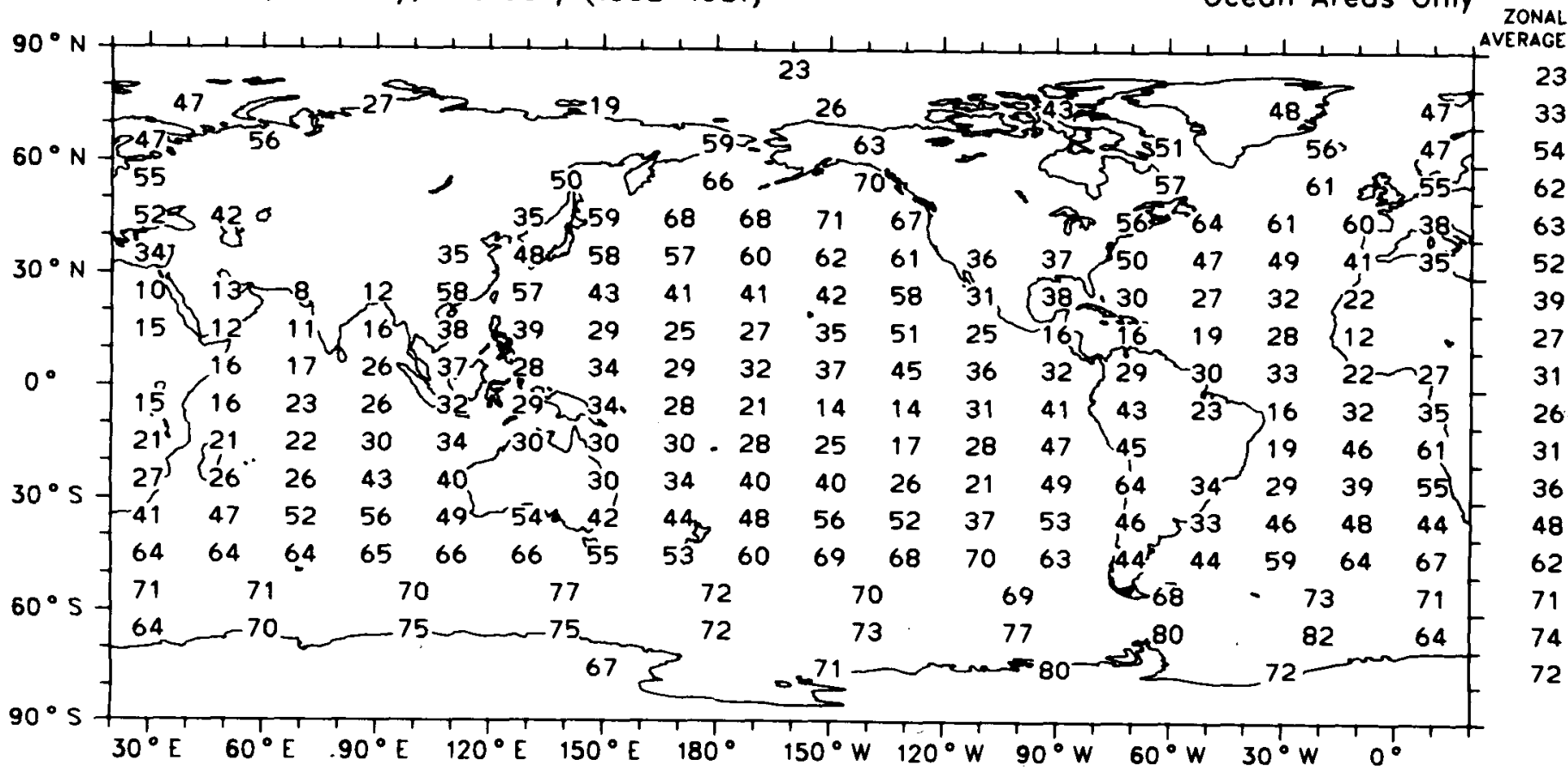

Map 134a

Global Average (Ocean) $44 \%$

\section{Stratus + Stratocumulus + Fog \\ Frequency of Occurrence (\%)}

March, April, May (1952-1981)

Ocean Areas Only

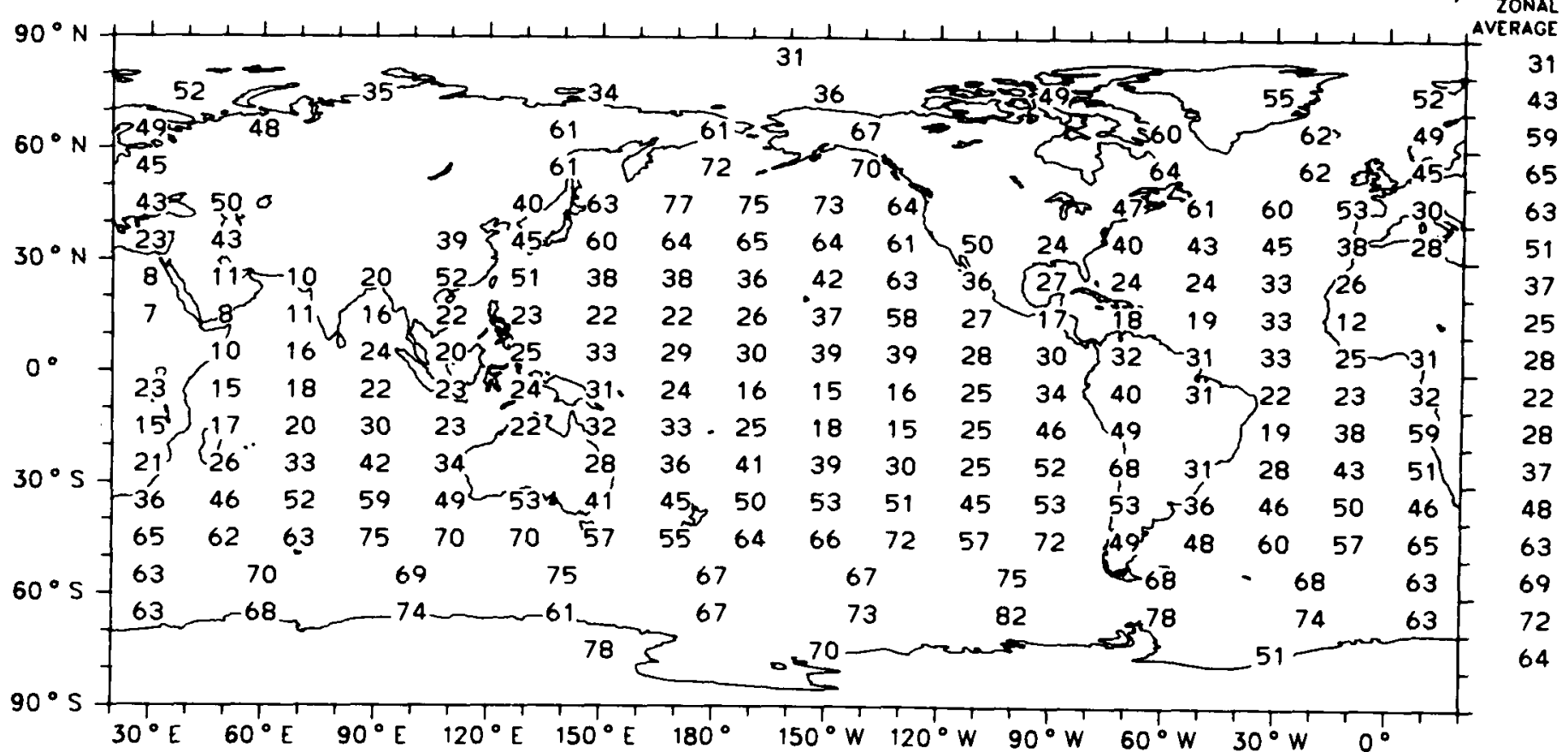

Map 134b

Global Average (Ocean) $43 \%$ 


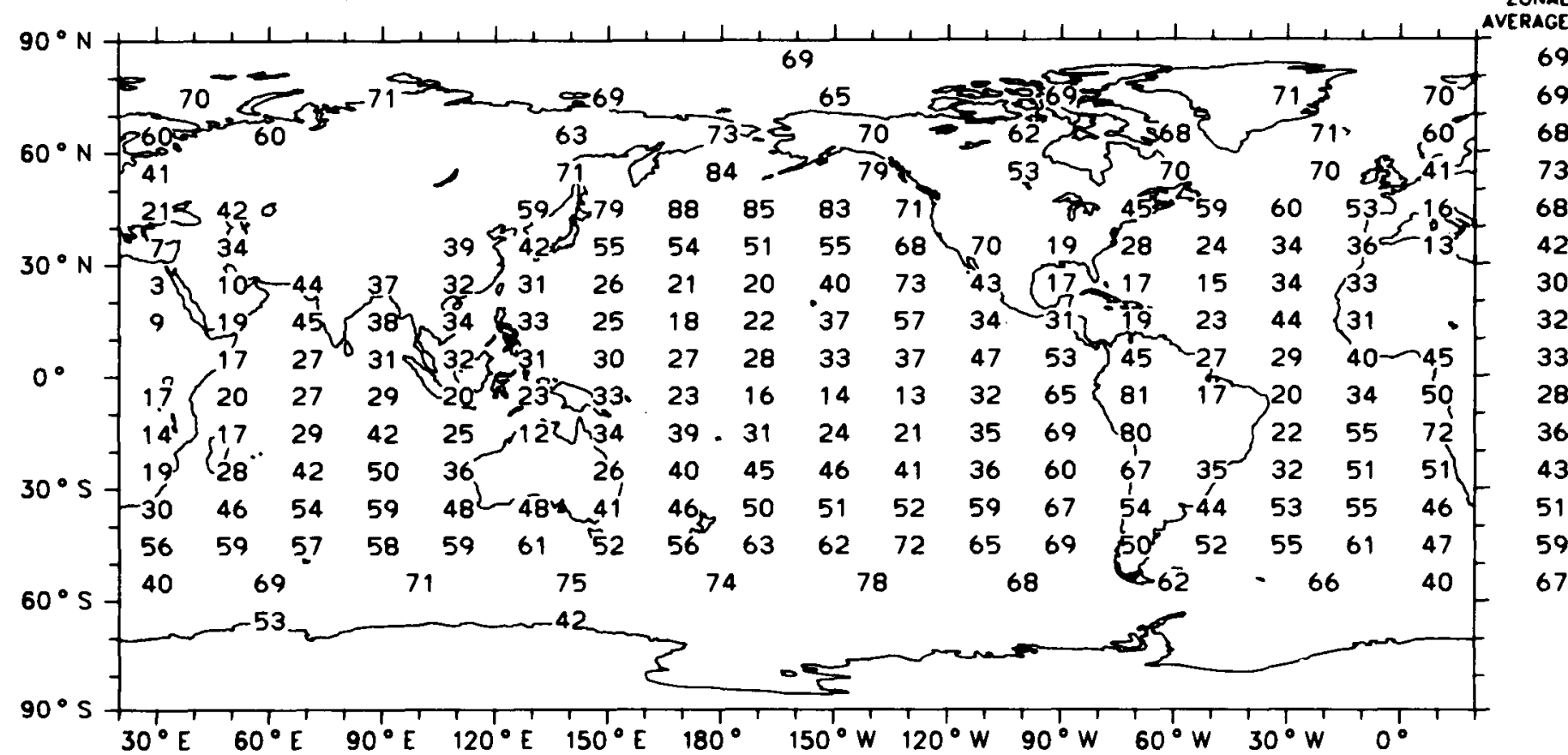

Map 134c

Global Averoge (Ocean) $45 \%$

Stratus + Stratocumulus + Fog

Frequency of Occurrence (\%)

September, October, November (1952-1981)

Ocean Areas Only

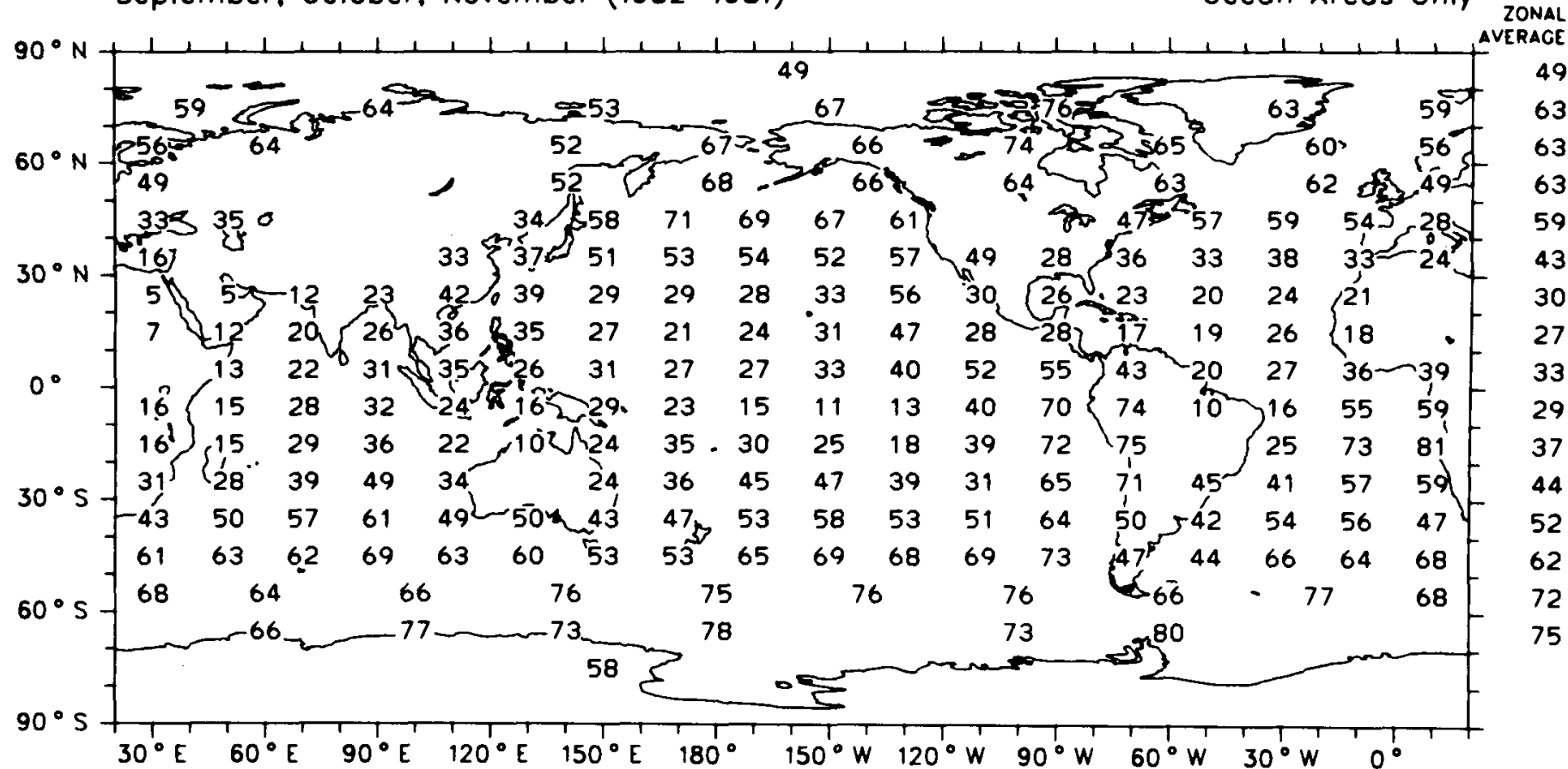

Map 134d

Global Average (Ocean) $46 \%$ 
Stratus + Stratocumulus + Fog

Amount-When-Present (\%)

December, January. February (1952-1981)

Ocean Areas Only

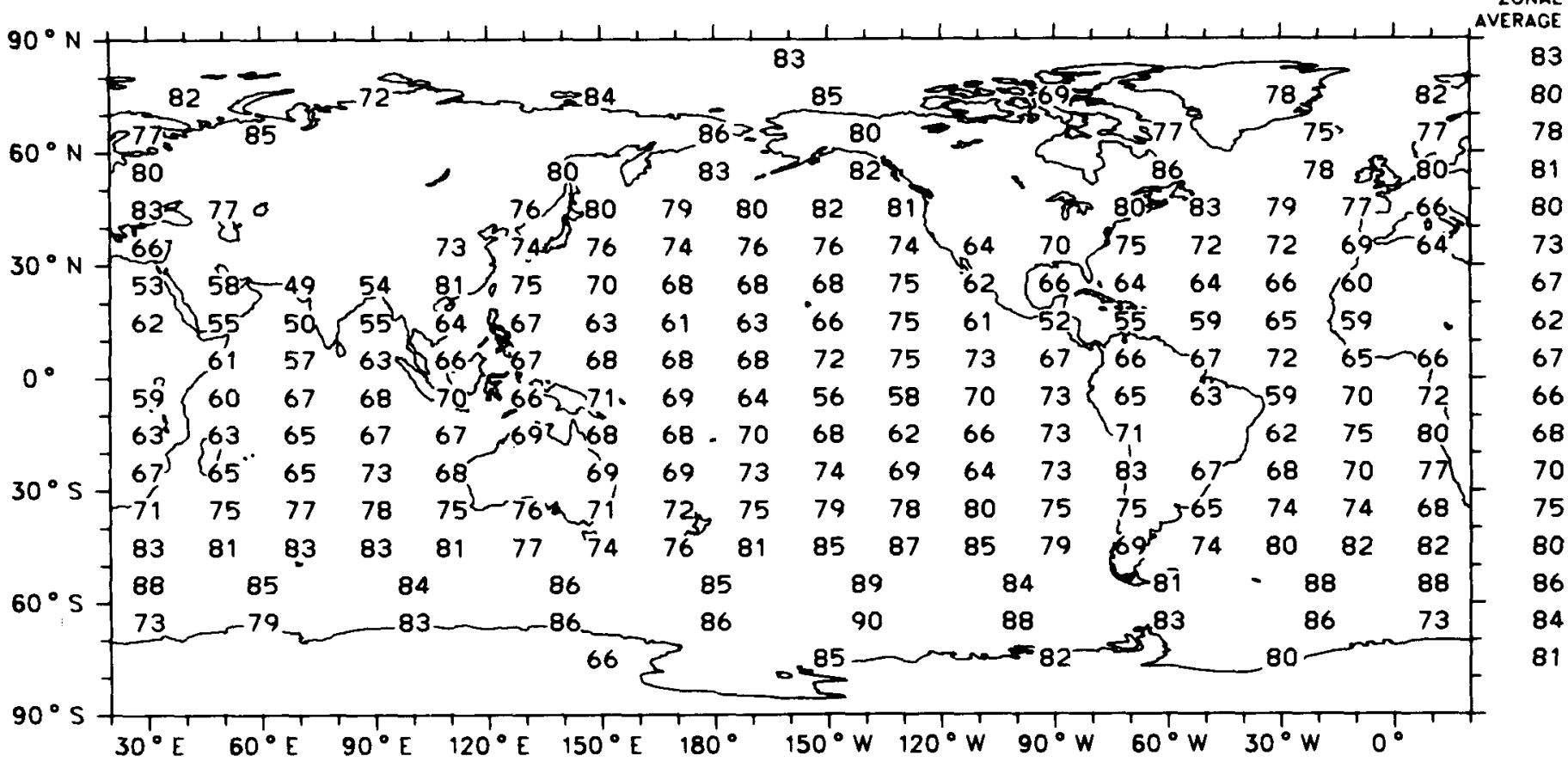

Global Averoge (Ocean) $73 \%$

Map 135a

\section{Stratus + Stratocumulus + Fog}

Amount-When-Present (\%)

March, April, Moy (1952-1981)

Ocean Areas Only

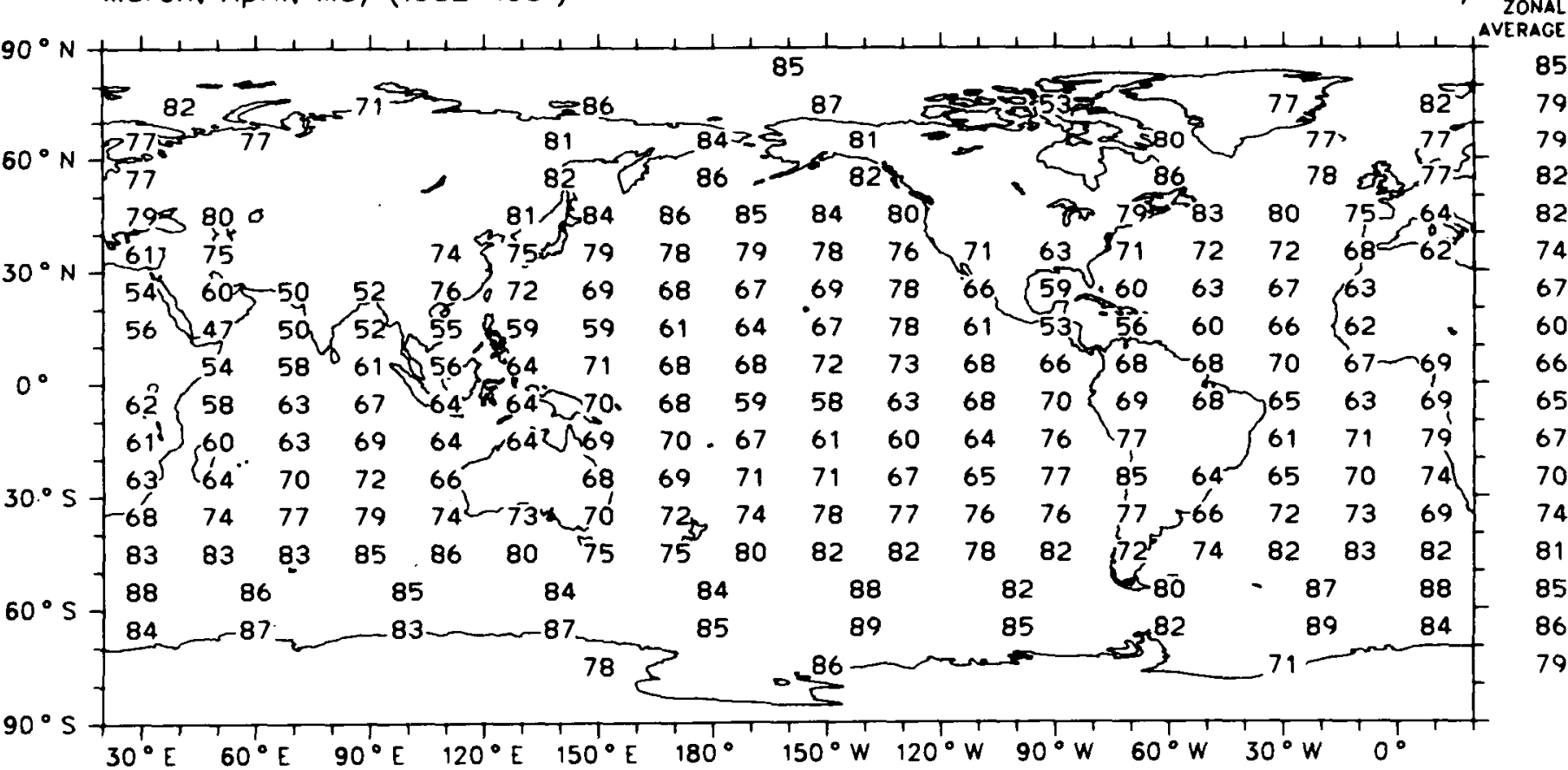

Globol Average (Ocean) $72 \%$

Map 135b 


\section{Stratus + Stratocumulus + Fog}

Amount-When-Present (\%)

June, July, August (1952-1981)

ZONAL

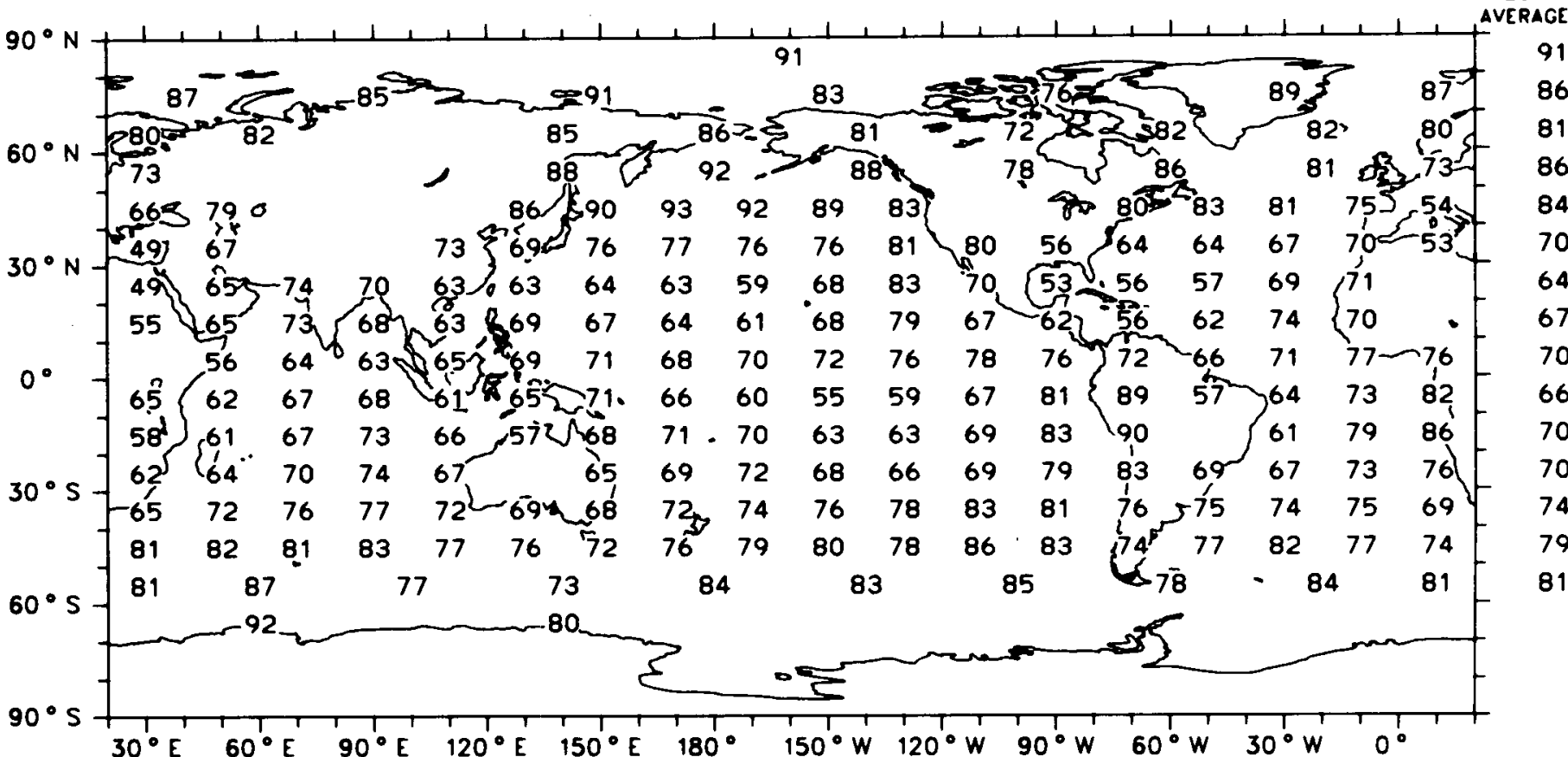

Globol Averoge (Ocean) $73 \%$

Map 135c

Stratus + Stratocumulus + Fog

Amount-When-Present (\%)

September, October. November (1952-1981)

Ocean Areas Only

ZONAL

$90^{\circ} \mathrm{N}$

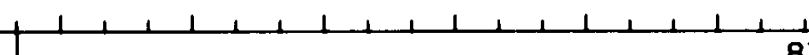

\section{7} $1,1, t^{\text {AVERAGE }}$

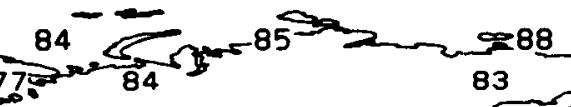

$8383=2$<smiles>C1CCC[Sb]2CC2CC1</smiles>
80 \% 79 $85 \frac{5}{5} \quad 847$ $60^{\circ} \mathrm{N}$

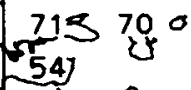

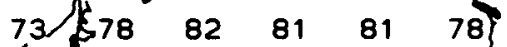
वo 76529

78 73 گु6 747374

7373

$7 0 \quad 6 4 \longdiv { 6 7 }$ $30^{\circ} \mathrm{N}$ 44 525-56

$70 \% 67$

6564

$\begin{array}{llll}73 & 74 & 73 & 73 \\ 64 & 64 & 63 & 76\end{array}$

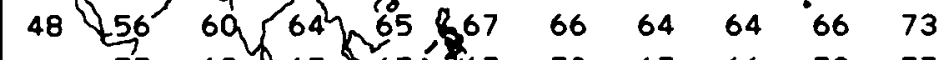

$0^{\circ}$

56 62676707070

$\begin{array}{llll}67 & 66 & 73 & 77\end{array}$

64

63. 60 . 6061

78462 78 7872

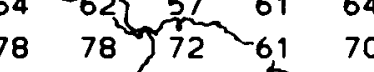

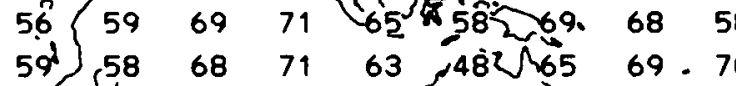

$30^{\circ} \mathrm{s}$

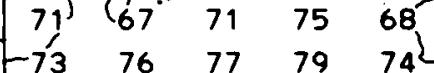

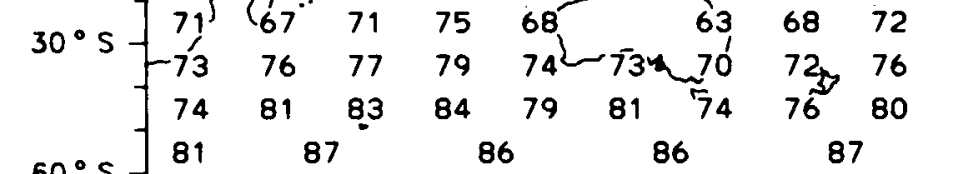

$69 \cdot 70-65$

5254

70

$\begin{array}{ll}70 & 83\end{array}\left\{\begin{array}{l}86 \\ 88\end{array}\right.$

4757

68 735, 640

$1<0$

$4\left\{\begin{array}{l}60 \\ 62\end{array}\right.$

$\{62$

781

$60^{\circ}$

$81 \quad 87$

$-76$

88

$-87$

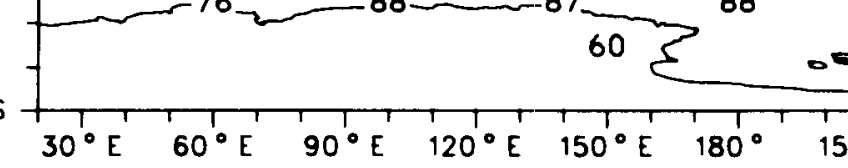

88

$90^{\circ} \mathrm{s}$

Global Averoge (Oceon) $73 \%$

Map 135d 


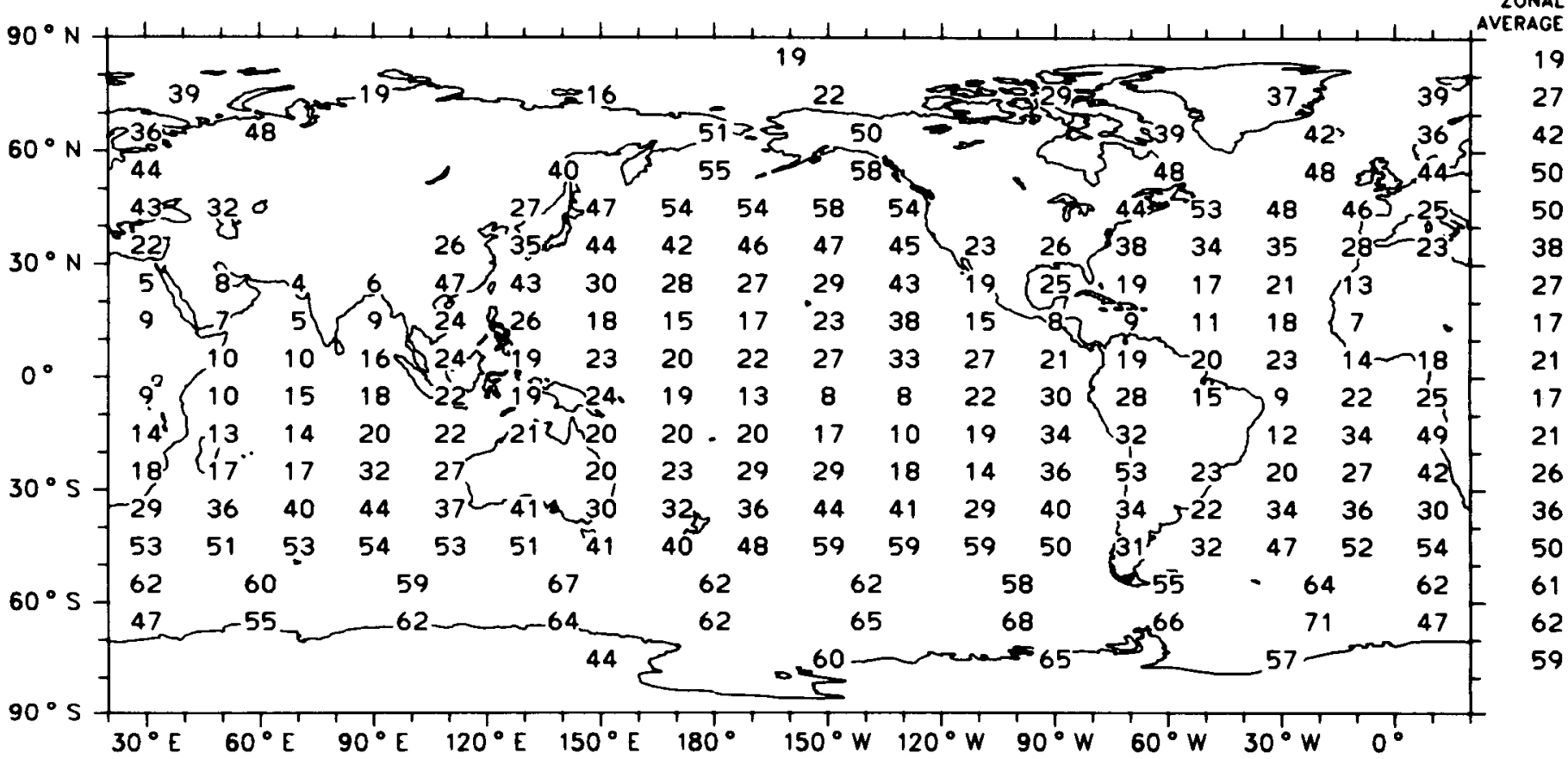

Map 136a

Global Average (Ocean) $34 \%$

\section{Stratus + Stratocumulus + Fog \\ Average Cloud Amount (\%)}

Morch. April. May (1952-1981)

Oceon Areas Only

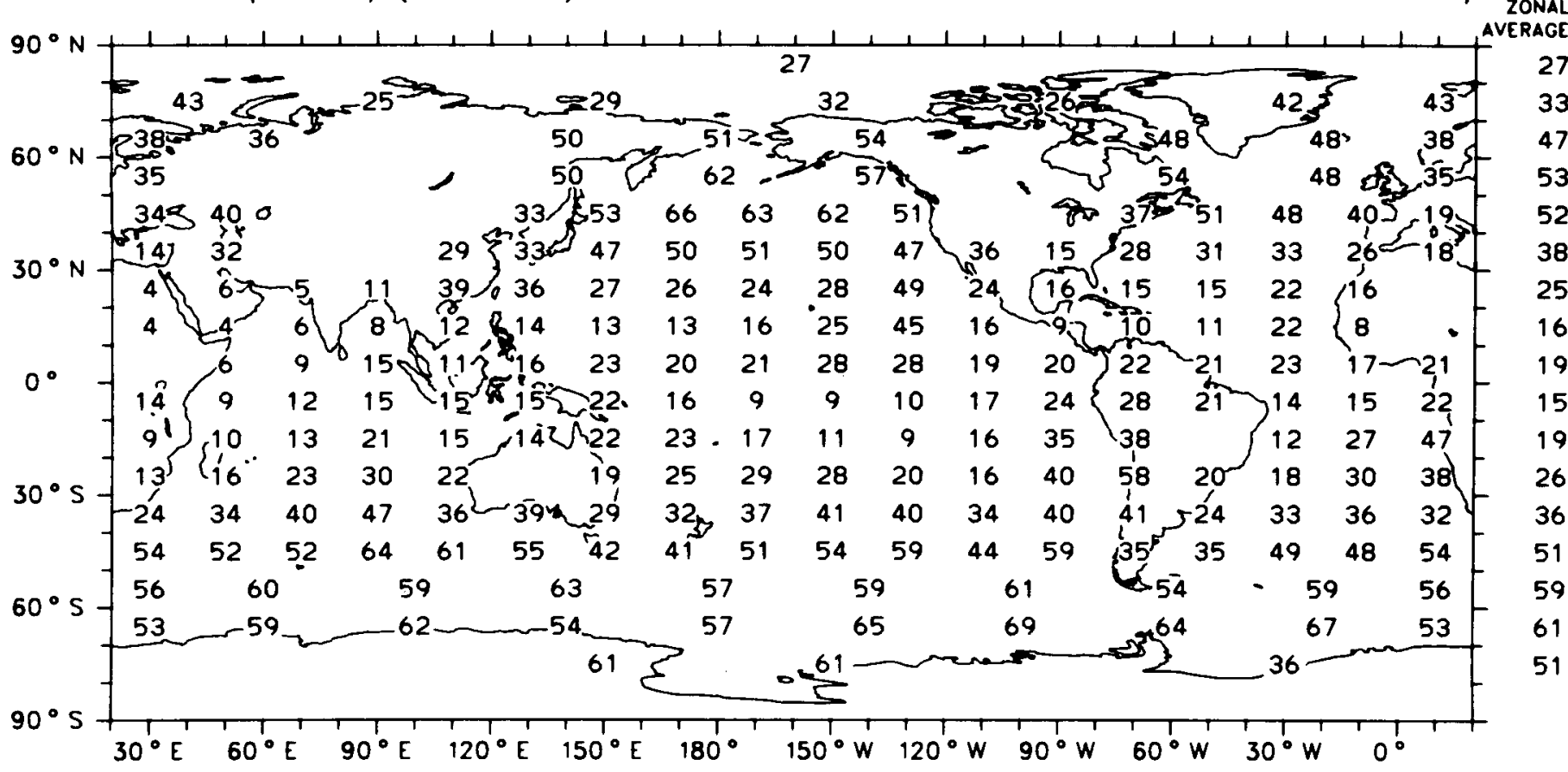

Map 136b 
June. July. August (1952-1981)

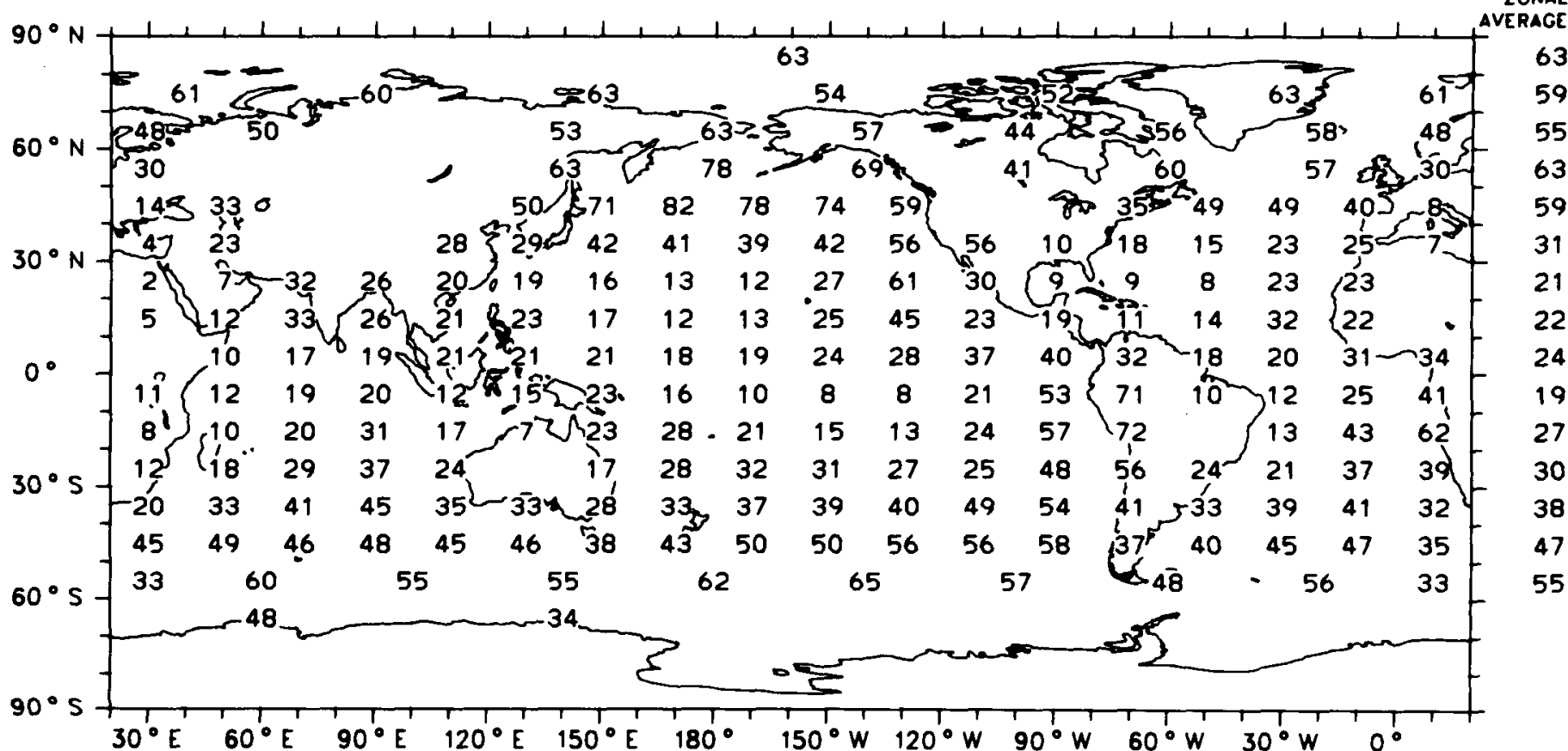

Map 136c

Globol Average (Ocean) $34 \%$

Stratus + Stratocumulus + Fog

Average Cloud Amount (\%)

September. October. November (1952-1981)

Ocean Areas Only

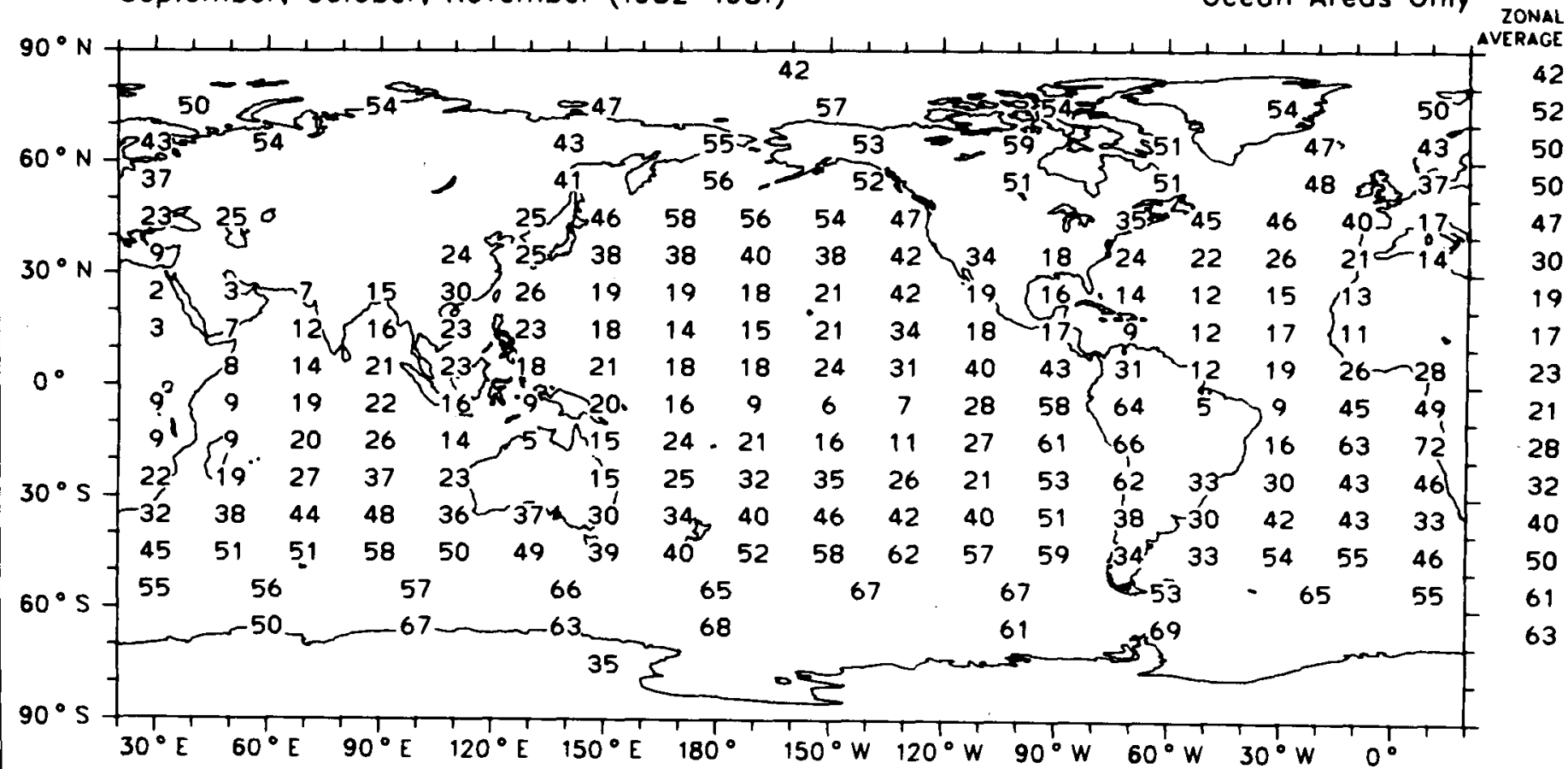

Map 136d

Global Average (Ocean) $35 \%$ 
Stratus + Stratocumulus (excluding fog)

Average Base Height (decameters)

December, January. February (1954-1981)

Ocean Areas Only

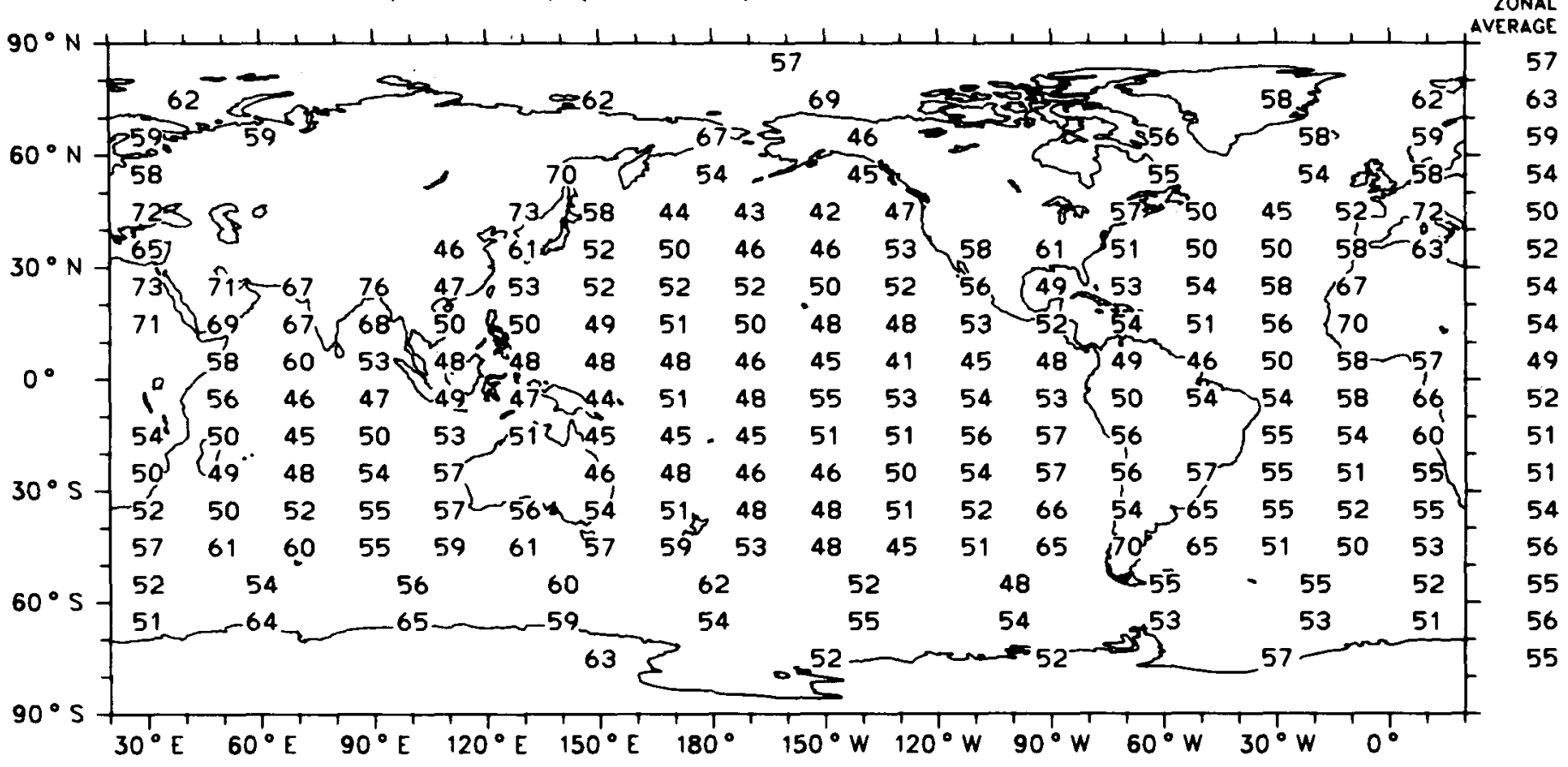

Global Average (Ocean) 532 meters

Map 137a

Stratus + Stratocumulus (excluding fog)

Average Base Height (decameters)

March, April, May (1954-1981)

Ocean Areas Only

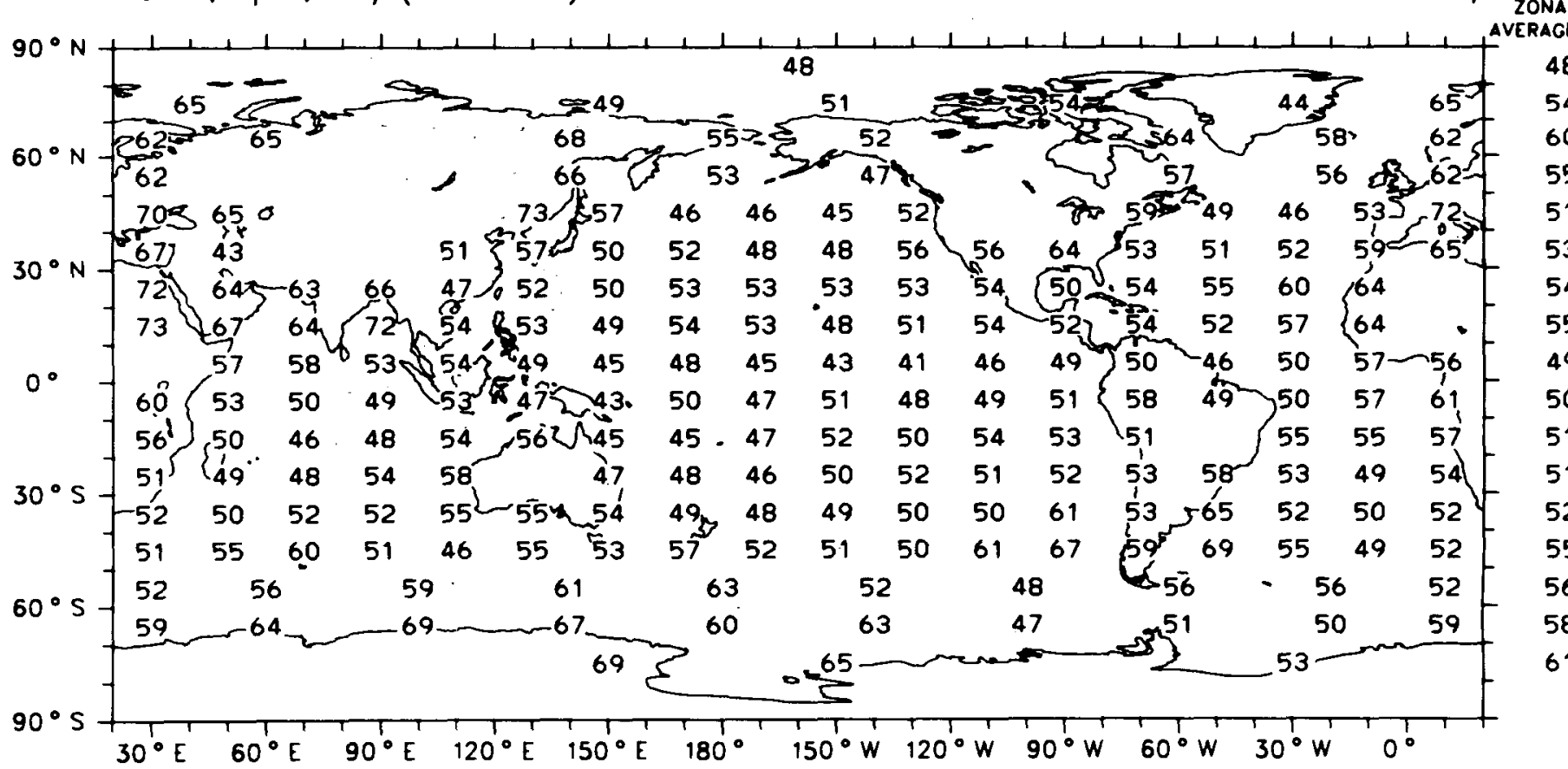


Stratus + Stratocumulus (excluding fog)

Average Base Height (decameters)

( June, July, August (1954-1981)

Oceon Areos Only

ZONAL

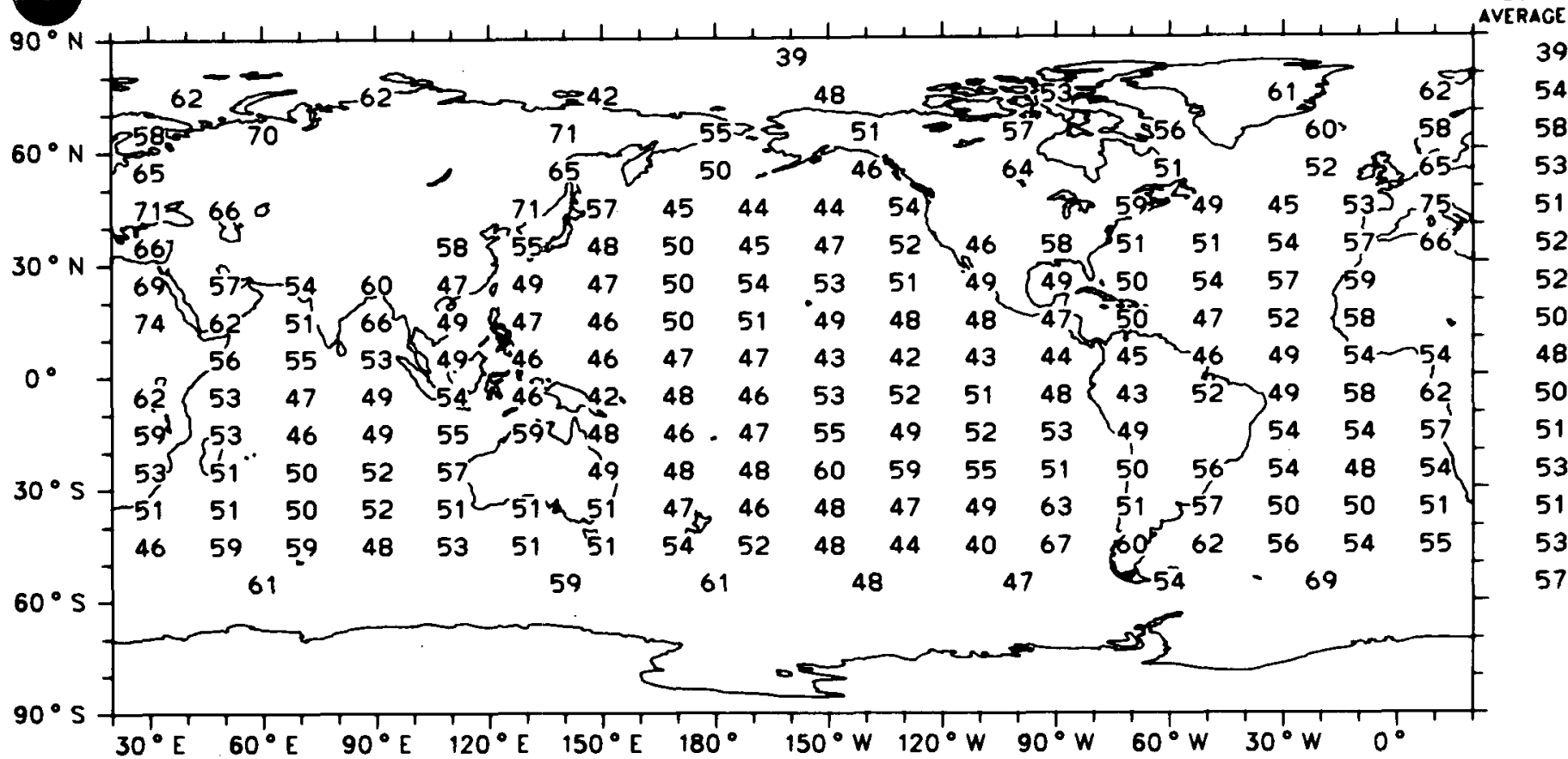

Global Averoge (Ocean) 515 meters

Map 137c

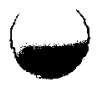

\section{Stratus + Stratocumulus (excluding fog) \\ Average Base Height (decameters)}

September, October, November (1952-1981)

Ocean Areas Only

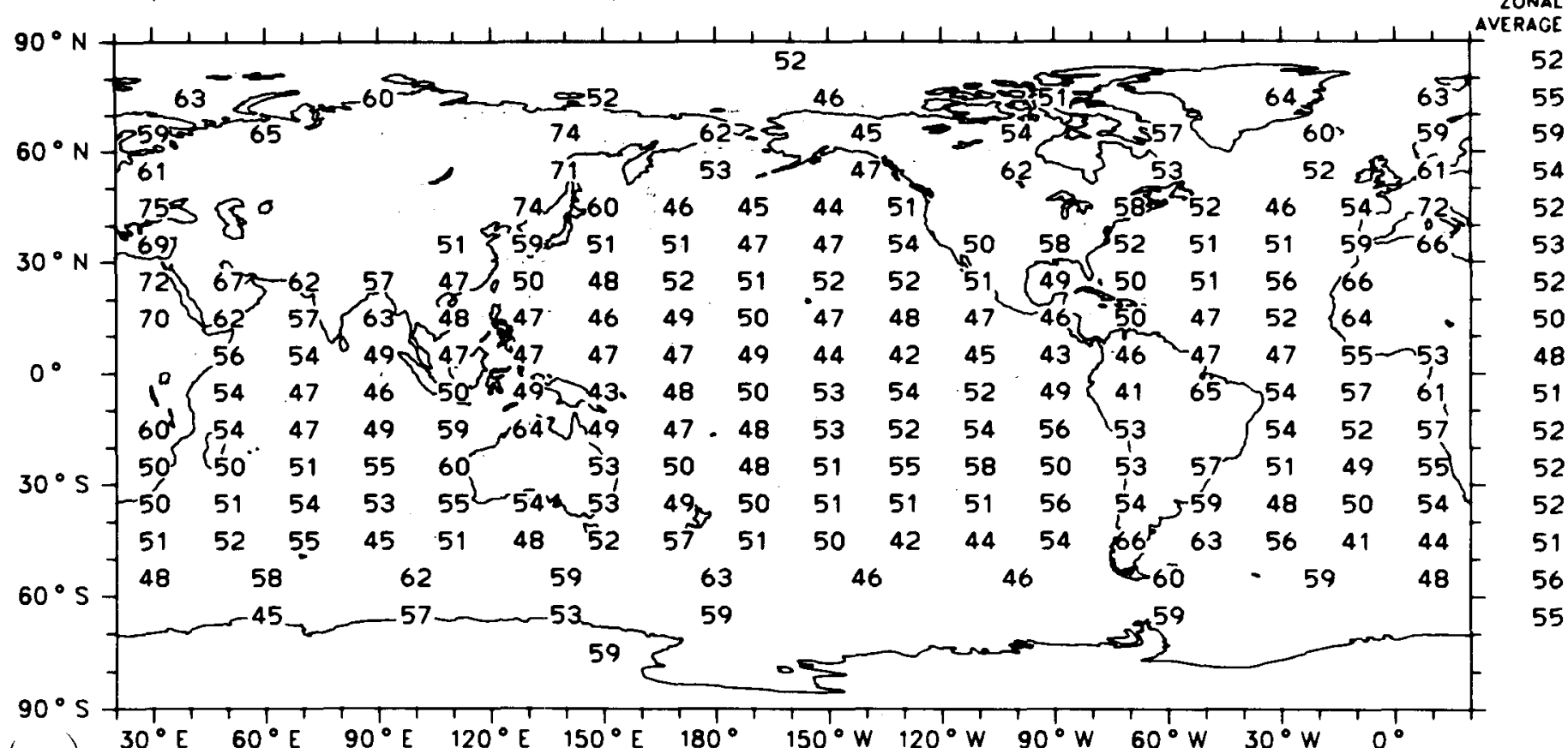


Stratus + Stratocumulus + Fog

Amplitude of Diurnal Cycle (0.1\% Cloud Amount)

December, January, February (1952-1981)

Ocean Areas Only

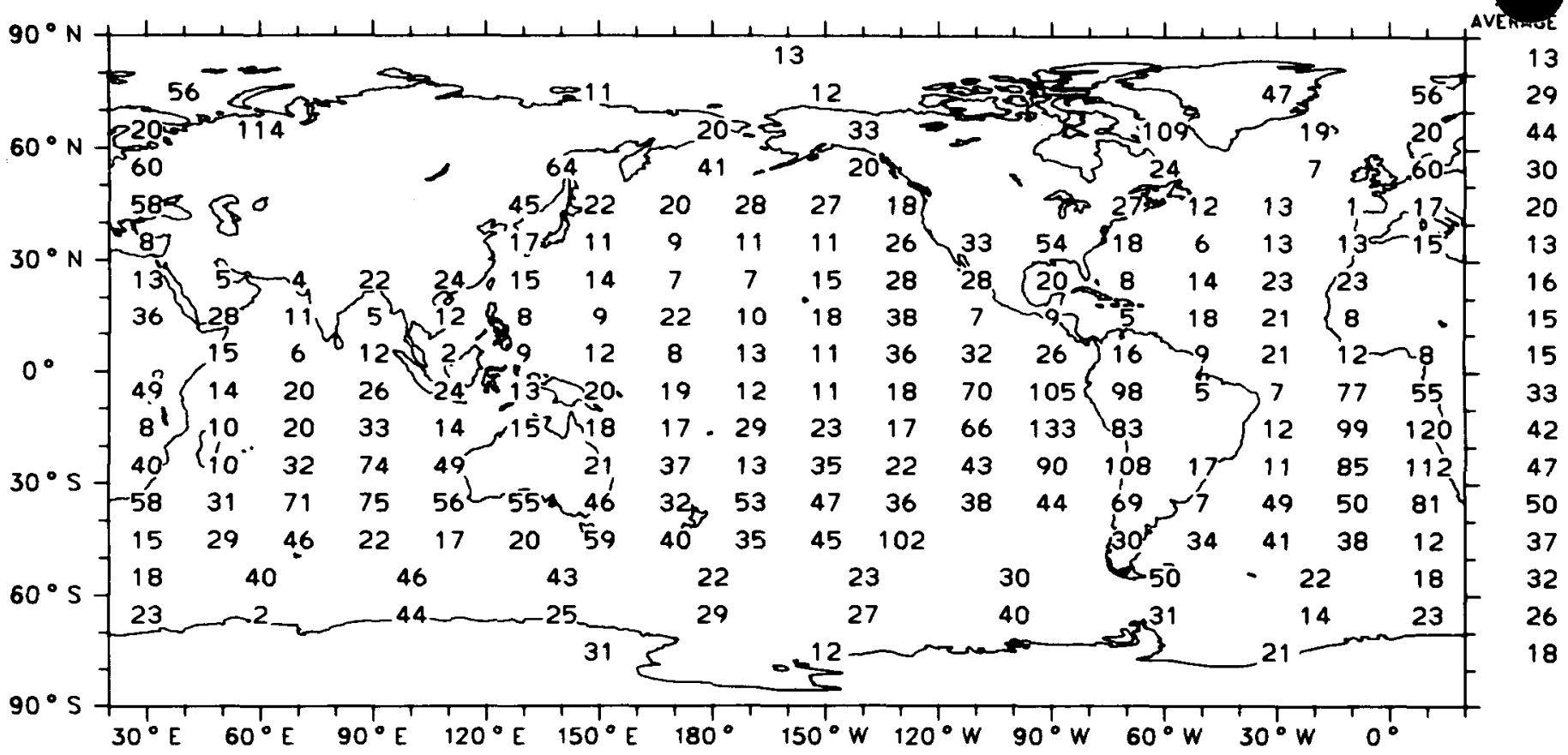

Map 138a

Global Average (Ocean) $3.0 \%$

\section{Stratus + Stratocumulus + Fog}

Phase of Diurnal Cycle (Local Time of Maximum Cloud Amount)

December. January, February (1952-1981)

Ocean Areas Only

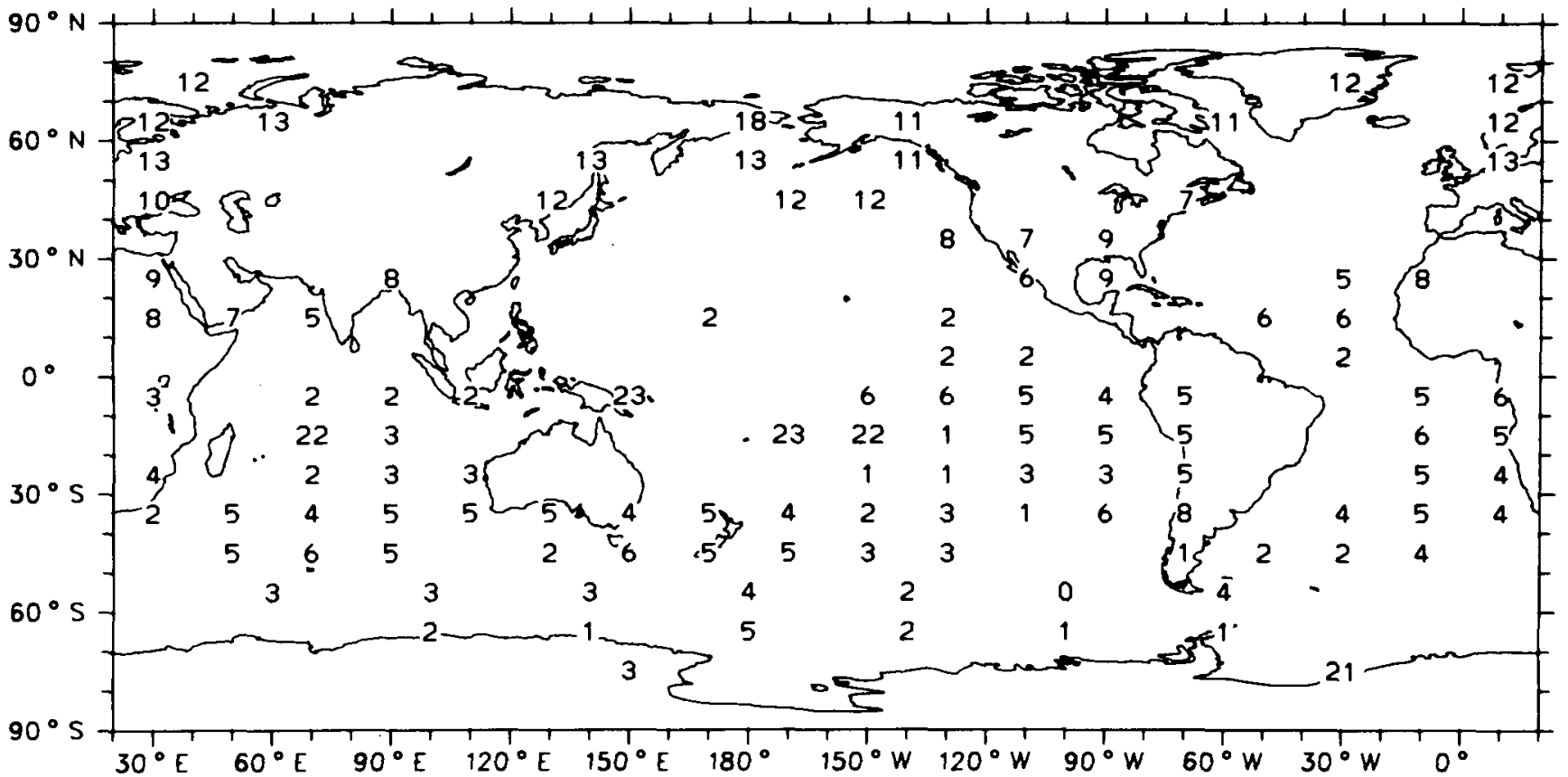

Map 138b 


\section{Stratus + Stratocumulus + Fog}

Amplitude of Diurnal Cycle ( $0.1 \%$ Cloud Amount)

March. April, May (1952-1981)

Oceon Areas Only

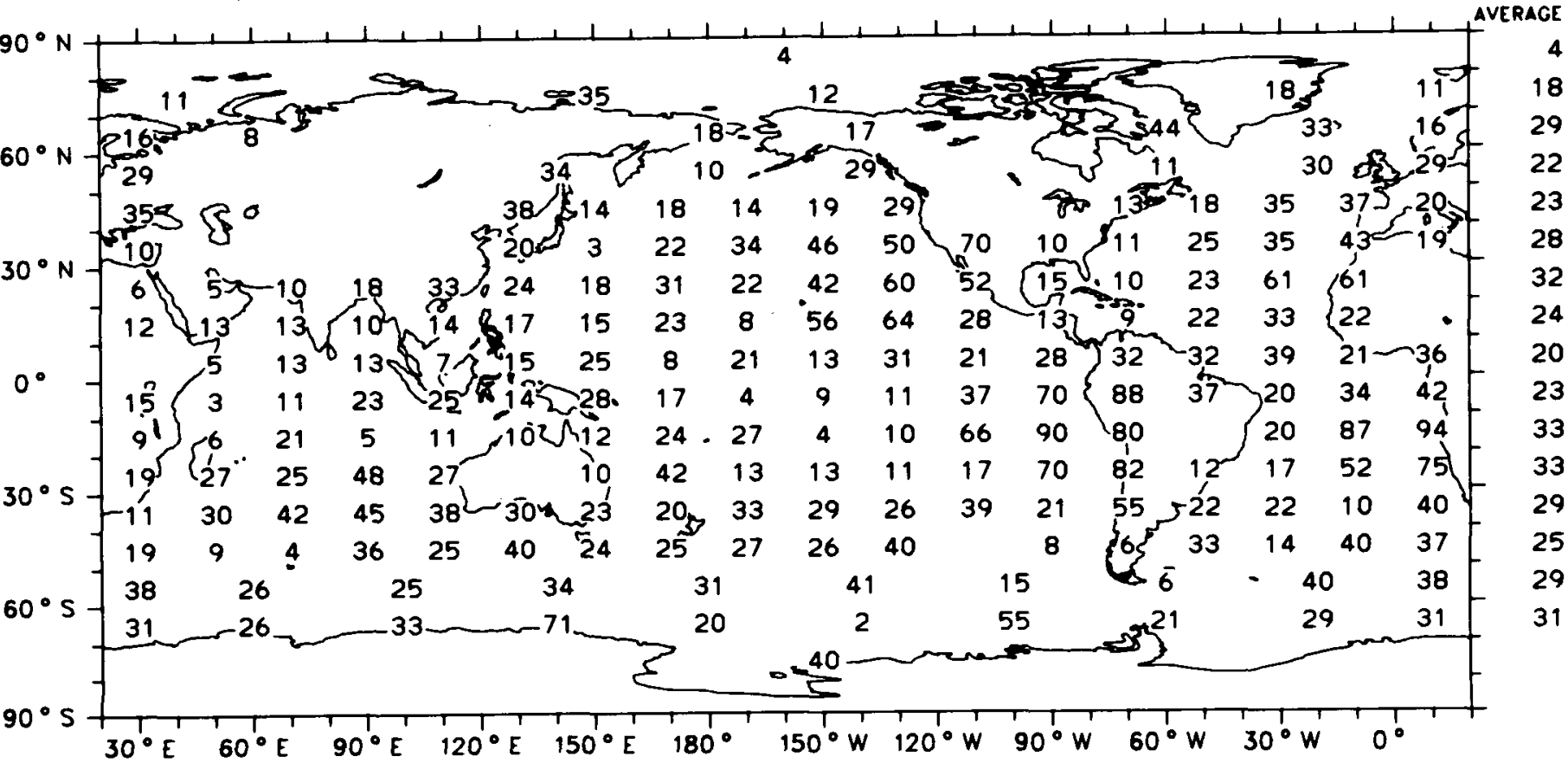

Map 138c

Global Average (Ocean) $2.7 \%$

Stratus + Stratocumulus + Fog

Phase of Diurnal Cycle (Local Time of Maximum Cloud Amount)

Morch. April, Moy (1952-1981)

Ocean Areas Only

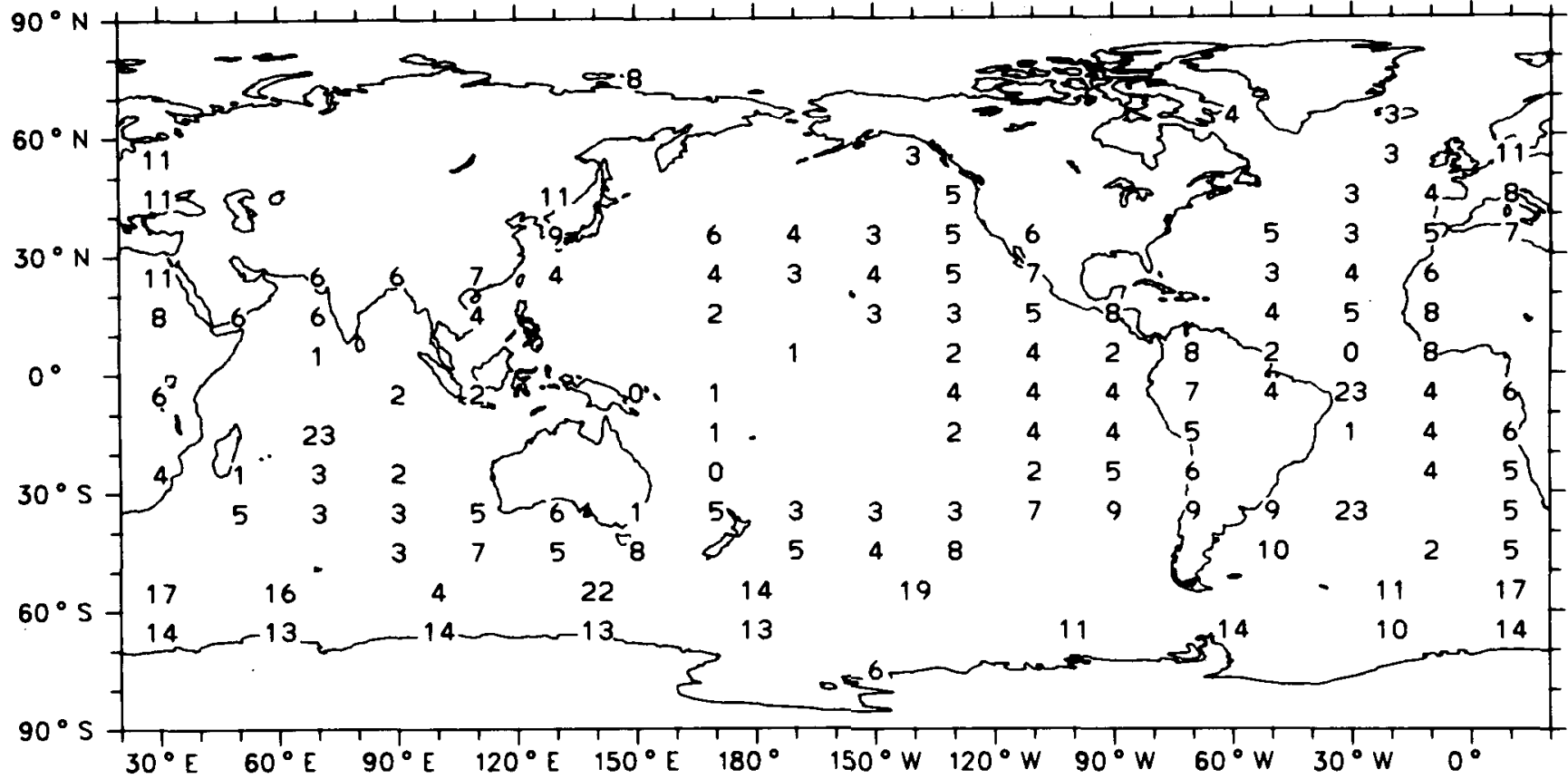

Map 138d 
Stratus + Stratocumulus + Fog

Amplitude of Diurnal Cycle (0.1\% Cloud Amount)

June, July, August (1952-1981)

Ocean Areas Only

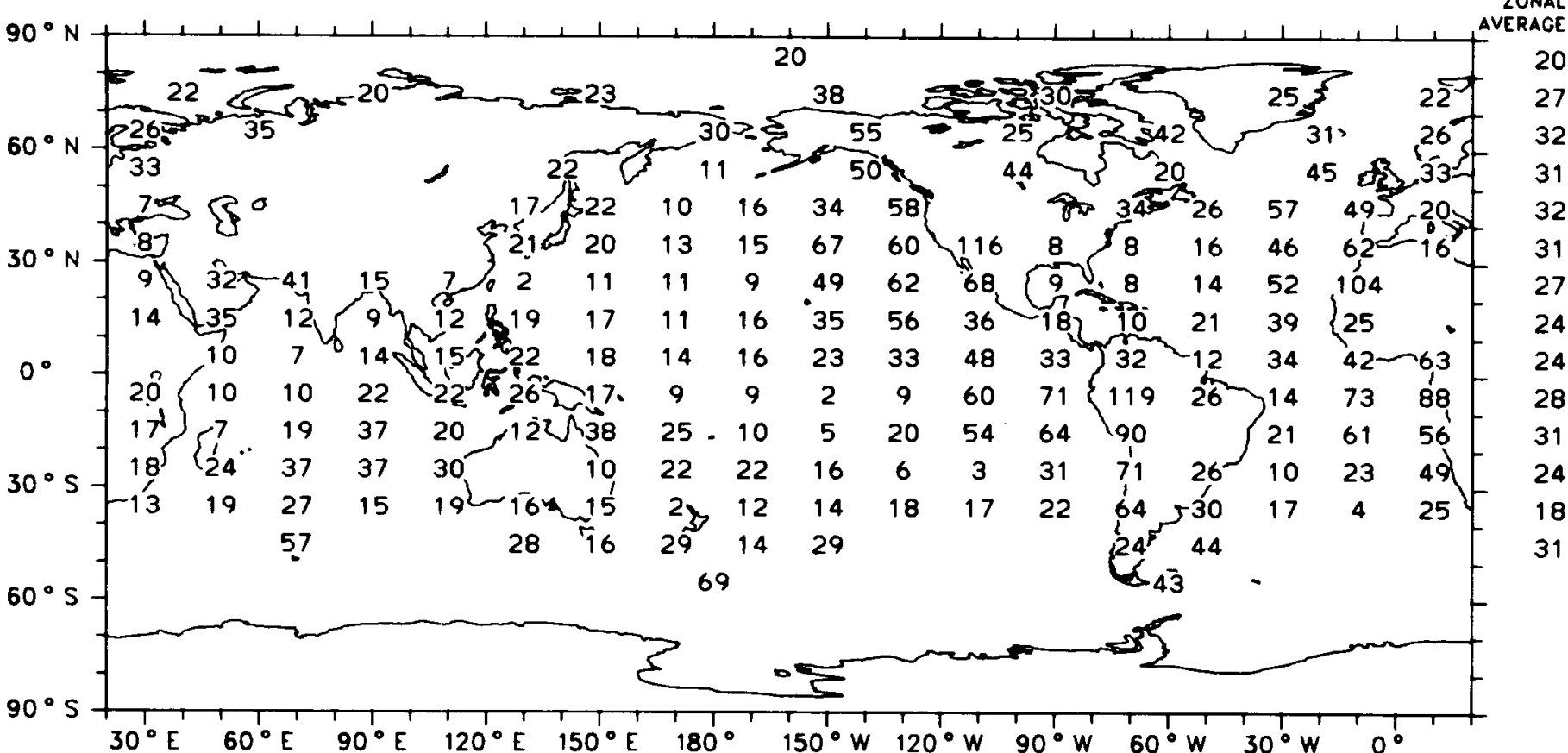

Global Average (Ocean) $2.7 \%$

Map 139a

Stratus + Stratocumulus + Fog

Phase of Diurnal Cycle (Local Time of Maximum Cloud Amount) June. July. August (1952-1981)

Ocean Areas Only

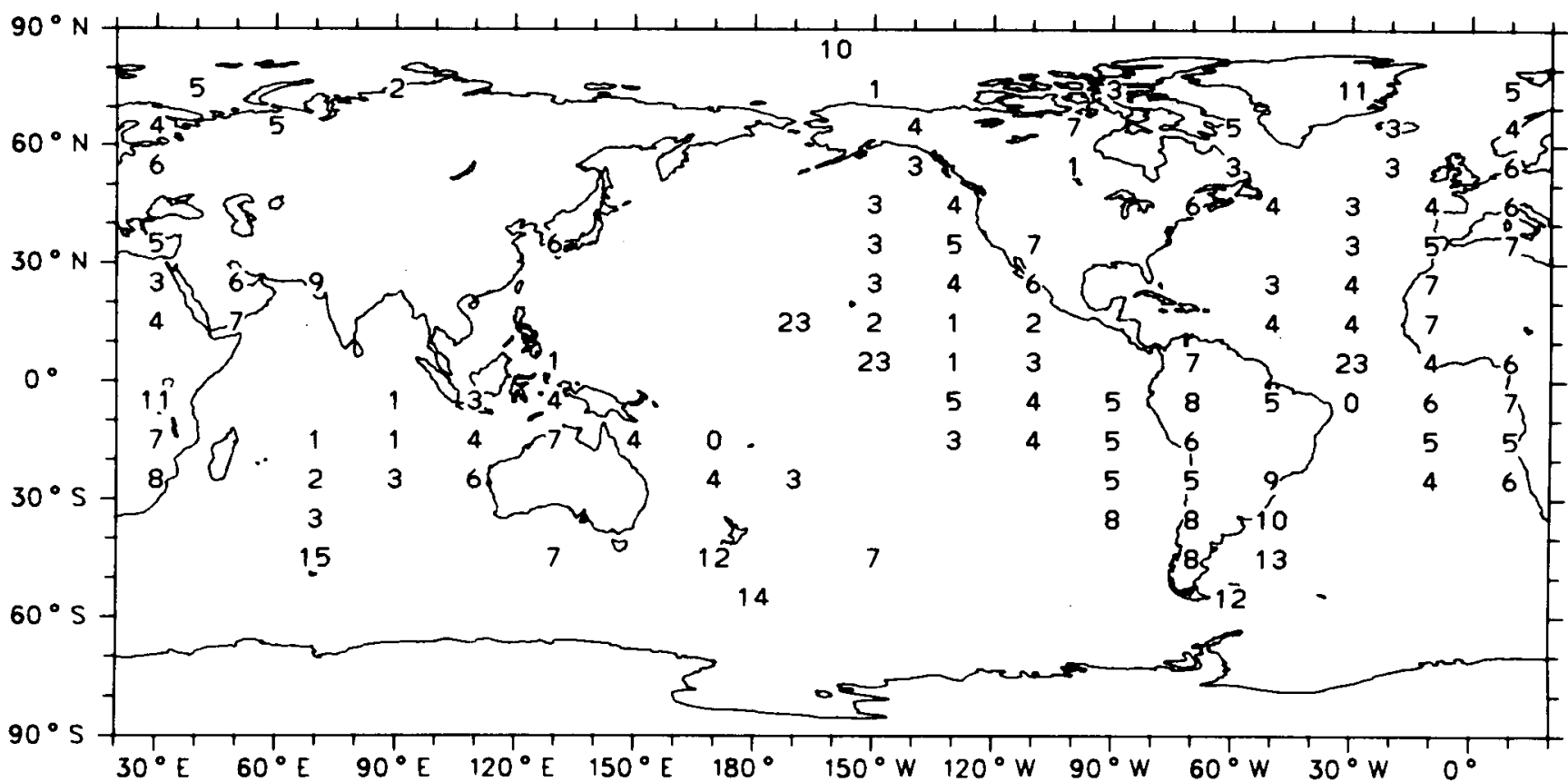

Map 139b 


\section{Stratus + Stratocumulus + Fog}

Amplitude of Diurnal Cycle (0.1\% Cloud Amount)

September, October, November (1952-1981)

Oceon Areos Only

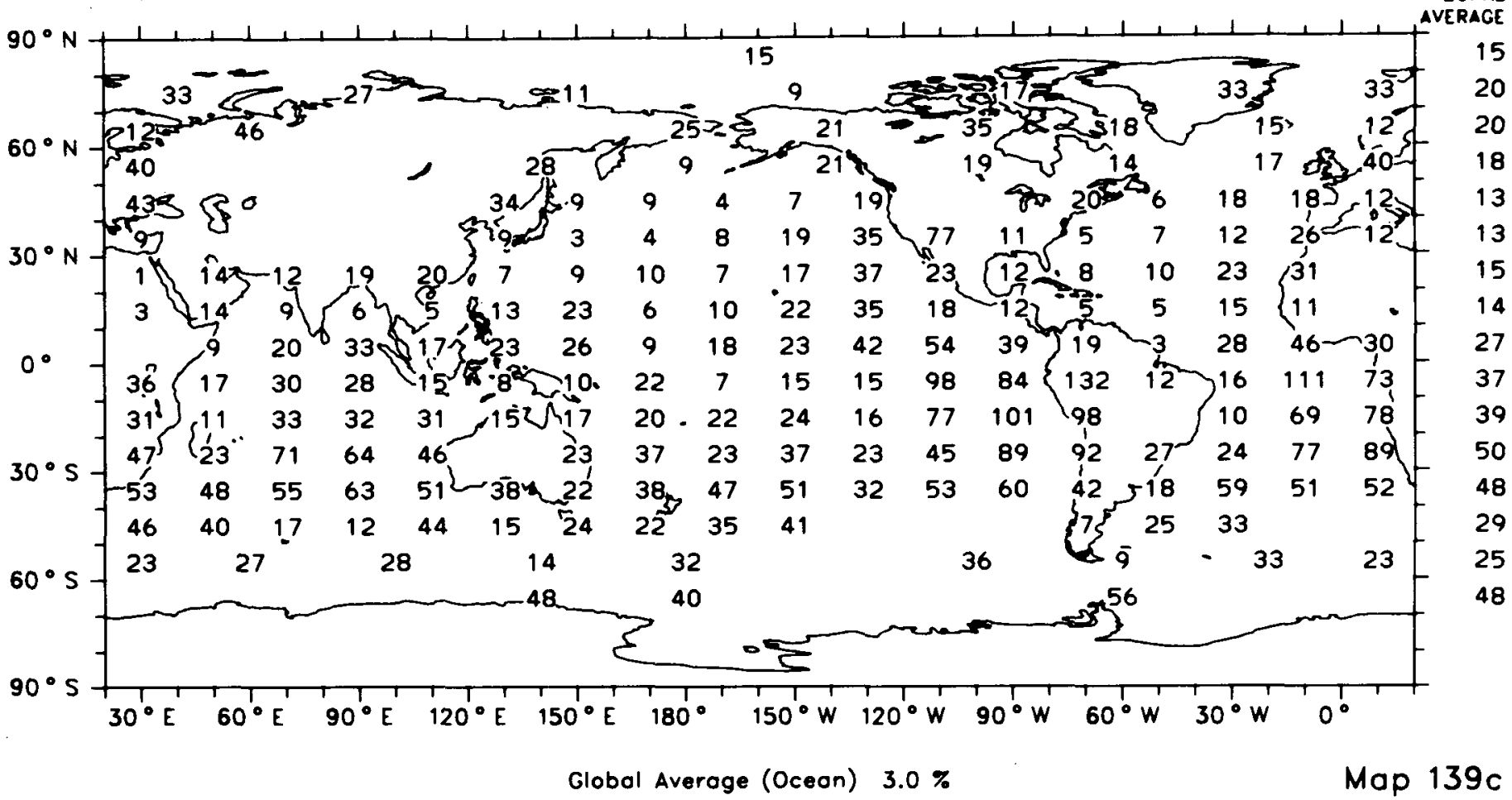

Stratus + Stratocumulus + Fog

Phase of Diurnal Cycle (Local Time of Maximum Cloud Amount)

September, October, November (1952-1981)

Ocean Areas Only

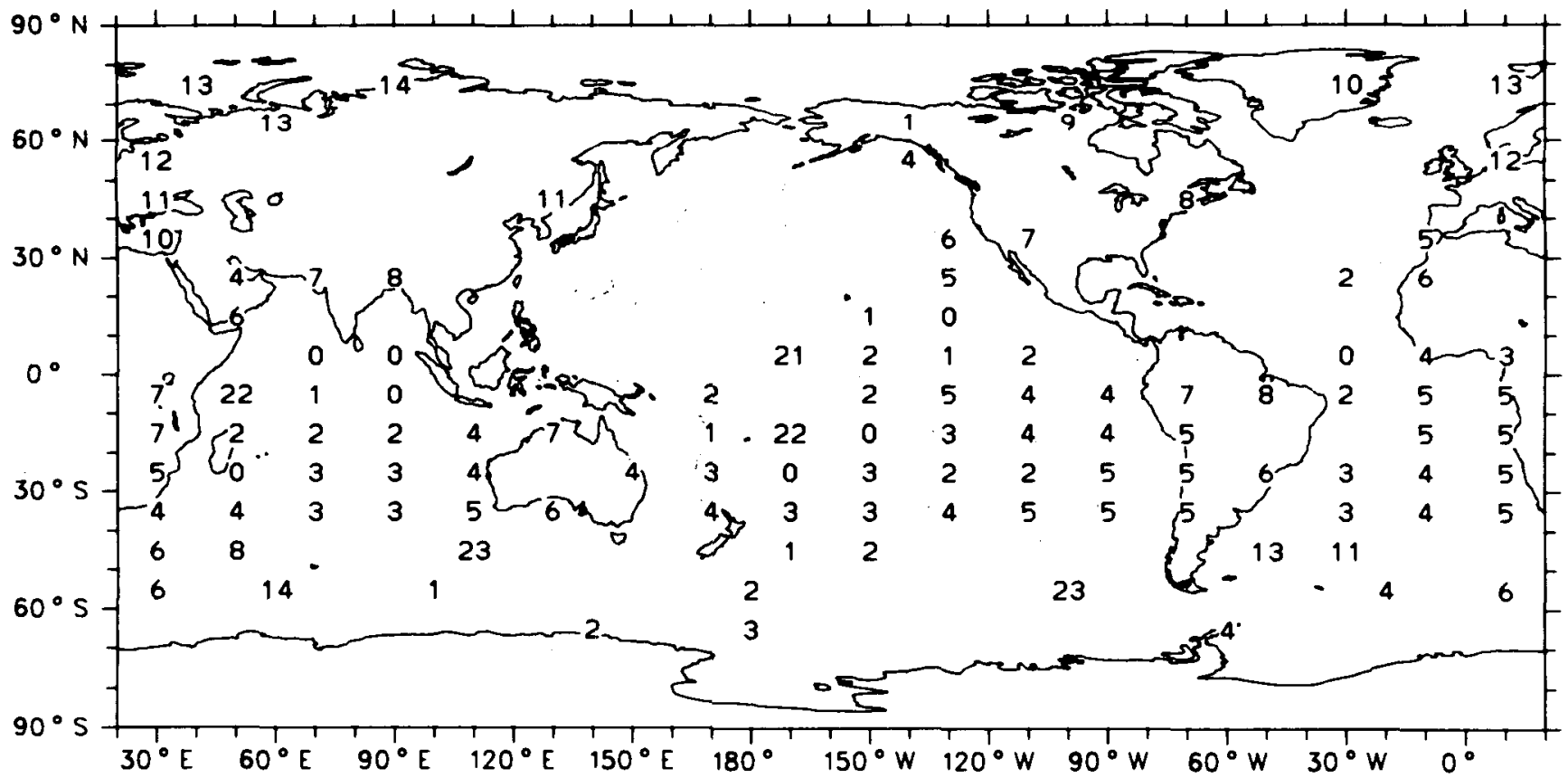

Map 139d 
Interannual Variation of Stratus + Stratocumulus + Fog :

Standard Deviation (detrended) of Seasonal Means (0.1\% Cloud Amount)

December, January, February (1952-1981)

Ocean Areas Only

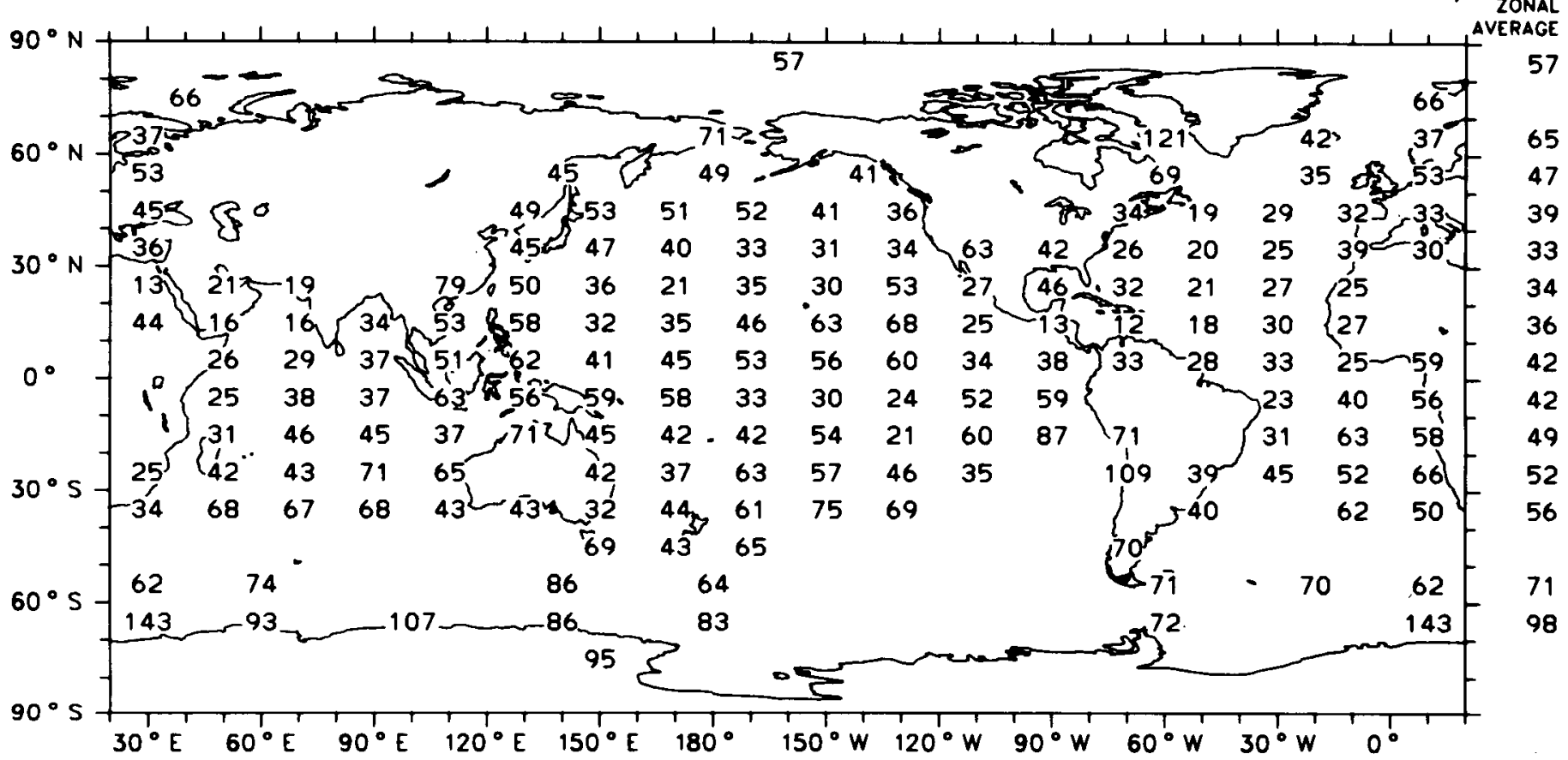

Map 140a

Global Average (Ocean) $4.9 \%$

Interannual Variation of Stratus + Stratocumulus + Fog :

Standard Deviation (detrended) of Seasonal Means (0.1\% Cloud Amount) March. April, May (1952-1981)

Ocean Areos Only

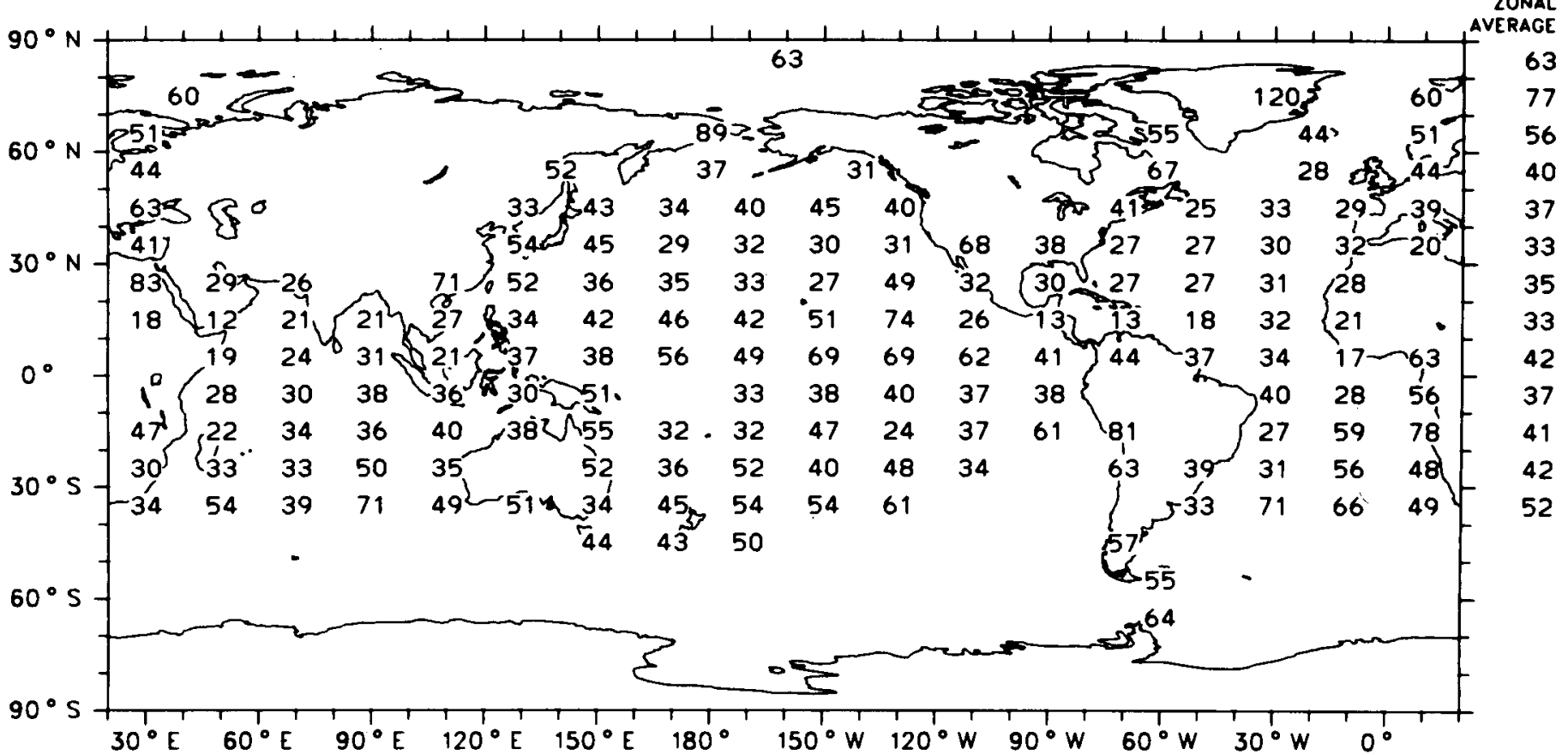

Map 140b

Global Average (Ocean) $4.1 \%$ 
Interannual Variation of Stratus + Stratocumulus + Fog :

Standard Deviation (detrended) of Seasonal Means (0.1\% Cloud Amount) June. July, August (1952-1981)

Ocean Areas Only

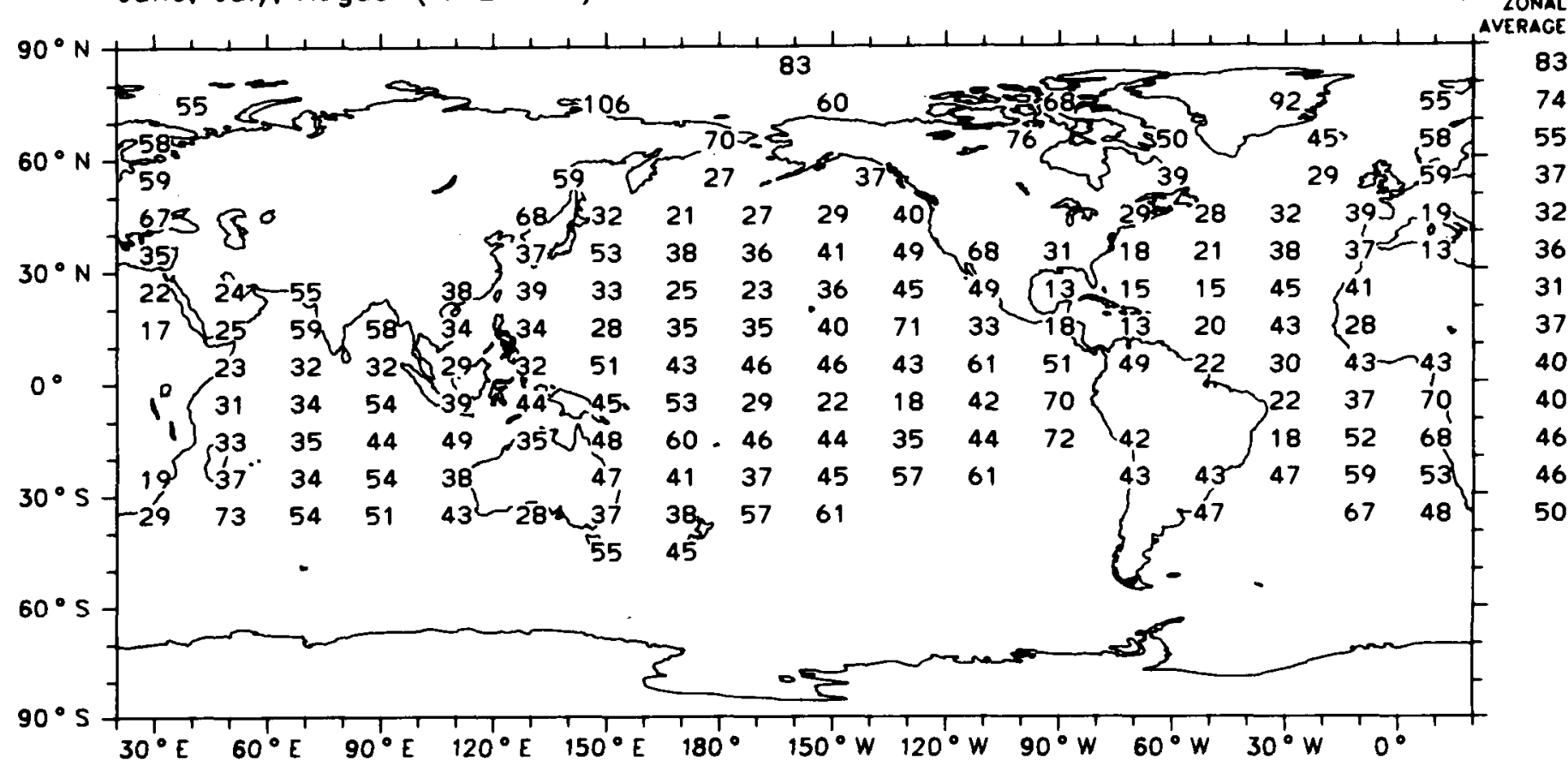

Map 140c

Global Averoge (Oceon) $4.2 \%$

Interannual Variation of Stratus + Stratocumulus + Fog :

Standard Deviation (detrended) of Seasonal Means (0.1\% Cloud Amount)

September. October. November (1952-1981)

Ocean Areas Only

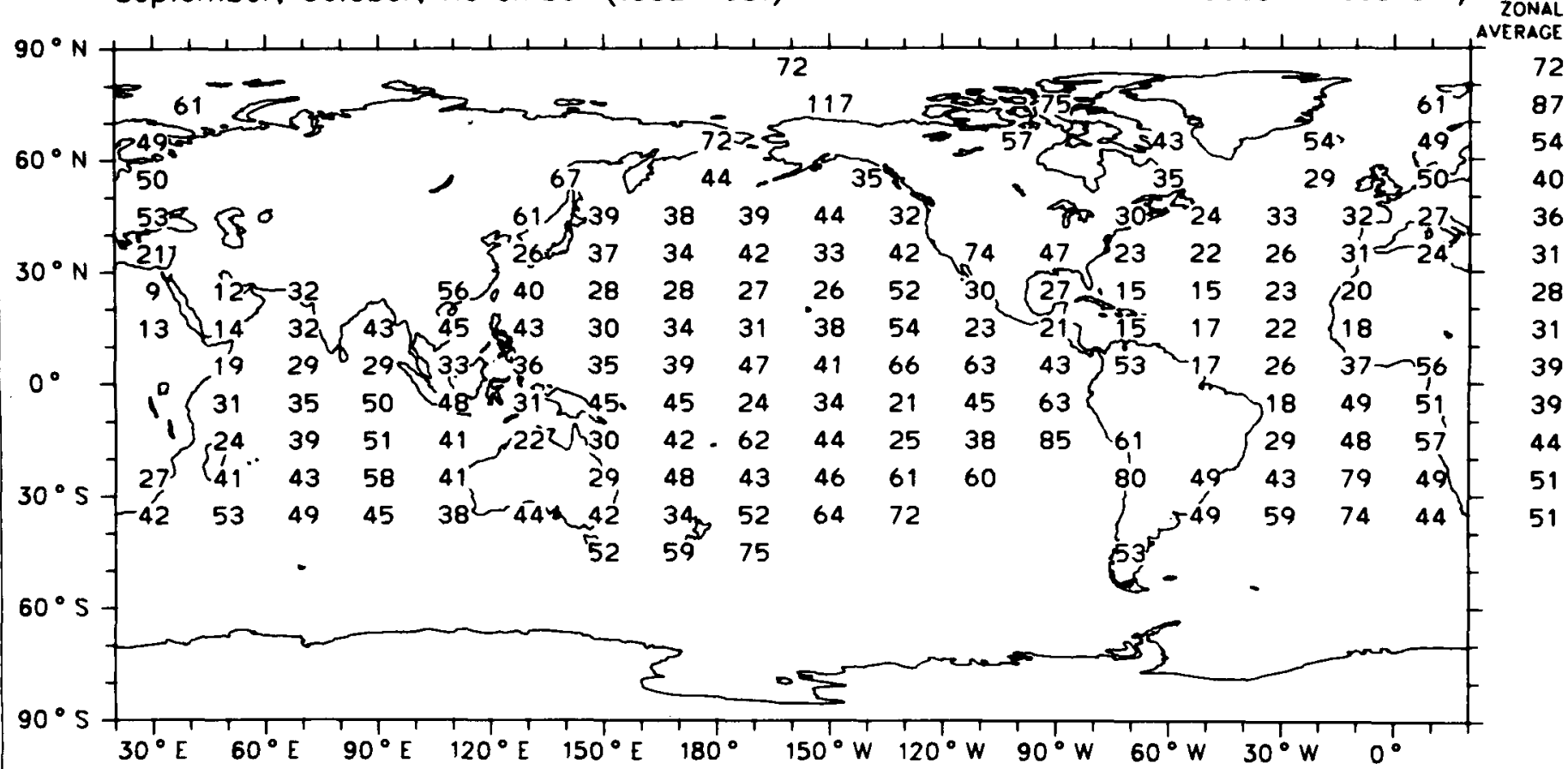

Map 140d

Global Averoge (Oceon) $4.2 \%$ 
Trend of Stratus + Stratocumulus + Fog :

Change in \%-Cloud-Amount from 1952 to 1981

December, January. February (1952-1981)

Ocean Areos Only

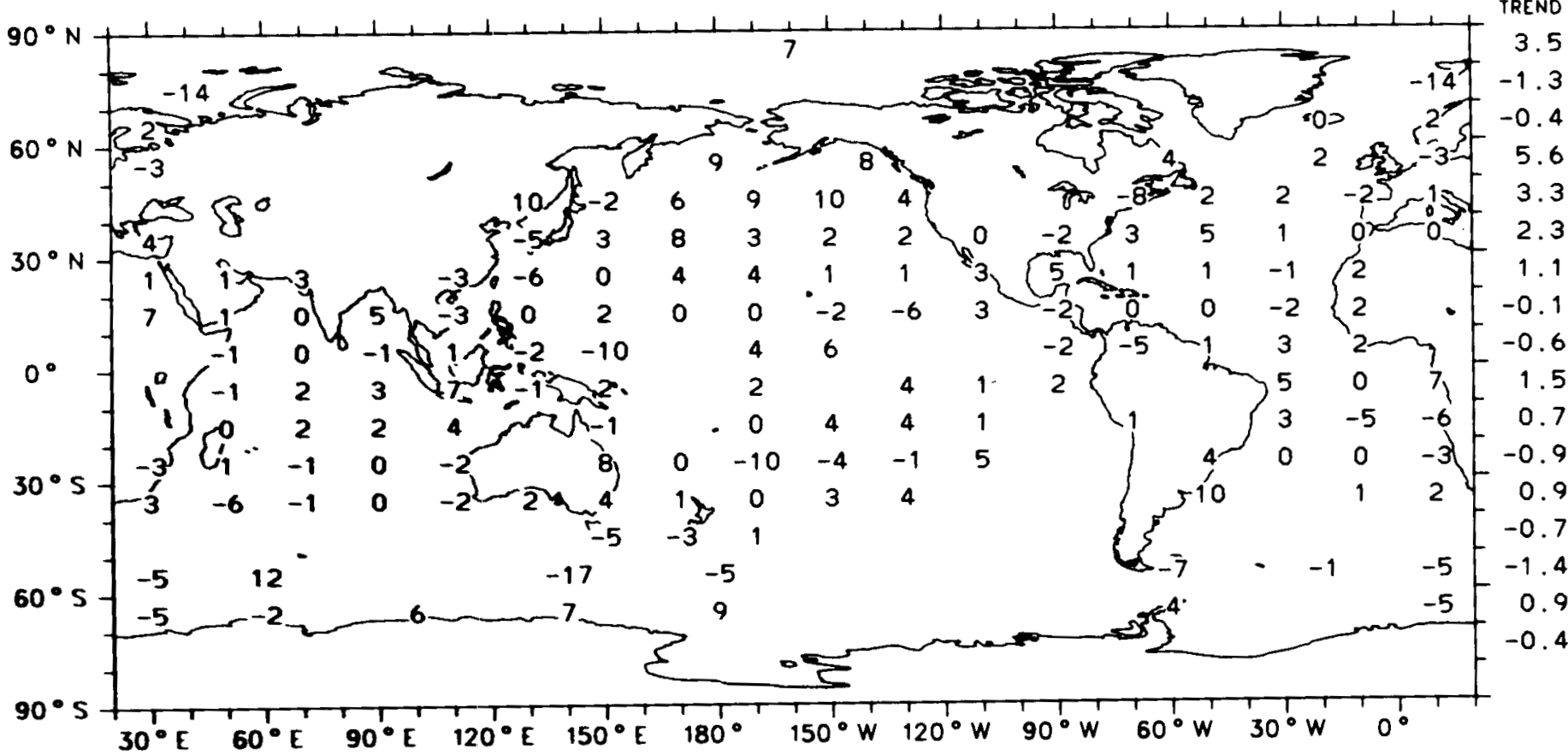

Global Trend (Ocean) $0.5 \%$

Map 1410

Trend of Stratus + Stratocumulus + Fog :

Change in \%-Cloud-Amount from 1952 to 1981

March. April. May (1952-1981)

Ocean Areas Only

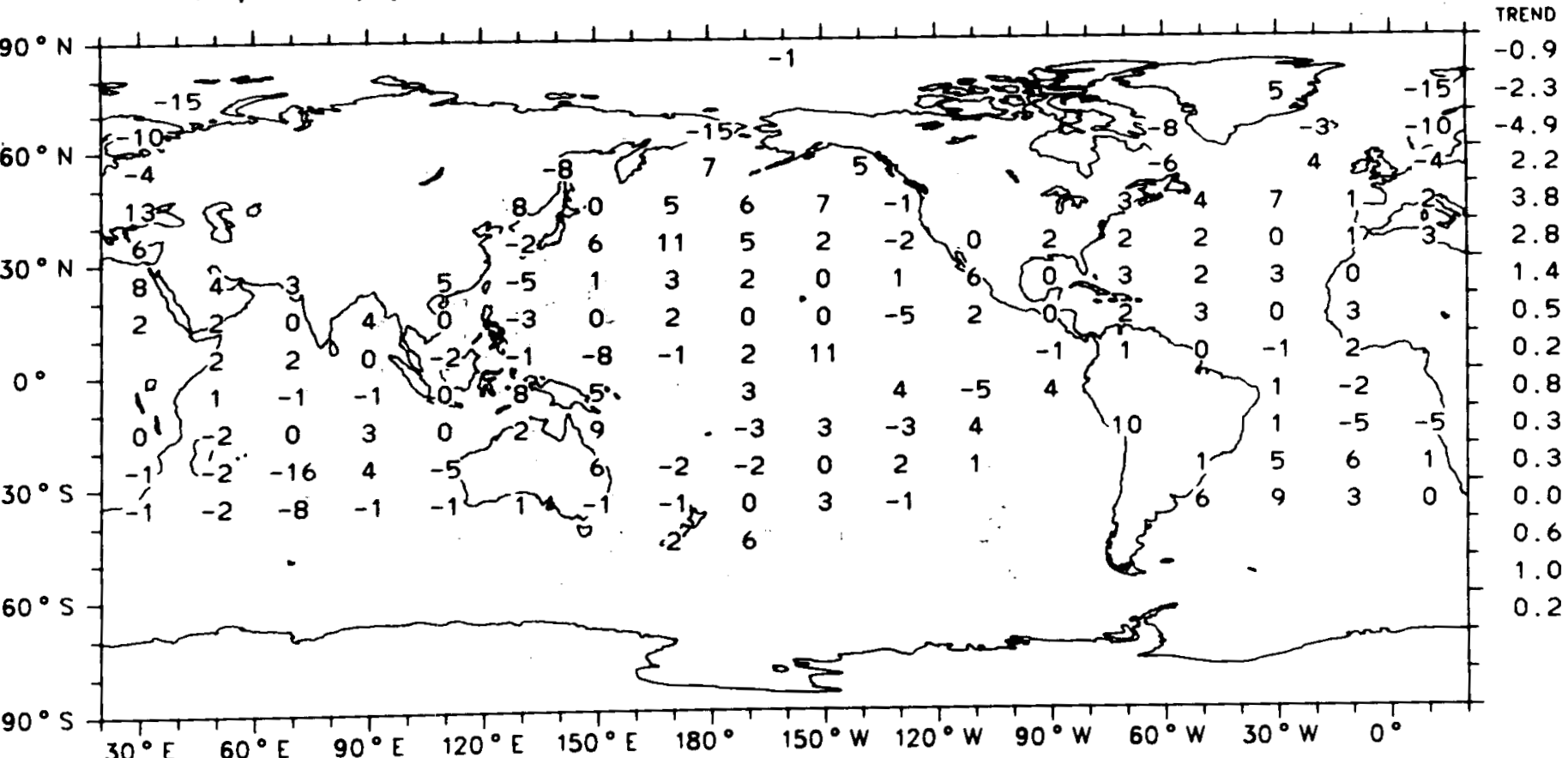

Global Trend (Ocean) $0.7 \%$

Mop 141b 
Trend of Strałus + Stratocumulus + Fog :

Change in \%-Cloud-Amount from 1952 to 1981

June, July, August (1952-1981)

Ocean Areas Only

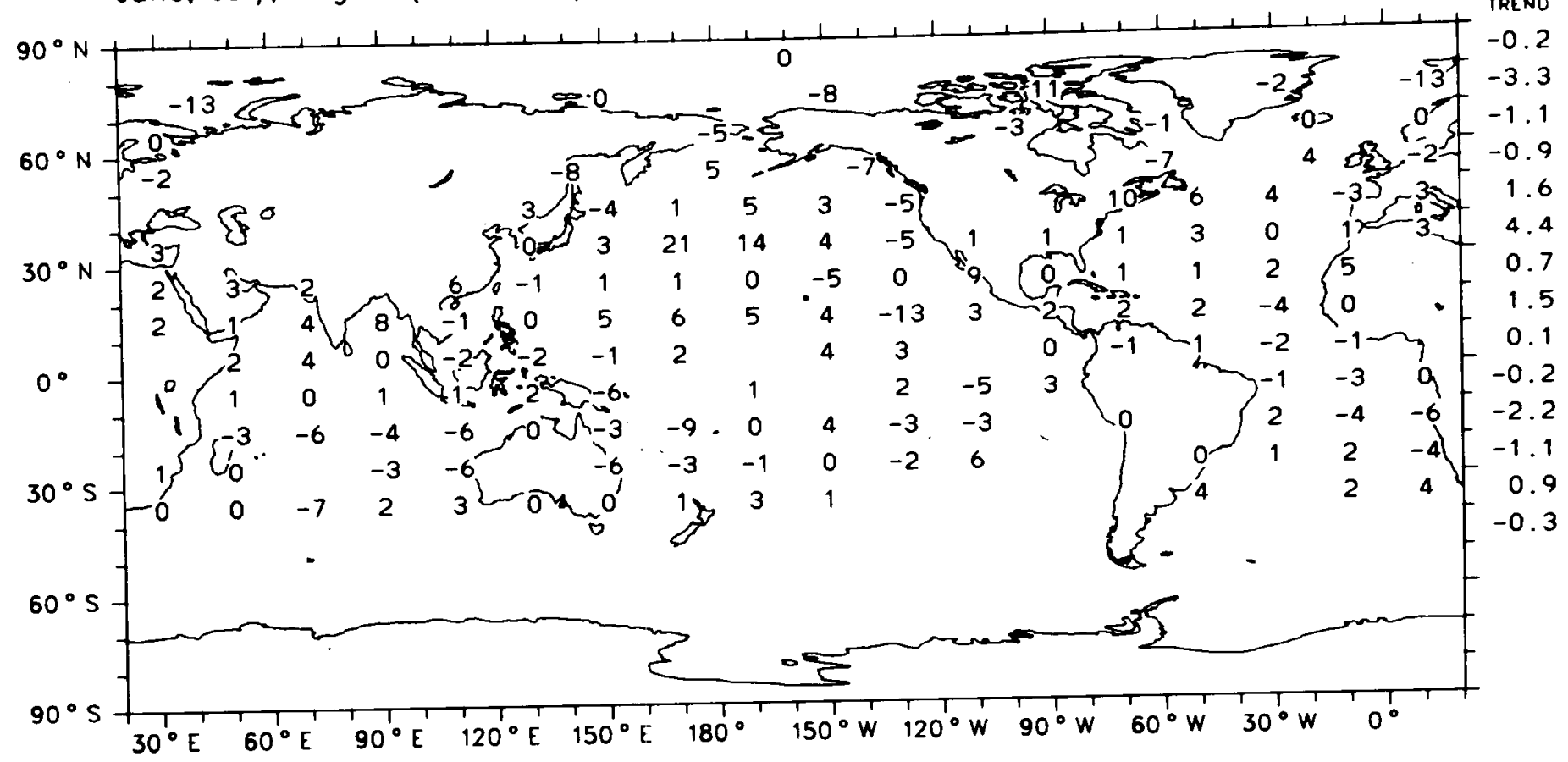

Global Trend (Oceon) $0.2 \%$

Map 141c

Trend of Stratus + Stratocumulus + Fog :

Change in \%-Cloud-Amount from 1952 to 1981

September. October. November (1952-1981)

Ocean Areos Only

ZONAL TREND

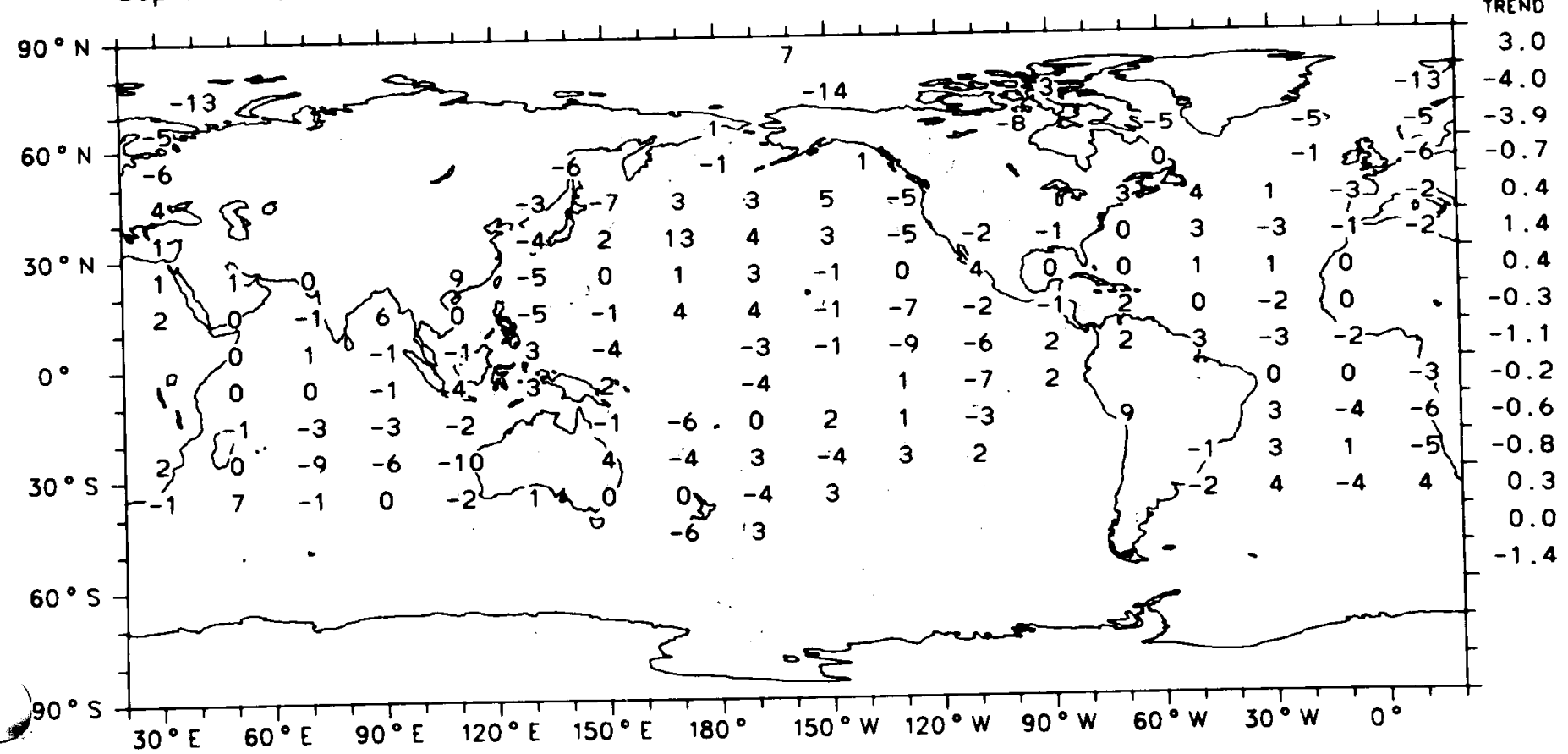

Global Trend (Oceon) $-0.3 \%$

Map 141d 
Nimbostratus

Frequency of Occurrence (\%)

December, January. February (1952-1981)

Ocean Areas Only

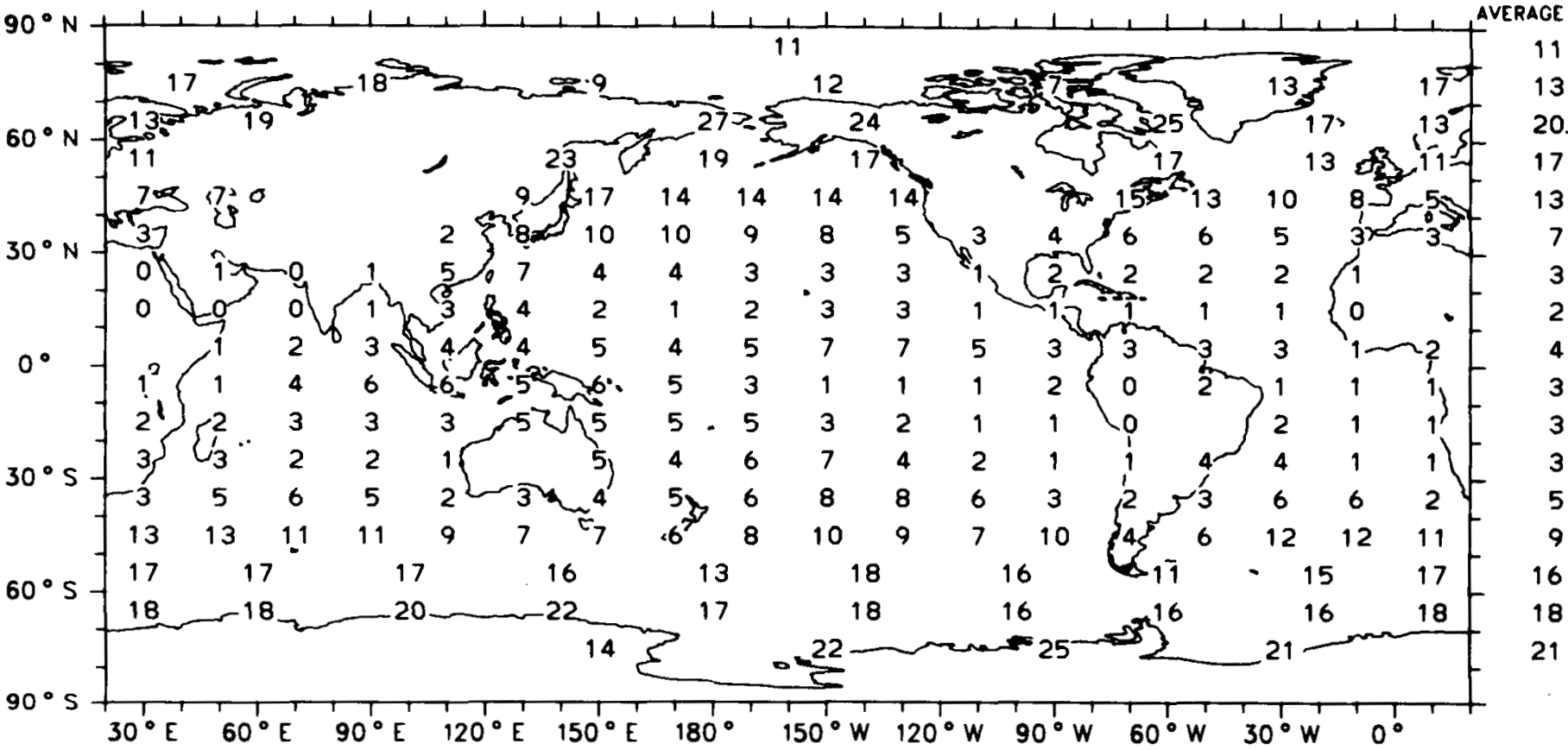

Map 1420

Global Average (Ocean) $7 \%$

Nimbostratus

Frequency of Occurrence (\%)

March. April. May (1952-1981)

Ocean Areas Only

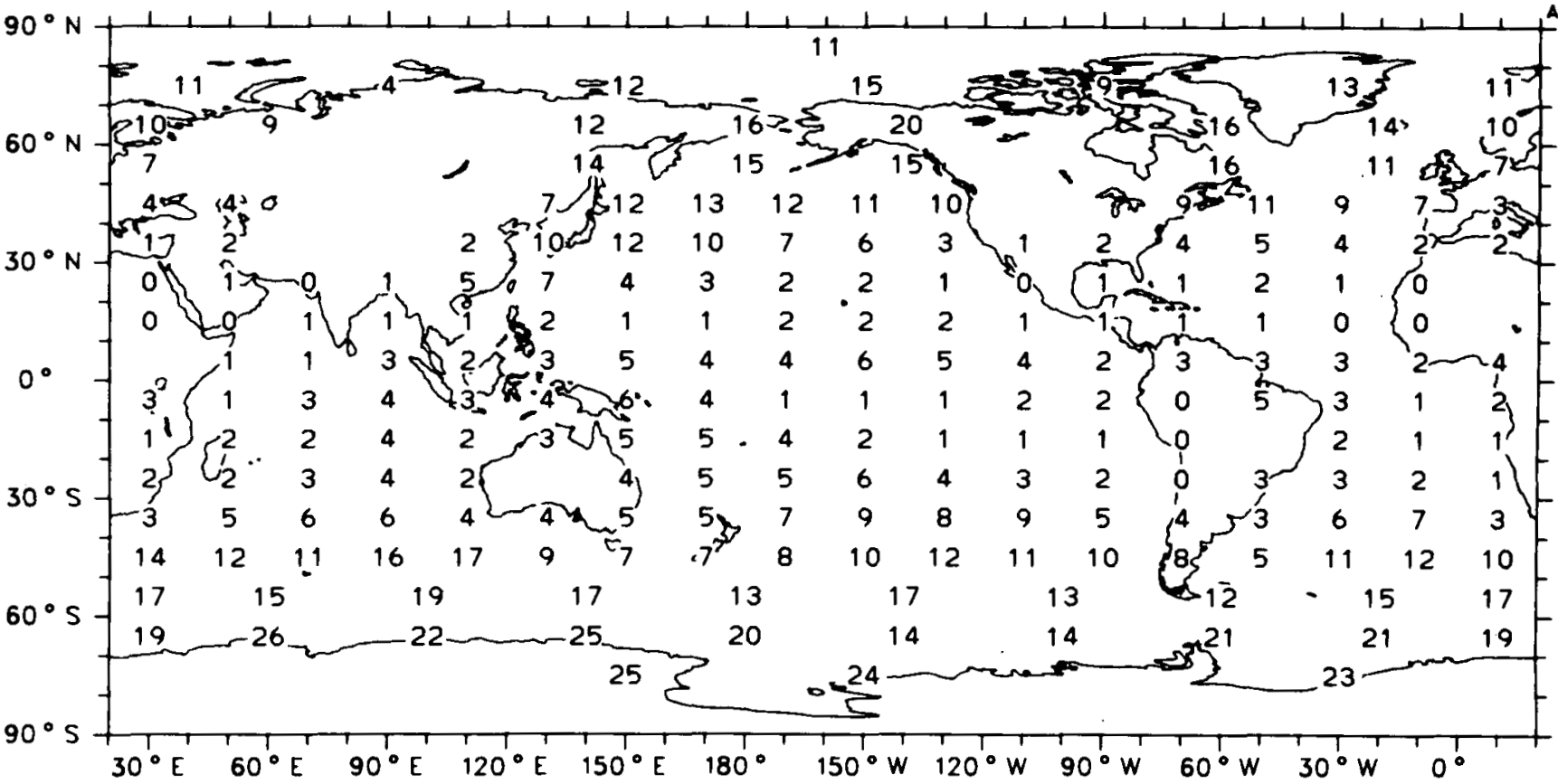
VERAGE

Map 142b

Globol Averoge (Ocean) $7 \%$ 


\section{Nimbostratus}

Frequency of Occurrence (\%)

June, July. August (1952-1981)

Ocean Areas Only

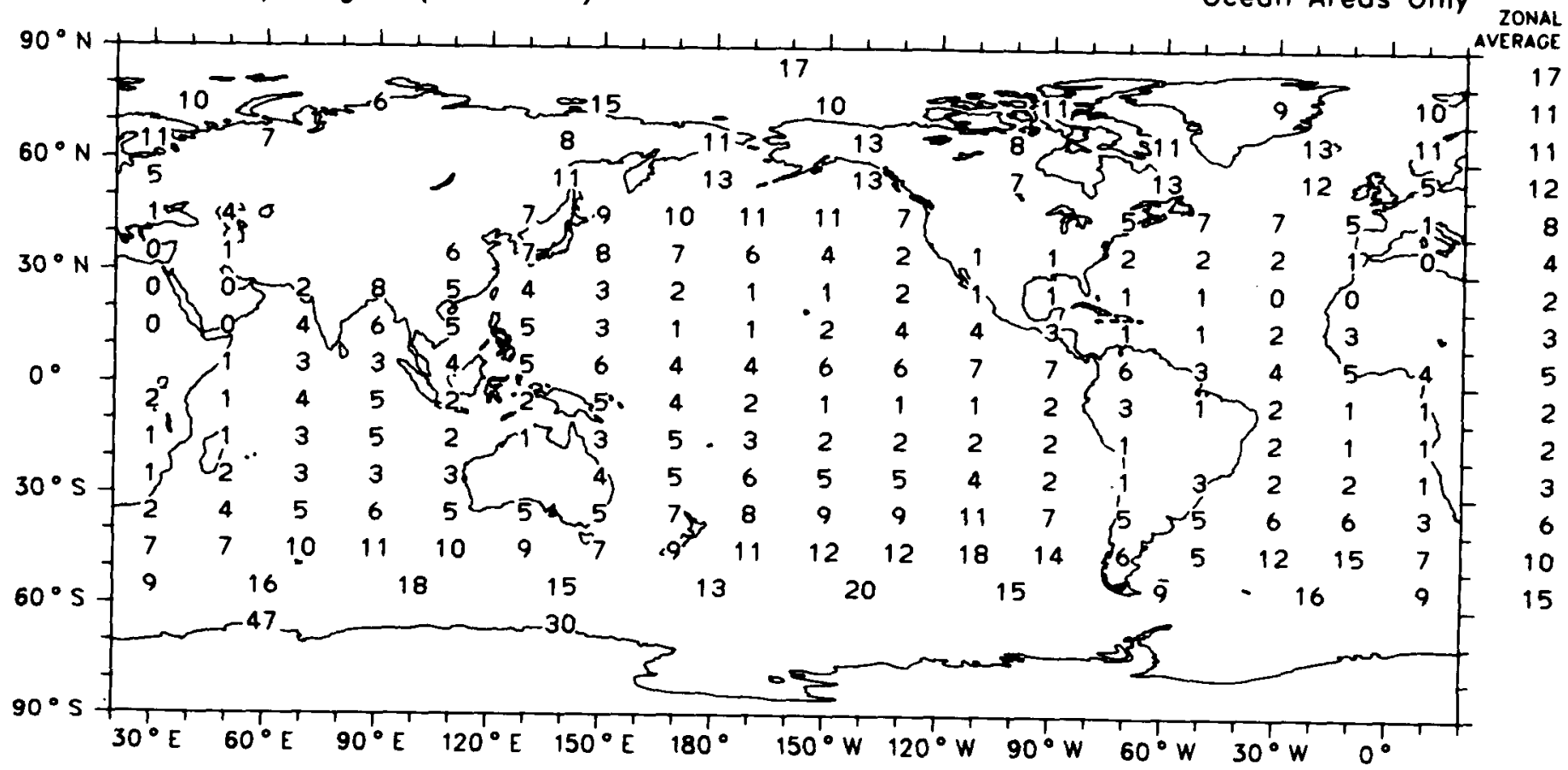

Map 142c

Global Averoge (Oceon) $6 \%$

Nimbostratus

Frequency of Occurrence (\%)

September. October, November (1952-1981)

Ocean Areas Only

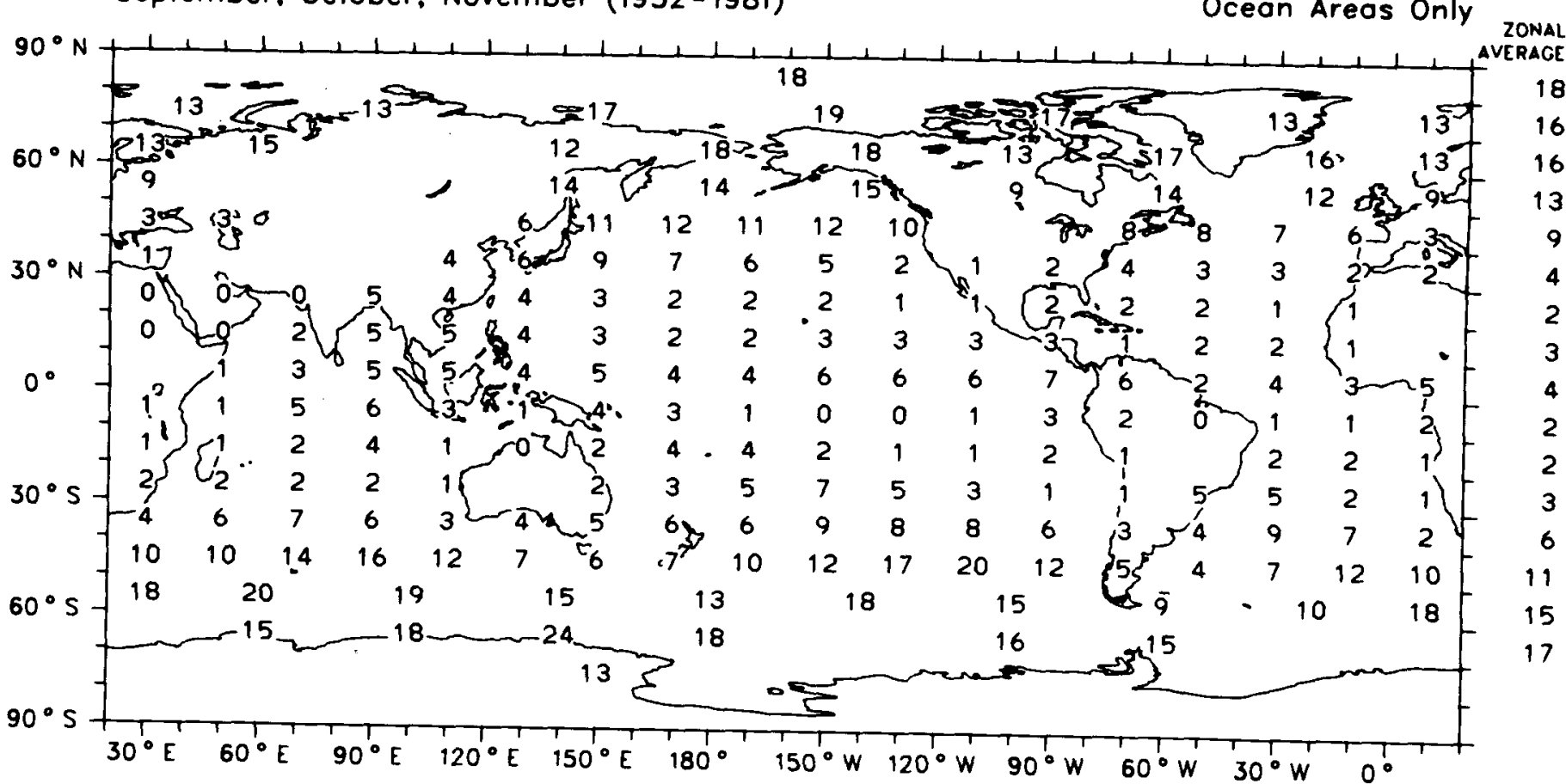

Map 142d

Global Average (Ocean) $7 \%$ 
Nimbostratus

Amount-When-Present (\%)

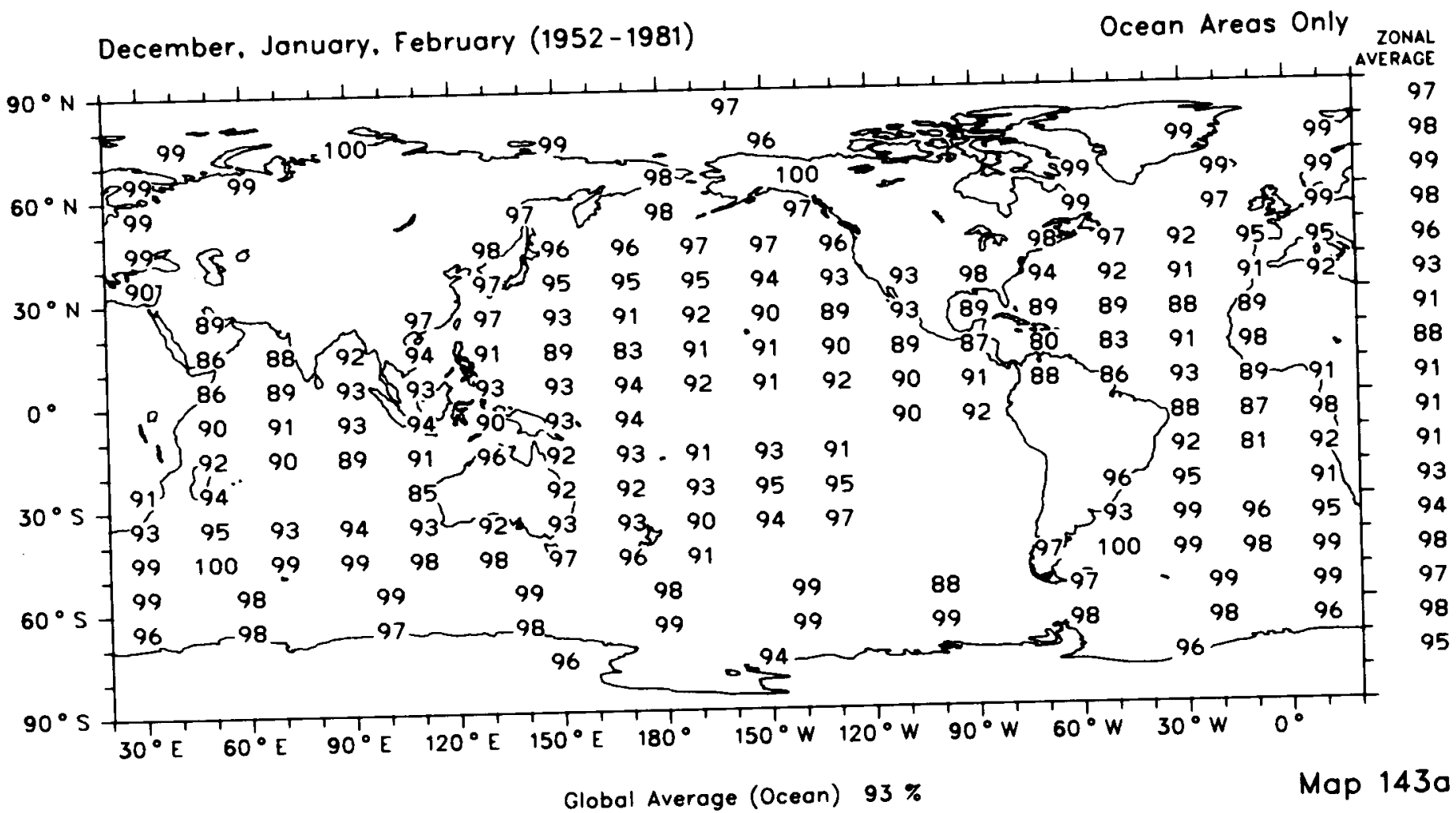

Nimbostratus

Amount-When-Present (\%)

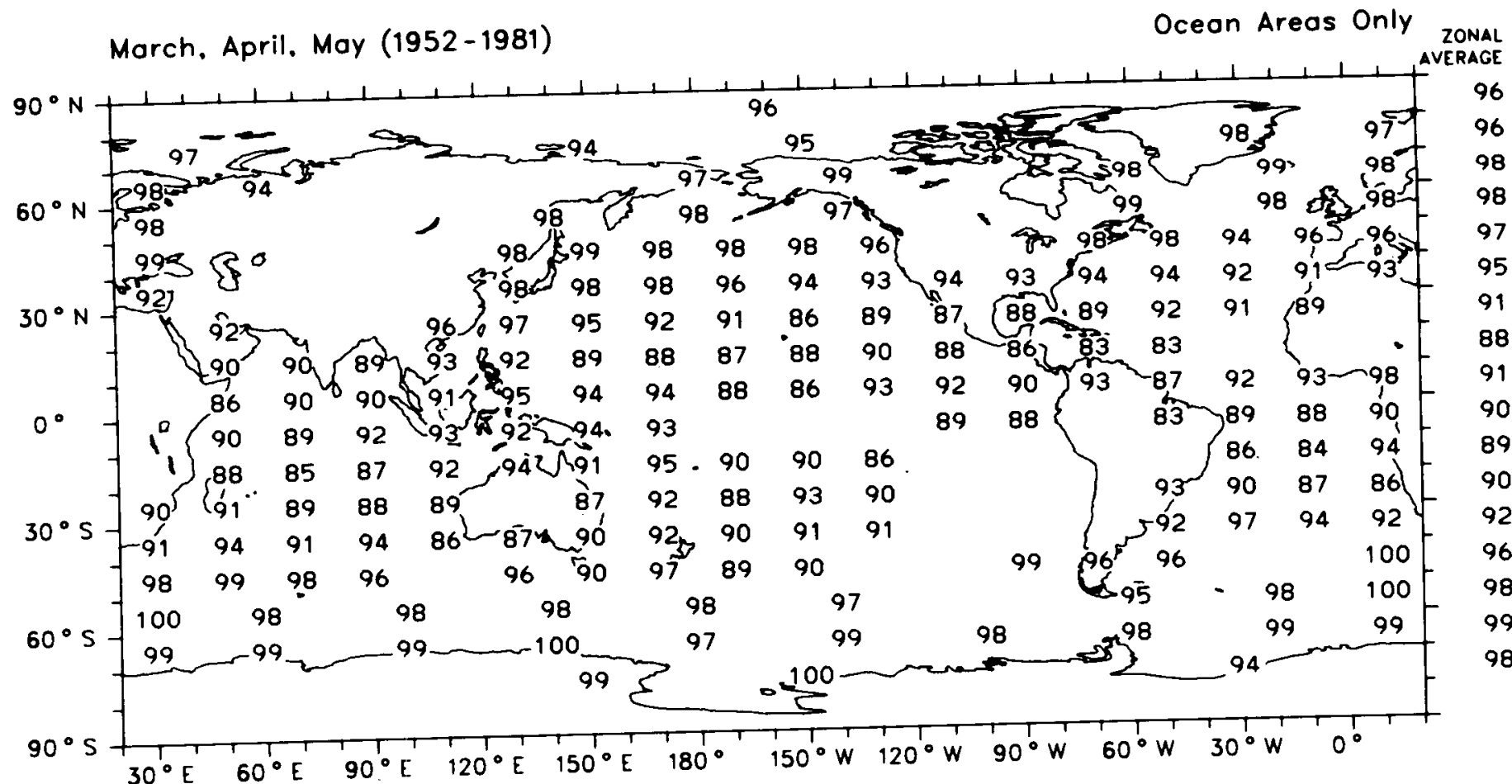

Global Average (Ocean) $93 \%$

Map 143b 
Nimbostratus

Amount-When-Present (\%)

June. July. August (1952-1981)

Ocean Areas Only

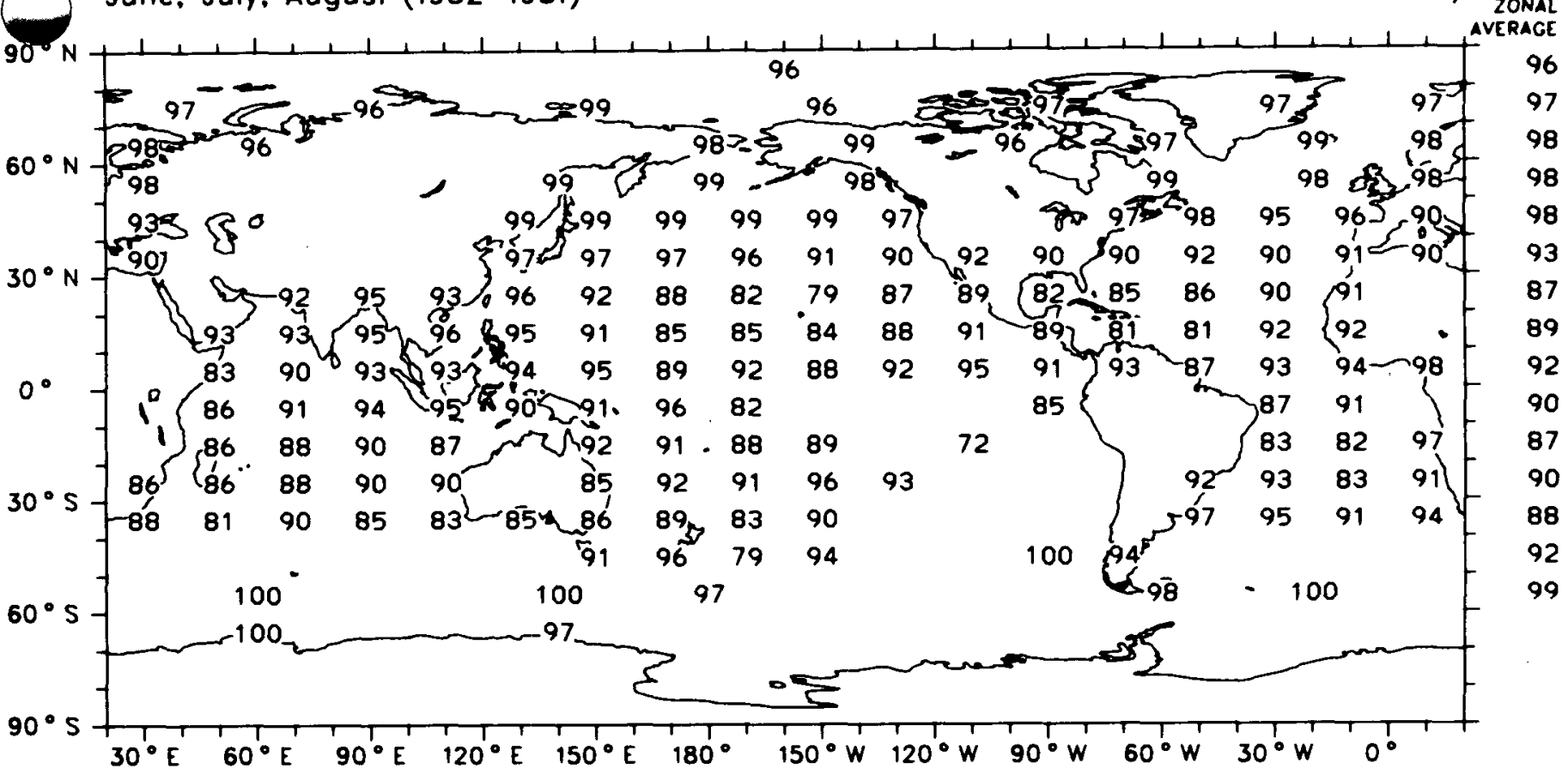

Global Average (Oceon) $91 \%$

Map 143c

Nimbostratus

Amount-When-Present (\%)

September, October, November (1952-1981)

Ocean Areas Only

ZONAL

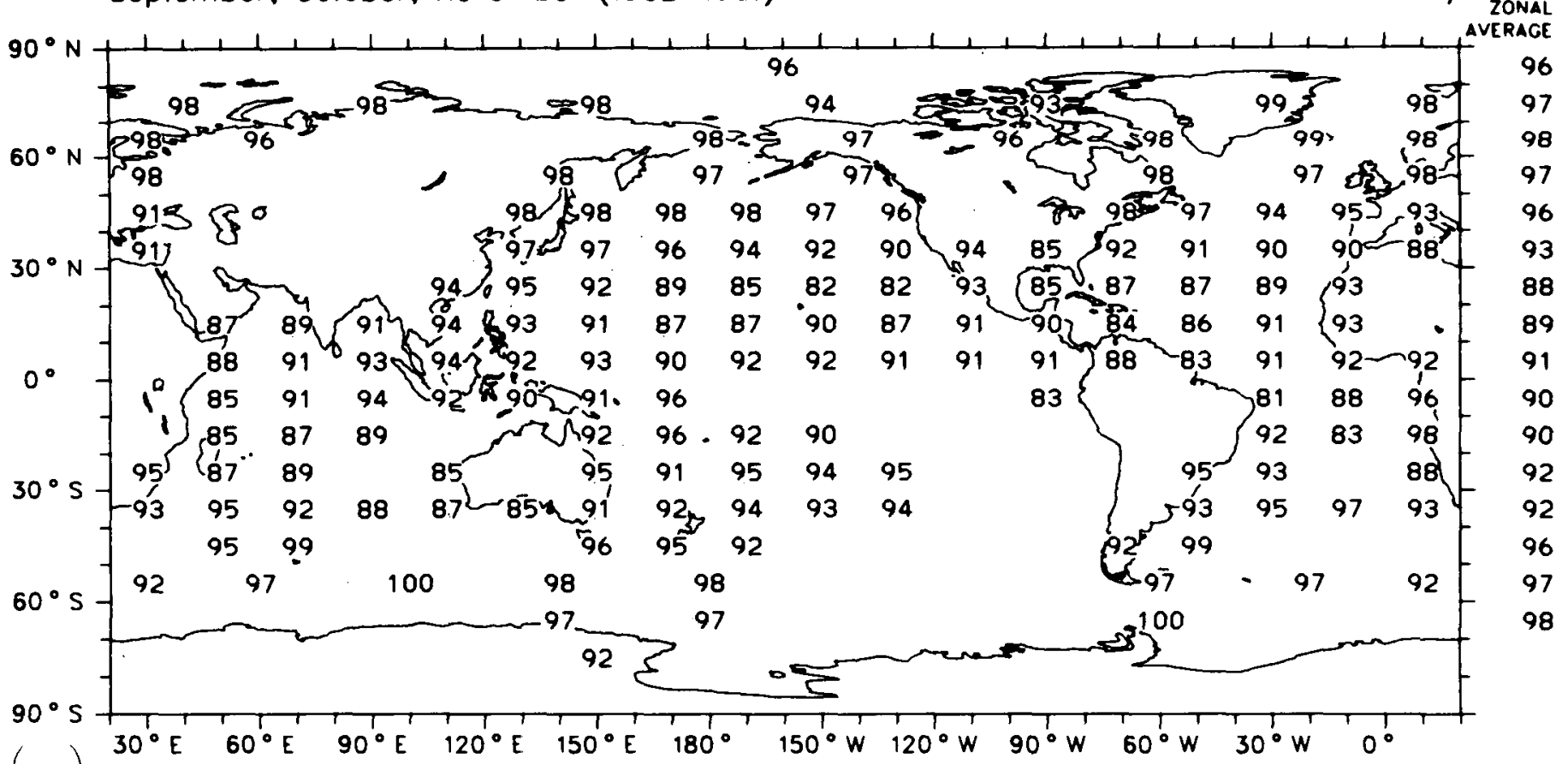

Globol Averoge (Oceon) $93 \%$

Map 143d 


\section{Nimbostratus}

Average Cloud Amount (\%)

December, January, February (1952-1981)

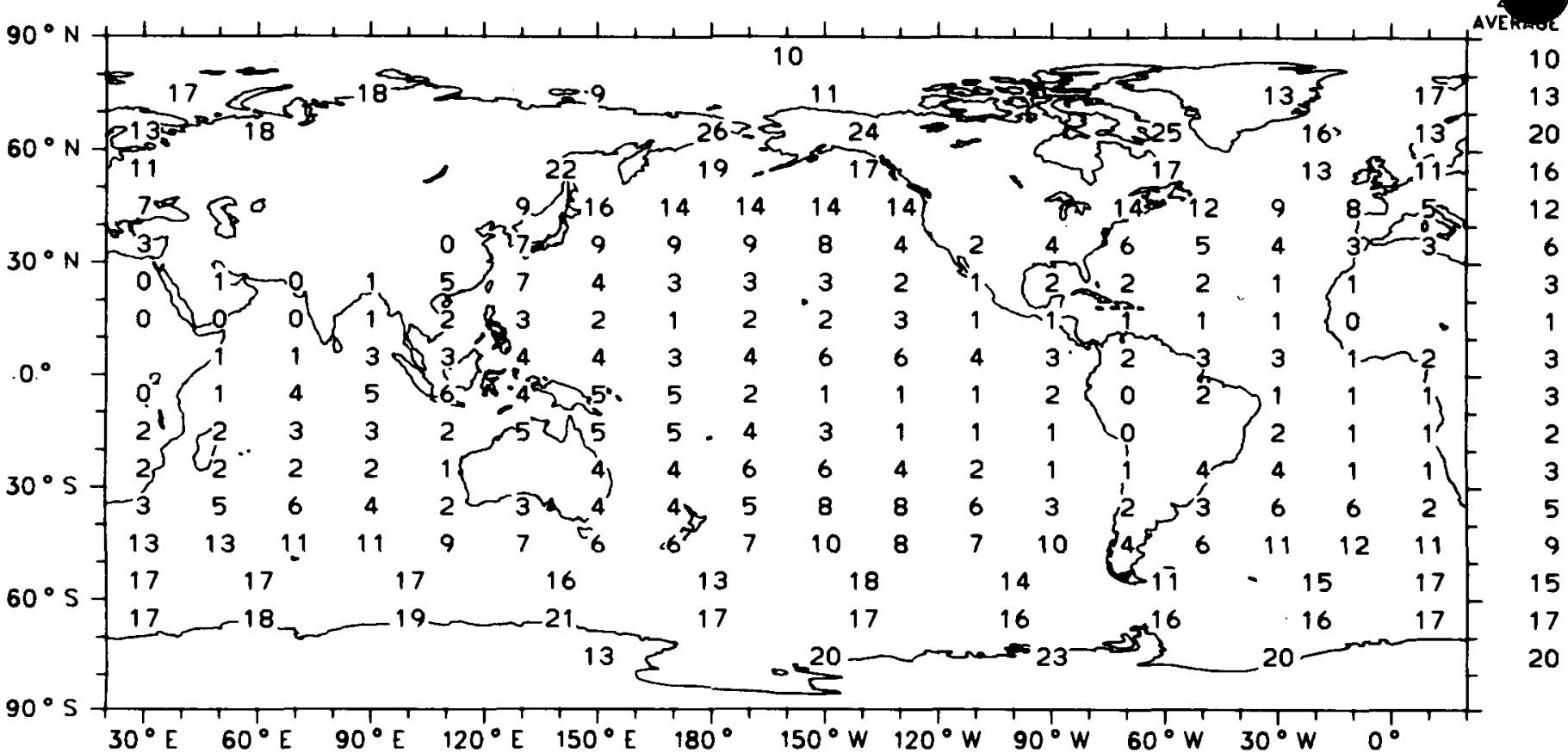

Map 144a

Globol Average (Ocean) $7 \%$

\section{Nimbostratus}

Average Cloud Amount (\%)

March, April, May (1952-1981)

Ocean Areas Only

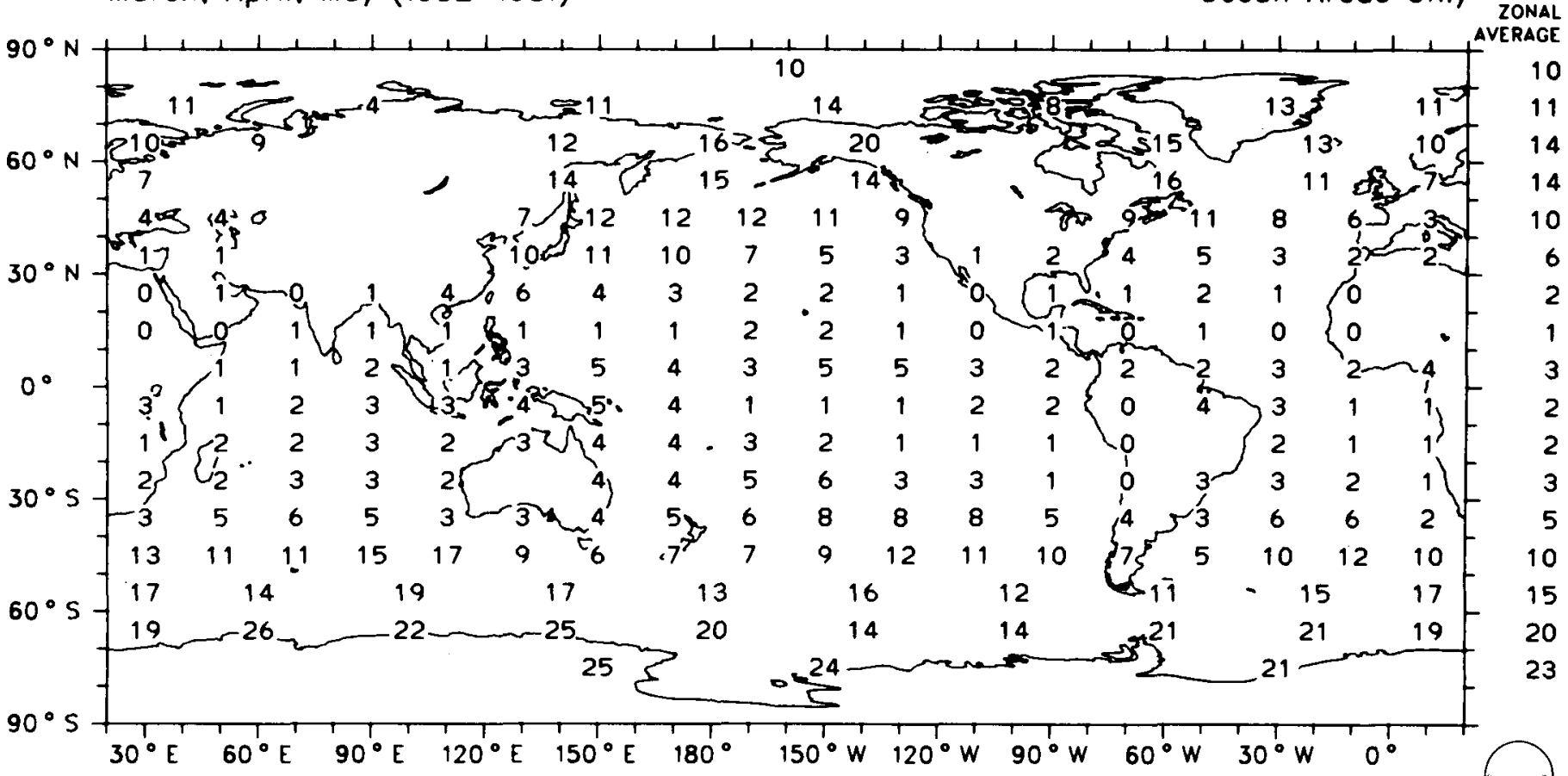

Map 144b

Global Average (Ocean) $6 \%$ 


\section{Nimbostratus}

Average Cloud Amount (\%) June. July, August (1952-1981)

Ocean Areas Only ZONAL

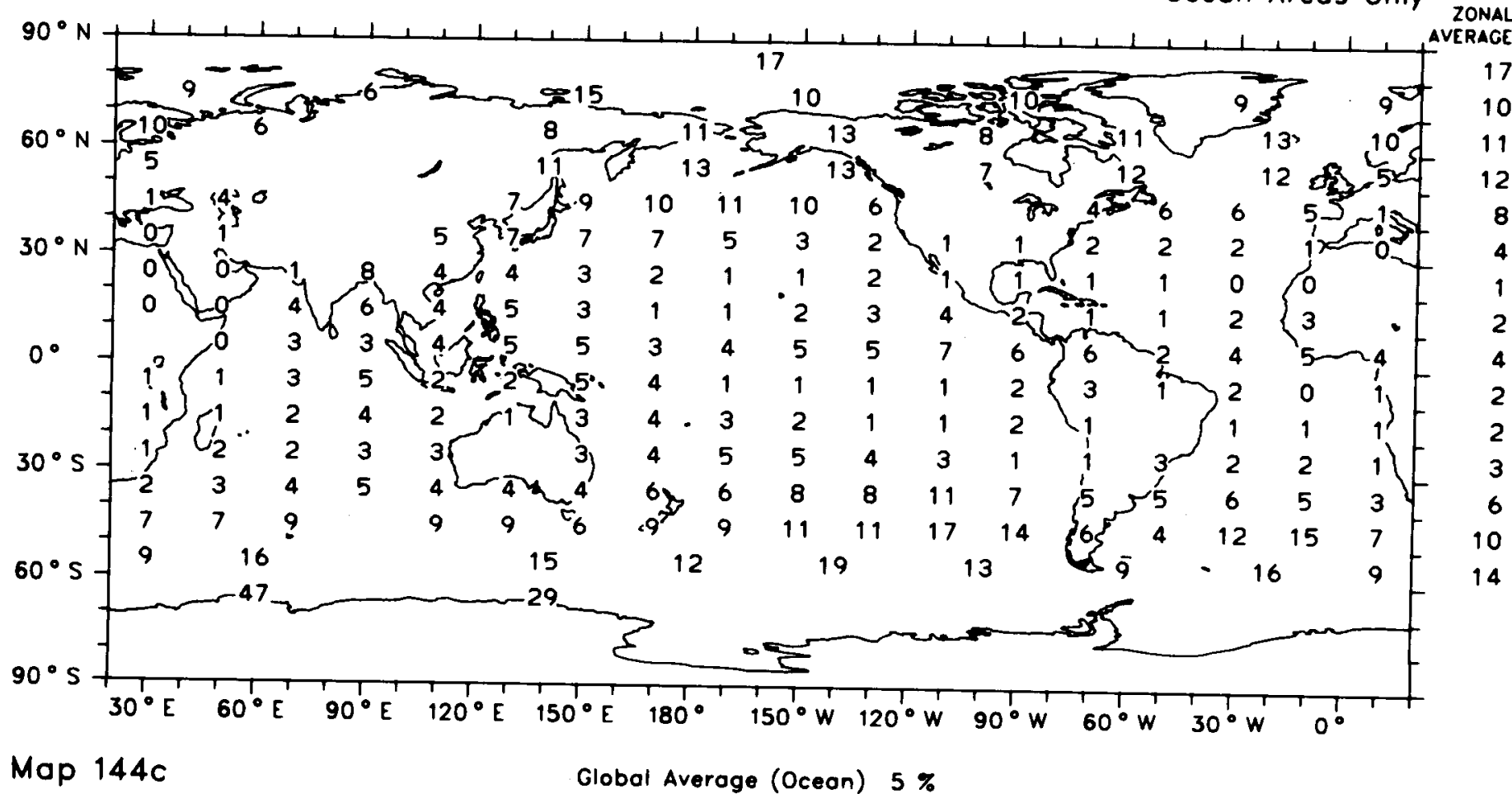

Nimbostratus

Average Cloud Amount (\%)

September. October, November (1952-1981)

Ocean Areas Only

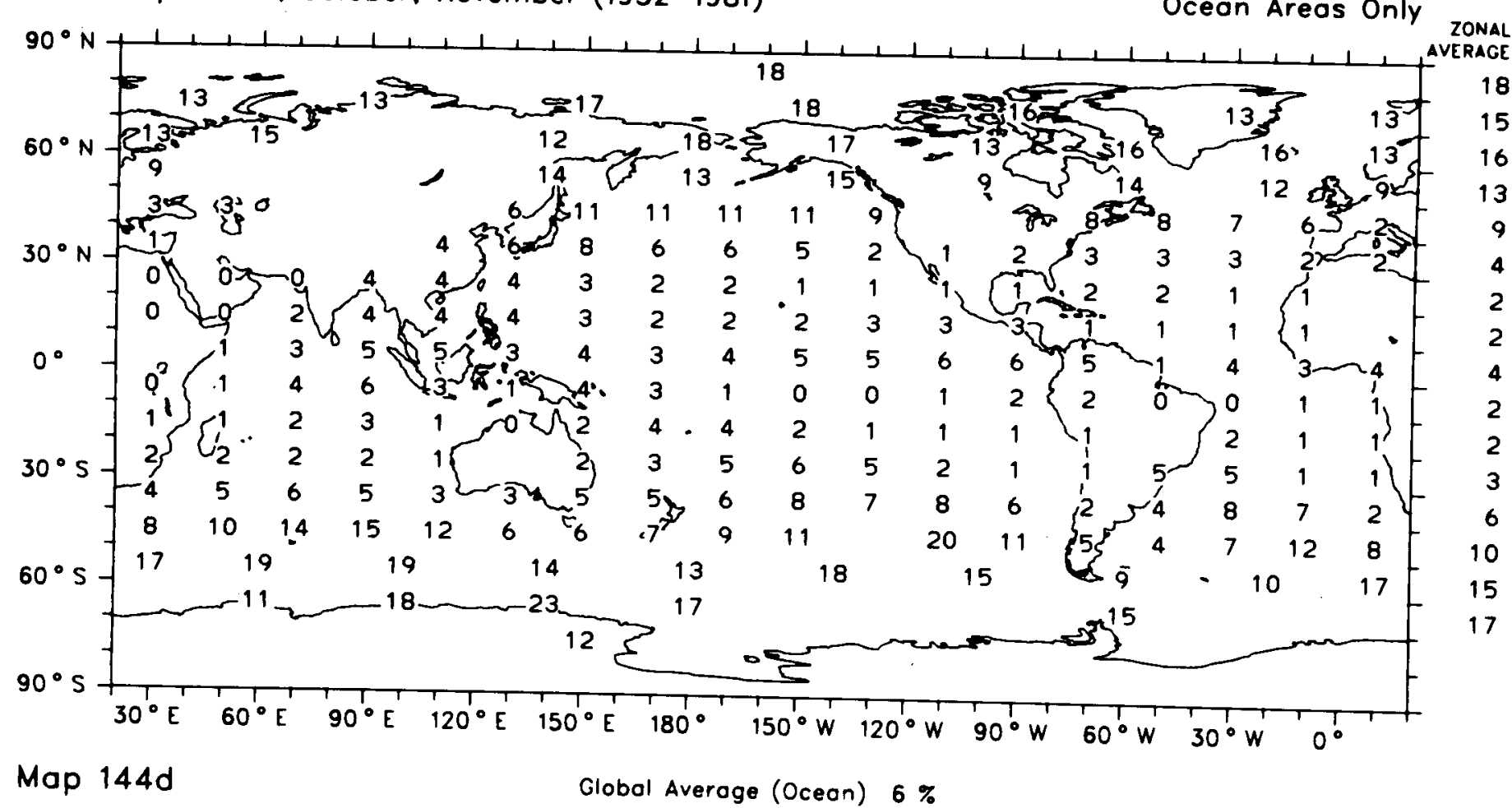




\section{Nimbostratus}

Amplitude of Diurnal Cycle (0.1\% Cloud Amount)

December. Jonuary. February (1952-1981)

Ocean Areas Only

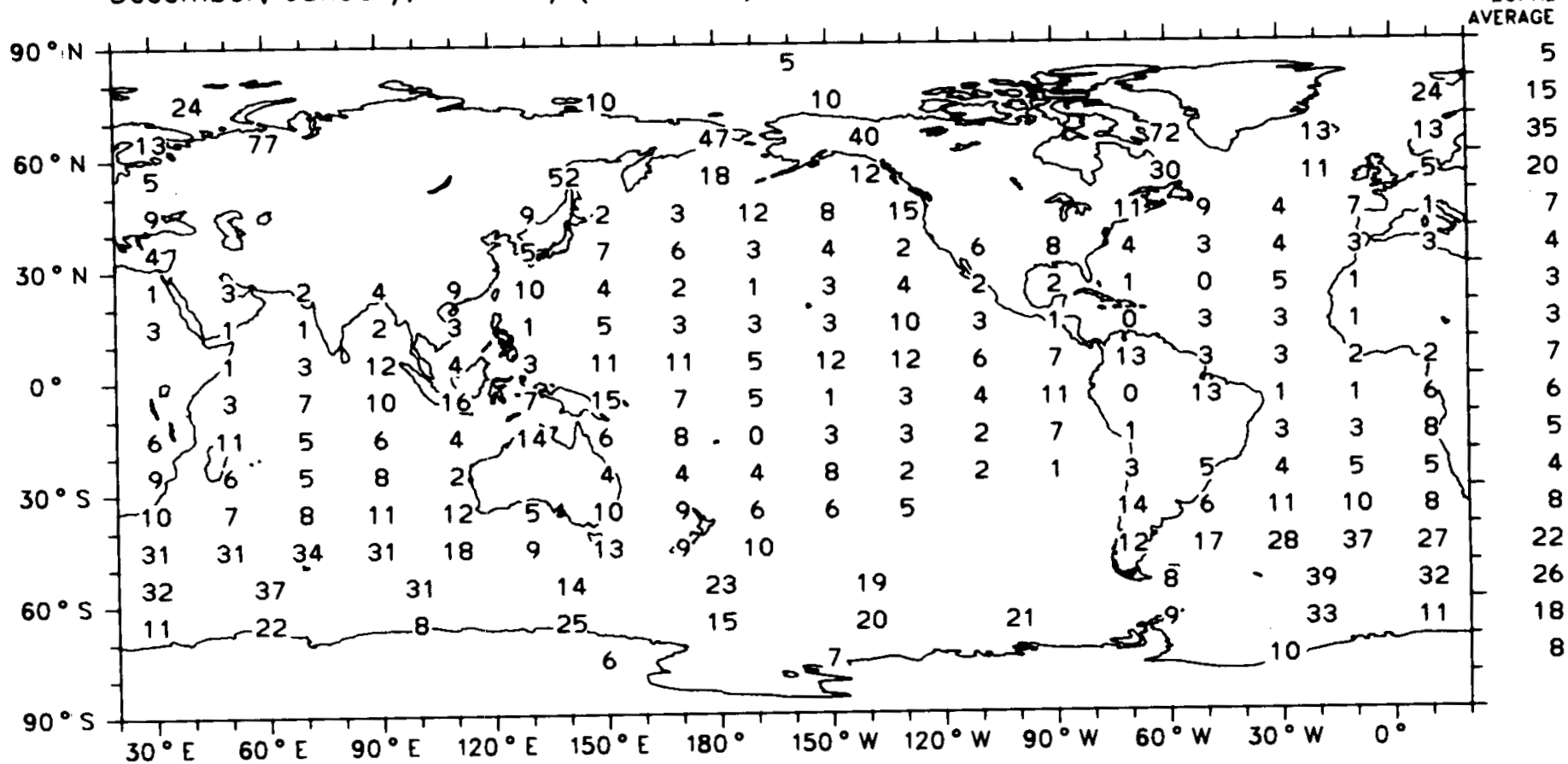

Global Average (Ocean) $1.0 \%$

Map 145o

\section{Nimbostratus}

Phase of Diurnal Cycle (Local Time of Maximum Cloud Amount) December, Jonuary, February (1952-1981)

Ocean Areas Only

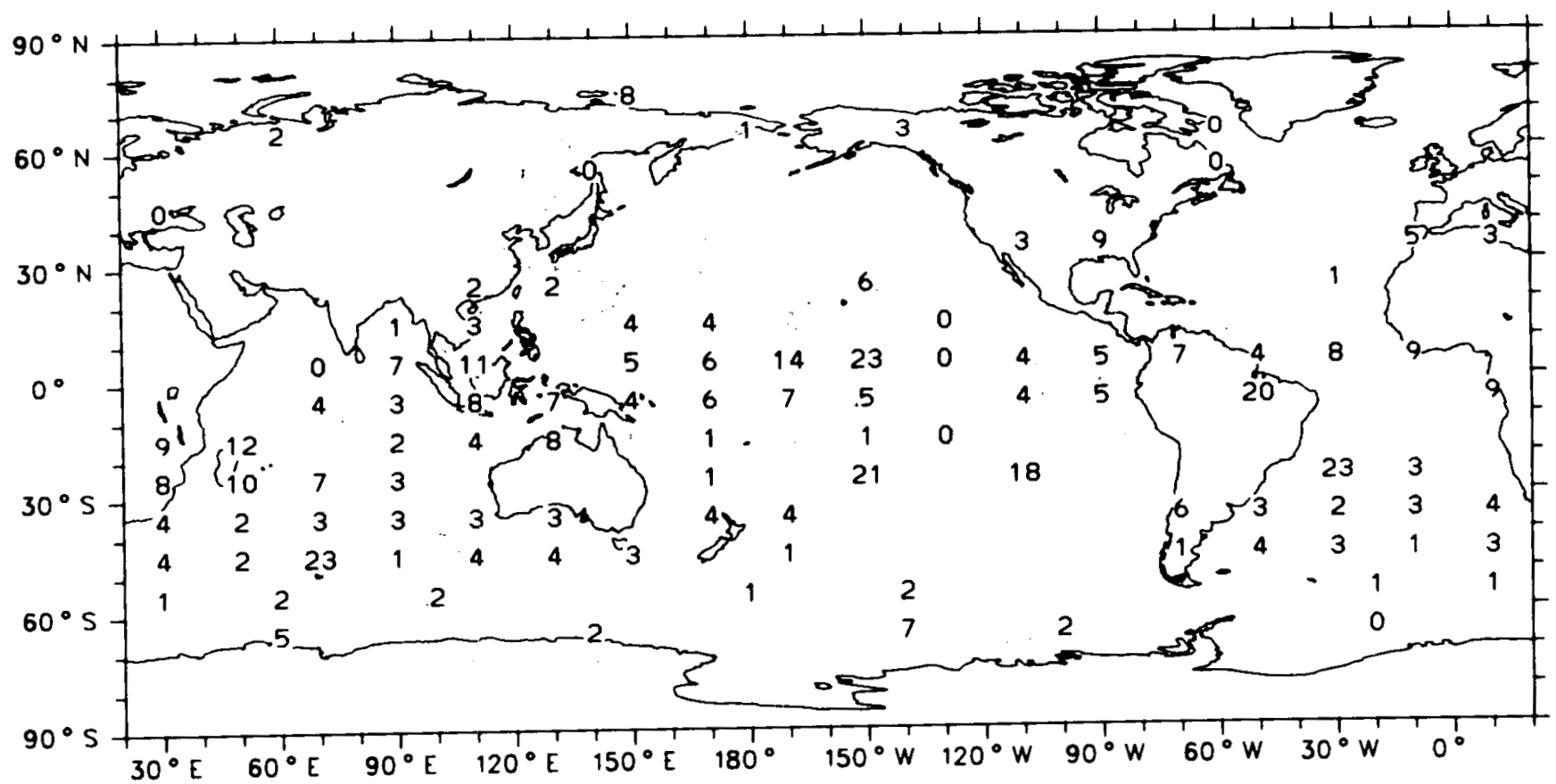

Map 145b 


\section{Nimbostratus}

Amplitude of Diurnal Cycle ( $0.1 \%$ Cloud Amount)

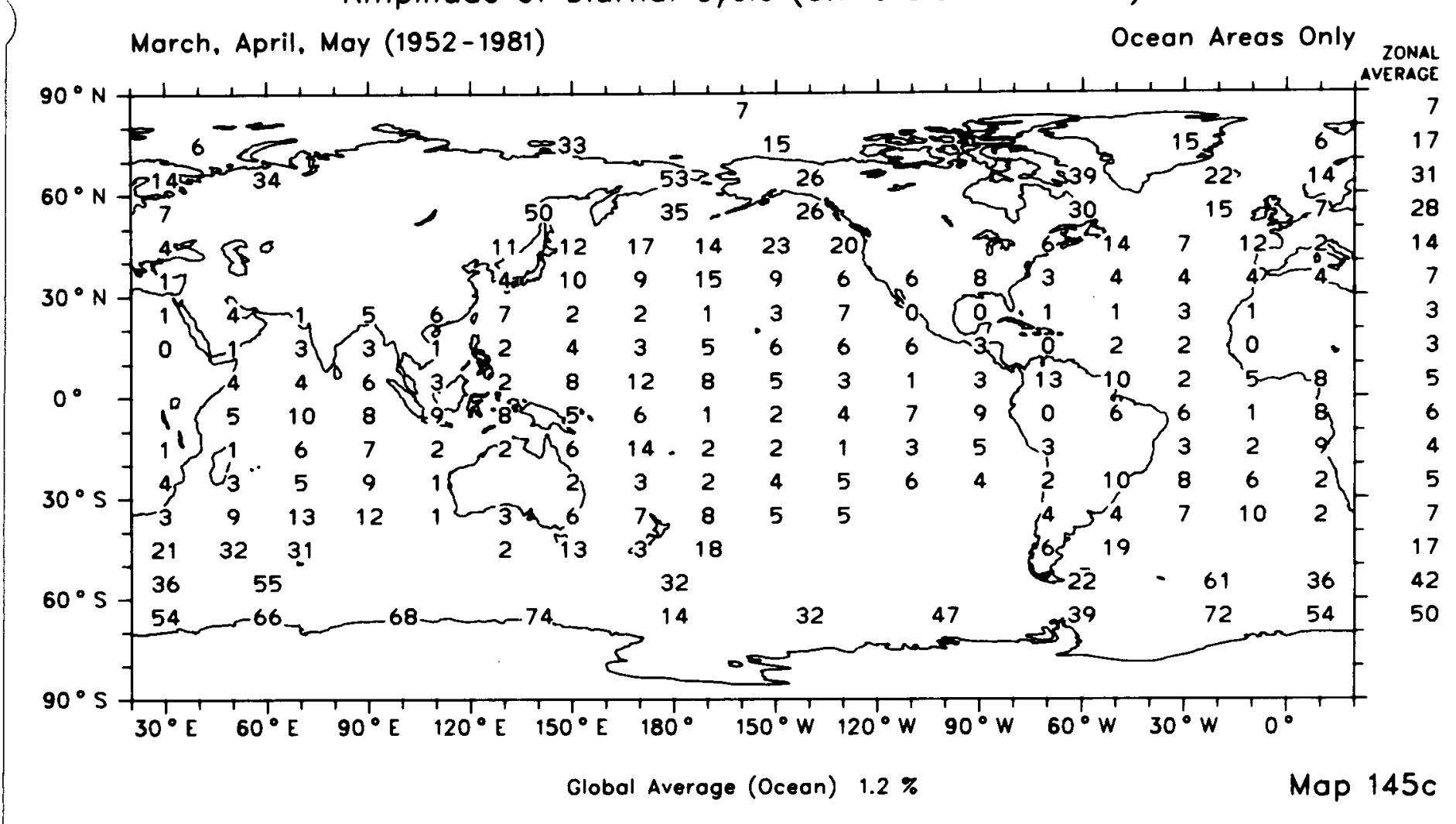

\section{Nimbostratus}

Phase of Diurnal Cycle (Local Time of Maximum Cloud Amount) Morch, April. Moy (1952-1981)

Ocean Areas Only

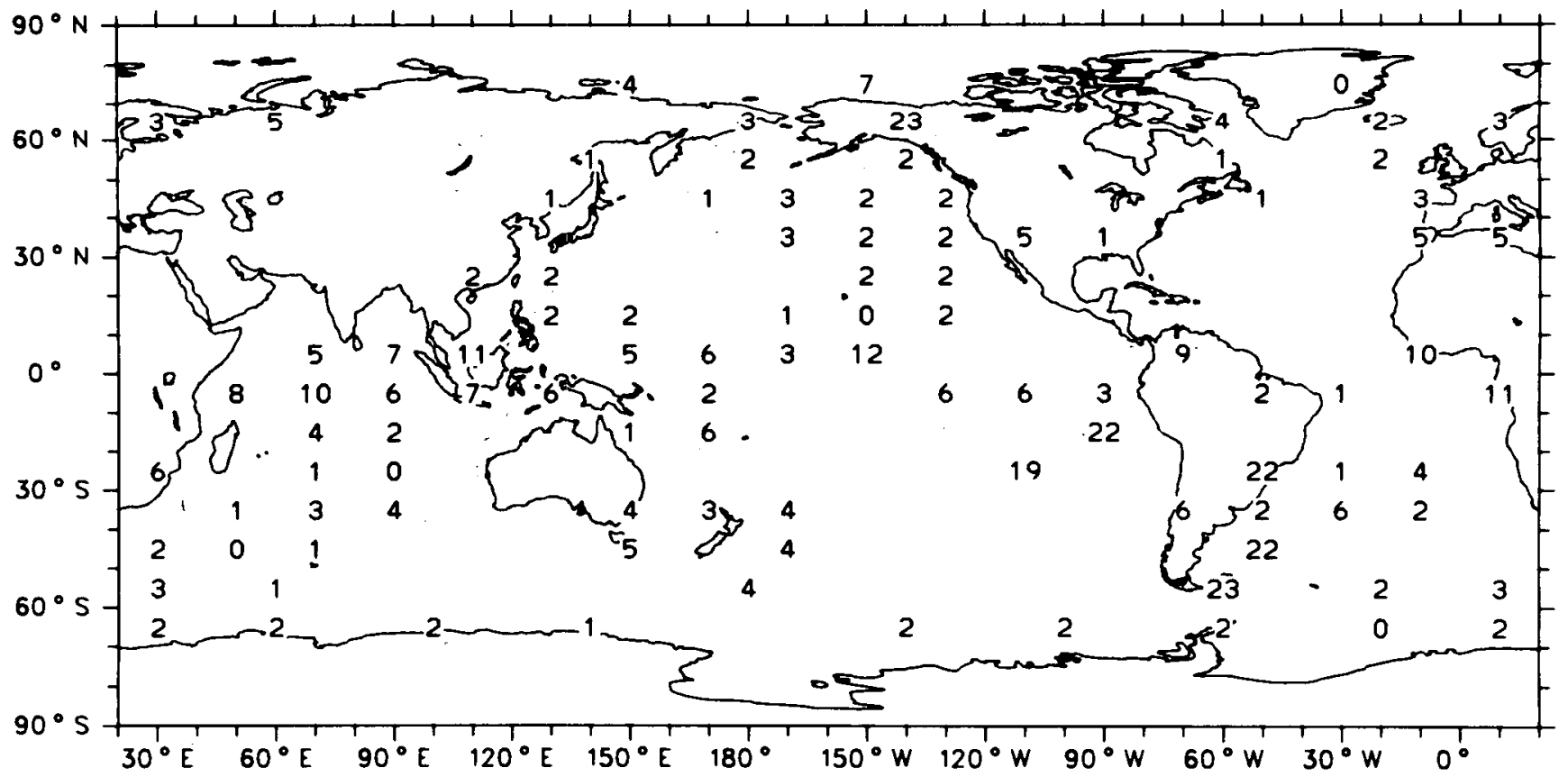

Map 145d 
Nimbostratus

Amplitude of Diurnal Cycle (0.1\% Cloud Amount) June, July, August (1952-1981)

Ocean Areas Only

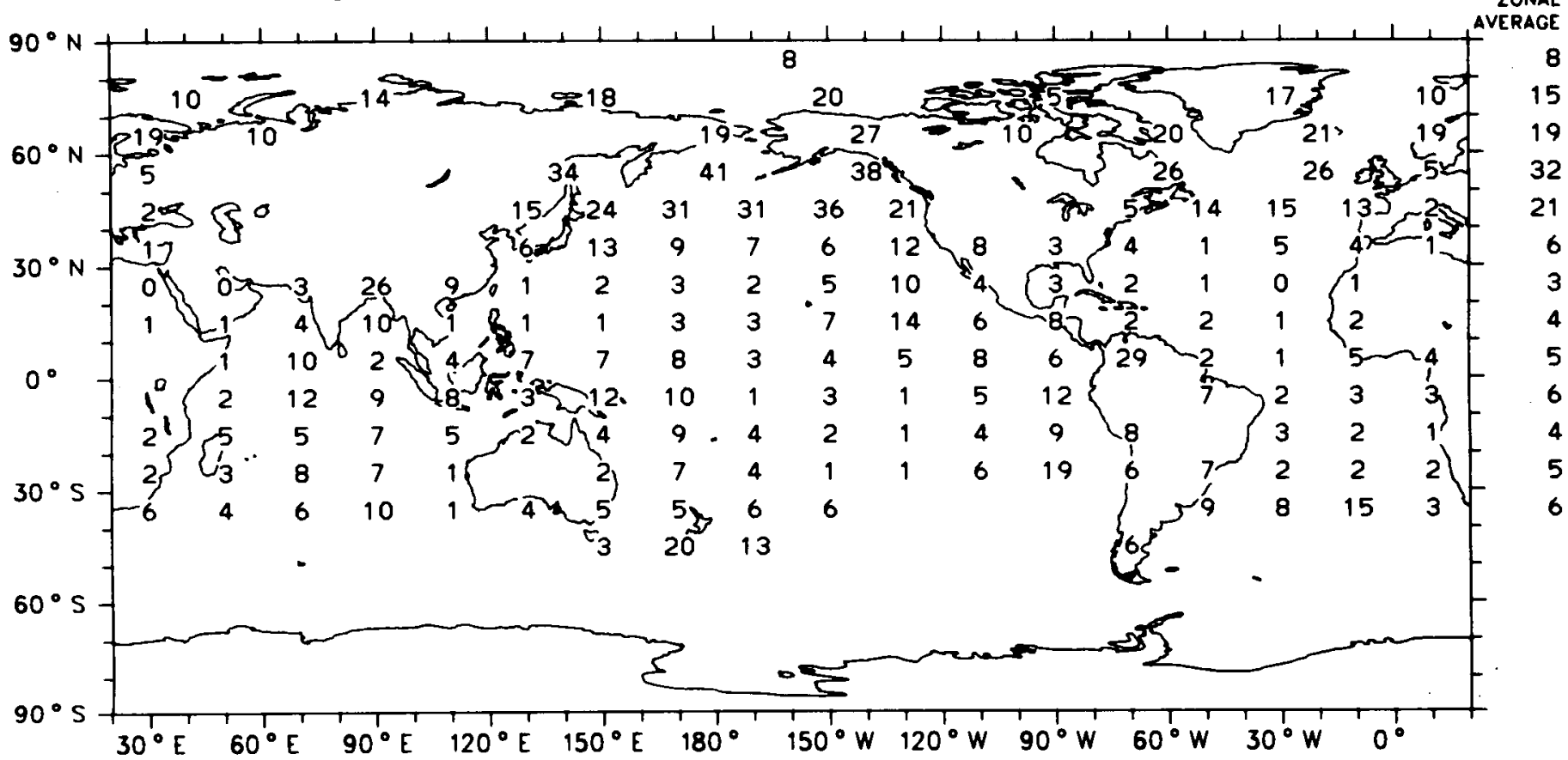

Map 146a

Global Average (Oceun) $0.7 \%$

Nimbostratus

Phase of Diurnal Cycle (Local Time of Maximum Cloud Amount) June, July. August (1952-1981)

Ocean Areas Only

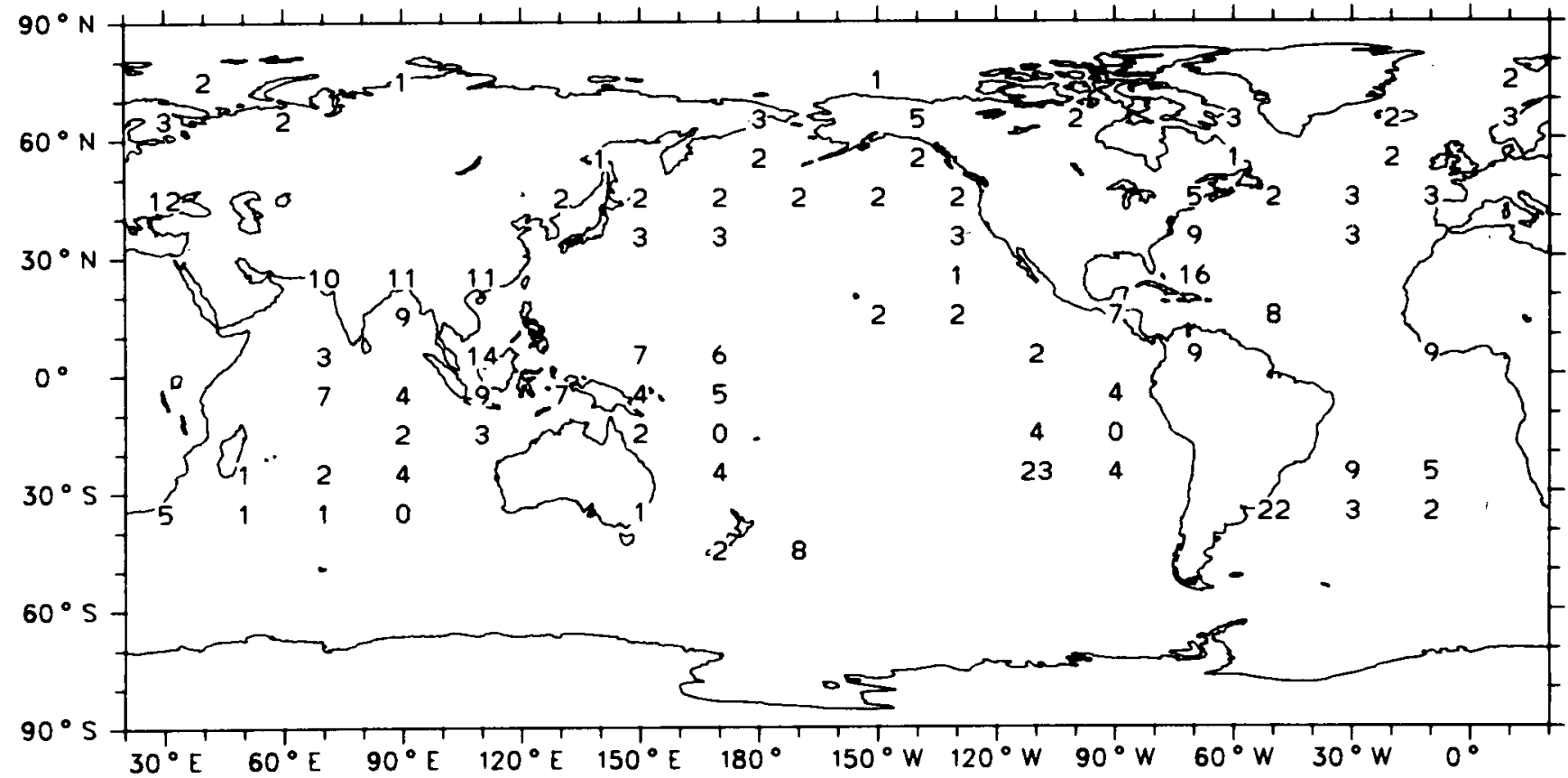

Map 146b 


\section{Nimbostratus}

Amplitude of Diurnal Cycle ( $0.1 \%$ Cloud Amount)

September, October. November (1952-1981)

Oceon Areas Only

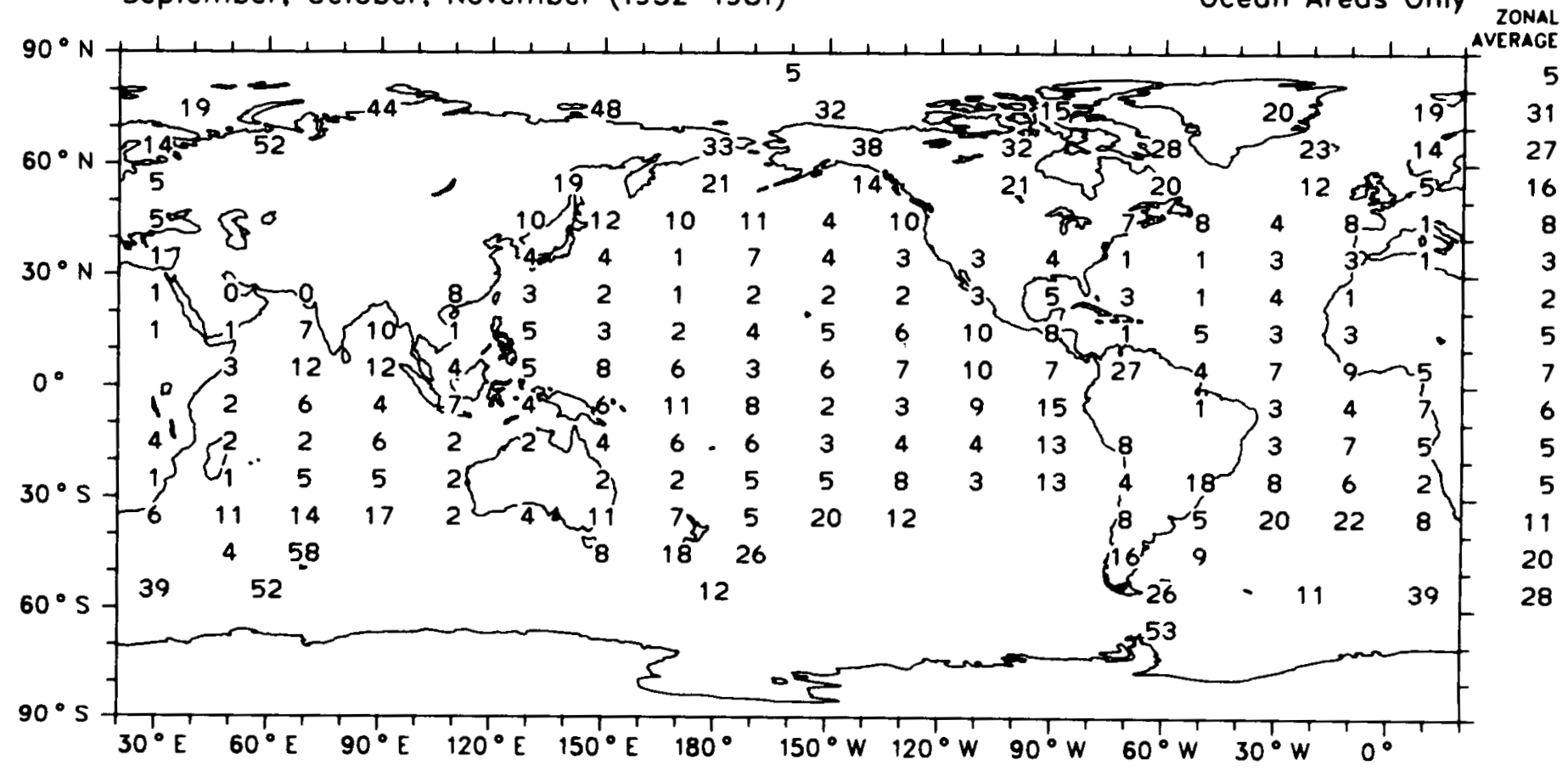

Map 146e

Global Averoge (Ocean) $1.0 \%$

Nimbostratus

Phase of Diurnal Cycle (Local Time of Maximum Cloud Amount) September, October. November (1952-1981)

Ocean Areas Only

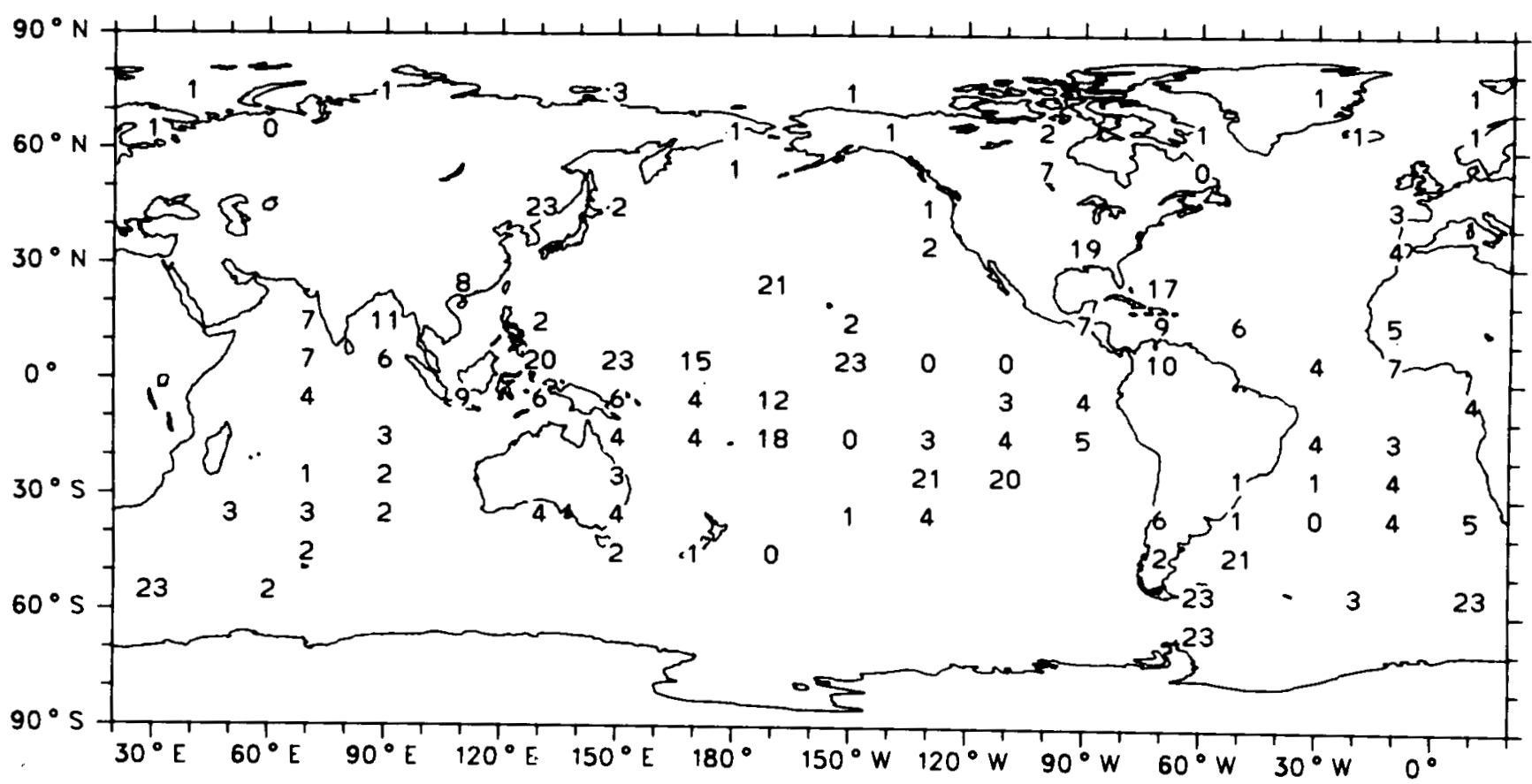

Map 146d 


\section{Interannual Variation of Nimbostratus :}

Standard Deviation (detrended) of Seasonal Means (0.1\% Cloud Amount) December, January, February (1952-1981)

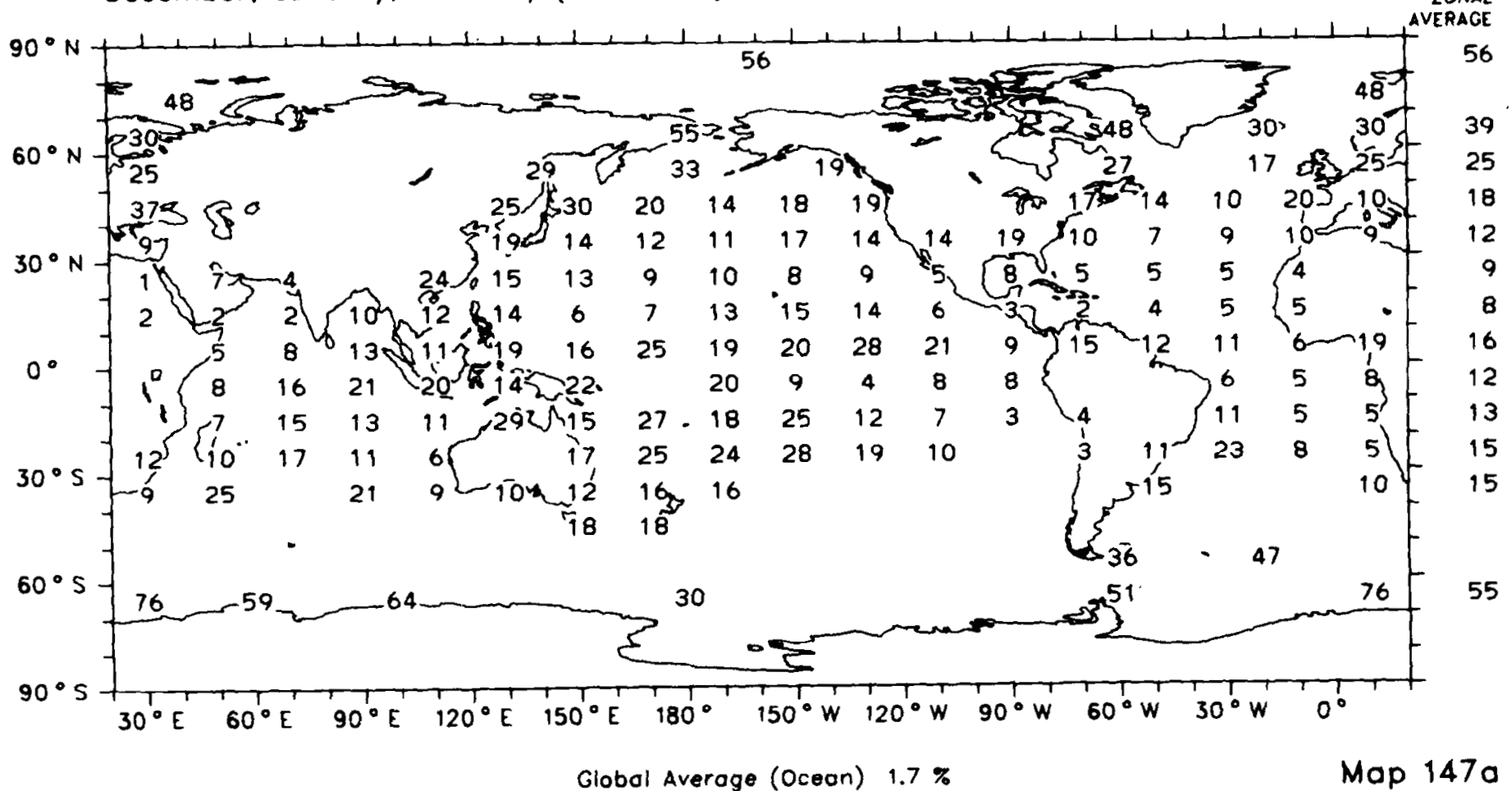

Interannual Variation of Nimbostratus :

Standard Deviotion (detrended) of Seasonal Means (0.1\% Cloud Amount) March. April. Moy (1952-1981)

Oceon Areas Only zONAL

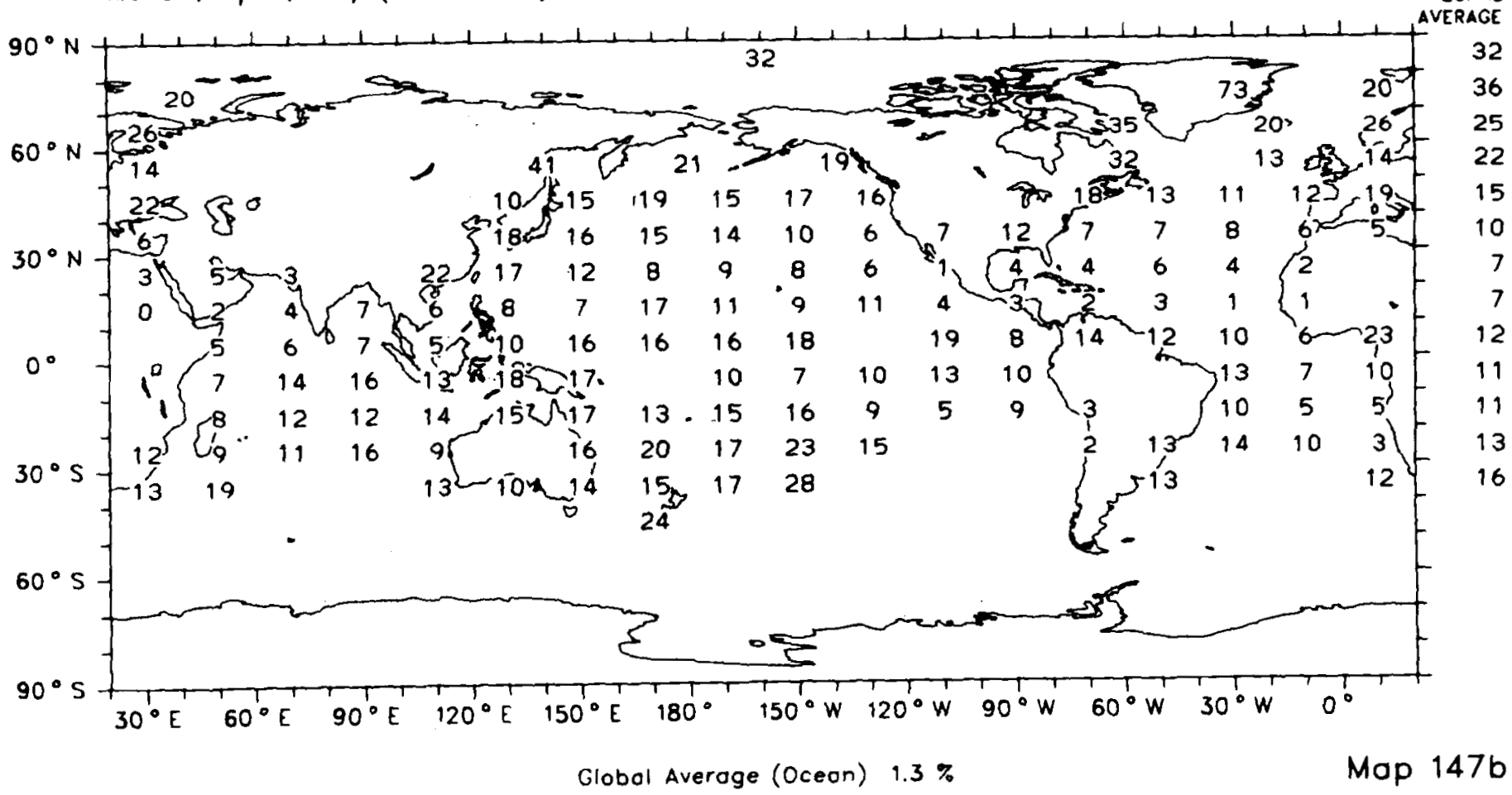


Interannual Variation of Nimbostratus :

Standard Deviation (detrended) of Seasonal Means (0.1\% Cloud Amount) June, July, August (1952-1981)

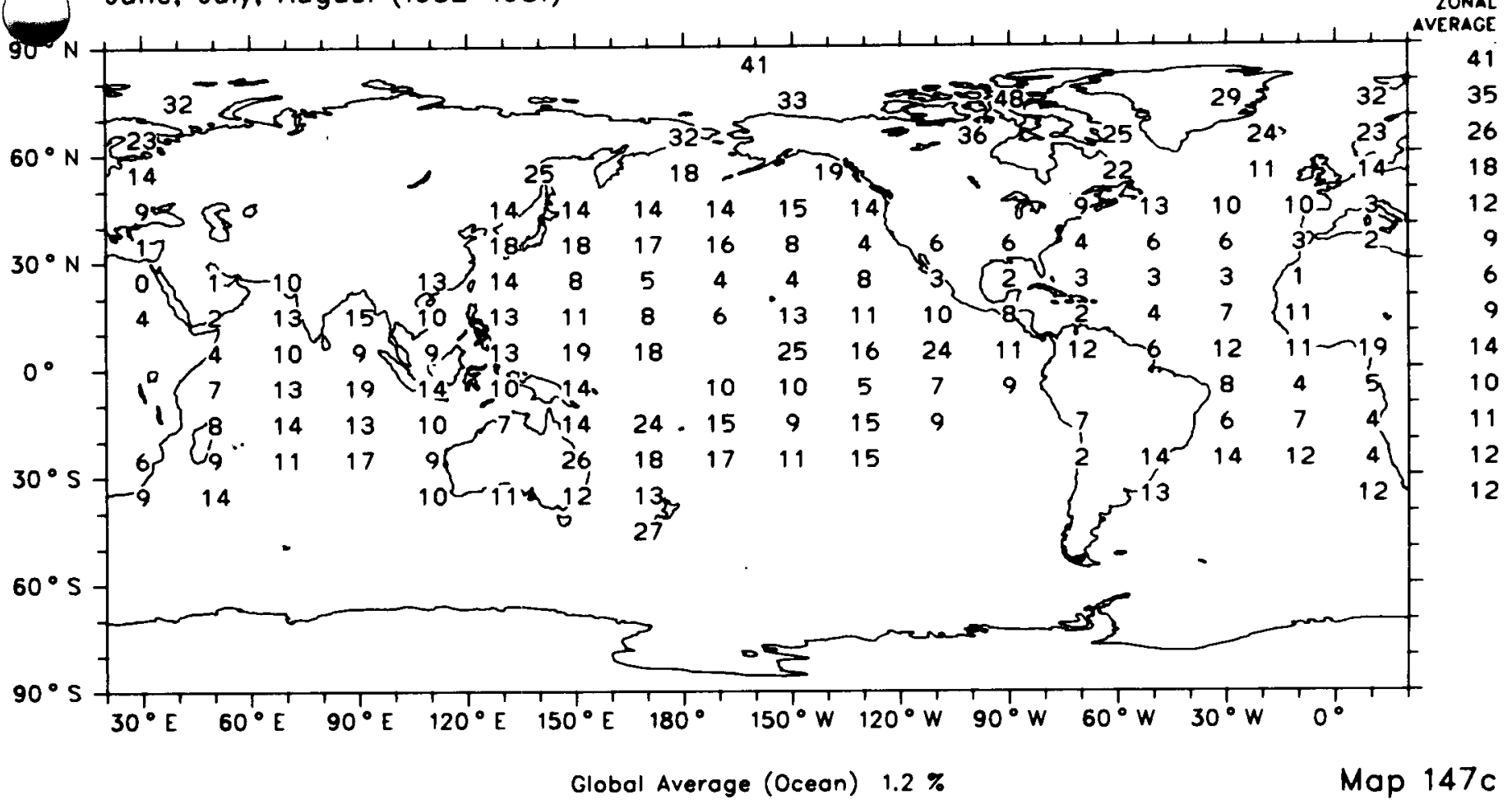

Interannual Variation of Nimbostratus :

Standard Deviation (detrended) of Seasonal Means (0.1\% Cloud Amount) September, October, November (1952-1981)

Ocean Areos Only

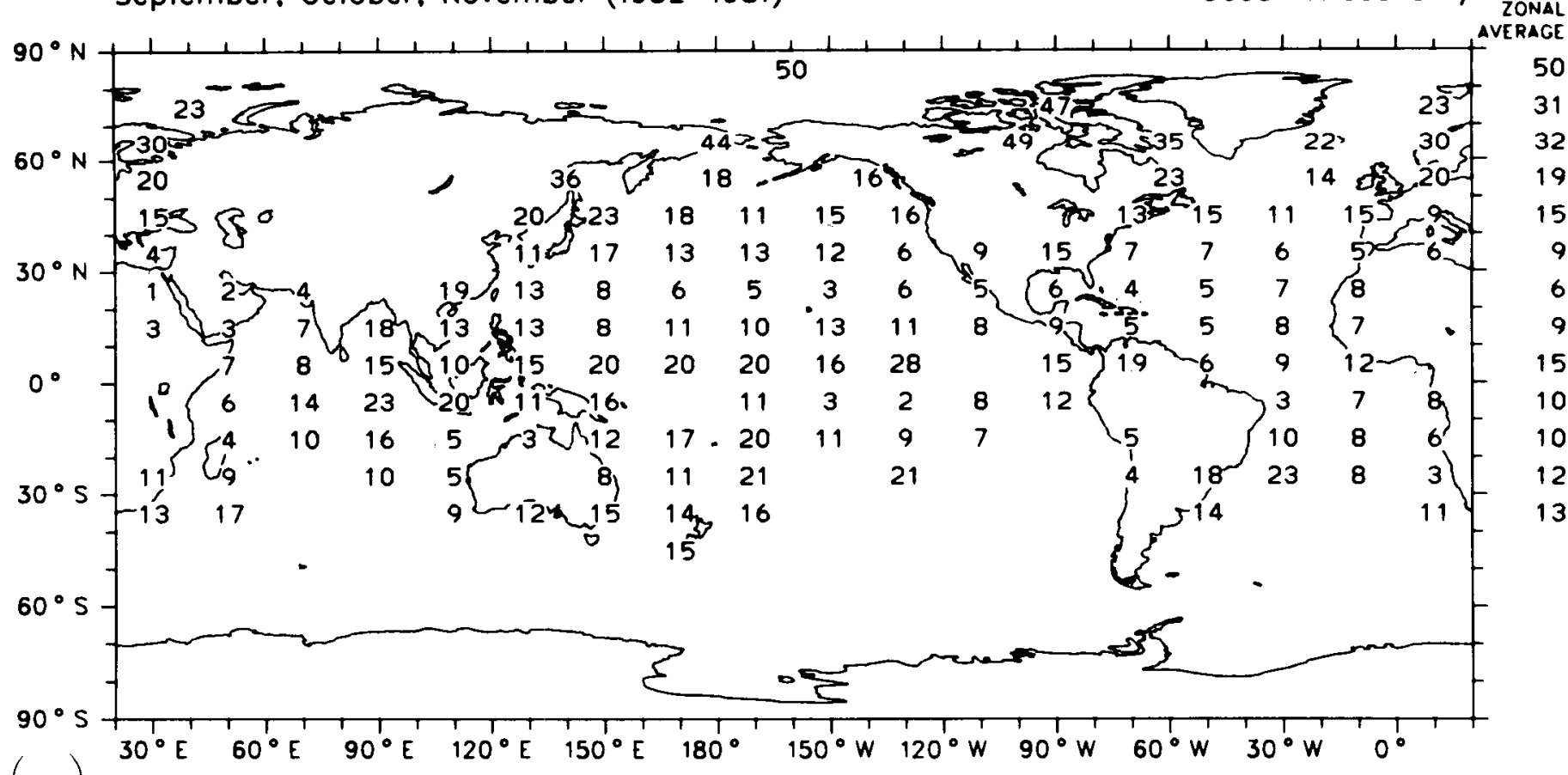


Trend of Nimbostratus :

Change in \%-Cloud-Amount from 1952 to 1981

December, January. February (1952-1981)

Ocean Areas Only

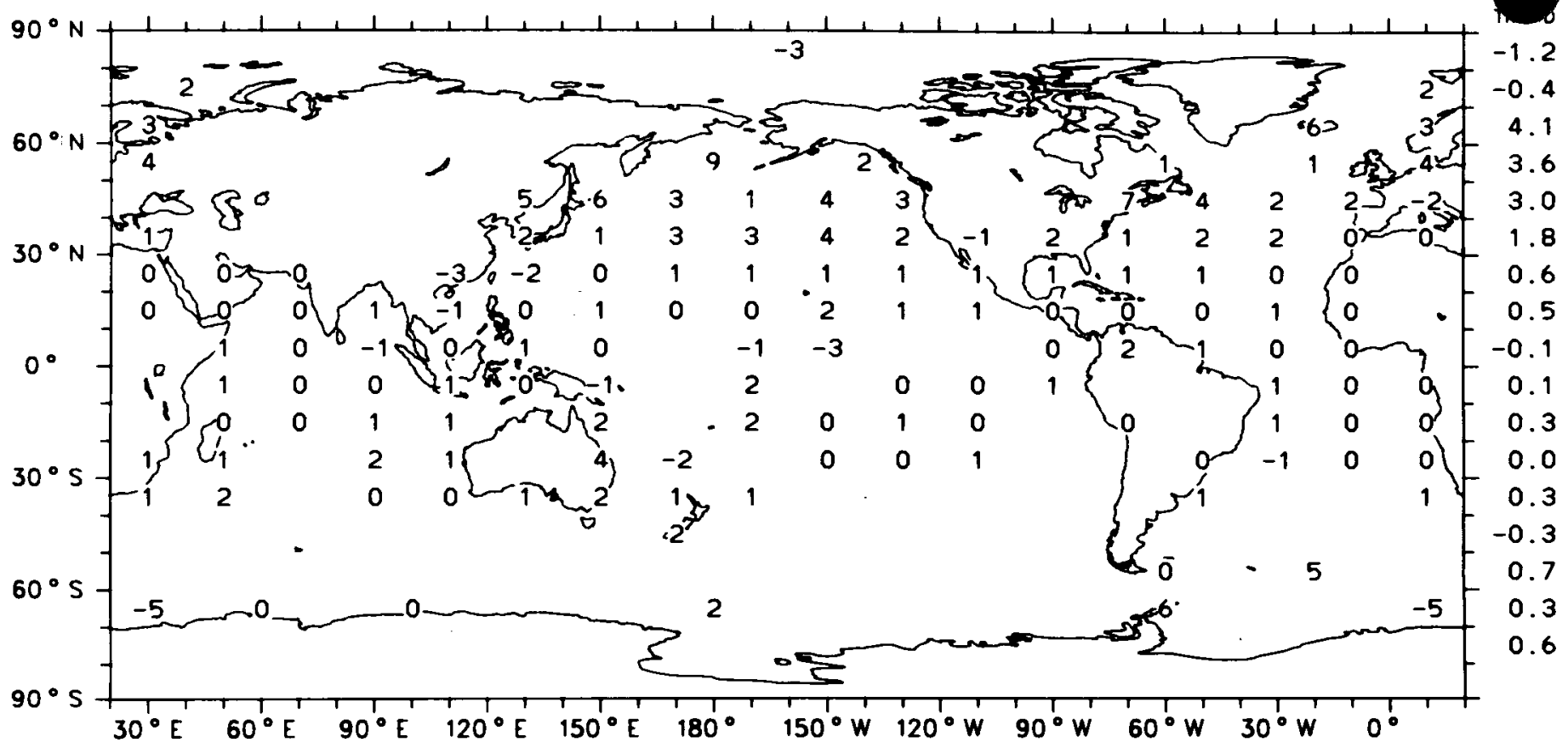

Map 148a

Global Trend (Ocean) $0.6 \%$

Trend of Nimbostratus :

Change in \%-Cloud-Amount from 1952 to 1981 March. April, May (1952-1981)

Ocean Areas Only

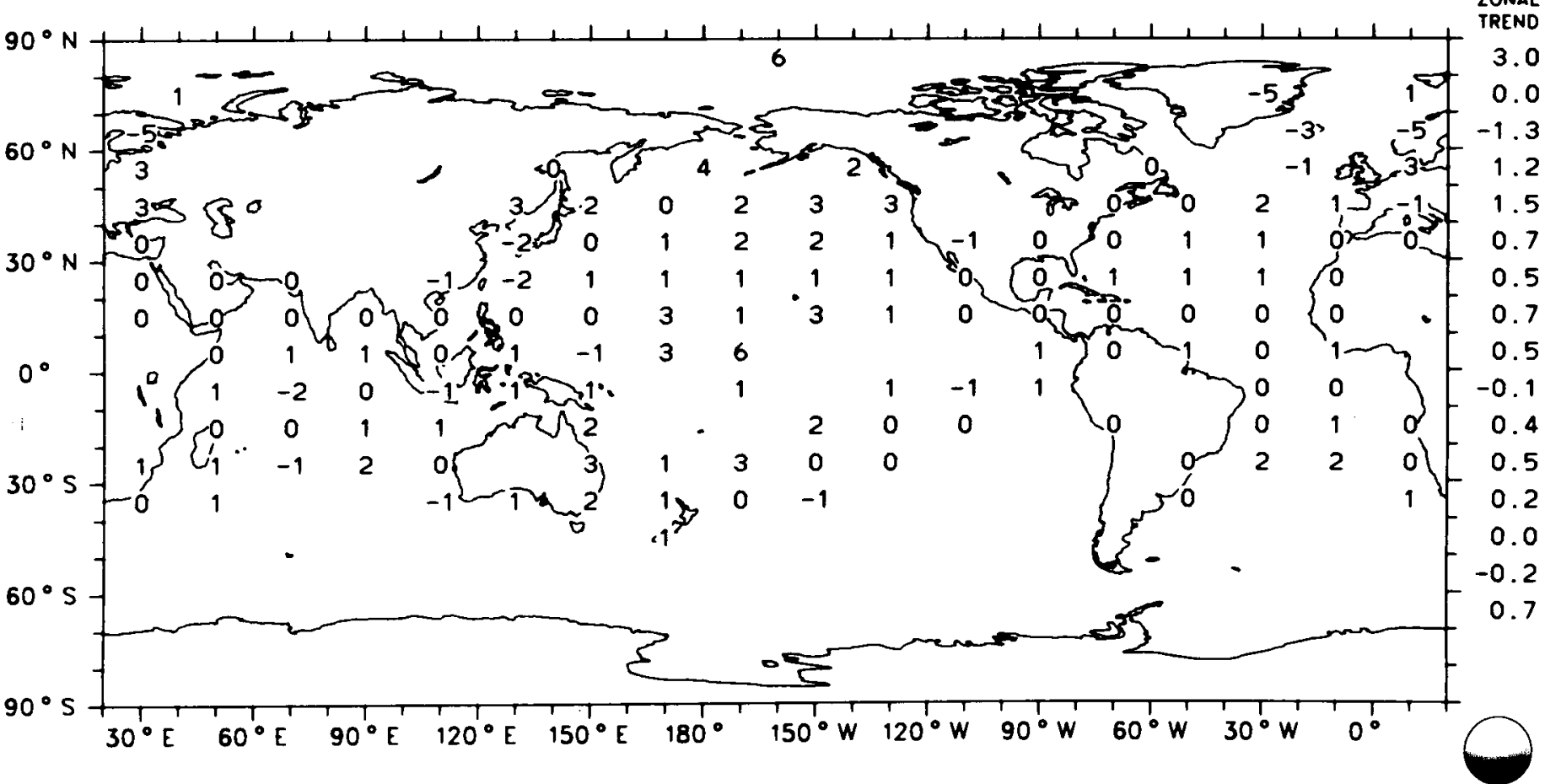

Map 148b

Global Trend (Ocean) $0.4 \%$ 
Trend of Nimbostratus :

Change in \%-Cloud-Amount from 1952 to 1981 June, July, August (1952-1981)

Oceon Areos Only

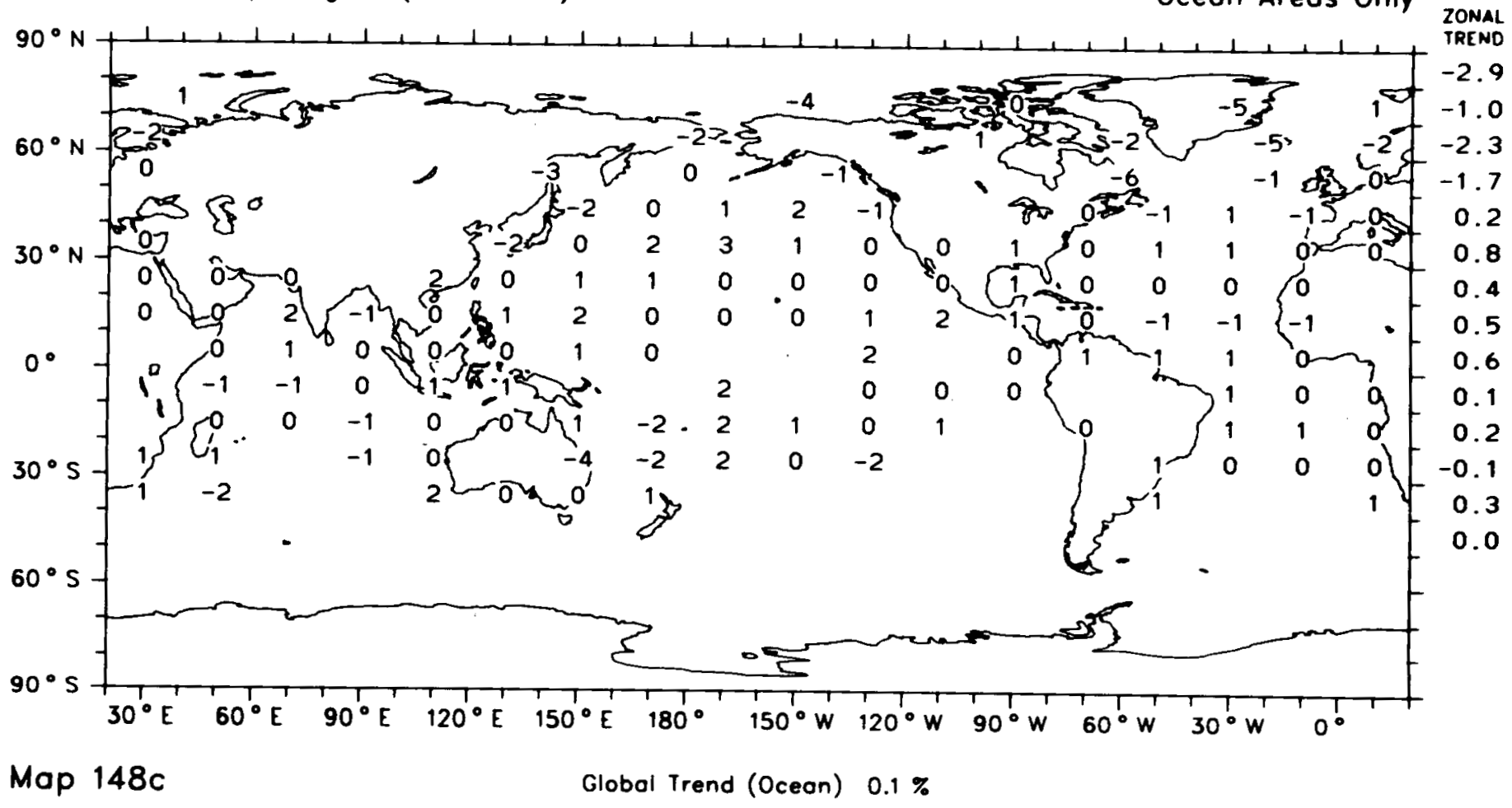

Trend of Nimbostratus :

Change in \%-Cloud-Amount from 1952 to 1981

September, October, November (1952-1981)

Ocean Areas Only

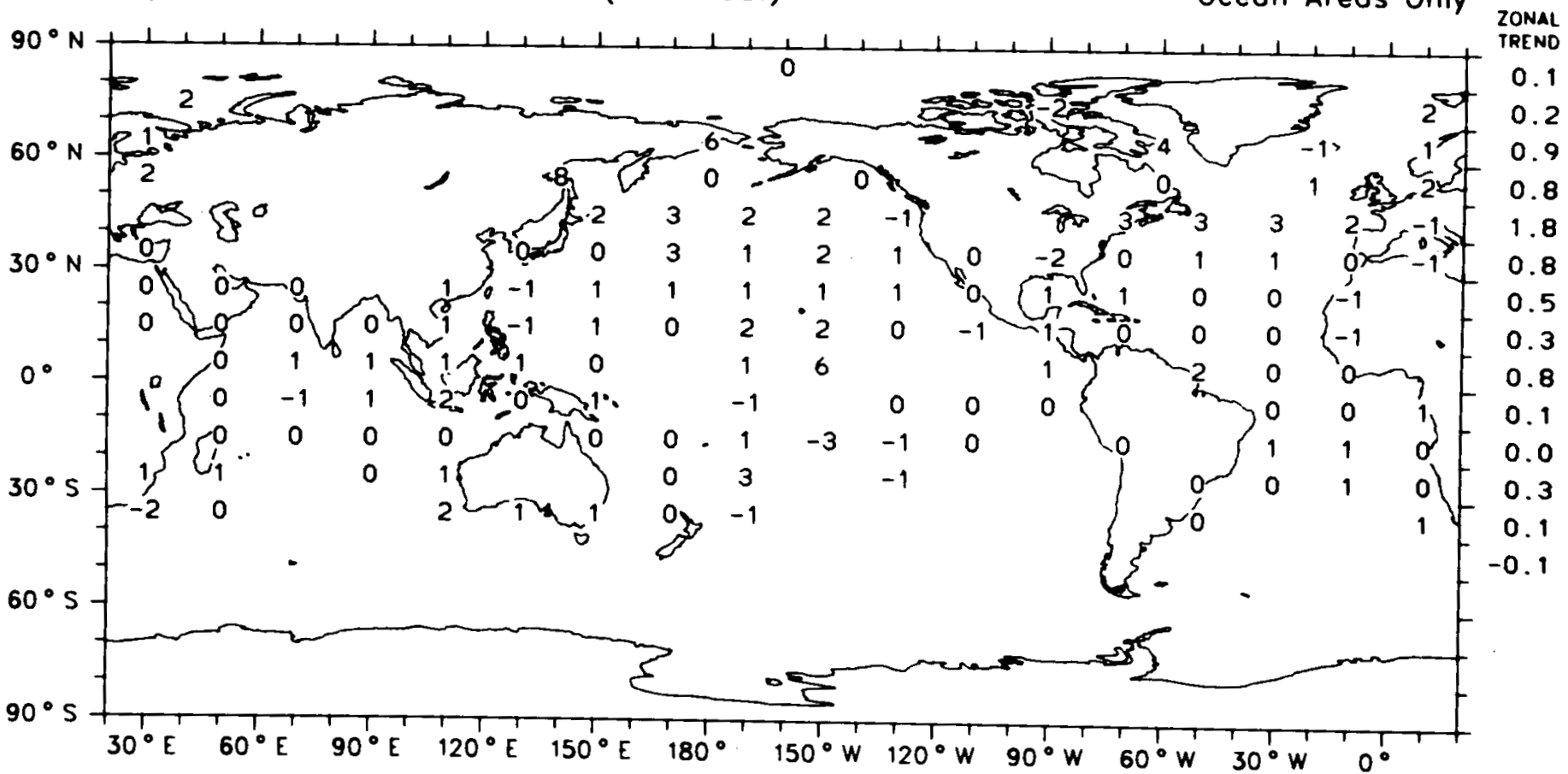

Map 148d

Global Trend (Oceon) $0.3 \%$ 
Altostratus + Altocumulus

Frequency of Occurrence (\%), 6-18 LT

December, January, February (1952-1981)

Ocean Areas Only

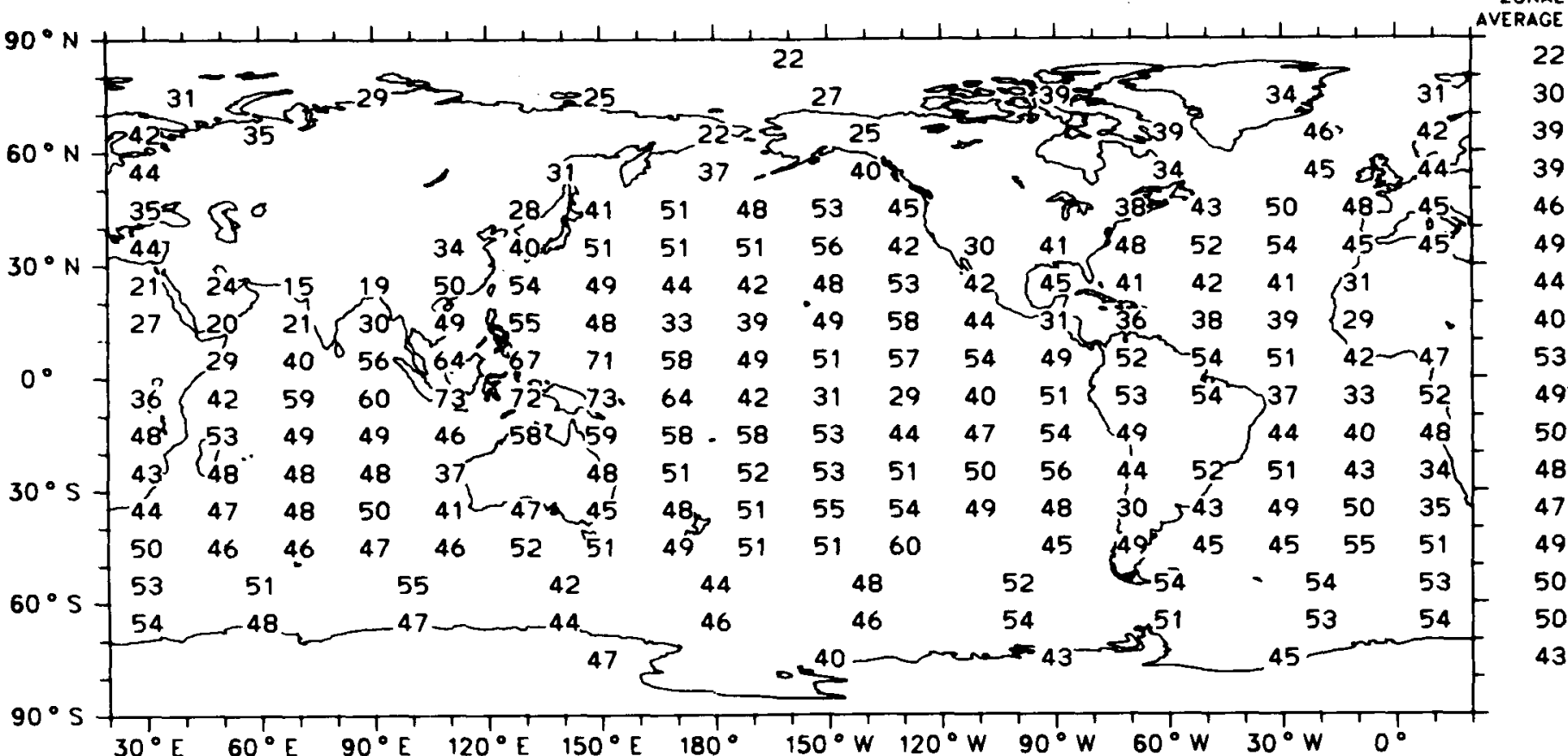

Globol Average (Ocean) $47 \%$

Map 149a

\section{Altostratus + Altocumulus}

Frequency of Occurrence (\%), 6-18 LT Morch. April, Moy (1952-1981)

Ocean Areas Only

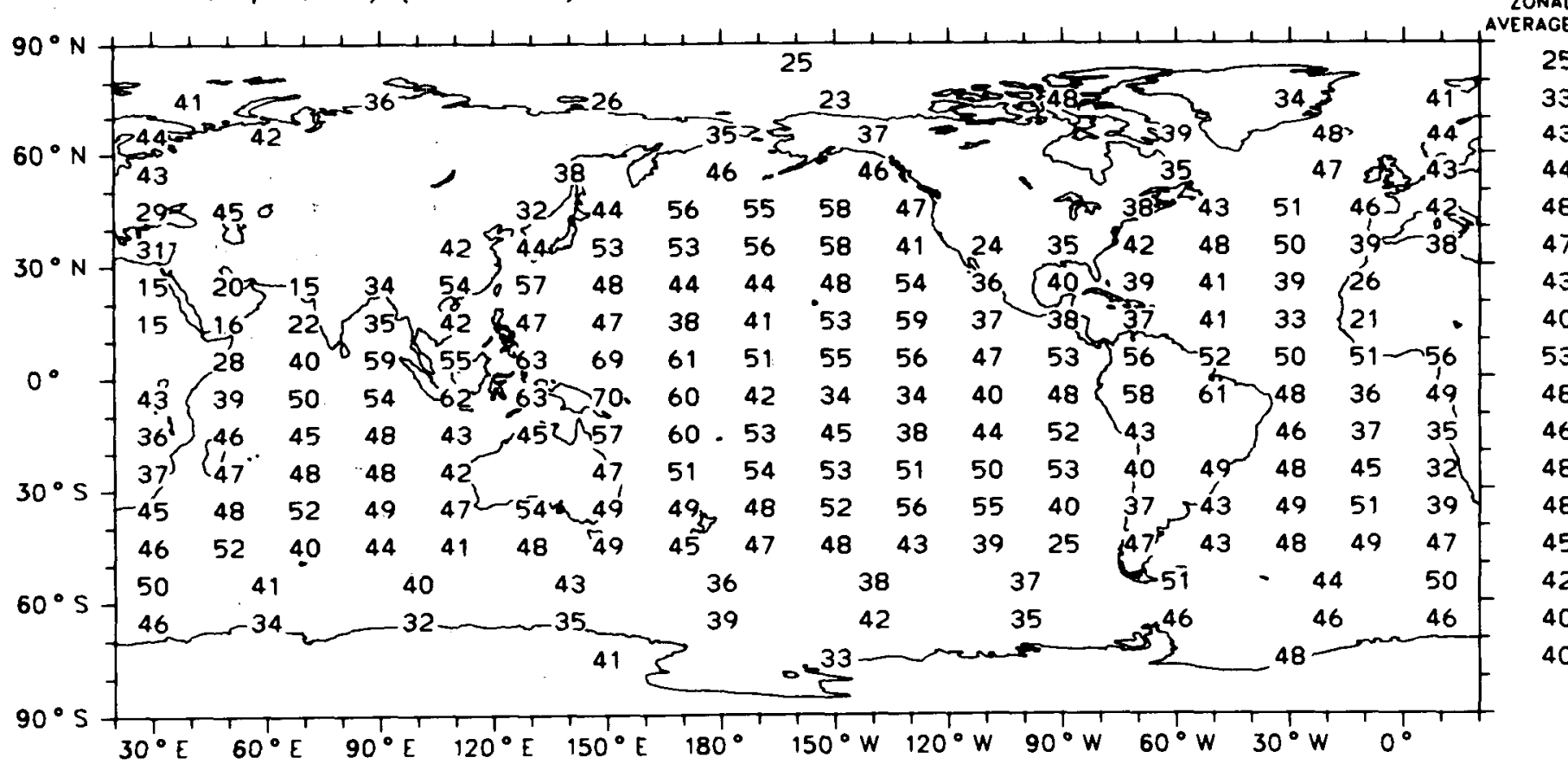

Global Averoge (Oceon) $45 \%$

Map 149b 
Altostratus + Altocumulus

Frequency of Occurrence (\%), 6-18 LT

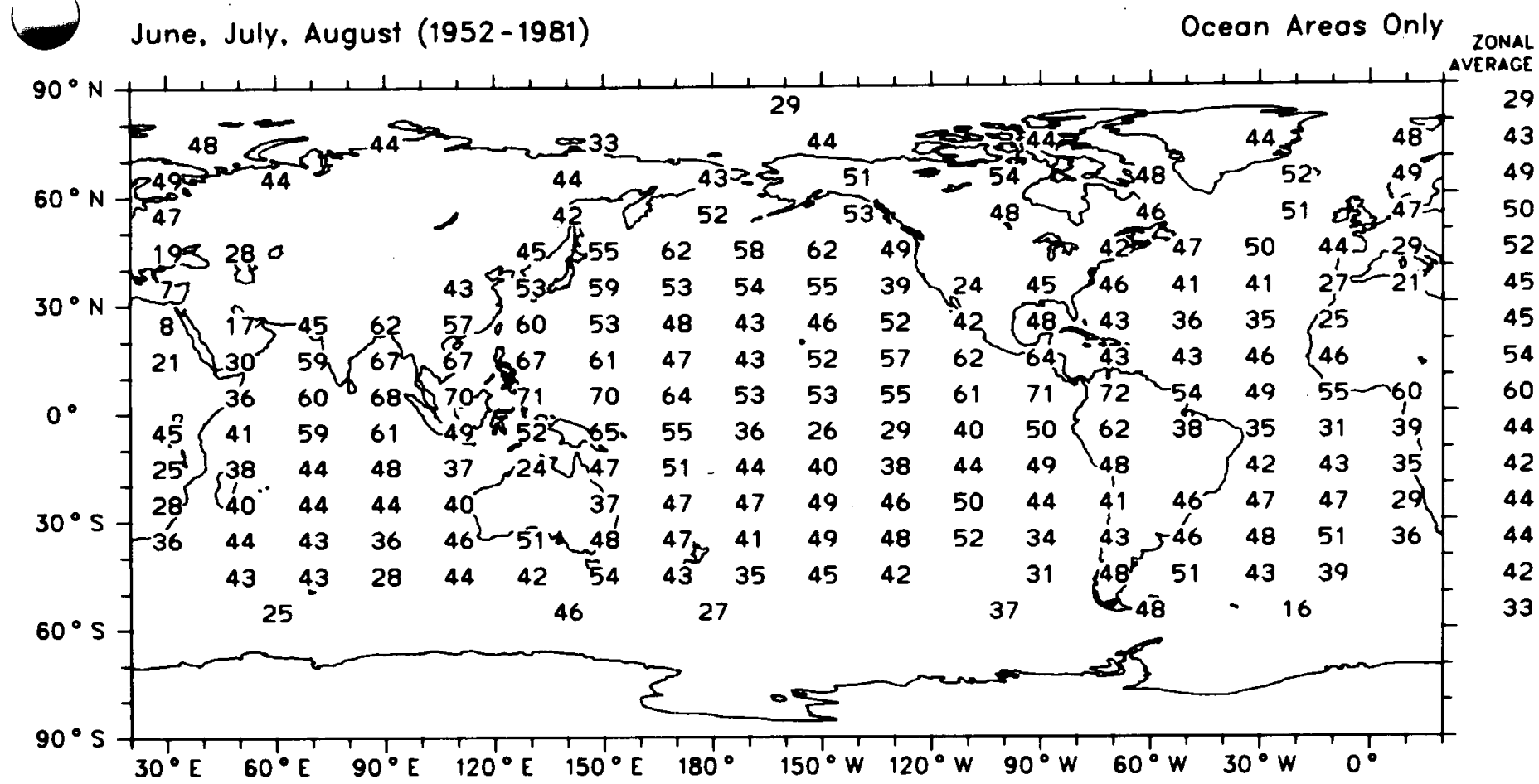

Global Average (Oceon) $46 \%$

Map 149c

\section{Altostratus + Altocumulus}

Frequency of Occurrence (\%), 6-18 LT

September. October. November (1952-1981)

Ocean Areas Only

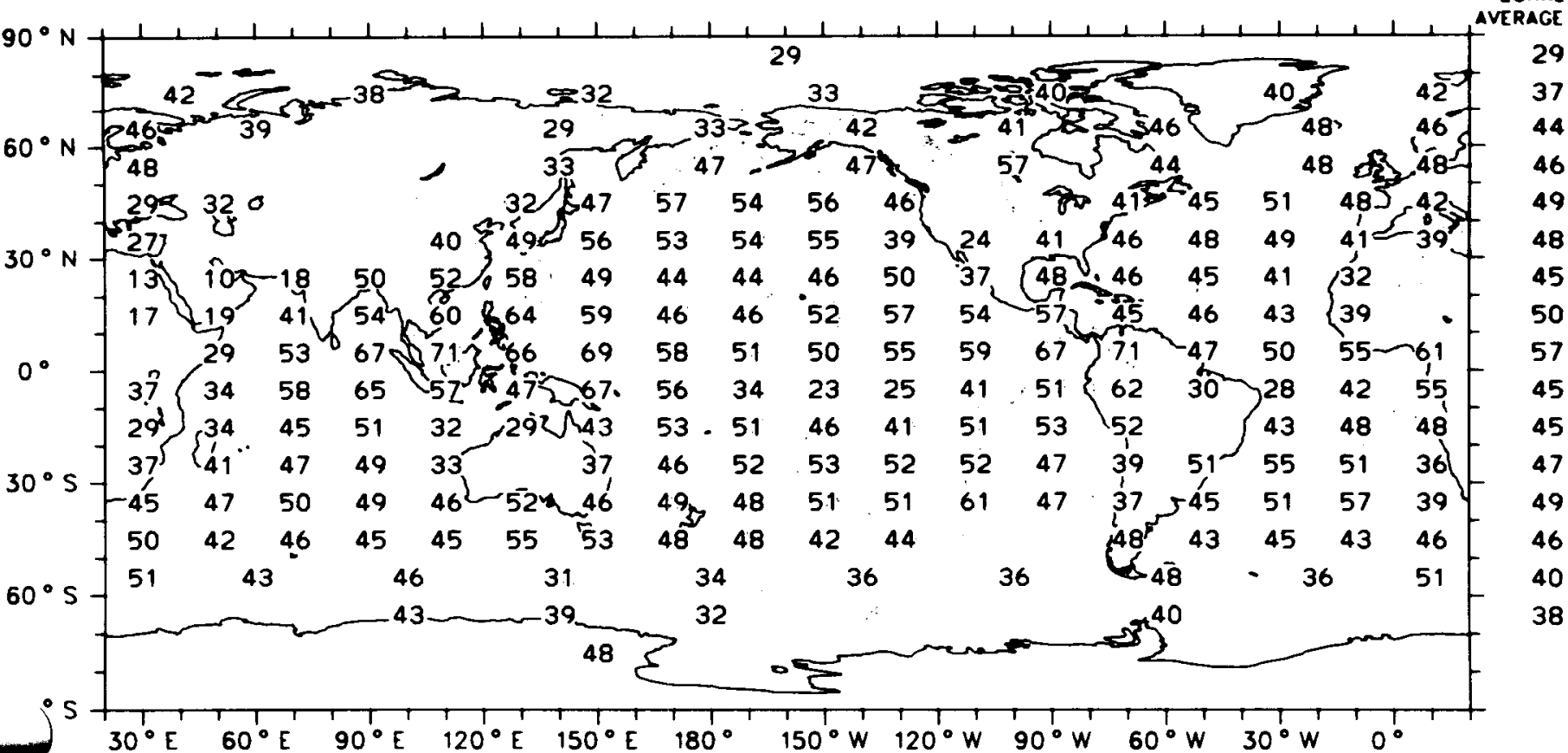

Global Averoge (Ocean) $47 \%$

Map 149d 
Altostratus + Altocumulus

Amount-When-Present (\%), 6-18 LT

December. January. February (1952-1981)

Oceon Areas Only

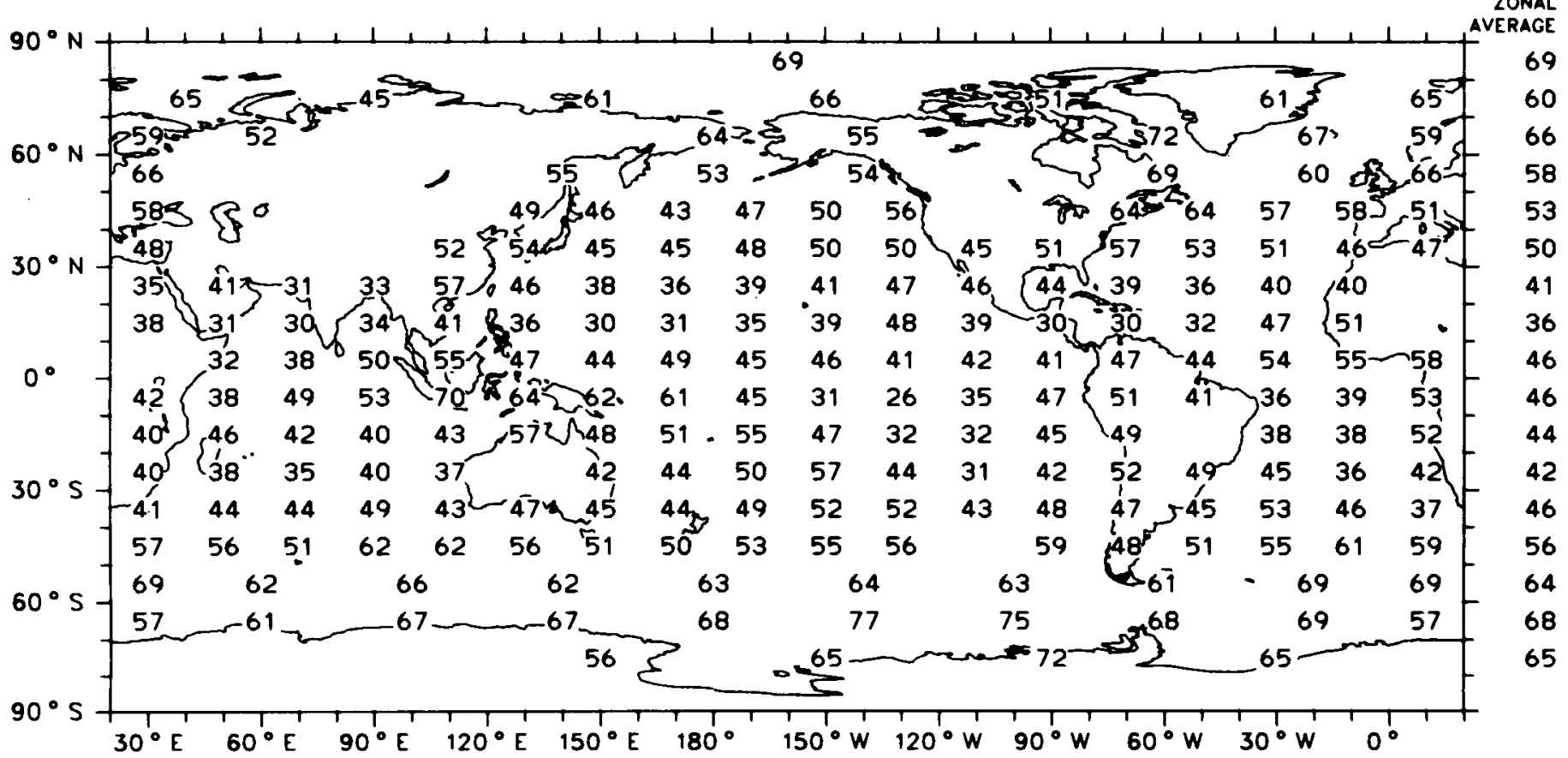

Map $150 a$

Global Average (Ocean) $49 \%$

Altostratus + Altocumulus

Amount-When-Present (\%), 6-18 LT

Morch, April, Moy (1952-1981)

Ocean Areas Only

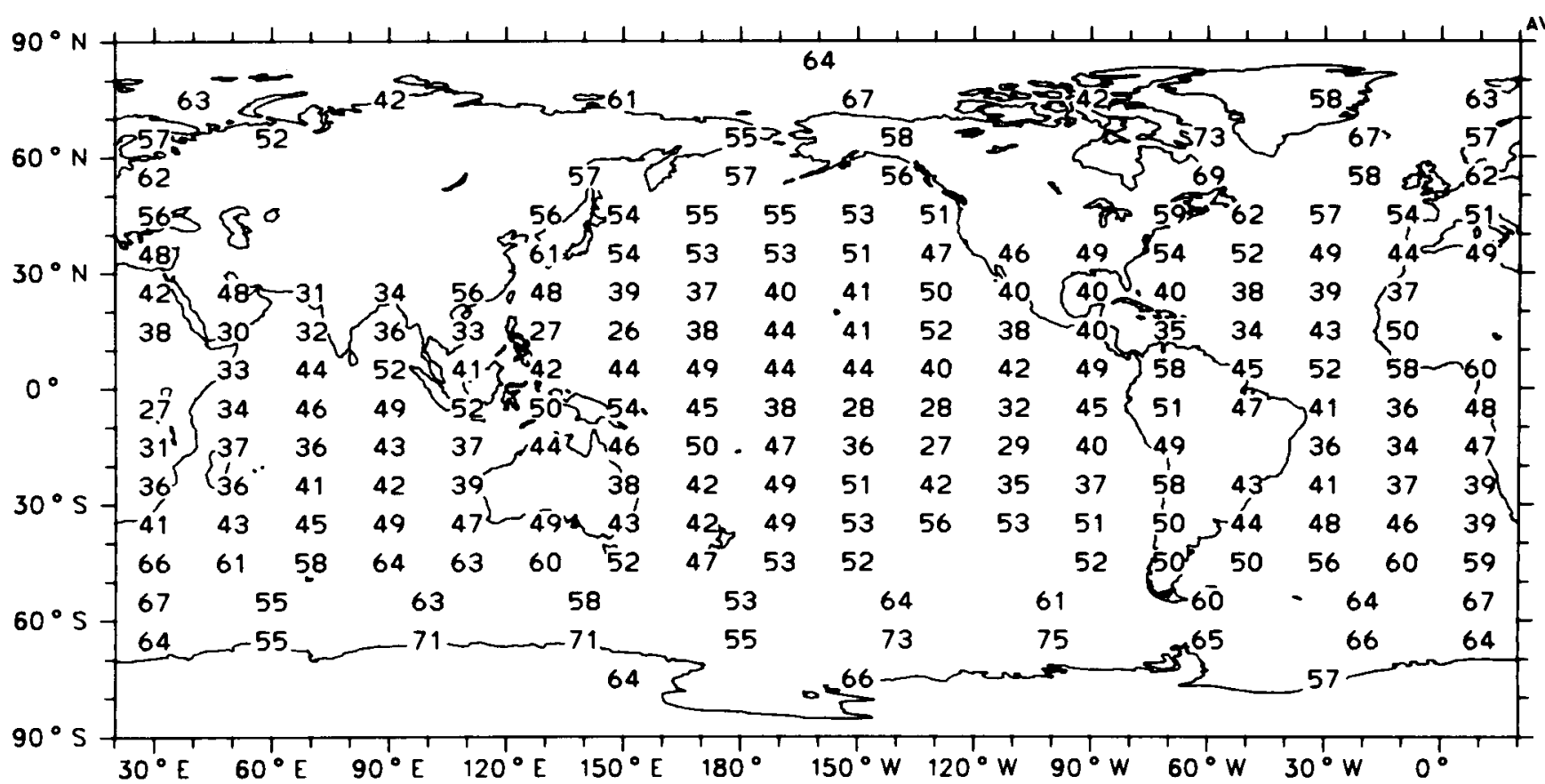
ZONAL RAGE 58 64 59 55 


\section{Altostratus + Altocumulus}

Amount-When-Present (\%), 6-18 LT

June, July, August (1952-1981)

Oceon Areas Only

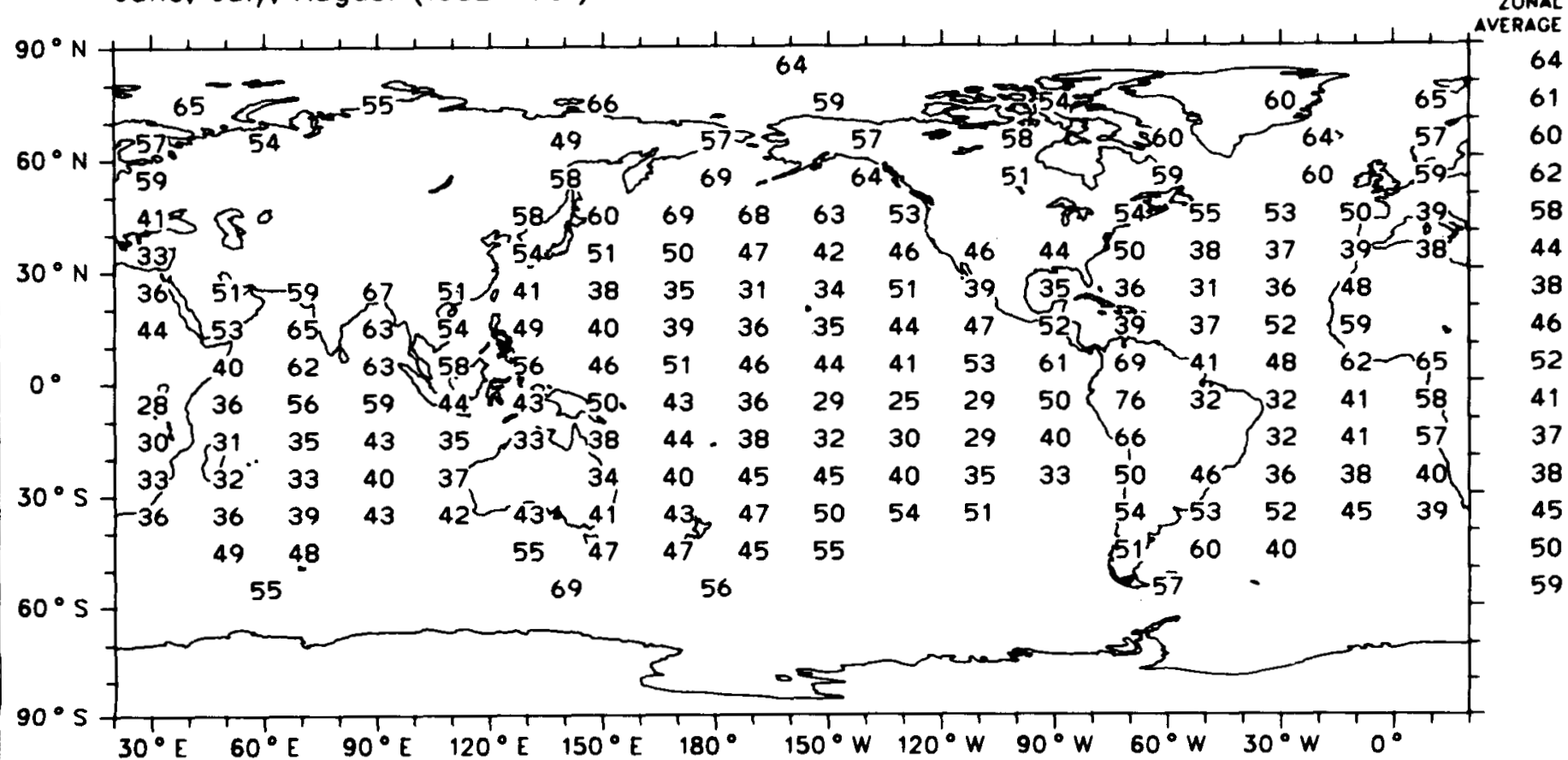

Map $150 c$

Global Averoge (Ocean) $47 \%$

Altostratus + Altocumulus

Amount-When-Present (\%), 6-18 LT

September, October, November (1952-1981)

Oceon Areos Only

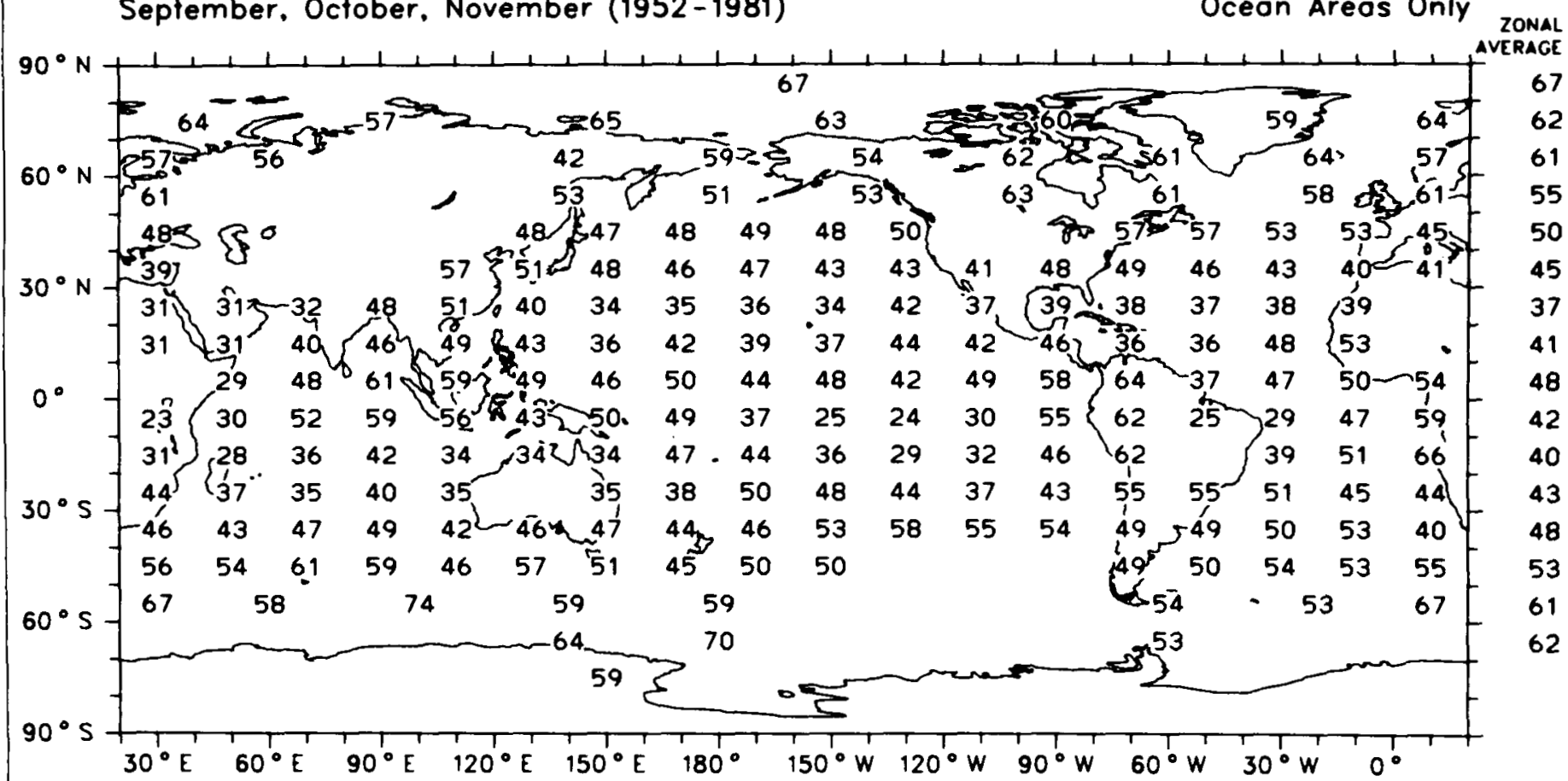

Map 150d

Globol Averoge (Oceon) $48 \%$ 
Altostratus + Altocumulus

Average Cloud Amount (\%), 6-18 LT

December, January. February (1952-1981)

Ocean Areas Only

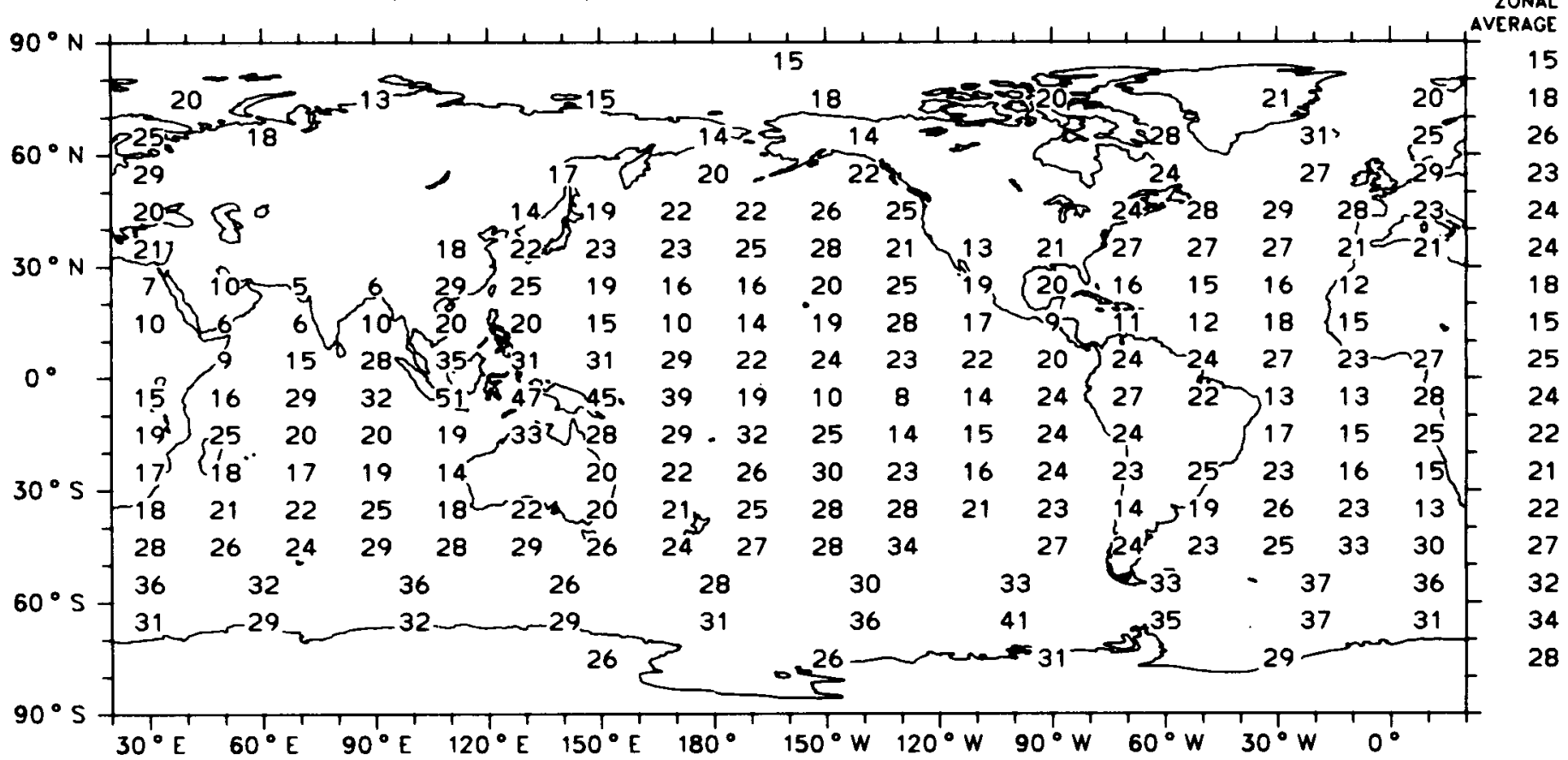

Global Average (Ocean) $23 \%$

Map 151a

Altostratus + Altocumulus

Average Cloud Amount (\%), 6-18 LT

March, April, May (1952-1981)

Oceon Areas Only

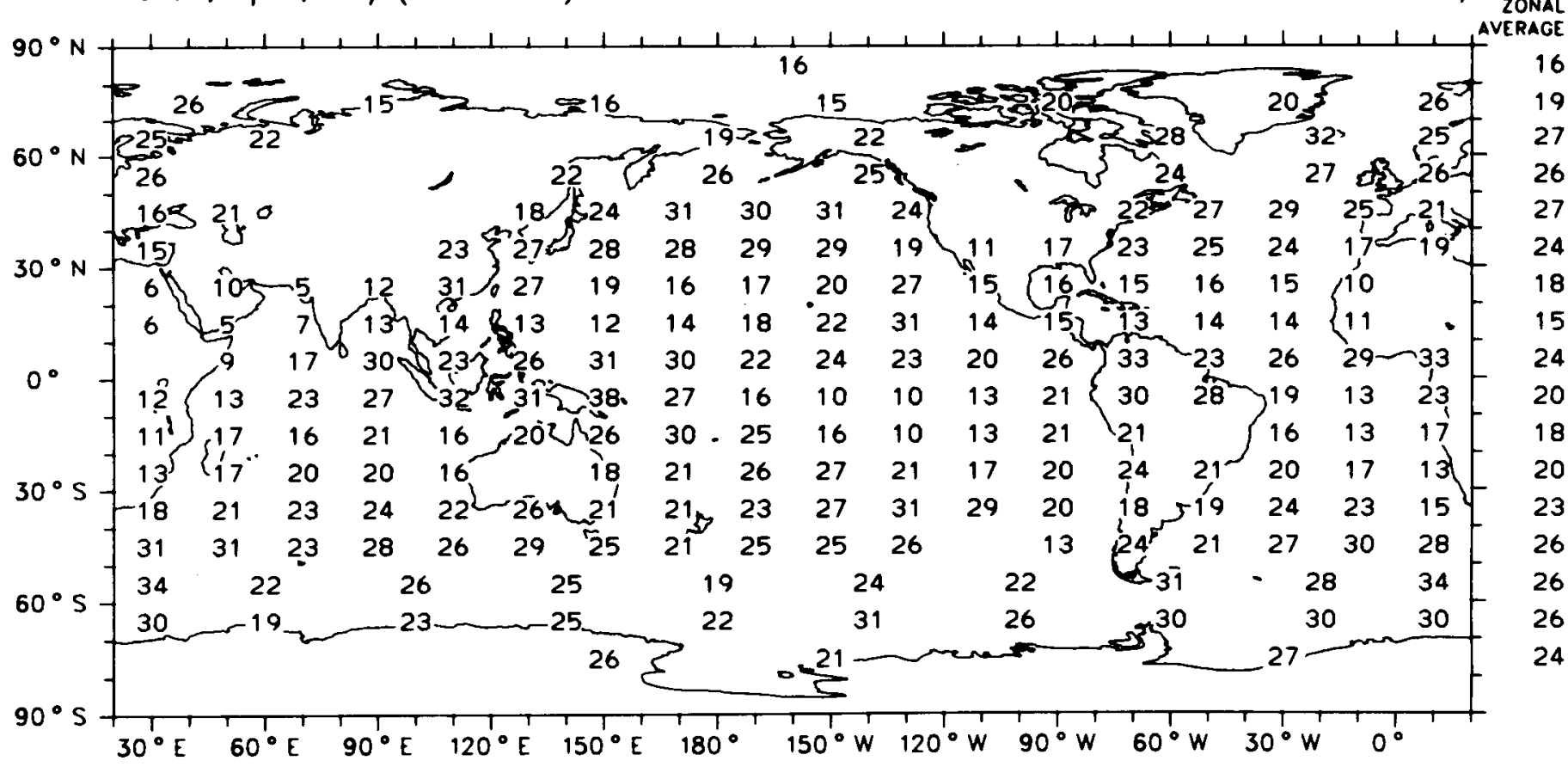

Global Average (Oceon) $22 \%$

Map 151b 
Altostratus + Altocumulus

Average Cloud Amount (\%), 6-18 LT

June, July, August (1952-1981)

Ocean Areas Only

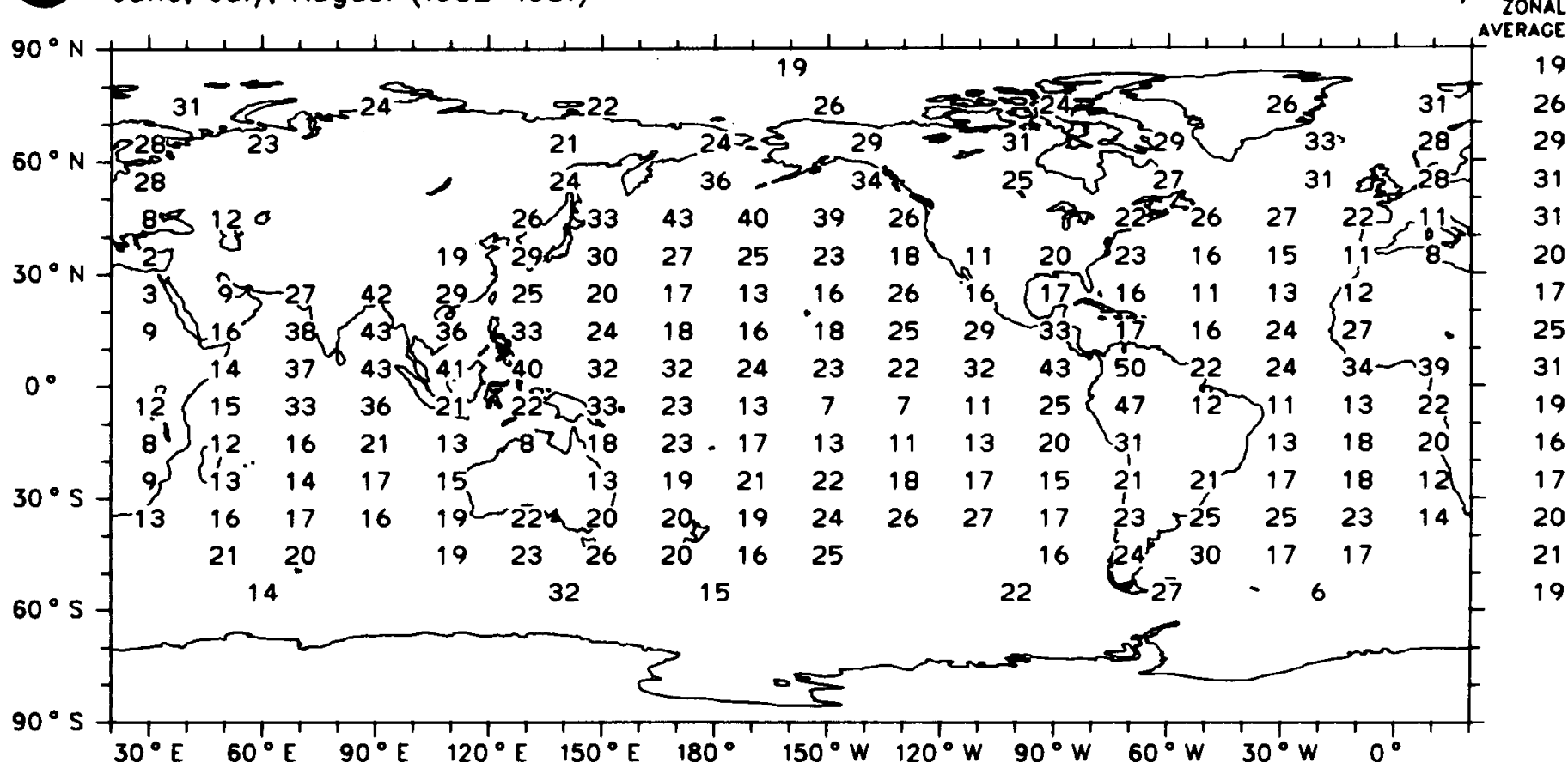

Global Averoge (Ocean) $22 \%$

Map 151c

\section{Altostratus + Altocumulus}

Average Cloud Amount (\%), 6-18 LT

September, October, November (1952 - 1981)

Ocean Areas Only

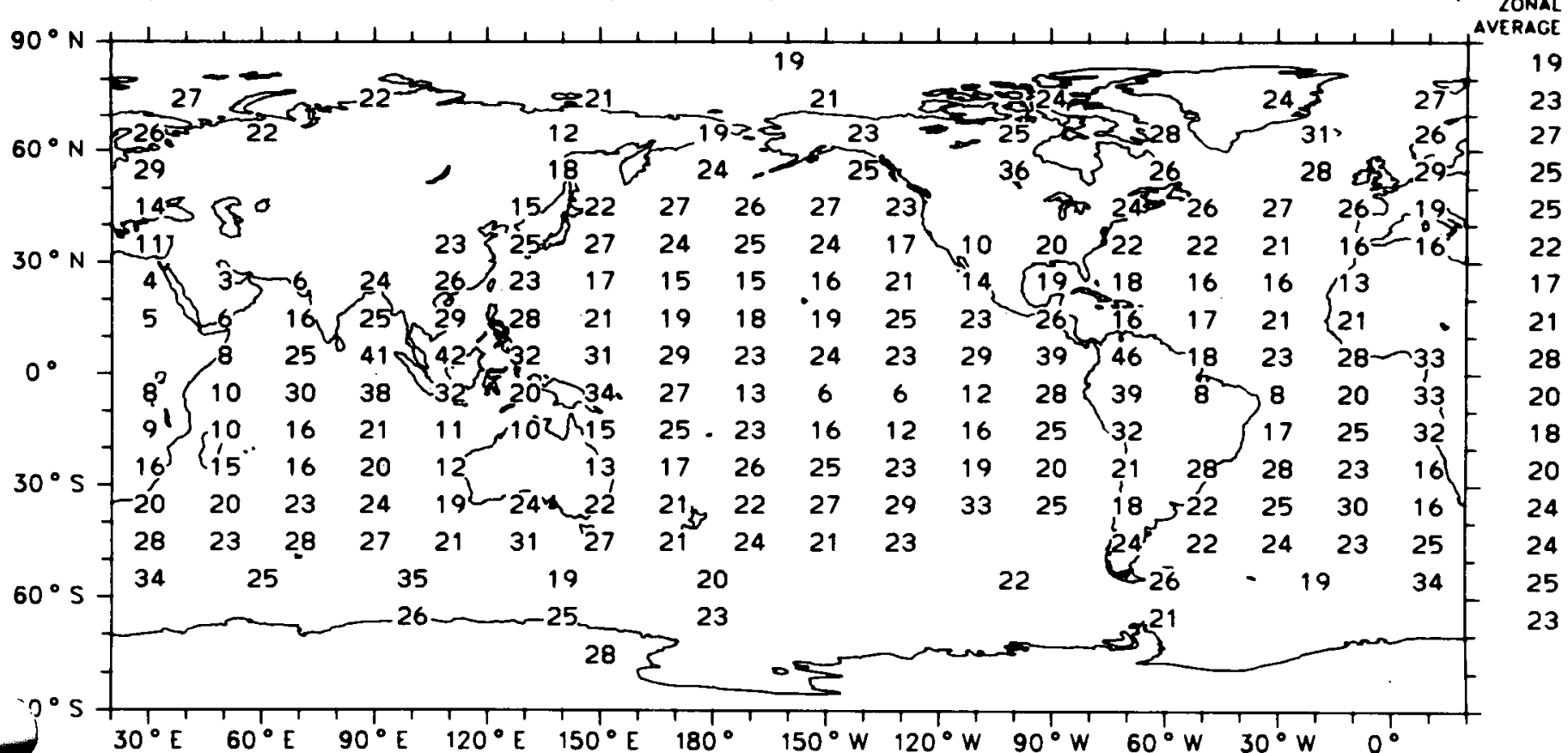

Global Averoge (Ocean) $22 \%$

Map 151d 
Interannual Variation of Altostratus + Altocumulus (6-18 LT) :

Standard Deviation (detrended) of Seasonal Means (0.1\% Cloud Amount)

December. January. February (1952-1981)

Ocean Areas Only

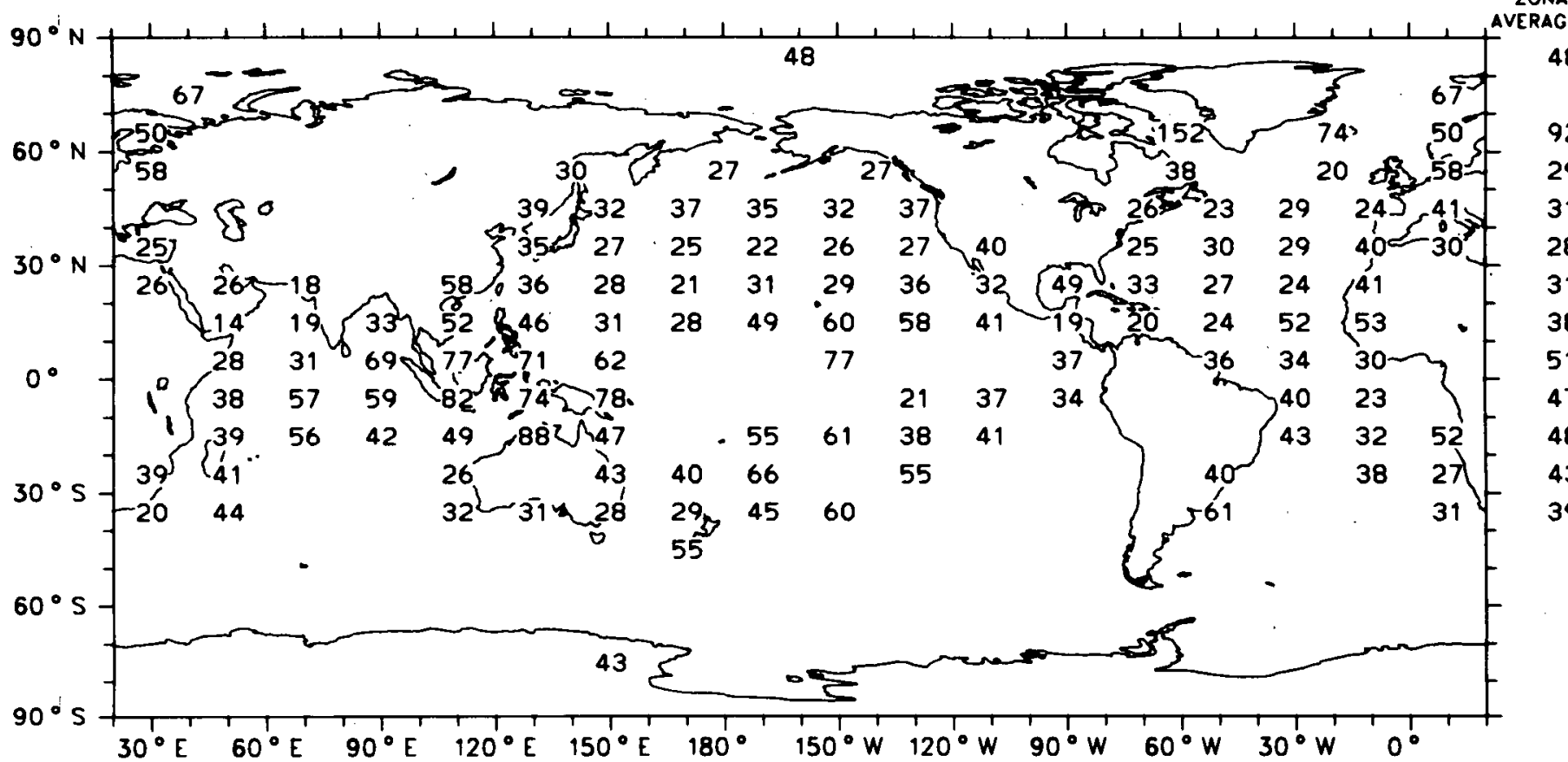

Map 152a

Global Average (Oceon) $4.2 \%$

Interannual Variation of Altostratus + Altocumulus (6-18 LT) : Standard Deviation (detrended) of Seasonal Means (0.1\% Cloud Amount) Morch, April, Moy (1952-1981)

Ocean Areas Only

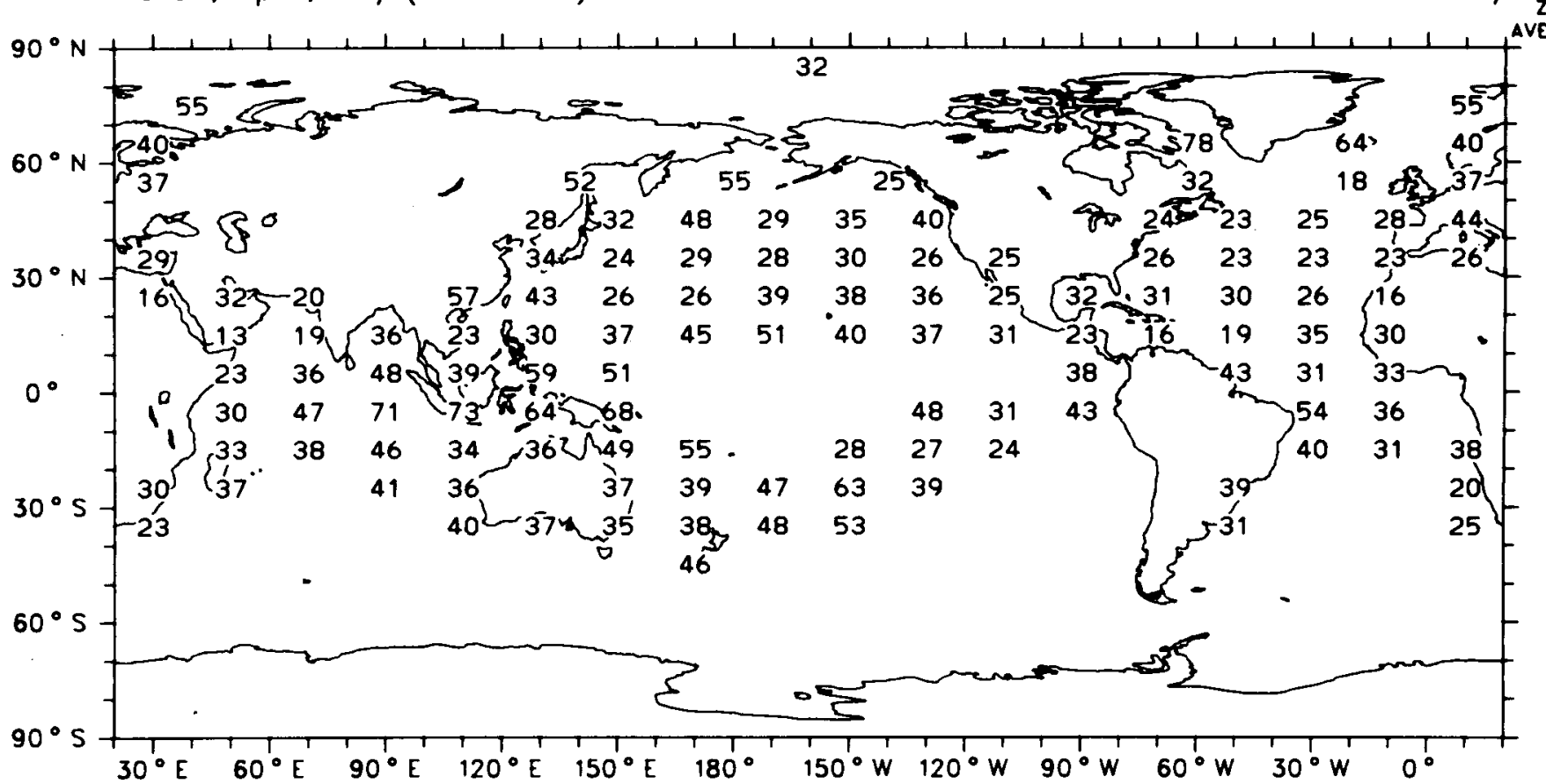

Map $152 b$ 
Interannual Variation of Altostratus + Altocumulus (6-18 LT) :

Standard Deviation (detrended) of Seasonal Means (0.1\% Cloud Amount) June, July, August (1952-1981)

Oceon Areos Only

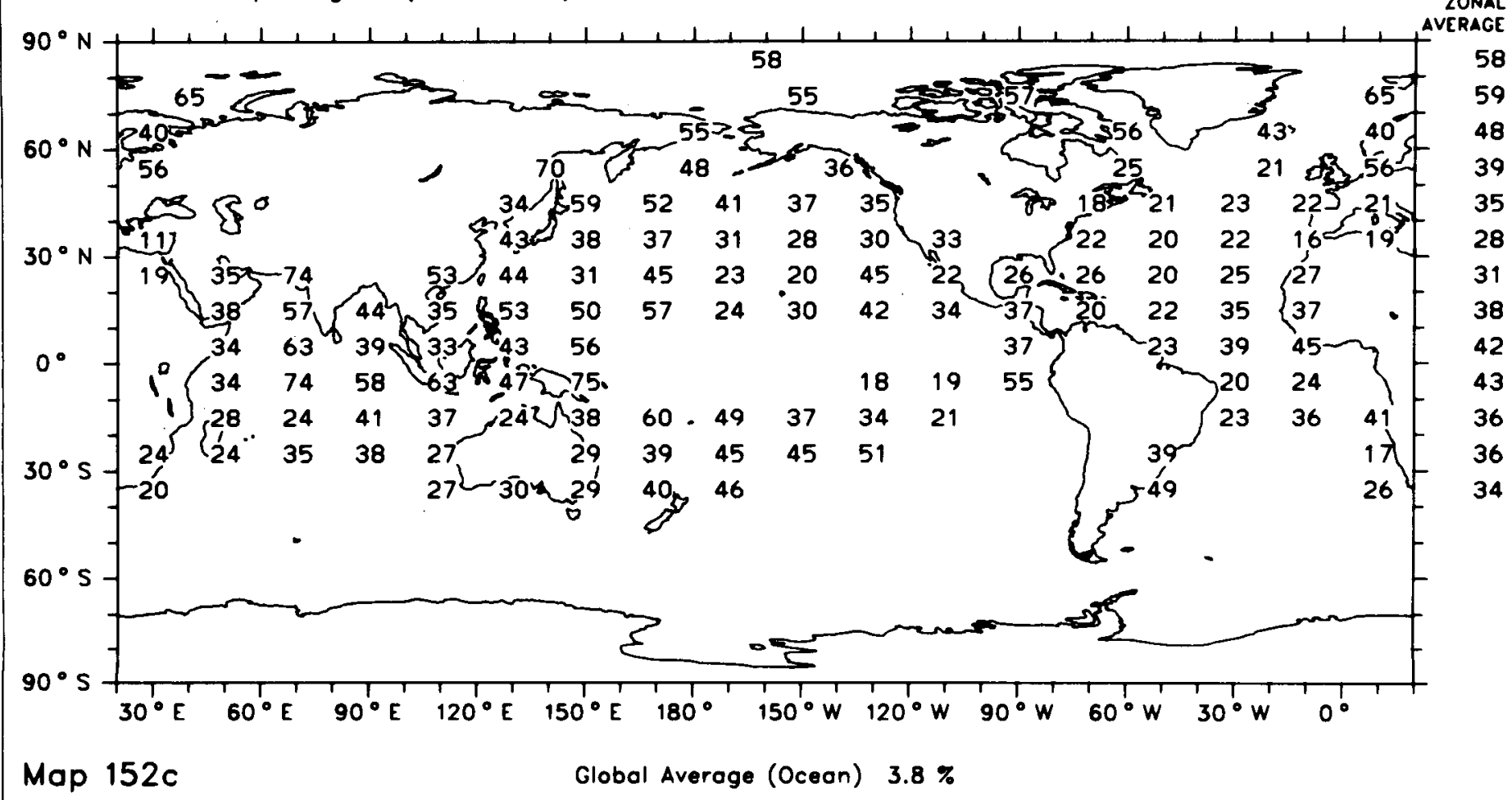

Interannual Variation of Altostratus + Altocumulus (6-18 LT) :

Standard Deviation (detrended) of Seasonal Means (0.1\% Cloud Amount)

September, October. November (1952-1981)

Ocean Areos Only

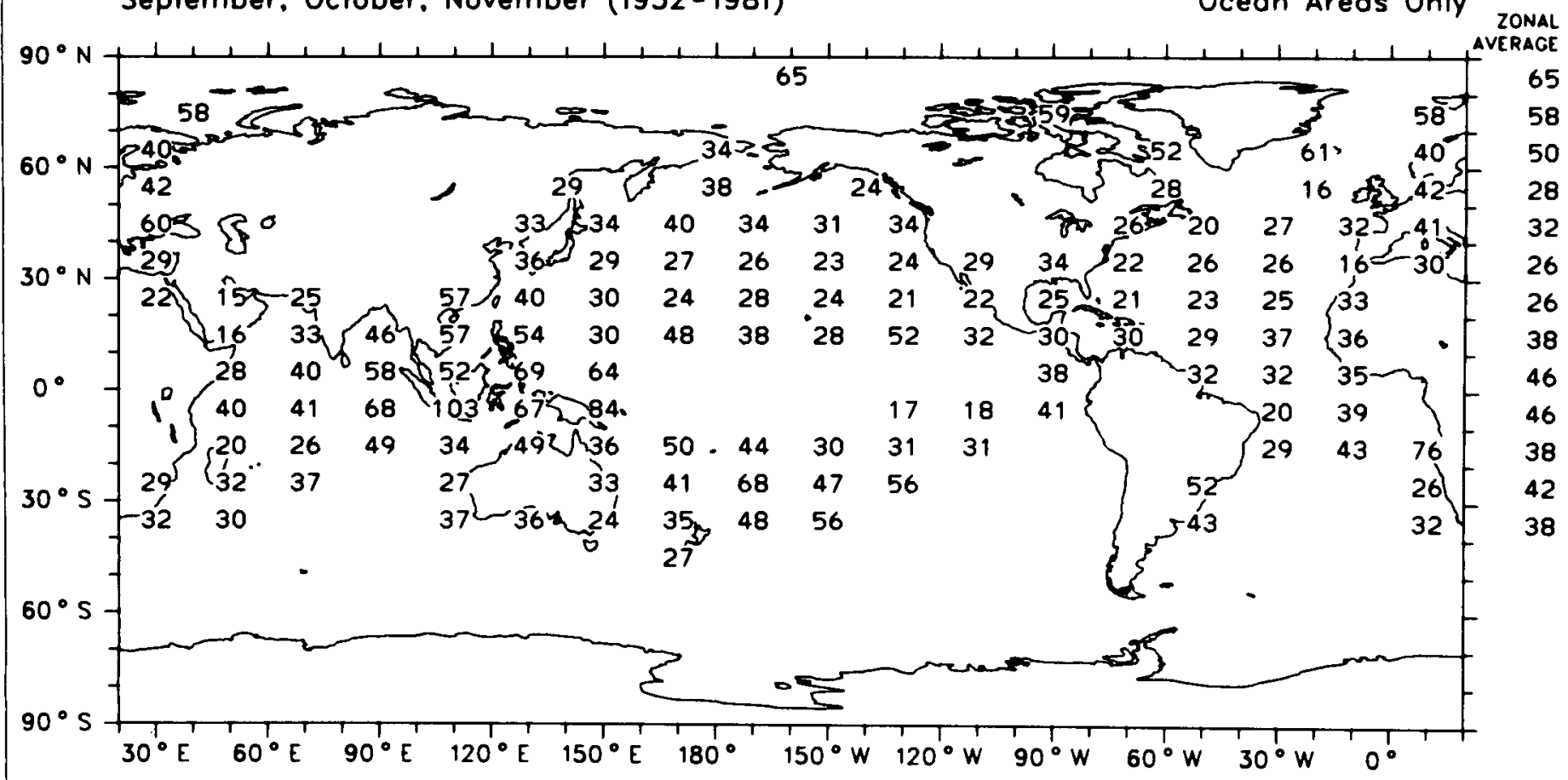

Map 152d

Global Average (Ocean) $3.9 \%$ 
Trend of Altostratus + Altocumulus (6-18 LT) :

Change in \%-Cloud-Amount from 1952 to 1981

December, January, February (1952-1981)

Ocean Areas Only

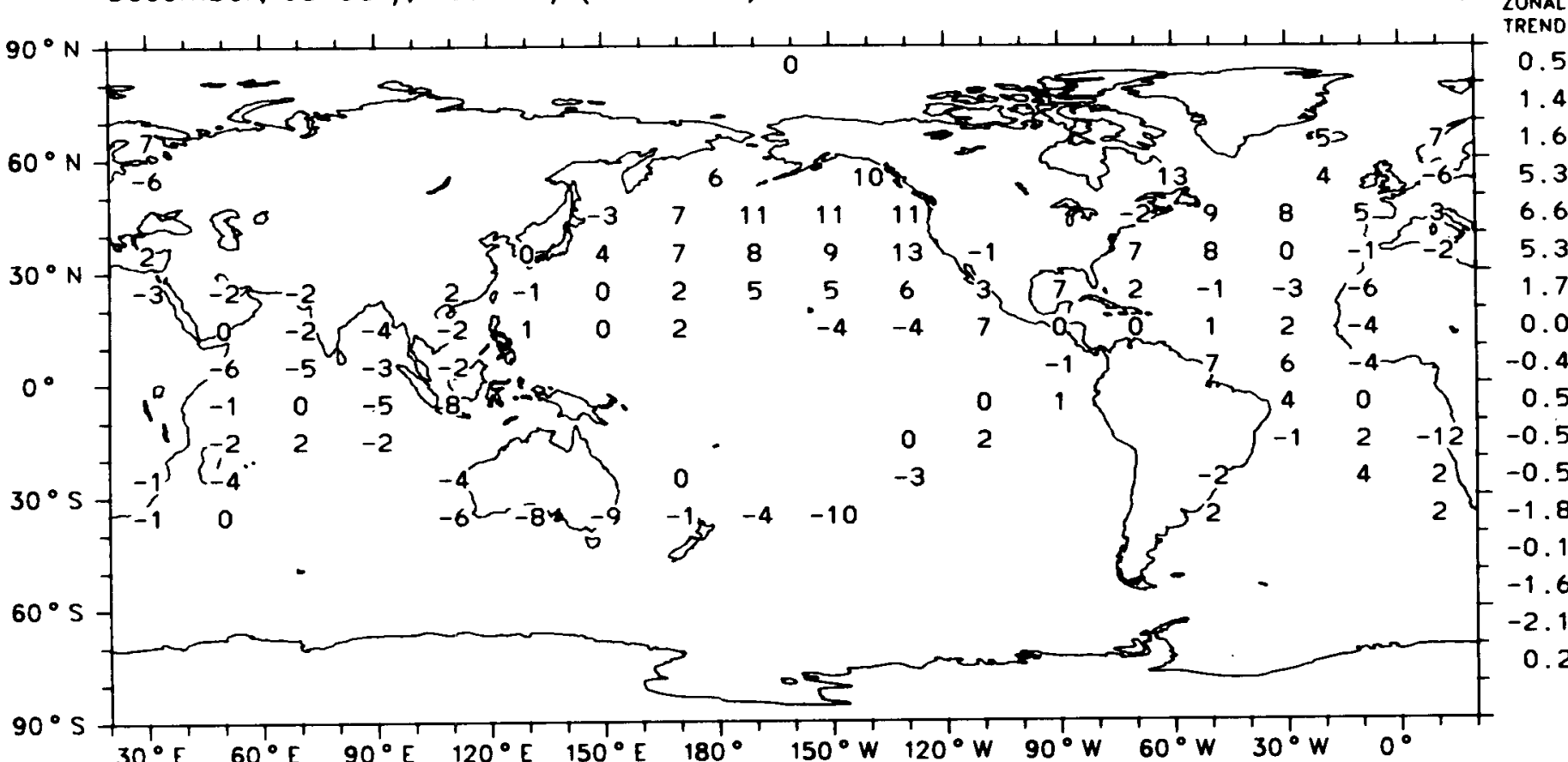

Global Trend (Ocean) $0.4 \%$

Map 153a

Trend of Altostratus + Altocumulus (6-18 LT) :

Change in \%-Cloud-Amount from 1952 to 1981

March, April, May (1952-1981)

Ocean Areas Only

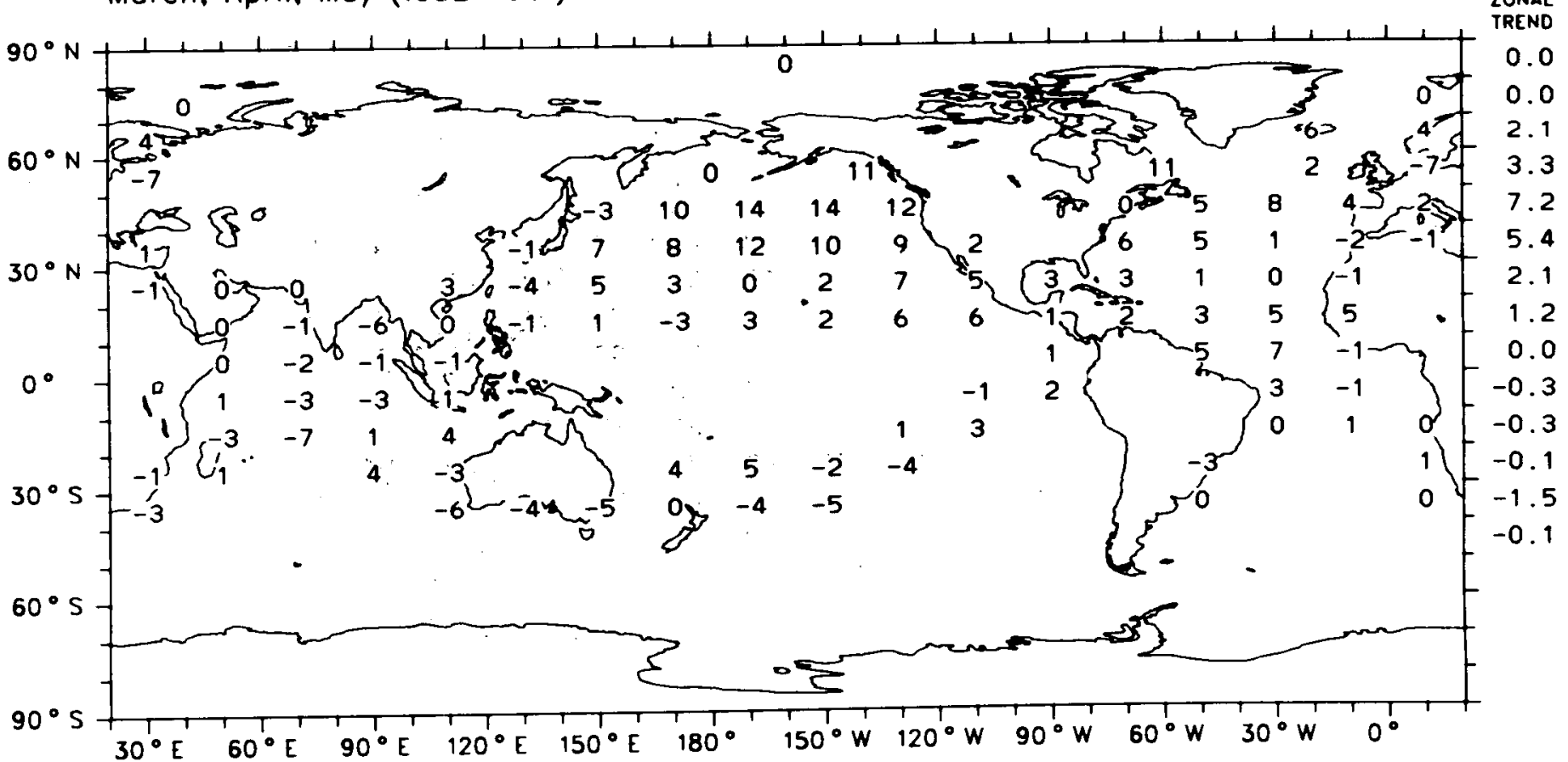

Global Trend (Ocean) $0.7 \%$

Map 153b 
Trend of Altostratus + Altocumulus (6-18 LT):

Change in \%-Cloud-Amount from 1952 to 1981

June, July, August (1952-1981)

Oceon Areas Only

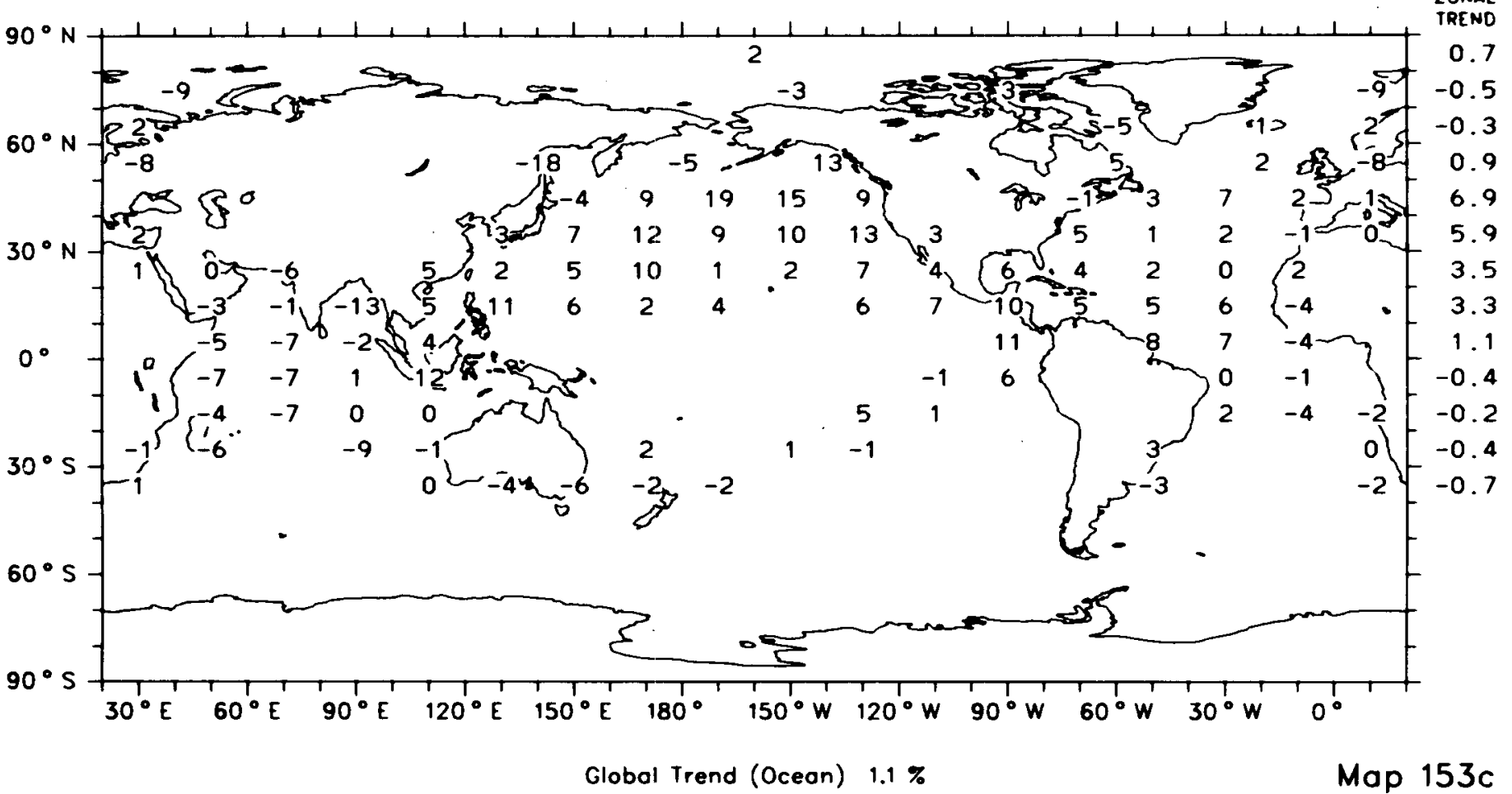

Trend of Altostratus + Altocumulus (6-18 LT) :

Change in \%-Cloud-Amount from 1952 to 1981

September, October, November (1952-1981)

Ocean Areas Only

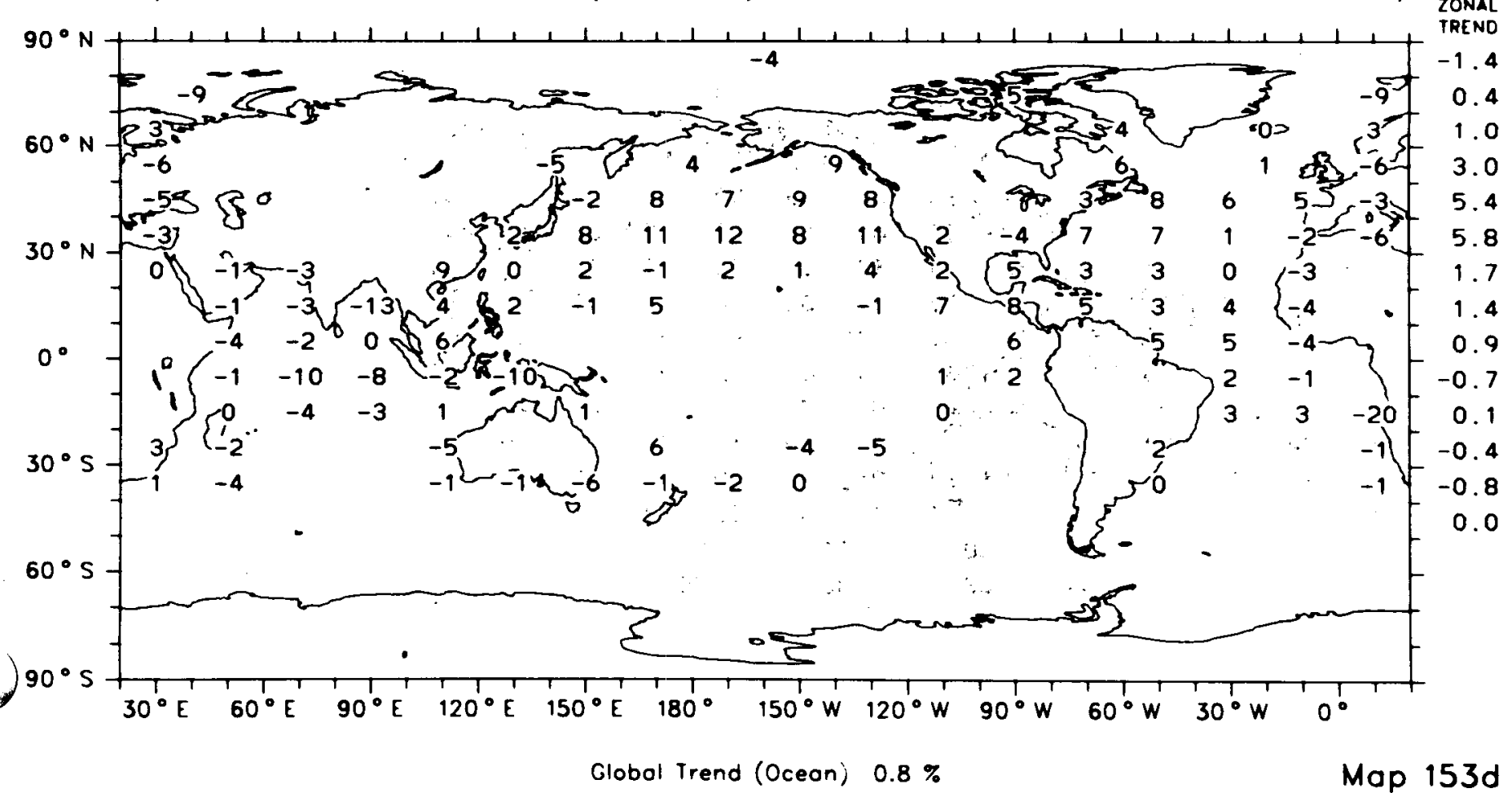


Cirrus + Cirrostratus + Cirrocumulus

Frequency of Occurrence (\%), 6-18 LT

December, Januory, February (1952-1981)

Ocean Areas Only

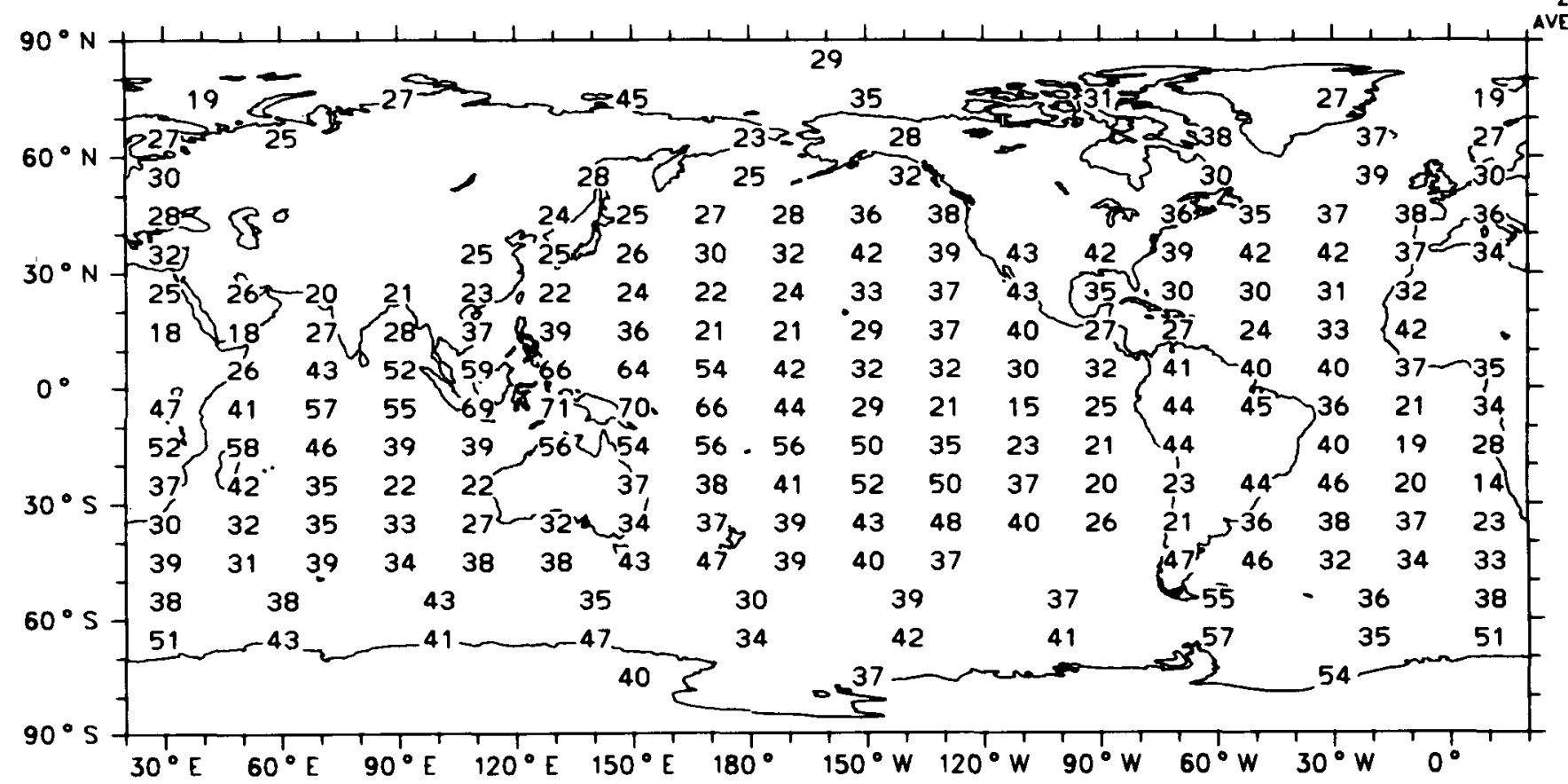

Map $154 a$

Global Average (Ocean) $37 \%$

Cirrus + Cirrostratus + Cirrocumulus

Frequency of Occurrence (\%), 6-18 LT

Morch. April, May (1952-1981)

Ocean Areas Only

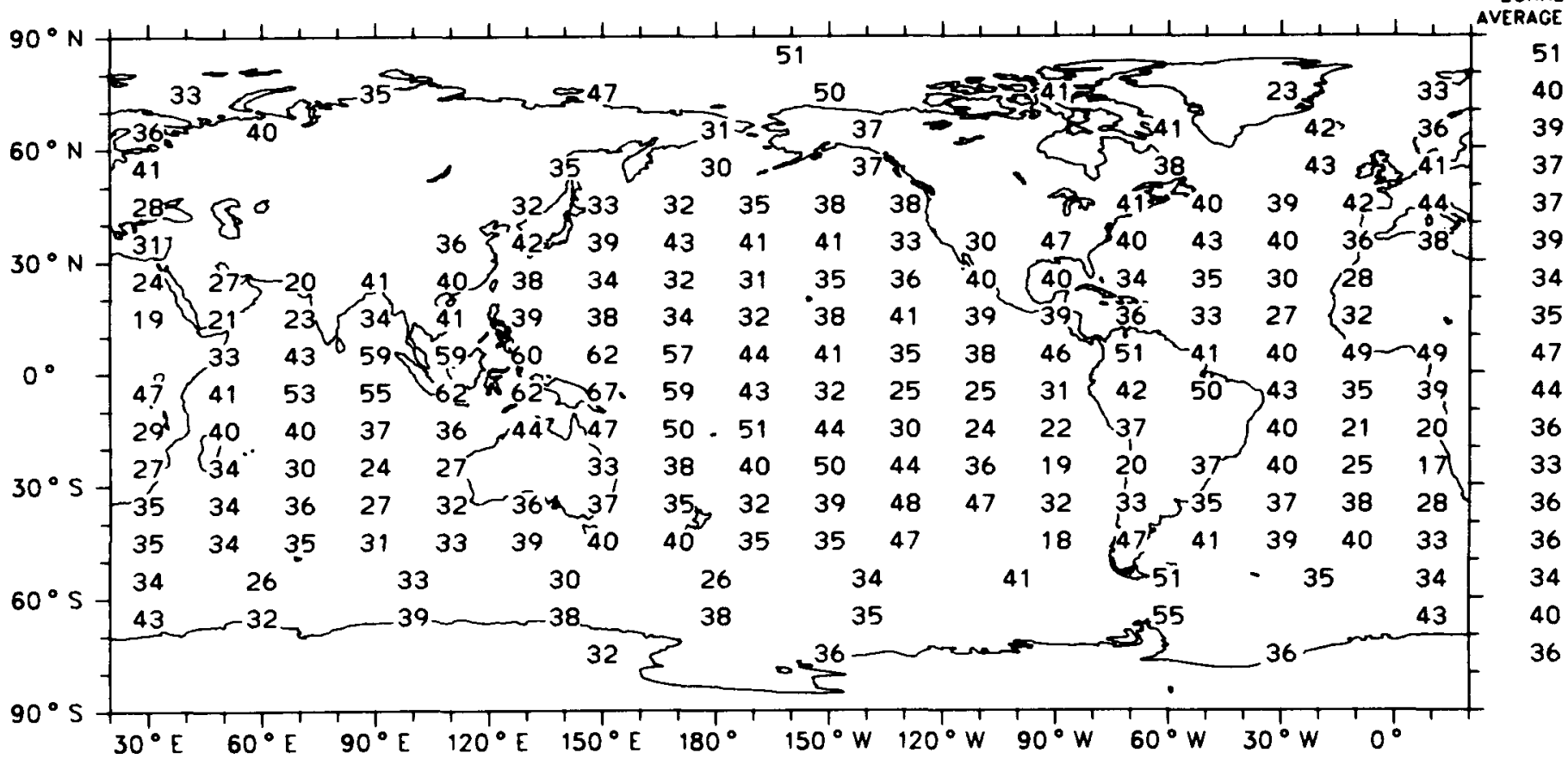

Map 154b

Global Averoge (Oceon) $38 \%$ 
Cirrus + Cirrostratus + Cirrocumulus

Frequency of Occurrence (\%), 6-18 LT

June, July, August (1952-1981)

Ocean Areos Only

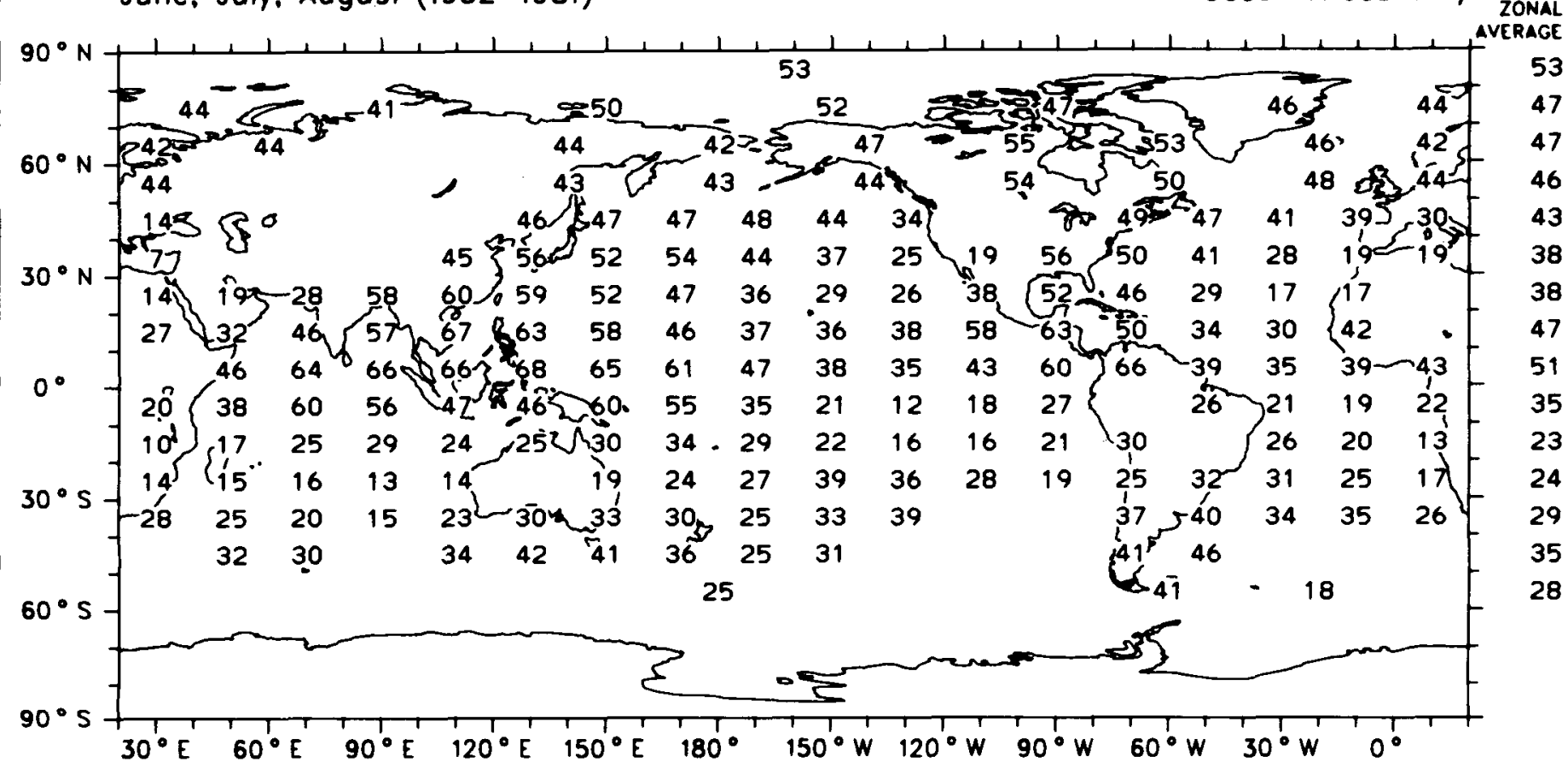

Map 154c

Global Average (Ocean) $36 \%$

Cirrus + Cirrostratus + Cirrocumulus

Frequency of Occurrence (\%), 6-18 LT

September, October, November (1952-1981)

Ocean Areas Only

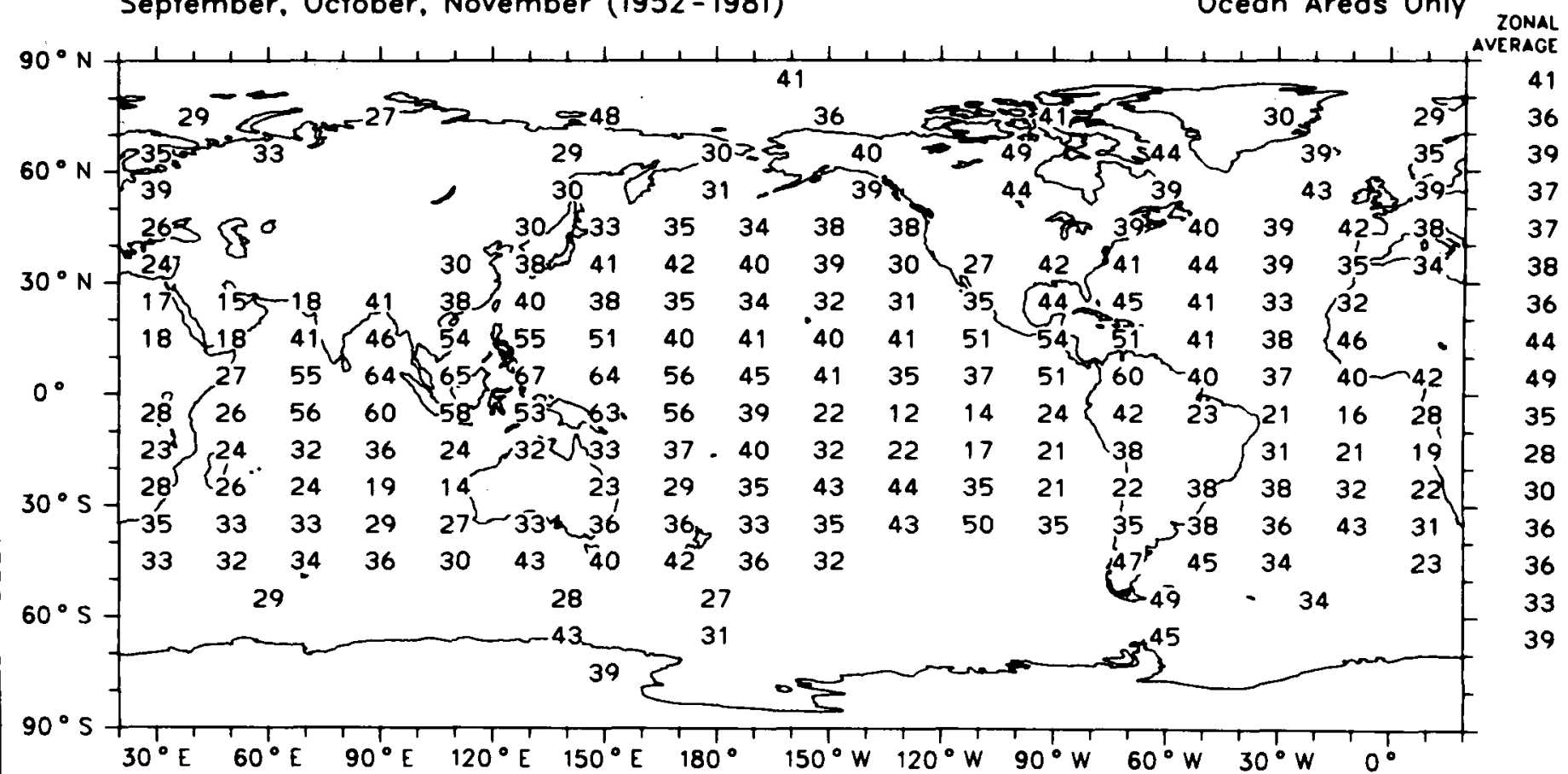

Map 154d

Global Average (Oceon) $37 \%$ 
Cirrus + Cirrostratus + Cirrocumulus

Amount-When-Present (\%), 6-18 LT

December. January, February (1952-1981)

Ocean Areas Only

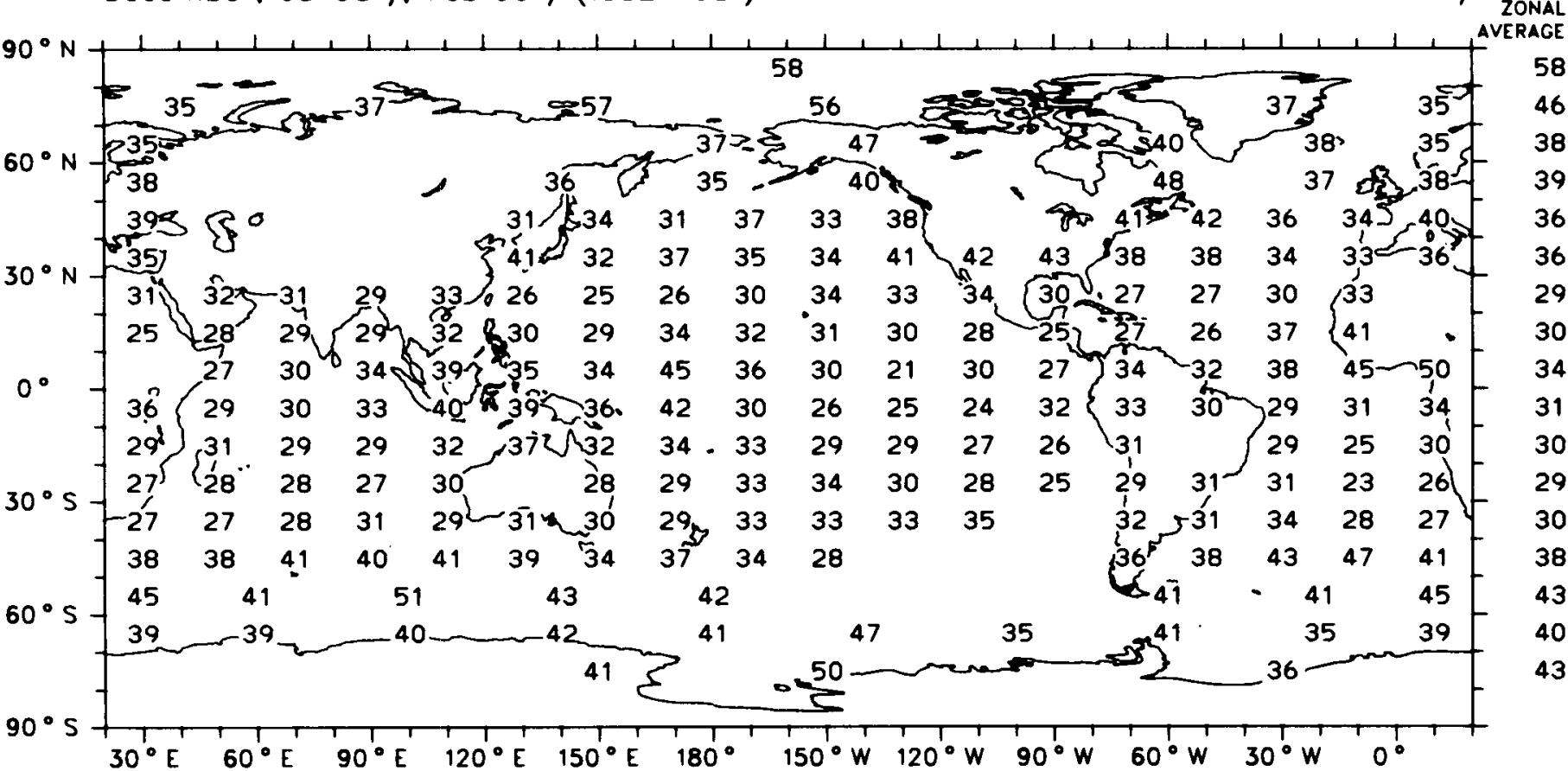

Global Average (Ocean) $34 \%$

Map 155a

Cirrus + Cirrostratus + Cirrocumulus

Amount-When-Present (\%), 6-18 LT

Morch. April. Moy (1952-1981)

Ocean Areas Only

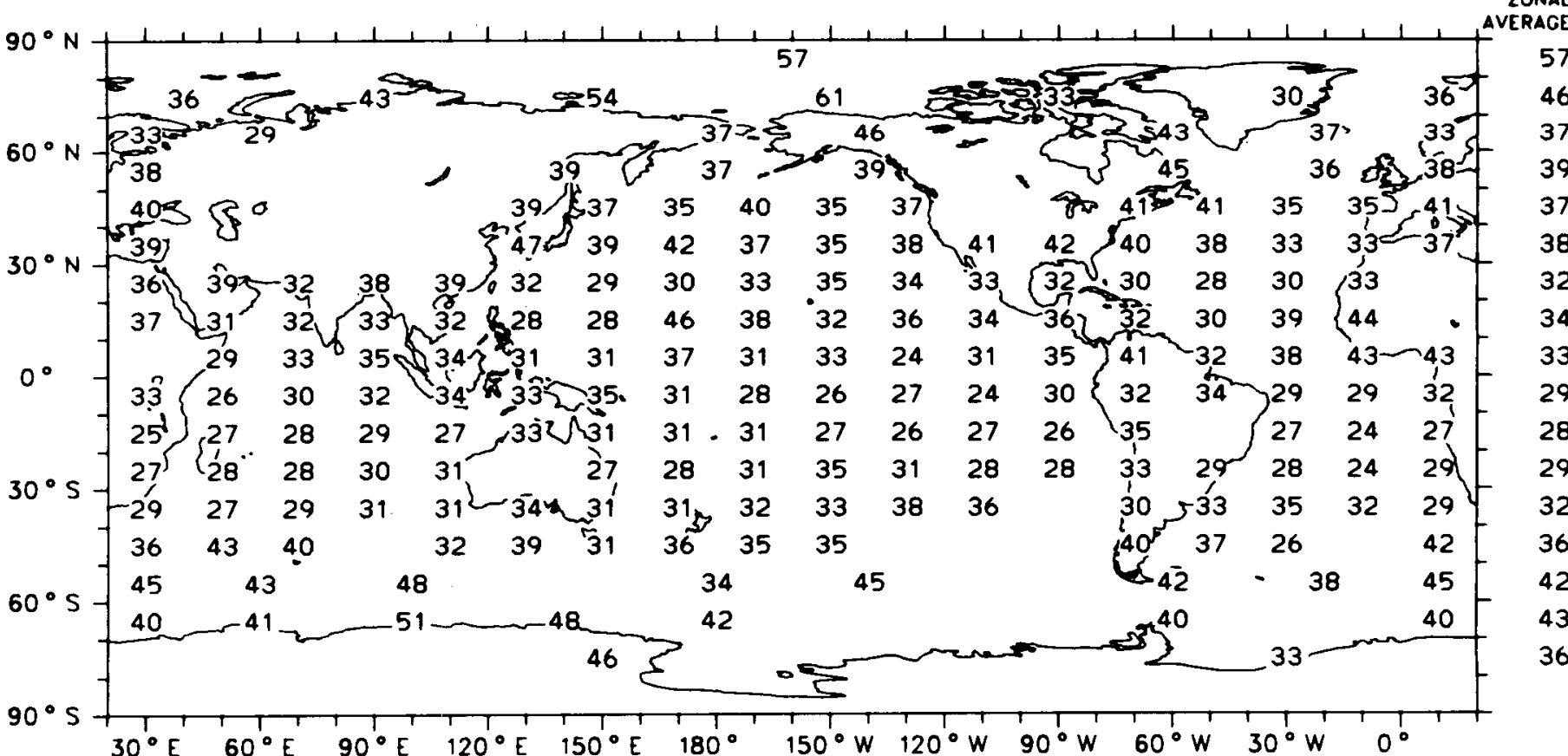

Global Average (Ocean) $34 \%$

Map 155b 
June. July. August (1952-1981)

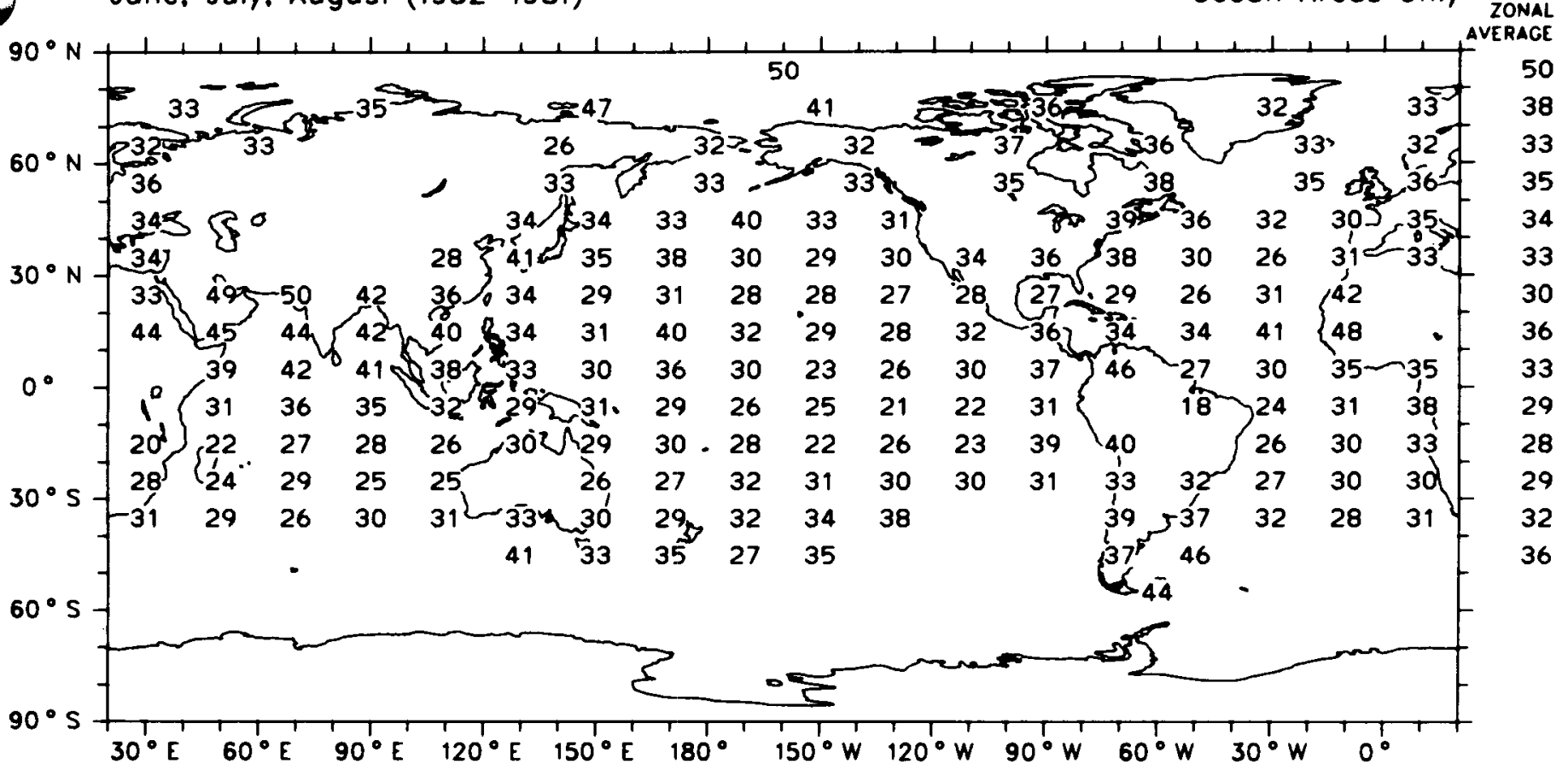

Global Averoge (Ocean) $32 \%$

Map 155c

\section{Cirrus + Cirrostratus + Cirrocumulus \\ Amount-When-Present (\%), 6-18 LT}

September, October. November (1952-1981)

Ocean Areas Only

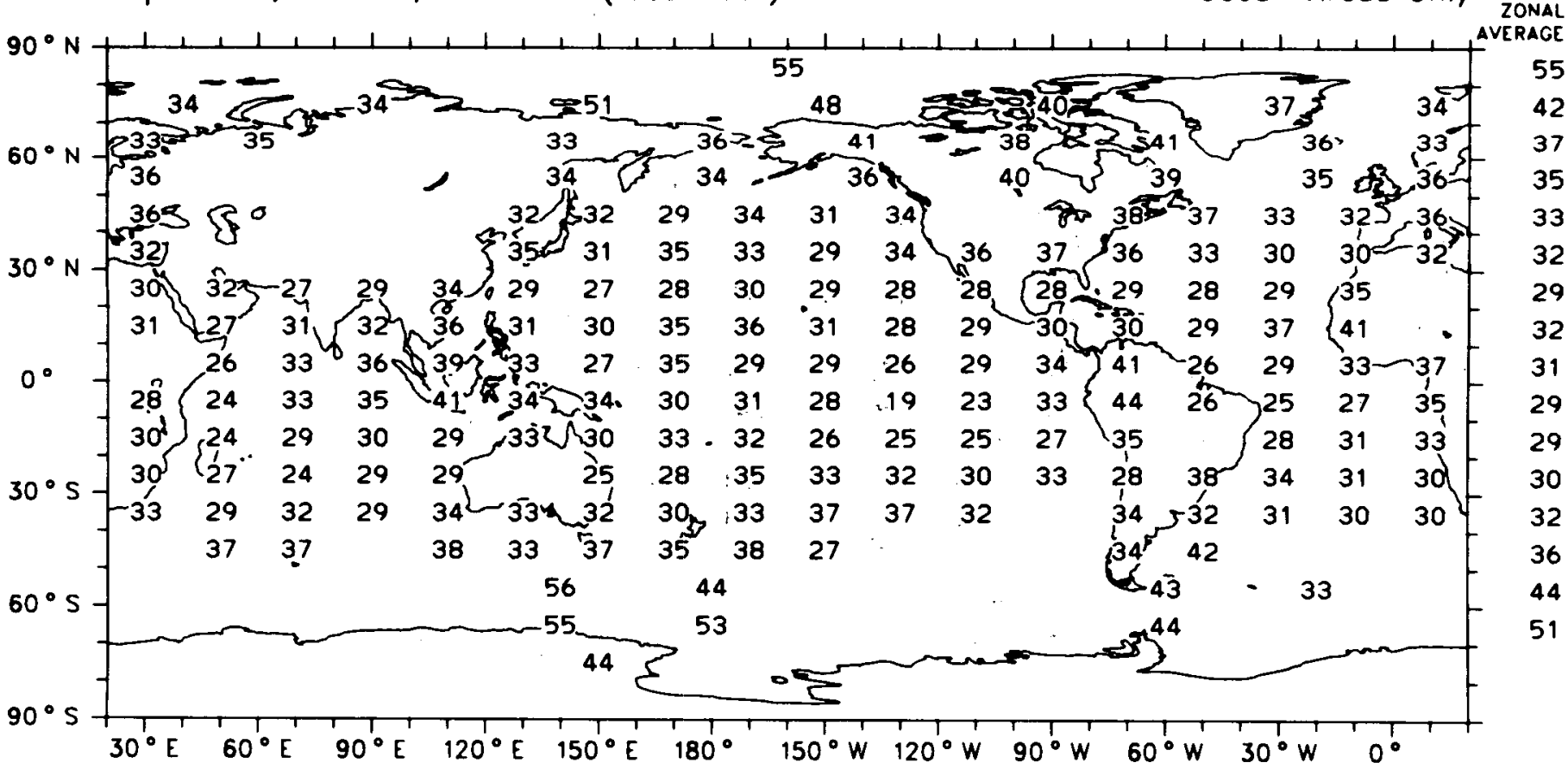




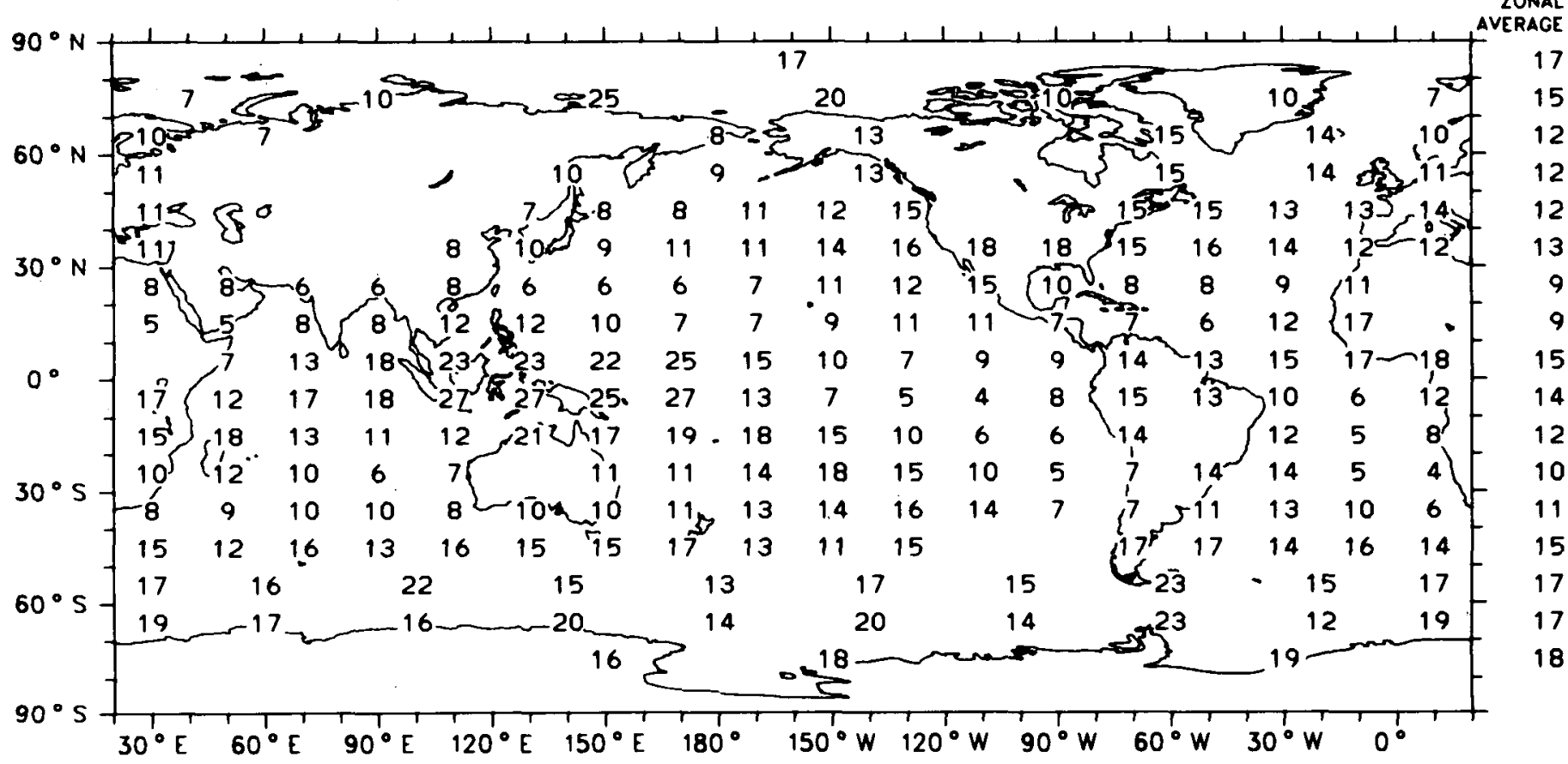

Map 156a

Global Average (Oceon) $13 \%$

Cirrus + Cirrostratus + Cirrocumulus

Average Cloud Amount (\%), 6-18 LT

Morch. April, May (1952-1981)

Ocean Areas Only

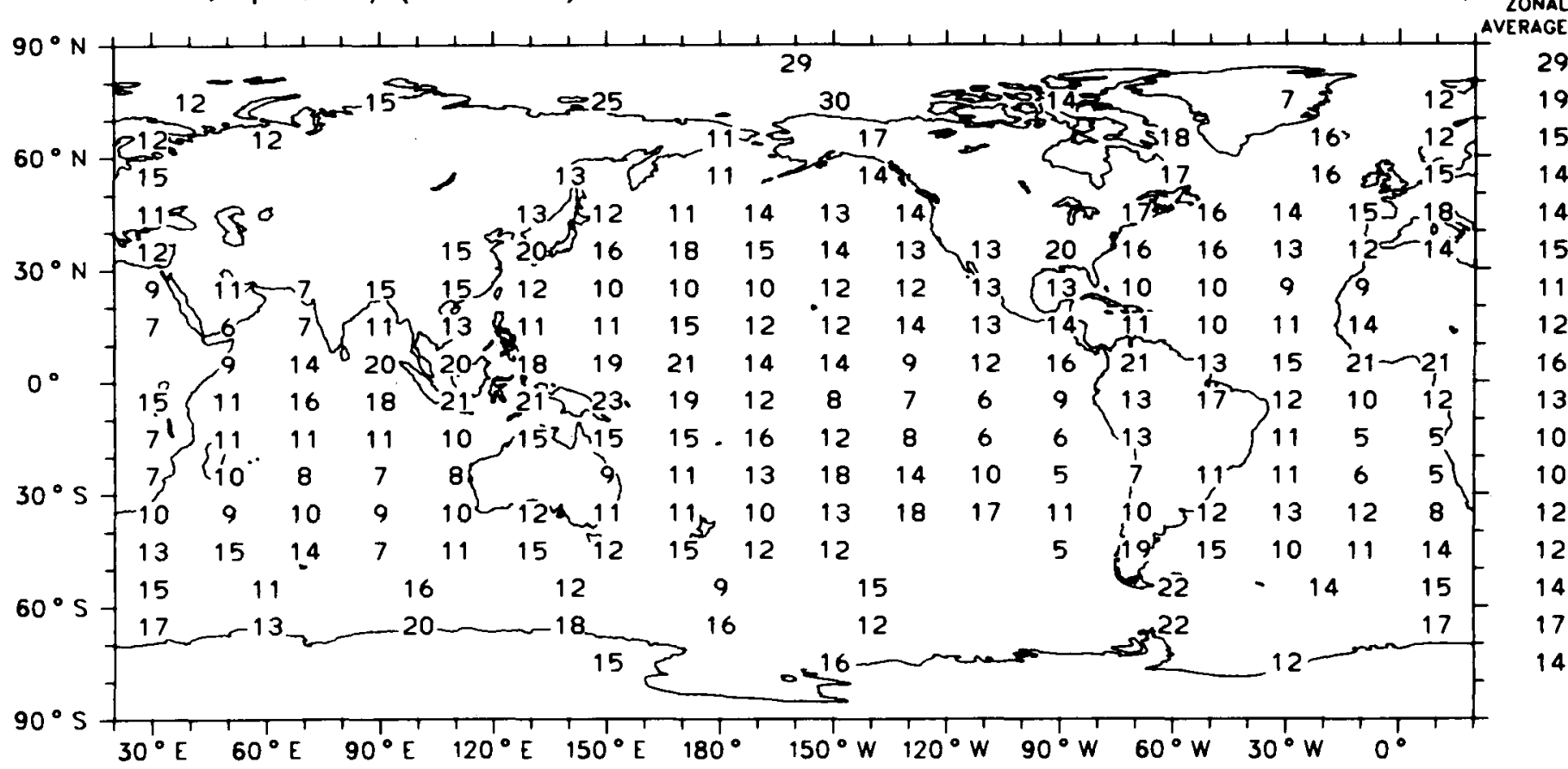

Map 156b

Global Average (Oceon) $13 \%$ 


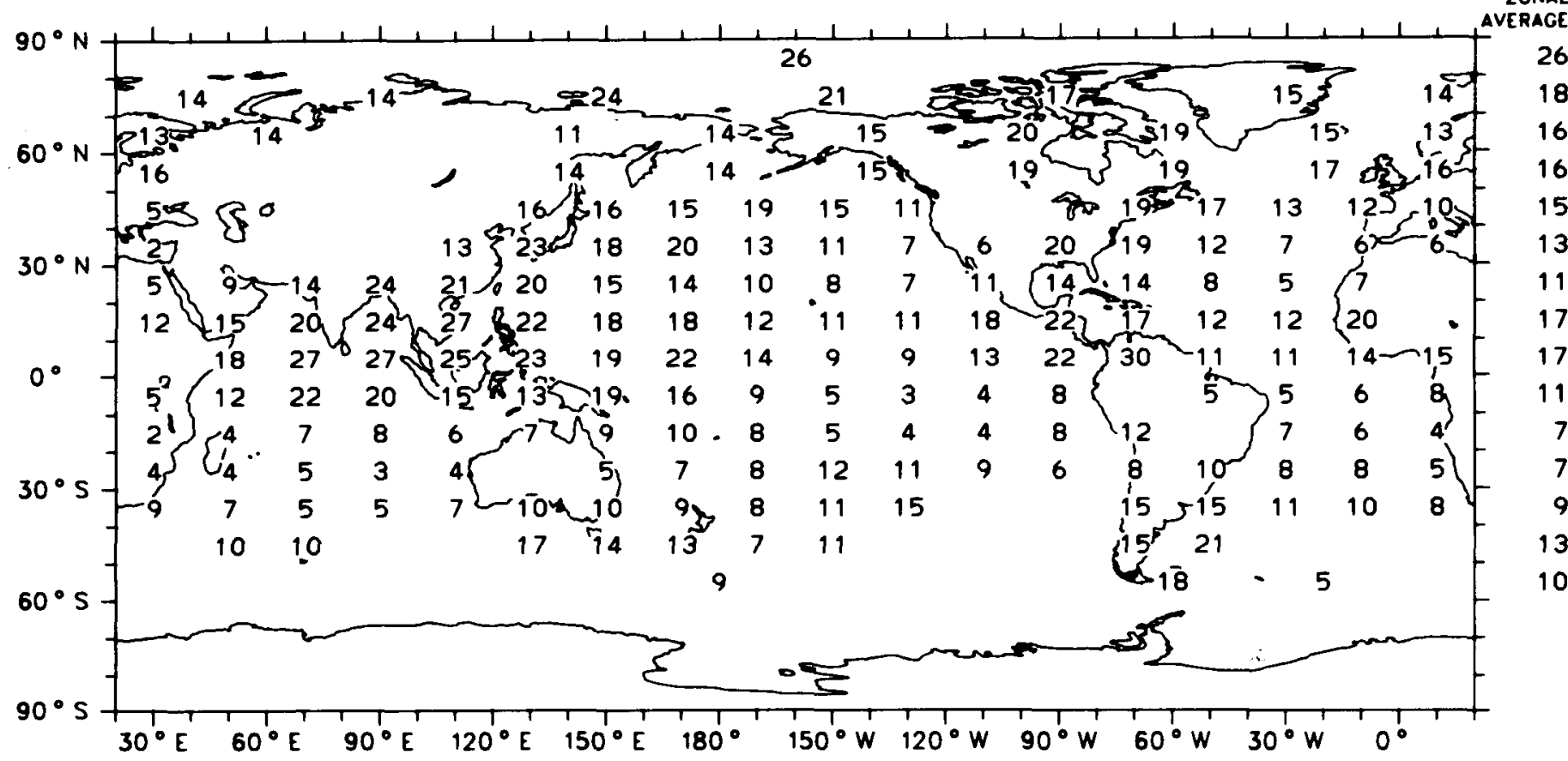

Map 156c

Globol Averoge (Oceon) $12 \%$

\section{Cirrus + Cirrostratus + Cirrocumulus}

Average Cloud Amount (\%), 6-18 LT

September, October, November (1952-1981)

Ocean Areas Only

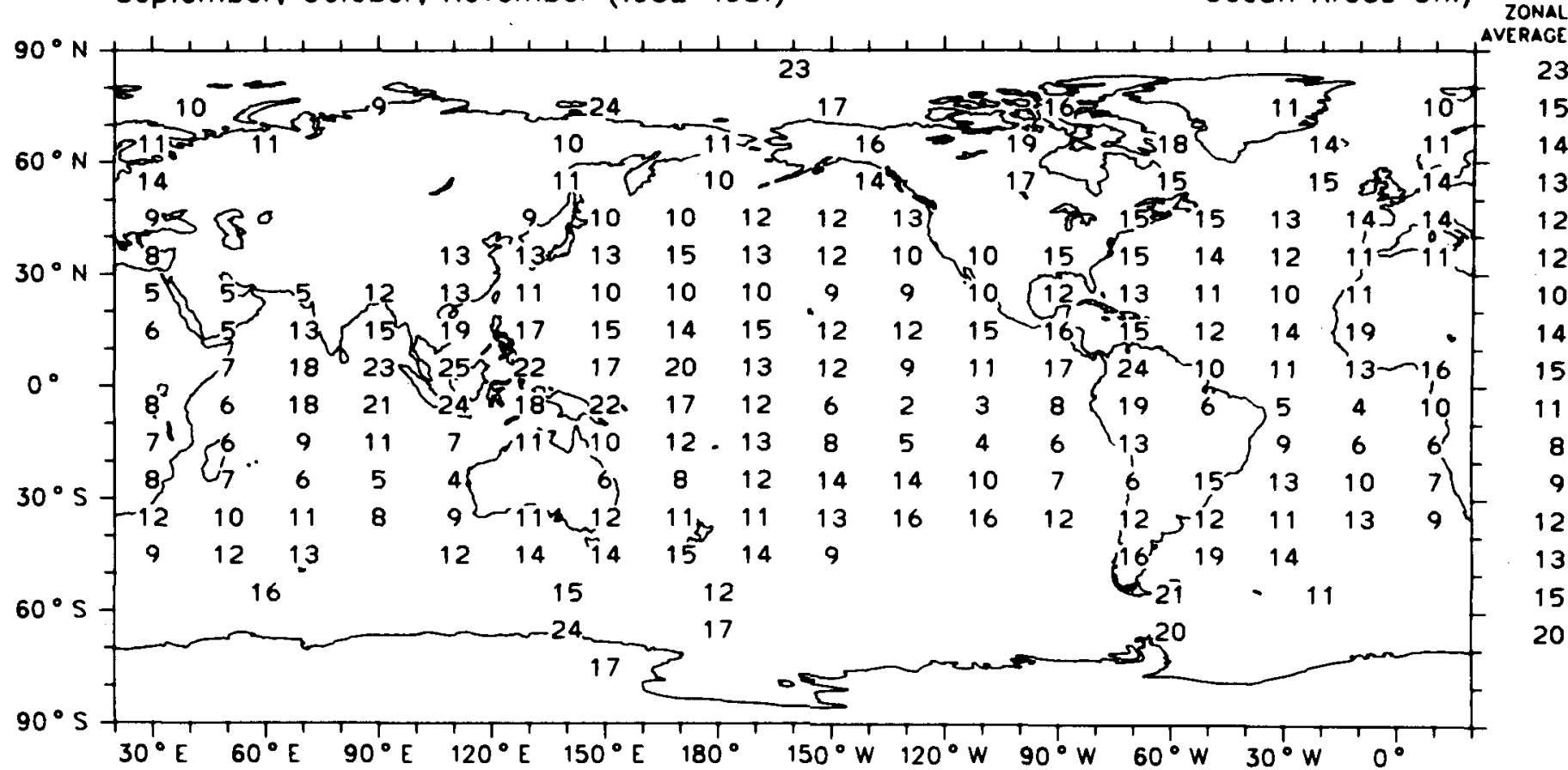

Map 156d

Globol Averoge (Ocean) $13 \%$ 
Interannual Variation of Cirrus + Cirrostratus + Cirrocumulus (6-18 LT) : Standard Deviation (detrended) of Seasonal Means (0.1\% Cloud Amount) December. Januory. February (1952-1981) Oceon Areos Only zONAL

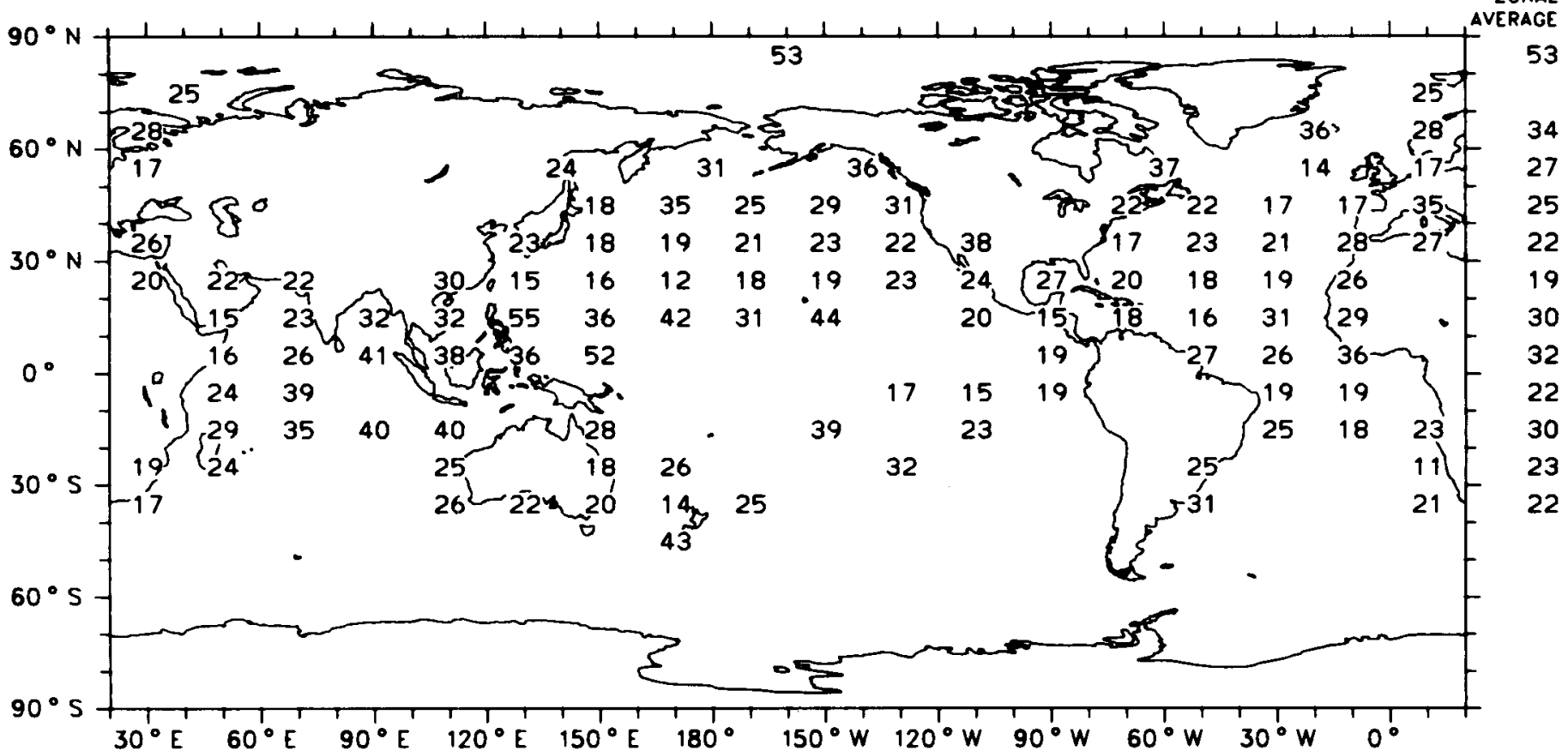

Interannual Variation of Cirrus + Cirrostratus + Cirrocumulus (6-18 LT) : Standard Deviation (detrended) of Seasonal Means (0.1\% Cloud Amount) Morch. April. May (1952-1981) Ocean Areas Only

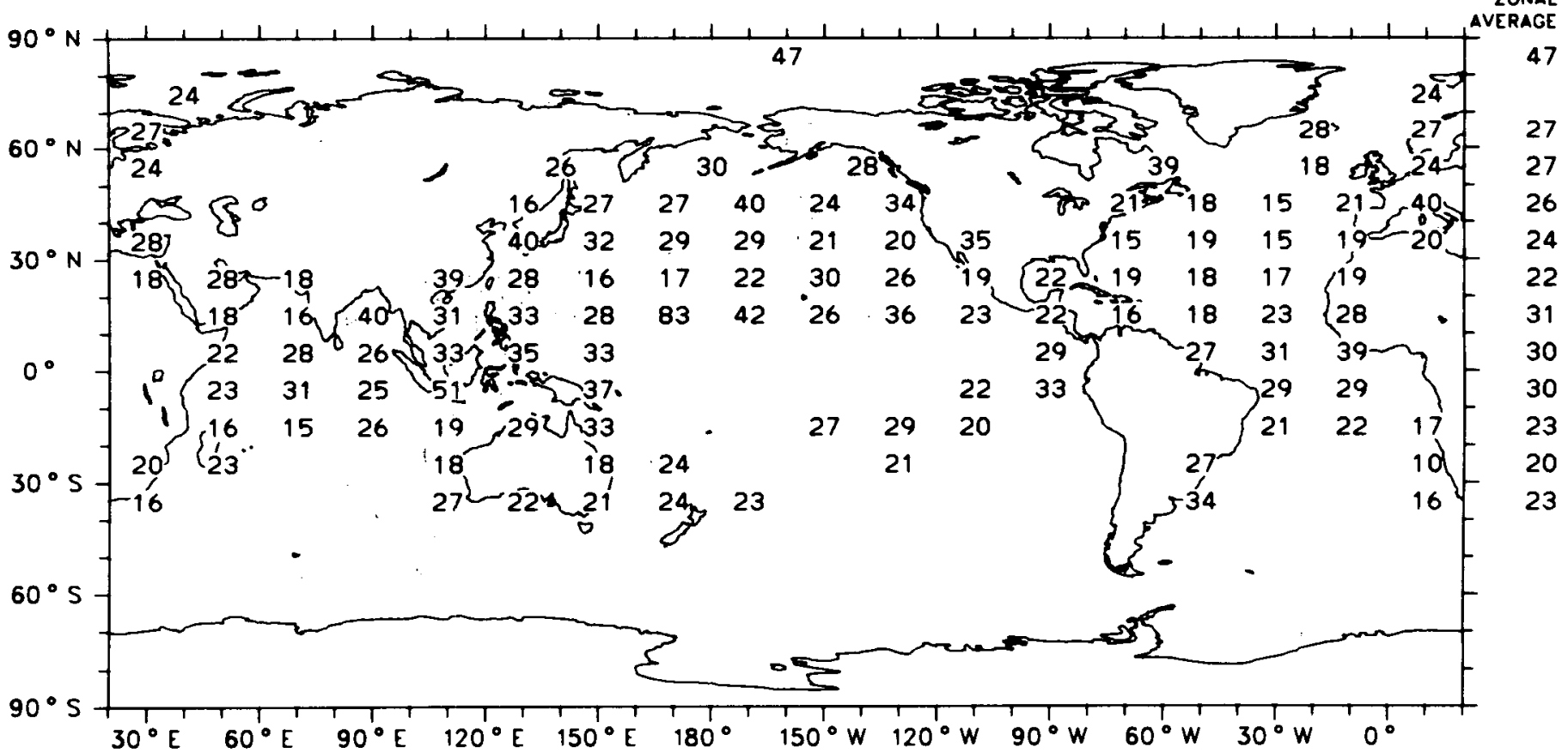


Interannual Variation of Cirrus + Cirrostratus + Cirrocumulus (6-18 LT) : Standard Deviation (detrended) of Seasonal Means ( $0.1 \%$ Cloud Amount) June, July, August (1952-1981)

Ocean Areas Only

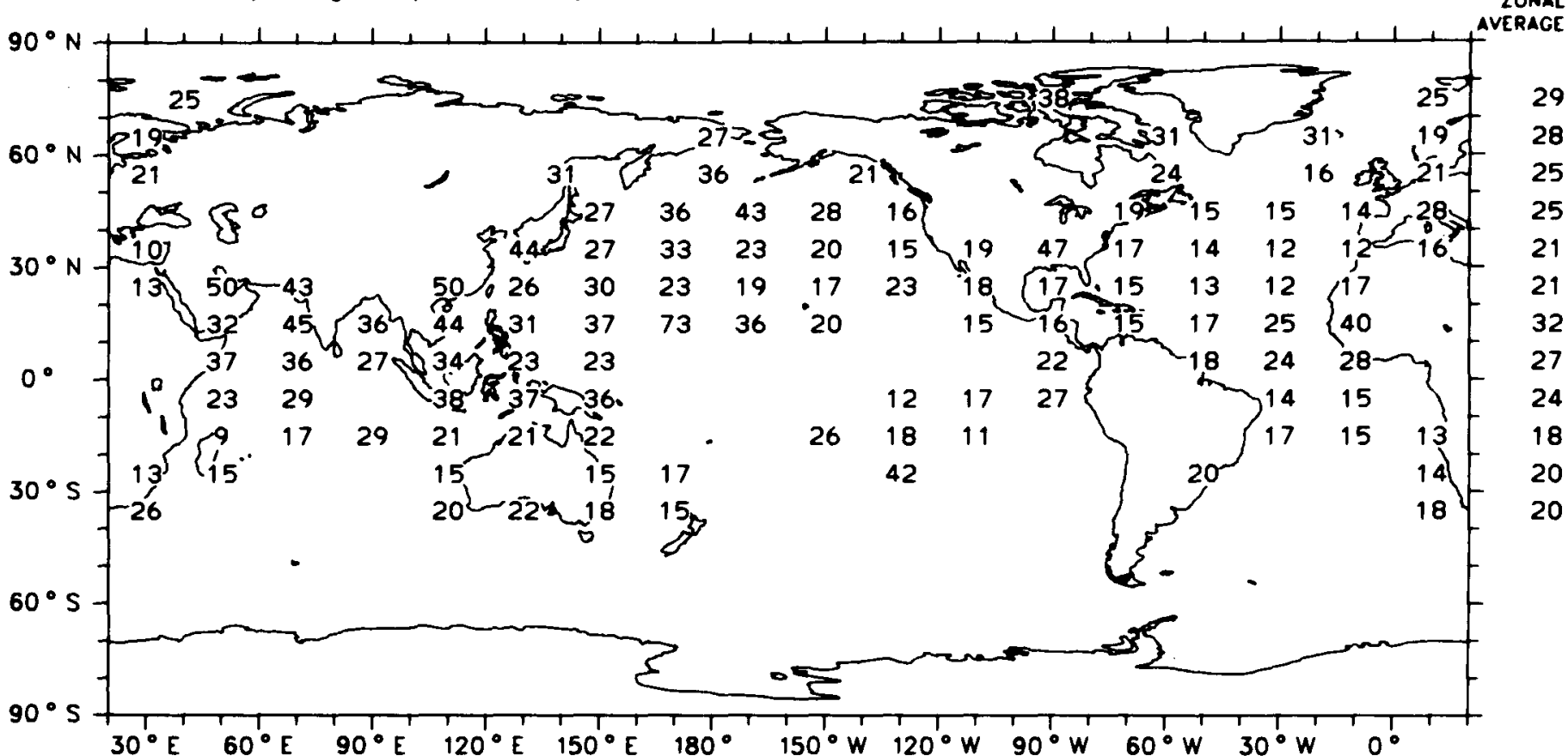

Global Average (Ocean) $2.3 \%$

Map 157c

Interannual Variation of Cirrus + Cirrostratus + Cirrocumulus (6-18 LT) :

Standard Deviation (detrended) of Seasonal Means ( $0.1 \%$ Cloud Amount)

September, October, November (1952-1981)

Ocean Areas Only

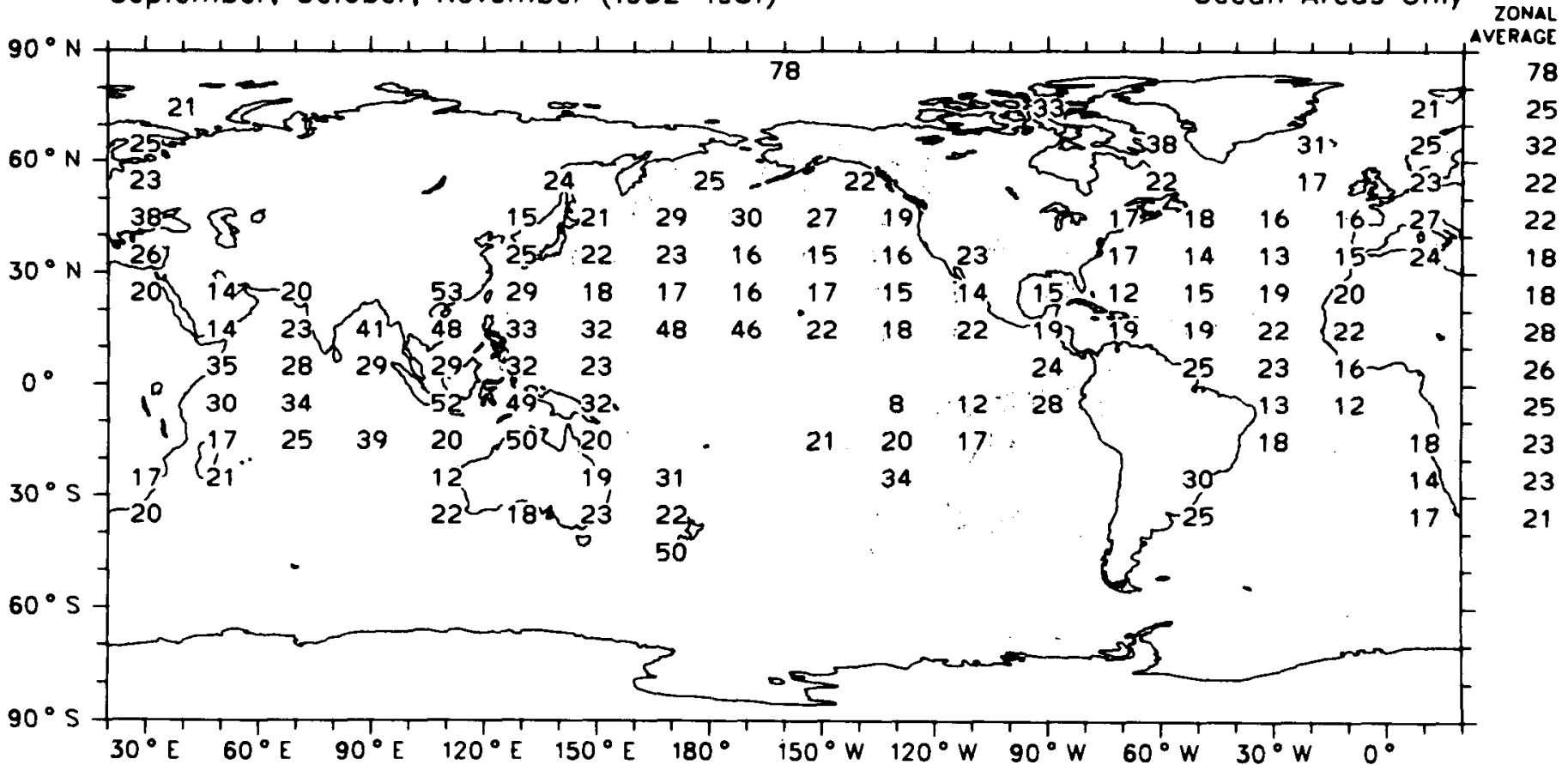


Trend of Cirrus + Cirrostratus + Cirrocumulus (6-18 LT) :

Change in \%-Cloud-Amount from 1952 to 1981

December, January. February (1952-1981)

Ocean Areas Only

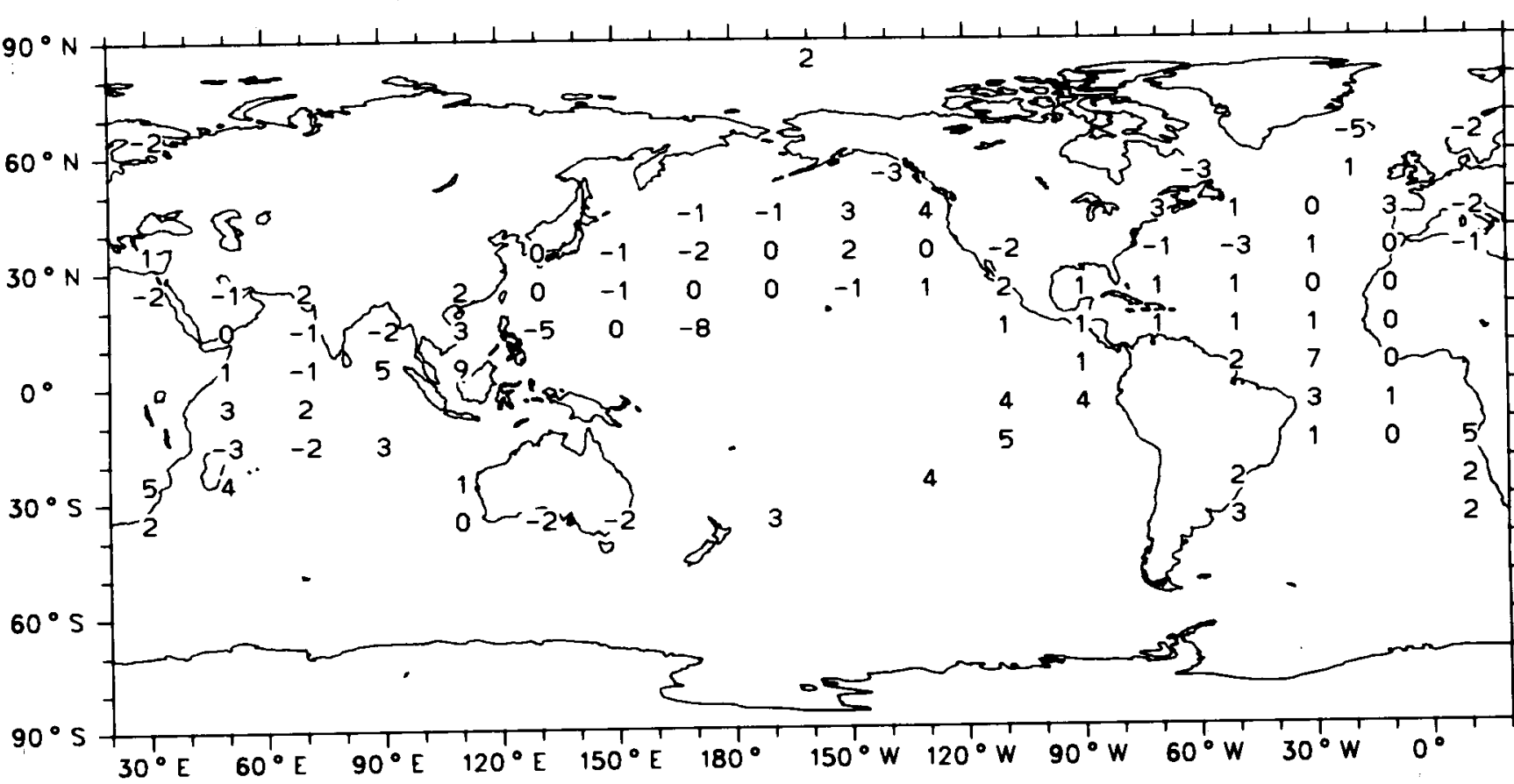

Map 158a

Global Trend (Oceon) $0.5 \%$

Trend of Cirrus + Cirrostratus + Cirrocumulus (6-18 LT) :

Change in \%-Cloud-Amount from 1952 to 1981

Morch, April, Moy (1952-1981)

Ocean Areas Only

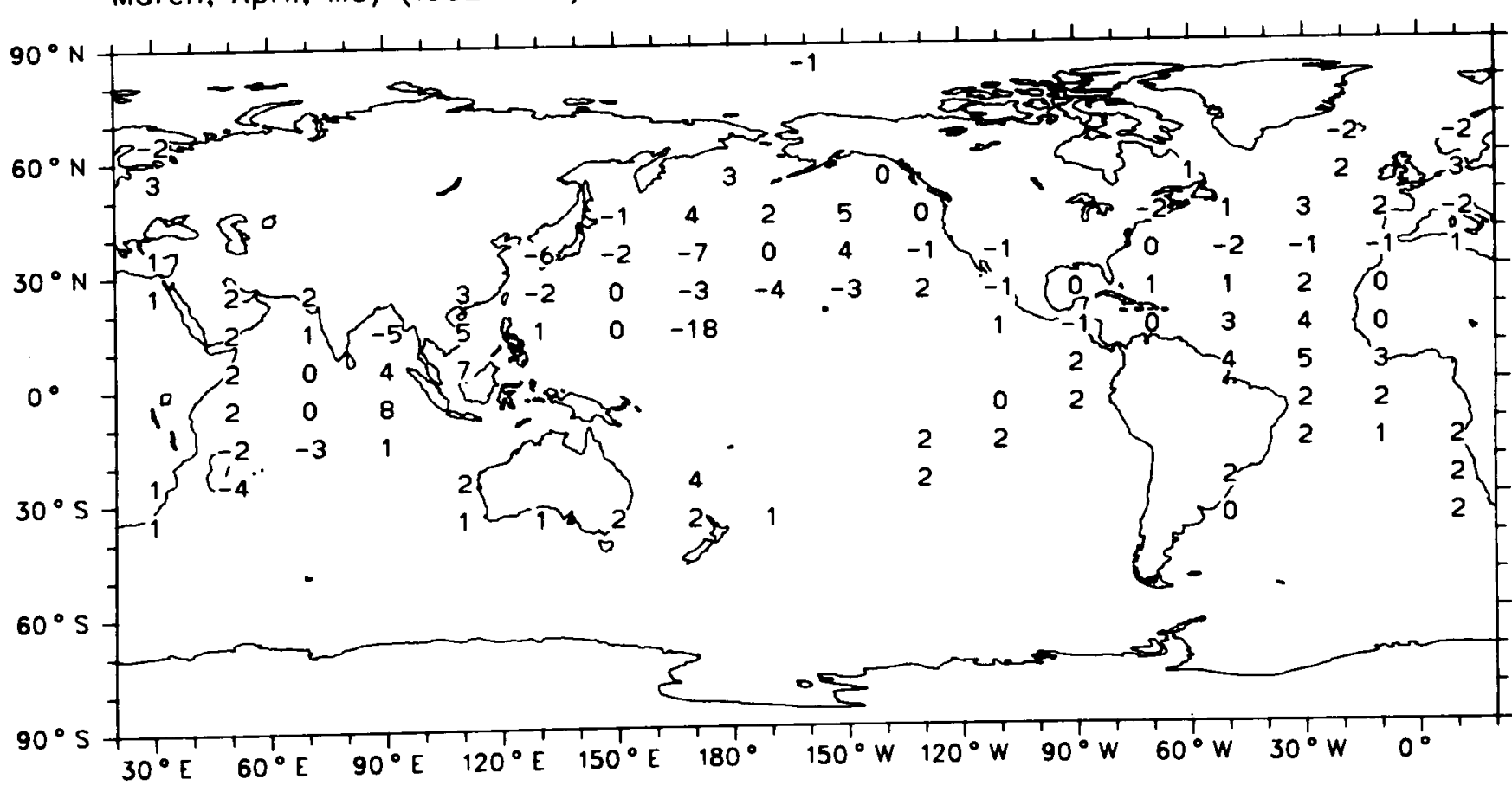


Trend of Cirrus + Cirrostratus + Cirrocumulus (6-18 LT) :

Change in \%-Cloud-Amount from 1952 to 1981

June, July, August (1952-1981)

Ocean Areas Only

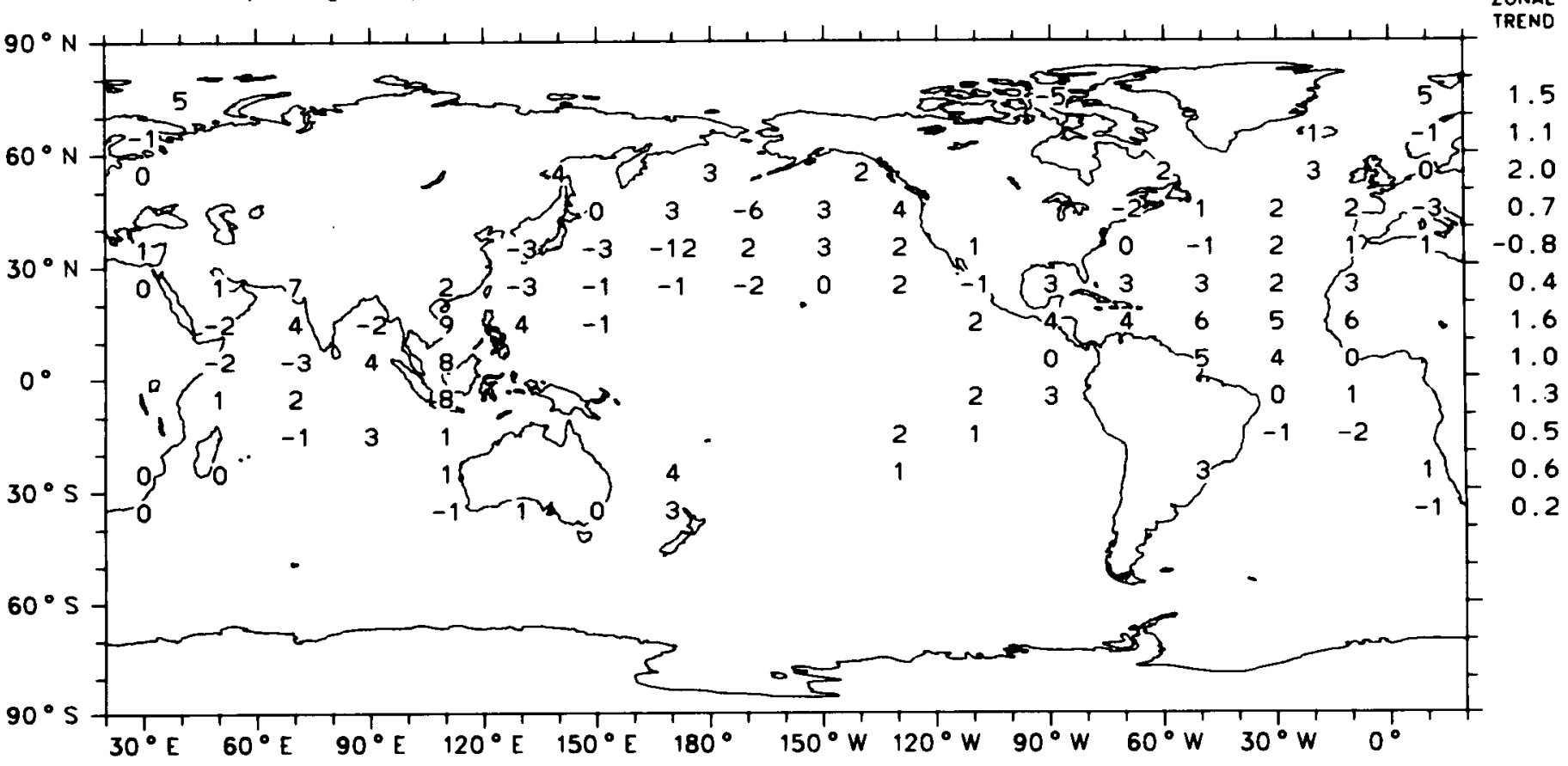

Map 158c

Global Trend (Ocean) $0.6 \%$

Trend of Cirrus + Cirrostratus + Cirrocumulus (6-18 LT) :

Change in \%-Cloud-Amount from 1952 to 1981

September, October. November (1952-1981)

Ocean Areas Only

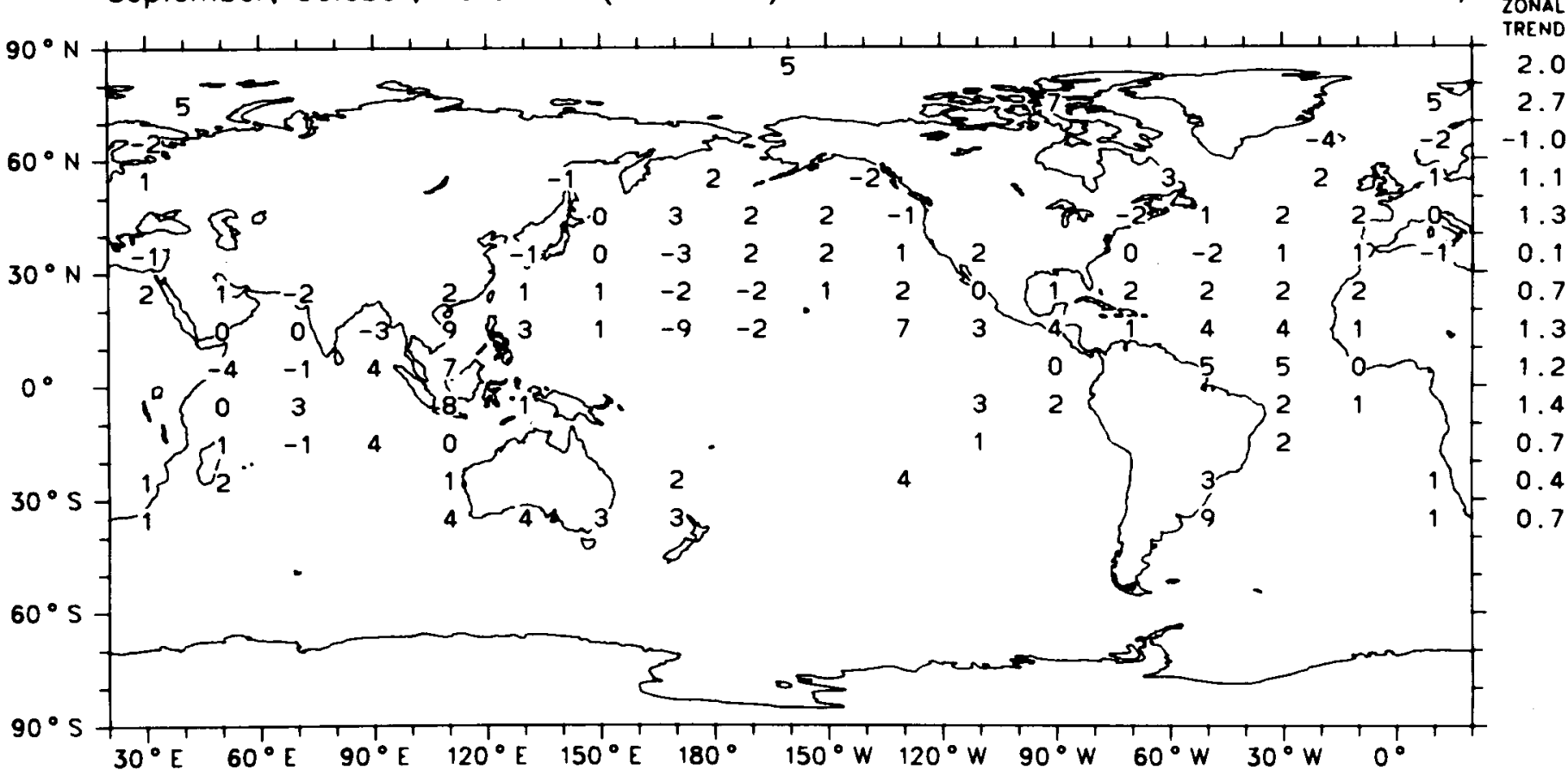

Map 158d

Global Trend (Ocean) $0.7 \%$ 
Sky Obscured due to Fog

Frequency of Occurrence (\%)

December. January. February (1952-1981)

Ocean Areas Only

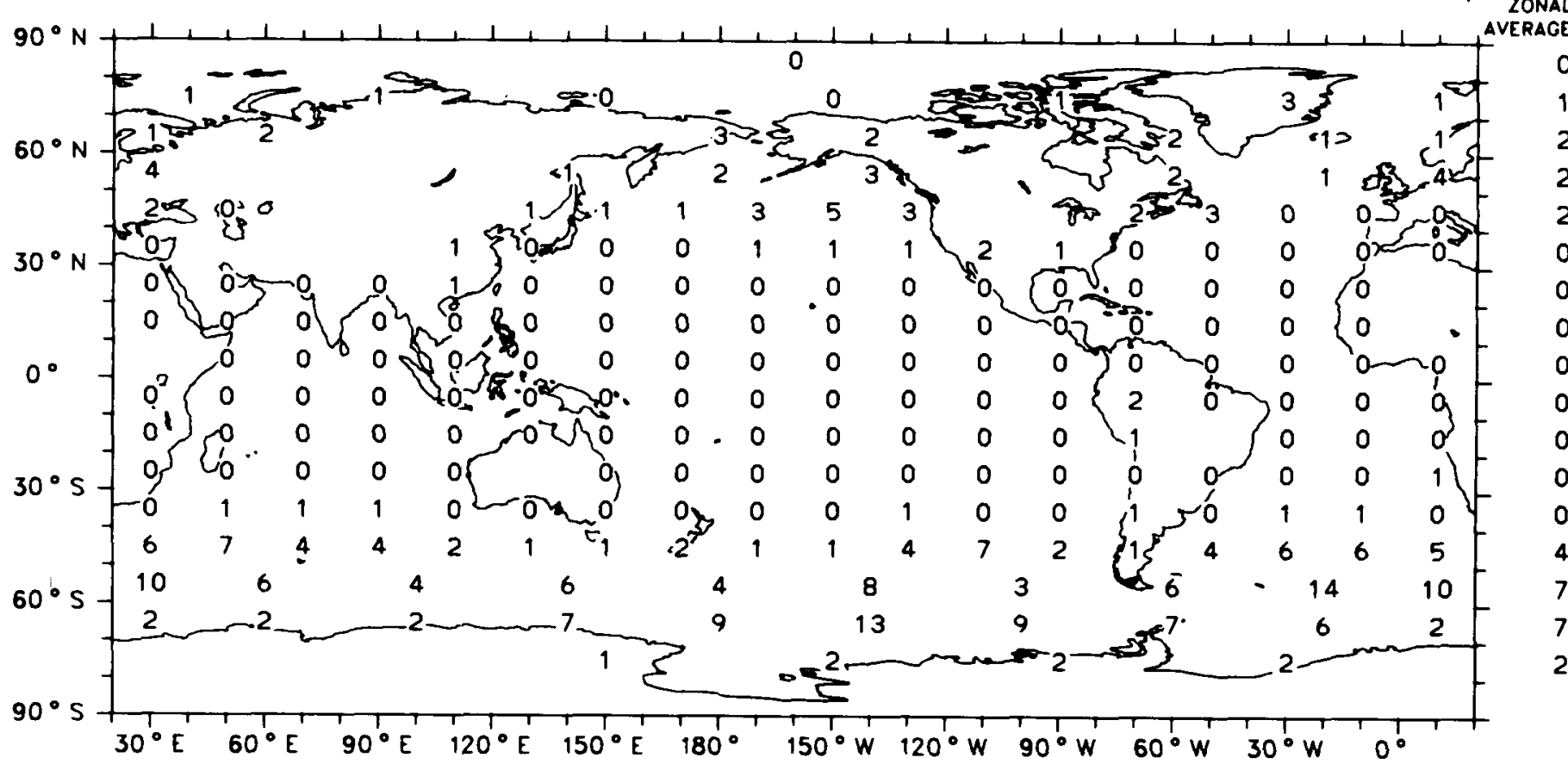

Global Average (Oceon) $1 \%$

Map 159a

Sky Obscured due to Fog

Frequency of Occurrence (\%)

March, April, Moy (1952-1981)

Ocean Areos Only

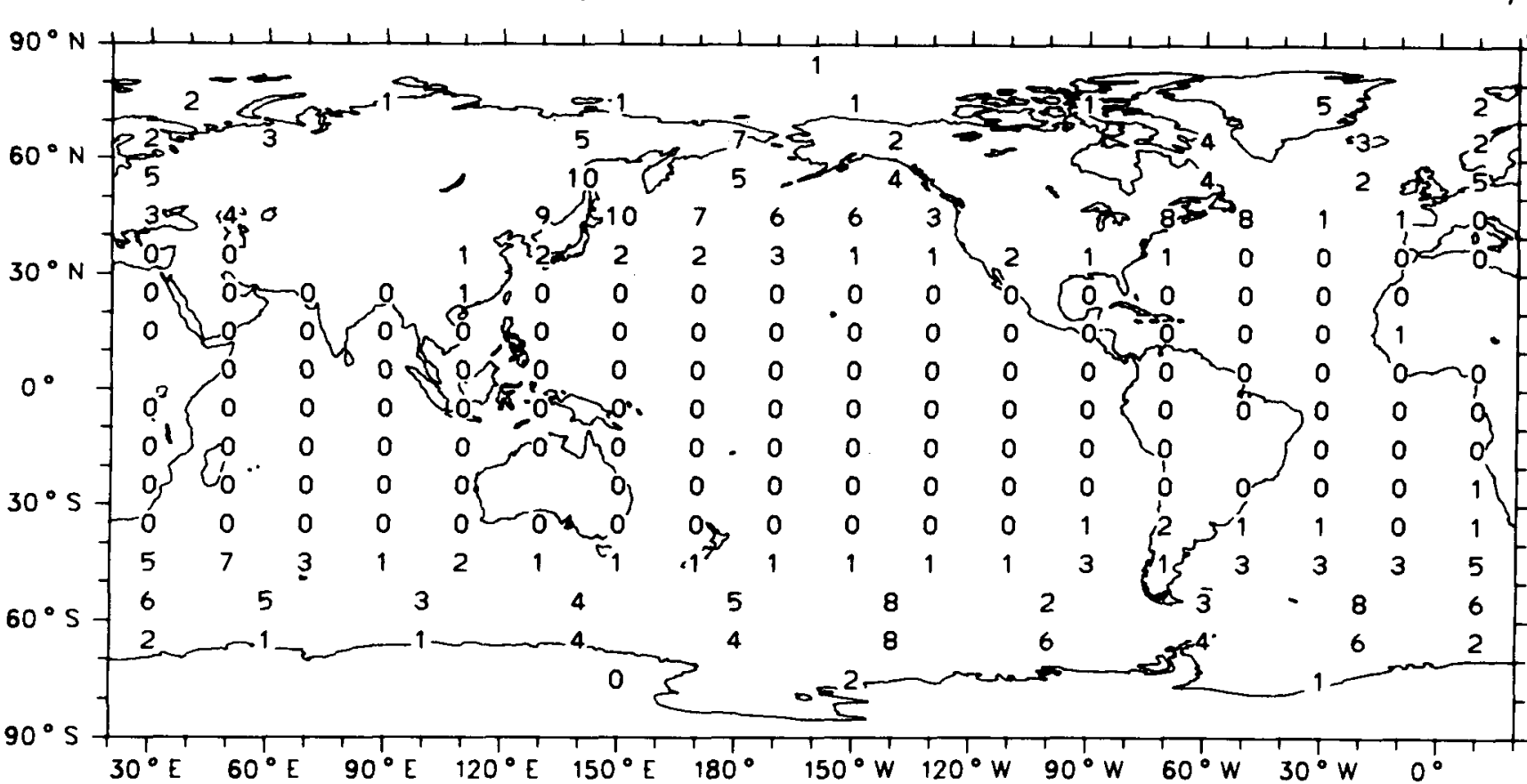

ZONAL AVERAGE 
Sky Obscured due to Fog

Frequency of Occurrence (\%)

June, July, August (1952-1981)

Ocean Areas Only

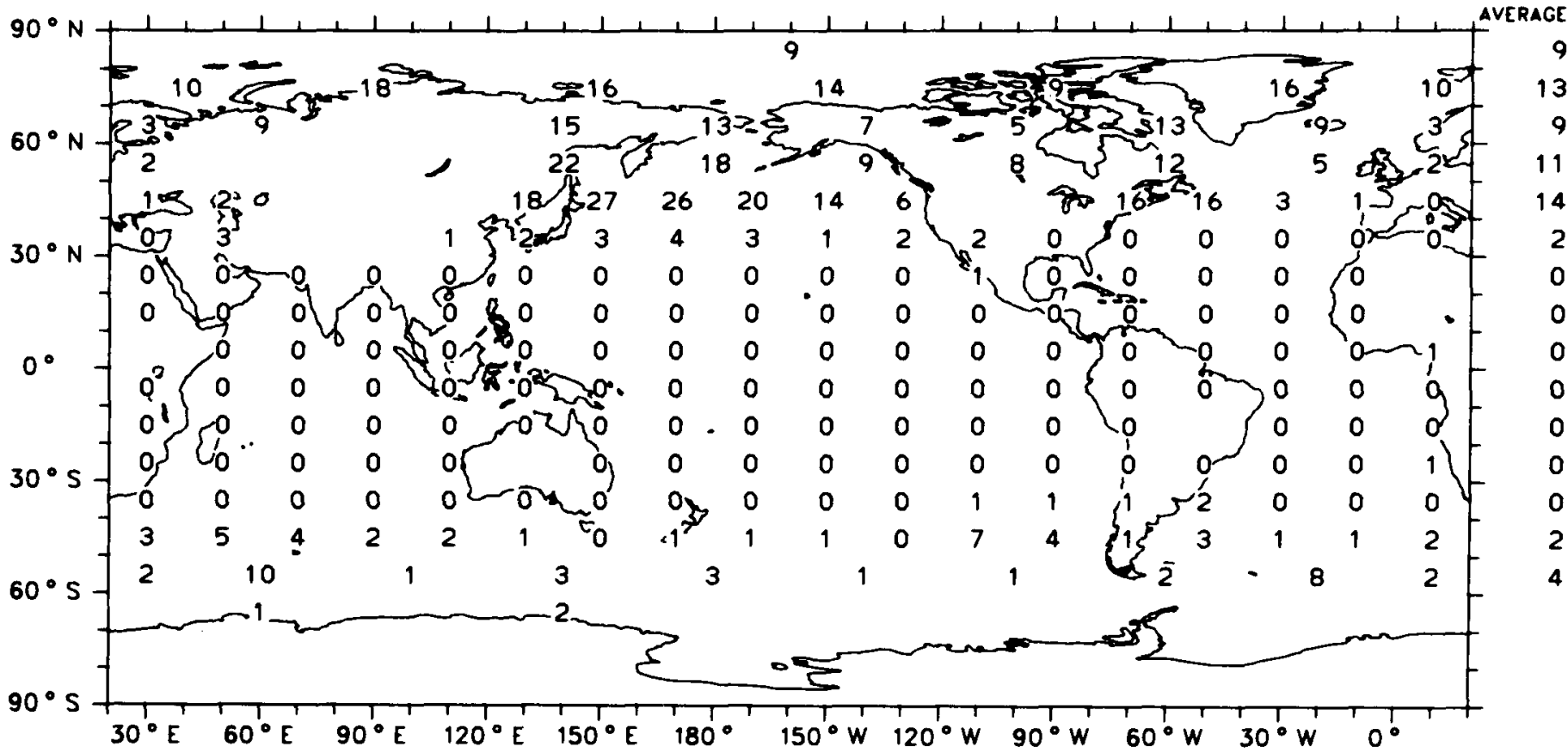

Global Average (Oceon) $2 \%$

Map 159c

Sky Obscured due to Fog

Frequency of Occurrence (\%)

September. October. November (1952-1981)

Ocean Areas Only

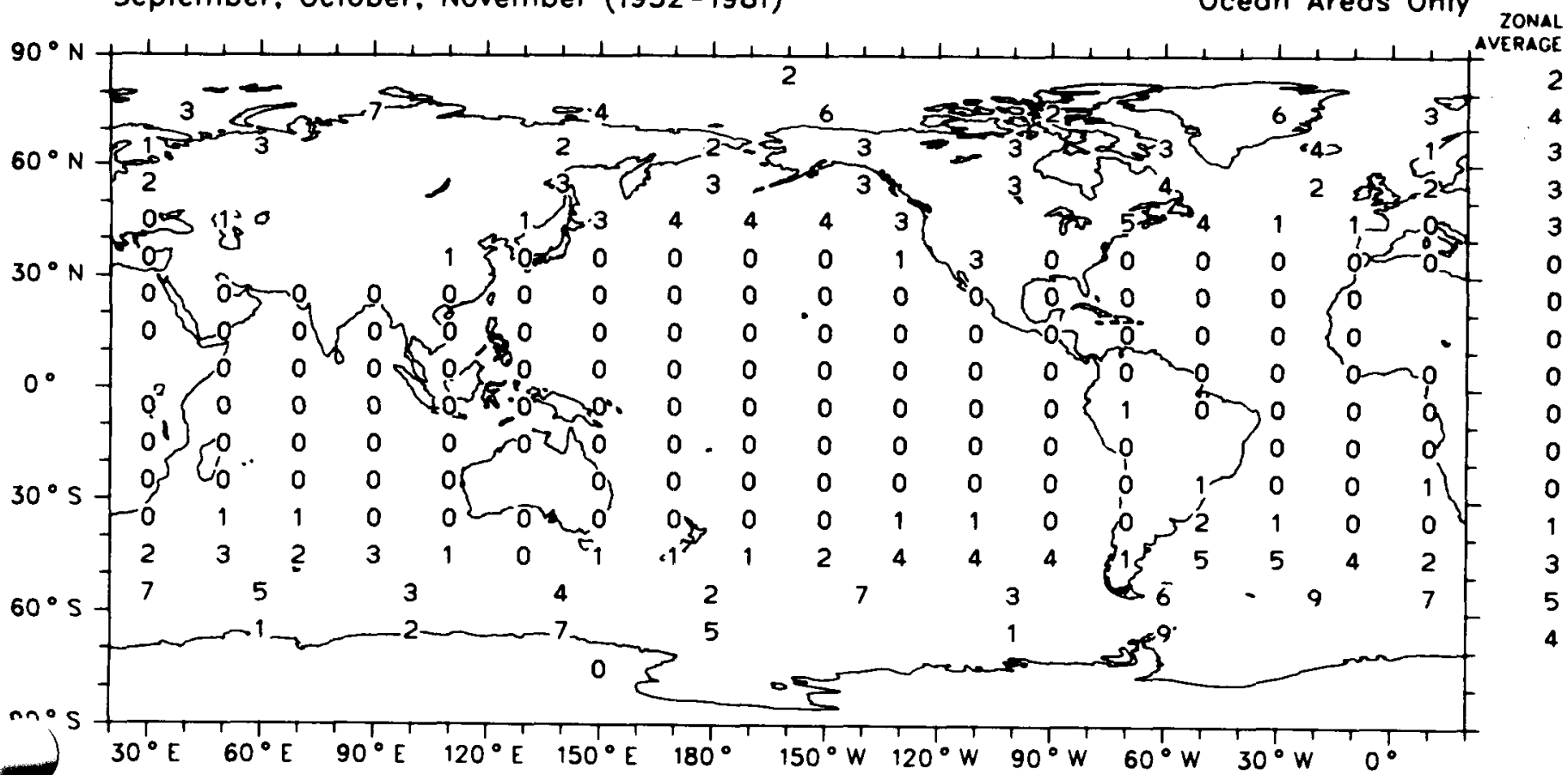

Global Average (Ocean) $1 \%$

Map 159d 
Sky Obscured due to Fog

Amplitude of Diurnal Cycle ( $0.1 \%$ Frequency-of-Occurrence)

December, January. February (1952-1981)

Ocean Areas Only

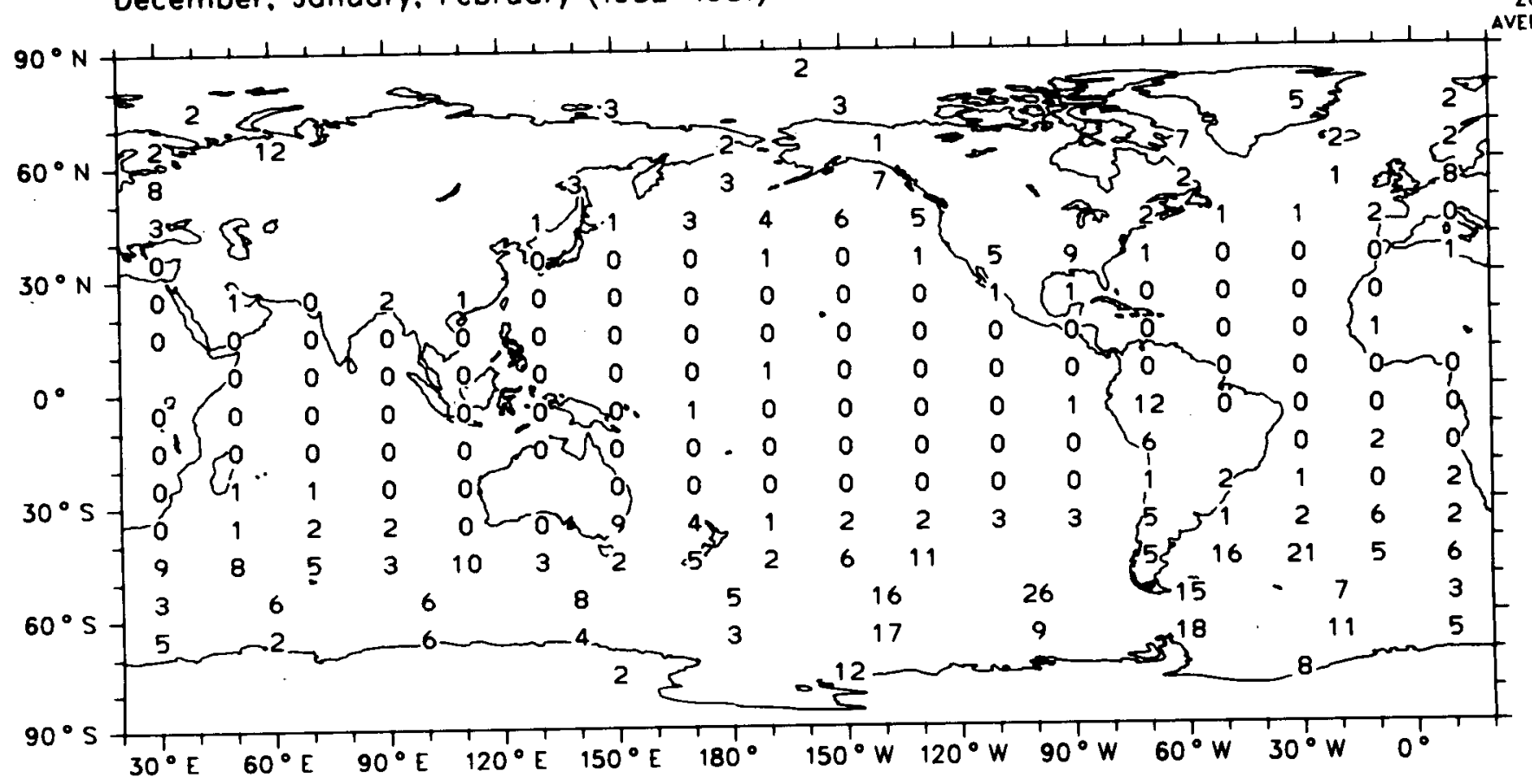

Map 160a

Global Averoge (Ocean) $0.3 \%$

Sky Obscured due to Fog

Phase of Diurnal Cycle (Local Time of Maximum Frequency of Occurrence) December, January, February (1952-1981)

Ocean Areas Only

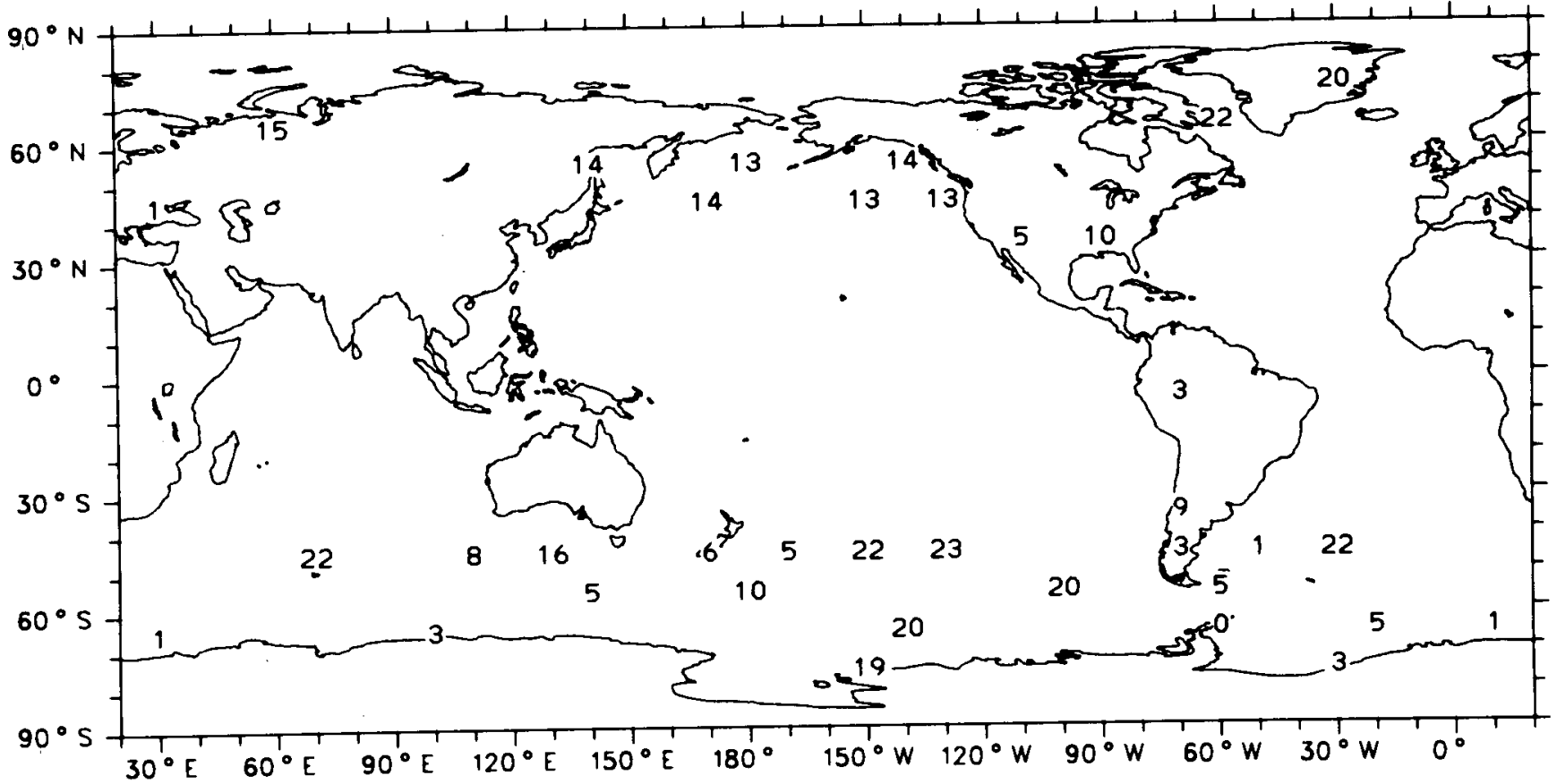

Map $160 b$ 
Sky Obscured due to Fog

Amplitude of Diurnal Cycle (0.1\% Frequency-of-Occurrence)

March, April, May (1952-1981)

Ocean Areas Only

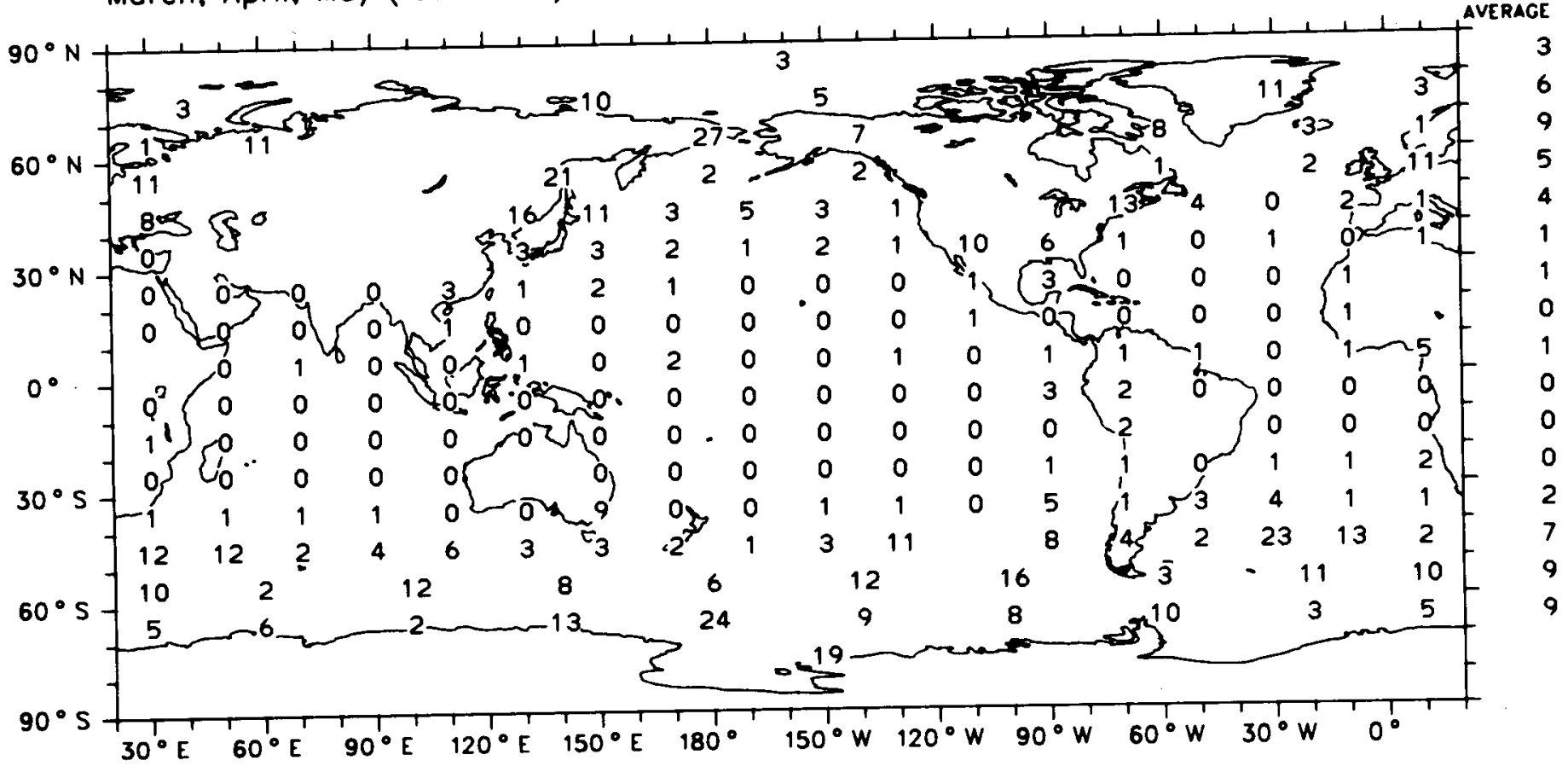

Map 160c

Global Averoge (Ocean) $0.3 \%$

Sky Obscured due to Fog

Phase of Diurnal Cycle (Local Time of Maximum Frequency of Occurrence) Morch, April, May (1952-1981)

Ocean Areas Only

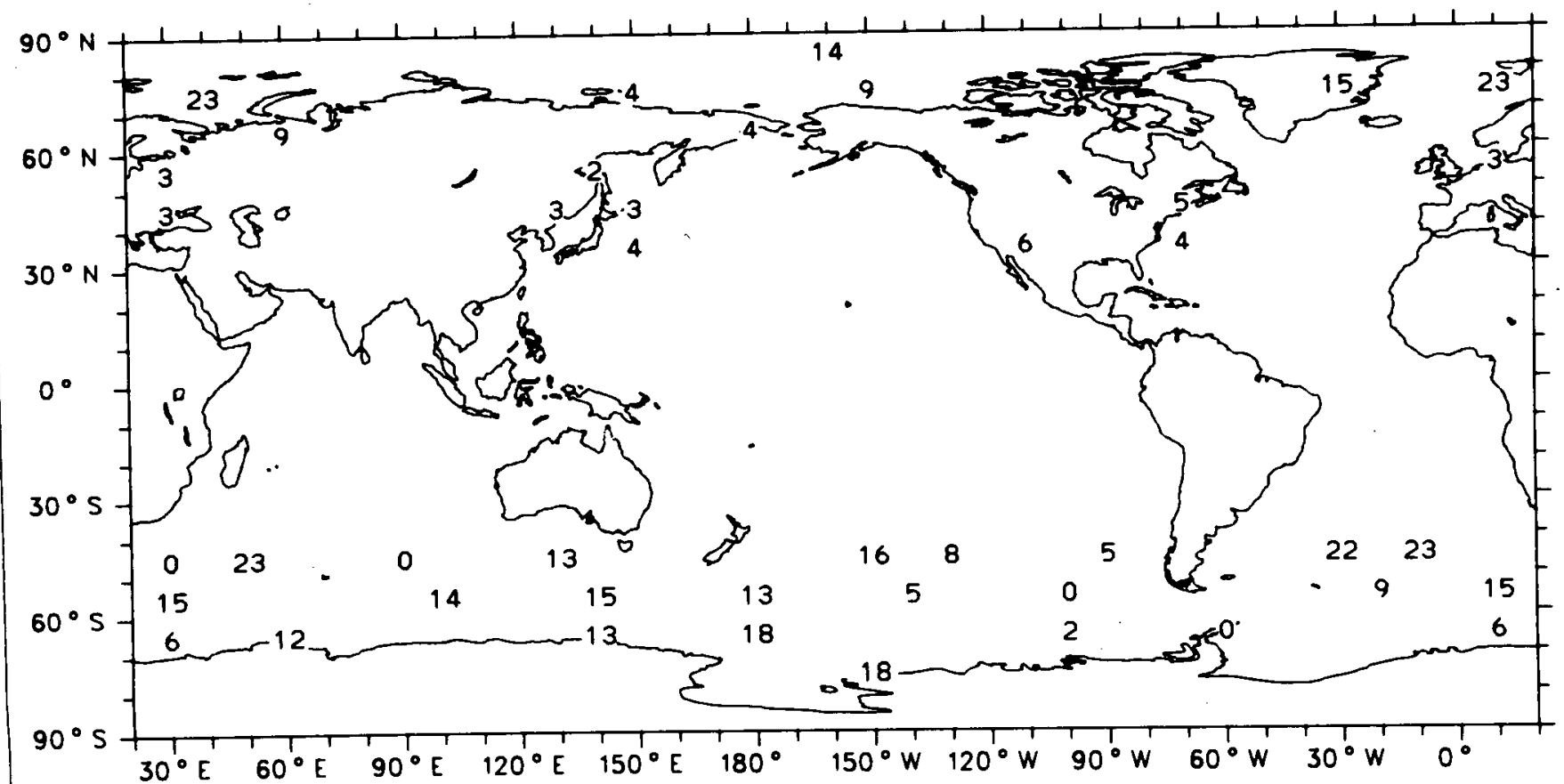

Mop 160d 
Sky Obscured due to Fog

Amplitude of Diurnal Cycle (0.1\% Frequency-of-Occurrence)

June, July. August (1952-1981)

Ocean Areas Only

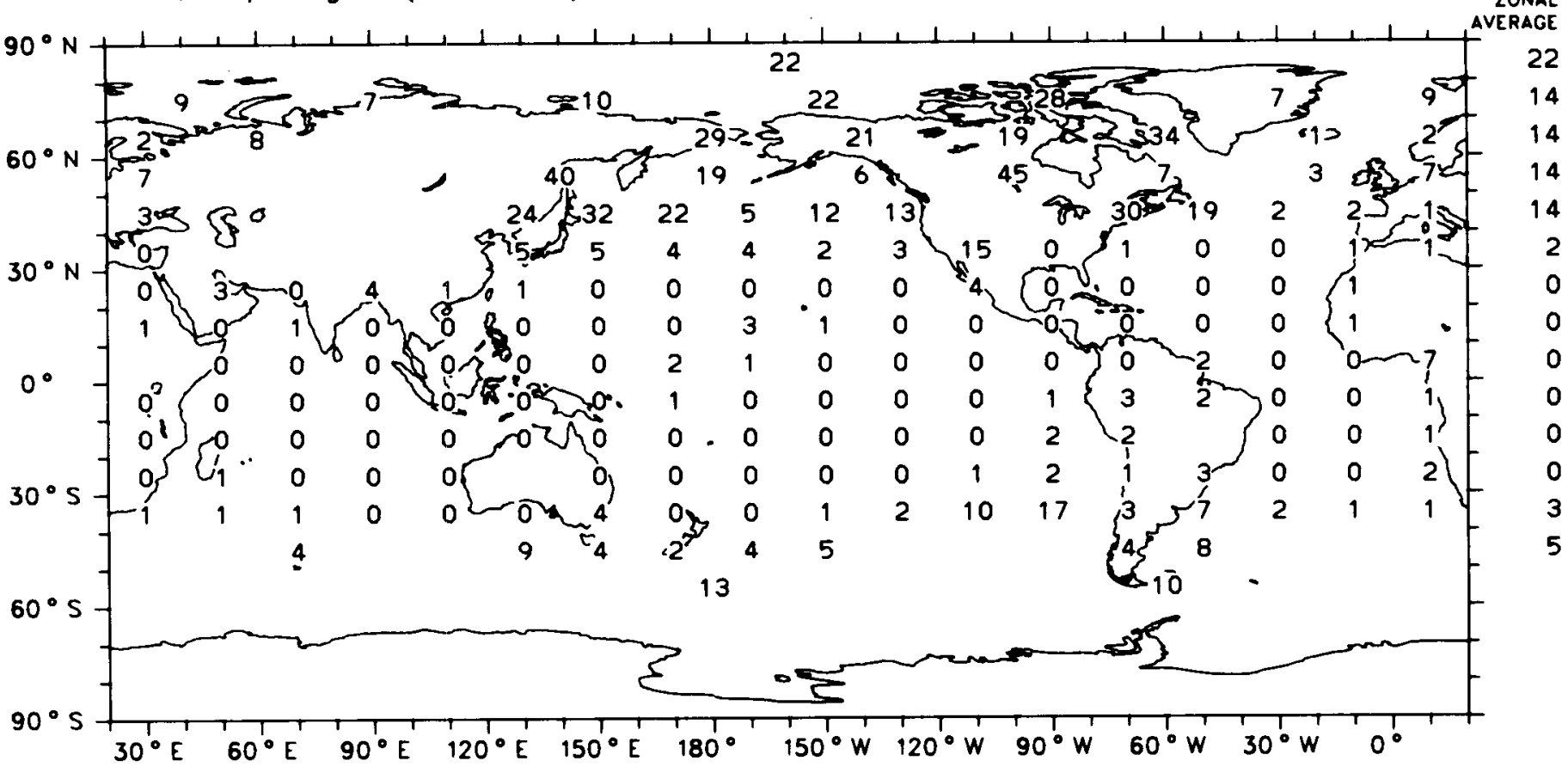

Global Average (Ocean) $0.3 \%$

Map 161a

Sky Obscured due to Fog

Phase of Diurnal Cycle (Local Time of Maximum Frequency of Occurrence) June. July. August (1952-1981)

Ocean Areas Only

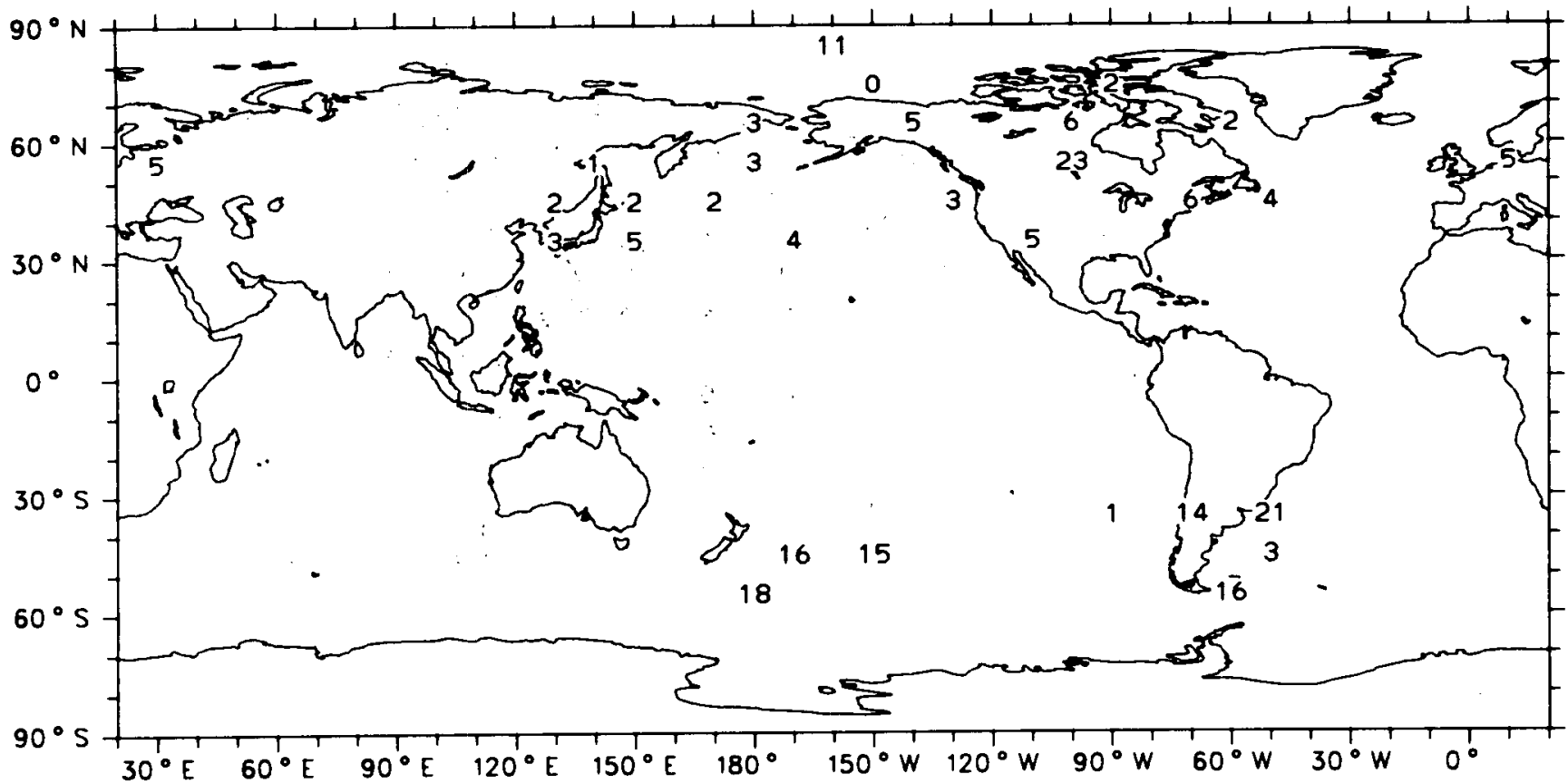

Map 161b 
Sky Obscured due to Fog

Amplitude of Diurnal Cycle (0.1\% Frequency-of-Occurrence)

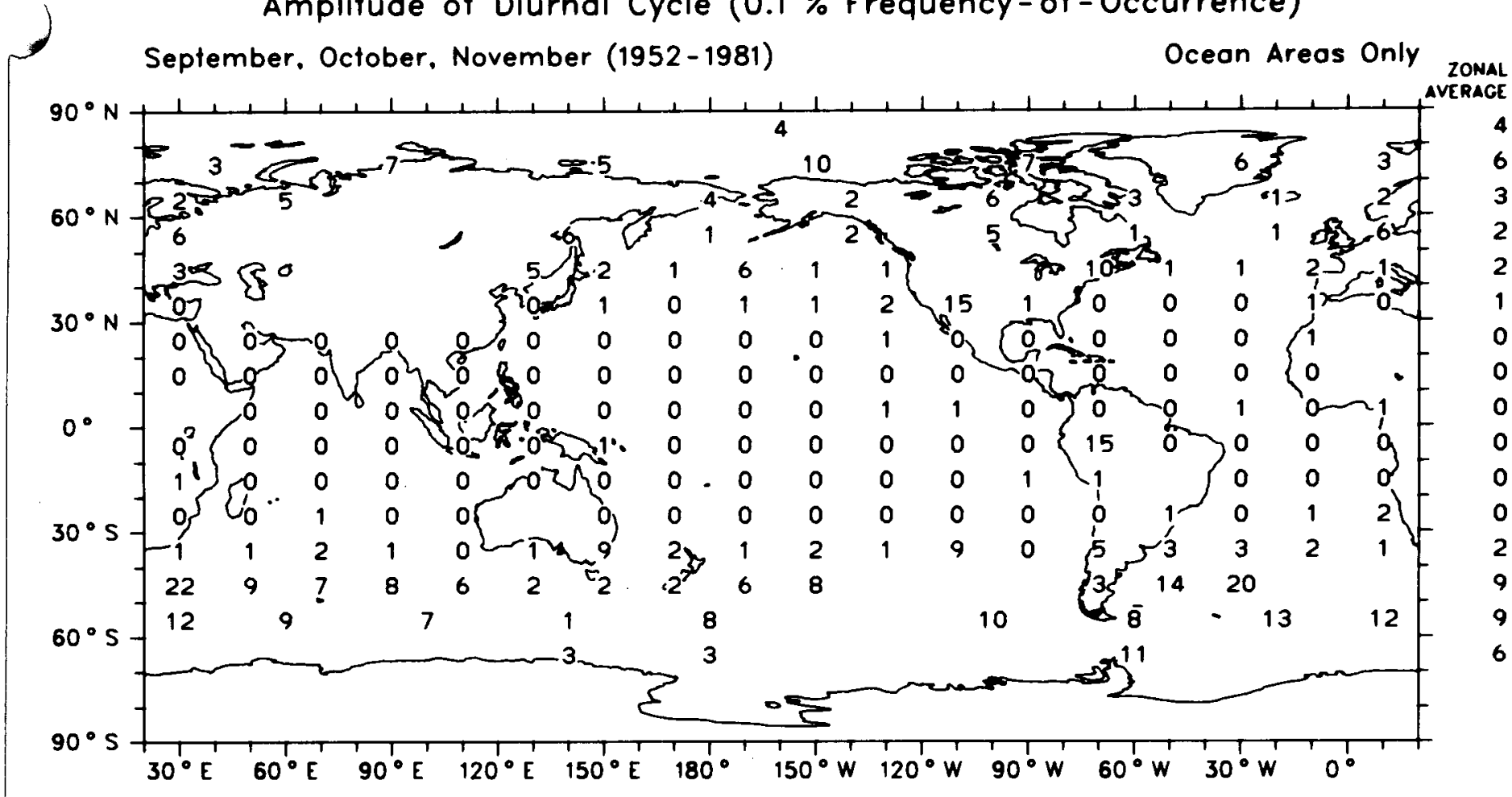

Global Average (Ocean) $0.2 \%$

Map 161c

Sky Obscured due to Fog

Phase of Diurnal Cycle (Local Time of Maximum Frequency of Occurrence) September, October, November (1952-1981)

Ocean Areas Only

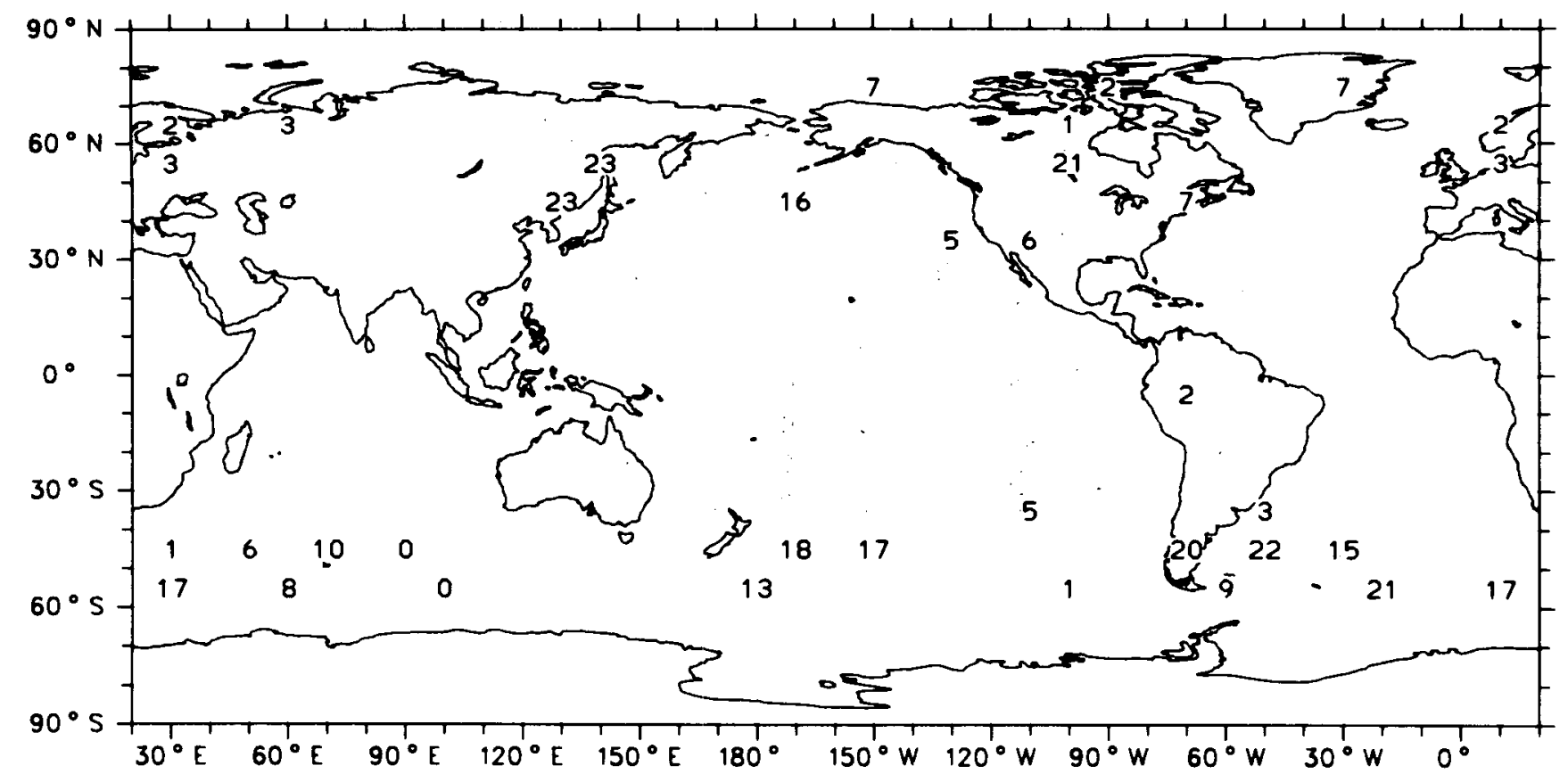

Map 161d 
Interannual Variation of Sky-Obscured-due-to-Fog :

Standard Deviation (detrended) of Seasonal Means (0.1\% Frequency of Occurrence) December, January. February (1952-1981)

Ocean Areas Only

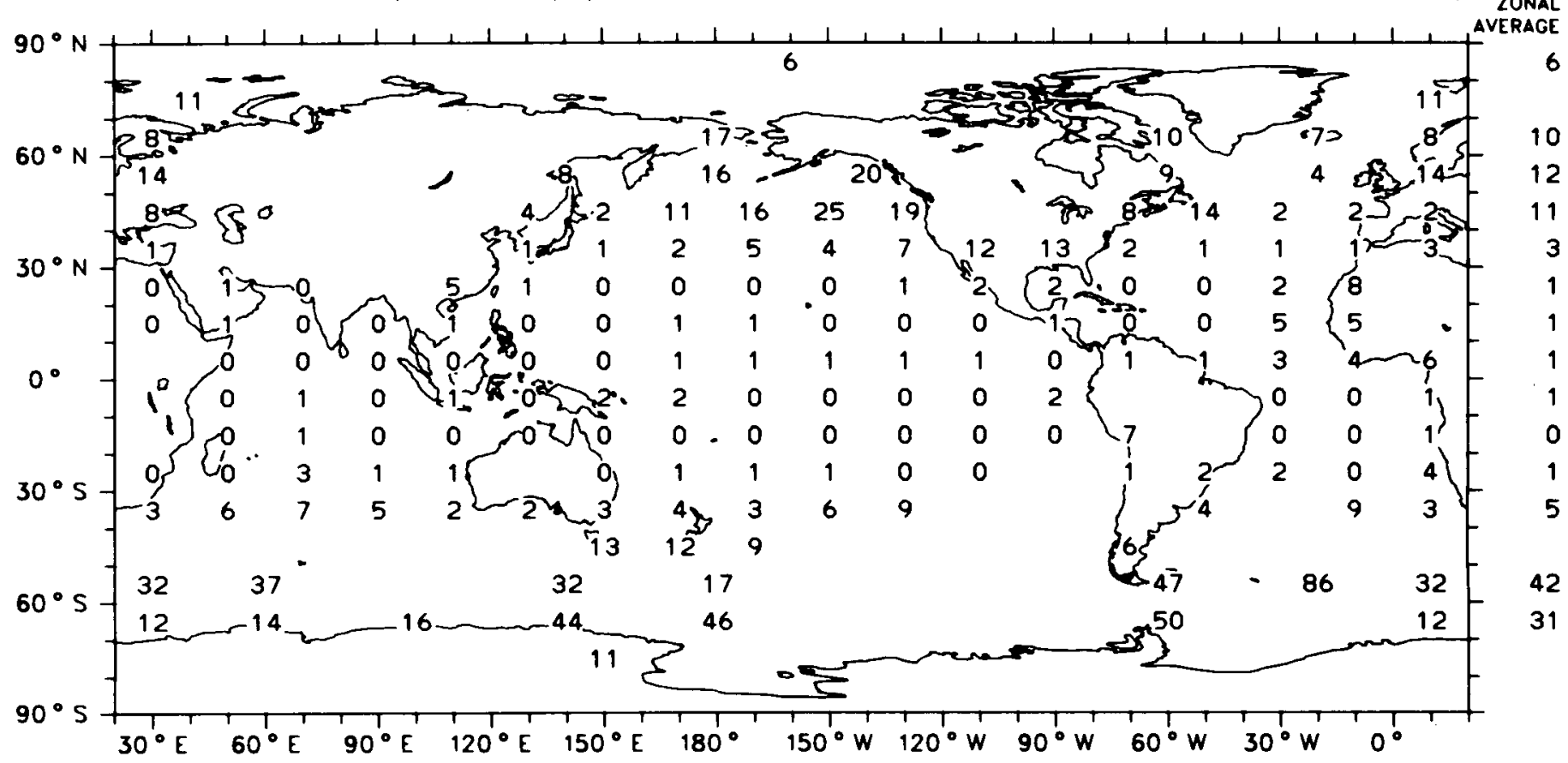

Map $162 a$

Global Average (Oceon) $0.7 \%$

Interannual Variation of Sky-Obscured-due-to-Fog :

Standard Deviation (detrended) of Seasonal Means (0.1\% Frequency of Occurrence) March, April, May (1952-1981)

Ocean Areos Only

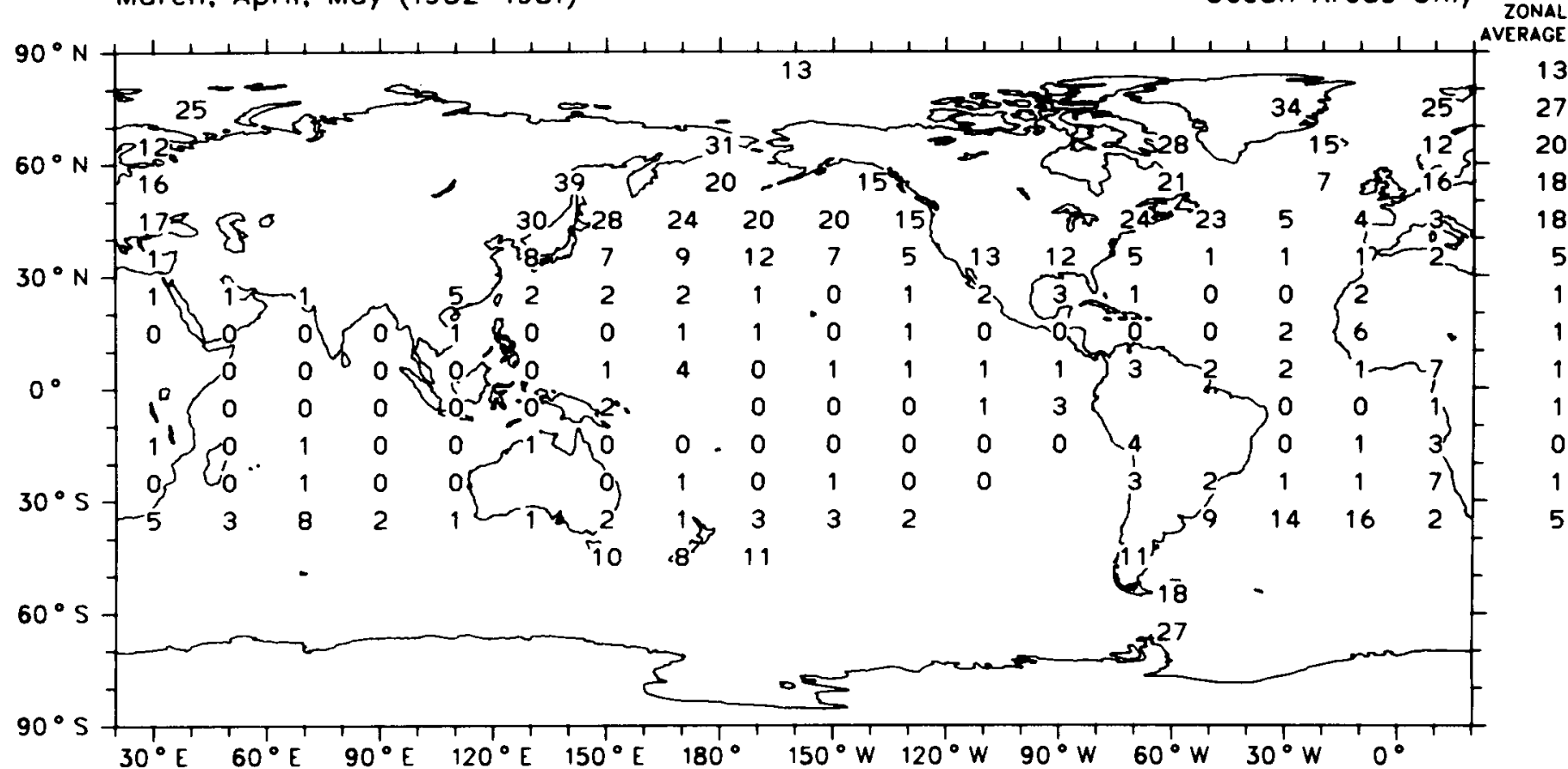

Map 162b

Global Averoge (Ocean) $0.4 \%$ 
Interannual Variation of Sky-Obscured-due-to-Fog:

Standard Deviation (detrended) of Seasonal Means (0.1\% Frequency of Occurrence) June, July. August (1952-1981)

Oceon Areas Only

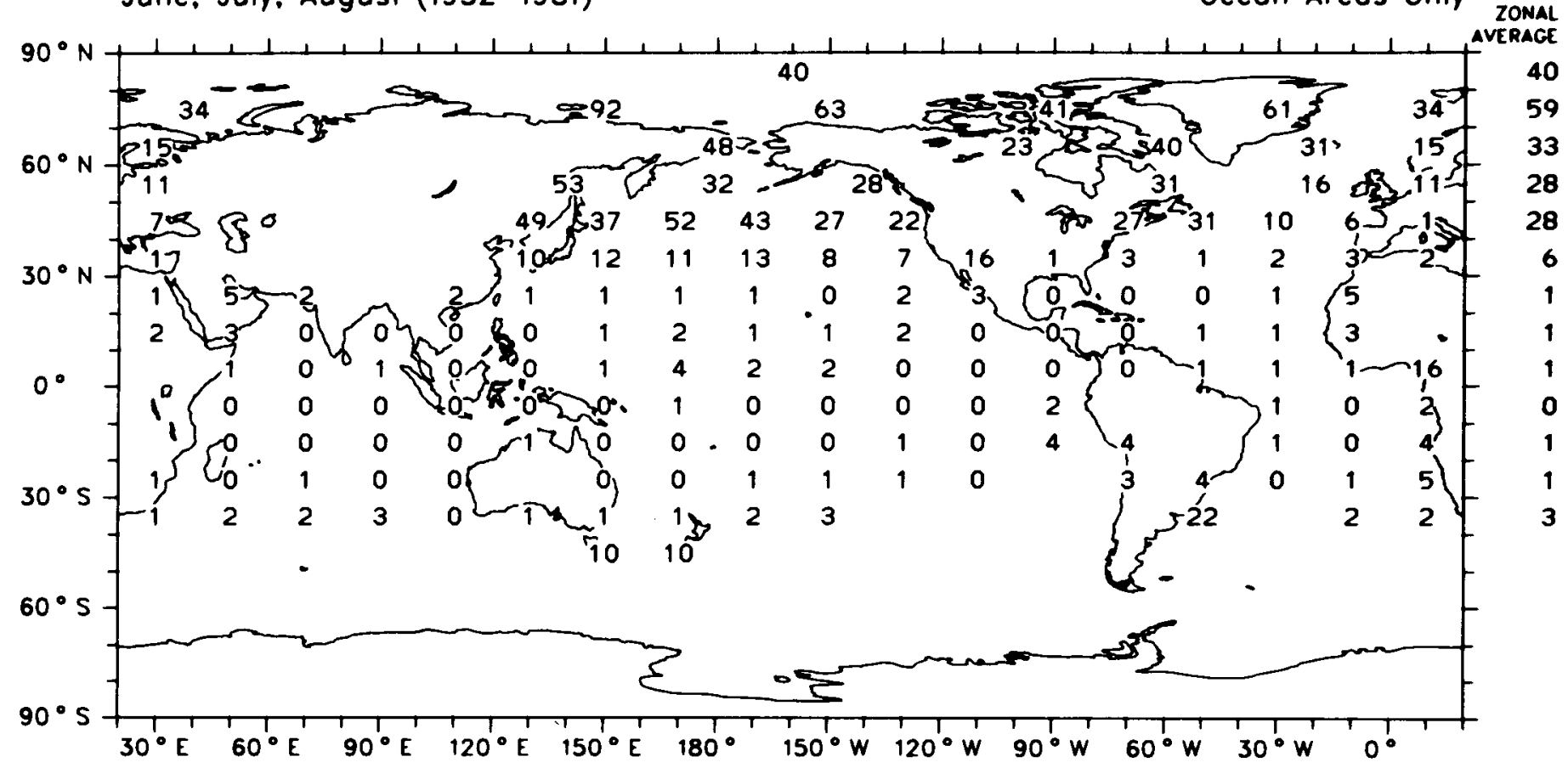

Map 162c

Global Average (Ocean) $0.7 \%$

Interannual Variation of Sky-Obscured-due-to-Fog :

Standard Deviation (detrended) of Seasonal Means (0.1\% Frequency of Occurrence) September, October. November (1952-1981)

Ocean Areas Only

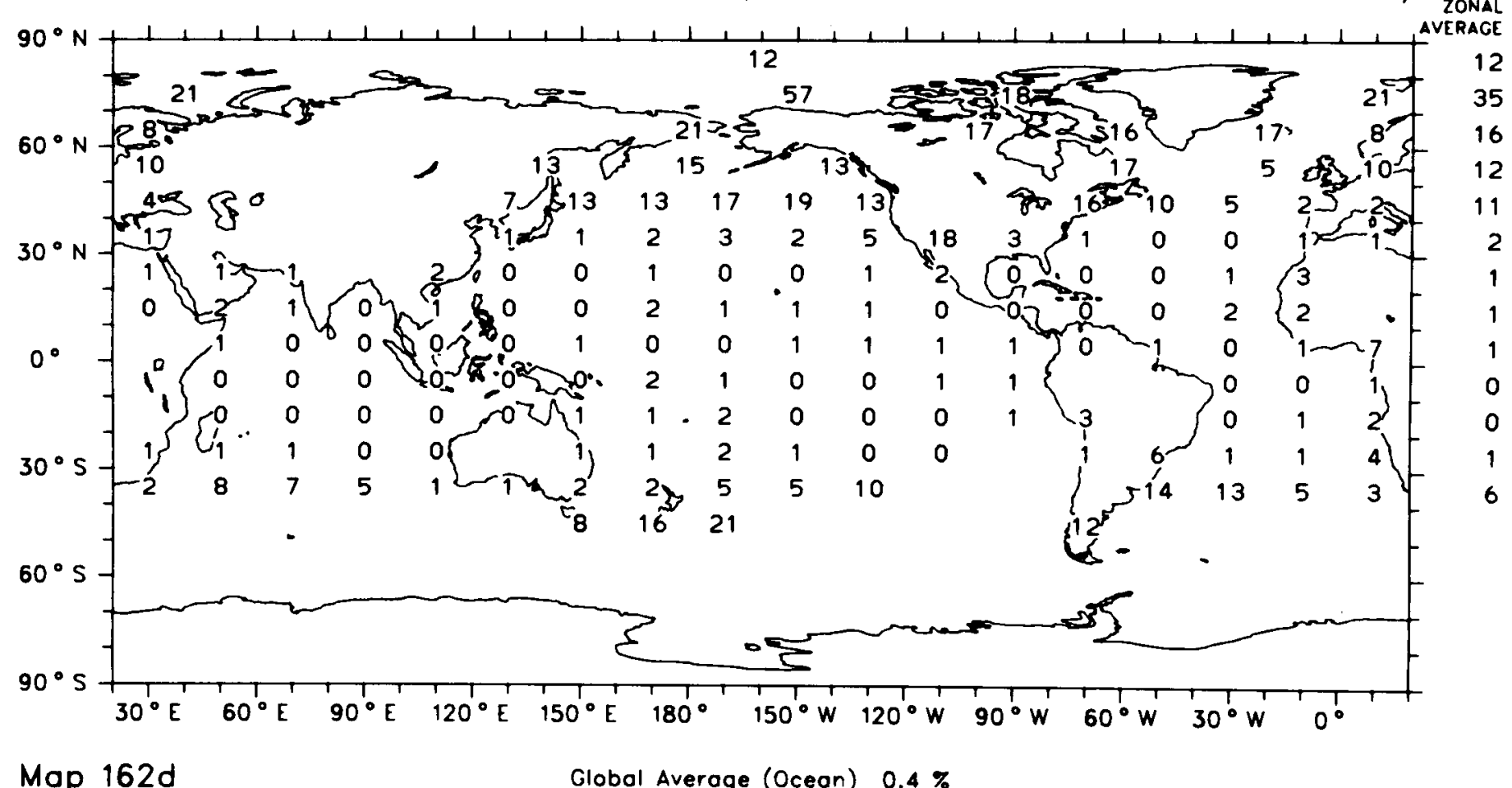


Trend of Sky-Obscured-due-to-Fog :

Change in \%-Frequency-of-Occurrence from 1952 to 1981

December, January. February (1952-1981)

Ocean Areas Only

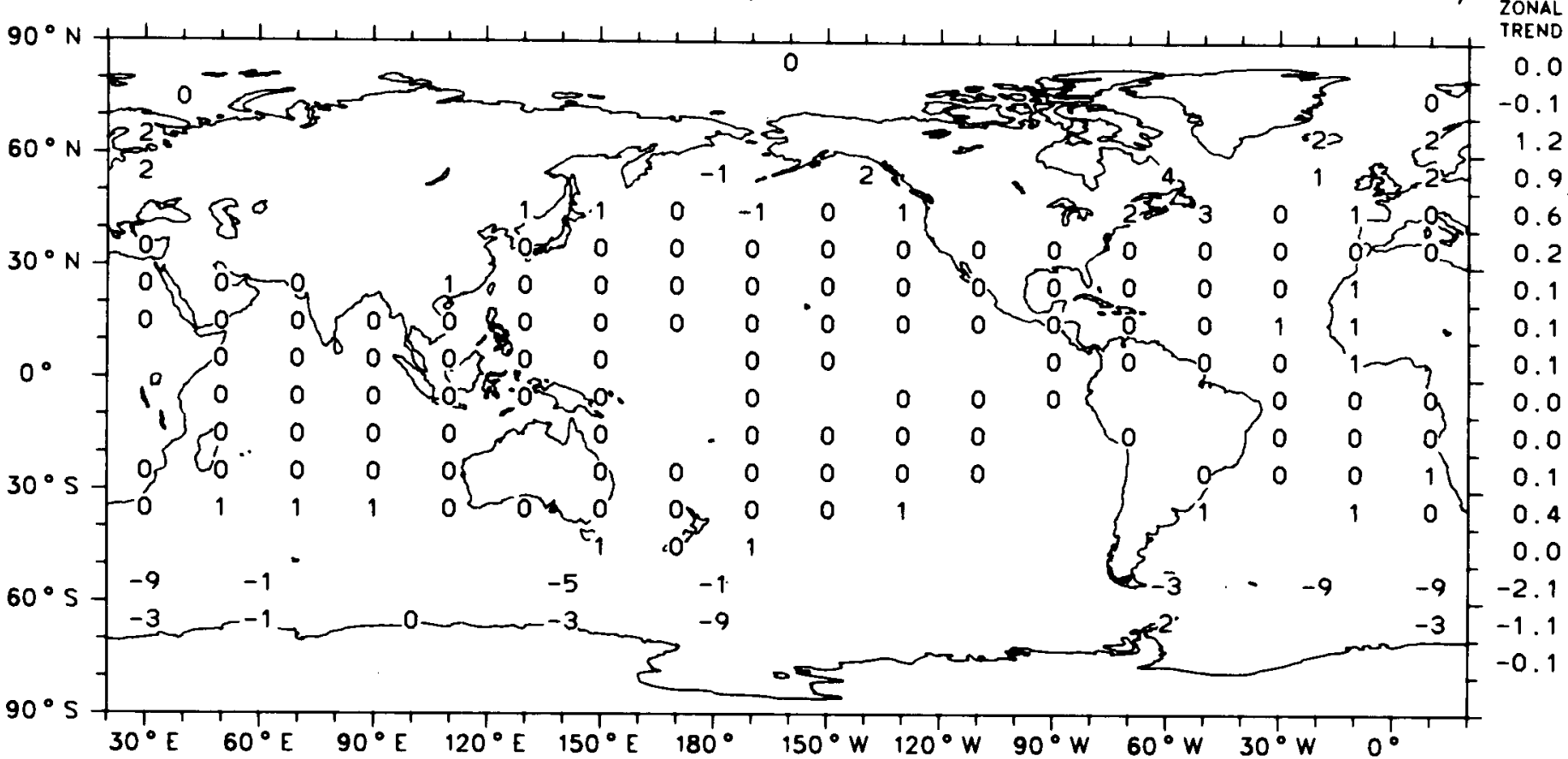

Global Trend (Ocean) $-0.1 \%$

Map 163a

Trend of Sky-Obscured-due-to-Fog :

Change in \%-Frequency-of-Occurrence from 1952 to 1981

March, April, May (1952-1981)

Ocean Areas Only

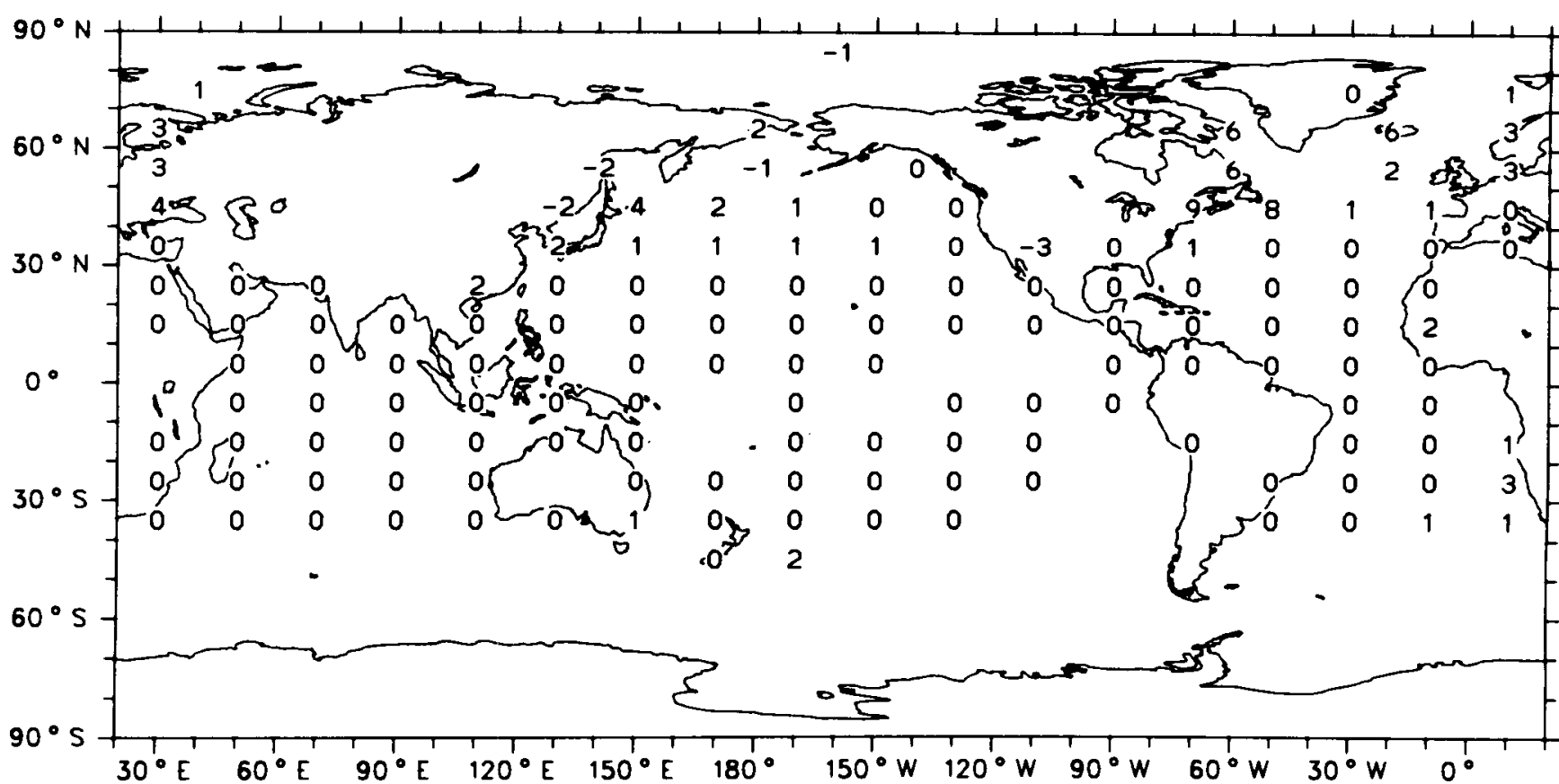

ZONAL TREND $-0.4$ 0.1 3.8 1.0 2.4 
Trend of Sky-Obscured-due-to-Fog :

Change in \%-Frequency-of-Occurrence from 1952 to 1981 June, July. August (1952-1981)

Ocean Areas Only

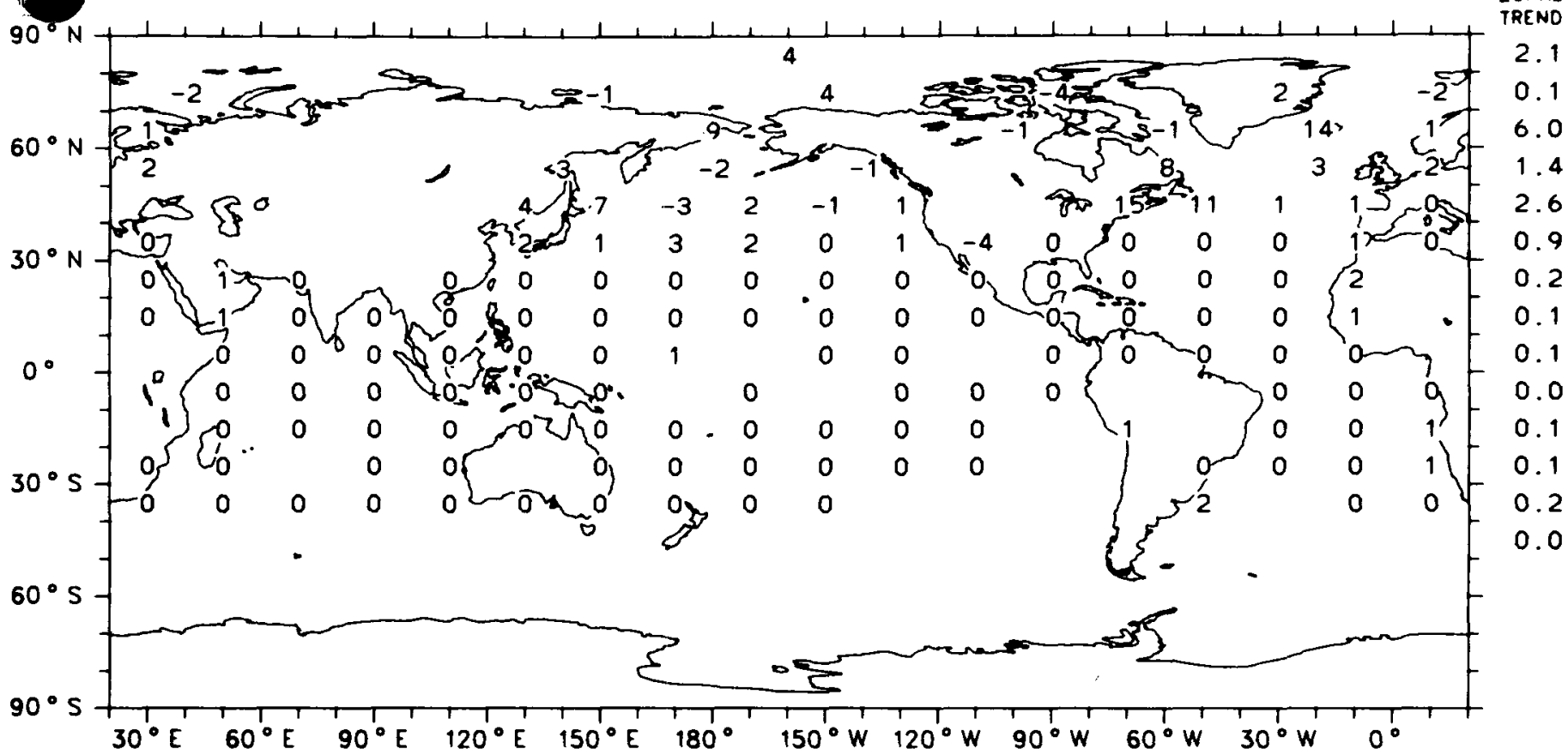

Global Trend (Ocean) $0.4 \%$

Map 163c

Trend of Sky-Obscured-due-to-Fog :

Change in \%-Frequency-of-Occurrence from 1952 to 1981 September. October. November (1952-1981)

Ocean Areas Only

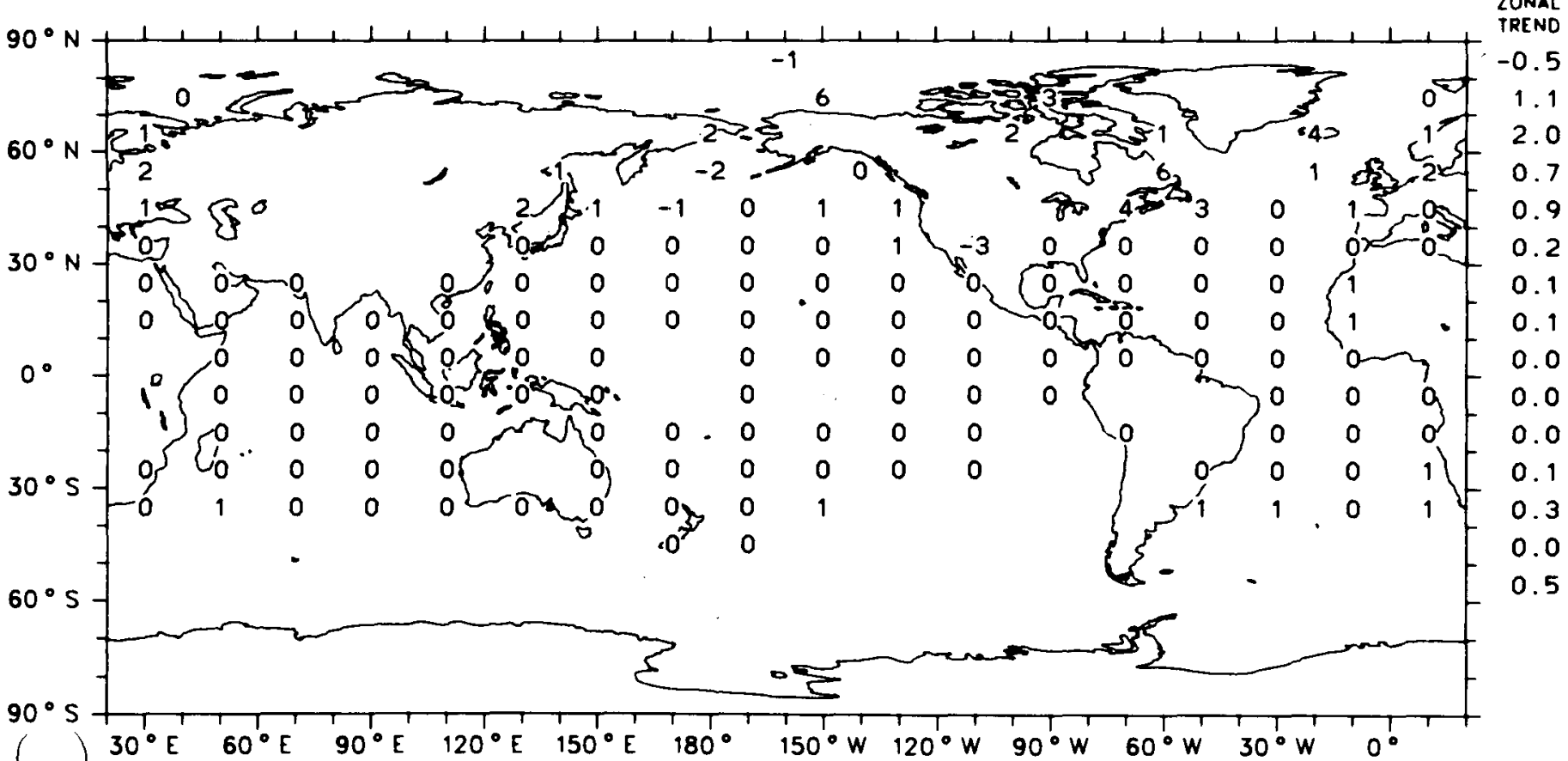

Global Trend (Oceon) $0.2 \%$

Map 163d 


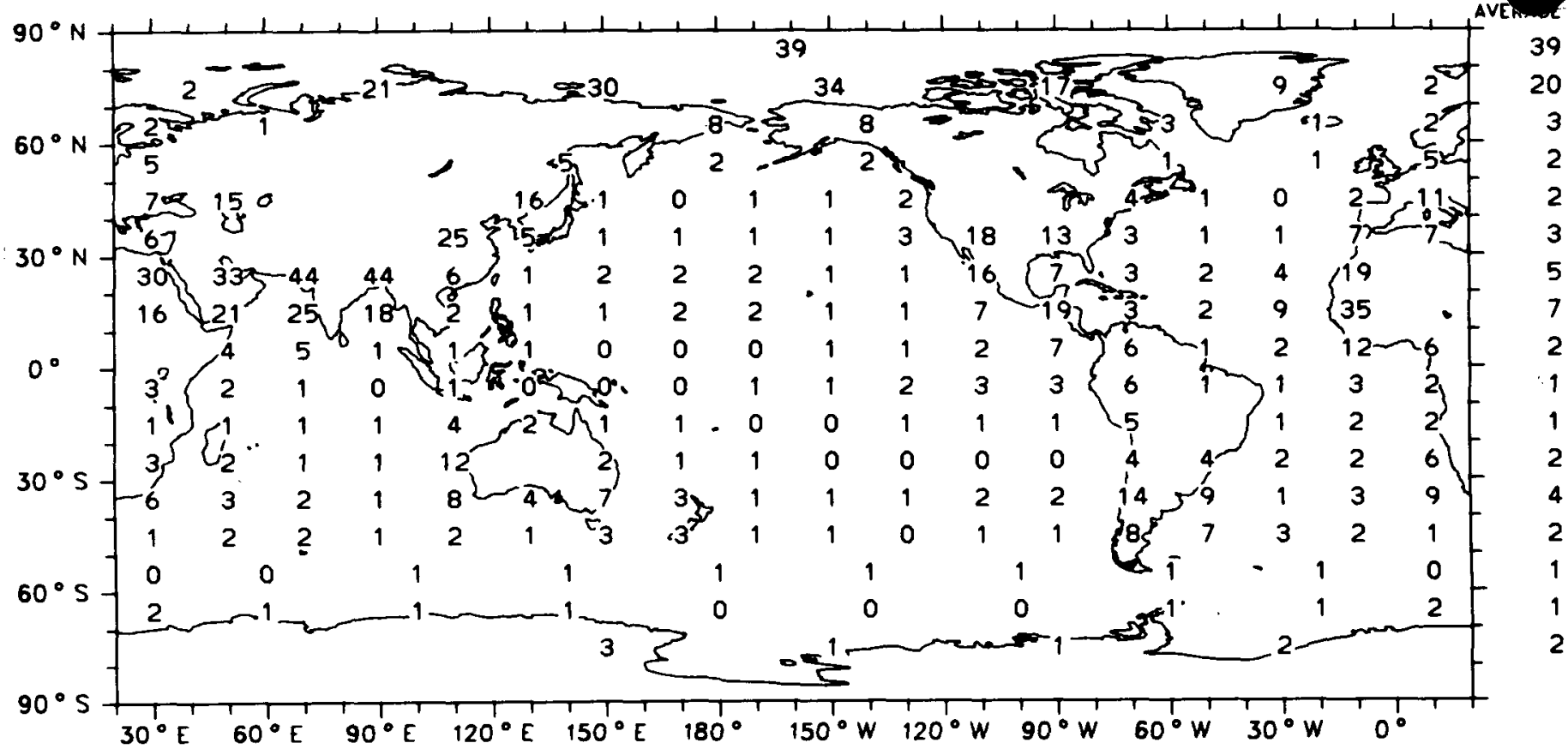

Map 164a

Global Average (Ocean) $3 \%$

\section{Completely Clear Sky}

Frequency of Occurrence (\%), 6-18 LT March. April. Moy (1952-1981)

Ocean Areas Only

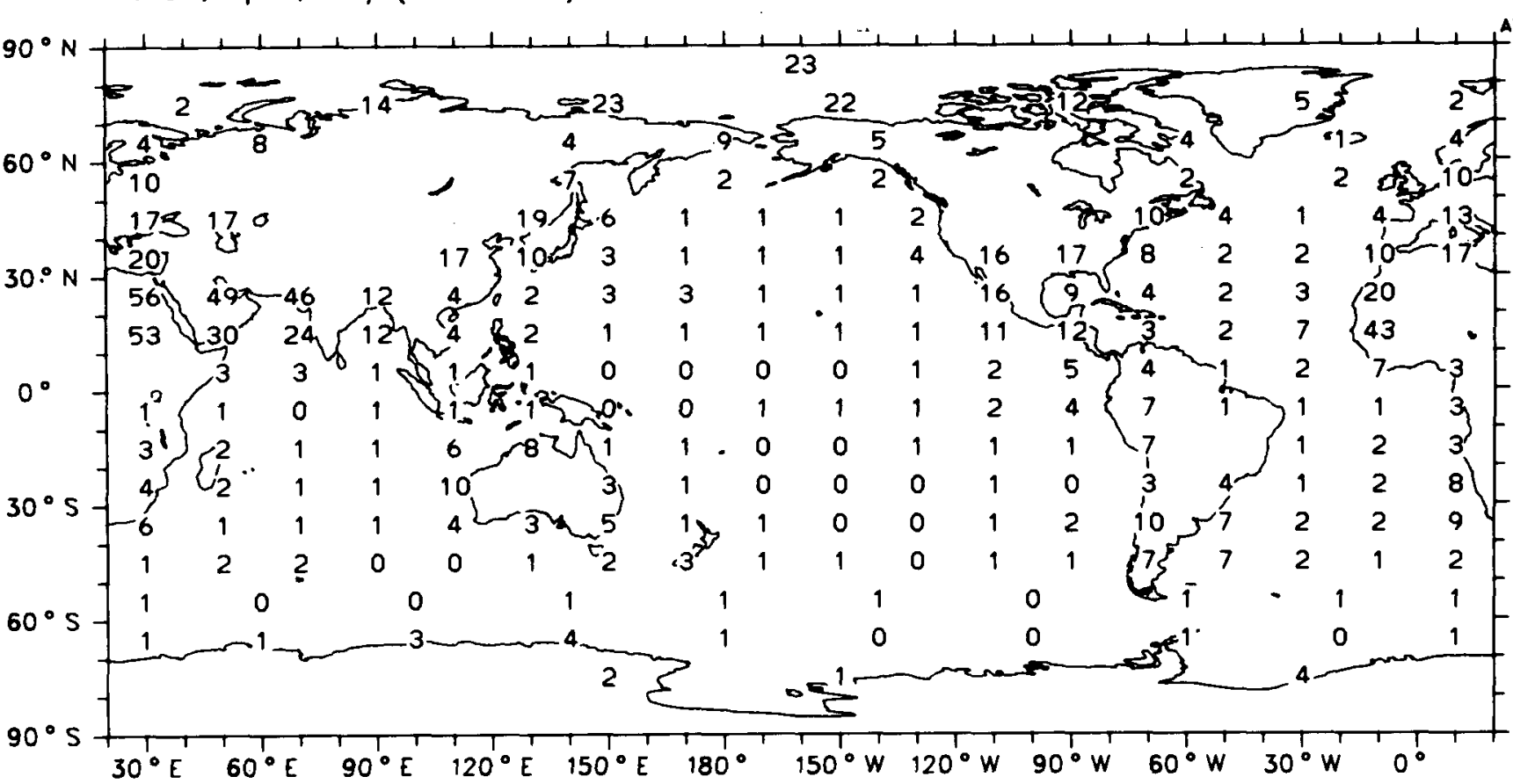

Map 164b

Globol Average (Ocean) $3 \%$ 


\section{Completely Clear Sky}

Frequency of Occurrence (\%), 6-18 LT

June. July, Augusł (1952-1981)

Ocean Areas Only

ZONAL

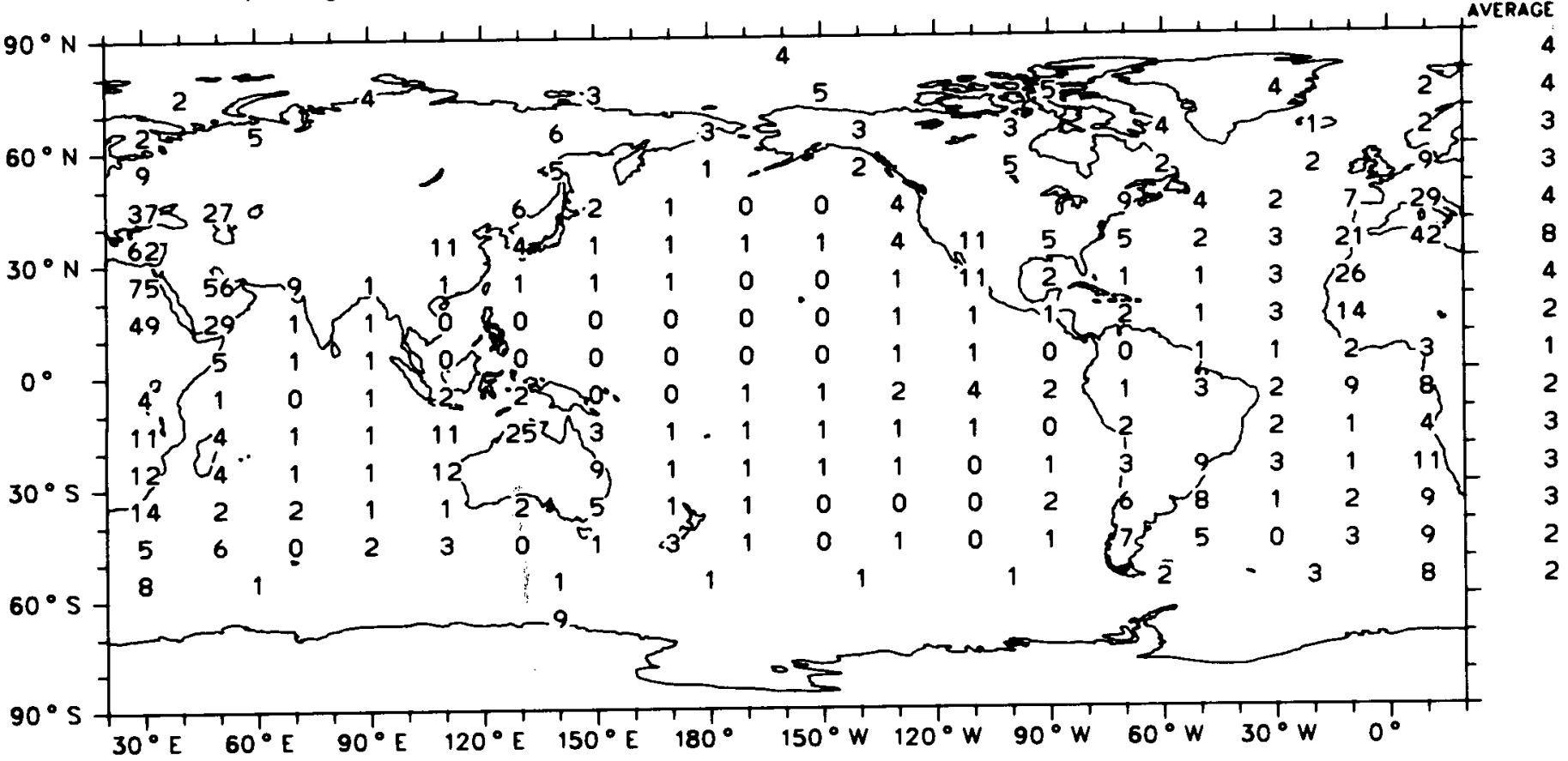

Map 164c

Global Average (Ocean) $3 \%$

\section{Completely Clear Sky}

Frequency of Occurrence (\%), 6-18 LT

September, October, November (1952-1981)

Ocean Areas Only

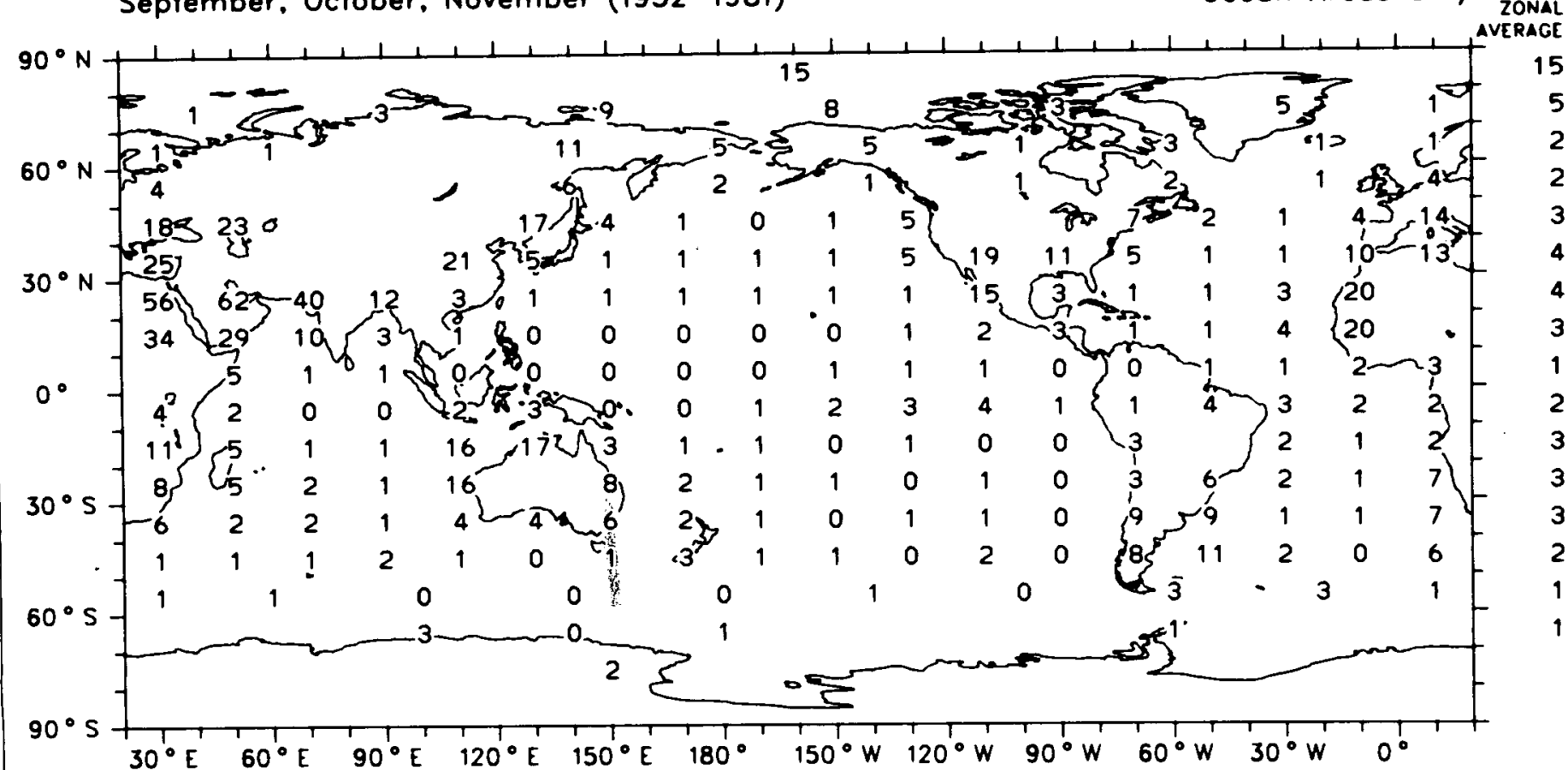

Map 164d

Global Averoge (Ocean) $3 \%$ 
Interannual Variation of Completely Clear Sky, 6-18 LT:

Standard Deviation (detrended) of Seasonal Means ( $0.1 \%$ Frequency of Occurrence)

December, Jonuory, February (1952-1981)

Oceon Areos Only

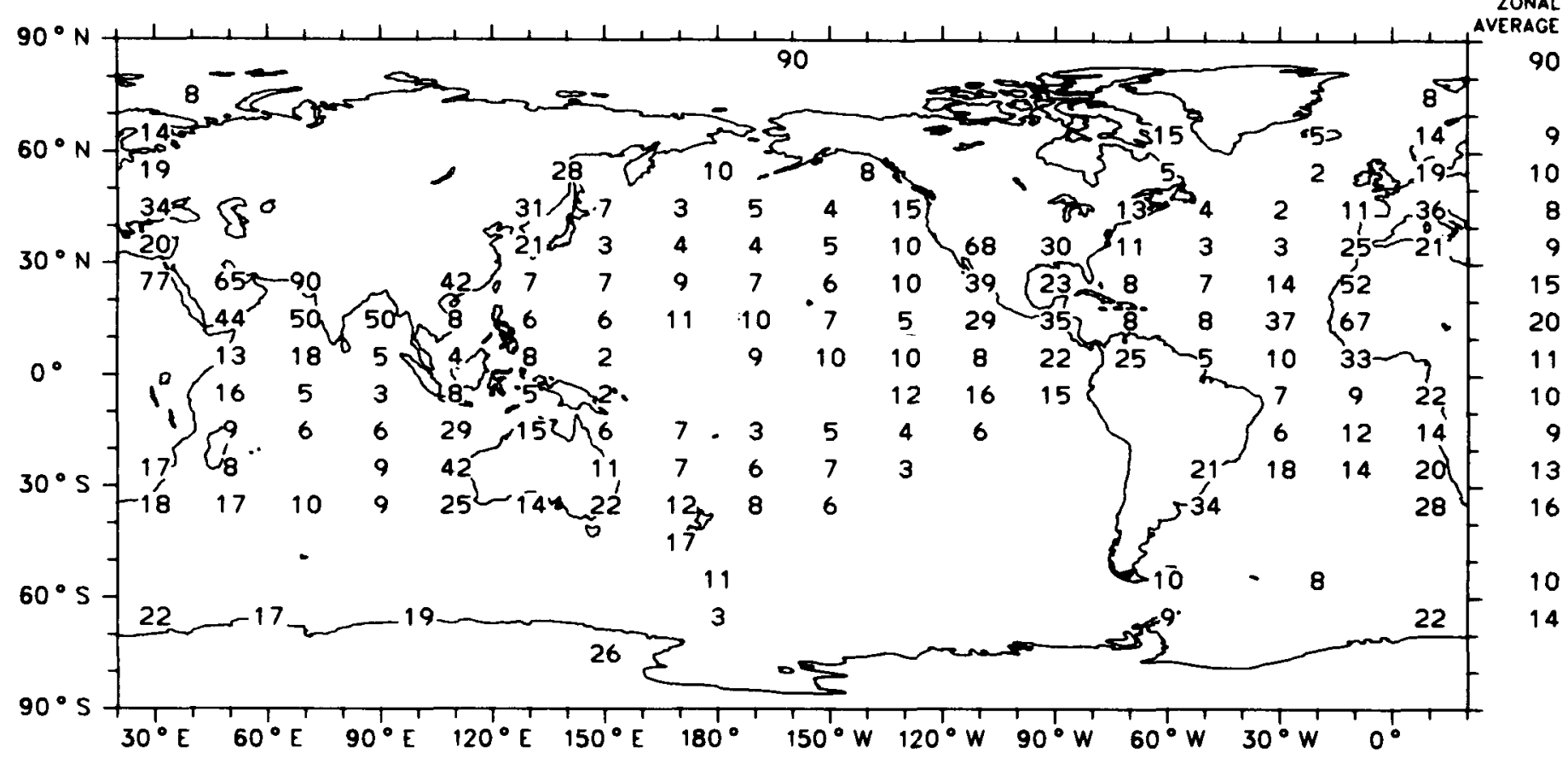

Global Average (Ocean) i.3\%

Map 165a

Interannual Variation of Completely Clear Sky, 6-18 LT:

Standard Deviation (detrended) of Seasonal Means ( $0.1 \%$ Frequency of Occurrence) March. April. May (1952-1981)

Ocean Areas Only zONAL

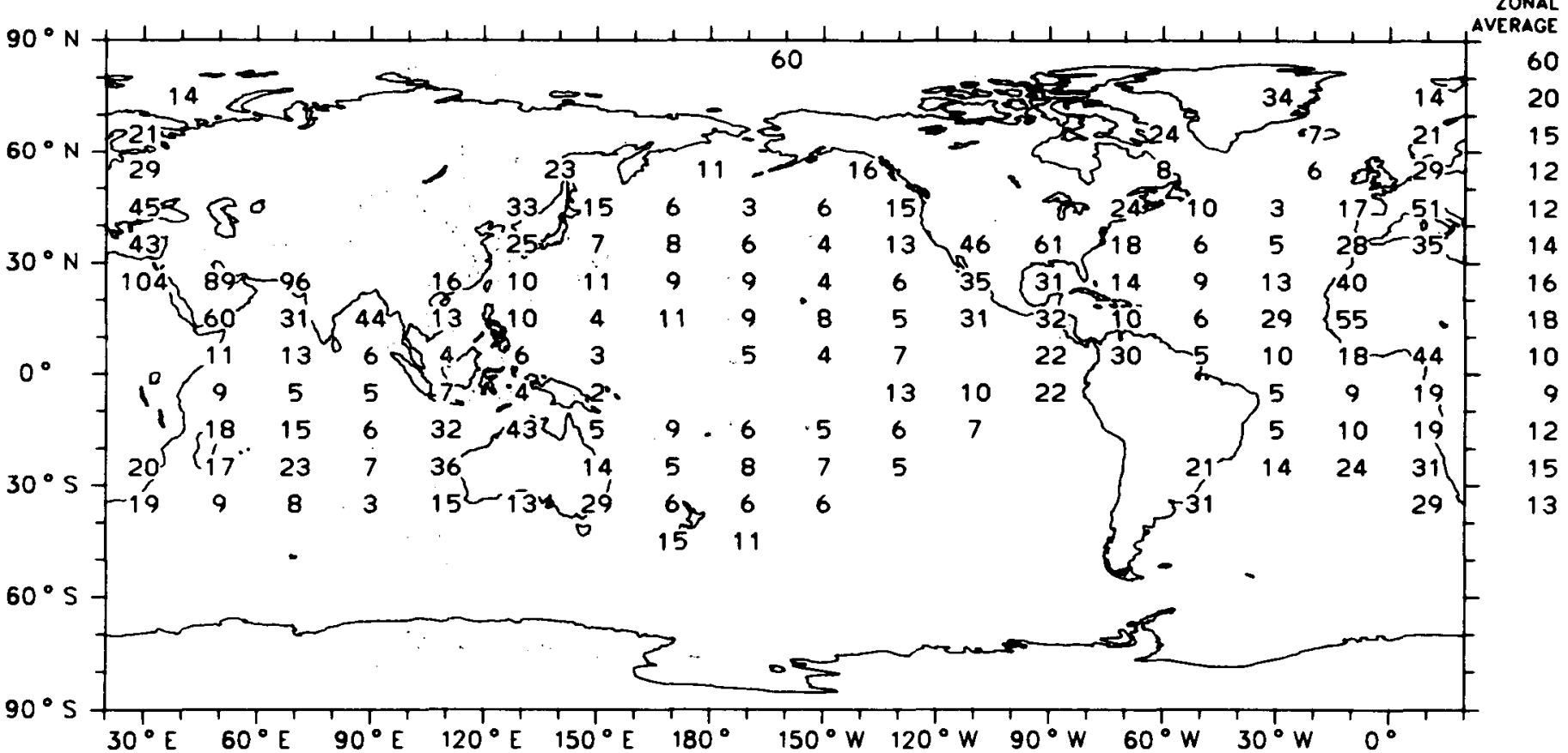

Global Average (Ocean) $1.4 \%$

Map 165b 
Interannual Variation of Completely Clear Sky, 6-18 LT:

Standard Deviation (detrended) of Seasonal Means ( $0.1 \%$ Frequency of Occurrence)

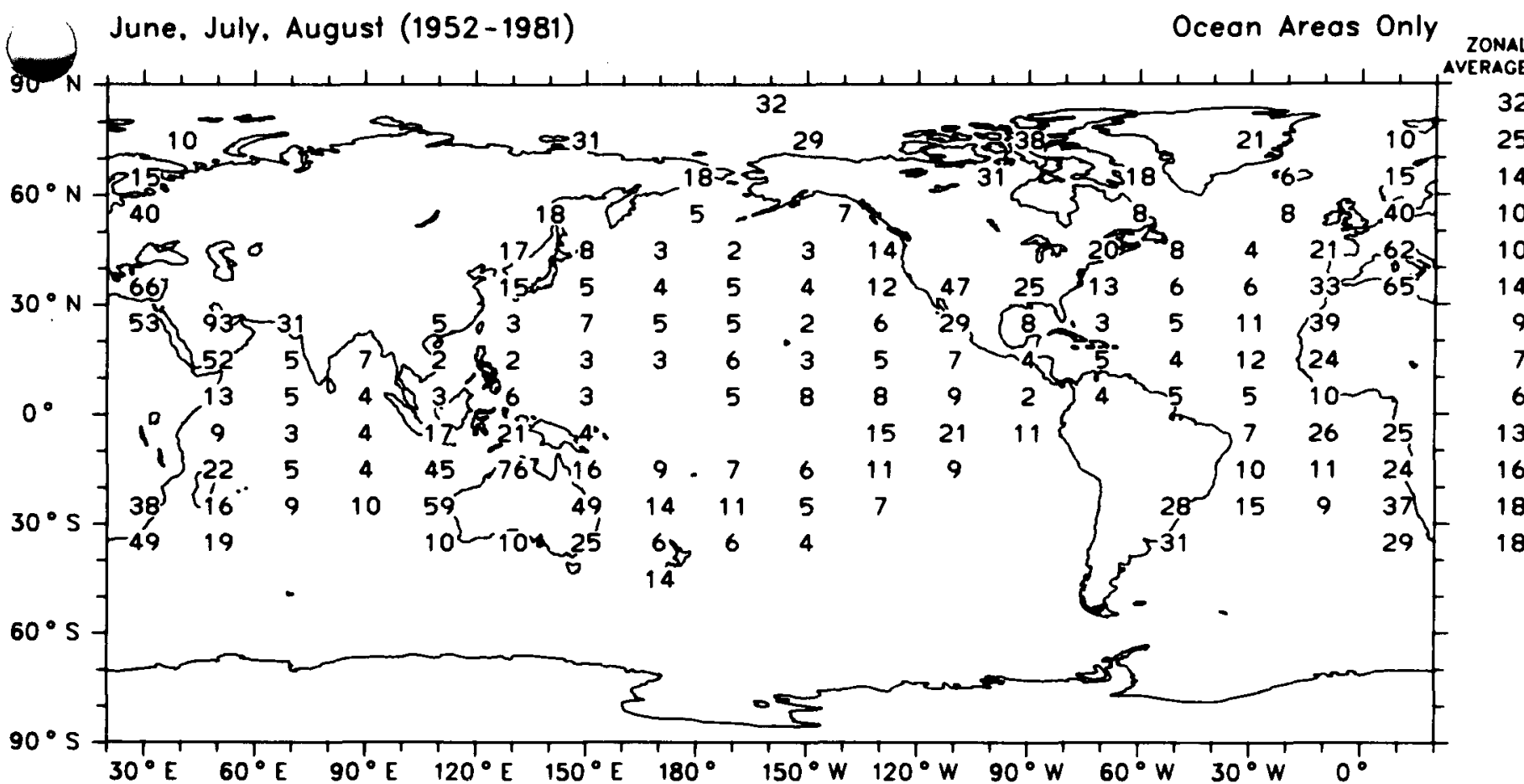

Global Average (Ocean) $1.3 \%$

Map 165c

Interannual Variation of Completely Clear Sky, 6-18 LT:

Standard Deviation (detrended) of Seasonal Means (0.1\% Frequency of Occurrence) September, October, November (1952-1981)

Ocean Areos Only

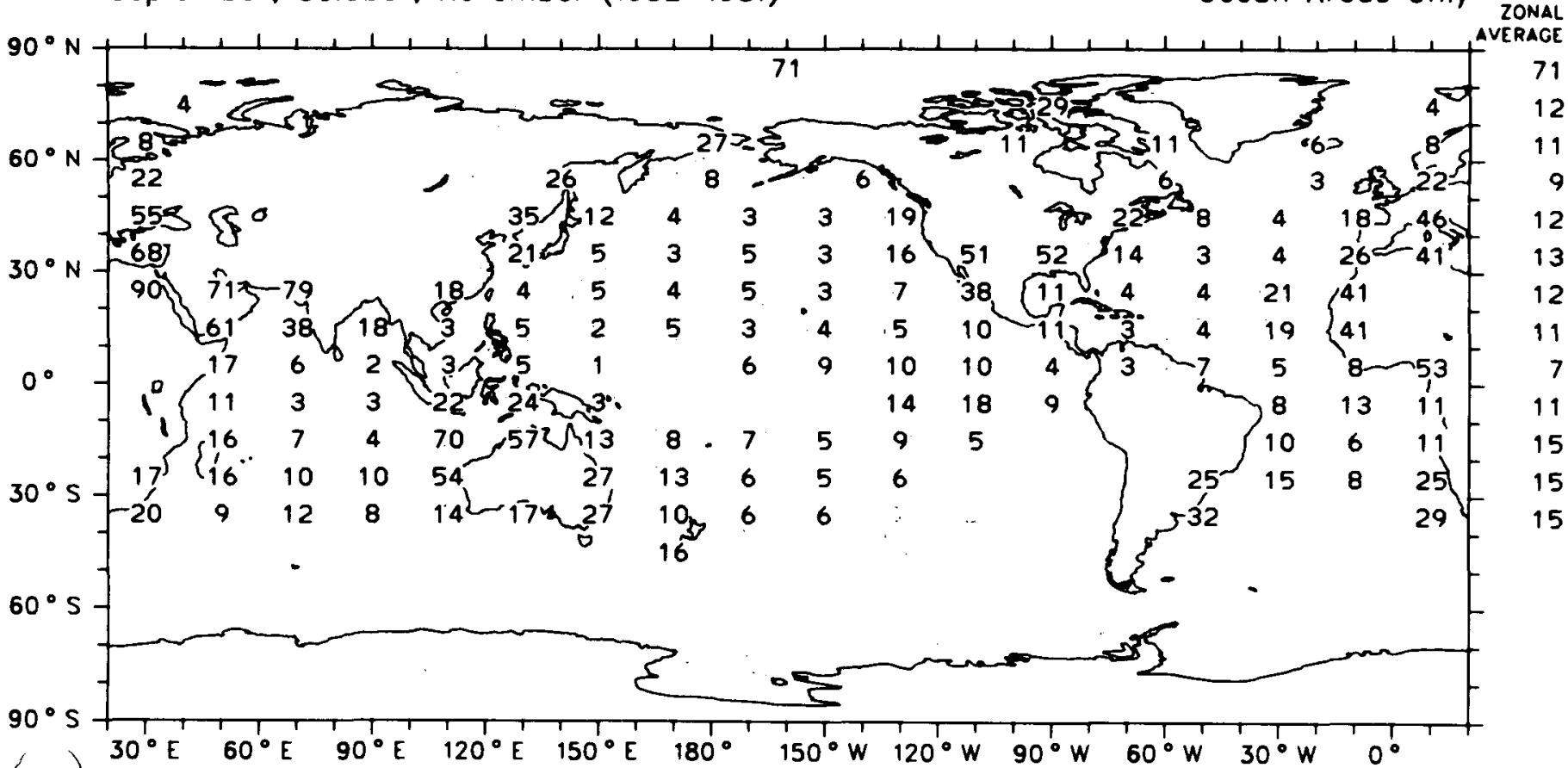

Globol Average (Ocean) $1.3 \%$

Map 165d 
Trend of Completely Clear Sky, 6-18 LT:

Change in \%-Frequency-of-Occurrence from 1952 to 1981

December. January, February (1952-1981)

Ocean Areas Only

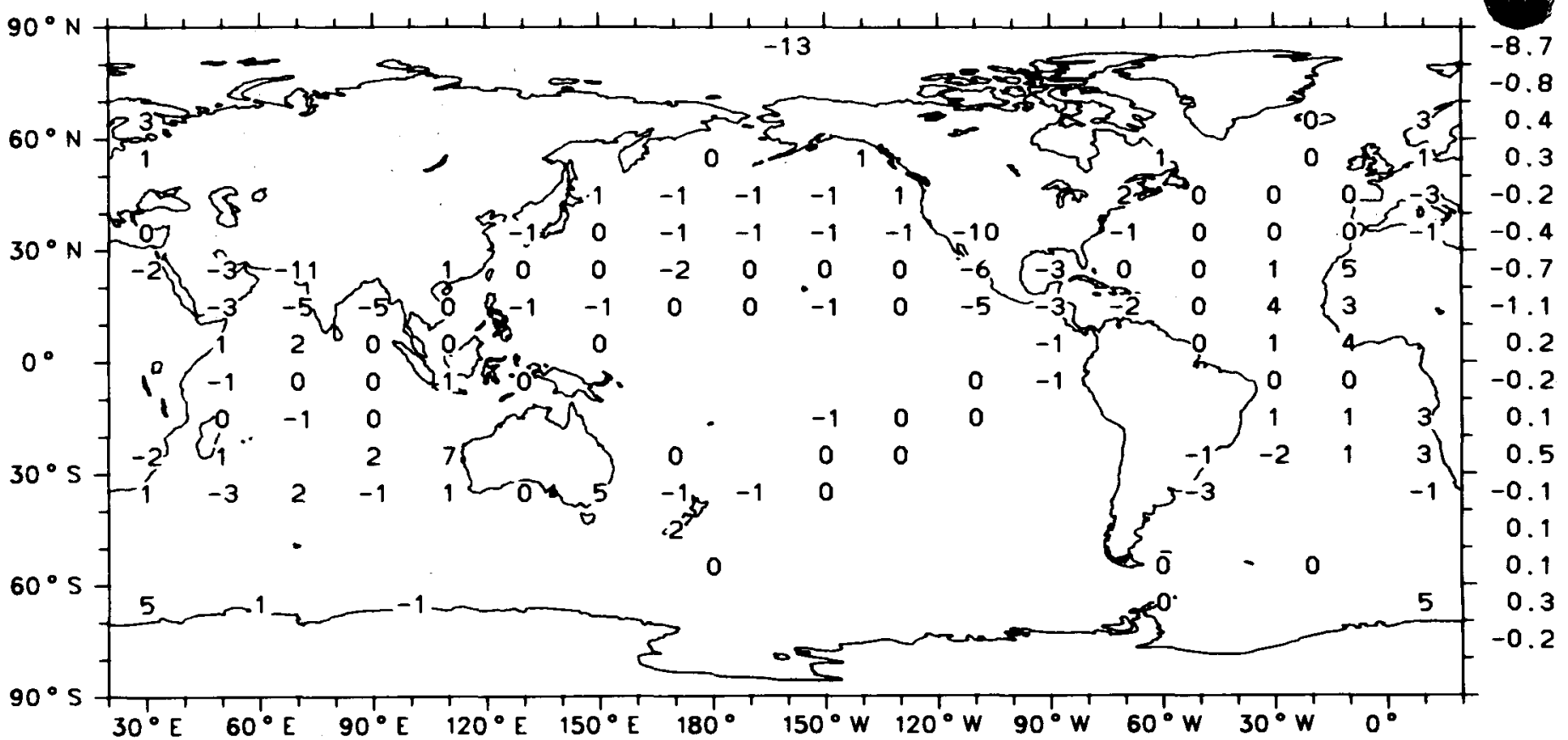

Map 166a

Global Trend (Ocean) $-0.2 \%$

Trend of Completely Clear Sky. 6-18 LT:

Change in \%-Frequency-of-Occurrence from 1952 to 1981 March, April, Moy (1952-1981)

Ocean Areas Only

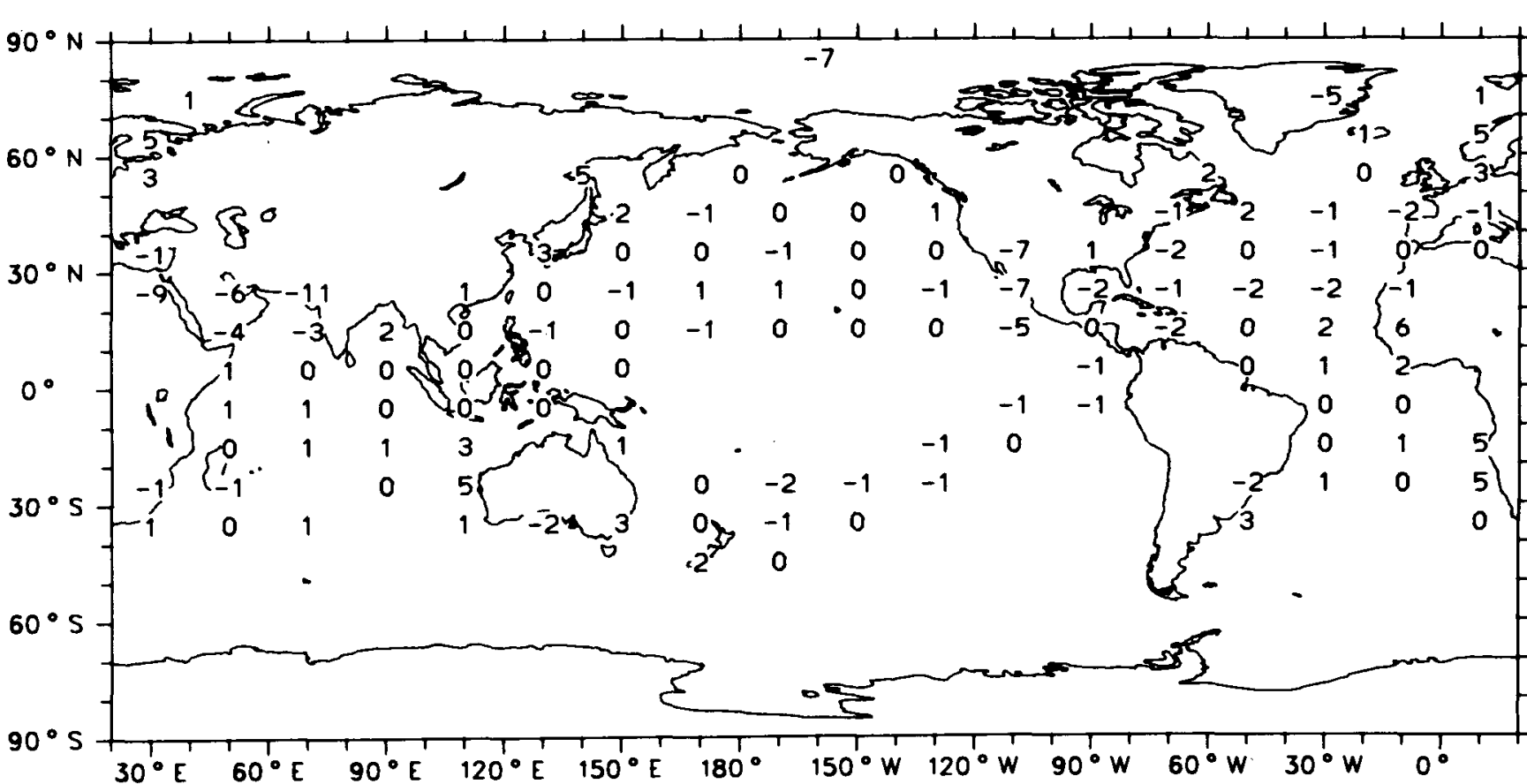


Trend of Completely Clear Sky, 6-18 LT:

Change in \%-Frequency-of-Occurrence from 1952 to 1981 June, July, August (1952-1981)

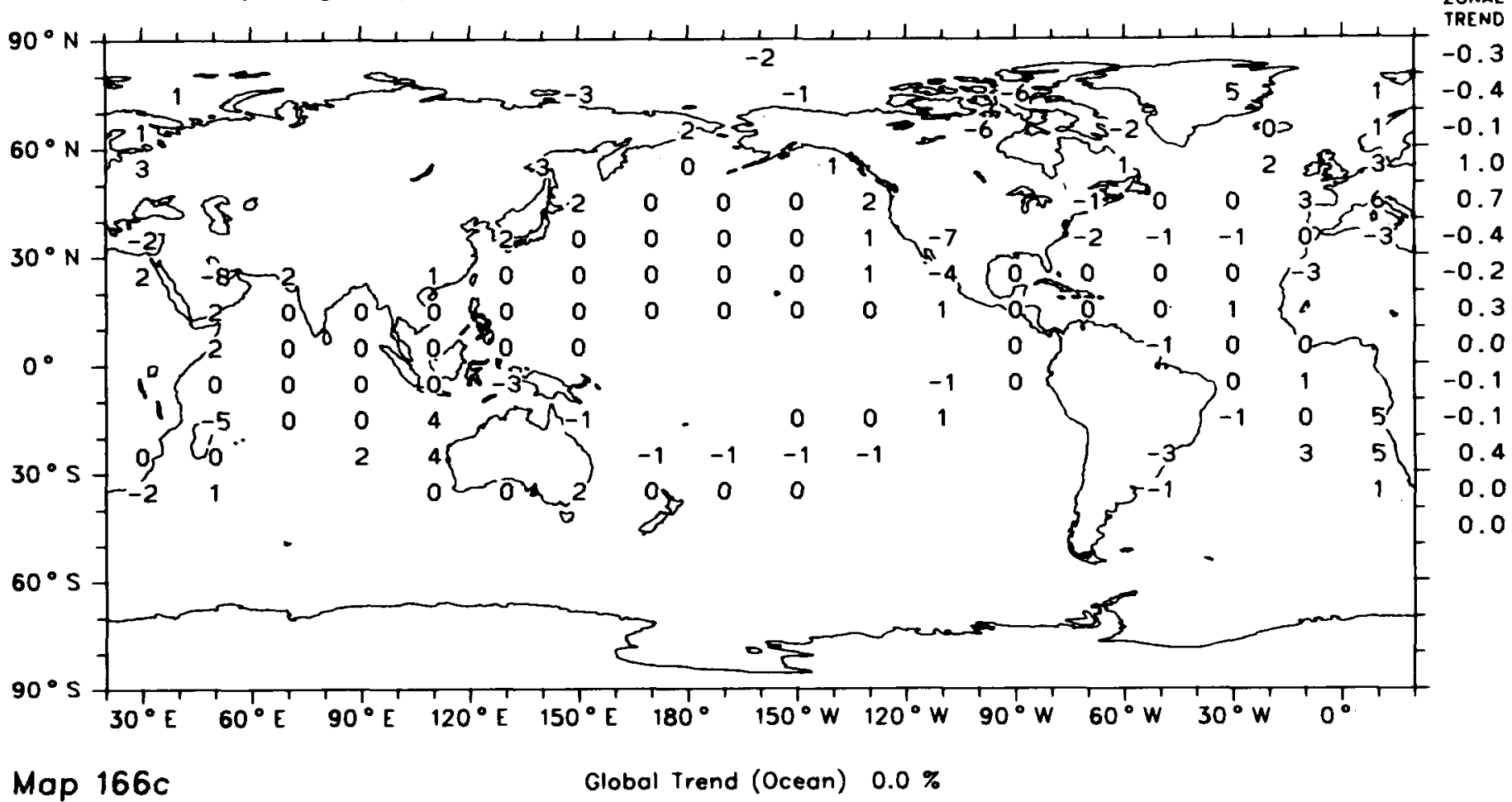

Trend of Completely Clear Sky, 6-18 LT:

Change in \%-Frequency-of-Occurrence from 1952 to 1981

September, October, November (1952-1981)

Oceon Areos Only

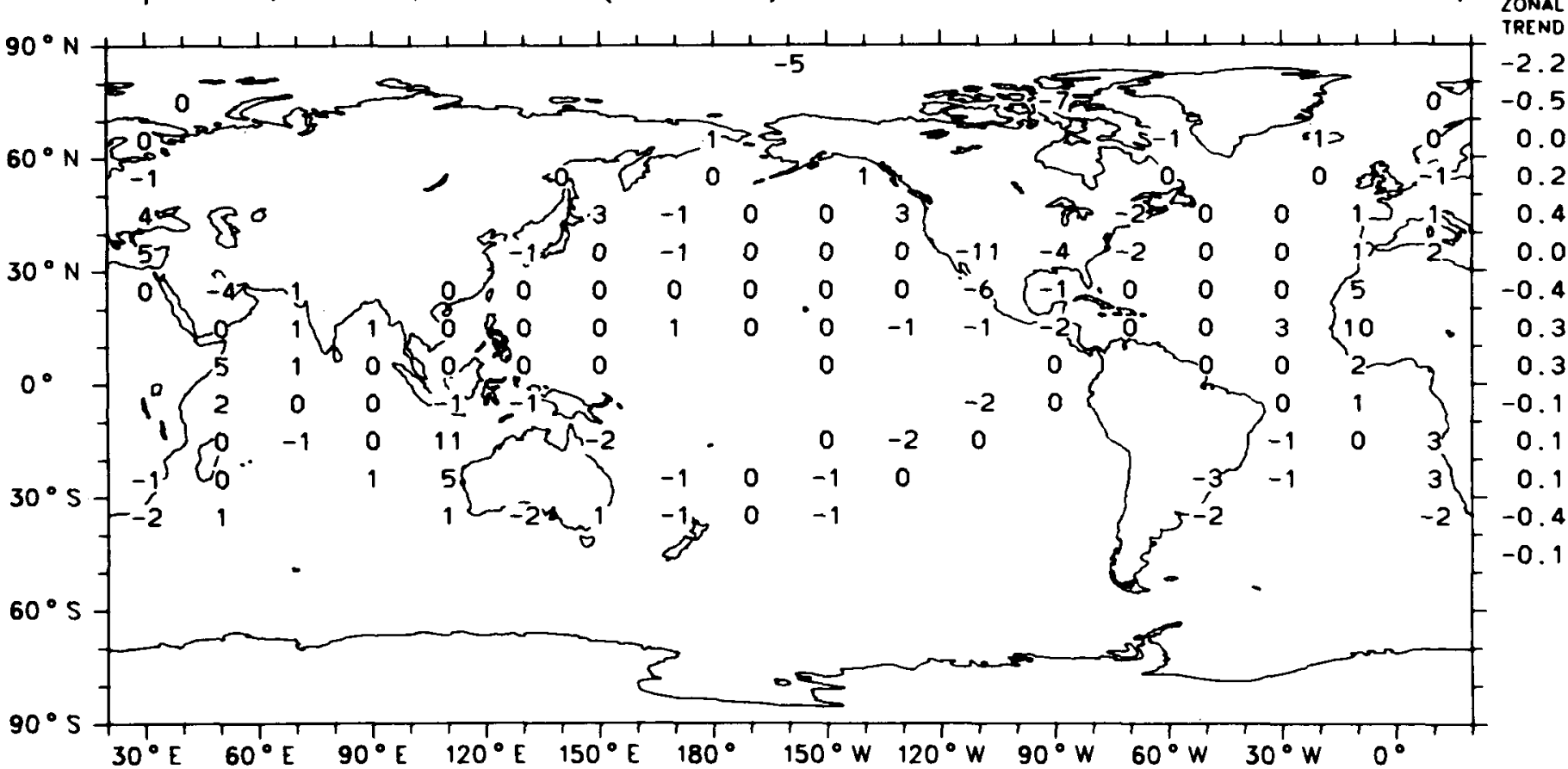

Map 166d

Globol Trend (Oceon) $0.0 \%$ 


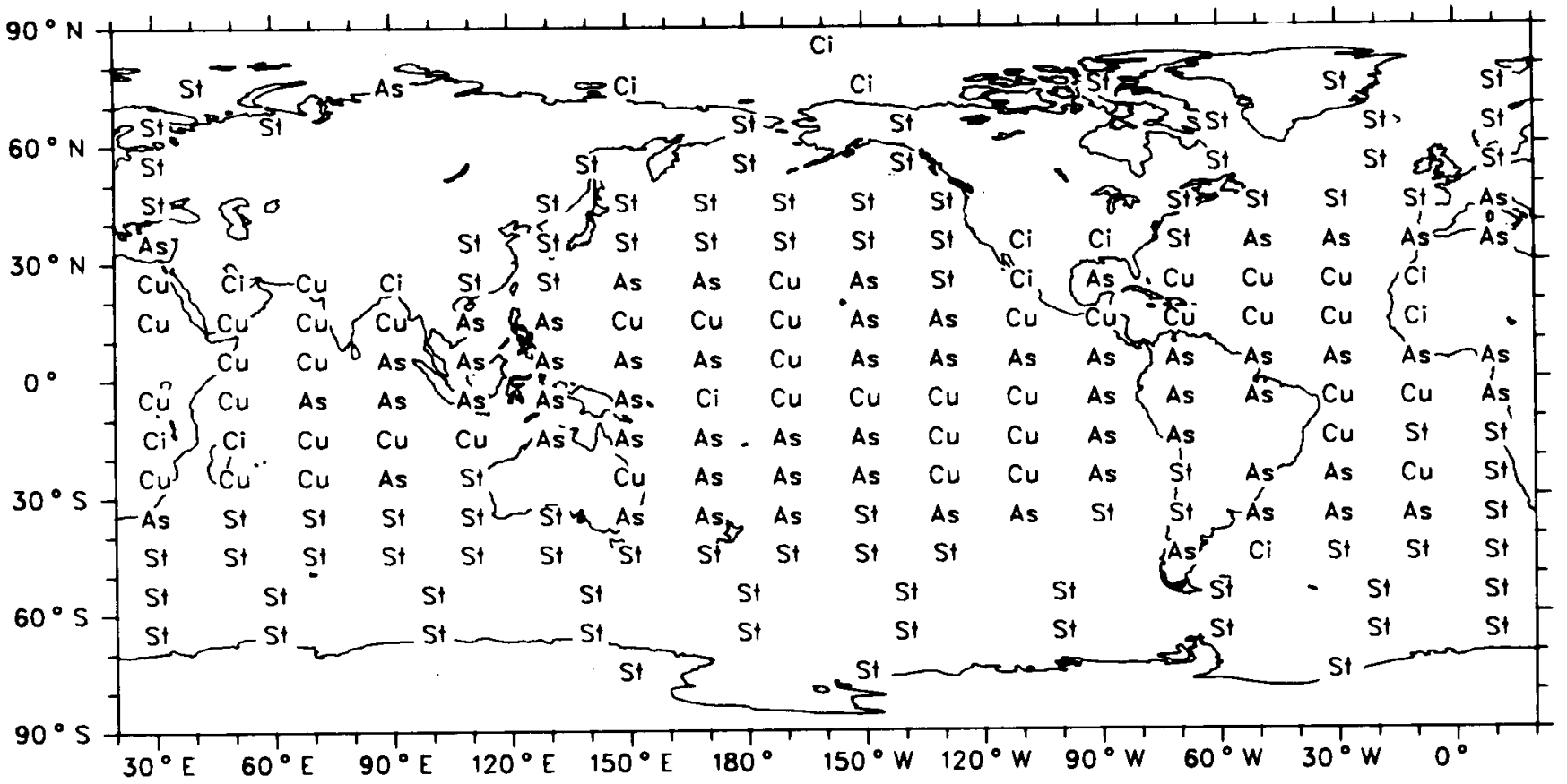

Map 167a

\section{Most-Frequently-Occurring Cloud Type}

March. April. May (1952-1981)

Ocean Areas Only

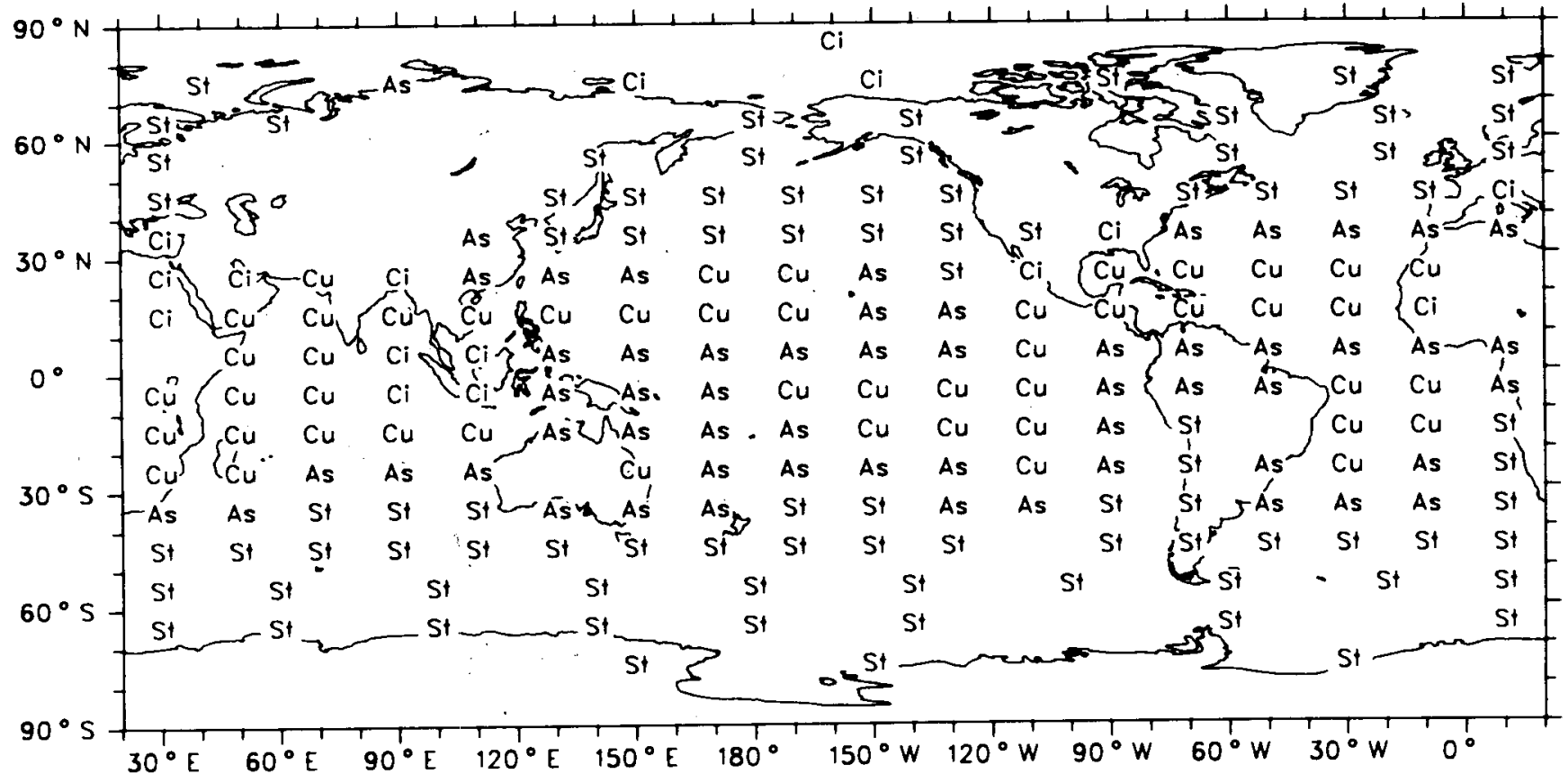

Map 167b 
Most-Frequently-Occurring Cloud Type

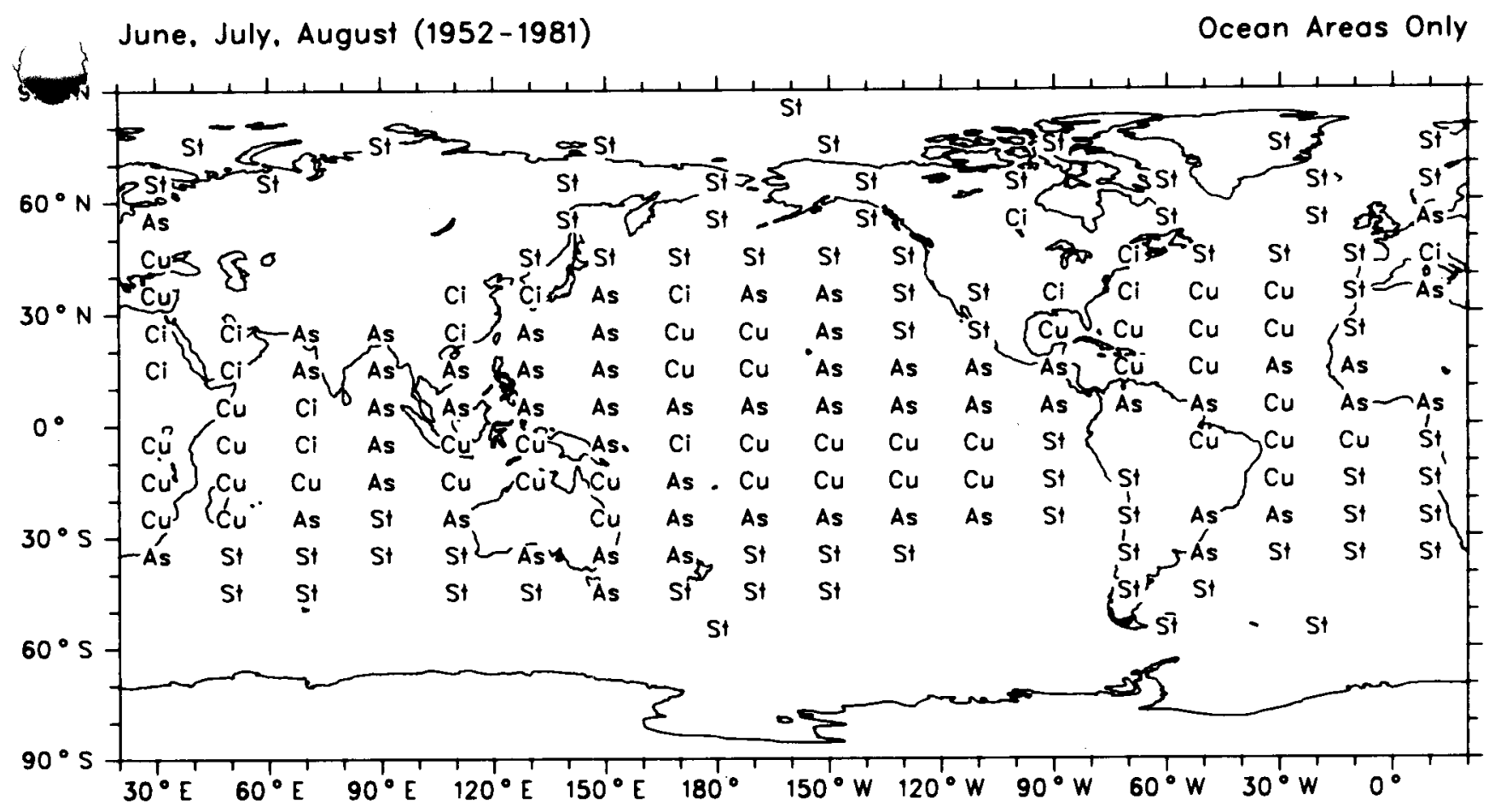

Map 167c

Most-Frequently-Occurring Cloud Type

September, October, November (1952 - 1981)

Ocean Areas Only

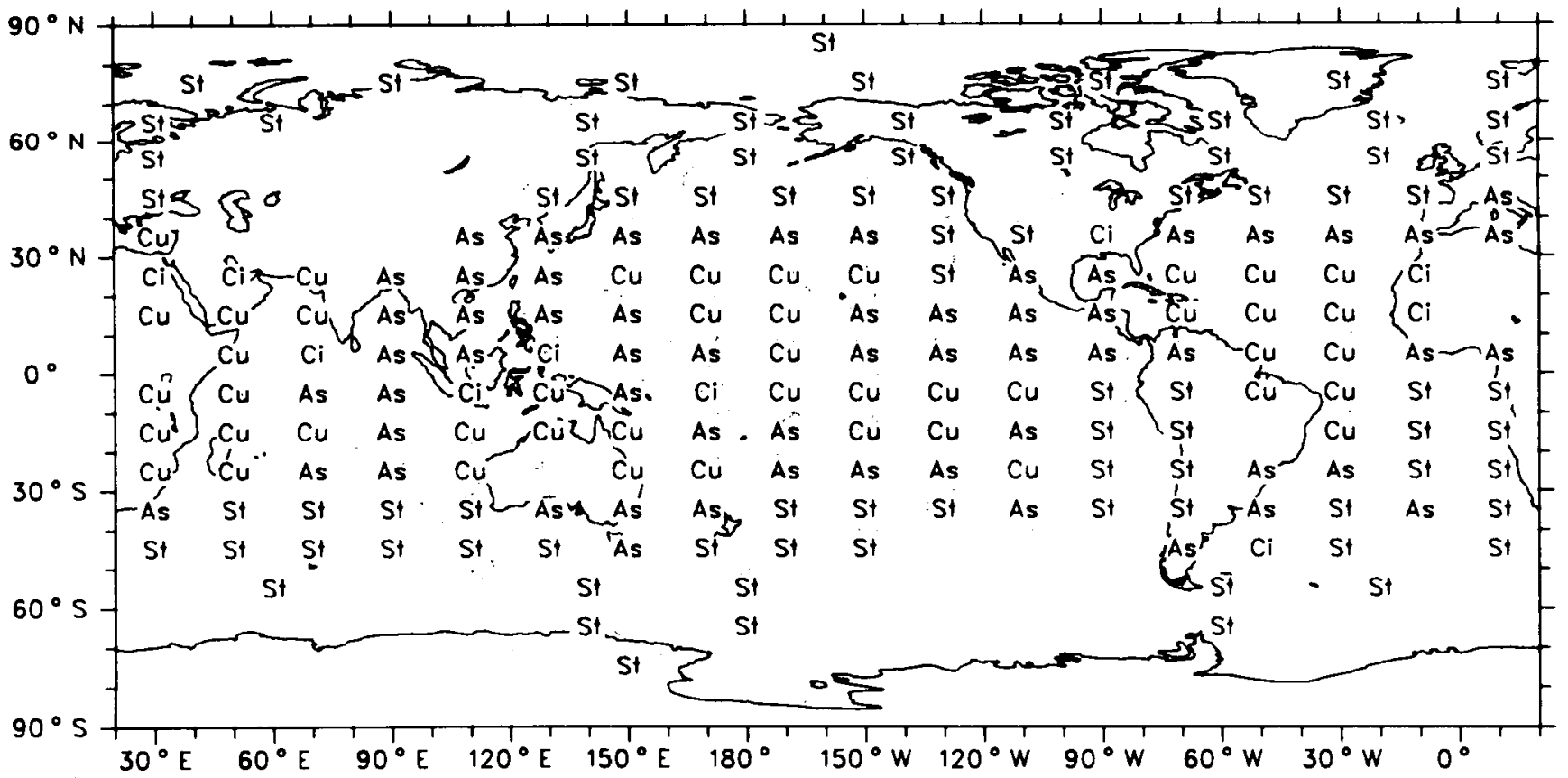

(1)

Map 167d 
Type Contributing Most to Total Cloud Cover

December, January. February (1952-1981)

Ocean Areas Only

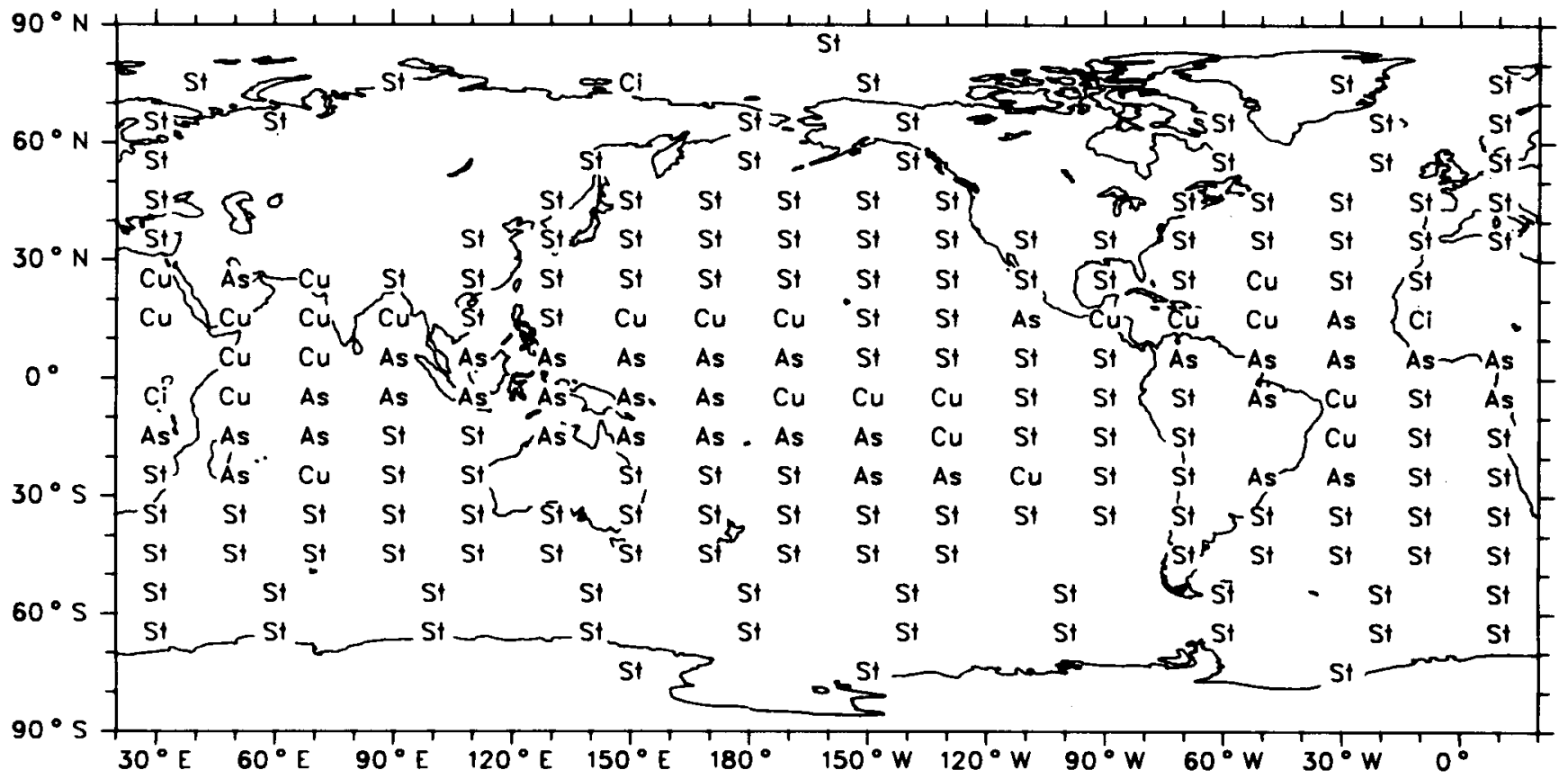

Map 168a

Type Contributing Most to Total Cloud Cover March, April, May (1952-1981)

Oceon Areas Only

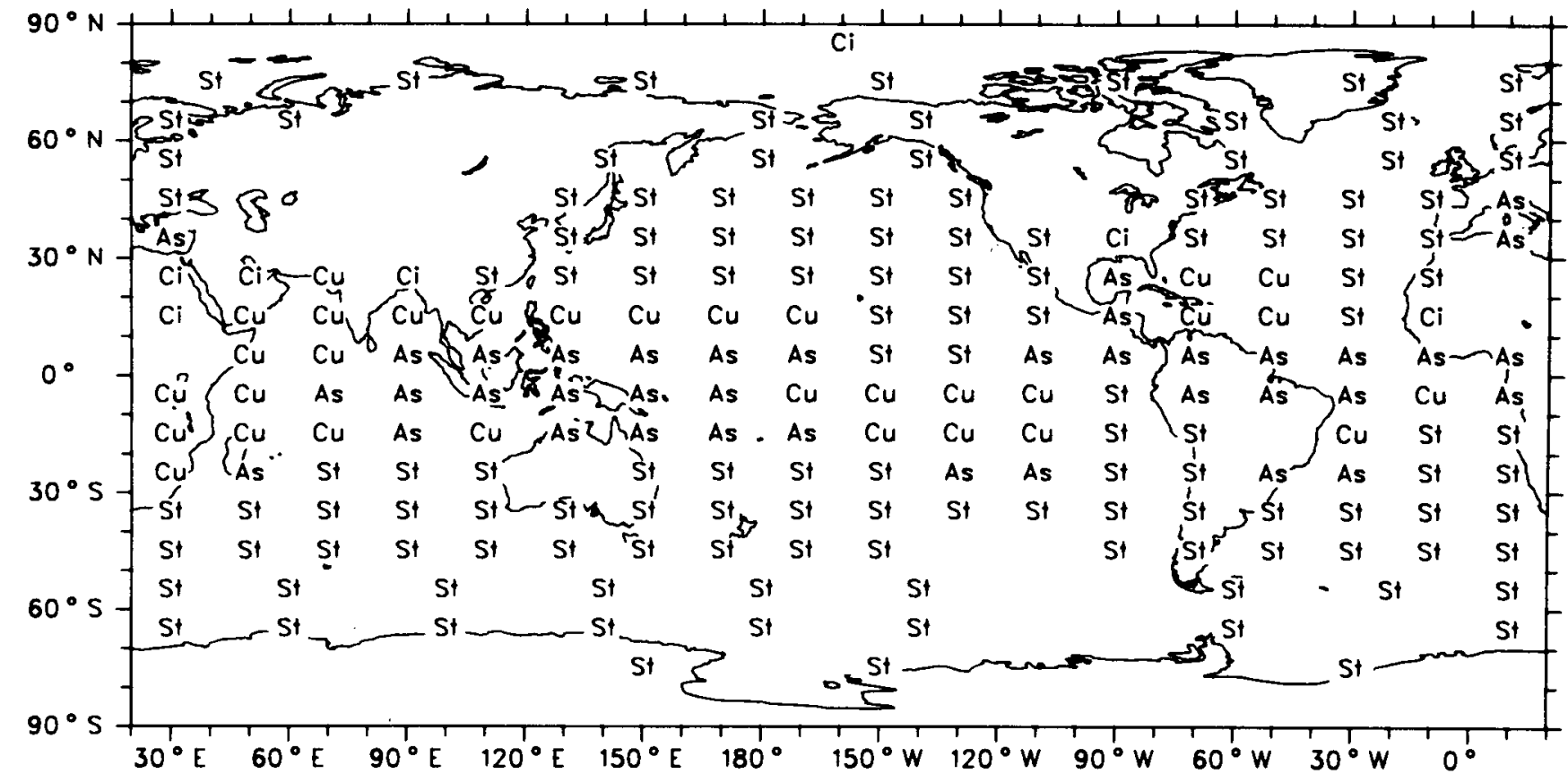

Map 168b 
Type Contributing Most to Total Cloud Cover June, July. August (1952-1981)

Ocean Areas Only

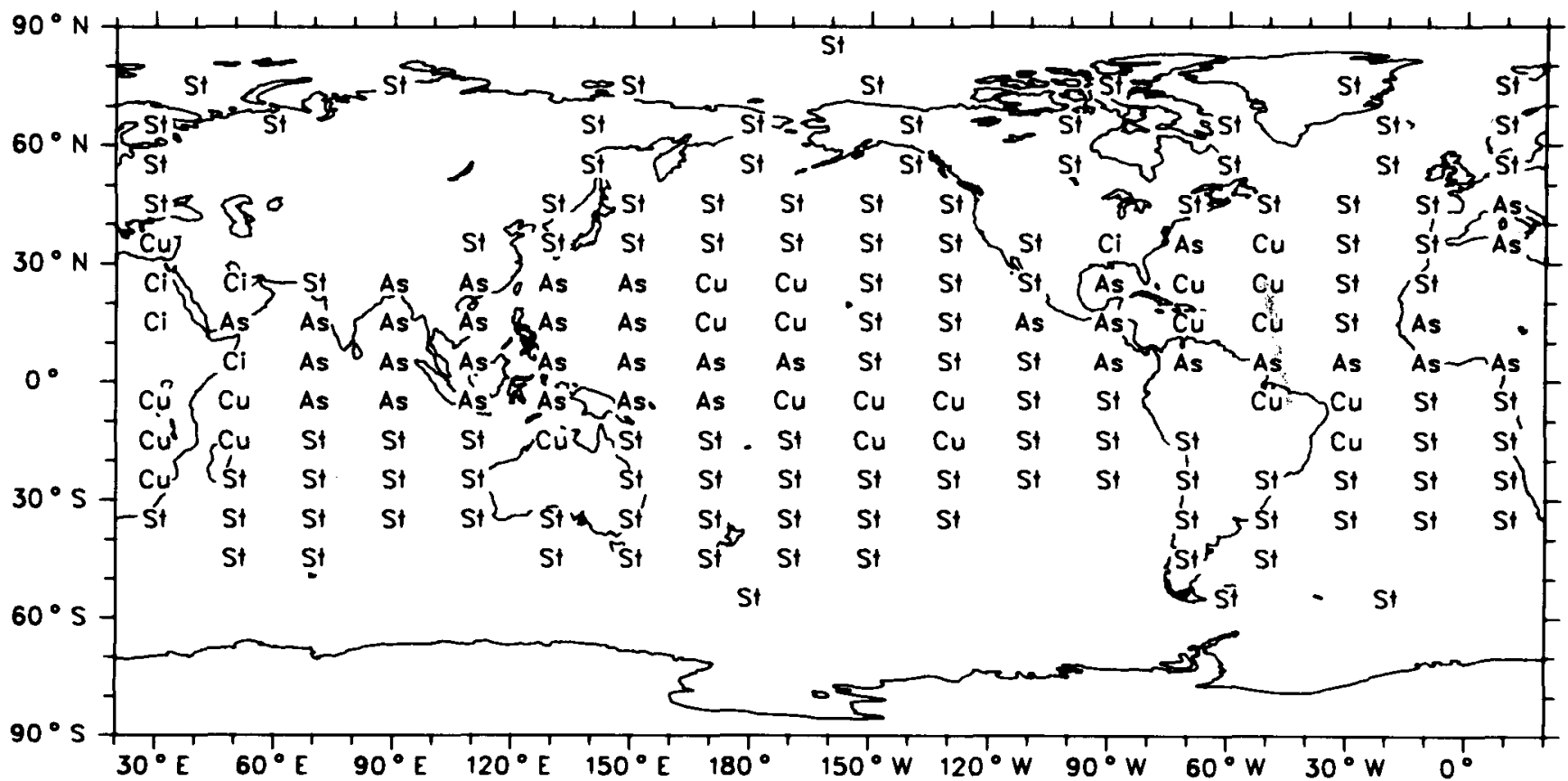

Map 168c

Type Contributing Most to Total Cloud Cover

September, October. November (1952-1981)

Ocean Areas Only

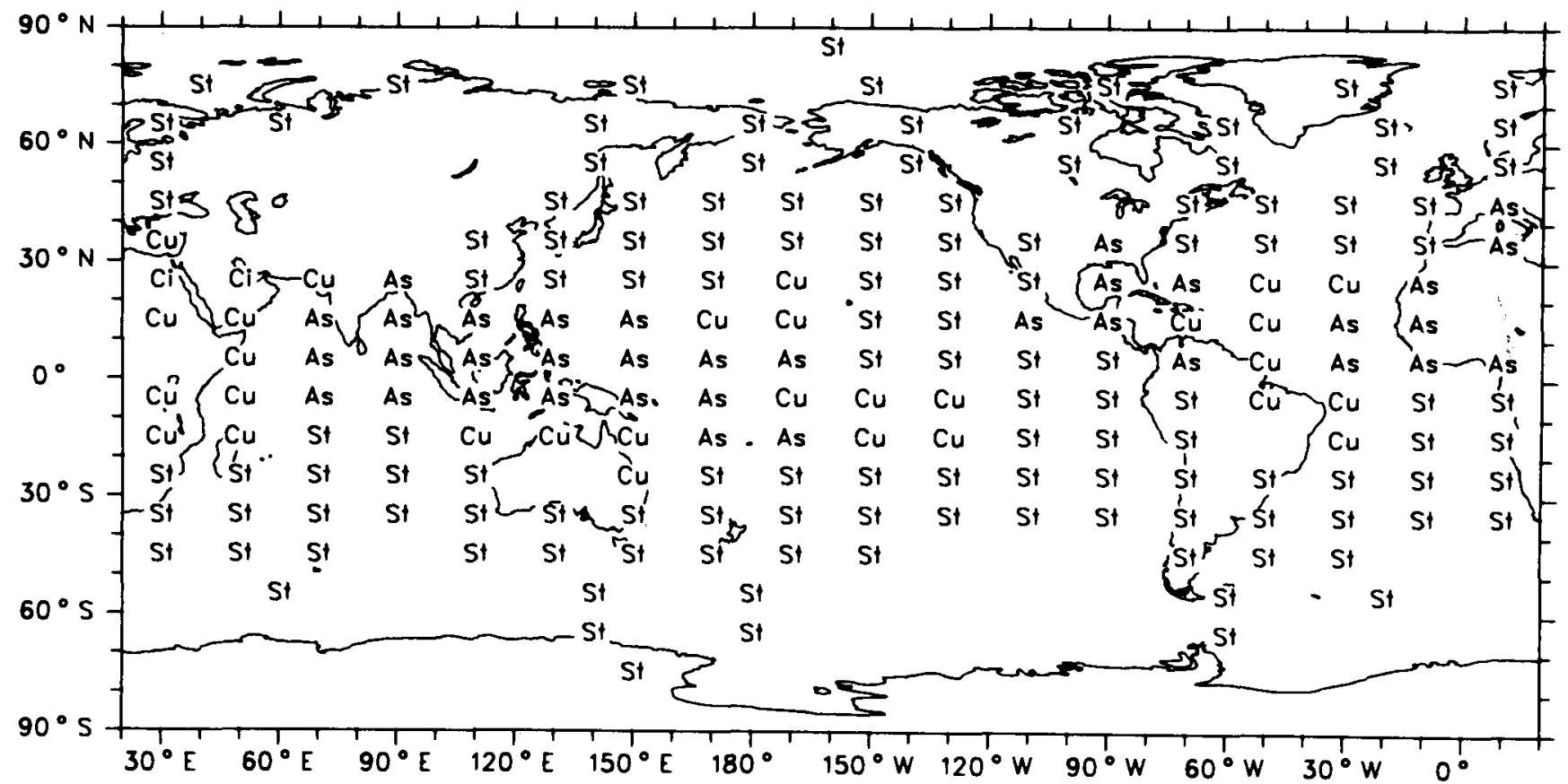

Map 168d 


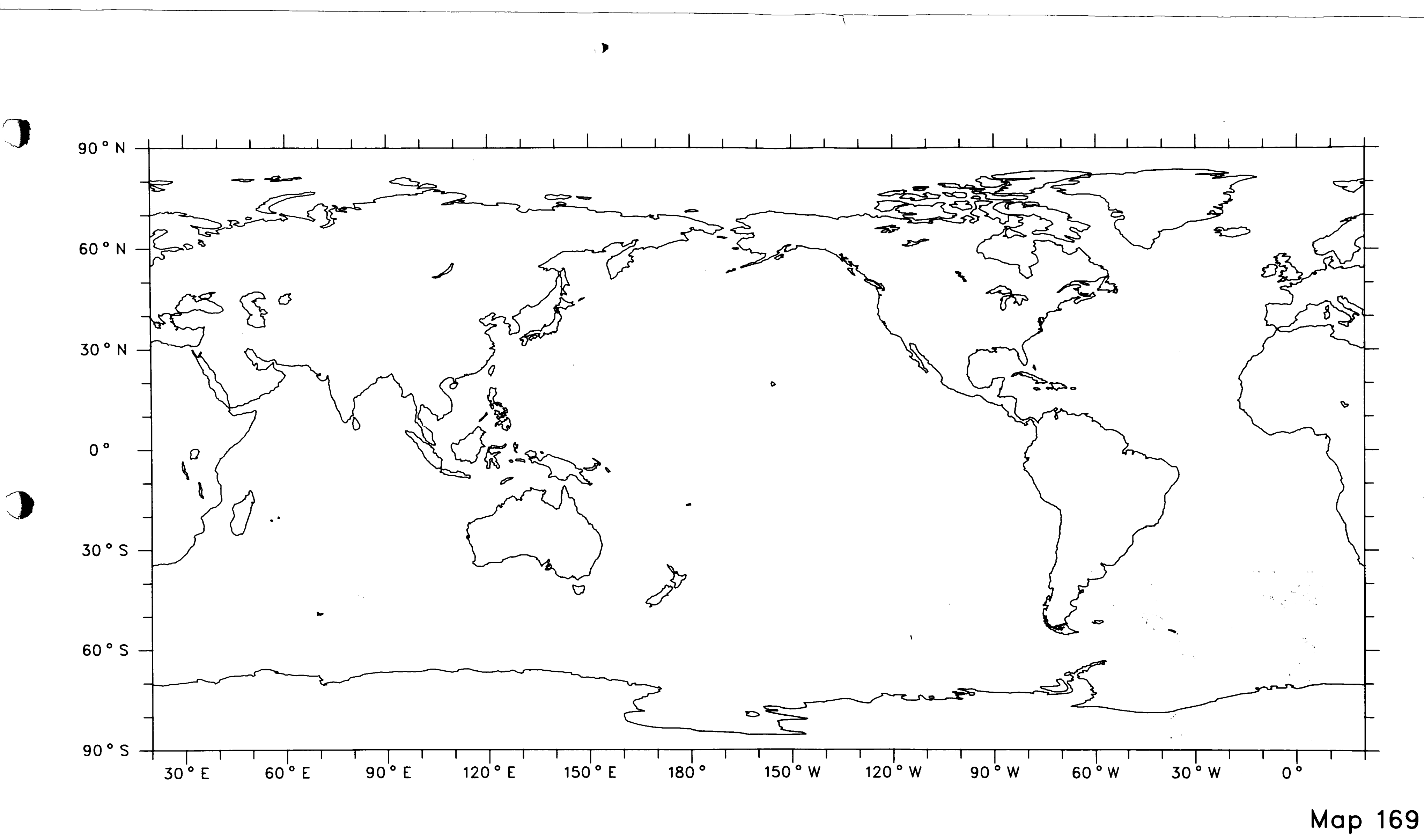




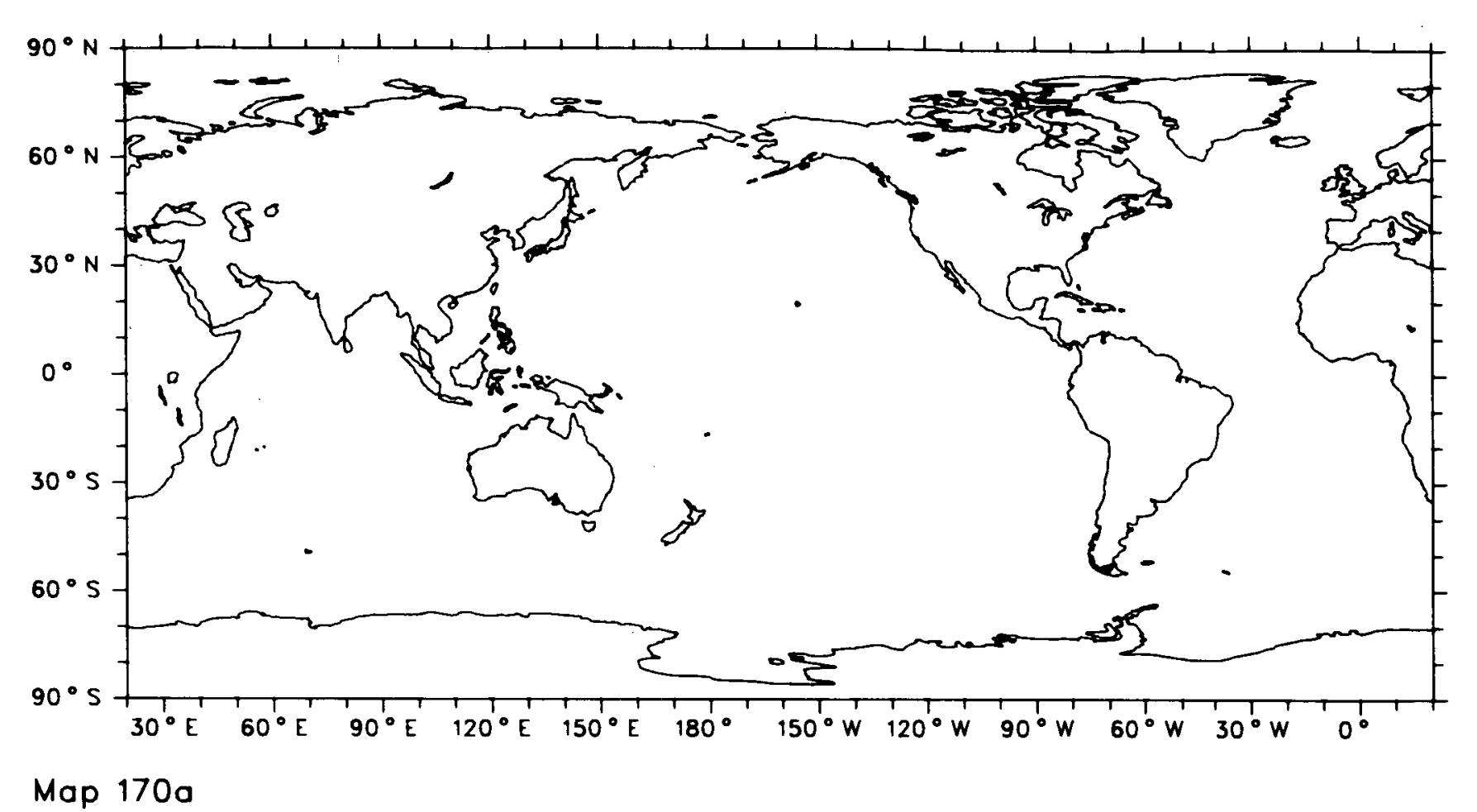

Map 1700

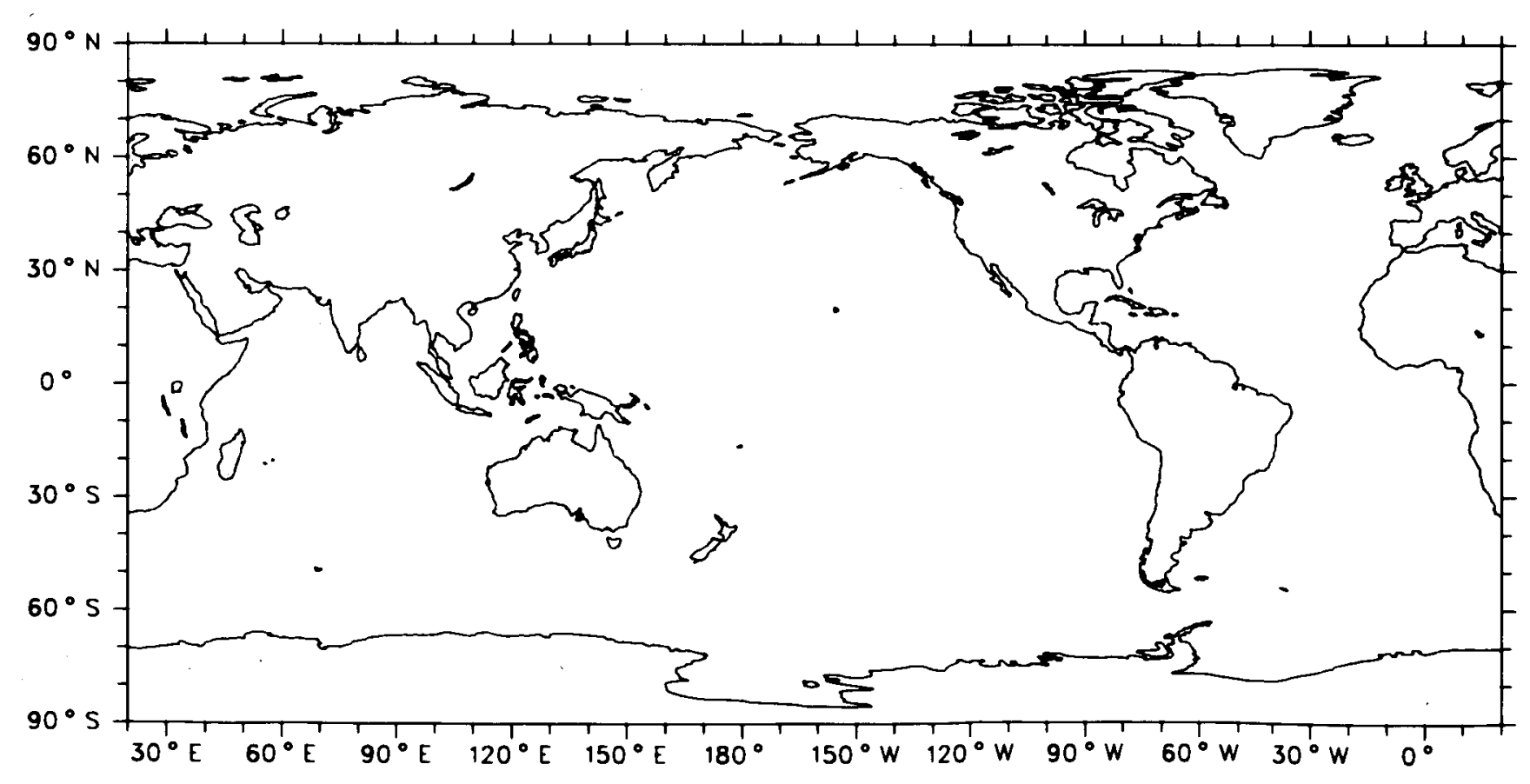

Map 170b

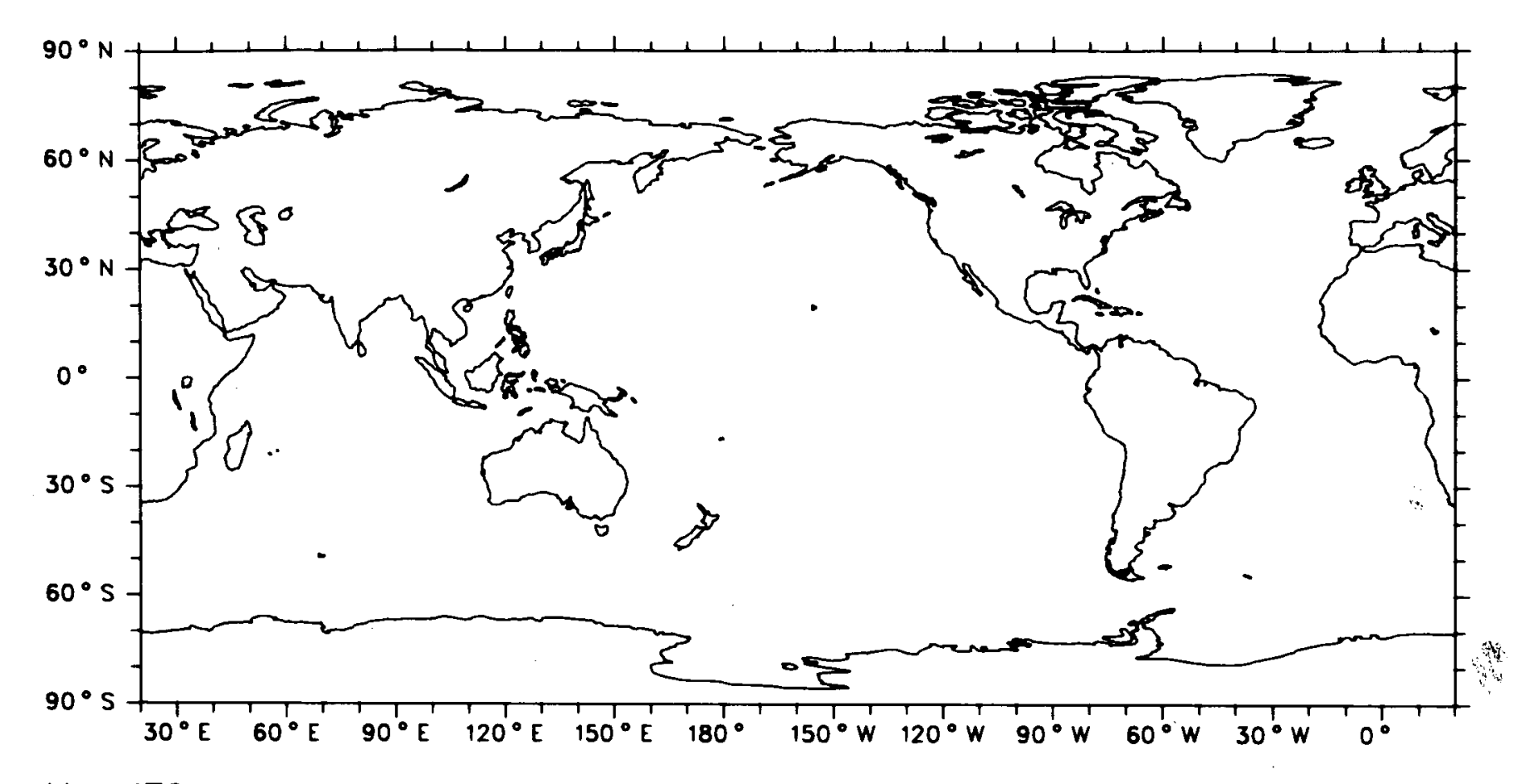

Map 170c

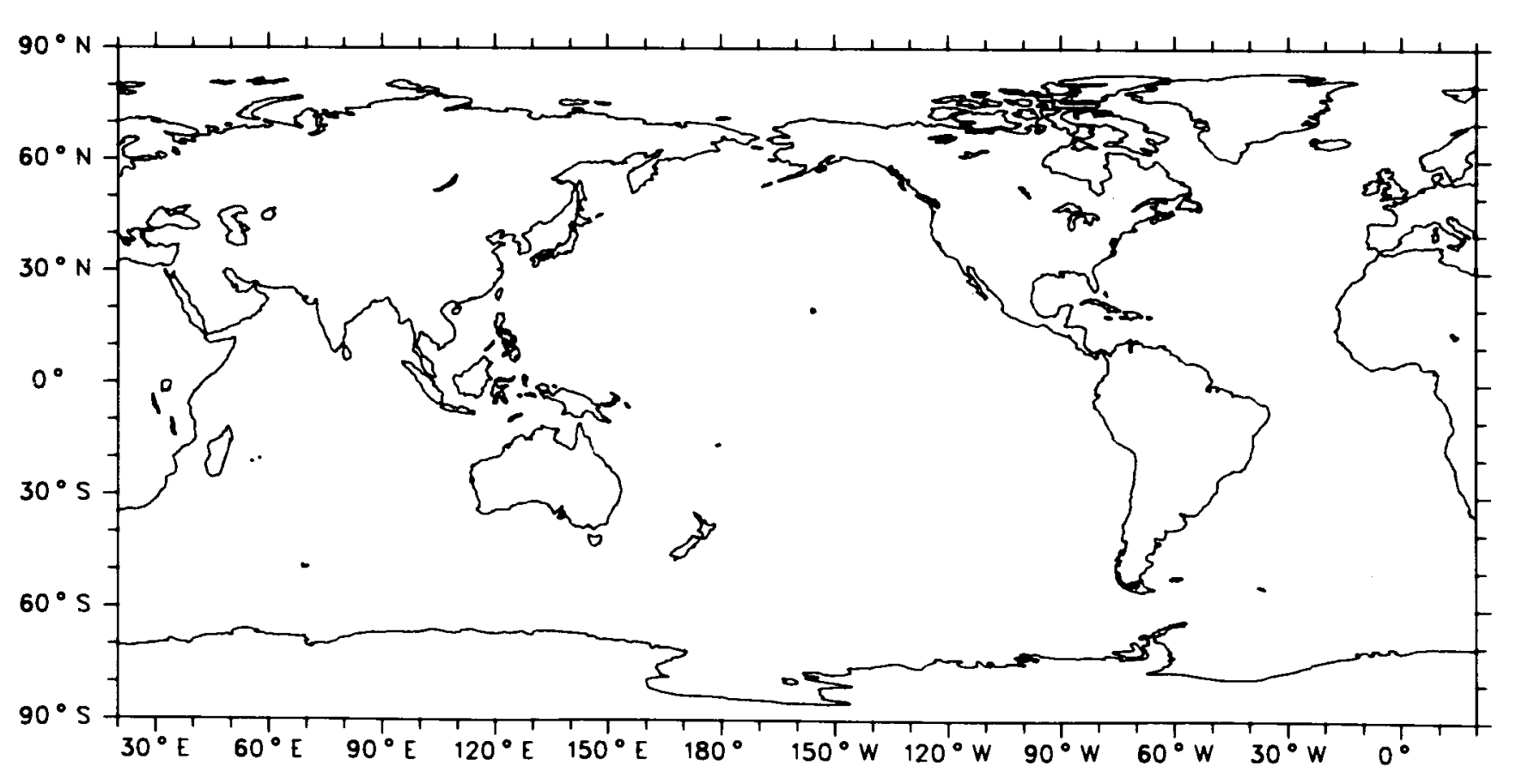

Map 170d 